Göttinger Studien

zu den Kriminalwissenschaften

\title{
Tanja Köhler
}

\section{Straffällige Frauen}

Eine Untersuchung der

Strafzumessung und Rückfälligkeit 

Tanja Köhler

Straffällige Frauen

This work is licensed under the Creative Commons License 3.0 "by-nd", allowing you to download, distribute and print the document in a few copies for private or educational use, given that the document stays unchanged and the creator is mentioned. You are not allowed to sell copies of the free version.

SORER RIGHIS RESERNED 
erschienen als Band 22 in der Reihe „Göttinger Studien zu den Kriminalwissenschaften“ im Universitätsverlag Göttingen 2012 
Tanja Köhler

Straffällige Frauen

Eine Untersuchung der

Strafzumessung und Rückfälligkeit

Göttinger Studien zu den

Kriminalwissenschaften

Band 22

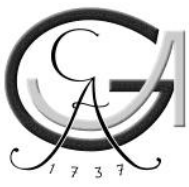

Universitätsverlag Göttingen

2012 


\section{Bibliographische Information der Deutschen Nationalbibliothek}

Die Deutsche Nationalbibliothek verzeichnet diese Publikation in der Deutschen Nationalbibliographie; detaillierte bibliographische Daten sind im Internet über $<$ http://dnb.ddb.de $>$ abrufbar.

Herausgeber der Reibe

Institut für Kriminalwissenschaften

Juristische Fakultät der Georg-August-Universität Göttingen

Profs. Drs. Kai Ambos, Gunnar Duttge, Jörg-Martin Jehle, Uwe Murmann

\section{Autorenkontakt}

e-mail: Tanja.Koehler@jura.uni-goettingen.de

e-mail: t.koehler@ostfalia.de

Dieses Buch ist auch als freie Onlineversion über die Homepage des Verlags sowie über den OPAC der Niedersächsischen Staats- und Universitätsbibliothek

(http://www.sub.uni-goettingen.de) erreichbar und darf gelesen, heruntergeladen sowie als Privatkopie ausgedruckt werden. Es gelten die Lizenzbestimmungen der

Onlineversion. Es ist nicht gestattet, Kopien oder gedruckte Fassungen der freien

Onlineversion zu veräußern.

Satz und Layout: Tanja Köhler mit Unterstützung von Tim Krause und Patrick Fresow Umschlaggestaltung: Kilian Klapp

(C) 2012 Universitätsverlag Göttingen

http://univerlag.uni-goettingen.de

ISBN: 978-3-86395-049-1

ISSN: $1864-2136$ 


\section{Vorwort}

Diese Arbeit wurde im Wintersemester 2011/12 von der Juristischen Fakultät der Georg-August Universität Göttingen als Dissertation angenommen. Die Literatur wurde bis August 2011 ausgewertet.

An erster Stelle möchte ich mich ganz besonders herzlich bei meinem Doktorvater, Herrn Prof. Dr. Jörg-Martin Jeble, bedanken, der die Dissertation betreut und begleitet hat. Darüber hinaus hat er mir stets mit Ehrlichkeit, Vertrauen, Ratschlägen und Tatkraft bei meinen beruflichen Plänen Hilfestellung geleistet. Dies weiß ich sehr zu schätzen.

Danken möchte ich auch Herrn Prof. Dr. Axel Dessecker für die zügige Erstellung des Zweitgutachtens sowie die hilfreichen Anmerkungen.

$\mathrm{Zu}$ großem Dank verpflichtet bin ich ferner Frau Sabine Hobmann-Fricke, die mich durch weiterführende Diskussionen und Ideen, vor allen Dingen aber bei den statistischen Auswertungen und methodischen Fragestellungen mit viel Geduld unterstützt hat. Zudem danke ich Herrn Dr. Stefan Harrendorf für die Anregungen und konstruktive Kritik, die mich in meiner Arbeit vorangebracht haben.

Meine Kollegen in der Rechtsanwaltskanzlei mep $+\mathrm{k}$ in Braunschweig haben mir durch flexible Arbeitszeiten, Vertrauen, Verständnis und Gespräche die Arbeit an der Dissertation erleichtert. Gleiches gilt für Fran Prof. Dr. Ute-Ingrid Haas von der Ostfalia Hochschule für angewandte Wissenschaften Braunschweig/Wolfenbüttel. Hierfür möchte ich mich ganz herzlich bedanken. 
Großer Dank gebührt ferner meinen Freunden Nils Köthe und Annika Wollburg, die die vorliegende Arbeit Korrektur gelesen haben. Ferner möchte ich Patrick Fresow und Tim Krause für die Hilfe bei der Formatierung der Arbeit und Xenia Schmidt für die Unterstützung beim Umgang mit Excel und SPSS sowie für die letzte Kontrolle der Berechnungen danken.

Meinen Eltern danke ich dafür, dass sie mir schon immer mit auf den Weg gegeben haben, wie wichtig es ist, sich im Leben Ziele zu setzen und diese zu verwirklichen. Damit haben sie den Grundstein für diese Arbeit gelegt.

Meiner Familie und meinen Freunden gilt ebenfalls mein herzlichster Dank dafür, dass sie mich während der Arbeit an der Dissertation auch auf andere Gedanken gebracht haben. Ich konnte daraus viel Kraft schöpfen.

Mein größter Dank gilt jedoch Flori, der mich oft in gestresster Stimmung ertragen musste und mich gleichwohl stets in meinem Vorhaben bestärkt und jederzeit mit voller Kraft unterstützt hat. Ohne seine Hilfe und Liebe wäre vieles schwerer gefallen.

Braunschweig, Mai 2012

Tanja Köbler 


\section{Inhaltsverzeichnis}

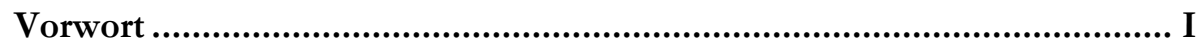

Abbildungs- und Tabellenverzeichnis................................................III

Abkürzungsverzeichnis …................................................................ XXI

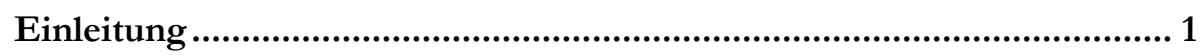

Kapitel 1: Straffällige Frauen im Hell- und Dunkelfeld 5

1. Quellen empirischer Daten................................................................................ 5

1.1 Polizeiliche Kriminalstatistik ............................................................................. 6

1.2 Strafverfolgungsstatistik .............................................................................. 6

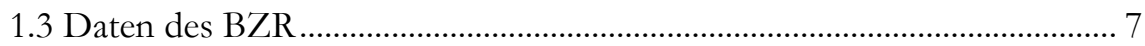

1.4 Grenzen der Aussagekraft und Fehlerquellen der amtlichen

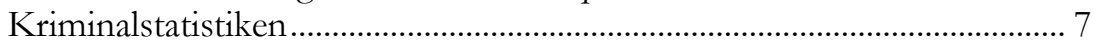

1.5 Dunkelfeldforschung .............................................................................. 9

2. Umfang, Struktur und Entwicklung der Frauenkriminalität .............................. 12

2.1 Umfang, Struktur und Entwicklung der Tatverdächtigen .......................... 12

2.1.1 Häufigkeit und Alter der Tatverdächtigen ......................................... 12 
2.1.2 Deliktstruktur der Tatverdächtigen ................................................. 15

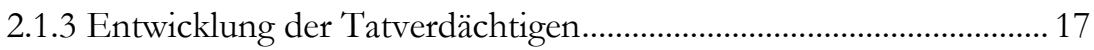

2.2 Umfang und Struktur im Dunkelfeld...................................................... 21

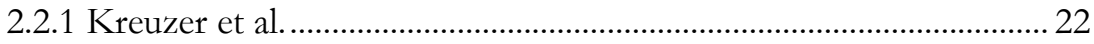

2.2.2 Mansel/ Hurrelmann......................................................................... 23

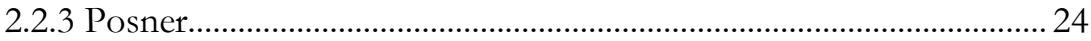

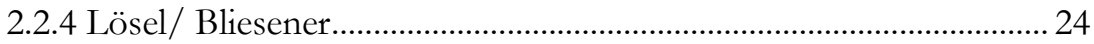

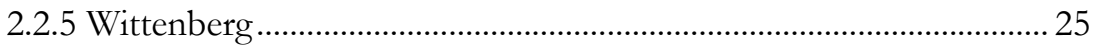

2.2.6 Ausgewählte Studien zum weiblichen Anteil an Gewaltkriminalität ...................................................................... 25

2.2.7 Schülerbefragungen des Kriminologischen Forschungs-

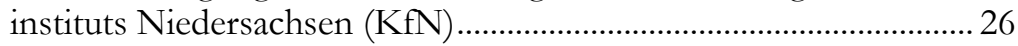

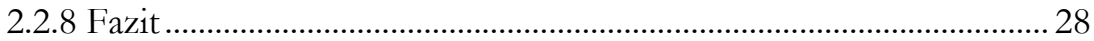

2.3 Umfang, Struktur und Entwicklung der Verurteilten............................... 29

2.3.1 Häufigkeit und Alter der Verurteilten................................................. 29

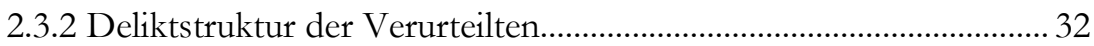

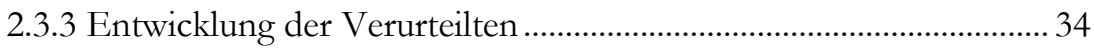

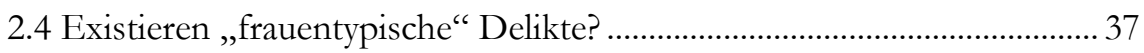

3. Selektionsprozess im Laufe der Strafverfolgung .............................................. 38

3.1 Vom Dunkelfeld bis zur gerichtlichen Aburteilung.................................. 38

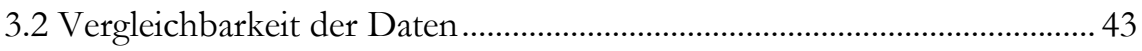

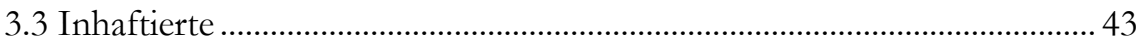

Kapitel 2: Erklärungsansätze für das Phänomen der Frauenkriminalität $\quad 45$

1. Historischer Überblick über ältere biologische Erklärungsansätze..................4 47

2 Erklärungsansätze für die Kriminalitätsbelastung von Frauen ......................... 50

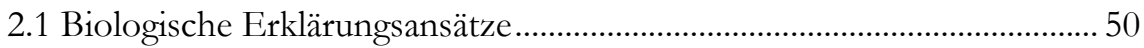

2.1.1 Allgemeine Darstellung und Anwendbarkeit auf das weibliche Geschlecht .......................................................................... 50

2.1.2 Modifikation für frauenspezifische Belange..................................... 51

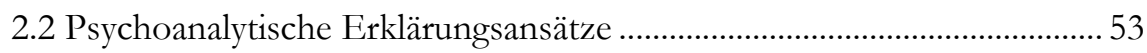

2.2.1 Allgemeine Darstellung und Anwendbarkeit auf das weibliche Geschlecht. 
2.2.2 Modifikation für frauenspezifische Belange .................................. 54

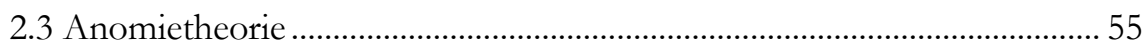

2.3.1 Allgemeine Darstellung und Anwendbarkeit auf das weibliche

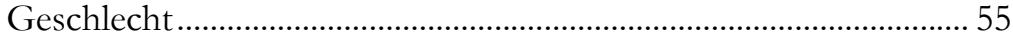

2.3.2 Modifikation für frauenspezifische Belange ..................................... 57

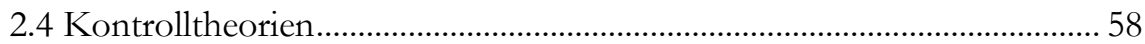

2.4.1 Allgemeine Darstellung und Anwendbarkeit auf das weibliche Geschlecht...................................................................................... 58

2.4.2 Modifikation für frauenspezifische Belange ...................................... 60

2.5 Theorie der differentiellen Assoziation ..................................................... 61

2.5.1 Allgemeine Darstellung und Anwendbarkeit auf das

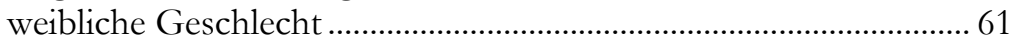

2.5.2 Modifikation für frauenspezifische Belange .................................... 62

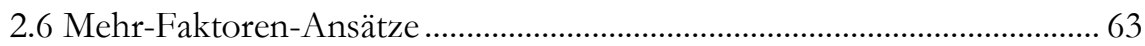

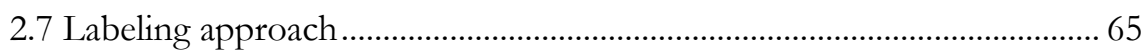

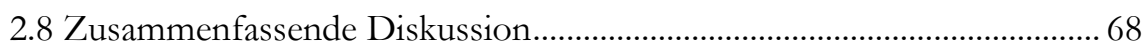

3. Erklärungsansätze für die geringere Kriminalitätsbelastung von Frauen....... 69

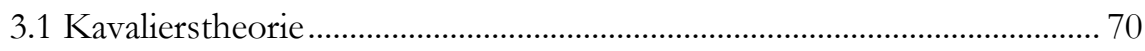

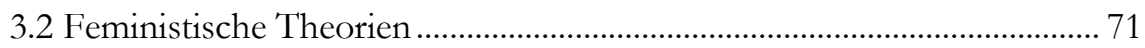

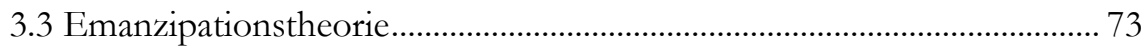

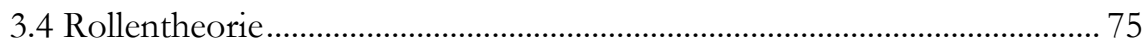

3.5 Zusammenfassende Diskussion.............................................................. 79

Kapitel 3: Anlage der eigenen Untersuchung 81

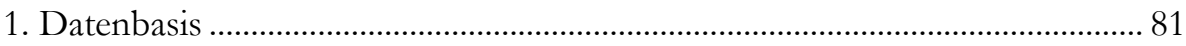

1.1 Rückfalluntersuchungen für die Basisjahre 1994 und 2004..................... 81

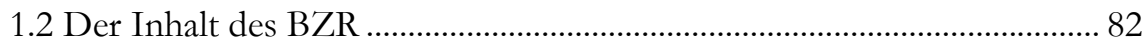

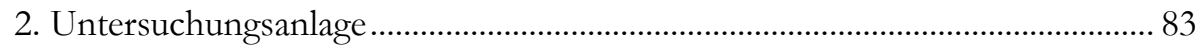

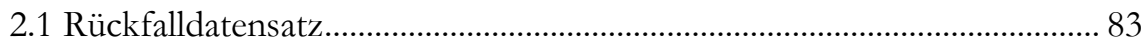

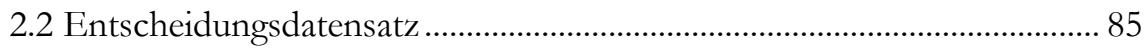

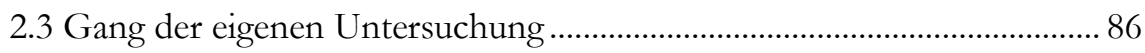

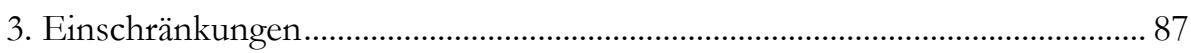

3.1 Nichtberücksichtigung strafprozessualer Verfahrenseinstellungen ........ 88

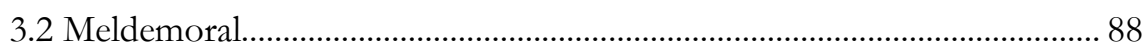


3.3 Fehlerhafte Eintragungen ........................................................................ 89

3.4 Tilgungs- und Löschvorschriften............................................................. 90

3.5 Gesetzesänderungen und zeitliche Rahmenbedingungen.......................... 92

3.6 Begrenzung auf Geschlecht, Alter und Nationalität................................. 92

3.7 Namensänderungen .................................................................................... 92

\section{Kapitel 4: Frauenkriminalität im Querschnitt 93}

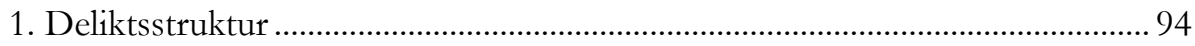

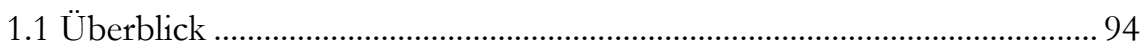

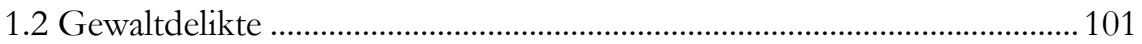

1.2.1 Gruppierung der Gewaltdelikte ........................................................ 101

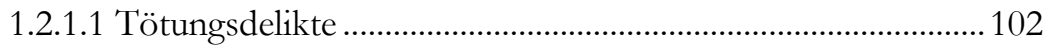

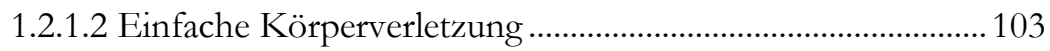

1.2.1.3 Sonstige Körperverletzungsdelikte............................................ 103

1.2.1.4 Sonstige Gewaltdelikte ........................................................... 104

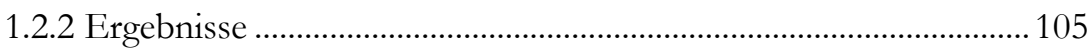

1.3 Eigentums-, Vermögens- und Urkundendelikte ....................................... 111

1.3.1 Gruppierung der Eigentums-, Vermögens und Urkundendelikte ................................................................................... 111

1.3.1.1 Besonders schwerer und qualifizierter Diebstahl.................... 111

1.3.1.2 Einfacher Diebstahl und Unterschlagung...............................111

1.3.1.3 Betrug u.a............................................................................. 112

1.3.1.4 Erschleichen von Leistungen ...................................................112

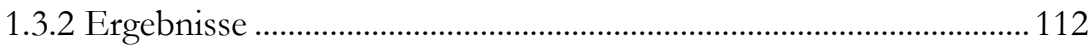

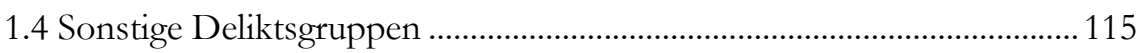

1.4.1 Gruppierung der sonstigen Deliktsgruppen .................................... 115

1.4.1.1 Fahrlässige Körperverletzung und Tötung ..............................115

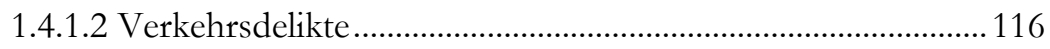

1.4.1.3 Delikte nach BtMG..................................................................116

1.4.1.4 Sonstige Delikte........................................................................ 116

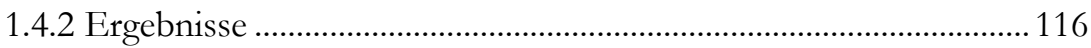

2. Soziodemographische Daten........................................................................119

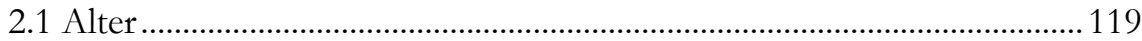


2.2 Nationalität

Kapitel 5: Sanktionierung der Frauenkriminalität

1. Existiert ein „Frauenbonus“?

1.1 Theoretische Grundlage.

1.2 Bisherige deutsche Forschungsergebnisse zur geschlechtsspezifischen Bevorzugung....

1.2.1 Mildere Behandlung durch die Anzeigeerstatter....

1.2.2 Mildere Behandlung durch die Strafverfolgungsbehörden und Gerichte

1.2.2.1 Polizei

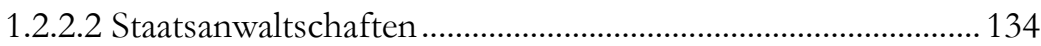

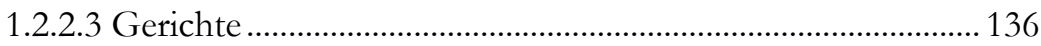

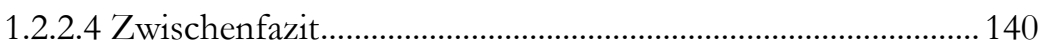

2. Eigene Forschungsergebnisse auf der Grundlage der Daten des BZR.

2.1 Anteile der Geschlechter an der Art der Bezugsentscheidung...........

2.2 Sanktionierung nach Jugendstrafrecht. 146

2.2.1 Verteilung der jugendstrafrechtlichen Reaktionen. 146

2.2.2 Dauer der Jugendstrafe ohne Bewährung 147

2.2.3 Strafaussetzung zur Bewährung 149

2.2.4 Anwendung des \105 I JGG 150

2.3 Sanktionierung nach allgemeinem Strafrecht. 153

2.3.1 Verteilung der Sanktionen des StGB 154

2.3.2 Dauer der Freiheitsstrafe ohne Bewährung. 155

2.3.3 Strafaussetzung zur Bewährung. 156

2.3.4 Geldstrafe 159

2.3.5 Verkehrsrechtliche Sanktionen 160

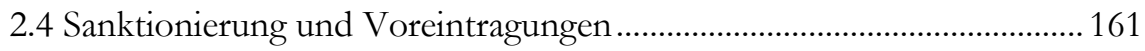

2.4.1 Begriff der Voreintragung.............................................................. 161

2.4.2 Anzahl und Art der schwersten Voreintragungen ......................... 163

2.4.3 Sanktionierung nach Jugendstrafrecht und Voreintragungen....... 165

2.4.4 Sanktionierung nach allgemeinem Strafrecht und Voreintragungen 
2.5 Sanktionierung nach Deliktsgruppen...................................................... 170

2.5.1 Art der Bezugsentscheidung nach Deliktsgruppen...........................170

2.5.2 Art der Bezugsentscheidung und einschlägige Voreintragungen............................................................. 175

2.6 Sanktionierung bei Diebstahl gem. \242 StGB ...................................... 179

2.6.1 Sanktionierung nach Jugendstrafrecht ............................................. 182

2.6.2 Sanktionierung nach allgemeinem Strafrecht.................................... 184

2.6.3 Sanktionierung und Voreintragungen ............................................... 187

2.6.3.1 Anzahl und Art der schwersten Voreintragungen .................. 187

2.6.3.2 Sanktionierung nach Jugendstrafrecht und Voreintragungen........................................................................ 189

2.6.3.3 Sanktionierung nach allgemeinem Strafrecht und Voreintragungen........................................................................ 191

2.6.3.4 Einschlägige Voreintragungen ................................................ 194

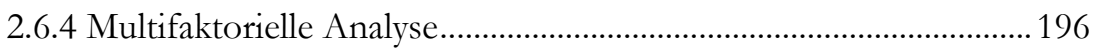

2.7 Sanktionierung bei Betrug gem. \263 StGB ........................................... 198

2.7.1 Sanktionierung nach Jugendstrafrecht ..............................................200

2.7.2 Sanktionierung nach allgemeinem Strafrecht....................................200

2.7.3 Sanktionierung und Voreintragungen ................................................. 201

2.7.3.1 Anzahl und Art der schwersten Voreintragungen .................. 201

2.7.3.2 Sanktionierung nach Jugendstrafrecht und Voreintragungen...................................................................... 201

2.7.3.3 Sanktionierung nach allgemeinem Strafrecht und

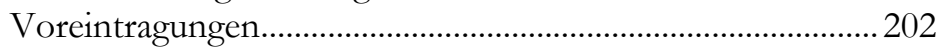

2.7.3.4 Einschlägige Voreintragungen .................................................204

2.7.4 Multifaktorielle Analyse..................................................................206

3. Gesamtfazit: Geschlechtsspezifische Bevorzugung: „Frauenbonus“" oder nicht? ................................................................................207

Kapitel 6: Rückfallkriminalität von Frauen 209

1. Die Bedeutung der Rückfälligkeit und der Rückfallstatistik............................ 209

2. Die Entwicklung der Rückfallstatistik.............................................................2212

2.1 Die Rückfalldaten in der Kriminalstatistik des Deutschen Reiches 
2.2 Die Rückfallstatistiken auf der Grundlage der Daten des

Bundeszentralregisters

2.2.1 Die Rückfallstatistik der Dienststelle Bundeszentralregister des Generalbundesanwalts.

2.2.2 Die neu konzipierte Rückfalluntersuchung.

2.2.2.1 Die erste Rückfalluntersuchung für das

Bezugsjahr 1994

2.2.2.2 Die zweite Rückfalluntersuchung für das Bezugsjahr 2004

3. Bisherige deutsche Forschungsergebnisse zur

Rückfallkriminalität von Frauen.

4. Rückfallkriminalität von Frauen auf der Grundlage der Daten des

Bundeszentralregisters

4.1 Der Rückfallbegriff ...

4.2 Folgeentscheidungen im Verhältnis zu den Bezugsentscheidungen..... 222

4.3 Art der Folgeentscheidung nach Sanktionsart der

Bezugsentscheidung.

4.3.1 Überblick

4.3.2 Art der Folgeentscheidung nach Geldstrafe

4.3.3 Art der Folgeentscheidungen nach freiheitsentziehenden Sanktionen.

4.4 Folgeentscheidungen und Voreintragungen

4.4.1 Art der Folgeentscheidung nach Anzahl und Art der

Voreintragungen bei Jugendlichen und Heranwachsenden.

4.4.2 Art der Folgeentscheidung nach Anzahl und Art der Voreintragungen bei Erwachsenen

4.5 Folgeentscheidungen und Deliktsgruppen.

4.5.1 Art der Folgeentscheidungen und Deliktsgruppen. 233

4.5.2 Art der Folgeentscheidung nach Art der

Bezugsentscheidung und Deliktsgruppe. 235

4.5.2.1 Sonstige Gewaltdelikte 236

4.5.2.2 Besonders schwerer und qualifizierter Diebstahl.

4.5.2.3 Delikte nach BtMG

4.6 Einschlägige Voreintragung, Bezugsentscheidung und einschlägiger Rückfall 
4.6.1 Bezugsentscheidung und einschlägiger Rückfall 239

4.6.2 Einschlägige Voreintragung, Bezugsentscheidung und einschlägiger Rückfall. 242

4.6.2.1 Gewaltdelikte 242

4.6.2.2 Vermögensdelikte i.w.S. 244

4.6.2.3 Sonstige Delikte. 247

4.7 Rückfallgeschwindigkeit 249

4.8 Folgeentscheidungen nach Alter und Nationalität. 251

4.9 Zwischenfazit. 253

5. Rückfallkriminalität von Frauen und Männern im Vergleich auf der Grundlage der Daten des Bundeszentralregisters 254

5.1 Art der Folgeentscheidung. 254

5.2 Rückfallrate nach Sanktionsart der Bezugsentscheidung.... 255

5.3 Rückfallgeschwindigkeit 256

5.4 Folgeentscheidungen beim Diebstahl gem. I 242 StGB. 257

5.4.1. Art der Folgeentscheidung 257

5.4.2 Folgeentscheidung und Voreintragungen 262

5.4.3 Multifaktorielle Analyse 267

5.4.4 Einschlägige Voreintragung, Bezugsentscheidung und einschlägiger Rückfall. 269

5.5 Folgeentscheidung beim Betrug gem. \ 263 StGB 271

5.5.1 Art der Folgeentscheidung. 271

5.5.2 Folgeentscheidung und Voreintragungen 274

5.5.3 Multifaktorielle Analyse. 276

5.5.4 Einschlägige Voreintragung, Bezugsentscheidung und einschlägiger Rückfall.

5.6 Zwischenfazit 279

6. Gesamtfazit 280

Kapitel 7: Zusammenfassung und Bewertung der Ergebnisse

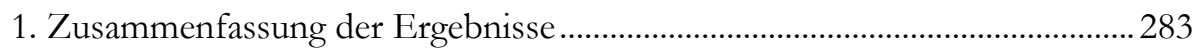

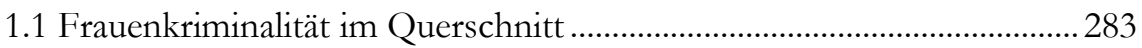

1.1.1 Umfang und Struktur der Frauenkriminalität ...............................283

1.1.2 Alter 284 
1.1.3 Nationalität..................................................................................... 285

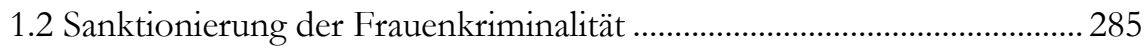

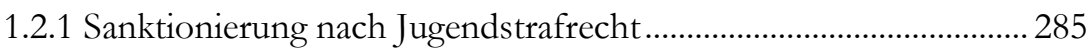

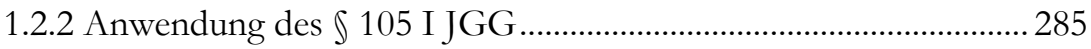

1.2.3 Sanktionierung nach allgemeinem Strafrecht................................ 286

1.2.4 Sanktionierung und Voreintragungen............................................ 286

1.2.5 Sanktionierung und Deliktsgruppen ............................................. 287

1.2.6 Sanktionierung bei Diebstahl gem. \ 242 StGB ............................ 288

1.2.7 Sanktionierung bei Betrug gem. \263 StGB ................................ 289

1.3 Rückfallkriminalität von Frauen................................................................ 289

1.3.1 Rückfallrate nach Sanktionsart der Bezugsentscheidung..............290

1.3.2 Folgeentscheidung und Voreintragungen ..................................... 290

1.3.3 Folgeentscheidung und Deliktsgruppen........................................ 291

1.3.4 Einschlägige Voreintragung, Bezugsentscheidung und einschlägiger Rückfall ................................................................. 291

1.3.5 Rückfallgeschwindigkeit .............................................................. 291

1.3.6 Alter und Nationalität...................................................................... 291

1.4 Die Rückfallkriminalität von Frauen und Männern im Vergleich......... 292

1.4.1 Folgeentscheidung beim Diebstahl gem. \ 242 StGB ................... 292

1.4.2 Folgeentscheidung beim Betrug gem. \ 263 StGB ....................... 294

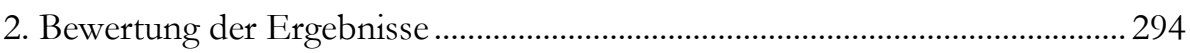

Literaturverzeichnis .......................................................................297

Tabellenanhang ................................................................................317 



\section{Abbildungs- und Tabellenverzeichnis}

Schaubild 1.1: TVBZ für Deutsche nach Geschlecht und Altersgruppe, 2009

Schaubild 1.2: Deliktsstruktur von tatverdächtigen Frauen, 2009

Schaubild 1.3: TVBZ nach Diebstahlsart, Geschlecht und Altersgruppe, 2009

Tabelle 1.1: Entwicklung der Tatverdächtigen bei Straftaten insgesamt ab 1995

Schaubild 1.4: Entwicklung der TVBZ von Frauen bei Straftaten insgesamt ab 1995

Schaubild 1.5: Entwicklung der TVBZ von Männern bei Straftaten insgesamt ab 1995 .

Schaubild 1.6: VBZ für Deutsche nach Geschlecht und Altersgruppe, 2009 30

Schaubild 1.7: TVBZ und VBZ für Deutsche nach Geschlecht und Altersgruppe, 2009.

Schaubild 1.8: Deliktsstruktur von verurteilten Frauen, 2009 33

Tabelle 1.2: $\quad$ Entwicklung der Verurteilten bei Straftaten insgesamt seit 1995 
Schaubild 1.9: Entwicklung der VBZ von Frauen bei Straftaten insgesamt seit 1995

Schaubild 1.10: Entwicklung der VBZ von Männern bei Straftaten insgesamt seit 1995

Tabelle 1.3: $\quad$ Modell der statistischen Erfassung im Gang der Strafverfolgung, Strafzumessung und Strafvollstreckung (vereinfacht)

Schaubild 1.11: ,Trichtermodell“ der Strafverfolgung (ohne Verkehrsdelikte) für Frauen, 2009

Schaubild 1.12: „Trichtermodell“ der Strafverfolgung (ohne Verkehrsdelikte) für Männer, 2009

Schaubild 3.1: $\quad$ Strukturmodell des Rückfalldatensatzes 2004-2007. 86

Tabelle 3.1: Entfernungs- und endgültiger Löschzeitpunkt für verschiedene Geburtsjahrgänge 93

Schaubild 4.1: Deliktsstruktur von Frauen nach Deliktsgruppe....................... 97

Schaubild 4.2: Grobe Deliktsstruktur von Frauen............................................... 98

Schaubild 4.3: Grobe Deliktsstruktur von Männern.......................................... 98

Schaubild 4.4: Anteil von Frauen und Männern an Deliktsgruppen ............... 99

Schaubild 4.5: Anteil von Frauen und Männern an ausgewählten Delikten 100

Schaubild 4.6: Gewaltdelikte von Frauen........................................................... 108

Schaubild 4.7: Gewaltdelikte von Männern........................................................ 108

Schaubild 4.8: Anteil von Frauen und Männern an Gewaltdelikten............... 110

Schaubild 4.9: Vermögensdelikte i.w.S. von Frauen ........................................ 115

Schaubild 4.10: Vermögensdelikte i.w.S. von Männern...................................... 115

Schaubild 4.11: Anteil von Frauen und Männern an Vermögensdelikten i.w.S

Schaubild 4.12: Anteil von Frauen und Männern an sonstigen Deliktsgruppen

Schaubild 4.13: Bezugsentscheidung nach Alter und Geschlecht. 122

Schaubild 4.14: Anteil der jeweiligen Altersstufe an verschiedenen Vermögensdelikten i.w.S. von Frauen

Schaubild 4.15: Anteil der jeweiligen Altersstufe an den sonstigen Deliktsgruppen für Frauen

Schaubild 4.16: Anteil von Nichtdeutschen an verurteilten Frauen und Männern insgesamt differenziert nach Deliktsgruppen 
Tabelle 4.1: Anteil der Nichtdeutschen an der weiblichen bzw. männlichen Wohnbevölkerung und den weiblichen bzw. männlichen Verurteilten im Jahr 2004

Schaubild 4.17: Deliktsstruktur von nichtdeutschen Frauen 128

Schaubild 4.18: Altersverteilung von deutschen und nichtdeutschen Frauen mit und ohne $\iint 45,47 \mathrm{JGG}$

Schaubild 5.1: Anteil von Frauen und Männern an der Art der Bezugsentscheidung..

Schaubild 5.2: Jugendstrafrechtliche Reaktionen nach Geschlecht

Schaubild 5.3: Dauer der Jugendstrafe ohne Bewährung nach Geschlecht

Schaubild 5.4: Aussetzungsquote bei Jugendstrafe nach Geschlecht

Tabelle 5.1: Anwendung des JGG oder StGB auf heranwachsende Frauen und Männer

Schaubild 5.5: Anwendungshäufigkeit des \105 JGG nach

Deliktsgruppen und Geschlecht

Schaubild 5.6: Sanktionen des StGB nach Geschlecht

Schaubild 5.7: Dauer der Freiheitsstrafe ohne Bewährung nach

Geschlecht.

Schaubild 5.8: Aussetzungsquote bei Freiheitsstrafe nach Geschlecht.........159

Tabelle 5.2: Bewährungsunterstellung nach Geschlecht. 160

Tabelle 5.3: Bewährungsunterstellung nach Dauer der bedingten Freiheitsstrafe und Geschlecht

Schaubild 5.9: Anzahl der Tagessätze bei Geldstrafe nach Geschlecht

Tabelle 5.4: Verkehrsrechtliche Sanktion nach Geschlecht für Verkehrsdelikte ohne sowie unter Alkoholeinfluss ................. 162

Schaubild 5.10: Anzahl der Voreintragungen nach Geschlecht ....................... 165

Schaubild 5.11: Art der schwersten Voreintragung nach Geschlecht .............. 166

Schaubild 5.12: Jugendstrafrechtliche Reaktionen nach Anzahl der Voreintragungen und Geschlecht.

Schaubild 5.13: Jugendstrafrechtliche Reaktionen nach Art der schwersten Voreintragung und Geschlecht.

Schaubild 5.14: Sanktionen des StGB nach Anzahl der Voreintragungen und Geschlecht

Schaubild 5.15: Sanktionen des StGB nach Art der schwersten

Voreintragung und Geschlecht

Schaubild 5.16: Jugendstrafrechtliche Reaktionen nach Deliktsgruppe von Frauen 
Schaubild 5.17: Jugendstrafrechtliche Reaktionen nach Deliktsgruppe von Männern.

Schaubild 5.18: Sanktionen des StGB nach Deliktsgruppe von Frauen .......... 175

Schaubild 5.19: Sanktionen des StGB nach Deliktsgruppe von Männern...... 176

Tabelle 5.5: Bestimmung der einschlägigen Voreintragungen..................... 178

Schaubild 5.20: Jugendstrafrechtliche Reaktionen nach Einschlägigkeit der Voreintragungen und Geschlecht.

Schaubild 5.21: Sanktionen des StGB nach Einschlägigkeit der Voreintragungen und Geschlecht.

Schaubild 5.22: Jugendstrafrechtliche Reaktionen aufgrund von Diebstahl nach Geschlecht.

Schaubild 5.23: Aussetzungsquote bei Jugendstrafe aufgrund von Diebstahl nach Geschlecht.

Schaubild 5.24: Sanktionen des StGB aufgrund von Diebstahl nach Geschlecht

Schaubild 5.25: Aussetzungsquote bei Freiheitsstrafe aufgrund von Diebstahl nach Geschlecht

Schaubild 5.26: Anzahl der Tagessätze bei Geldstrafe aufgrund von Diebstahl nach Geschlecht

Schaubild 5.27: Bezugsentscheidungen aufgrund von Diebstahl nach Anzahl der Voreintragungen und Geschlecht

Schaubild 5.28: Bezugsentscheidungen aufgrund von Diebstahl nach Art der schwersten Voreintragung und Geschlecht

Schaubild 5.29: Jugendstrafrechtliche Reaktionen aufgrund von

Diebstahl nach Anzahl der Voreintragungen und Geschlecht

Schaubild 5.30: Jugendstrafrechtliche Reaktionen aufgrund von Diebstahl nach Art der schwersten Voreintragung und Geschlecht

Schaubild 5.31: Sanktionen des StGB aufgrund von Diebstahl nach Anzahl der Voreintragungen und Geschlecht

Schaubild 5.32: Sanktionen des StGB aufgrund von Diebstahl nach Art der schwersten Voreintragung und Geschlecht

Schaubild 5.33: Jugendstrafrechtliche Reaktionen aufgrund von Diebstahl nach Einschlägigkeit der Voreintragungen und Geschlecht.

Schaubild 5.34: Sanktionen des StGB aufgrund von Diebstahl nach Einschlägigkeit der Voreintragungen und Geschlecht. 
Schaubild 5.35: Sanktionen des StGB aufgrund von Diebstahl unter

Berücksichtigung multipler Faktoren nach Geschlecht

Schaubild 5.36: Sanktionen des StGB aufgrund von Betrug nach Anzahl der Voreintragungen und Geschlecht

Schaubild 5.37: Sanktionen des StGB aufgrund von Betrug nach Art der schwersten Voreintragung und Geschlecht

Schaubild 5.38: Jugendstrafrechtliche Reaktionen aufgrund von Betrug nach Einschlägigkeit der Voreintragungen und Geschlecht.

Schaubild 5.39: Sanktionen des StGB aufgrund von Betrug nach

Einschlägigkeit der Voreintragungen und Geschlecht. 208

Schaubild 5.40: Sanktionen des StGB aufgrund von Betrug unter

Berücksichtigung multipler Faktoren nach Geschlecht

Schaubild 6.1: Art der Bezugsentscheidung und Art der Folgeentscheidung innerhalb von 3 Jahren von Frauen

Schaubild 6.2: Art der Folgeeintragung nach Sanktionsart der Bezugsentscheidung.... 226

Schaubild 6.3: Art der Folgeentscheidung nach Geldstrafe ............................ 227

Schaubild 6.4: Art der Folgeentscheidung nach Jugendstrafe ........................ 228

Schaubild 6.5: Art der Folgeentscheidung nach Freiheitsstrafe ...................... 229

Schaubild 6.6: Rückfallrate nach Dauer der unbedingten Jugend- und Freiheitsstrafen der Bezugsentscheidung

Schaubild 6.7: Art der Folgeentscheidung nach Anzahl der Voreintragungen für jugendliche und heranwachsende Frauen

Schaubild 6.8: Art der Folgeentscheidung nach Art der schwersten Voreintragung für jugendliche und heranwachsende Frauen 232

Schaubild 6.9: Art der Folgeentscheidung nach Anzahl der Voreintragungen für erwachsene Frauen

Schaubild 6.10: Art der Folgeentscheidung nach Art der schwersten Voreintragung für erwachsene Frauen

Schaubild 6.11: Art der Folgeentscheidung nach Deliktsgruppen 236

Schaubild 6.12: Art der Folgeentscheidung nach Art der Bezugsentscheidung aufgrund von sonstigen Gewaltdelikten.

Schaubild 6.13: Art der Folgeentscheidung nach Art der Bezugsentscheidung aufgrund von besonders schwerem und qualifiziertem Diebstahl 
Schaubild 6.14: Art der Folgeentscheidung nach Art der Bezugsentscheidung aufgrund von Delikten nach BtMG

Tabelle 6.1: Bestimmung des einschlägigen Rückfalls .

Schaubild 6.15: Art des Rückfalls nach Deliktsgruppen der Bezugsentscheidung.

Schaubild 6.16: Einschlägige Voreintragungen und Rückfälle bei Bezugsentscheidungen aufgrund von Körperverletzungsdelikten.

Schaubild 6.17: Einschlägige Voreintragungen und Rückfälle bei Bezugsentscheidungen aufgrund von sonstigen Gewaltdelikten.

Schaubild 6.18: Einschlägige Voreintragungen und Rückfälle bei Bezugsentscheidungen aufgrund von Diebstahlsdelikten ..... 247

Schaubild 6.19: Einschlägige Voreintragungen und Rückfälle bei Bezugsentscheidungen aufgrund von Täuschungsdelikten ...248

Schaubild 6.20: Einschlägige Voreintragungen und Rückfälle bei Bezugsentscheidungen aufgrund von Verkehrsdelikten 250

Schaubild 6.21: Einschlägige Voreintragungen und Rückfälle bei Bezugsentscheidungen wegen Delikten nach dem BtMG .... 251

Schaubild 6.22: Dauer bis zum ersten Rückfall nach Altersgruppen 252

Schaubild 6.23: Art der Folgeentscheidung nach Altersgruppe in der Bezugsentscheidung.

Schaubild 6.24: Rückfallrate nach Art der Bezugsentscheidung und Nationalität

Schaubild 6.25: Sanktionsart der Folgeeintragung nach Geschlecht ............... 257

Schaubild 6.26: Rückfallrate nach Sanktionsart der Bezugsentscheidung....... 258

Schaubild 6.27: Dauer bis zum ersten Rückfall nach Geschlecht 259

Schaubild 6.28: Art der Folgeentscheidung bei Bezugsentscheidungen aufgrund von Diebstahl nach Geschlecht 260

Schaubild 6.29: Art der Folgeentscheidung nach Sanktionsart der Bezugsentscheidung aufgrund von Diebstahl nach Geschlecht

Schaubild 6.30: Art der Folgeentscheidung nach Jugendstrafe aufgrund von Diebstahl nach Geschlecht.

Schaubild 6.31: Art der Folgeentscheidung nach Freiheitsstrafe aufgrund von Diebstahl nach Geschlecht 263

Schaubild 6.32: Art der Folgeentscheidung nach Geldstrafe aufgrund von Diebstahl und Geschlecht. 
Schaubild 6.33: Art der Folgeentscheidung nach Anzahl der

Voreintragungen bei Bezugsentscheidungen aufgrund

von Diebstahl nach Geschlecht

(Jugendliche/ Heranwachsende)

Schaubild 6.34: Art der Folgeentscheidung nach Art der schwersten

Voreintragung bei Bezugsentscheidungen aufgrund von Diebstahl nach Geschlecht

(Jugendliche/ Heranwachsende)

Schaubild 6.35: Art der Folgeentscheidung nach Anzahl der

Voreintragungen bei Bezugsentscheidungen aufgrund

von Diebstahl nach Geschlecht (Erwachsene)

Schaubild 6.36: Art der Folgeentscheidung nach Art der schwersten

Voreintragung bei Bezugsentscheidungen aufgrund

von Diebstahl nach Geschlecht (Erwachsene)

Schaubild 6.37: Art der Folgeentscheidung nach Bezugsentscheidungen

aufgrund von Diebstahl nach Einschlägigkeit der

Voreintragungen und Geschlecht

Schaubild 6.38: Art der Folgeentscheidung nach dem StGB nach

Bezugsentscheidung aufgrund von Diebstahl unter

Berücksichtigung multipler Faktoren nach Geschlecht

Schaubild 6.39: Einschlägige Rückfalle nach Bezugsentscheidungen aufgrund von Diebstahl nach Geschlecht.

Schaubild 6.40: Einschlägige Voreintragungen und Rückfälle nach

Bezugsentscheidungen aufgrund von Diebstahl nach

Geschlecht

Schaubild 6.41: Art der Folgeentscheidung bei Bezugsentscheidungen aufgrund von Betrug und Geschlecht

Schaubild 6.42: Art der Folgeentscheidung nach Freiheitsstrafe aufgrund von Betrug nach Geschlecht

Schaubild 6.43: Art der Folgeentscheidung nach Anzahl der

Voreintragungen bei Bezugsentscheidungen aufgrund von Betrug nach Geschlecht (Erwachsene)

Schaubild 6.44: Art der Folgeentscheidung nach Art der schwersten

Voreintragung bei Bezugsentscheidungen aufgrund

von Betrug nach Geschlecht (Erwachsene)..

Schaubild 6.45: Art der Folgeentscheidung nach dem StGB nach

Bezugsentscheidung aufgrund von Betrug unter

Berücksichtigung multipler Faktoren nach Geschlecht

Schaubild 6.46: Einschlägige Rückfälle nach Bezugsentscheidungen aufgrund von Betrug nach Geschlecht 
Schaubild 6.47: Einschlägige Voreintragungen und Rückfälle nach Bezugsentscheidungen aufgrund von Betrug nach Geschlecht..... 


\section{Abkürzungsverzeichnis}

a.a.O.

a.F.

AJS

ASR

AsylVerfG

AufenthG

AuslG

Bd.

BewHi

BGBl.

BGHSt

BKA

BMFSFJ

BMI

BMJ

BritJCrim

BT am angegebenen Ort

alte Fassung

American Journal of Sociology

American Sociological Review

Asylverfahrensgesetz

Aufenthaltsgesetz

Ausländergesetz

Band

Bewährungshilfe

Bundesgesetzblatt

Entscheidungssammlung des Bundes-

gerichtshofes in Strafsachen

Bundeskriminalamt

Bundesministerium für Familie, Senioren, Frauen und Jugend

Bundesministerium des Innern

Bundesministerium der Justiz

British Journal of Criminology

Besonderer Teil 


\begin{tabular}{|c|c|}
\hline BtM & Betäubungsmittel \\
\hline BtMG & Betäubungsmittelgesetz \\
\hline BVerfG & Bundesverfassungsgericht \\
\hline BVerfGE & $\begin{array}{l}\text { Entscheidungssammlung des Bundes- } \\
\text { verfassungsgerichtes }\end{array}$ \\
\hline BZR & Bundeszentralregister \\
\hline BZRG & Bundeszentralregistergesetz \\
\hline Crim & Criminolgy \\
\hline CrimDel & Crime and Delinquency \\
\hline Diss. & Dissertation \\
\hline et al. & und andere (et alii) \\
\hline Fn. & Fußnote \\
\hline FS & Festschrift \\
\hline GA & Goltdammer`s Archiv für Strafrecht \\
\hline h.M. & herrschende Meinung \\
\hline Hrsg. & Herausgeber \\
\hline HwbKrim & Handwörterbuch der Kriminologie \\
\hline i.w.S. & im weiteren Sinne \\
\hline JGG & Jugendgerichtsgesetz \\
\hline JQuantCrime & Journal of Quantitative Criminology \\
\hline JResCrimDel & $\begin{array}{l}\text { Journal of Research in Crime and } \\
\text { Delinquency }\end{array}$ \\
\hline Kap. & Kapitel \\
\hline $\mathrm{KB}$ & Kriminalsoziologische Bibliografie \\
\hline $\mathrm{KFN}$ & $\begin{array}{l}\text { Kriminologisches Forschungsinstitut } \\
\text { Niedersachsen }\end{array}$ \\
\hline KJ & Kritische Justiz. \\
\hline KrimJ & Kriminologisches Journal \\
\hline KrimZ & Kriminologische Zentralstelle e.V. \\
\hline KZfSS & $\begin{array}{l}\text { Kölner Zeitschrift für Soziologie und Sozial- } \\
\text { psychologie }\end{array}$ \\
\hline m.w.N. & mit weiteren Nachweisen \\
\hline MschrKrim & $\begin{array}{l}\text { Monatsschrift für Kriminologie und Straf- } \\
\text { rechtsreform }\end{array}$ \\
\hline NK & Neue Kriminalpolitik. \\
\hline NStZ & Neue Zeitschrift für Strafrecht \\
\hline PKS & Polizeiliche Kriminalstatistik \\
\hline PSB & Periodischer Sicherheitsbericht \\
\hline Rdn. & Randnummer \\
\hline RG & Reichsgericht \\
\hline
\end{tabular}


StatBA

StGB

StPO

StVG

StVS

TKZ

TVBZ

VBZ

ZfRSoz

ZfStrVo

ZJJ

ZSE

ZStW
Statistisches Bundesamt

Strafgesetzbuch

Strafprozessordnung

Straßenverkehrsgesetz

Strafverfolgungsstatistik

Textkennziffer

Tatverdächtigenbelastungszahl

Verurteiltenbelastungszahl

Zeitschrift für Rechtssoziologie

Zeitschrift für Strafvollzug und Straffälligen-

bilfe

Zeitschrift für Jugendkriminalrecht und Jugendhilfe

Zeitschrift für Soziologie der Erziebung und Sozialisation

Zeitschrift für die gesamte Strafrechtswissenschaft 



\section{Einleitung}

Straffällige Frauen sind in den letzten Jahren vermehrt Gegenstand öffentlicher Diskussionen gewesen. Die medialen Darstellungen in diesem Bereich erwecken den Eindruck eines enormen quantitativen Anstiegs der Kriminalität von Frauen, aber auch einer erhöhten Gewaltbereitschaft. ${ }^{1}$ Hierdurch gerät immer wieder in den Hintergrund, dass weibliche Kriminalität nach wie vor sowohl qualitativ als auch quantitativ eine andere, nämlich geringere, Ausprägung als die von Männern aufweist. Dies dürfte wohl auch der Grund dafür sein, dass Untersuchungen über straffällige Frauen im Vergleich zu solchen über straffällige Männer selten sind. Bezeichnend ist, dass sich der Begriff der „Frauenkriminalität“ herausgebildet hat. Im Gegensatz dazu spricht man nicht von „Männerkriminalität“, sondern vielmehr nur von Kriminalität, wobei hiermit in der Regel die Gesamtheit von Straftaten männlicher Täter gemeint ist ${ }^{2}$ oder zumindest assoziiert wird. Entsprechend verbindet man mit dem Begriff des „Verbrechers“ die Vorstellung, der Täter sei stets ein Mann. ${ }^{3}$ Die Untersuchungen, die sich mit straffälligen Frauen auseinandersetzen, beschäftigen sich zumeist mit der „besonderen“ Struktur weiblicher

\footnotetext{
1 Vgl. bspw.: http://www.focus.de/panorama/welt/tid-11851/maedchengewalt-da-habe-ichrotgesehen_aid_328860.html.

${ }^{2}$ So auch Schneider, Frauenkriminalität und Frauenstrafvollzug, in: Gedächtnisschrift für Hilde Kaufmann, S. 267.

${ }^{3}$ Kaufmann, in: MSchrKrim 1967, S. 143.
} 
Kriminalität. Auch haben sich schon einige Autoren in Kriminologie und Soziologie mit der Frage der Ursachen dieses Phänomens auseinandergesetzt. Die vielgeäußerte Feststellung, Frauenkriminalität finde kaum Beachtung, ist daher dahingehend zu modifizieren, dass vor allen Dingen kaum empirische Untersuchungen existieren, die sich mit straffälligen Frauen auseinandersetzen. ${ }^{4}$ Brökling stellte bereits 1980 fest, dass die Kriminalität von Frauen ,unter Hinweis auf den statistisch unbedeutenden Anteil an der Gesamtkriminalität zu einem Randphänomen “5 verkommt. Diese Aussage trifft noch heute zu. Insbesondere die in der vorliegenden Untersuchung im Mittelpunkt stehenden Bereiche der Strafzumessung verurteilter Frauen und deren Rückfälligkeit werden in der Literatur stiefmütterlich behandelt.

Die hier vorgestellte Untersuchung soll dazu beitragen, diese Lücke zu schlieBen. Erstmals wird in Deutschland eine Untersuchung über die Sanktionierungspraxis der Gerichte gegenüber weiblichen Delinquenten und die Rückfallkriminalität weiblicher Straftäter durch Analyse eines bundesweiten Verurteilungsjahrganges durchgeführt. Die zu analysierenden Daten basieren auf den Erhebungen für die kürzlich veröffentlichte bundesweite Rückfalluntersuchung 2004-20076. Für diese Erhebung wurden anhand der personenbezogenen Eintragungen im Bundeszentral- und Erziehungsregister alle im Basisjahr 2004 strafrechtlich Sanktionierten oder aus der Haft Entlassenen erfasst und während eines dreijährigen Rückfallzeitraumes weiterverfolgt, um zu erkennen, ob sie wieder straffällig geworden sind.

Die eigene Untersuchung befasst sich folglich mit der im Bundeszentral- und Erziehungsregister erfassten Kriminalität von Frauen. ${ }^{7}$ Die Rohdaten konnten für eine detaillierte Untersuchung der Täterinnen genutzt werden.

Kapitel 1 gibt zunächst einen Überblick über Umfang, Struktur und Entwicklung von Frauenkriminalität anhand der Daten der Polizeilichen Kriminalstatistik (PKS) und der Strafverfolgungsstatistik (StVS). Zudem werden einige ausgewählte Dunkelfelduntersuchungen kurz skizziert. Dadurch wird ein Rahmen geschaffen, in den die nachfolgenden Ergebnisse der eigenen Untersuchung eingebettet werden können.

In Kapitel 2 werden sodann Erklärungsansätze, zum einen für die Kriminalitätsbelastung von Frauen und zum anderen für die im Vergleich zu Männern geringere Kriminalitätsbelastung von Frauen, diskutiert.

Die eigene Untersuchungsanlage wird zusammen mit den zu untersuchenden Forschungsfragen in Kapitel 3 dargestellt. Hierbei wird sowohl auf die zugrundelie-

\footnotetext{
${ }^{4}$ So auch Franke, S. 9.

${ }^{5}$ Brökling, S. 1.

${ }^{6} \mathrm{Jeble} /$ Albrecht/Hohmann-Fricke/Tetal, Legalbewährung nach strafrechtlichen Sanktionen. Eine bundesweite Rückfalluntersuchung, 2010.

${ }^{7}$ Lediglich in Kapitel 1 wird auf die der PKS und StVS zugrundeliegenden Daten zurückgegriffen sowie ein kurzer Überblick über Dunkelfelduntersuchungen gegeben.
} 
gende Datenbasis als auch auf Einschränkungen der Untersuchungsanlage eingegangen.

Die empirischen Ergebnisse der Auswertung der BZR-Daten werden in den Kapiteln 4-6 dargestellt. In Kapitel 4 erfolgt, in Anknüpfung an Kapitel 1, mit Hilfe einer Querschnittsanalyse ein Überblick über die Struktur der Frauenkriminalität differenziert nach Delikt, Alter und Nationalität. Zudem werden für den weiteren Verlauf der Untersuchung handhabbare Deliktsgruppen gebildet.

Den Schwerpunkt der Untersuchung stellen Kapitel 5 und 6 dar: Kapitel 5 befasst sich mit den rechtlichen Reaktionen auf Frauenkriminalität. Vor der eigenen Auswertung werden zunächst die Ergebnisse einiger, für die vorliegende Untersuchung relevanter, Studien zusammenfassend dargestellt. Es folgt, wie in Kapitel 4 im Querschnitt, eine detaillierte Auswertung der Daten bezüglich der Sanktionierungspraxis der Gerichte nach Alter, Delikt, Nationalität und Vorstrafenbelastung. Die Delikte Diebstahl gem. \ 242 StGB und Betrug gem. \ 263 StGB rücken hier besonders in den Fokus. Im Vordergrund steht die Frage, ob sich ein „Frauenbonus" auf justizieller Ebene nachweisen lässt.

Im Anschluss wird mit Hilfe einer Längsschnittanalyse die Rückfallkriminalität von Frauen abgebildet (Kapitel o). Nach einem kurzen Abriss zur geschichtlichen Entwicklung der Rückfallstatistik und Aufarbeitung des Forschungsstands wird nun auch der Rückfall in Abhängigkeit von Delikt, Alter sowie Nationalität zunächst nur für die Frauen analysiert. Durch die Mitberücksichtigung der Voreintragungen ist es möglich, die kriminelle Karriere von Täterinnen abzubilden. Ferner wird die Rückfallgeschwindigkeit analysiert. Sodann folgt eine Analyse der Rückfallkriminalität von Frauen und Männern im Vergleich. Anknüpfend an die Auswertungen in Kapitel 5 werden die rechtlichen Reaktionen auf rückfällige Frauen und Männer, soweit sie im Register erfasst sind, analysiert. In diesem Zusammenhang liegt der Fokus erneut auf den Delikten Diebstahl und Betrug. Die Frage des „Frauenbonus“ wird aufgegriffen.

Im 7. Kapitel werden die Ergebnisse schließlich zusammengefasst und bewertet. 



\section{Kapitel 1: Straffällige Frauen im Hell- und Dunkelfeld}

Mit der Darstellung statistischer Daten sowie von Forschungsergebnissen dient dieses Kapitel dazu, einen empirischen Rahmen zur Frauenkriminalität herzustellen, in den die eigenen Untersuchungsergebnisse hineingestellt werden können. Für die Abbildung des Hellfelds werden aktuelle Daten zu den polizeilich registrierten Tatverdächtigen und justiziell Abgeurteilten gesammelt und ausgewertet. Darüber hinaus erfolgt ein Überblick über Studien, die sich mit dem Dunkelfeld der Frauenkriminalität beschäftigt haben. Anhand der dadurch gewonnenen Ergebnisse werden Umfang, Struktur und Entwicklung der Kriminalität von Frauen erörtert.

\section{Quellen empirischer Daten}

Um Umfang, Struktur und Entwicklung der Frauenkriminalität darzustellen, kann zunächst als quantitative Datenquelle auf amtliche Kriminal- und Strafrechtspflegestatistiken zurückgegriffen werden. In Deutschland stehen hierfür die Polizeiliche Kriminalstatistik und die Strafrechtspflegestatistiken (Staatsanwaltschaftsstatistik, Justizgeschäftsstatistik der Strafgerichte, Strafverfolgungsstatistik, Bewährungshilfestatistik und Strafvollzugsstatistik) zur Verfügung. 


\subsection{Polizeiliche Kriminalstatistik}

In der auf Bundesebene vom Bundeskriminalamt seit 1953 geführten Polizeilichen Kriminalstatistik (PKS) werden die von der Polizei bearbeiteten, rechtswidrigen Straftaten („Fälle"), einschließlich der mit Strafe bedrohten Versuche und der vom Zoll bearbeiteten Rauschgiftdelikte, registriert. Nicht enthalten sind jedoch Ordnungswidrigkeiten, Staatsschutz- und Verkehrsdelikte. Zudem werden die von der Staatsanwaltschaft, von den Finanzbehörden und den Zollbehörden (außer den Rauschgiftdelikten) unmittelbar und abschließend bearbeiteten Vorgänge sowie die Straftaten von Soldaten der Bundeswehr, deren Ermittlung der Disziplinarvorgesetzte selbstständig durchgeführt hat, nicht berücksichtigt. ${ }^{8}$

Darüber, ob die in der PKS von der Polizei registrierten Sachverhalte auch aus justizieller Sicht „Straftaten“ darstellen, gibt die PKS keine Auskunft. Ebenso sagt sie nichts über die der Polizei verborgen gebliebene Kriminalität aus. ${ }^{9}$ Außer den Straftaten werden auch die Tatverdächtigen nach Geschlecht, Alter, Nationalität und Delikt erfasst. „Tatverdäcbtiger ist jeder, der nach dem polizeilichen Ermittlungsergebnis aufgrund zureichender tatsäcblicher Anbaltspunkte verdäcbtig ist, eine rechtswidrige (Straf-)Tat begangen zu baben. Dazu zäblen auch Mittäter, Anstifter und Gebilfen" "Folglich kann die PKS für die vorliegende Untersuchung als Erkenntnismittel für Umfang, Struktur und Entwicklung der tatverdächtigen Frauen auf polizeilicher Ebene dienen.

\subsection{Strafverfolgungsstatistik}

Von den oben aufgezählten Strafrechtspflegestatistiken ist für die vorliegende Untersuchung allein die Strafverfolgungsstatistik (StVS) interessant, denn die Staatsanwaltschaftsstatistik und die Justizgeschäftsstatistik der Strafgerichte verzichten bei ihren Angaben auf eine Differenzierung nach Geschlecht der Beschuldigten bzw. Angeschuldigten. Es werden vorrangig Verfahren gezählt. Auch die Bewährungshilfe- und die Strafvollzugsstatistik sind keine ausreichenden Erkenntnismittel für den Umfang und die Struktur von Frauenkriminalität, da sie sich nur auf kleine Untergruppen aus der Gesamtheit aller Verurteilten beziehen. So gibt die Bewährungshilfestatistik lediglich Auskunft über die Verurteilten, die einem hauptamtlichen Bewährungshelfer unterstellt sind; die Strafvollzugsstatistik bezieht sich ausschließlich auf Gefangene und Verwahrte.

Die StVS weist bereits seit über einem Jahrhundert Angaben über abgeurteilte Personen aus. Abgeurteilte sind Angeklagte, gegen die rechtskräftige Strafbefehle erlassen wurden bzw. Strafverfahren nach Eröffnung des Hauptverfahrens durch Urteil oder Einstellungsbeschluss rechtskräftig abgeschlossen worden sind. Die Zahl der Abgeurteilten setzt sich also aus den Verurteilten und aus Personen zu-

\footnotetext{
${ }^{8}$ BKA (Hrsg.), PKS 2009, S. 8 f.; BMI/ BMJ (Hrsg.), PSB I, S. 15

${ }_{9}^{9}$ Meier, Kriminologie, $\int 5$, Rdn. 8.

10 BKA (Hrsg.), PKS 2009, S. 20.
} 
sammen, gegen die andere Entscheidungen (u.a. Freispruch) ergangen sind. ${ }^{11}$ Ordnungswidrigkeiten werden, wie in der PKS, nicht erfasst. Die StVS enthält delikts- und personenbezogene Angaben. Zwar sind die Zahlen für Frauen zumeist nicht dargestellt; sie lassen sich jedoch aufgrund der Angabe der Gesamtzahlen und der Zahlen für die Männer berechnen. Die StVS eignet sich mithin als Erkenntnismittel zur Darstellung von Umfang, Struktur und Entwicklung der Frauenkriminalität auf gerichtlicher Ebene.

\subsection{Daten des Bundeszentralregisters}

Die vorliegende Untersuchung konnte in einer Sonderstudie auf die Daten der ersten und zweiten gesamtdeutschen Rückfalluntersuchung für das Bezugsjahr $1994^{12}$ bzw. 200413, die auf den Daten des Bundeszentralregisters (BZR) beruht, zurückgreifen. Die Daten des BZR bieten eine ausgezeichnete Basis für eine umfassende empirische Untersuchung des Umfangs und der Struktur der weiblichen Kriminalität, denn sie geben Auskunft über alle Verurteilungen im jeweiligen Bezugsjahr. Aufgrund der Daten des BZR ist es u.a. möglich, umfassend über Sanktion, Delikt, Vorstrafen, Alter und Geschlecht der Sanktionierten zu informieren. Gleichwohl soll nicht in diesem Kapitel, sondern erst an späterer Stelle auf diese Datenbasis zurückgegriffen werden. In diesem Kapitel soll vor allen Dingen ein aktueller Gesamtüberblick über weibliche Kriminalität gegeben werden. Hier bietet die Strafverfolgungsstatistik, die ebenfalls Informationen zu den justiziell Sanktionierten enthält, zum einen den Vorteil, dass aktuelle Daten für das Jahr 2009 zur Verfügung stehen. Zum anderen kann mit den Daten der Strafverfolgungsstatistik aufgrund der periodischen Erscheinungsweise die Kriminalitätsentwicklung dargestellt werden. Mit den dieser Untersuchung zur Verfügung stehenden Daten des BZR ließen sich zum jetzigen Zeitpunkt lediglich die Bezugsjahre 1994 und 2004 gegenüberstellen, wodurch keine hinreichenden Aussagen zur Entwicklung der Kriminalität der Frauen getroffen werden könnten. Eine regelmäßige Absammlung der BZR-Daten soll dies jedoch zukünftig ermöglichen. ${ }^{14}$

\subsection{Grenzen der Aussagekraft und Fehlerquellen der amtlichen Kriminalstatistiken}

Bei der kriminalstatistischen Analyse ist immer zu bedenken, dass die Kriminalstatistiken kein exaktes Abbild der Kriminalitätswirklichkeit bieten. Die Statistiken

\footnotetext{
11 StatBA (Hrsg.), Fachserie 10: Rechtspflege, Reihe 3: Strafverfolgung 2009, S. 13; im Folgenden Strafverfolgungsstatistik (StVS).

12 Jeble/Heinz/Sutterer, Legalbewährung nach strafrechtlichen Sanktionen. Eine kommentierte Rückfallstatistik, 2003.

${ }^{13}$ Jeble/Albrecht/Hobmann-Fricke/Tetal, Legalbewährung nach strafrechtlichen Sanktionen. Eine bundesweite Rückfalluntersuchung 2004 bis 2007, 2010.

${ }^{14}$ Vgl. hierzu auch Jeble/Albrecht/Hohmann-Fricke/Tetal, Legalbewährung nach strafrechtlichen Sanktionen, 2010, S. 21.
} 
Frauenkriminalität im Hell- und Dunkelfeld

messen vielmehr Ergebnisse von Entscheidungsprozessen der einzelnen Kontrollinstanzen. Die PKS misst die Verdachtssituation, wie sie sich nach der Beurteilung der Polizeibeamten zum Zeitpunkt der Abgabe der Akten an die Staatsanwaltschaft darstellt. Die StVS misst das Ergebnis der richterlichen Überzeugungsbildung. ${ }^{15}$ Die Grenzen der Aussagekraft sowie die Fehlerquellen sind deshalb zu berücksichtigen, wenn man anhand einer Analyse Aussagen zu (Frauen-) Kriminalität treffen möchte.

Eine Fehlerquelle ist die Art und Weise der Meldung der Taten zur Statistik. Die Meldungen der Dienststellen der Polizei und der Geschäftsstellen der Justiz sind nicht immer genau und zuverlässig. ${ }^{16}$ Nachteil der PKS ist, dass sie als Verdachtsstatistik eine ausgeprägte Tendenz zur strafrechtlichen Überbewertung aufweist, da bei der polizeilichen Ermittlung im Zweifel der als schwerer zu beurteilende Sachverhalt angenommen wird. Dies führt dazu, dass der Umfang der schweren Kriminalität im Verhältnis zur leichteren stark überzeichnet wird. ${ }^{17}$

Eine weitere Beschränkung des Aussagewertes, die allen Kriminal- und Rechtspflegestatistiken immanent ist, ist die Tatsache, dass die Delikte nur gezählt, aber nicht gewichtet werden, da die PKS und die StVS auf dem Prinzip der numerischen Häufigkeitszählung beruhen. ${ }^{18}$ Lediglich bei den Eigentums- und Vermögensdelikten wird die Schwere des Deliktes von der PKS im Ansatz, nämlich über den Geldwert der erlangten Beute erfasst. Die Intensität einer begangenen Körperverletzung wird dagegen nicht ausgewiesen. ${ }^{19}$ Dies ist insbesondere bei der Bildung von Deliktsgruppen, wie etwa „Gewaltkriminalität“ in der PKS problematisch. In dieser Gruppe zählt ein Mord genauso viel wie eine gefährliche Körperverletzung, wobei letztere gem. \224 Abs. 1 Nr. 4 StGB bereits bei einer gemeinschaftlichen Tatbegehung vorliegt. ${ }^{20}$ Eine weitere Differenzierung wäre jedoch gerade für die von Frauen begangenen Delikte wünschenswert, denn im Dunkelfeld zeichnet sich eine verhältnismäßig hohe Begehung leichter Körperverletzungen und eine geringe Begehung besonders gewalttätiger Delikte ab. ${ }^{21}$

Beim Vergleich mehrerer Jahrgänge einer Statistik sind stets gesellschaftliche und rechtliche Änderungen zu beachten. Insbesondere sind demographische Veränderungen (beispielsweise Veränderung der Bevölkerung nach Zahl und Struktur, Zuwanderung) sowie veränderte Kontrollpraxis (beispielsweise Veränderungen im

${ }^{15}$ BMI/BMJ (Hrsg.), PSB I, S. 5; Heinz, Kriminalität der Deutschen nach Alter und Geschlecht im Spiegel von Polizeilicher Kriminalstatistik und Strafverfolgungsstatistik, S. 15.

${ }_{16}$ Meier, Kriminologie, $\ 5$, Rdn. 13.

${ }_{17}$ Meier, Kriminologie, \5, Rdn. 13; Göppinger, \23, Rdn. 32; BMI/BMJ (Hrsg.), PSB I, S. 20 f.

${ }^{18}$ Heinz, Kriminalität von Deutschen nach Alter und Geschlecht im Spiegel von Polizeilicher Kriminalstatistik und Strafverfolgungsstatistik, S. 17.

${ }^{19}$ Heinz, in: BewHi 2002, S. 131, 133.

${ }^{20}$ Beispiel nach Heinz, Kriminalität von Deutschen nach Alter und Geschlecht im Spiegel von Polizeilicher Kriminalstatistik und Strafverfolgungsstatistik, S. 17.

${ }^{21}$ Vgl. hierzu Kap. 1, 2.2. 
Anzeigeverhalten, geänderte Ermittlungsintensität oder -strategie) und veränderte Erfassungsmodalitäten im Blick zu behalten. ${ }^{22}$

Zu bedenken ist ferner, dass die Daten der amtlichen Statistiken keinerlei Aussage über die Sozialisation der Probanden zulassen. Der Einfluss von sozialen Kontakten, Lebensweise, Bildung, Berufstätigkeit oder ähnlichen Faktoren, die auf die Kontrollinstanzen Einfluss haben könnten, muss hier daher außer Betracht bleiben und anhand von Einzelfallstudien untersucht werden.

Insbesondere wird die Aussagekraft der Statistiken dadurch geschmälert, dass ein Teil der begangenen Straftaten den Strafverfolgungsbehörden nicht bekannt wird. Der Umfang dieses Dunkelfelds hängt von verschiedenen Faktoren, vor allem von der je nach der Art des Delikts unterschiedlichen Anzeigebereitschaft der Bevölkerung, ab. Auch deshalb bieten die Statistiken kein getreues Bild der Verbrechenswirklichkeit.

Gleichwohl sind die amtlichen Kriminal- und Rechtspflegestatistiken aufgrund ihres oben beschriebenen Informationsgehalts als Erkenntnismittel für die hier vorliegende Untersuchung nützlich. ${ }^{23}$

\subsection{Dunkelfeldforschung}

Würde sich die Analyse auf die Auswertung der Statistiken beschränken, so würde sich der Aussagegehalt auf das den Strafverfolgungsbehörden bekannt gewordene „Hellfeld“ begrenzen. Für einen umfassenden Überblick über weibliche Kriminalität muss aber das Dunkelfeld mit betrachtet werden.

Unter dem Begriff des Dunkelfeldes der Kriminalität wird die Summe jener Delikte verstanden, die den Strafverfolgungsbehörden durch Nichtentdeckung oder Nichtanzeige nicht bekannt werden und deshalb in der Kriminalstatistik auch gar nicht erscheinen. ${ }^{24}$ Ohne Zusatzinformationen aus der Dunkelfeldforschung bleibt gänzlich ungewiss, ob Umfang, Struktur und Entwicklung der registrierten Fälle und Tatverdächtigen nicht nur durch ein unterschiedliches und in hohem Maße sozialem Wandel unterliegendes Anzeigeverhalten ${ }^{25}$ sowie durch eine ebenfalls im zeitlichen Verlauf unterschiedlich ausgeprägte und fokussierte Kontrolltätigkeit der Strafverfolgungsbehörden entstanden sind. Daher soll im weiteren Verlauf dieses Kapitels auch auf einzelne Dunkelfeldstudien eingegangen werden.

Dabei ist jedoch zu berücksichtigen, dass sich mit den gegenwärtig verfügbaren sozialwissenschaftlichen Methoden, namentlich mit Täter- und Opferbefra-

\footnotetext{
${ }_{22}$ Meier, Kriminologie, \5, Rdn. 14; Göppinger, \23, Rdn. 33; BMI/BMJ (Hrsg.), PSB I, S. 18 f; vgl. ferner Ausführungen unter Kap. 1, 3.

${ }^{23}$ Generell zur Unverzichtbarkeit der Statistiken als Planung- und Kontrollinstrument: Heinz, Kriminalität der Deutschen nach Alter und Geschlecht im Spiegel der Polizeilichen Kriminalstatistik und Strafverfolgungsstatistik, S. 10.

24 Schwind, \$2, Rdn. 34.

${ }^{25}$ Heinz, Kriminalität von Deutschen nach Alter und Geschlecht im Spiegel von Polizeilicher Kriminalstatistik und Strafverfolgungsstatistik, S. 8.
} 
gungen, nur ein Teil des Dunkelfeldes erhellen lässt. Es gibt Fall- und Tätergruppen, die sich nicht oder nur mit unverhältnismäßig großem Aufwand erforschen lassen. Die Grenzen der Dunkelfeldforschung beruhen zum einen auf den allgemeinen methodischen Problemen von Stichprobenbefragungen, zum anderen auf speziellen Problemen des Befragungstyps. Hierzu zählen die beschränkte Erfragbarkeit bestimmter, besonders schwerer Delikte, die Verständlichkeit der Deliktsfragen, die Erinnerungsfähigkeit der Befragten und der Wahrheitsgehalt der Aussagen. Auch Dunkelfeldforschungen verhelfen also nicht dazu, ein genaues Abbild der Kriminalitätswirklichkeit zu konstruieren. Gemessen wird immer nur die Selbstbeurteilung und Selbstauskunft der Befragten. Hinzu kommt, dass sich dies alles über die Zeit hinweg ändern kann. ${ }^{26}$

Dunkelfeldforschungen können die Kriminalstatistiken daher nicht ersetzen, sind jedoch eine notwendige Ergänzung. Sie dienen, zumindest für Teilbereiche, dazu, die stattfindenden Selektionsprozesse, insbesondere hinsichtlich der Anzeige, zu erkennen, quantitativ einzuordnen und in ihrer Bedeutung für das kriminalstatistische Bild zu bewerten. ${ }^{27}$

So ergab beispielsweise eine Studie ${ }^{28}$ zum Anzeigeverhalten in Bochum, in der mit jeweils mindestens 10 Jahren auseinander liegenden Messzeitpunkten (1975, 1986, 1998) Daten zum Anzeigeverhalten erhoben worden sind, dass die Summe der angezeigten und nicht angezeigten Körperverletzungen zwischen 1975 und 1986 weitestgehend konstant blieb, wohingegen zwischen 1986 und 1998 eine deutliche Zunahme zu verzeichnen war. Diese Zunahmen waren überwiegend auf eine veränderte Anzeigebereitschaft zurückzuführen. Denn während die absoluten Zahlen nach der PKS um über $100 \%$ zunahmen, stiegen Hell- und Dunkelfelddaten zusammen nur um $20 \%$. In Bochum beruhten dementsprechend 2/3 der Zunahme polizeilich registrierter Körperverletzungsdelikte auf einer Veränderung der Anzeigebereitschaft. ${ }^{29} \mathrm{Ob}$ diese Ergebnisse über Bochum hinaus auch bundesweite Bestätigung finden, kann mangels bundesweiter wiederholt durchgeführter Dunkelfeldforschung nicht beantwortet werden. ${ }^{30}$

Schließlich muss man sich auch die Frage stellen, ob speziell gegenüber weiblichen Tätern ein anderes Anzeigeverhalten an den Tag gelegt wird und es dadurch zu Verzerrungen im Hellfeld kommt.

Hierauf deutet eine von IPSOS-Deutschland durchgeführte Opferbefragung von 2.081 Personen hin. ${ }^{31} \mathrm{Im}$ Rahmen des Projekts wurde überprüft, inwiefern

\footnotetext{
26 Schwind, \2, Rdn. 66; Kun₹ \21, Rdn. 23 ff.

${ }^{27}$ Hein₹, in: BewHi 2002, S. 131, 134; ders., Kriminalität von Deutschen nach Alter und Geschlecht im Spiegel von Polizeilicher Kriminalstatistik und Strafverfolgungsstatistik, S. 9.

${ }_{28}$ Vgl. Schwind/Fetchenhauer/Ablborn/Weiß, Kriminalitätsphänomene im Langzeitvergleich am Beispiel einer deutschen Großstadt (Bochum), 1975, 1986, 1998.

29 Schwind/Fetchenbauer/Ablborn/Weiß, S. 142.

${ }^{30}$ So auch Heinz, Kriminalität von Deutschen nach Alter und Geschlecht im Spiegel von Polizeilicher Kriminalstatistik und Strafverfolgungsstatistik, S. 9.

31 Mansel, in: Lamnek/Boatca (Hrsg.), Geschlecht, Gewalt, Gesellschaft, S. 384, 391 f.
} 
das Anzeigeverhalten von Opfern oder Zeugen einer Straftat von spezifischen Merkmalen des vermeintlichen Täters abhängt. Aus den Daten geht hervor, dass weibliche Opfer gegenüber männlichen Tätern seltener auf eine Anzeige verzichten als gegenüber Frauen. Männliche Opfer verzichten seltener bei weiblichen Tätern auf die Erstattung einer Anzeige. Dies könnte daran liegen, dass Männer, als das vermeintlich „starke“ Geschlecht, die gegen sie gerichteten Aktionen der Frauen zwar seltener als Straftat definieren. Wenn sie aber vom Vorliegen einer Straftat ausgehen, so reagieren sie konsequent und bringen das entsprechende Verhalten überproportional häufig zur Anzeige. 32 Allerdings ist die Fallzahl in der Konstellation männliches Opfer und weiblicher Täter mit 15 Fällen sehr gering.

Ein unterschiedliches, namentlich zurückhaltenderes Anzeigeverhalten von Männern, die Opfer weiblicher Täter werden, wird insbesondere im häuslichen Milieu vermutet. ${ }^{3}$

Eine Hellfelduntersuchung der Berliner Polizei34 zu häuslicher Gewalt stellt fest, dass ein Viertel der in Berlin im häuslichen Milieu registrierten Fälle (24,3 \%) der gefährlichen und schweren Körperverletzungen von Frauen an Männern verübt wird. Der Anteil weiblicher Täter mit männlichen Opfern bei der einfachen Körperverletzung liegt hingegen nur bei 11,7\%.35 Fraglich ist daher, wie der hohe Anteil weiblicher Täter an den gefährlichen und schweren Körperverletzungen zu erklären ist. Man könnte vermuten, dass Männer die Wahrscheinlichkeit, dass sie ernst genommen werden, dann höher einschätzen, wenn sie etwas „schwerwiegenderes" vorzuweisen haben. Auch fehlendes Unrechtsempfinden für leichte Körperverletzungen durch Frauen, Scham der Betroffenen und die Annahme des Stereotyps, dass ein Mann kein Opfer sein kann, könnten mögliche Gründe für die geringere Anzahl der angezeigten einfachen Körperverletzungen sein. ${ }^{36}$ Ohne Informationen aus dem Dunkelfeld kann diese Frage allerdings nur schwer beantwortet werden.

Eine Pilotstudie ${ }^{37}$ zur Gewalt gegen Männer im Auftrag des Bundesministeriums für Familie, Senioren, Frauen und Jugend aus dem Jahr 2002 kommt zu dem Ergebnis, dass jedem vierten von rund 200 befragten Männern mindestens einmal ein Akt körperlicher Gewalt durch die Partnerin widerfuhr. ${ }^{38}$ Noch häufiger wird

32 Mansel, in: Lamnek/Boatca (Hrsg.), Geschlecht, Gewalt, Gesellschaft, S.384, 391 f.

33 Vgl. zu dieser Problematik: Kavemann, Gewalt in Paarbeziehungen, in: Elz (Hrsg.), Täterinnen, S. 104-114.

${ }^{34}$ Kommoß, Opfer- und Tatverdächtigenstruktur häuslicher Gewalt aus der „Sicht“ der Berliner Polizei 2001, in: Berliner Forum Gewaltprävention Nr. 1/2002, S. 73-76.

35 Kommoß, in: Berliner Forum Gewaltprävention 2002, S. 73, 75.

${ }^{36}$ Siehe ausführlich dazu: BMFSFJ (Hrsg.), Gewalt gegen Männer - Personale Gewaltwiderfahrnisse von Männern in Deutschland. Pilotstudie, S. $192 \mathrm{ff}$.

37 Walter/Len₹/Puchert, in: Jungnitz/Lenz/Puchert et al. (Hrsg.), Gewalt gegen Männer - Personale Gewaltwiderfahrnisse von Männern in Deutschland, S. 139-195.

38 Walter/Len₹/Puchert, in: Jungnitz/Lenz/Puchert et al. (Hrsg.), Gewalt gegen Männer - Personale Gewaltwiderfahrnisse von Männern in Deutschland, S. 139, 146 ff. 
von psychischer Gewalt berichtet. ${ }^{39}$ Hier sind allerdings die geringe Anzahl der befragten Personen sowie die eigene Definition des Gewaltbegriffs der Befragten zu berücksichtigen.

Es ist folglich nicht auszuschließen, dass gerade für weibliche Täter häuslicher Gewalt ein großes Dunkelfeld existiert. Weitere Untersuchungen, insbesondere zum Anzeigeverhalten, sind wünschenswert.

Insgesamt machen die Ergebnisse der beispielhaft aufgeführten Studien deutlich, dass die sich letztendlich in den Statistiken widerspiegelnde Kriminalität von unterschiedlichen Faktoren im Dunkelfeld, insbesondere auch vom Anzeigeverhalten der Bevölkerung, abhängig ist. Die Dunkelfeldforschung ist daher ein bedeutsames Instrument neben den offiziellen Kriminalstatistiken.

\section{Umfang, Struktur und Entwicklung der Frauenkriminalität}

Als nächstes wird ein Überblick über Umfang, Struktur und Entwicklung der weiblichen Kriminalität anhand der Daten der PKS, der StVS und einiger ausgewählter Dunkelfeldstudien geboten. Da Kriminalität, wie allgemein bekannt, ein überwiegend männliches Phänomen ist, soll in diesem Zusammenhang, in einigen Bereichen, auch auf die Kriminalität der Männer eingegangen werden, um Vergleiche zu ermöglichen und die Besonderheiten für das weibliche Geschlecht herauszuarbeiten.

\subsection{Umfang, Struktur und Entwicklung der Tatverdächtigen}

\subsubsection{Häufigkeit und Alter der Tatverdächtigen}

Im Jahr 2009 beträgt der Anteil der weiblichen Tatverdächtigen im gesamten deutschen Bundesgebiet insgesamt, d.h. Kinder, Jugendliche, Heranwachsende und Erwachsene einbezogen, 24,6\% ${ }^{40}$. Gemessen an dem weiblichen Bevölkerungsanteil in Deutschland, der in den letzten Jahren stetig bei leicht über $50 \%$ liegt ${ }^{41}$, stellt dies eine eindeutige quantitative Unterrepräsentation der Frauen an der Kriminalitätsbelastung dar. Der Anteil der Nichtdeutschen an allen tatverdächtigen Frauen im Jahr 2009 beträgt knapp $20 \% .42$

39 Walter/Lenz/Puchert, in: Jungnitz/Lenz/Puchert et al. (Hrsg.), Gewalt gegen Männer - Personale Gewaltwiderfahrnisse von Männern in Deutschland, S. 139, $157 \mathrm{ff}$.

40 Die Gesamtzahl der Tatverdächtigen beträgt 2009 ca. 2,2 Millionen im gesamten deutschen Bundesgebiet; davon waren nach ,alter“ Zählung 554.454 (24,6 \%) weiblich und 1.695 .885 männlich (75,4\%), vgl. BKA (Hrsg.), PKS 2009, S. 72.

${ }^{41}$ Für das Jahr 2009 liegt der weibliche Bevölkerungsanteil bei 51 \%, vgl. http:/ /www.destatis.de.

42 BKA (Hrsg.), PKS 2009, Tabelle 33. Es wurden wieder die Zahlen nach der ,alten“ Zählung berücksichtigt. 
Umfang, Struktur und Entwicklung der Tatverdächtigenzahlen werden durch demographische Veränderungen, wie beispielsweise Größe, Zusammensetzung und Entwicklung der Bevölkerung, beeinflusst. ${ }^{43}$ Statistisch wird diesen Veränderungen dadurch Rechnung getragen, dass die absoluten Zahlen auf einen konstant gesetzten Bevölkerungsanteil bezogen werden. Für die Tatverdächtigen geschieht dies durch die Berechnung der Tatverdächtigenbelastungszahlen (TVBZ). Nach der Definition der PKS ist die TVBZ die Zahl der ermittelten Tatverdächtigen, errechnet auf 100.000 Einwohner des entsprechenden Bevölkerungsanteils, jeweils ohne Kinder unter 8 Jahren. ${ }^{44}$ Für die nichtdeutschen Tatverdächtigen kann eine reelle TVBZ jedoch nicht errechnet werden, weil in der Einwohnerstatistik die amtlich nicht gemeldeten Ausländer fehlen, die sich hier legal (z.B. als Touristen, Geschäftsreisende, Besucher, Grenzpendler, Stationierungsstreitkräfte oder Diplomaten) oder illegal aufhalten. ${ }^{45}$ Daher weist die PKS nur die TVBZ für Deutsche aus.

\footnotetext{
${ }^{43}$ Hein₹, Kriminalität der Deutschen nach Alter und Geschlecht im Spiegel von Polizeilicher Kriminalstatistik und Strafverfolgungsstatistik, S. 18.

${ }^{44}$ BKA (Hrsg.), PKS 2009, S. 15.

${ }^{45}$ BKA (Hrsg.), PKS 2009, S. 97.
} 
Schaubild 1.1: TVBZ für Deutsche nach Geschlecht und Altersgruppe, 2009

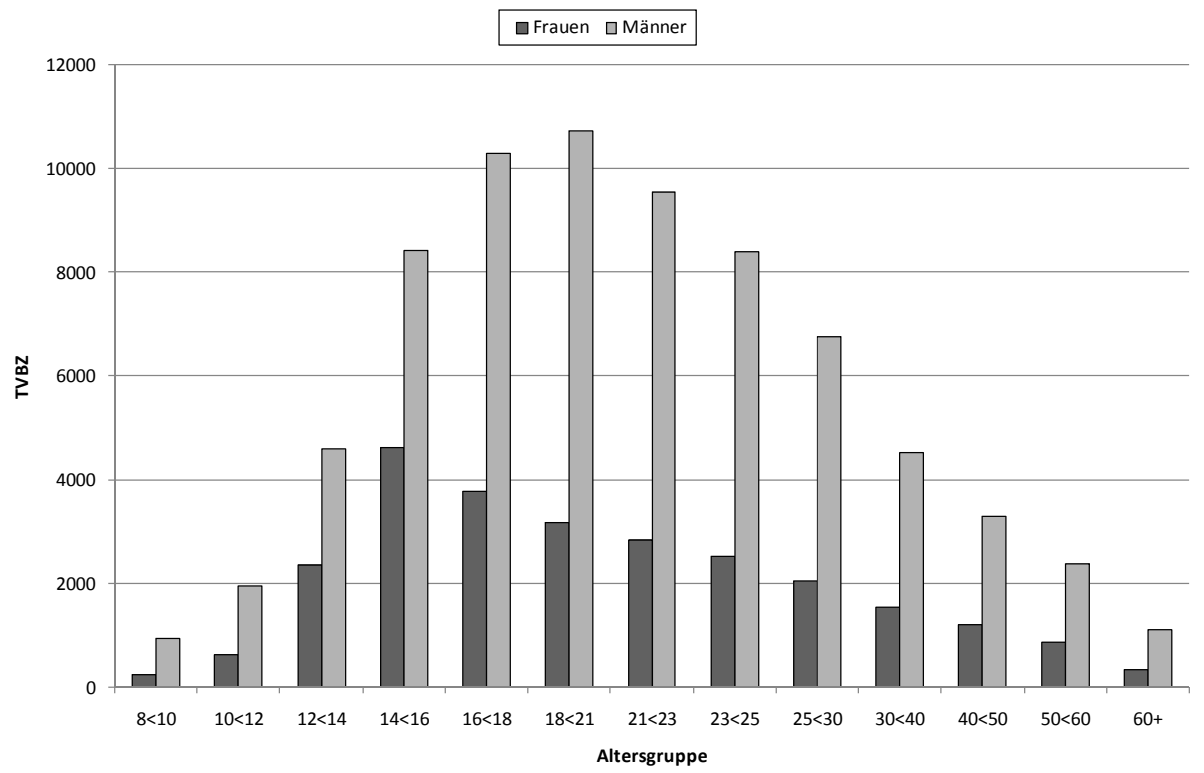

Quelle: BKA (Hrsg.), PKS 2009, Tab. 61; Absolutzablen siehe Tabelle 1.1 a im Anhang.

Schaubild 1.1 zeigt die TVBZ für Deutsche nach Geschlecht und Altersgruppe bezogen auf Gesamtdeutschland für das Jahr 2009. Die Kriminalitätsbelastung der Frauen ist in allen Altersgruppen erheblich geringer als die der Männer. Die Alterskurve ist für beide Geschlechter linkssteil und rechtsschief, d.h. die Belastung steigt zunächst steil an und fällt dann wieder ab. Für die männlichen Tatverdächtigen erreicht die TVBZ ihren Gipfel in der Gruppe der Heranwachsenden (18-21 Jahre). Bei den weiblichen Tatverdächtigen ist hingegen die Gruppe der 14-16jährigen Jugendlichen am höchsten belastet. Diese Ergebnisse lassen darauf schließen, dass die registrierte Kriminalität junger Menschen häufig auf diese Altersphase beschränkt bleibt. ${ }^{46}$ Ferner ist zu berücksichtigen, dass sich die Überrepräsentation junger Menschen unter den Tatverdächtigen relativiert, wenn man die Art und Schwere des begangenen Deliktes mitbetrachtet. Bei den Jugendlichen dominieren Diebstahlsdelikte. ${ }^{47}$ Im Unterschied dazu weist die Kriminalität der Erwachsenen ein breiteres Deliktsspektrum mit meist höheren Schäden auf. ${ }^{48}$

\footnotetext{
${ }^{46}$ So auch Heinz, Kriminalität der Deutschen nach Alter und Geschlecht im Spiegel von Polizeilicher Kriminalstatistik und Strafverfolgungsstatistik, S. 28.

${ }^{47}$ Vgl. hierzu die Ausführungen unter Kap.1, 2.2.

48 Genauer hierzu Heinz, Kriminalität der Deutschen nach Alter und Geschlecht im Spiegel von Polizeilicher Kriminalstatistik und Strafverfolgungsstatistik, S. 28 f.
} 


\subsubsection{Deliktstruktur der Tatverdächtigen}

Richtet man den Blick nun auf die Struktur der im Jahr 2009 ermittelten Delikte, die den weiblichen Tatverdächtigen zur Last gelegt werden, so lässt sich feststellen, dass weibliche Tatverdächtige mit $28 \%$ am häufigsten mit einfachem Diebstahl und Unterschlagung in Erscheinung treten (vgl. Schaubild 1.2).

\section{Schaubild 1.2: Deliktsstruktur von tatverdächtigen Frauen, 2009}

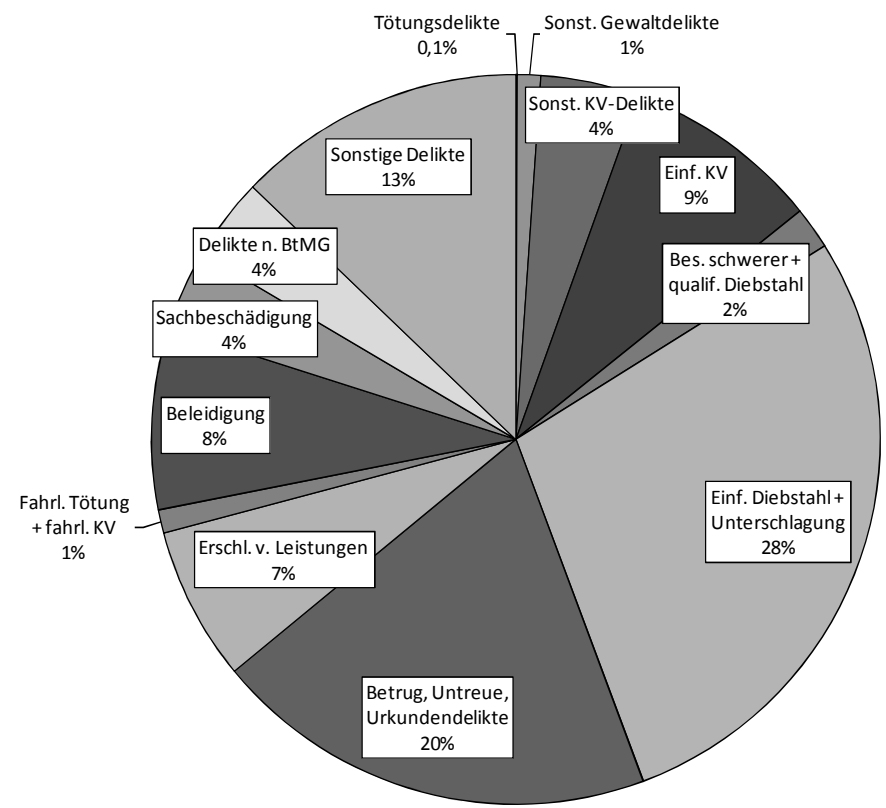

Quelle: BKA (Hrsg.), PKS 2009, Tab. 48 sowie Tabellenanhang; Absolutzablen siehe Tabelle $1.2 \mathrm{a}$ im Anhang.

Am zweithäufigsten begehen sie Betrug-, Untreue- und Urkundendelikte mit insgesamt $20 \%$. Die beiden zuletzt genannten Kategorien machen insgesamt einen Anteil von fast $50 \%$ an der Gesamtkriminalität der weiblichen Tatverdächtigen aus. Von den übrigen Delikten sind vor allen Dingen die einfache Körperverletzung mit 9\%, die Beleidigung mit $8 \%$ sowie die das Erschleichen von Leistungen mit $7 \%$ nennenswert. Sonstige Körperverletzungsdelikte ${ }^{49}$ machen einen Anteil von $4 \%$ aus. Der Anteil für Tötungsdelikte ${ }^{50}$, sonstige Gewaltdelikte ${ }^{51}$ sowie für

\footnotetext{
${ }^{49}$ In dieser Kategorie wurden $\iint$ 224-226 StGB berücksichtigt, vgl. Tab. 1.2a im Anhang.

${ }^{50}$ Berücksichtigt wurden $\$ \$ 211,212$ sowie $\$ 227 \mathrm{StGB}$, vgl. Tab. 1.2a im Anhang.

${ }^{51}$ Hierzu wurden die $\int S 113,177,178$, 239a, 239b, 249-252, 255, 316 a StGB gezählt, vgl. Tab. 1.2a im Anhang.
} 
fahrlässige Tötung und fahrlässige Körperverletzung 52 fällt mit $0,1 \%$ sowie $1 \%$ noch niedriger aus.

Auch schwerere Diebstahlsformen, nämlich der besonders schwere und qualifizierte Diebstahl, nehmen in der gesamten Deliktsstruktur nur einen Anteil von $2 \%$ ein. Weibliche Tatverdächtige sind mithin insbesondere im Bereich der leichteren Delinquenz auffällig, wohingegen schwerere Delikte, wie beispielsweise Tötungsdelikte eher selten begangen werden. Der Anteil der sonstigen Delikte an den von den weiblichen Tatverdächtigen im Jahr 2009 begangenen Delikten beträgt insgesamt $13 \% .53$

Da der Diebstahl das von Frauen am häufigsten begangene Delikt ist und die PKS hier weitere Differenzierungen nach der Art des Diebstahls zulässt, soll diesbezüglich eine genauere Betrachtung erfolgen.

Die TVBZ ist sowohl bei den Frauen als auch bei den Männern für den Diebstahl am höchsten. Im Jahr 2009 beträgt sie 366 für die Frauen und 861 für die Männer. ${ }^{54}$ Die TVBZ der Männer beträgt folglich selbst bei einem Delikt, bei welchem die Frauen relativ hoch belastet sind, mehr als das Doppelte.

Schaubild 1.3: TVBZ nach Diebstablsart, Geschlecht und Altersgruppe, 2009

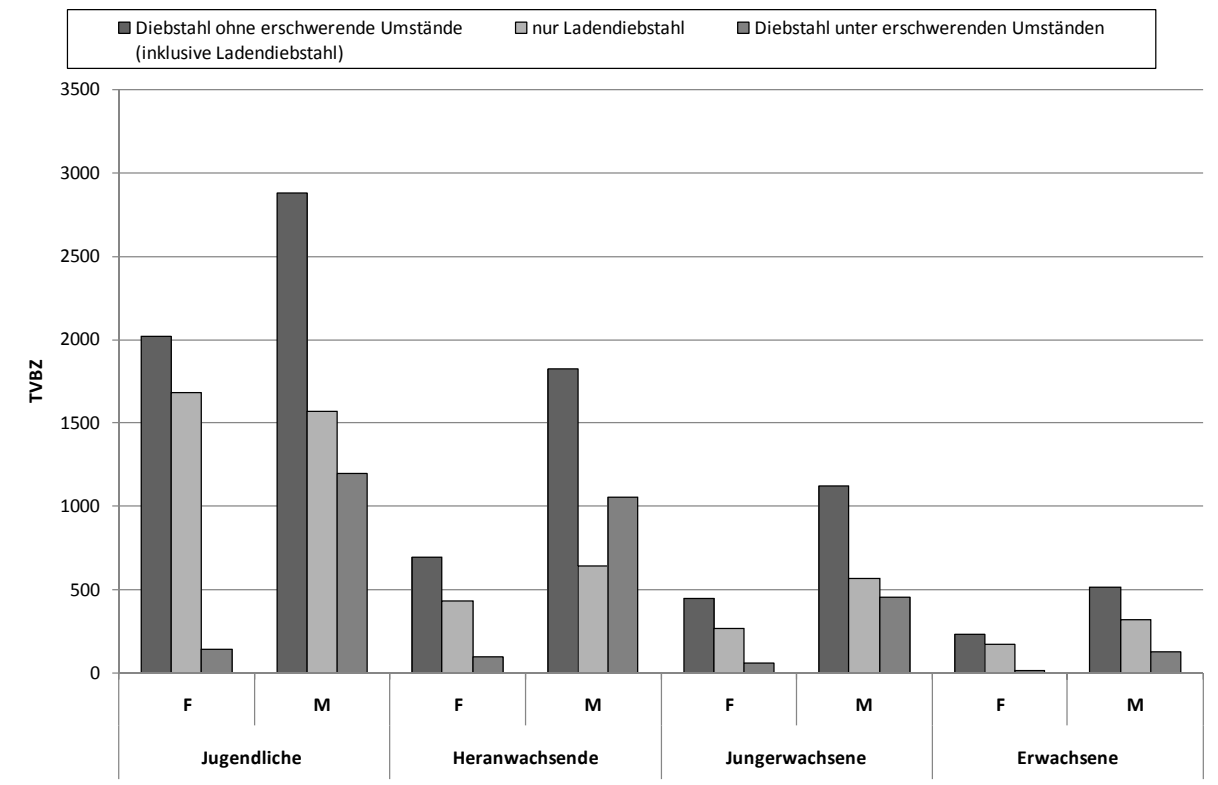

Quelle: BKA (Hrsg.), PKS 2009, Tab. 64b, 64c; Absolutrablen siehe Tabelle 1.3 a im Anhang.

\footnotetext{
52 Hierbei handelt es sich um Delikte die außerhalb des Straßenverkehrs begangen wurden.

${ }^{53} \mathrm{Vgl}$. eine genauere Aufschlüsselung dieser Gruppe in Tab. 1.2a im Anhang.

${ }^{54}$ BKA (Hrsg.), PKS 2009, S. 103 f.
} 
Schaubild 1.3 nimmt eine differenziertere Betrachtung vor. Es gibt die TVBZ der Tatverdächtigen für das Jahr 2009 nach Art des Diebstahls, Geschlecht und Altersgruppe wieder. In keiner anderen Deliktsgruppe gleichen sich die Belastungszahlen der weiblichen und männlichen Tatverdächtigen derart an wie in der Gruppe des Diebstahls. Beide Geschlechter sind am höchsten mit dem Diebstahl ohne erschwerende Umstände in der Gruppe der Jugendlichen belastet. Die TVBZ für die Frauen beträgt hier 2.017 und die der Männer 2.880. Die hohe Belastung wird besonders deutlich, wenn man einen Vergleich mit der durchschnittlichen TVBZ mit Kriminalität insgesamt anstellt: Diese liegt bei $1.244^{55}$ bei den weiblichen und bei 2.47756 bei den männlichen Tatverdächtigen.

Auffallend ist, dass Frauen bei Diebstählen unter erschwerenden Umständen wieder erheblich unterrepräsentiert sind. In der am höchsten belasteten Altersstufe der Jugendlichen liegt die TVBZ hier bei lediglich 140, wohingegen die der männlichen Jugendlichen bei 1.195 angesiedelt ist. Zudem ist interessant, dass die TVBZ der weiblichen Jugendlichen in der Untergruppe „Ladendiebstahl“ mit 1.682 sogar höher als bei den Männern mit 1.572 ist.

Betrachtet man die Altersstruktur insgesamt, ist ferner erwähnenswert, dass 45,4 \% der tatverdächtigen Frauen über 60 Jahre wegen Diebstahls ohne erschwerende Umstände aufgefallen sind. ${ }^{57}$ Eine Erklärung hierfür könnte die Altersarmut sein, ${ }^{58}$ die vor allen Dingen Frauen betrifft, und durch niedrige Renten bzw. sehr geringe Einkommensbezüge hervorgerufen wird.

\subsubsection{Entwicklung der Tatverdächtigen}

Tabelle 1.1 zeigt, dass die absoluten Zahlen weiblicher wie männlicher Tatverdächtiger im Beobachtungszeitraum bis zum Jahr 2004 kontinuierlich leicht gestiegen sind und seitdem auf etwas niedrigerem Niveau nahezu stagnieren. Der Anteil der Frauen an der Gesamtkriminalität bewegt sich dabei zwischen $22 \%$ und, aktuell, $25 \%$.

\footnotetext{
55 BKA (Hrsg.), PKS 2009, S. 97, 104.

${ }^{56}$ BKA (Hrsg.), PKS 2009, S. 97.

${ }^{57}$ BKA (Hrsg.), PKS 2009, S. 91.

58 Schwind, \$3, Rdn. 35.
} 
Tabelle 1.1: Entwicklung der Tatverdächtigen bei Straftaten insgesamt ab 1995

\begin{tabular}{|l|c|c|c|c|c|}
\hline & \multicolumn{2}{|c|}{ Frauen } & \multicolumn{2}{c|}{ Männer } & Gesamt \\
\hline $\mathbf{1 9 9 5}$ & $\mathbf{n}$ & $\%$ & $\mathbf{n}$ & $\%$ & \\
\hline $\mathbf{1 9 9 6}$ & 467.309 & $22 \%$ & 1.650 .795 & $78 \%$ & 2.118 .104 \\
\hline $\mathbf{1 9 9 7}$ & 597.352 & $22 \%$ & 1.715 .941 & $78 \%$ & 2.213 .293 \\
\hline $\mathbf{1 9 9 8}$ & 539.375 & $23 \%$ & 1.780 .520 & $77 \%$ & 2.319 .895 \\
\hline $\mathbf{1 9 9 9}$ & 527.816 & $23 \%$ & 1.735 .324 & $77 \%$ & 2.263 .140 \\
\hline $\mathbf{2 0 0 0}$ & 528.972 & $23 \%$ & 1.757 .400 & $77 \%$ & 2.286 .372 \\
\hline $\mathbf{2 0 0 1}$ & 528.978 & $23 \%$ & 1.751 .633 & $77 \%$ & 2.280 .611 \\
\hline $\mathbf{2 0 0 2}$ & 547.600 & $24 \%$ & 1.778 .549 & $76 \%$ & 2.326 .149 \\
\hline $\mathbf{2 0 0 3}$ & 555.099 & $24 \%$ & 1.800 .062 & $76 \%$ & 2.355 .161 \\
\hline $\mathbf{2 0 0 4}$ & 567.996 & $24 \%$ & 1.816 .272 & $76 \%$ & 2.384 .268 \\
\hline $\mathbf{2 0 0 5}$ & 548.724 & $24 \%$ & 1.764 .412 & $76 \%$ & 2.413 .136 \\
\hline $\mathbf{2 0 0 6}$ & 550.049 & $24 \%$ & 1.733 .078 & $76 \%$ & 2.283 .127 \\
\hline $\mathbf{2 0 0 7}$ & 554.738 & $24 \%$ & 1.740 .145 & $76 \%$ & 2.294 .883 \\
\hline $\mathbf{2 0 0 8}$ & 549.604 & $24 \%$ & 1.706 .089 & $76 \%$ & 2.255 .693 \\
\hline $\mathbf{2 0 0 9 5 9}$ & 554.454 & $25 \%$ & 1.695 .885 & $75 \%$ & 2.250 .339 \\
\hline
\end{tabular}

Quelle: BKA (Hrsg.), PKS der jeweiligen Jahrgänge, Tab. 32.

Die Gesamtzuwachsrate der Tatverdächtigen auf der Basis 1995 liegt 2009 bei etwa $6 \%$. Im gleichen Zeitraum beträgt die Zuwachsrate für die weiblichen Tatverdächtigen $19 \%$, wohingegen die männlichen Tatverdächtigen mit einer ca. 3\%igen Erhöhung unter der Gesamtzuwachsrate liegen. Der Anstieg der weiblichen Tatverdächtigen ist mithin um ein Vielfaches höher. Dabei ist jedoch zu berücksichtigen, dass die absolute Gesamtzahl aller tatverdächtigen Frauen sehr viel niedriger ist, als die der Männer (vgl. Tabelle 1.1). Die Zuwachsraten fallen dementsprechend höher aus. Nach wie vor sind Frauen aber weitaus seltener polizeilich registriert.

Betrachtet man die Entwicklung der TVBZ der Frauen seit 1995 anhand der Zuwachsrate (vgl. Schaubild 1.4) für die Jugendlichen, Heranwachsenden und Erwachsenen, so fällt auf, dass die Zahlen für alle Altersgruppen erheblich gestiegen sind.

${ }^{59}$ Hier wurde die Anzahl der Tatverdächtigen nach der ,alten“ Zählung zugrunde gelegt. 
Schaubild 1.4: Entwicklung der TVBZ von Frauen bei Straftaten insgesamt ab 1995

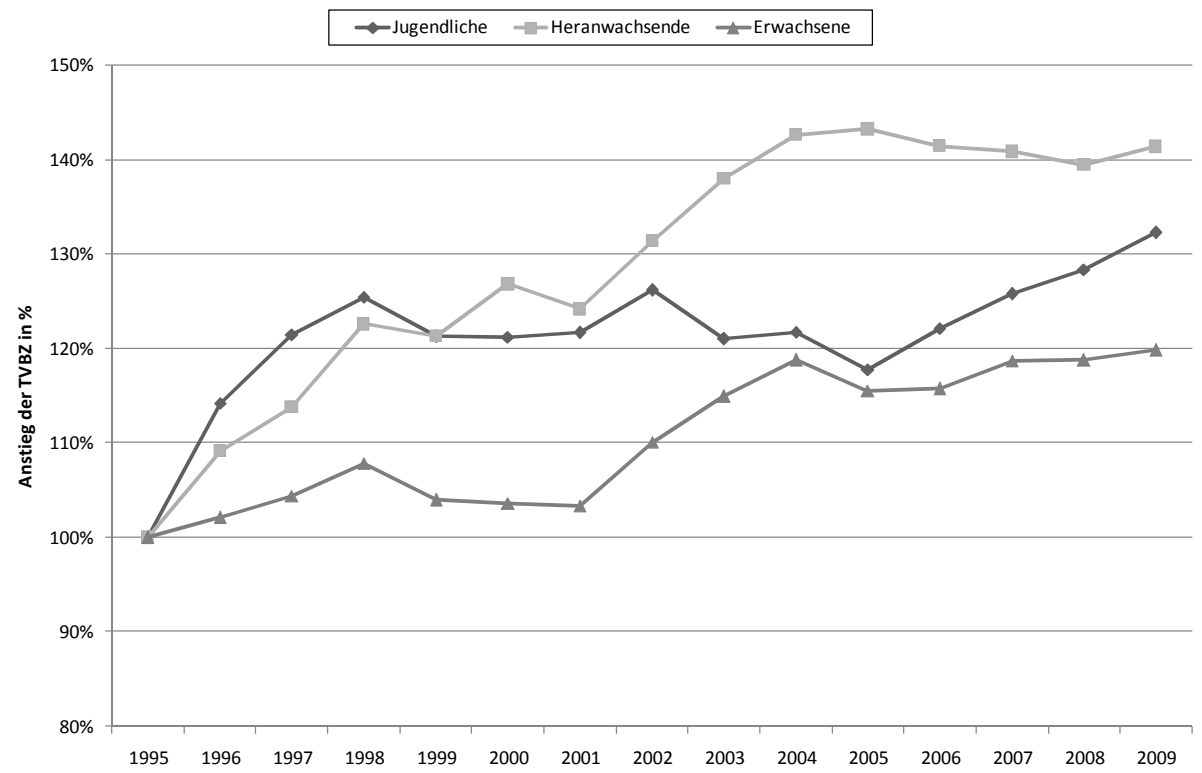

Quelle: BKA (Hrsg.), PKS der jeweiligen Jahrgänge, Tab. 33, 61; Absolutzablen siebe Tabelle 1.4a im Anhang.

Besonders deutlich wird dieser Verlauf, wenn man die Entwicklung der TVBZ der 18 bis unter 21-jährigen heranwachsenden Tatverdächtigen betrachtet. Von 1995 bis $2009^{60}$ beträgt hier die Zuwachsrate $41 \%$, ist allerdings seit 2005 leicht rückläufig. Im Gegensatz dazu steigt die TVBZ für die Jugendlichen nach einem kurzen Rückgang seit 2005 kontinuierlich, liegt jedoch mit $32 \%$ insgesamt unter der Zuwachsrate für die heranwachsenden Frauen im Beobachtungszeitraum. Am geringsten ist die TVBZ der erwachsenen Frauen in Höhe von $20 \%$ angestiegen.

Bei den männlichen Tatverdächtigen stellt sich die Entwicklung anders dar (vgl. Schaubild 1.5): Hier ist bis zum Jahr 2009 die höchste Gesamt-Zuwachsrate mit $13 \%$ für die erwachsenen Tatverdächtigen zu verzeichnen. Seit 2004 sind die Zahlen jedoch rückläufig. Bei den Heranwachsenden lässt sich für die Männer ein 9\%iger und für die Jugendlichen sogar lediglich ein 1\%iger Zuwachs im Beobachtungszeitraum verzeichnen.

\footnotetext{
${ }^{60} \mathrm{Da}$ die PKS seit 2009 die TVBZ nur für die Tatverdächtigen nach der neuen Zählung aufweist, wurde die hier zugrunde liegende TVBZ für das Jahr 2009 mit den Daten aus BKA (Hrsg.), PKS 2009, Tab. 33 und 61 berechnet.
} 
Schaubild 1.5: Entwicklung der TVBZ von Männern bei Straftaten insgesamt ab 1995

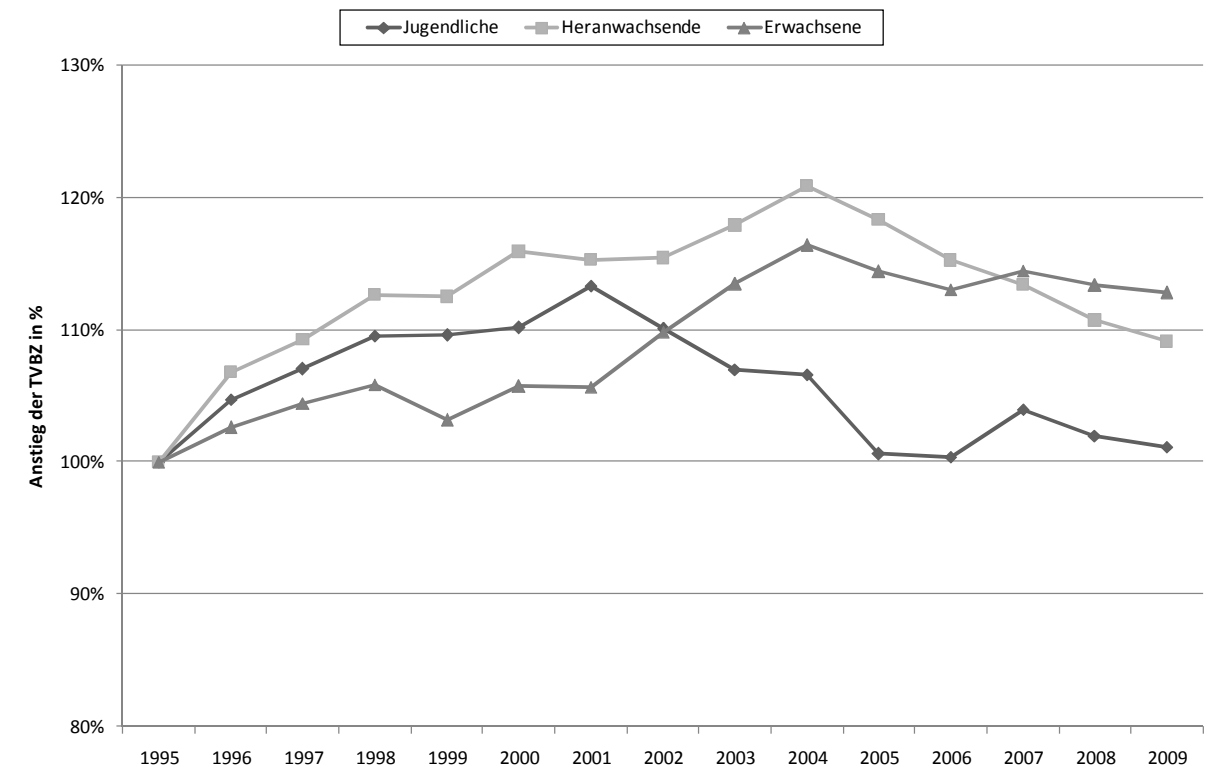

Quelle: BKA (Hrsg.), PKS der jeweiligen Jabrgänge, Tab. 33, 61; Absolutzablen siebe Tabelle 1.5 a im Anhang.

Die Ergebnisse vermitteln zunächst den Eindruck, weibliche Kriminalität sei im Gegensatz zu der männlichen besorgniserregend gestiegen. Bei der Interpretation ist jedoch zu berücksichtigen, dass Männer nach wie vor insgesamt viel höher belastet sind als Frauen. Zwar sind für die Frauen für alle Altersgruppen von 1995 bis 2009 höhere Zuwachsraten zu verzeichnen, dies relativiert sich jedoch, wenn man die niedrigen absoluten Zahlen berücksichtigt. Eine Erhöhung in diesem Bereich macht sich daher sehr viel deutlicher bemerkbar.

Ein Eckdatenvergleich der TVBZ 1995 und $2008^{61}$ ergibt, dass die Zuwachsraten bei den Körperverletzungsdelikten für beide Geschlechter besonders ausgeprägt ist: Während die Belastung mit schwereren Delikten wie beispielsweise Tötungs- oder Raubdelikten in etwa gleich geblieben, z.T. sogar leicht gesunken ist, sind die TVBZ für die einfache Körperverletzung bei den Frauen von 54 auf 118, bei den Männern von 390 auf 616 und die TVBZ für gefährliche und schwere

${ }^{61}$ Hier wurde das Jahr 2008 zugrunde gelegt, da in der PKS seit 2009 eine neue Zählweise eingeführt wurde: Danach werden die Tatverdächtigen, die in mehreren Bundesländern auffällig geworden sind, nur noch einmal erfasst. Die Zahlen sind daher nicht ohne weiteres mit denen der Vorjahre vergleichbar, vgl. hierzu: BKA (Hrsg.), PKS 2009, S. 7, S. 72.; zwar sind die Tatverdächtigen nach der alten Zählung differenziert nach Altersgruppen angegeben (vgl. Tab. 33), allerdings nicht differenziert nach Delikt, sodass vorliegend aus Gründen der Vergleichbarkeit das Jahr 2008 gewählt wurde. 
Körperverletzung von 27 auf 54 (Frauen) sowie 195 auf 335 (Männer) angestiegen. ${ }^{62}$

\subsection{Umfang und Struktur im Dunkelfeld}

Die polizeilich registrierte Kriminalität ist, wie bereits erwähnt, ein nicht repräsentativer Ausschnitt der Kriminalitätswirklichkeit. Ein Großteil der Delikte verbleibt aus unterschiedlichsten Gründen im Dunkelfeld, da sie beispielsweise nicht angezeigt oder vom Opfer oder von Dritten nicht als Straftat bewertet werden. „Es kann daher nicht von einer feststehenden Relation zwischen begangenen und statistisch erfassten Straftaten ausgegangen werden. "63 Um einen umfassenden Überblick über den Umfang und die Struktur der Frauenkriminalität zu liefern, muss daher das Dunkelfeld mit betrachtet werden. Fraglich ist, ob sich die oben festgestellte Unterrepräsentation der Frau an der Gesamtkriminalität sowie ihre relativ größere Beteiligung bei Bagatelldelikten durch Dunkelfelduntersuchungen bestätigen lassen. Vielleicht lässt sich aber auch die These der Vertreter der sog. Gleichverteilungstheorie ${ }^{64}$, Frauen begingen mindestens genauso viele Straftaten wie Männern, diese blieben jedoch eher im Verborgenen oder würden von den Strafverfolgungsbehörden seltener geahndet, bekräftigen. ${ }^{65}$

Das Dunkelfeld der nicht polizeilich bekannt gewordenen Straftaten lässt sich insbesondere für den Bereich der Frauenkriminalität schwer ermitteln. Für eine zuverlässige Einschätzung des Umfangs weiblicher Kriminalität bedürfte es wiederholter repräsentativer Täterinnenbefragungen über alle Altersgruppen hinweg. ${ }^{66}$ Leider liegen solche Untersuchungen nicht vor, weshalb an dieser Stelle vor allem keine hinreichend konkreten Aussagen zur Entwicklung der weiblichen Kriminalität getroffen werden können. Aber auch bzgl. Umfang und Struktur kann immer nur ein kleiner Ausschnitt des Dunkelfeldes „erleuchtet“ werden. Befragungen, die zumeist an Schülerinnen oder Studentinnen durchgeführt wurden, können als Indiz für die Ausprägung der Kriminalität von Frauen im Dunkelfeld herangezogen werden. Um einen Eindruck, gerade im Zusammenhang zu der zuvor dargestellten Frauenkriminalität, wie sie sich nach der PKS darstellt, zu gewinnen, werden im Folgenden einige ausgewählte Dunkelfeldforschungsergebnisse vorgestellt. Der Schwerpunkt der Erläuterung wird auf den geschlechtsspezifischen Ergebnissen liegen, auch wenn die Studien zum Teil eine andere Schwer-

\footnotetext{
${ }^{62}$ BKA (Hrsg.), PKS Zeitreihen 1987-2009, Tab. 40, http://www.bka.de/pks/zeitreihen/index.html.

63 BKA (Hrsg.), PKS, Vorbem., alljährlich formuliert.

$64 \mathrm{Vgl}$. hierzu ausführlich unter Kap. 2, 2.

65 So beispielsweise Pollak, S. 151.

66 Brubns/Wittmann, in: Raithel/Mansel (Hrsg.), Kriminalität und Gewalt, S. 41, 58.
} 
punktsetzung zum Inhalt haben, wie beispielsweise ein Vergleich der Jugenddelinquenz in Ost- und Westdeutschland. ${ }^{67}$

\subsubsection{Kreuzer et al.}

Kreuzer führte seit 1973 kontinuierlich Delinquenzbefragungen in unterschiedlichen Populationen und Altersstufen junger Menschen zwischen 13 und 20 Jahren zur ungleichen Belastung der Geschlechter mit Delinquenz durch. ${ }^{68}$

Basierend auf diesen Untersuchungen befragte Krämer ${ }^{69}$ im Wintersemester 1988/1989 1.447 Studierenden des 1. Semesters in Gießen. ${ }^{70}$ Aus der Befragung ergibt sich, dass die durchschnittliche Delinquenzbelastung der Frauen bei $28 \%$, die der Männer dagegen bei ca. 55 \% liegt. ${ }^{71}$ Dabei weisen ca. $30 \%$ der Studentinnen und nur $11 \%$ der Studenten eine sehr geringe Belastung mit Delinquenz auf. Dementsprechend sind die jungen Männer bei relativ schweren Delikten mit 31 \% gegenüber $1 \%$ wesentlich höher belastet als die jungen Frauen. Im Bereich der Körperverletzung liegt die Relation der weiblichen zu männlichen Studierenden bei 1:3. Bei den Diebstahlsdelikten nähern sich die Geschlechter hingegen an. So haben rund $35 \%$ der Studentinnen und etwa $45 \%$ der Studenten angegeben, schon einen Ladendiebstahl begangen zu haben. ${ }^{72}$

In der Tradition der Gießener Delinquenzbefragungen untersuchten Kreuzer et al. ${ }^{33}$ ferner 3.318 verwertbare Fragebögen von Studienanfängern aus Gießen, Jena und Potsdam aus dem Jahr 1990. ${ }^{74}$ Danach begingen 44,7 \% der Männer in Westund 46,4 \% der Männer in Ostdeutschland sowie 37,7 \% der Frauen in West- und $37 \%$ der Frauen in Ostdeutschland schon mindestens einmal einen Ladendiebstahl. ${ }^{75}$ Das „Schwarzfahren“ stellte sich als von beiden Geschlechtern sehr häufig begangenes Delikt dar. Im Westen gaben $78 \%$ der Männer und rund $75 \%$ der Frauen an, mindestens einmal ein Verkehrsmittel ohne gültigen Fahrausweis benutzt zu haben, wohingegen im Osten die Prävalenzraten bei mehr als $90 \%$ bei den Männern und $87 \%$ bei den Frauen lagen. ${ }^{76}$ Bei der Beteiligung an einer Schlägerei klaffen die Zahlen der Männer und Frauen wieder weit auseinander: So

\footnotetext{
${ }^{67}$ Vgl. hierzu Kreuzer/Görgen/Krüger/Münch/Schneider, Jugenddelinquenz in Ost und West; Kreuzer/Görgen/Münch/Schneider, Delinquenz im Systemvergleich, in: Boers/Ewald/Kerner/Lautsch/ Sessar (Hrsg.), Sozialer Umbruch und Kriminalität, Bd. 1, S. 137-164.

${ }^{68}$ Kreuzer, in: Gedächtnisschrift für Hilde Kaufmann, S. 291, 296.

${ }^{69}$ Diese Zahl bezieht sich nur auf die verwertbaren Fragebögen.

${ }^{70}$ Krämer, Delinquenz, Suchtmittelumgang und andere Formen abweichenden Verhaltens: Ein Geschlechtervergleich.

71 Krämer, S. 103.

72 Krämer, S. 100 ff.

${ }^{73}$ Kreuzer/Görgen/Krüger/Münch/Schneider, Jugenddelinquenz in Ost und West; Kreuz̨er/Görgen/ Münch/Schneider, in: Boers/Ewald/Kerner/Lautsch/Sessar (Hrsg.), Sozialer Umbruch und Kriminalität, Bd. 1, S. 137-164.

${ }^{74}$ Kreuzer/Görgen/Krüger/Münch/Schneider, Jugenddelinquenz in Ost und West, S. 73 ff.

75 Kreuzer/Görgen/Krüger/Münch/Schneider, Jugenddelinquenz in Ost und West, S. 86 ff.

${ }^{76}$ Kreuzer/Görgen/Krüger/Münch/Schneider, Jugenddelinquenz in Ost und West, S. 98 f.
} 
gaben 9,9\% der Frauen in West- und 12,9\% der Frauen und Ostdeutschland die Beteiligung an einer Schlägerei zu; bei den Männern sind es hingegen 33,6 \% in West- und 44,7\% in Ostdeutschland. ${ }^{77}$ Diese Unterrepräsentation der Frauen findet sich auch bei der Sachbeschädigung und Bedrohung wieder. ${ }^{78}$

Insgesamt bestätigen diese Befunde die ungleiche Belastung der Geschlechter mit Delinquenz auch im Dunkelfeld, wobei insbesondere bei Verhaltensweisen, die Gewalt gegen eine Person oder Sache beinhalten, der weibliche Anteil deutlich geringer ist, während sich bei der leichteren Eigentums- und Vermögensdelinquenz die Prävalenzraten deutlich einander annähern.

\subsubsection{Mansel/Hurrelmann}

Mansel/Hurrelmann ${ }^{79}$ befragten 1988 und 1996 in Nordrhein-Westfalen Schülerinnen und Schüler des 7. und 9. Schuljahrgangs. ${ }^{80}$ Insgesamt nahmen über 3.000 Personen aller Schulformen (Gymnasium, Haupt- Real- und Gesamtschule) teil. Die Fragestellung zielte auf Gewalt- und Eigentumsdelikte ab. Es wurde erfragt, ob die Schülerinnen und Schüler Delikte wie Sachbeschädigung, Körperverletzung, Erpressung, Raub, einfacher Diebstahl, schwerer Diebstahl/ Einbruchdiebstahl und Urkundenfälschung im jeweils vergangenen Jahr begangen hatten. 20,5 \% (1988) bzw. 22,5 \% (1996) der Schülerinnen gaben an, schon einmal jemanden absichtlich geschlagen oder verprügelt zu haben. Bei den Schülern betrugen die Raten 34,3 \% (1988) und 42,6 \% (1996) und waren mithin bei der zweiten Befragung fast doppelt so hoch wie die der Schülerinnen. Ein anderes Ergebnis konnte für die Frage nach der Begehung von Diebstahl erzielt werden: Hier gaben zunächst 6,6 \% dann 16,2 \% der weiblichen Befragten zu, Sachen von anderen mitgenommen zu haben. Die Anteile der männlichen Befragten liegen bei 13,4 \% (1988) und 23,5 \% (1996). ${ }^{81}$ Hier bestätigt sich wieder der große Abstand zwischen den Anteilen der Geschlechter an einem Delikt mit Gewaltpotential (Körperverletzung). Aber auch die Prävalenzraten für den Diebstahl waren hier bei den Schülern im Vergleich zu den Schülerinnen deutlich höher.

\footnotetext{
77 Kreųer/Görgen/Krüger/Münch/Schneider, Jugenddelinquenz in Ost und West, S. 106 f.

78 Kreuzer/Görgen/Krüger/Münch/Schneider, Jugenddelinquenz in Ost und West, S. 110 f.

79 Mansel/Hurrelmann, Aggressives und delinquentes Verhalten Jugendlicher im Zeitvergleich - Befunde der 'Dunkelforschung` aus den Jahren 1988, 1990 und 1996, in: KZfSS 1998, S. 78-109.

80 Zudem wurden noch im Jahr 1990 Schüler und Schülerinnen der 9. und 10. Jahrgangsstufe und im Jahr 1996 Schüler und Schülerinnen des 7. und 9. Schuljahrgangs in Sachsen befragt. Hier werden allerdings die Ergebnisse aus Nordrhein-Westfalen vorgestellt.

81 Mansel/Hurrelmann, in: KZfSS 1998, S. 78, 95.
} 


\subsubsection{Posner}

Posner ${ }^{82}$ wertete Erhebungsbögen einer Bevölkerungsbefragung (Ost- und Westdeutschland) aus dem Jahr 1993 aus. Die Probanden waren im Alter zwischen 16 und 34.83 Posner stellte fest, dass es bei Gewalttaten in Ost- wie in Westdeutschland eine große Diskrepanz zwischen Männern und Frauen gibt. So gaben 20 \% der befragten Männer in Ost- und $19 \%$ in Westdeutschland an, jemals eine Gewalttat begangen zu haben, wohingegen die Raten bei Frauen nur 3,6\% in Ostund 6,4\% in Westdeutschland betragen. 24,3\% der befragten ost- und 31,7\% der westdeutschen Männer haben schon mindestens einmal in ihrem Leben ein Eigentumsdelikt begangen. Dagegen gaben 19,7\% der befragten ost- und 33,8\% der westdeutschen Frauen die Begehung eines solchen Delikts an. ${ }^{84}$ Die höhere Belastung der Frauen im Westen bei Eigentumsdelikten deutet nach Auffassung Posners auf Gelegenheitsstrukturen hin, ,aufgrund der verbreiteten Tradition von Warenhäusern und Selbstbedienungsläden. "85

\subsubsection{Lösel/Bliesener}

Lösel/Bliesenerø6 untersuchten seit Mitte der 90er Jahre auf der Basis eines sozialkognitiven Lern- und Entwicklungsmodells die Bedingungen des aggressiven Verhaltens in der Schule, der allgemeinen Delinquenz und des nicht nur strafrechtlich relevanten, dissozialen Verhaltens. Hierzu fand u.a. eine querschnittliche Befragung von insgesamt 1.163 Schülerinnen und Schülern in der 7. und 8. Jahrgangsstufe in Nürnberg und Erlangen statt. Die Datenerhebung der uns hier interessierenden Delinquenzbelastung erfolgte über Fragebögen.

Die Auswertung der Fragebögen ergab bei einem Vergleich der Geschlechter, dass der Geschlechterunterschied bei Aggressionsdelikten ${ }^{87}$ am ausgeprägtesten ist. Bei Eigentumsdelikten ${ }^{88}$ sind die Unterschiede geringer und beim Schwarzfahren und der Zechprellerei findet sich eine ähnliche Prävalenz. ${ }^{89}$

82 Posner, Die Täterbefragung im Kontext „Sozialer Umbruch und Kriminalität“, in:

Boers/Gutsche/Sessar (Hrsg.), Sozialer Umbruch und Kriminalität in Deutschland, S. 157-182.

${ }^{83}$ Posner, in: Boers/Gutsche/Sessar (Hrsg.), Sozialer Umbruch und Kriminalität in Deutschland, S. $157,158$.

84 Posner, in: Boers/Gutsche/Sessar (Hrsg.), Sozialer Umbruch und Kriminalität in Deutschland, S. $157,164$.

85 Posner, in: Boers/Gutsche/Sessar (Hrsg.), Sozialer Umbruch und Kriminalität in Deutschland, S. 157, 164.

${ }^{86}$ Lösel/Bliesener, Aggression und Delinquenz unter Jugendlichen; Lösel/Bliesener/Averbeck, Erlebensund Verhaltensproblem von Tätern und Opfern, in: Holtappels et al. (Hrsg.), Forschung über Gewalt an Schulen, S. 137-154.

${ }^{87}$ Hierzu zählen die Autoren u.a. Raub, vorsätzliche Körperverletzung, Waffengebrauch, Sachbeschädigung.

${ }^{88}$ Hierunter fassen die Autoren u.a. den Ladendiebstahl, Fahrraddiebstahl, Diebstahl von und aus Kraftfahrzeugen, Betrug zusammen.

${ }^{89}$ Lösel/ Bliesener, S. 53 f. 


\subsubsection{Wittenberg}

Wittenberg ${ }^{90}$ führte in den Jahren 2000-2003 mehrfach Befragungen von Schülerinnen und Schülern der 7.-11. Jahrgangsstufe unterschiedlicher Schulformen in drei Städten durch. Er kam bei einem Vergleich der Täteranteile von männlichen und weiblichen Jugendlichen in Bezug auf Ladendiebstahl, Fahrraddiebstahl und Einbruch zu dem Ergebnis, dass das Verhältnis der Täteranteile mit der unterschiedlichen Schwere des Delikts variiert. Einbruch wurde von Jungen ca. 4-mal häufiger begangen als von Mädchen, wohingegen Ladendiebstahl meist nur unter 1,5-mal häufiger von Jungen als von Mädchen verübt wurde. ${ }^{91}$

Diese Studie bestätigt somit vor allen Dingen den hohen Frauenanteil beim Ladendiebstahl, wie er bereits nach den Daten der PKS festgestellt wurde.

\subsubsection{Ausgewählte Dunkelfeldstudien zum weiblichen Anteil an Gewaltkriminalität}

Der Bereich des Geschlechterabstands bei Gewaltdelinquenz wurde im Vergleich zu anderen Deliktsformen relativ ausführlich erforscht. ${ }^{92}$ Unterschiedliche empirische Dunkelfeldstudien zu geschlechtsspezifischen Unterschieden kommen zu dem Ergebnis, dass weniger Frauen als Männer Gewaltdelikte begehen und zudem Frauen im Durchschnitt leichtere Straftaten verüben.

Schwind et al. ${ }^{33}$ kamen nach einer Befragung von Bochumer Schülern der Jahrgangsstufen 7 bis 13 im Jahr 1993 zu dem Ergebnis, dass aggressives Verhalten eher von Jungen als von Mädchen ausgeht. ${ }^{94}$ Nach der Befragung von 240 Schülerinnen und 197 Schülern liegt die Geschlechterrelation für tätliche sexuelle Belästigung bei 1:2, für Raub, Erpressung und Bedrohung sowie für tätliche Gewalt gegen Lehrer bei 1:4, für Nötigung bei 1:5, für ernstere Schlägereien unter Schülern bei 1:14 und für den Gebrauch von Waffen bei 1:20.95

Auch Stenke/Bergelt/Börner ${ }^{96}$ haben in Sachsen von Ende 1995 bis Anfang 1996 zufällig ausgesuchte Schülerinnen und Schüler der 6. und 8. Klasse sowie der Abschlussklassen der Sekundarstufe I befragt. Die Geschlechterrelation für aktive Beteiligung an einer Prügelei betrug 1:4, ebenso für Belästigung und Bedrohung sowie für das Mitführen einer Waffe. ${ }^{97}$

Ähnliche Ergebnisse findet man auch in anderen Untersuchungen mit Schülerinnen und Schülern. ${ }^{98}$

\footnotetext{
90 Wittenberg, Diebstahlskriminalität von Jugendlichen.

91 Wittenberg, S. 216.

92 So auch Brubns/Wittmann, in: Raithel/Mansel (Hrsg.), Kriminalität und Gewalt, S. 41, 47.

93 Schwind/Roitsch/Ablborn/Gielen, Gewalt in der Schule am Beispiel von Bochum.

94 Schwind/Roitsch/Ablborn/Gielen, Gewalt in der Schule am Beispiel von Bochum, S. 166.

95 Schwind/Roitsch/Ablborn/Gielen, Gewalt in der Schule am Beispiel von Bochum, S. 165.

96 Stenke/Bergelt/Börner, in: Forschungsgruppe Schulevaluation (Hrsg.), Gewalt als soziales Problem in Schulen, S. 85-114.

97 Stenke/Bergelt/Börner, in: Forschungsgruppe Schulevaluation (Hrsg.), Gewalt als soziales Problem in Schulen, S. 85, 92.

98 Vgl. Zusammenstellung bei Hermann, Geschlechtsspezifische Aspekte der Gewaltprävention.
} 
Popp/Meier/Tillmann ${ }^{99}$ werteten Daten aus dem 1995 durchgeführten Forschungsprojekt „Gewalt an Schulen“100 der Universität Bielefeld, bei dem 3.540 Schülerinnen und Schüler im Alter zwischen 11 und 17 Jahren des Bundeslandes Hessen befragt wurden, aus. Zusätzlich wurden die Daten hierauf aufbauender, drei Jahre später durchgeführter, qualitativer Fallstudien miteinbezogen, um sodann die weiblichen Täter zu analysieren. $15 \%$ der Mädchen und $47 \%$ der Jungen gaben an, an einer Prügelei beteiligt gewesen zu sein. Insgesamt waren die befragten Jungen an physischen Gewalthandlungen mehr als doppelt bis dreimal so häufig beteiligt wie Mädchen. ${ }^{101}$

In einer Studie von Heitmeyer et al. ${ }^{102}$ über Jugendliche zwischen 15 und $22 \mathrm{Jah}-$ ren in Ost- und Westdeutschland gaben 15,5\% der männlichen und 4,8\% der weiblichen Befragten an, im letzten Jahr eine Sachbeschädigung begangen zu haben. Für die Körperverletzung von Fremden liegen die Raten bei 12,8 \% für die Jungen und 2,3\% bei den Mädchen und bei Raub 11,2\% (Jungen) zu 4,8\% (Mädchen). ${ }^{103}$

Die dargestellten Studien kommen folglich alle zu dem Ergebnis, dass Frauen bzw. Mädchen weniger gewaltbereit sind als Männer bzw. Jungen. Jugendgewalt scheint ein überwiegend männliches Phänomen zu sein. Gleichwohl ist bei dieser Aussage zu berücksichtigen, dass auch männliche Jugendliche hauptsächlich im Bereich der Bagatellkriminalität auffällig werden. ${ }^{104}$

2.2.7 Schülerbefragungen des Kriminologischen Forschungsinstituts Niedersachsen (KFN)

Das KFN führt seit 1998 kontinuierlich Delinquenzbefragungen von Schülerinnen und Schülern in einer Vielzahl von Städten und Landkreisen verschiedener Bundesländer durch. Datenbasis sind repräsentative Befragungen von Schülerinnen und Schülern der 9. Jahrgangsstufen aller Schulformen.

$1998^{105}$ wurden insgesamt 16.190 Schülerinnen und Schüler in neun Städten und Gemeinden in der BRD befragt. Die Befragung hat ergeben, dass bei Gewalt gegen Sachen und Gewalt gegen Personen ein erheblicher Unterschied zwischen der weiblichen und männlichen Delinquenz besteht. Nach dieser KFN-Studie von 1998 gaben Mädchen halb so oft Körperverletzungsdelikte und Erpressung an wie

\footnotetext{
99 Popp/Meier/Tillmann, Es gibt auch Täterinnen: Zu einem bisher vernachlässigten Aspekt der schulischen Gewaltdiskussion, in: ZSE 2001, S. 170-191.

100 Popp, Geschlechtersozialisation und Gewalt an Schulen, in: Holtappels/Heitmeyer/Melzer/ Tillmann (Hrsg.), Forschung über Gewalt an Schulen, S. 207-224.

101 Popp/Meier/Tillmann, in: ZSE 2001, S. 170, 172.

102 Heitmeyer/Collmann/Conrads et al., Gewalt, Schattenseiten der Individualisierung bei Jugendlichen aus unterschiedlichen Milieus, 1995.

${ }^{103}$ Heitmeyer/Collmann/Conrads et al., S. 276.

${ }^{104}$ So auch Kuckuck, Jugendgewalt - ein männliches und weibliches Phänomen, S. 42.

$105 \mathrm{Wetzels/Enzmann/Mecklenburg/Pfeiffer,} \mathrm{Jugend} \mathrm{und} \mathrm{Gewalt,} 2001$.
} 
Jungen, während ihre Raten bei Raub und Bedrohung mit einer Waffe ca. ein Drittel ausmachen. ${ }^{106}$

Im Jahr $2000^{107}$ befragte das KFN Schülerinnen und Schüler in den Städten Hamburg, Hannover, Leipzig und München sowie dem Landkreis Friesland. Insgesamt konnten 10.460 Fragebögen ausgewertet werden. 50,7\% der Befragten sind männlich und 49,3\% weiblich. ${ }^{108}$ Die Befragung hat ergeben, dass leichtere Delikte im Dunkelfeld der Mädchenkriminalität überwiegen. So gaben $63 \%$ der Schülerinnen Schwarzfahren an, rund ein Viertel nannte Ladendiebstahl, ein Zehntel Sachbeschädigung und $8 \%$ personale Gewalt. Die selbstberichtete Delinquenz beim Schwarzfahren und beim Ladendiebstahl weist nahezu gleiche Anteile bei den befragten weiblichen und männlichen Neuntklässlern aus, bei Sachbeschädigung erreichen die weiblichen Jugendlichen fast die Hälfte der männlichen Werte, bei der personalen Gewalt ${ }^{109}$ liegen ihre Angaben bei einem Drittel und bei Einbrüchen und Fahrraddiebstählen erreichen sie ein Viertel der prozentualen Anteile der männlichen Jugendlichen. ${ }^{110}$ Entsprechend haben die männlichen Befragten im Vergleich zu den weiblichen einen ca. dreimal so hohen Anteil an der personalen Gewalt. ${ }^{111}$

Die Schülerbefragung aus dem Jahr $2005^{112}$ erstreckte sich auf sieben Städte mittlerer Größe und zwei Gemeinden. Die Stichprobe hatte eine Größe von 14.301 befragten Schülerinnen und Schülern. ${ }^{113}$ Die Analyse der Stichproben ergab, dass sich der Anteil der Geschlechter beim Schwarzfahren nicht signifikant voneinander unterscheidet. Ebenso sind die Geschlechterunterschiede beim Ladendiebstahl sehr gering. ${ }^{114}$ Bei den anderen Delikten sind es allerdings zumeist mehr als doppelt so viel männliche wie weibliche Täter, die ein Delikt begangen haben, sodass der Geschlechterunterschied dort stark ausgeprägt ist. ${ }^{115}$

Ebenso wurde bei der Schülerbefragung $2006^{116}$ in Hannover festgestellt, dass fast die Hälfte aller Ladendiebstähle von Mädchengruppen begangen wird. ${ }^{117}$

\footnotetext{
106 Wetzels/En:mann/Mecklenburg/Pfeiffer, 2001, S. 194 f.

107 Wilmers/En₹mann/Schäfer et al., Jugendliche in Deutschland zur Jahrtausendwende: Gefährlich oder gefährdet?, 2002.

108 Wilmers/Enæmann/Schäfer et al., 2002, S. 22 f.

${ }^{109}$ Diese Kategorie beinhaltet die Delikte Raub, Erpressung, Drohung mit der Waffe und Körperverletzung.

110 Wilmers/Enzmann/Schäfer et al., 2002, S. 87 ff.

111 Wilmers/Enżmann/Schäfer et al., 2002, S. 89.

112 Baier/Pfeiffer/Windzio/Rabold, Gewalterfahrungen, Schulabsentismus, und Medienkonsum von Kindern und Jugendlichen, 2006.

113 Baier/Pfeiffer/Windzio/Rabold, 2006, S. 34.

114 Baier/Pfeiffer/Windrio/Rabold, 2006, S. 136.

115 Baier/Pfeiffer/Windzio/Rabold, 2006, S. 136.

116 Rabold/Baier/Pfeiffer, Jugendgewalt und Jugenddelinquenz in Hannover. Aktuelle Befunde und Entwicklung seit 1998, 2008.

117 Rabold/Baier/Pfeiffer, 2008, S. 46.
} 
In einer 2008,118 bei 3.517 Stader Schülern zwischen 11 und 19 Jahren, durchgeführten Befragung, berichteten 29,3\% der Jungen, aber nur 7,2 \% der Mädchen, zumindest selten eine Waffe bei sich zu tragen. Das häufige Mitführen ist bei den Schülern fast sechsmal so oft verbreitet wie unter den Schülerinnen. Darüber hinaus ergibt sich, auch bei der Betrachtung der innerhalb der Schule verübten delinquenten Daten, ein deutlicher Geschlechterunterschied: 6,9\% der Jungen, aber nur 2,7\% der Mädchen haben in der Schule eine Sachbeschädigung begangen; 3,2 \% der Jungen, aber nur 0,8 \% der Mädchen haben in der Schule einen Diebstahl bis 50 Euro ausgeführt; 10,4\% der Jungen, hingegen nur 6,6\% der Mädchen haben eine Körperverletzung verübt. ${ }^{119}$

Für eine neuere Studie des KFN in den Jahren 2007 und $2008^{120}$ wurden 44.610 verwertbare Fragebögen von Schülerinnen und Schülern der 9. Jahrgangsstufe aus 61 repräsentativ ausgewählten Landkreisen untersucht. Von den befragten Mädchen gaben 23,6 \% und von den befragten Jungen 43,6 \% an, in den letzten zwölf Monaten vor der Befragung eine Straftat begangen zu haben. ${ }^{121}$

Insgesamt wurde festgestellt, das Jungen 1,9-mal so häufig delinquentes Verhalten zeigen als Mädchen. Bei Gewaltdelikten ist der Anteil sogar 3,2-mal so hoch. Beim Ladendiebstahl zeigte sich allerdings, dass der Anteil mit 12,4\% für die Schülerinnen und 14,2 \% der Schüler fast gleich hoch ist. ${ }^{122}$

Die Täterbefragungen des KFN haben ein großes Maß an Repräsentativität, da das Verhalten von Schülerinnen und Schülern in Gebieten unterschiedlichsten Charakters in Gesamtdeutschland untersucht wurde und so eine hohe Beteiligungszahl zustande kam. Insbesondere die zuletzt durchgeführte deutschlandweite Befragung konnte auf eine große Datenbasis zurückgreifen. Zudem bietet die Befragung von Schülerinnen und Schülern der 9. Jahrgangsstufe den Vorteil, dass verschiedene Bevölkerungsschichten erreicht werden und Jugendliche dieses Alters $^{123}$ entsprechend der Alters-Kriminalitäts-Kurve schon eine verhältnismäßig hohe Täterquote aufweisen. ${ }^{124}$

\subsubsection{Fazit}

Die hier herangezogenen Dunkelfeldstudien unterscheiden sich in der Erhebungsweise zum Teil erheblich voneinander: Die Stichproben und die verwendeten Fragebögen waren unterschiedlich. Weiter variierte das Alter der Probanden ebenso wie die Beschäftigung und die Erhebungsregion. Auch lag der Schwer-

\footnotetext{
118 Baier/Rabold/Kappes/Kudlacek, Sicherheit und Kriminalität in Stade, Ergebnisse einer Schüler- und Erwachsenenbefragung, 2009.

119 Baier/Rabold/Kappes/Kudlacek, 2009, S. 110 f.

120 Baier/Pfeiffer/Simonsen/Rabold, Jugendliche in Deutschland als Opfer und Täter von Gewalt, 2009.

121 Baier/Pfeiffer/Simonsen/Rabold, 2009, S. 69.

122 Baier/Pfeiffer/Simonsen/Rabold, 2009, S. 69.

123 Das Durchschnittsalter liegt in allen Studien bei etwa 15 Jahren.

124 Baier/Pfeiffer/Simonsen/Rabold, 2009, S. 27.
} 
punkt der Studien auf der Betrachtung unterschiedlicher Delikte, weshalb sie nur sehr eingeschränkt vergleichbar sind. Gleichwohl enthalten die dargestellten empirischen Untersuchungen wichtige Informationen zur Kriminalität im Dunkelfeld in Bezug auf Schülerinnen und Studentinnen und sie bestätigen die Ergebnisse der Auswertungen des Hellfelds: Umfang und Struktur weiblicher Kriminalität unterscheidet sich von der Kriminalität der Männer. Frauen begehen weniger Straftaten und zudem begehen sie im Vergleich häufiger minderschwere und seltener schwerwiegende Delikte als Männer. Allerdings ist der Abstand im Dunkelfeld, insbesondere bei der Bagatellkriminalität, geringer als im Hellfeld. Die aufgezählten Studien belegen, dass sich die eklatanten geschlechtspezifischen Unterschiede im Hellfeld der Kriminalität in Dunkelfelduntersuchungen zumindest relativieren. Hierbei ist jedoch zu berücksichtigen, dass bei den weniger schwerwiegenden Delikten auch von einer geringeren Anzeigebereitschaft und einer geringeren Verfolgungsintensität auszugehen ist. Ferner beziehen sich die Befragungsergebnisse auf junge Menschen, bei denen auch im Hellfeld ein geringerer Geschlechterabstand besteht. ${ }^{125}$ Bei dem Vergleich zwischen Daten der amtlichen Statistik und Täterbefragungen ist ferner zu bedenken, dass diese sich nicht nur durch ihr spezifisches Zustandekommen, sondern auch durch die unterschiedlich erhobene Deliktsbreite und Deliktsdefinition unterscheiden. Zudem ist die Altersklassifizierung häufig nicht identisch. Gleichwohl berechtigen diese Ergebnisse zu der zusammenfassenden Feststellung, dass männliche Jugendliche und junge Erwachsene eine erheblich höhere Gewaltbelastung aufweisen als weibliche, wobei sich dieser Befund bei bagatellhaften Eigentumsdelikten nicht in dieser Form wiederfindet. ${ }^{126}$

\subsection{Umfang, Struktur und Entwicklung der Verurteilten}

\subsubsection{Häufigkeit und Alter der Verurteilten}

Nach der Begriffsbestimmung der StVS sind Verurteilte Angeklagte, gegen die nach allgemeinem Strafrecht Freiheitsstrafe, Strafarrest oder Geldstrafe (auch durch einen rechtskräftigen Strafbefehl) verhängt worden ist, oder deren Straftat nach Jugendstrafrecht mit Jugendstrafe, Zuchtmittel oder Erziehungsmaßregeln geahndet wurde. ${ }^{127}$

Im Jahr 2009 waren 18,5\%128 der Verurteilten im gesamten deutschen Bundesgebiet weiblich. Für das Jahr 2009 beträgt der Ausländeranteil unter den verurteilten Frauen $18 \% .129$

\footnotetext{
125 So auch Heinz, Kriminalität in Deutschland, III.1.2.

126 So auch Wilmers/Enzmann/Schäfer et al., Jugendliche in Deutschland zur Jahrtausendwende, 2002.

127 StatB A (Hrsg.), StVS 2009, S. 13.

128 Die absolute Zahl für die Verurteilten insgesamt, beträgt im Jahr 2009 844.520; hiervon sind 688.550 Männer und 155.970 Frauen.

129 StatBA (Hrsg.), StVS 2009, S. 474.
} 
Auch für die Verurteilten wird nun ein Überblick über die Altersstruktur, mit Hilfe der Verurteiltenbelastungszahl (VBZ), gegeben. Die VBZ ist die Zahl der rechtskräftig Verurteilten, errechnet auf 100.000 Einwohner des entsprechenden Bevölkerungsanteils. ${ }^{130}$

Schaubild 1.6: VBZ für Deutsche nach Gescblecht und Altersgruppe, 2009

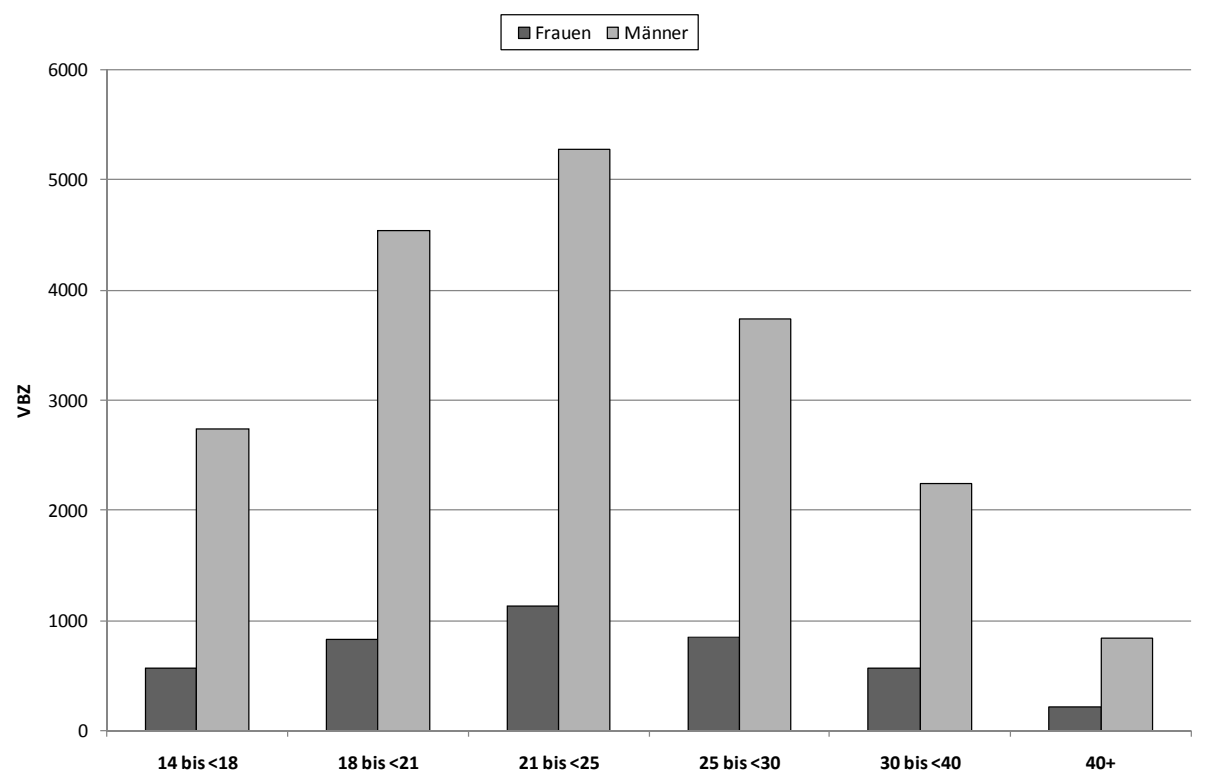

Quelle: StatBA (Hrsg.), StVS 2009, Tab. 1.2; Absolutrablen siehe Tabelle 1.6a im Anbang.

Betrachtet man die Belastungen der deutschen Verurteilten in den einzelnen Altersgruppen (vgl. Schaubild 1.0), so ist auffällig, dass der Belastungsgipfel von Männern und Frauen hier, im Gegensatz zu den Tatverdächtigen, in derselben Altersgruppe liegt: Die Jungerwachsenen $(21$ bis $<25)$ weisen die höchste Belastung auf, was das Ergebnis des Selektionsprozesses sein dürfte, weil informelle Erledigungen in der Statistik nicht miterfasst werden. 131

Wenn man die TVBZ und VBZ für das Jahr 2009 noch einmal graphisch miteinander vergleicht, fällt besonders auf, dass die TVBZ deutlich höher sind (vgl. Schaubild 1.7). Dies könnte zum einen daran liegen, dass die PKS zu einer Überbewertung der erfassten Sachverhalte tendiert, die sozusagen auf gerichtlicher Ebene wieder ausgeglichen wird. ${ }^{132}$

\footnotetext{
130 StatB $A$ (Hrsg.), StVS 2009, S. 15.

131 So auch Heinそ, Kriminalität von Deutschen nach Alter und Geschlecht, S. 29.

132 Vgl. Kap. 1, 1.4.
} 
Schaubild 1.7: TVBZ und VBZ für Deutsche nach Geschlecht und Altersgruppe, 2009

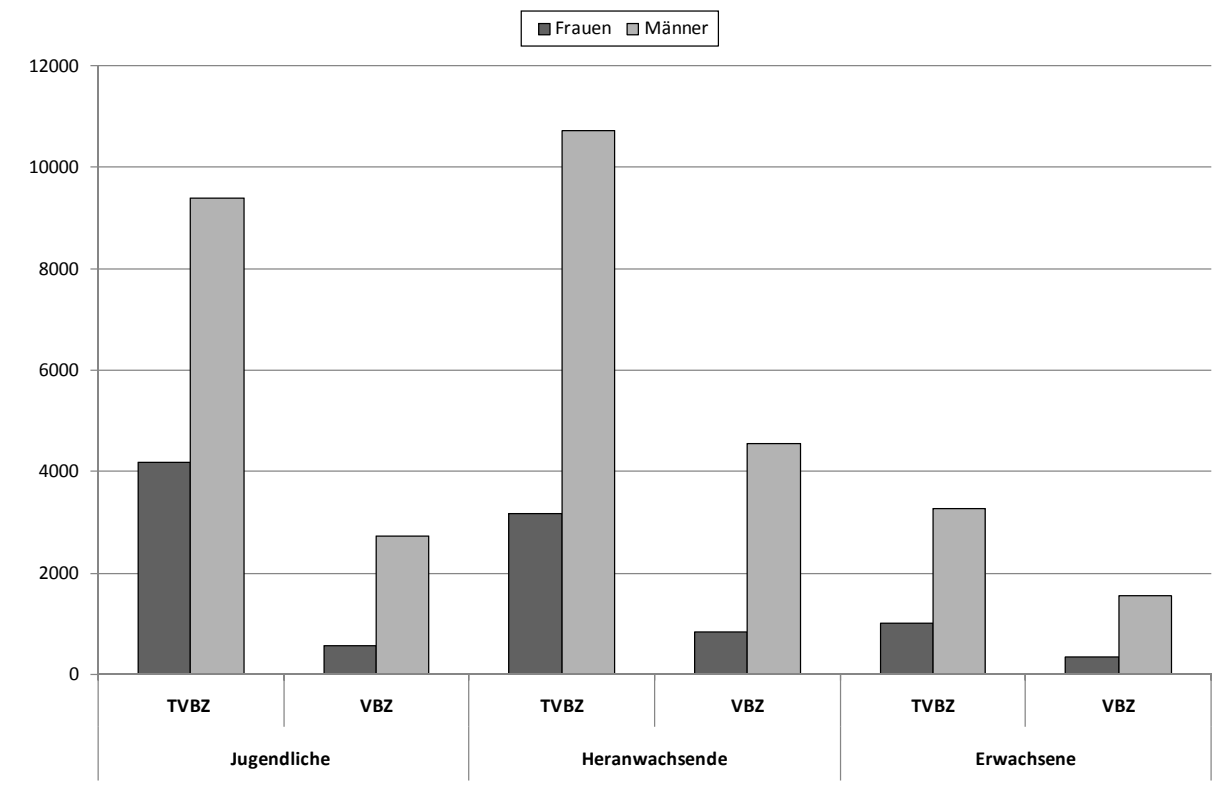

Quelle: BKA (Hrsg.), PKS 2009, Tab. 61 sowie StatBA (Hrsg.), StVS 2009, Tab. 1.1; Absolutrahlen siebe Tabelle 1.7 a im Anbang.

Zum anderen könnte eine Zunahme der Einstellungen aus Opportunitätsgründen, bei jungen Tatverdächtigen besonders $\int 45$ JGG, eine Rolle spielen. ${ }^{133}$ Bei schwereren Deliktsformen kann eine etwaige Zunahme der Einstellungen wegen minderer Schwere allerdings keine Erklärung für die Auseinanderentwicklung der Belastungszahlen sein. Hier könnte ein verändertes Anzeigeverhalten der Bevölkerung eine Rolle spielen. ${ }^{134}$ Hierfür liefert auch eine Studie der Kriminologischen Forschungsgruppe der bayerischen Polizei im Bayerischen Landeskriminalamt ${ }^{135}$ Anhaltspunkte. Die Forschungsgruppe wertete Ermittlungs- und Strafakten der 1989 und 1998 in München wegen Gewaltkriminalität registrierten Heranwachsenden und Jungerwachsenen aus. Sie kam zu dem Ergebnis, dass der prozentuale Anteil der als „minder schwer“ beurteilten Fälle deutlich zugenommen hat. Wenn es zu einer Zunahme insbesondere von leichterer Gewaltkriminalität gekommen sein sollte, so wäre zu erwarten gewesen, dass auch die Einstellungen aus Opportunitätsgründen zunehmen müssten. Entgegen den Erwartungen stellte die Forschungsgruppe allerdings fest, dass vor allem der Anteil der mangels hinreichen-

\footnotetext{
133 Heinz, Kriminalität der Deutschen nach Alter und Geschlecht, S. 32.

134 So auch Heinz, Kriminalität in Deutschland unter Berücksichtigung der Jugend- und Gewaltkriminalität, Aktualisierte Fassung 2005, S. 11.

135 Elsner/Molnar, Kriminalität Heranwachsender und Jungerwachsener in München.
} 
den Tatverdachts gem. $₫ 170$ Abs. 2 StPO eingestellten Ermittlungsverfahren deutlich zugenommen hat. Diese Ergebnisse deuten darauf hin, dass vermehrt Vorfälle angezeigt werden, bei denen zwar die Tatbeteiligung bekannt, aber der Tathergang unklar bleibt. Die Forscher vermuten deshalb, dass es aufgrund einer erhöhten Sensibilisierung der Öffentlichkeit für Gewaltdelikte zu mehr Anzeigen gekommen ist. ${ }^{136}$ Diese Erklärung kann für Männer und Frauen gleichermaßen gelten. Bei den Frauen könnte allerdings erschwerend hinzutreten, dass es neben der Sensibilisierung der Öffentlichkeit für Gewaltdelikte, auch zu einer Sensibilisierung der Öffentlichkeit für Frauenkriminalität gekommen ist. Denn seit längerer Zeit wird die Frau als Gewalttäterin, insbesondere bezogen auf Mädchen und junge Frauen, in den Medien ${ }^{137}$ diskutiert. Es ist daher nicht auszuschließen, dass auch vermehrt Opfer von Frauen Anzeige erstattet haben. ${ }^{138}$

\subsubsection{Deliktstruktur der Verurteilten}

Die Deliktsverteilung für weibliche Verurteilte nach den Daten der StVS zeigt ähnliche Schwerpunkte wie die für weibliche Tatverdächtige nach den Daten der PKS.

Schaubild 1.8 verdeutlicht hier ebenfalls ein Überwiegen der Gruppen Betrug, Untreue und Urkundendelikte (Betrug u.a.) sowie Diebstahl und Unterschlagung. Am häufigsten findet mit 26\% eine Verurteilung in der Kategorie Betrug u.a. statt. Zu einer Verurteilung wegen Diebstahls oder Unterschlagung kam es nur noch in $21 \%$ der Fälle. Ferner fallen die Kategorien Sachbeschädigung mit $1 \%$ und Beleidigung mit $2 \%$ kaum noch ins Gewicht. Gewaltdelikte machen, wie bei den Tatverdächtigen auch bei den Verurteilten, nur einen kleinen Anteil an der Gesamtkriminalität von Frauen aus. Zählt man die Tötungsdelikte ${ }^{139}$, sonstigen Gewaltdelikte ${ }^{140}$ und sonstige Körperverletzungsdelikte ${ }^{141}$ zusammen, kommt man lediglich auf einen Anteil von $4 \%$. Die einfache Körperverletzung liegt immerhin noch bei $3 \%$ der Verurteilungen zugrunde. Delikte nach dem BtMG können in $4 \%$ der Fälle verzeichnet werden. Im Gegensatz zur PKS enthält die StVS Informationen über die Verkehrsdelikte. Schaubild 1.8 lässt sich entnehmen, dass Frauen diese relativ häufig begehen. Zählt man die Verkehrsdelikte ohne und unter Alkoholeinfluss zusammen, kommt man auf einen Anteil von $17 \%$ an den Gesamtverurteilungen. Die fahrlässige Körperverletzung und fahrlässige Tötung macht $1 \%$ aus. Hier ist zu berücksichtigen, dass die StVS zwischen fahrlässigen Körperverletzungen und Tötungen im und außerhalb des Straßenverkehrs differenziert.

\footnotetext{
136 Elsner/Molnar, S. 174 ff.

${ }_{137}$ Beispielsweise http://www.spiegel.de/panorama/justiz/0,1518,533810,00.html.

138 Vgl. zur Anzeigebereitschaft gegenüber Frauen Mansel, in: Lamnek/Boatca (Hrsg.), S. 391 f. sowie Ausführungen unter Kap. 1, 1.5.

139 In dieser Kategorie wurden $\$ \int 211,212$ sowie $\ 227$ StGB berücksichtigt.

140 Hierzu wurden die $\$ \int 113,177,178,239$ a, 239b, 249-252, 255, 316 a StGB gezählt.

141 Berücksichtigt wurden SS 224-226 StGB.
} 


\section{Schaubild 1.8: Deliktsstruktur von verurteilten Frauen, 2009}

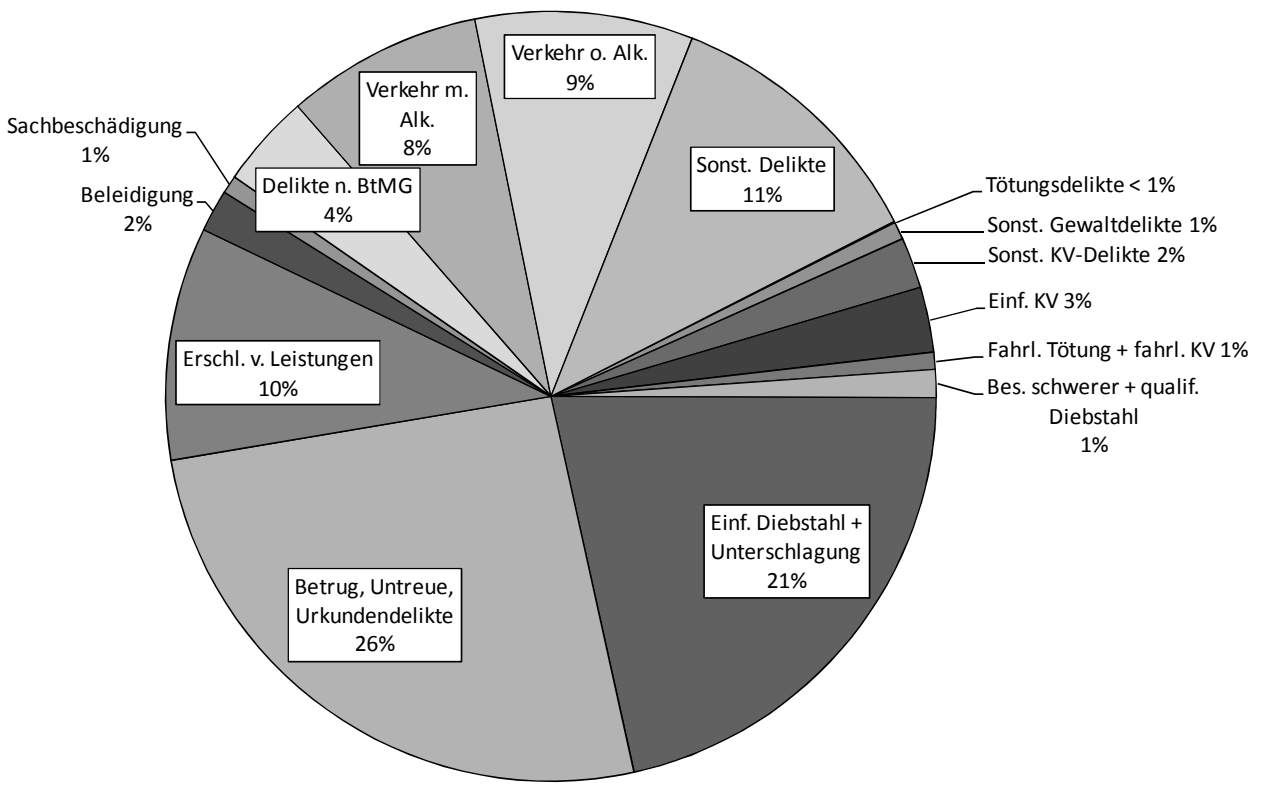

Quelle: StatBA (Hrsg.), StVS 2009, Tab. 2.1; Absolutzablen siebe Tabelle 1.8 a im Anbang.

Die in Schaubild 1.8 ausgewiesenen fahrlässigen Tötungen und Körperverletzungen beziehen sich daher nur auf solche außerhalb des Straßenverkehrs; solche mit verkehrsrechtlichem Bezug sind der jeweiligen Gruppe der Verkehrsdelikte zugeordnet.

Insgesamt bestätigen die Daten der StVS zu den verurteilten Frauen das bereits durch die Auswertung der Daten der PKS gewonnene Bild über die Struktur weiblicher Kriminalität: Frauen begehen in erster Linie Betrügereien und Diebstähle. Auch Verkehrsdelikte machen einen erwähnenswerten Anteil an der Gesamtkriminalität aus. Nur ein kleiner Anteil von Frauen sind Gewalttäterinnen. Die restlichen Delikte verteilen sich über den Bereich der Bagatellkriminalität.

Die kleinen Abweichungen bei der Struktur zwischen den tatverdächtigen und verurteilten Frauen dürften dem Selektionsprozess im Strafverfahren durch beispielsweise Einstellungen geschuldet sein, die vor allen Dingen bei geringer Schwere des begangenen Delikts in Betracht kommen. Vermutlich kommt Frauen, die wie festgestellt zumeist im Bereich der Bagatelldelikte auffällig sind, dieser Prozess besonders zugute. Nicht zu vergessen ist auch, dass eine 100\%ige Vergleichbarkeit schon aufgrund der unterschiedlichen Datenerhebungsmethoden nicht besteht. Gerade die Nichtberücksichtigung der Verkehrsdelikte in der PKS 
führt zu einer Umverteilung der Deliktsstruktur für Tatverdächtige im Vergleich zu den Verurteilten. ${ }^{142}$

\subsubsection{Entwicklung der Verurteilten}

Tabelle 1.2 verdeutlicht zunächst die geringe Anzahl verurteilter Frauen im Vergleich zu den verurteilten Männern.

Tabelle 1.2: Entwicklung der Verurteilten bei Straftaten insgesamt seit 1995

\begin{tabular}{|c|c|c|c|c|c|}
\hline & \multicolumn{2}{|c|}{ Frauen } & \multicolumn{2}{|c|}{ Männer } & \multirow[t]{2}{*}{ Gesamt } \\
\hline & $\mathrm{n}$ & $\%$ & $\mathrm{n}$ & $\%$ & \\
\hline 1995 & 114.975 & $15 \%$ & 645.014 & $85 \%$ & 759.989 \\
\hline 1996 & 117.407 & $15 \%$ & 646.283 & $85 \%$ & 763.690 \\
\hline 1997 & 121.587 & $16 \%$ & 658.943 & $84 \%$ & 780.530 \\
\hline 1998 & 127.582 & $16 \%$ & 663.967 & $84 \%$ & 791.549 \\
\hline 1999 & 127.177 & $17 \%$ & 632.484 & $83 \%$ & 759.661 \\
\hline 2000 & 124.414 & $17 \%$ & 608.319 & $83 \%$ & 732.733 \\
\hline 2001 & 121.313 & $17 \%$ & 597.389 & $83 \%$ & 718.702 \\
\hline 2002 & 121.990 & $17 \%$ & 597.761 & $83 \%$ & 719.751 \\
\hline 2003 & 128.336 & $17 \%$ & 607.961 & $83 \%$ & 736.297 \\
\hline 2004 & 138.478 & $18 \%$ & 637.324 & $82 \%$ & 775.802 \\
\hline 2005 & 140.890 & $18 \%$ & 639.769 & $82 \%$ & 780.659 \\
\hline 2006 & 135.892 & $18 \%$ & 615.495 & $82 \%$ & 751.387 \\
\hline \multicolumn{6}{|c|}{ Ab 2007 sind die Zahlen für Gesamtdeutschland berücksichtigt. } \\
\hline 2007 & 161.577 & $18 \%$ & 736.054 & $82 \%$ & 897.631 \\
\hline 2008 & 158.618 & $18 \%$ & 716.073 & $82 \%$ & 874.691 \\
\hline 2009 & 155.970 & $18 \%$ & 688.550 & $82 \%$ & 844.520 \\
\hline
\end{tabular}

Quelle: StatBA (Hrsg.), StVS der jeweiligen Jahrgänge, Tab. 1.1.

Vergleicht man die Entwicklung der Verurteilten von 1995 bis 2006 für die alten Bundesländer und Gesamtberlin anhand der absoluten Zahlen (Tabelle 1.2), so stellt man fest, dass der Anteil verurteilter Frauen deutlich unter dem der verurteilten Männer liegt. Er reicht von $15 \%$ im Jahr 1995 bis zu aktuell $18 \%$.

142 Näher dazu: Kap. 1, 3. 
Dies ergibt für die verurteilten Frauen bis Ende der 1990er-Jahre einen etwa 10\%igen Anstieg, und nach kurzzeitigem Rückgang Anfang des Jahrtausends bis 2005 einen weiteren Zuwachs um $10 \%$. Die absolute Zahl der verurteilten Männer ist über die Jahrtausendwende um knapp 10\% gesunken, bis 2005 jedoch wieder in Nähe des Ausgangsniveaus gestiegen. 2006 ist es wiederum zu einem Anstieg gekommen. Der Eckdatenvergleich der Jahre 1995 und 2006 ergibt einen etwa 5\%igen Rückgang bei den Männern und einen Anstieg von knapp $20 \%$ bei den Frauen.

Die Zahlen ab dem Jahr 2007 sind mit denen der vorherigen Jahrgänge nicht zu vergleichen, da die StVS ab diesem Zeitpunkt die Zahlen für Gesamtdeutschland ausweist. Ab 2007 ist sowohl für Frauen als auch für Männer eine rückläufige Tendenz erkennbar (vgl. Tabelle 1.2).

Der Zuwachs weiblicher Verurteilter durchzieht sämtliche Altersgruppen (vgl. Schaubild 1.9).

Schaubild 1.9: Entwicklung der VBZ von Frauen bei Straftaten insgesamt seit 1995

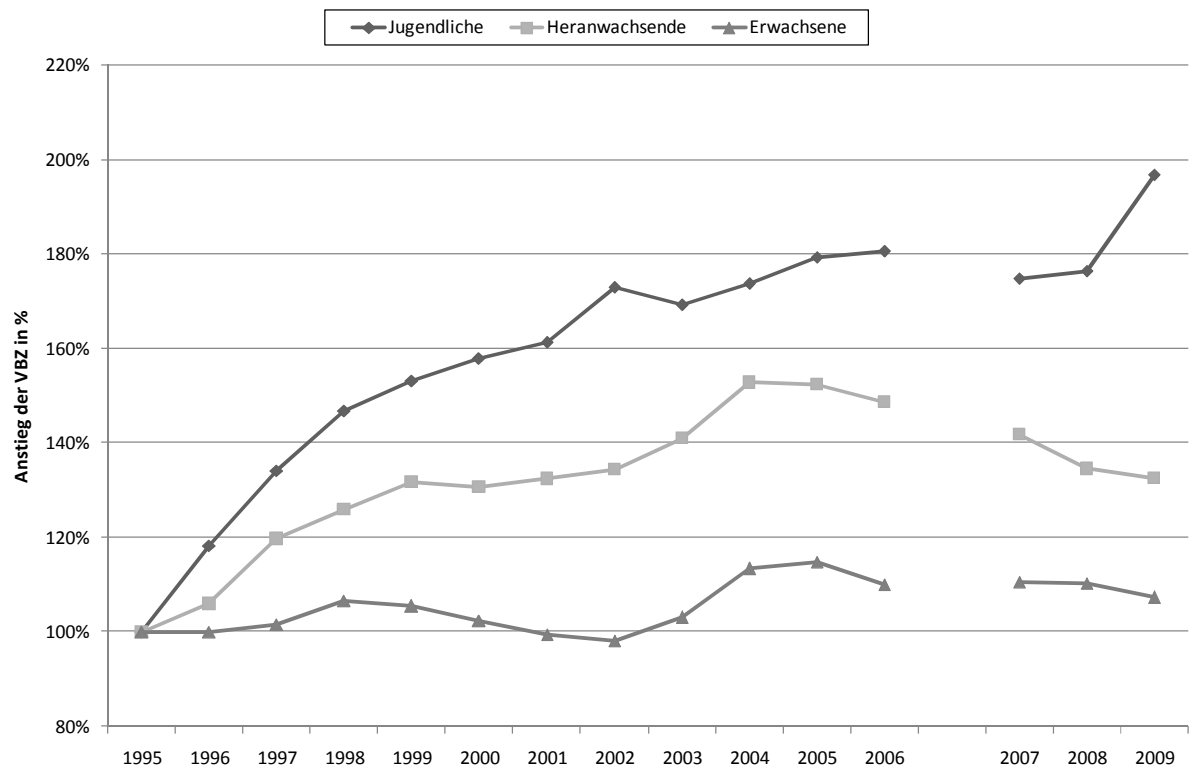

Quelle: StatBA (Hrsg.), StVS der jeweiligen Jahrgänge, Tab. 1.1; Absolutzablen siehe Tabelle 1.9a im Anhang.

Aus dem Eckdatenvergleich der Jahre 1995 und 2006 ergibt sich, dass sich die Gesamtzuwachsrate, der in dieser Zeit stetig angestiegenen VBZ für die weiblichen jugendlichen Verurteilten, fast verdoppelt hat. Die VBZ der heranwachsenden Verurteilten ist um $49 \%$ gestiegen; die der weiblichen Erwachsenen hat um $10 \%$ zugelegt, wobei die Zahlen für die Heranwachsenden seit 2004 und für die 
Erwachsenen seit 2005 rückläufig sind. Die Zahlen für Gesamtdeutschland ab 2007 bestätigen die rückläufige Tendenz für heranwachsende Frauen. Die VBZ der erwachsenen Frauen bewegt sich in etwa auf dem gleichen Niveau wie bereits im Jahr 2006. Besonders auffällig ist die Gruppe der jugendlichen Verurteilten: 2007 sind die VBZ zunächst leicht gesunken. Von 2008 bis 2009 ist ein starker Anstieg zu verzeichnen.

Schaubild 1.10: Entwicklung der VBZ von Männern bei Straftaten insgesamt seit 1995

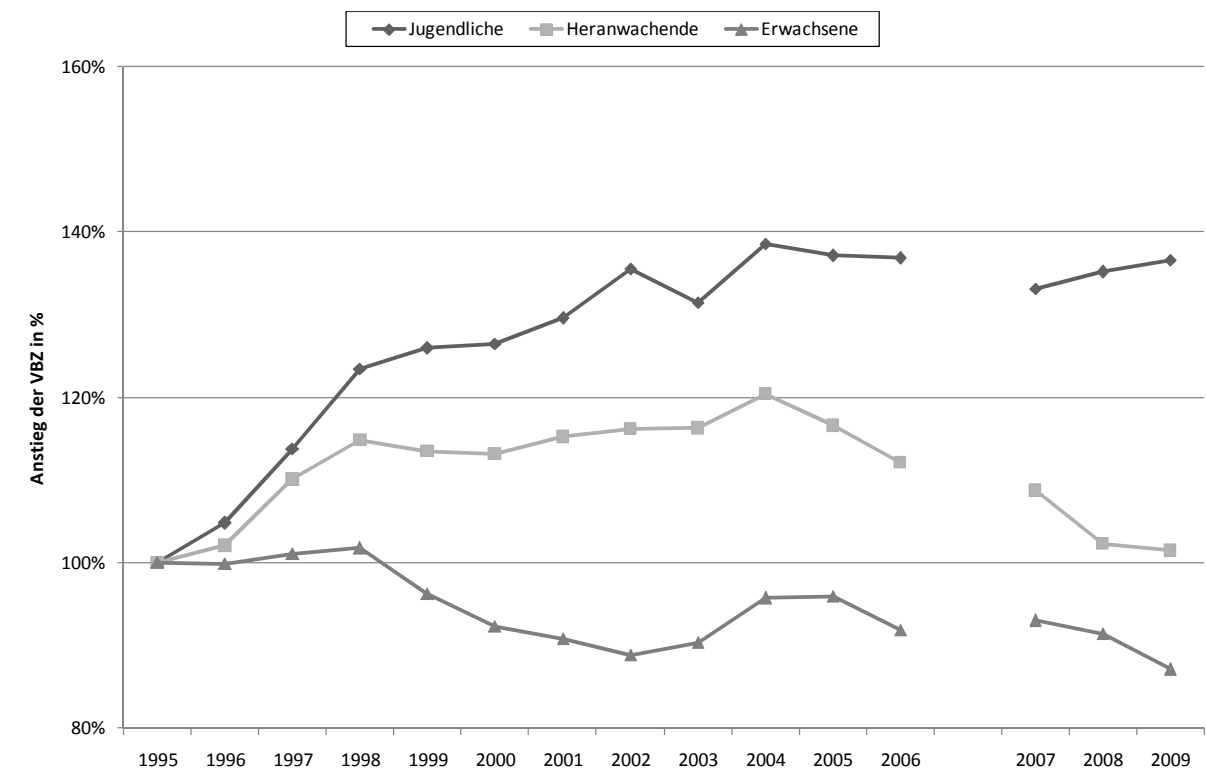

Quelle: StatBA (Hrsg.), StVS der jeweiligen Jahrgänge, Tab. 1.1; Absolutzablen siebe Tabelle 1.10a im Anbang.

Schaubild 1.10 macht deutlich, dass auch die VBZ der männlichen jugendlichen Verurteilten, nach Durchschreitung einer Talsohle von 2002-2003, im Eckdatenvergleich 1995 und 2006, um fast $40 \%$ gestiegen ist. Die VBZ der Heranwachsenden ist bis 2004 stetig gestiegen und seitdem wieder sinkend. Bei den männlichen erwachsenen Verurteilten ist, im Gegensatz zu den Frauen, die VBZ im Beobachtungszeitraum sogar um $8 \%$ gesunken. Für die Altersgruppe der heranwachsenden und erwachsenen Männer ist seit 2007 ein Rücklauf der Zahlen zu beobachten. Bei den Jugendlichen zeigt sich hingegen wieder eine steigende Tendenz.

In der Gesamtschau muss zunächst wieder festgehalten werden, dass Frauen trotz dieses stetigen Anstiegs der weiblichen Verurteilten nach wie vor deutlich unterrepräsentiert sind. Der Geschlechterunterschied ist hier mit einem Frauenanteil von 18,5 \% an den Verurteilten insgesamt noch ausgeprägter als bei den Tat- 
verdächtigen mit einem Frauenanteil von 24,6 \%. Gleichwohl ist die VBZ bei den Frauen stärker angestiegen als bei den Männern.

\subsection{Existieren „frauentypische“ Delikte?}

Nicht allein die Darstellung der Deliktsstruktur von Frauen, sondern auch die Herausarbeitung des Frauenanteils an den einzelnen Delikten bedarf einer besonderen Betrachtung. Es stellt sich die Frage, ob es trotz des generell niedrigen Anteils von Frauen an der Gesamtkriminalität sog. „frauentypische“ Delikte gibt. Dazu muss zunächst geklärt werden, was unter „frauentypisch“ zu verstehen ist.

Denkbar wäre, solche Delikte als „frauentypisch“ zu bezeichnen, die Frauen besonders häufig innerhalb ihrer eigenen Deliktsstruktur begehen, die also ,als überdurchschnittlich im Verbältnis zur sonstigen Beteiligung der Frauen" "43 auffallen. Nach den obigen Ergebnissen müssten danach vor allen Dingen Diebstahl und Betrug als „frauentypisch“ bezeichnet werden. Diese Definition lässt jedoch zum einen außer Acht, dass diese Delikte ebenfalls häufiger von Männern als von Frauen begangen werden. Und zum anderen begehen auch Männer diese Delikte besonders häufig, sodass es verfehlt wäre von „,frauentypisch“ zu sprechen. Es handelt sich hierbei vielmehr um Straftaten die, unter Beachtung ihrer jeweils eigenen Deliktsstruktur, sowohl von Männern als auch von Frauen besonders häufig begangen werden.

Folglich sollte von „frauentypischen“ Delikten nur gesprochen werden, wenn ein Delikt tatsächlich auf Grundlage der absoluten Zahlen häufiger von Frauen begangen wird als von Männern. Fraglich ist, ob sich solche Straftaten anhand des statistischen Zahlenmaterials nachweisen lassen.

Betrachtet man die aktuellen Zahlen der PKS aus dem Jahr 2009144, stellt man fest, dass der Anteil der weiblichen Tatverdächtigen bei der Verletzung der Fürsorge- und Erziehungspflicht 71,9\% \% 145 beträgt. Auch bei der Entziehung Minderjähriger und bei Missbrauch von Scheck- und Kreditkarten liegt ihr Anteil mit $49,1 \% 0^{146}$ und $44,6 \%{ }^{147}$ verhältnismäßig hoch. Zudem weisen der Betrug zum Nachteil von Sozialversicherungen $\left(42,1 \%{ }^{148}\right)$, sonstiger Sozialleistungsbetrug $\left(45,6 \%{ }^{149}\right)$ und der einfache Ladendiebstahl $\left(40,2 \%{ }^{150}\right)$ hohe Anteile auf. ${ }^{151}$ Mithin gibt es nach den Daten der PKS lediglich einen Straftatbestand, bei dem Frauen häufiger tatverdächtig sind als Männer und der dementsprechend nach der

\footnotetext{
143 Göppinger 1980, S. 504.

${ }^{144}$ Die folgenden Prozentwerte basieren auf eigener Berechnung aufgrund BKA (Hrsg.), PKS 2009, Tabelle 20 im Anhang.

145 Absolutzahlen: Frauen 1.342, Männer 524.

146 Absolutzahlen: Frauen 909, Männer 943.

147 Absolutzahlen: Frauen 1.233, Männer 1.534.

148 Absolutzahlen: Frauen 2.221, Männer 3.006.

149 Absolutzahlen: Frauen 7.897, Männer 9.391.

150 Absolutzahlen: Frauen 7.897, Männer 9.391.

151 BKA (Hrsg.), PKS 2009, Tabelle 20 im Anhang.
} 
obigen Definition als frauentypisch zu bezeichnen wäre, nämlich die Verletzung der Fürsorge- und Erziehungspflicht gem. \171 StGB. Bei einigen wenigen anderen Straftatbeständen reicht der Anteil der Frauen nahezu an den der Männer heran. Hierbei ist jedoch zu berücksichtigen, dass einige dieser Kategorien gar keine eigenen Straftatbestände nach dem StGB darstellen, wie der Ladendiebstahl, der Betrug zum Nachteil von Sozialversicherungen und der sonstige Sozialleistungsbetrug. Dies sind lediglich für die PKS gebildete Untergruppierungen des \242 StGB bzw. \263 StGB. Betrachtet man den Anteil der weiblichen Tatverdächtigen an diesen Straftatbeständen im Ganzen, so ist dieser wieder um ein Wesentliches niedriger als bei den männlichen Tatverdächtigen.

Der Begriff „frauentypische“ Delikte findet folglich kaum einen Anwendungsbereich, da solche, bis auf die oben erwähnte Ausnahme, zumindest nach den Daten der PKS 2009 nicht existieren. Ob dies auch für die Ebene der Verurteilten gilt, soll an späterer Stelle mit den dieser Untersuchung zugrunde liegenden Daten des BZR noch überprüft werden. ${ }^{152}$

Der hohe Anteil an der Verletzung der Fürsorge- und Erziehungspflicht dürfte sich im Übrigen unter anderem dadurch erklären, dass Frauen nach wie vor häufiger als Männer die Kindererziehung übernehmen und dementsprechend die Möglichkeit der Tatbegehung für Frauen um ein Vielfaches höher ist. ${ }^{153}$

Festzustellen bleibt, dass es Delikte gibt, die Frauen unter Betrachtung ihrer Deliktsstruktur besonders häufig begehen, wie beispielsweise Diebstahl und Betrug. Dies allein kann jedoch kein Merkmal für eine Frauentypizität sein. Delikte, bei denen Frauen im Vergleich zu den Männern einen fast 50\%igen Anteil oder im Einzelfall sogar einen über 50\%igen Anteil der Fälle ausmachen, existieren kaum, sodass der Begriff „frauentypisch“ in diesem Zusammenhang kaum einen Anwendungsbereich findet.

\section{Selektionsprozess im Laufe der Strafverfolgung}

\subsection{Vom Dunkelfeld bis zur gerichtlichen Aburteilung}

Bei der Darstellung des Umfangs und der Struktur weiblicher Kriminalität ist zu berücksichtigen, dass „Kriminalisierung das Ergebnis einer oft konfliktreichen Auseinandersetzung mit prinzipiell sanktionswürdigen strafrechtlich relevantem abweichendem Verbalten" "54 ist. Unterschiedliche Akteure, z.B. die Anzeigeerstatter (Polizei oder andere Per-

\footnotetext{
152 Vgl. Kap. 4.

153 Nach Jacobsen ist das Ergebnis, die Verletzung der Fürsorge- und Erziehungspflicht sei ein ,frauentypisches“ Delikt tautologisch, „, da die Pflichtverletzung bereits auf einer politischen Zuweisung von geschlechterspezifischen Aufgaben berubt. "Sie kommt zu dem Schluss bei $\$ 171$ StGB handele es sich um „eine nicht mehr tragbare Verflechtung sozialer Beziebungen (...), denen mittels einer strafgerichtlichen Verurteilung Einhalt geboten werden soll.", vgl. Jacobsen, S. 68.

154 Geiger/Steinert, S. 4.
} 
sonen aus der Bevölkerung), die Ermittler und Strafverfolger, die Richter, die Vollstrecker, die Gesetzgeber, nehmen über die verschiedenen Stufen der Strafverfolgung die Kriminalisierung vor, wobei es zu einem Ausfilterungsprozess kommt. ${ }^{155}$ Das Ergebnis dieser Selektion lässt sich mit den amtlichen Statistiken, der PKS, der Strafverfolgungs-, Strafvollzugs- und der Bewährungshilfestatistik erfassen (vgl. Tabelle 1.3). ${ }^{156}$

Tabelle 1.3: Modell der statistischen Erfassung im Gang der Strafverfolgung, Strafzumessung und Strafvollstreckung (vereinfacht)

\begin{tabular}{|c|c|c|}
\hline Verfahrensabschnitt & Meldende Behörde & Datensammlung \\
\hline $\begin{array}{l}\text { Ermittlungsverfahren } \\
\text { Tatverdacht } \\
\text { Abgabe an StA } \\
\text { Anhängige Verfahren } \\
\text { Schlussverfügung } \\
\text { (Anklage, Einstellung etc.) }\end{array}$ & $\begin{array}{l}\text { Polizei } \\
\text { Staatsanwaltschaft } \\
\text { Staatsanwaltschaft }\end{array}$ & $\begin{array}{l}\text { Polizeil. Kriminalstatistik } \\
\text { Verfahrensregister } \\
\text { Staatsanwaltschaftsstatistik } \\
\text { (Geschäftsstatistik) }\end{array}$ \\
\hline Zwischenverfahren & Gericht & $\begin{array}{l}\text { Zählkartenerhebung in Straf- } \\
\text { und Bußgeldverfahren } \\
\text { (Geschäftsstatistik) }\end{array}$ \\
\hline $\begin{array}{l}\text { Hauptverfahren } \\
\text { Aburteilung } \\
\text { Verurteilung }\end{array}$ & $\begin{array}{l}\text { Gericht } \\
\text { Staatsanwaltschaft } \\
\text { Staatsanwaltschaft }\end{array}$ & $\begin{array}{l}\text { Strafverfolgungsstatistik } \\
\text { Strafverfolgungsstatistik } \\
\text { Bundeszentralregister }\end{array}$ \\
\hline $\begin{array}{l}\text { Strafvollstreckung } \\
\text { Freiheitsstrafe } \\
\text { mit Bewährung } \\
\text { - Unterstellung unter Be- } \\
\text { währungshelfer - } \\
\text { ohne Bewährung } \\
\text { - soweit vollzogen - } \\
\text { Straferlass/ Straferledi- } \\
\text { gung }\end{array}$ & $\begin{array}{l}\text { Staatsanwaltschaft } \\
\text { Gericht } \\
\\
\text { Staatsanwaltschaft } \\
\text { JVA } \\
\text { Staatsanwaltschaft }\end{array}$ & $\begin{array}{l}\text { Bundeszentralregister } \\
\text { Bewährungshilfestatistik } \\
\text { Bundeszentralregister } \\
\text { Strafvollzugsstatistik } \\
\text { Bundeszentralregister }\end{array}$ \\
\hline Wiederverurteilung & $\begin{array}{l}\text { Staatsanwaltschaft/ bzw. } \\
\text { Gericht }\end{array}$ & $\begin{array}{l}\text { Bundeszentralregister (Basis } \\
\text { für die Rückfalluntersuchung) }\end{array}$ \\
\hline
\end{tabular}

Quelle: Jeble, Strafrechtspflege in Deutschland, 2009, S. 7.

155 Geiger/Steinert, S. 4.

156 Jeble, Strafrechtspflege in Deutschland, S. 7 ff. 
Kriminalstatistiken sind dementsprechend als aufeinander aufbauende Arbeitsnachweise der jeweiligen Kontrollinstanz, nie als unmittelbarer Ausdruck der Kriminalität per se zu verstehen. ${ }^{157}$

Der Gang der Strafverfolgung stellt, von der Ebene des Dunkelfeldes bis hin zur gerichtlichen Ebene, einen Selektionsprozess dar. Das Dunkelfeld ist, wie bereits festgestellt, die Summe der nicht entdeckten und nicht angezeigten Straftaten und lässt sich daher nicht genau schätzen. Die Anzahl der Tatverdächtigen ist in Abhängigkeit von den Aufklärungsquoten zu sehen. Die Aufklärungsquoten können sich ihrerseits nur auf die polizeilich erfassten Delikte, dementsprechend nicht auf das Dunkelfeld, beziehen. Die staatsanwaltliche und richterliche Fallbehandlung baut wiederum auf den polizeilichen Ermittlungen auf, die sich in der PKS niederschlagen. Zwischen der polizeilichen und gerichtlichen Ebene reduziert sich die Zahl der betroffenen Personen aufgrund von Einstellungen, z.B. wegen nicht hinreichender Beweislage oder Geringfügigkeit der Delikte, infolge der Verbindung mehrere Straftaten und infolge anderer Erledigungen durch die Staatsanwaltschaft. Schließlich erfolgt eine weitere Selektion durch die Art der verhängten Sanktion. ${ }^{158}$

Die Schaubilder 1.11 und 1.12 verdeutlichen den Selektionsprozess und ermöglichen zugleich einen Einblick in die Größenverhältnisse, wobei sich Schaubild 1.11 auf weibliche und Schaubild 1.12 auf männliche Straffällige bezieht. Die Zahlen berücksichtigen Gesamtdeutschland, da die Strafverfolgungsstatistik seit dem Jahr 2007 erstmals auch die neuen Bundesländer mit einschließt. Umfasst wird die Gesamtheit aller von Frauen bzw. Männern verübten Delikte ohne Verkehrsdelikte, da diese in der PKS nicht gezählt werden.

Die erste Stufe stellt das nicht genau ermittelbare Dunkelfeld dar. Dies dürfte um einiges größer sein als die in den amtlichen Statistiken registrierten Straftaten. ${ }^{159}$ Schaubilder 1.11 und 1.12 verdeutlichen, dass bereits das Dunkelfeld der Kriminalität für die Frauen kleiner ausfallen dürfte als für die Männer. ${ }^{160}$ Zwischen der Ebene des Dunkelfeldes und der der Tatverdächtigen findet eine weitere Ausfilterung statt: Rund die Hälfte aller polizeilich registrierten Straftaten scheidet aus, weil kein Tatverdächtiger ermittelt werden kann. ${ }^{161}$ Die registrierten Straftaten und aufgeklärten Fälle können jedoch nicht geschlechtsdifferenziert dargestellt werden, da hier keine Personen gezählt werden können. Diese wurden dementsprechend nicht in den Schaubildern 1.11 und 1.12 erfasst.

\footnotetext{
157 Heinz, Kriminalität von Deutschen nach Alter und Geschlecht im Spiegel von Polizeilicher Kriminalstatistik und Strafverfolgungsstatistik, 2004, S. 13; vgl. Ausführungen unter Kap. 1, 1.4.

158 Jeble, Strafrechtspflege in Deutschland, S. 7 ff.

$159 \mathrm{Vgl}$. auch die Ausführungen unter Kap. 1, 1.5.

$160 \mathrm{Vgl}$. Ausführungen unter Kap. 1, 2.2.

1612009 betrug die Aufklärungsquote für alle registrierten Straftaten 55,6 \%.
} 
Schaubild 1.11: „Trichtermodell“ der Strafverfolgung (obne Verkehrsdelikte) für Frauen, 2009

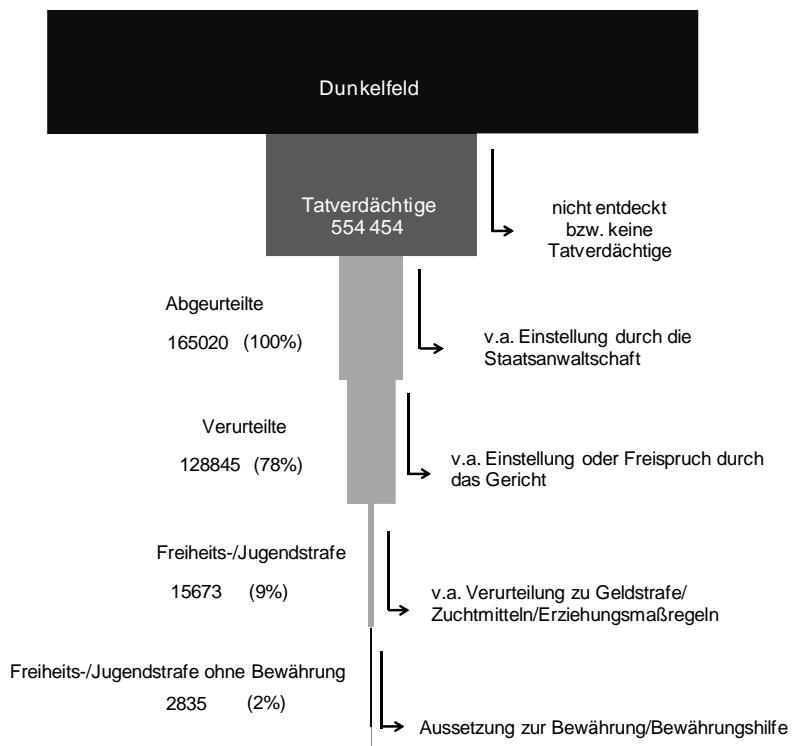

Quelle: BKA (Hrsg.), PKS 2009, Tab. 32 sowie StatBA (Hrsg.), StVS 2009, Tab. 2.1, 2.3 und 4.1; erstellt nach dem Vorbild bei Jehle, Strafrechtspflege in Deutschland, S. 9.

Schaubild 1.12: „Trichtermodell“ der Strafverfolgung (ohne Verkehrsdelikte) für Männer, 2009

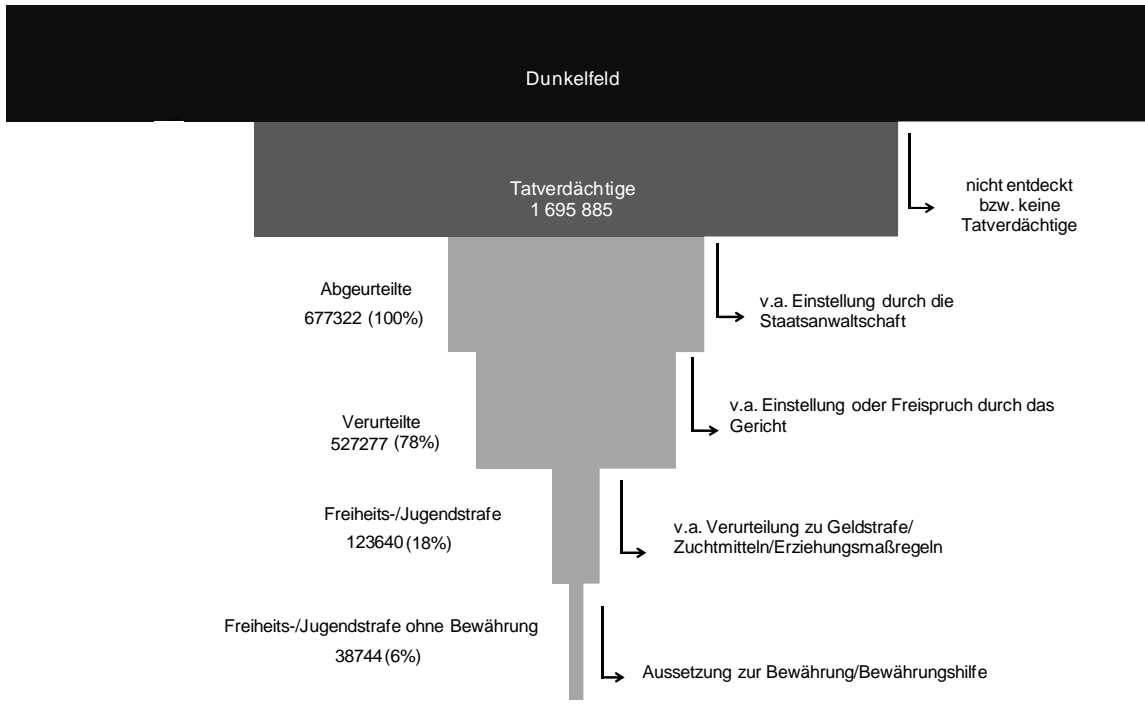

Quelle: BKA (Hrsg.), PKS 2009, Tab. 32 sowie StatBA (Hrsg.), StVS 2009, Tab. 2.1, 2.3 und 4.1; erstellt nach dem Vorbild von Jehle, Strafrechtspflege in Deutschland, S. 9. 
Der Filterprozess setzt vielmehr gleich bei den ermittelten Tatverdächtigen an, bei denen es sich sozusagen „um eine Auslese aus einem doppelten Dunkelfeld, des Dunkelfeldes der nicht angezeigten Taten und des Dunkelfeldes der zwar angezeigten Taten, aber der nicht ermittelten Tatverdächtigen" "62 handelt. Schaubilder 1.11 und 1.12 veranschaulichen zunächst den unterschiedlichen Umfang der Kriminalität der Geschlechter auf der Ebene der Tatverdächtigen: Im Jahr 2009 wurden 554.454 weibliche und 1.740.145 männliche Tatverdächtige ermittelt. Ausgehend von den in diesem Kapitel unter 2.2 vorgestellten Ergebnissen besteht zwar auch im Dunkelfeld ein Unterschied zwischen dem Kriminalitätsanteil der Geschlechter, dieser dürfte jedoch gerade für den von Frauen besonders relevanten Bereich der Bagatellkriminalität etwas geringer sein, sodass vermutlich bereits auf der Ebene der Tatverdächtigen für die Frauen ein intensiverer Ausfilterungsprozess stattfindet als für die Männer. ${ }^{163}$

Auch kann nicht genau abgebildet werden, was zwischen der polizeilichen und gerichtlichen Ebene geschieht. Jedenfalls reduziert sich infolge von Einstellungen die Anzahl der straffälligen Frauen auf 165.020 und die der straffälligen Männer auf 677.322, gegen die eine gerichtliche Entscheidung ergeht. Diese Zahl ist in den Schaubildern mit $100 \%$ angesetzt. Von den Abgeurteilten werden knapp $80 \%$ der Frauen und Männer verurteilt. Bei den verhängten Sanktionen handelt es sich überwiegend um Geldstrafen oder - im Falle von Jugendlichen und Heranwachsenden - um Erziehungsmaßregeln oder Zuchtmittel. Nur ein kleiner Teil wird zu einer Freiheits- oder Jugendstrafe verurteilt, wobei die Vollstreckung zumeist zur Bewährung ausgesetzt wird. Sowohl die Anzahl der weiblichen als auch die der männlichen Personen nimmt von Stufe zu Stufe ab.

In der Grundtendenz ergibt sich allerdings ein Bild, das über alle erfassten Dimensionen hinweg für ein gegenüber Männern vergleichsweise geringes Kriminalitätspotential von Frauen spricht. Verfolgt man die Kriminalstatistiken von der polizeilichen Ermittlung über die Aburteilung, Verurteilung bis hin zur Freiheitsbzw. Jugendstrafe ohne Bewährung, zeigt sich auf jeder Stufe ein jeweils geringerer Anteil weiblicher Personen. Der Selektionsprozess fällt für die straffälligen Frauen mithin stärker aus: Die Täter erhalten im Vergleich zu den Täterinnen mit $18 \%$ doppelt so häufig eine Freiheits- oder Jugendstrafe. Noch ausgeprägter ist der Unterschied dann bei den stationären Sanktionen: $6 \%$ der Männer und sogar nur $2 \%$ der Frauen erhalten Freiheits- oder Jugendstrafe ohne Bewährung.

\footnotetext{
162 BMI/BMJ (Hrsg.), PSB II, S. 9.

163 Jedoch ist zu berücksichtigen, dass die meisten Dunkelfeldstudien junge Menschen befragt haben, bei denen auch im Hellfeld ein geringerer Abstand bei der Kriminalitätsbelastung besteht. Ferner dürften Anzeigebereitschaft und Verfolgungsintensität bei Bagatelldelikten insgesamt geringer sein, vgl. Kap. 1, 2.2.8 sowie Heinz, Kriminalität in Deutschland, III.1.2.
} 


\subsection{Vergleichbarkeit der Daten}

Die amtlichen Statistiken und Register bedürfen hinsichtlich ihres Entstehungsund primären Verwendungszusammenhangs und letztlich ihrer Aussagequalität einer kritischen Interpretation. ${ }^{164}$ Bei der Interpretation der Daten in der oben gewählten Darstellungsweise anhand des „Trichtermodells“, sind vor allen Dingen die Grenzen der Vergleichbarkeit der einzelnen Statistiken zu berücksichtigen.

Die Daten der PKS können mit den Daten der Strafrechtspflegestatistiken nur schwer verglichen werden. Dies liegt daran, dass die Erfassungszeiträume unterschiedlich sind und auch die Erfassungsgrundsätze nicht übereinstimmen. ${ }^{165}$ So findet in der PKS eine andere Deliktsgruppierung als in der StVS statt. Die StVS kategorisiert nach den gesetzlichen Bestimmungen, wohingegen die PKS auch kriminologische Gesichtspunkte berücksichtigt. ${ }^{166}$ Aufgrund der unterschiedlichen Erfassungsmodalitäten, stammt nur ein Teil der Verurteilten aus den Tatverdächtigen desselben Berichtjahres. Darüber hinaus ist in der PKS u.a. die große Gruppe der Verkehrsdelikte nicht enthalten. Ferner enthält die StVS bis einschließlich 2006 im Wesentlichen ${ }^{167}$ nur die Daten für die früheren Bundesländer einschließlich Gesamt-Berlin, wohingegen sich die Daten der PKS auf das gesamte Bundesgebiet beziehen. Dies ermöglicht bis einschließlich zum Jahr 2006 einen Vergleich der Daten nur in Bezug auf das frühere Bundesgebiet und Gesamt-Berlin. Erfreulicherweise enthält die StVS seit 2007 erstmals die Zahlen für das gesamte Bundesgebiet, sodass eine vergleichende Gegenüberstellung vereinfacht wird. Auf der staatsanwaltlichen Ebene und bei den Strafgerichten werden in erster Linie Verfahren und nur teilweise Personen erfasst. ${ }^{168}$

Trotz dessen liefern die amtlichen Statistiken wichtige Hinweise für die Einschätzung von Ausprägungen in der Kriminalitätsentwicklung.

\subsection{Inhaftierte}

Das in den Schaubildern 1.11 und 1.12 dargestellte Trichtermodell weist die Ebene der Inhaftierten nicht aus, da eine Vergleichbarkeit hier besonders schwierig ist. ${ }^{169}$ Informationen über den Justizvollzug lassen sich den Daten der Strafvollzugsstatistik entnehmen, der ein anderes Erfassungskonzept als der PKS oder StVS zugrunde liegt: Die meisten Daten werden am 31.03. eines jeden Jahres erhoben. Es handelt sich folglich um eine stichtagsbezogene Statistik und nicht etwa um eine Eingangs- oder gar Erledigungsstatistik. Die Anzahl der so erfassten Inhaf-

\footnotetext{
${ }^{164}$ Vgl. hierzu Ausführungen unter Kap. 1, 1.4.

165 Meier, Kriminologie, \5, Rdn. 15; Schwind, \2, Rdn. 12.

166 Jeble, Strafrechtspflege in Deutschland, S. 6.

${ }^{167}$ Seit 1998 liegen Eckdaten für Brandenburg, Sachsen und Thüringen, seit 2002 auch für Mecklenburg-Vorpommern vor.

168 Jehle, Strafrechtspflege in Deutschland, S. 6; vgl. ferner zu der Problematik der Vergleichbarkeit der Daten: Heinz, Kriminalität von Deutschen nach Alter und Geschlecht, S. 6.

${ }^{169}$ So auch Schwind, $\$ 2$, Rdn. 13.
} 
tierten stimmt nicht mit der Anzahl der zu einer Freiheits-oder Jugendstrafe ohne Bewährung Verurteilten überein.

Von den Verurteilten gelangen nur diejenigen in den Justizvollzug, die als Sanktion eine Freiheits-oder Jugendstrafe ohne Bewährung erhalten haben, oder diejenigen, die zu einer Freiheits- oder Jugendstrafe mit Bewährung verurteilt wurden, deren Strafaussetzung jedoch widerrufen wurde. Ferner noch die Frauen und Männer, bei denen im Anschluss an eine Freiheitsstrafe eine Anordnung der Maßregel der Sicherungsverwahrung erfolgte oder die eine Ersatzfreiheitsstrafe für eine nicht bezahlte Geldstrafe verbüßen müssen. Hinzu kommen die Personen, die sich in Untersuchungs-, Zivil- oder Abschiebehaft befinden. ${ }^{170}$

Zum Stichtag 31.03.2009 waren 5,4 \% der Inhaftierten weiblich. ${ }^{171}$ Folglich hat sich der Frauenanteil durch den oben geschilderten Ausfilterungsprozess immer stärker reduziert, sodass schließlich nur dieser sehr geringe Anteil von Täterinnen im Strafvollzug verbleibt.

170 Jeble, Strafrechtspflege in Deutschland, S. 45.

171 StatB A (Hrsg.), Strafvollzugstatistik 2009, S. 14; vgl. ausführlich zum Frauenstrafvollzug bspw: Kawamura-Reindl, Frauenstrafvollzug in Deutschland, in: Elz (Hrsg.), Täterinnen, S. 213-236; Haverkamp, Frauen im Strafvollzug im Lichte der europäischen Strafvollzugsgrundsätze, in: Lösel/Bender/ Jehle (Hrsg.), Kriminologie und wissensbasierte Kriminalpolitik, S. 339-353; Klopp, Frauenstrafvollzug: Frauen im Strafvollzug in Europa; Boeblen, Frauen im Gefängnis: ihr Werdegang und ihre Bewährung. 


\section{Kapitel 2: Erklärungsansätze für das Phänomen der Frauenkriminalität}

Vor dem Hintergrund der in Kapitel 1 dargestellten Ergebnisse stellt sich die Frage nach den Ursachen für Frauenkriminalität.

$\mathrm{Zu}$ den Erklärungsansätzen für weibliche Kriminalität existieren bereits zahlreiche und umfangreiche Untersuchungen ${ }^{172}$, die im Wesentlichen danach fragen, ob Frauen per se weniger kriminell sind als Männer. Dabei wird häufig die Problematik aus dem Blickfeld verloren, warum Frauen überhaupt Straftaten begehen. Es ist zu überprüfen, ob für Kriminalitätsentstehung die gleichen Theorien und Begründungsansätze herangezogen werden können wie bei männlichen Tätern und ob eine Modifizierung für frauenspezifische Belange von Nöten ist. ${ }^{173}$

Daher werden im Folgenden zwei Fragestellungen problematisiert, nämlich warum Frauen kriminell und warum sie im Vergleich zu Männern weniger kriminell werden. Zunächst muss geklärt werden, wie „weniger kriminell“ zu interpretieren ist. In quantitativer Hinsicht bedeutet dieses „Weniger“ für die vorliegende Arbeit, dass Frauen zum einen eine geringere Kriminalitätsbelastung aufweisen, aber auch, dass Frauen seltener rückfällig werden. Die vorangegangenen Ausfüh-

\footnotetext{
172 Vgl. beispielsweise: Brökling, Frauenkriminalität; Franke, Frauen und Kriminalität; Funken, Frau - Frauen - Kriminelle: Zur aktuellen Diskussion über „Frauenkriminalität“; Theurer, Emanzipation - Der Schlüssel zur Erklärung der Frauenkriminalität? 173 Göppinger 2008, \24, Rdn. 143.
} 
rungen zum Umfang weiblicher Kriminalität konnten bereits belegen, dass Frauen geringer mit Kriminalität belastet sind, was es mithin zu erklären gilt. Der Aspekt der Rückfälligkeit wird erst an späterer Stelle aufgegriffen. Das „,weniger kriminell“" kann jedoch auch qualitativ verstanden werden, sodass hier zu überprüfen ist, ob und wenn ja, warum die von Frauen begangenen Straftaten weniger schwer sind. Dass weibliche Kriminelle eine andere Deliktsstruktur aufweisen, wurde ebenfalls bereits festgestellt. Frauen begehen in der Regel weniger schwerwiegende Delikte. Die Erklärungsansätze werden daher auch im Hinblick auf diese qualitative Betrachtungsweise diskutiert.

Schließlich ist zu beachten, dass die auseinanderzuhaltenden Fragen, warum Frauen kriminell und warum sie weniger kriminell werden als Männer, häufig nicht klar getrennt werden können. Dies liegt daran, dass die speziellen Theorien zur Erklärung von Kriminalität sich bei der Begründung für die Entstehung weiblicher Kriminalität zumeist auf vermeintliche Geschlechtsunterschiede beziehen, was letztendlich dazu führt, dass lediglich versucht wird, diese Differenz zu erklären. Um diese einseitige Sichtweise zu vermeiden und keine Begrenzung des Erklärungsgehalts herbeizuführen, wird unter Kapitel 2, 1, nach einem kurzen historischen Überblick, zunächst untersucht, warum Frauen überhaupt kriminell werden. Dabei liegt der Fokus auf der Frage, ob die wichtigsten „traditionellen“ Kriminalitätstheorien, welche blind gegenüber Geschlechterunterschieden sind, auch die Entstehung und die Spezifika weiblicher Kriminalität erklären können. ${ }^{174}$ Aufgrund der vielfachen und zum Teil unübersichtlichen Ausarbeitungen zu dieser Thematik werden nur die zentralen Ansätze herausgegriffen und zudem einige Forschungsarbeiten erörtert, die sich mit diesem Themenkomplex auseinandergesetzt haben. Erst im Anschluss an die jeweilige allgemeine Darstellung einiger ausgewählter Theorien und deren Anwendbarkeitskontrolle auf das weibliche Geschlecht wird eine Modifikation für frauenspezifische Belange erörtert, welche sich dann im Wesentlichen mit der Erklärung der geringeren Kriminalitätsbelastung von Frauen beschäftigen. Schließlich werden unter Kapitel 2, 2 die Ansätze diskutiert die sich nur mit einer Erklärung der geringeren Kriminalitätsbelastung beschäftigen.

${ }^{174}$ Gegen eine Anwendbarkeit Chesney-Lind, in: CrimDel 1989, S. 5, 19. 


\section{Historischer Überblick über ältere biologische Erklärungsansätze}

Im 19 Jahrhundert konzentrierte man sich bei der Erklärung von Kriminalität in erster Linie auf biologische und anthropologische Faktoren. ${ }^{175}$ Die frauenspezifischen Erklärungsansätze wurden dabei deutlich von dem damals vorherrschenden Frauenbild, der zumeist männlichen Autoren, geprägt. ${ }^{176}$ Bei der Suche nach den Ursachen geringerer Delinquenzbelastung von Frauen ließen die Vertreter dieser Ansätze soziale Aspekte außer Acht. Stattdessen werden Faktoren wie die physische Konstitution, Sexualität, Psyche, Intelligenz oder andere angeblich von biologisch-psychischen Determinanten beeinflusste geschlechtsspezifische Anlagen und weibliche Verhaltensmuster zur Grundlage von Erklärungsmodellen stilisiert. ${ }^{177}$ Diese Erklärungsversuche werden in der kriminologischen Literatur immer wieder aufgegriffen, weshalb die grundlegenden Annahmen kurz skizziert werden sollen.

Lombroso und Ferrero ${ }^{178}$ begründeten die geringere Kriminalitätsbelastung von Frauen und deren Schwerpunkt bei einzelnen Delikten mit ihrer biologischen Konstitution. Sie stützen sich auf die Annahme, Rechtsbrecher seien schon als solche geboren und stellten einen Atavismus dar. ${ }^{179}$ Jener Atavismus werde auch beim weiblichen Verbrecher deutlich, indem er sich in der Frühreife und der Annäherung an den männlichen Typus zeige. ${ }^{180}$ So sei die normale Frau weniger intelligent als der Mann sowie eitel, rachsüchtig und grausam, habe aber auch positive Eigenschaften wie Scham, Mutterliebe und Mitleid. ${ }^{181}$ Der weibliche Verbrechertyp sei gerade dadurch gekennzeichnet, dass die negativen Anlagen der weiblichen Natur vorhanden, die ausgleichenden positiven Eigenschaften jedoch nur in geringem Maße ausgeprägt und zusätzlich mit männlichen Eigenschaften, wie Kühnheit, Intelligenz und Vorliebe für typische männliche Laster, kombiniert seien. ${ }^{182}$ Darauf aufbauend stellten Lombroso und Ferrero die Hypothese auf, die Prostitution sei weibliches Äquivalent zur männlichen Kriminalität. ${ }^{183}$

Der Ansatz Lombrosos und Ferreros, die Frau begehe deshalb weniger Straftaten, weil ihr zum kriminell werden angeblich die Körperkraft und Intelligenz fehlten, wurde auch von anderen Autoren aufgegriffen. So erklärte beispielsweise Amelun-

\footnotetext{
${ }^{175}$ Erklärungsversuche für Frauenkriminalität lassen sich vereinzelt schon früher finden, vgl. Schmölzer, Geschlecht und Kriminalität: Zur kriminologischen Diskussion der Frauenkriminalität.

176 Kaiser, in: ZStW 1986, S. 658, 669.

177 So etwa Cremer, S. 182 ff.; Exner, S. 133 ff.

178 Lombroso/Ferrero, Das Weib als Verbrecherin und Prostituierte.

${ }^{179}$ Lombroso/Ferrero, S. 326 ff.

180 Lombroso/Ferrero, S. 351.

181 Lombroso/Ferrero, S. 72 f., 118 ff., 145, 150 f., 170 f.; Theurer, S. 19.

182 Lombroso/Ferrero, S. 446.

183 Lombroso/Ferrero, S. 579.
} 
$x^{184}$ die geringere Kriminalitätsbelastung als Mangel an Möglichkeiten, da die Frau kleiner, schwächer, ermüdsamer und langsamer sei als der Mann und dazu ein unausgeglichenes Gefäß- und Nervensystem habe. ${ }^{185}$ Möbius $^{186}$ stellte ebenfalls auf die physische Schwäche und niedrige Intelligenz der Frau ab. ${ }^{187}$

Wulffen 188 sprach von dem „Weib als Sexualverbrecherin“ und schloß sich der These Lombrosos, die geringere Kriminalitätsbelastung der Frau sei auf ihre biologische Inferiorität zurückzuführen, an. ${ }^{189}$ Aufgrund ihrer geschlechtsspezifischen Funktion sei sie kriminogenen Momenten ausgesetzt. Dabei könnten insbesondere Menstruation, Schwangerschaft und Klimakterium Kriminalität verursachen. ${ }^{190}$ Die Mehrzahl krimineller Auswirkungen bei der Frau stehe aus psychophysiologischen Gründen in einem bestimmten Zusammenhang mit ihrem Geschlechtsleben. ${ }^{191}$ Häufig wurden die mit Generationsvorgängen einhergehenden psychischen Schwankungen für kriminelles Handeln der Frau verantwortlich gemacht. ${ }^{192}$ Die vor und während der Menstruation auftretenden psychischen Veränderungen würden zu abweichendem Verhalten führen. ${ }^{193}$

Der Arzt Legrand du Saulle führte in diesem Zusammenhang im Jahr 1894 eine Untersuchung durch, bei der er feststellte, dass von 56 Pariser Ladendiebinnen zum Tatzeitpunkt 35 ihre Menstruation hatten. ${ }^{194}$ Auch in vergleichsweise jüngeren Untersuchungen wurde versucht einen möglichen Zusammenhangs von Kriminalität und der prämenstruellen Phase nachzuweisen. ${ }^{195}$

Neben diesen rein biologischen Erklärungsansätzen, gab es Konzepte die darauf abstellten, dass die naturgegebene Geschlechtsrolle die wahre Identität der Frau ausmache. Entsprechend bezeichnete der Soziologe Thomas ${ }^{196}$ Frauenkriminalität als Rebellion der Frau gegen ihre Rolle. Sie sei dem Mann gegenüber aufgrund ihres kleineren Gehirns biologisch untergeordnet. Thomas nahm in Analogie zur Tier- und Pflanzenwelt eine Kategorisierung der Natur der Geschlechter, in

\footnotetext{
184 Amelunxen, Die Kriminalität der Frau.

185 Amelunxen, S. 7.

186 Möbius, Über den physiologischen Schwachsinn des Weibes.

${ }^{187}$ Möbius, S. 15, 17, 27 f.

188 Wulffen, Das Weib als Sexualverbrecherin.

189 Wulffen, S. 42.

${ }^{190}$ Wulffen, S. 42; Brökling, S. 14; Funken, S. 18.

191 Wulfen, S. 4.

192 Herrfabrdt, Zur Kriminalität weiblicher Minderjähriger, S. 52.

${ }^{193}$ So Birnbaum, Kriminalpsychopathologie und psychobiologische Verbrecherkunde, S. 174 f.

${ }^{194}$ Legrand du Saulle, Nachweis bei Theurer, S. 35.

195 Dalton, 1961 nachgewiesen bei Widom/Ames, in: Moffitt/Mednick (Hrsg.), Biological Contribution to Crime Causation, S. 308, 318; Schmölzer weist darauf hin, dass diese Studien und die zugrundeliegenden Hypothese, durchaus noch als aktuell und nicht historisch einzustufen seien. Diese Einschätzung begründet sie mit zwei Strafrechtsfällen aus Großbritannien aus dem Jahr 1981, in denen verminderte Zurechnungsfähigkeit der Täterinnen angenommen wurde, weil sie sich unter dem Einfluss eines ,prämenstruellen Syndroms“ befunden hätten. Hierbei dürfte es sich allerdings um Einzelfälle gehandelt haben. Aktuell sind keine vergleichbaren Fälle bekannt.

196 Thomas, Sex and Society, 1907; Thomas, The unadjusted girl, 1925.
} 
katabolische, also männliche, und anabolische, gemeint sind weibliche, Eigenschaften, vor. Katabolisch stehe für Stärke, Energie und Zerstörungstrieb, wohingegen anabolisch für Passivität, Geduld und Stabilität stünde. ${ }^{197}$ Er betonte, ein Individuum sei in erster Linie ein biologisches Wesen. Allerdings müssten zur Erklärung der Frauenkriminalität auch psychologische und sozialstrukturelle Faktoren miteinbezogen werden. Kriminalität sei ein Phänomen unterprivilegierter, für Thomas gleichzusetzen mit amoralischen, Frauen. Kriminalität könne nur durch eine Zurückbesinnung auf die traditionelle Frauenrolle verhindert werden. ${ }^{198}$

Auch die Erklärung für die weibliche Deliktsstruktur orientierte sich an den grundsätzlichen Annahmen zur Entstehung von Frauenkriminalität. Als Gründe für ihren geringen Anteil an der Gewaltkriminalität wurden demnach beispielsweise die Sexualität oder körperliche Schwäche von Frauen sowie ihre behauptete Passivität und Angepasstheit angeführt. ${ }^{199}$ Insbesondere die Vertreter, die die körperliche Schwäche der Frau hervorhoben, betonen, dass Frauen sich in dieser Konsequenz anderer Mittel bedienten als Männer. So sei der Giftmord eine typische weibliche Domäne. ${ }^{200}$ Diebstähle würden relativ häufig begangen, da dies das Delikt der sexuell unbefriedigten Frau sei. ${ }^{201}$ Mergen ging sogar so weit zu behaupten, Frauen würden durch den Stehlakt zum Orgasmus gelangen. ${ }^{202}$ Der relativ hohe Frauenanteil an Beleidigungen ließe sich mit ihrem zänkischen Wesen erklären. Falschaussagen seien auf die Neigung der Frau zu Unaufrichtigkeit und Lüge zurückzuführen. Falsche Anschuldigungen hätten oft sexuellen Inhalt und seien gegen den Mann gerichtete sexuelle Aggression. ${ }^{203}$

Insgesamt gesehen sind die Ansätze geprägt von Stereotypen, Klischees und Vorurteilen und nur noch von historischer Bedeutung. ${ }^{204}$

\footnotetext{
197 Vgl. Thomas, Nachweis bei Franke, S. 35.

198 Vgl. Thomas, Nachweis bei Franke, S. 35 f.

${ }^{199}$ Vgl. hierzu zusammenfassend Ubl, in: Hilbig/Kajatin/Miethe (Hrsg.), Frauen und Gewalt, S. 91-104.

200 Gast, S. 30.

201 Schneider 1987, S. 571.

202 Mergen, S. 227.

${ }^{203}$ Mergen, S. 226.

204 So auch Möller, S. 13.
} 


\section{Erklärungsansätze für die Kriminalitätsbelastung von Frauen}

\subsection{Biologische Erklärungsansätze}

\subsubsection{Allgemeine Darstellung und Anwendbarkeit auf das weibliche Geschlecht}

Lombrosos Theorie vom geborenen Rechtsbrecher legte den Grundstein für verschiedene Forschungsarbeiten, welche sich mit der Rolle von Erbanlagen bei der Kriminalitätsentstehung befassten. Die biologischen Erklärungsansätze gehen von der Annahme einer genetisch bedingten Kriminalitätsentstehung aus. Sie stützen sich auf den grundsätzlichen Gedanken eines biologischen Determinismus, wonach alles menschliche Handeln biologisch begründet sei. ${ }^{205}$ Lombrosos Lehre vom geborenen Verbrecher ist zwar widerlegt, gleichwohl konnte nach wie vor nicht ausgeschlossen werden, dass auch der Vererbung für das Entstehen von Kriminalität Bedeutung zukommt. ${ }^{206} \mathrm{Um}$ einen Zusammenhang nachzuweisen, wurde die Zwillings- und Adoptionsforschung entwickelt. Auch Chromosomenanomalien werden als mögliche Ursache diskutiert. ${ }^{207}$

Die Zwillingsstudien ${ }^{208}$ stellen die Hypothese auf dass sich eineiige Zwillinge aufgrund übereinstimmender genetischer Anlagen in ihrem sozialen Verhalten mehr ähneln müssten als zweieiige Zwillinge, sofern Anlagefaktoren tatsächlich Bedeutung für kriminelles Verhalten zukäme. Daher wurden verschiedene getrennt oder gemeinsam aufwachsende Zwillingspaare beobachtet, um den Einfluss der Erbanlage bei der Verbrechensentstehung zu ermitteln. ${ }^{209}$ Cbristiansen $^{210}$ untersuchte 328 eineiige und 593 zweieiige Zwillingspaare. Die Studie ergab bei ersteren eine Konkordanz von $21 \%$ hinsichtlich des registrierten kriminellen Verhaltens, bei letzteren betrug die Übereinstimmung $8 \% .{ }^{211}$ Dieses Ergebnis wird von fast allen Zwillingsstudien bestätigt ${ }^{212}$ und das für beide Geschlechter gleichermaBen. ${ }^{213}$ Die Vermutung eines Einflusses der Erbanlagen auf kriminelles Verhalten von Frauen und Männern wird mithin bestätigt. Problematisch ist bei besagten Studien, dass der Einfluss von Umweltfaktoren auf kriminogenes Verhalten und

\footnotetext{
205 Brökling, S. 14

206 Schwind, \5, Rdn. 1.

207 Schwind, S 5, Rdn. 1 ff.

${ }^{208}$ Vgl. eine Zusammenstellung der wichtigsten Zwillingsstudien bei Zerbin-Rüdin, in: Göppinger/Vossen (Hrsg.), Humangenetik und Kriminologie: Kinderdelinquenz und Frühkriminalität, S. 1-18.

209 Theurer, S. 23.

${ }^{210}$ Christiansen, in: Mednick/Christiansen (Hrsg.), Biosocial base of criminal behavior, S. 89-108.

${ }^{211}$ Christiansen, in: Mednick/Christiansen (Hrsg.), Biosocial base of criminal behavior, S. 89, $96 \mathrm{f}$.

${ }^{212}$ Christiansen, in: Mednick/Christiansen (Hrsg.), Biosocial base of criminal behavior, S. 45, 72; Eysenck, Kriminalität und Persönlichkeit.

${ }^{213}$ Widom/Ames, in: Moffitt/Mednick (Hrsg.), Biological contribution to crime causation, S. 308, 324.
} 
das Zusammenspiel mit genetischen Anlagen nicht vollauf zu klären ist. ${ }^{214}$ Daher wurden Adoptionsstudien ${ }^{215}$ durchgeführt, um der Forschung über den Zusammenhang von Erbanlagen und Kriminalität Umwelteinflüsse zu exkludieren. Es wurde eine erhöhte Rate antisozialen oder kriminellen Verhaltens bei adoptierten Frauen festgestellt, die kriminelle biologische Mütter hatten. ${ }^{216}$ Die Zwillings- und Adoptionsstudien sprechen in ihren Ergebnissen zwar tendenziell für einen Einfluss der Erbanlagen auf kriminelles Verhalten beider Geschlechter, doch ist die Rolle von externen Umweltbedingungen, wie Erziehung oder familiäres Umfeld, und deren möglicher Einfluss nie genau einzuschätzen bzw. bei Untersuchungen auszuschließen. Die Resultate weisen eher darauf hin, dass Erbanlagen bei der Kriminalitätsentstehung zumindest einen Einfluss haben, zeigen aber keine konkret kriminalitätsauslösenden Persönlichkeitsmerkmale oder einen zwingenden Zusammenhang mit genetischer Disposition. ${ }^{217}$

\subsubsection{Modifikation für frauenspezifische Belange}

Der geringere Kriminalitätsanteil von Frauen wird von den Vertretern der biologischen Ansätze mit den Genen, Chromosomen und hormonellen Einflüssen begründet, die der Frau größere Stabilität verleihen. So geht beispielsweise Cremer218 davon aus, dass die weibliche Geschlechtschromosomenkonstitution den Frauen mehr Stabilität und damit mehr Widerstandskraft gegen kriminelle Versuchungen verleihen. ${ }^{219}$ Eine stabilisierende Wirkung des X-Chromosoms konnte jedoch wissenschaftlich nicht nachgewiesen werden. Die wenigen Untersuchungen ${ }^{220}$, die hierzu existieren, versuchten in der Regel, einen Zusammenhang zwischen weiblichen kriminellen Verhalten und den bei Frauen vorkommenden Geschlechtschromosomenaberrationen X0 oder XXX nachzuweisen. Die Anzahl der Probandinnen mit Aberrationen war jedoch so gering, dass ein Einfluss nicht nachweisbar war. So wurde in einer Untersuchung von 250 Gefängnisinsassen nur eine mit Aberration und bei einer anderen Studie von 200 jugendlichen Delinquenten nur zwei mit dieser Chromosomenabweichung gefunden. ${ }^{221}$

\footnotetext{
214 Theurer, S. 24.

215 Vgl. zu einer Zusammenstellung der wichtigsten Adoptionsstudien: Walters, in: Crim 1992, S. 595, 602 sowie Zerbin-Rüdin, in: Göppinger/Vossen (Hrsg.), Humangenetik und Kriminologie: Kinderdelinquenz und Frühkriminalität, S. 1-18.

216 Widom/Ames, in: Moffitt/Mednick (Hrsg.), Biological contribution to crime causation, S. 308, S. 324; Tellegen/Lykken/Bouchard/Wilcox/Segal/Rich, in: Journal of Personality and Social Psychology 1988, S. 1031, 1035 f.

217 Theurer, S. 26.

218 Cremer, Untersuchungen zur Kriminalität der Frau.

${ }^{219}$ Cremer, S. 220.

220 Telfer/Richardson/Chock, sowie Kaplan, Nachweis bei Theurer, S. 28 f.

${ }^{221}$ Nachweis bei Theurer, S. $28 \mathrm{f}$.
} 


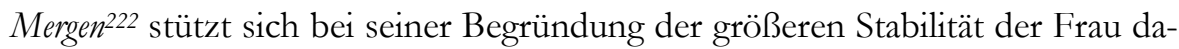
rauf, dass das Y-Chromosom aggressions- und kriminalitätsfördernd zu sein scheint. ${ }^{223}$ Die Existenz eines zusätzlichen Y-Chromosoms führe zu signifikant häufigerer Delinquenz. Mehrere Untersuchungen ${ }^{224}$ kamen zu dem Ergebnis, dass der Anteil von Männern mit dieser Chromosomenabweichung in den Gefängnissen höher ist, als der vermutete Anteil dieser Männer in der Gesamtbevölkerung. ${ }^{225}$ Bei genauerer Betrachtung der Gefängnisinsassen ließ sich jedoch ein erhöhtes Aggressionspotential der XYY-Probanden nicht entdecken.226 Abgesehen davon existieren Studien, die zu dem Ergebnis kommen, das XYY-Syndrom führe sogar zu weniger Kriminalität. ${ }^{227}$ Folglich ist eine geringere Kriminalitätsbelastung von Frauen aufgrund der unterschiedlichen Chromosomenstruktur nicht nachweisbar.

Vergleichsweise jüngere Untersuchungen 228 , vor allem aus der Soziobiologie, stellen für eine geringere Kriminalitätsbelastung von Frauen darauf ab, dass in den männlichen Sexualhormonen, den Androgenen, die Voraussetzung für Aggressivität liege. Die Untersuchungen stellen darauf ab, dass Männer universell gesehen ein höheres Aggressionspotential aufweisen, was sich bereits bei Neugeborenen zeige und bis zum Tod erhalten bleibe. Dies sei durch die Androgene zu erklären und werde auch durch einen Vergleich mit Primaten bestätigt, bei denen die Männchen über ein erhöhtes Aggressionspotential verfügen.229 Zu kritisieren ist jedoch die ausschließliche Betrachtung der Sexualhormone.

Für einen Einfluss biologischer Faktoren auf die weibliche Kriminalität spricht, dass trotz historisch bedingter Umweltveränderungen die Frau international gesehen eine weitaus geringere Kriminalitätsbelastung aufweist als der Mann. Dem kann entgegengehalten werden, dass sich dennoch auftretende zeitliche und örtliche Schwankungen der Kriminalitätsbelastung von Frauen mit einer „Naturkonstanten" kaum begründen lassen. ${ }^{230}$

Den Autoren, die Frauen aufgrund ihrer Chromosomen- oder Hormonstruktur eine größere Stabilität zuschreiben, kann zudem entgegengehalten werden, dass Männer, die nicht auffällig werden, erklärungsbedürftig bleiben.

\footnotetext{
222 Mergen, Der geborene Verbrecher.

223 Mergen, S. 37.

${ }^{224}$ Beispielsweise: Witkin/Mednik/Schulsinger et al., in: Mednick/Christiansen (Hrsg.), Biosocial bases of criminal behavior, S. 165-187; Hagemann-White, Sozialisation: Weiblich-männlich?

225 Hagemann-White (Fn. 224).

226 Hagemann-White, S. 36; Witken/Mednick/Schulsinger et al., in: Mednick/Christiansen (Hrsg.), Biosocial basis of criminal behavior, S. 165, 186.

227 Zang, in: Göppinger/Vossen (Hrsg.), Humangenetik und Kriminologie: Kinderdelinquenz und Frühkriminalität, S. 19-31.

228 Vgl. beispielsweise Dennen, in: Dennen (Hrsg.), The nature of the sexes, S. 107-124; Bjerke, in: Dennen (Hrsg.), The nature of the sexes, S. 95-106.

${ }_{229}$ Dennen, in: Dennen (Hrsg.), The nature of the sexes, S. 107, $117 \mathrm{ff}$.

${ }^{230}$ So auch Kaiser, in: ZStW 1986, S. 658, 671.
} 
Außerdem lassen die dargestellten Erklärungsansätze außer Betracht, dass das $\mathrm{Ma}$ des kriminogenen Einflusses biologischer Faktoren von der Intensität hemmender Faktoren im sozialen Bereich abhängt. Dies wird zum Teil von den Autoren selbst eingeräumt. Dennen stellt hierzu fest, dass Androgene lediglich die Möglichkeit zu aggressivem Verhalten vermittelten, Aggression an sich jedoch von mehreren Faktoren, wie beispielsweise dem sozialen Umfeld, abhänge. ${ }^{231}$

\subsection{Psychoanalytische Erklärungsansätze}

\subsubsection{Allgemeine Darstellung und Anwendbarkeit auf das weibliche Geschlecht}

Die auf Freud zurückgehenden psychoanalytischen Ansätze gehen davon aus, dass Kriminalität Ausdruck einer Persönlichkeitsstörung ist, deren Bedingungen in früheren Beeinträchtigungen der psychischen Entwicklung gesehen werden müsse.232 Innerhalb dieses Ansatzes existieren hauptsächlich zwei Strömungen zur Delinquenzerklärungen, wobei die erste Kriminalität aufgrund einer neurotischen Persönlichkeitsstruktur und die zweite Strömung Kriminalität aufgrund einer Verwahrlosungsstruktur annimmt. Insgesamt gehen jedoch alle psychoanalytischen Ansätze von einer Anomalie der Persönlichkeit des Kriminellen aus. ${ }^{233}$ Bedeutende Repräsentanten dieses Ansatzes sind beispielsweise Konopka234 und Epstein ${ }^{235}$. Konopka untersuchte 1966 eine Gruppe delinquenter Mädchen im Alter zwischen 14 und 19, die sich in einer staatlichen Fürsorgeeinrichtung aufhielten. Als Datenerhebungsmethode dienten teilnehmende Beobachtung sowie Gruppenund Einzelinterviews. Sie kam zu dem Ergebnis, Einsamkeit, ein negatives Selbstbildnis, Misstrauen und Angst gegenüber Autoritätspersonen sowie Kommunikationsdefizite seien spezifisch für jugendliche weibliche Kriminelle. ${ }^{236}$

Epstein versuchte durch Analyse des Selbstkonzepts delinquenter und normkonformer Mädchen, abweichendes Verhalten zu erklären. Sie ging von einem negativen Selbstkonzept delinquenter Mädchen aus. Im Rahmen der Studie wurde 21 delinquenten und einer Kontrollgruppe von nichtdelinquenten Mädchen ein Fragebogen vorgelegt, der das Selbstkonzept der Probandinnen, ihr Ego-Ideal und die Differenz zwischen Idealvorstellung und gegenwärtiger Lage erfassen sollte. Die Auswertung der Fragebögen ergab, dass sich die delinquenten Mädchen deutlich negativer beurteilten als die nichtdelinquente Vergleichsgruppe. Ihr Ego sei aufgrund einer nicht gelungenen Identifikation mit der sozialen Rolle unfähig, sich mit der Realität auseinanderzusetzen. Dies führe zu abweichendem Verhalten. ${ }^{237}$

\footnotetext{
${ }^{231}$ Dennen, in: Dennen (Hrsg.), The nature of the sexes, S. 107, 121.

232 Brökling, S. 22.

233 Funken, S. 22.

${ }^{234}$ Konopka, The adolescent girl in conflict.

235 Epstein, in: Smith College Studies in Social Work 1962, S. 220-234.

236 Konopka, S. 118 ff.; Brökling, S. 23 ff.

${ }^{237}$ Epstein, in: Smith College Studies in Social Work 1962, S. 220, 234; Brökling, S. 26 ff.
} 
Die vorgestellten Studien von Konopka und Epstein deuten beide an, dass Störungen des Entwicklungsprozesses zu einem Verlust von Selbstbeherrschung und sozialer Kompetenz führen, und dass dieser Zustand die Gefahr von Kriminalität erhöht. Die Gefahr bei dieser rein psychoanalytischen Sichtweise besteht darin, durch Konzentration auf das Individuum die gesellschaftlichen Ursachen abweichenden Verhaltens auszublenden und damit auch nicht das Gesamtphänomen zu erfassen. Zudem ist der Determinismus der psychoanalytischen Kriminologie, der abweichendes und konformes Verhalten auf unbewusste Impulse und Triebe zurückführt und von einem Zwang zu bestimmten Reaktionen ausgeht, kritikwürdig. 238 „Rationale“ Kriminalität, z.B. bei Wirtschaftsdelikten, ist so nicht zu erklären. Darüber hinaus weisen die Studien von Konopka und Epstein auch methodische Schwächen auf. ${ }^{239}$ Der Verzicht Konopkas auf eine Vergleichsgruppe macht ihre Aussagen unüberprüfbar. Auch wird die Kausalität der beobachteten emotionalen Störung für das abweichende Verhalten der Mädchen konstatiert, ohne den Zusammenhang zu prüfen. Den Befunden Epsteins lässt sich entgegenhalten, dass die gezogenen Schlussfolgerungen aufgrund der Unterschiede des Selbstkonzepts zwar psychoanalytisch, aber nicht empirisch konsequent sind, da sie aus den Daten der Erhebung nicht zwingend abzuleiten sind. Die psychoanalytischen Erklärungsmodelle sind gleichwohl grundsätzlich auf beide Geschlechter anwendbar.

\subsubsection{Modifikation für frauenspezifische Belange}

Soweit bekannt, existieren kaum kriminologische Untersuchungen, die sich mit der Erklärung geringerer Straffälligkeit von Frauen aus rein psychoanalytischer Sicht beschäftigen. Loos ${ }^{240}$ untersuchte die Rückfallkriminalität heranwachsender Frauen in den Jahren 1970-1975 des Landgerichtsbezirks Koblenz anhand von Gerichtsakten. Er stellte fest, dass erst eine Vielzahl negativer Einflüsse auf Frauen einwirken müsse ehe sie kriminell werden. Loos zog daraus den Schluss Frauen hätten ein strengeres „Über-Ich“241 als Männer und seien psychisch stabiler, weshalb sie seltener kriminell würden. ${ }^{242}$ Dem ist jedoch entgegenzuhalten, dass der Autor hier nur weibliche Probanden für seine Untersuchung heranzog. Für die von ihm getroffenen Schlussfolgerungen hätte er auch männliche Probanden als Vergleichsgruppe mit einbeziehen müssen, sodass diese Untersuchung den rein psychoanalytischen Ansatz nicht bestätigen kann.

\footnotetext{
238 Brökling, S. 28.

239 So auch Brökling, S. 29.

${ }^{240}$ Loos, Die Rückfallkriminalität heranwachsender Frauen.

${ }^{241}$ Der Begriff geht zurück auf das psychoanalytische Persönlichkeitsmodell von Freud. Danach stellt das „Über-Ich“ eine unbewusste psychische Instanz dar, welche moralische und sittliche Gebote und Verbote, Wertvorstellungen sowie kulturelle und gesellschaftliche Normen enthält (vgl. Freud, Abriss der Psychoanalyse, S. 136).

242 Loos, S. 149.
} 
Die psychoanalytischen Ansätze können die Unterschiede bei der Kriminalitätsbelastung der Geschlechter sowie die spezifische Deliktsstruktur weiblicher Kriminalität nicht erklären und greifen auch hinsichtlich der Interpretation ihrer Ursachen zu kurz, da sie Umweltfaktoren kaum einbeziehen.243

\subsection{Anomietheorie}

\subsubsection{Allgemeine Darstellung und Anwendbarkeit auf das weibliche Geschlecht}

Durkheim ${ }^{244}$ begründete Ende des 19. Jahrhunderts das Anomiekonzept, welches einen gesellschaftlichen Zustand beschreibt, der durch Normlosigkeit gekennzeichnet ist sowie durch eine überstarke Individualisierung der Gesellschaftsmitglieder einerseits und durch Diskrepanzen zwischen dem Anspruchsniveau der Gesellschaftsmitglieder und den nur begrenzt zu deren Befriedigung zur Verfügung stehenden Gütern andererseits. ${ }^{245}$ Merton ${ }^{246}$ griff die Anomietheorie von Durkheim im 20. Jahrhundert wieder auf und interpretiert abweichendes Verhalten als Symptom des Auseinanderfallens von kulturell vorgegebenen Zielen und der Verfügbarkeit von Mitteln, die zu ihrer Erreichung dienen. ${ }^{247}$ Durch Diskrepanz zwischen kulturell vorgegebenen Erwartungen und den von der sozialen Struktur bestimmten Wegen, diese Erwartungen zu befriedigen werde anomischer Druck hervorgerufen. Dieser sei schichtspezifisch unterschiedlich verteilt: Je niedriger der soziale Status, desto schwieriger sei es den sozial gebilligten Normen zur Zielerreichung zu folgen. Für unterprivilegierte Bevölkerungsgruppen werde kriminelles Verhalten mithin determiniert. ${ }^{248}$ Merton entwickelte fünf Handlungsalternativen, die es ermöglichen sich den institutionalisierten Mitteln und kulturellen Zielen individuell anzupassen: Konformität, Innovation, Ritualismus, Apathie und Rebellion. Diese Anpassungsformen stellen nach Merton die verschiedenen möglichen Verhaltensweisen unter anomischen Druck dar. ${ }^{249}$

Bisher sind nur wenige empirische Untersuchungen der Frage nachgegangen, inwiefern die Anomietheorie auf Frauen Anwendung finden kann.

Datesman, Scarpitti und Stephenson ${ }^{250}$ führten eine Befragung von 2.097 Schülerinnen und Schülern sowie von 103 männlichen und weiblichen Jugendlichen durch, die von 1968 bis 1969 vor einem Familiengericht erschienen waren. Es zeigte sich bei den Mädchen eine stärkere Verbindung von wahrgenommenen Chancen und Kriminalität als bei Jungen: Von den delinquent gewordenen Befrag-

\footnotetext{
243 Brökling, S. 28-31; Cohen, S. 106.

${ }^{244}$ Durkheim, Die Regeln der soziologischen Methode, 1999 (zuerst 1895).

245 Lamnek, Neue Theorien abweichenden Verhaltens, S. 18.

246 Merton, in: Sack/König (Hrsg.), Kriminalsoziologie.

247 Merton, in: Sack/König (Hrsg.), Kriminalsoziologie, S. 283, 289; Göppinger 2008, \ 10, Rdn. 30 ff.

248 Merton, in: Sack/König (Hrsg.), Kriminalsoziologie, S. 283, 292; Göppinger 2008, \10, Rdn. 31.

249 Merton, in: Sack/König (Hrsg.), Kriminalsoziologie, S. 283, 294; Göppinger 2008, \ 10, Rdn. 32 f.

${ }^{250}$ Datesman/Scarpitti/Stephenson, in: JResCrimDel 1975, S. 107-123.
} 
ten hatten mehr Mädchen (59,8 \%) als Jungen (55,9\%) einen niedrigen Skalenwert für wahrgenommene Chancen. In der Gruppe der nicht delinquent gewordenen Befragten, konnte häufiger für Jungen (30,4 \%) als für Mädchen $(21,4 \%)$ ein niedriger Skalenwert für wahrgenommene Chancen verzeichnet werden. ${ }^{251}$ Doch wendeten die Autoren selbst ein, die Validität der Untersuchungsergebnisse sei fraglich. Die bei der Untersuchung verwendeten Skalen seien im Hinblick auf die männliche Rolle entwickelt worden und konzentrierten sich daher auf schulische und berufliche Chancen. Mädchen hätten jedoch andere gesellschaftliche Ziele als Jungen, beispielsweise die Ehe, weshalb für sie andere Chancen bei der Realisierung eigener Vorstellungen zugrunde gelegt werden müssten. ${ }^{252}$ Diese Einschätzung der Autoren muss allerdings im historischen Kontext betrachtet werden und wird heutzutage in dieser Weise nicht mehr für die Mehrzahl der Täterinnen gelten.

Um die Anwendbarkeit der Anomietheorie auf beide Geschlechter zu überprüfen, befragten Simon, Miller und Aigner253 3.925 amerikanische Schüler und Schülerinnen aus verschiedenen Schulen und Distrikten. Die Fragebögen umfassten Fragen zur Deliktsbegehung der Probanden und Maßstäbe zur Messung der unabhängigen Variablen ${ }^{254}$ der verschiedenen Kriminalitätstheorien. Im Ergebnis zeigte sich bei beiden Geschlechtern eine gleich starke Beziehung zwischen diesen Variablen und angegebener Delinquenz, woraus gefolgert wurde, ein Mangel an Ausbildungs- oder Berufschancen sei bei keinem Geschlecht für die Deliktsbegehung relevant. 255

$\mathrm{Zu}$ einem ähnlichen Ergebnis gelangten Smith und Paternoster256. Die Befragung von 1.383 High-School Schülern und Schülerinnen über den Umfang ihres Marihuanakonsums und zu unabhängigen Variablen ${ }^{257}$ offenbarte, dass der durch die Diskrepanz zwischen Wünschen und realistischen Einschätzungen des späteren Werdegangs hervorgerufene Druck keine Auswirkung auf das abweichende Verhalten beider Geschlechter hat. ${ }^{258}$

Im Wesentlichen widersprechen diese Befunde für beide Geschlechter der Annahme einer Gültigkeit der Anomietheorie, 259 ein geschlechtsspezifischer Unterschied scheint nicht zu bestehen.

\footnotetext{
251 Datesman/Scarpitti/Stephenson, in: JResCrimDel 1975, S. 107, 116.

252 Datesman/Scarpitti/Stephenson, in: JResCrimDel 1975, S. 107, 121.

253 Simons/Miller/Aigner, in: JResCrimDel 1980, S. 42-57.

${ }^{254}$ Hierbei handelte es sich um folgende Variablen: parental rejection, educational opportunity, occupational opportunity, alienation from norms, values of friends, parental labeling und teacher labeling.

255 Simons/Miller/Aigner, in: JResCrimDel 1980, S. 42, 49.

256 Smith/Paternoster, in: JResCrimDel 1987, S. 140-172.

${ }^{257}$ Als Variable berücksichtigt wurden vieldiskutierte Einflussfaktoren einiger Kriminalitätstheorien: social bonds, differential association, strain und detterance.

258 Smith/Paternoster, in: JResCrimDel 1987, S. 140, 152.

259 a.A. Jacobsen, Sozialstruktur und Gender.
} 


\subsubsection{Modifikation für frauenspezifische Belange}

Nach der Anomietheorie entsteht abweichendes Verhalten nur, wenn die Ziele mit legitimen Mitteln nicht erreicht werden können. Die niedrigere Kriminalitätsrate von Frauen erkläre sich dadurch, dass sie andere Ziele hätten als Männer. Anstatt nach Wohlstand und Erfolg strebten Frauen primär nach Zielen, die mit einem traditionellen Rollenbild verbunden seien, wie Ehe und Familie. Diese Ziele seien einfach mit legitimen Mitteln zu erreichen. ${ }^{260}$ Nach Barton ${ }^{261}$ lasse sich die unterschiedliche Kriminalitätsbelastung daher mit dem unterschiedlichen Rollenmuster der Geschlechter erklären. Frauen, die dem typischen Rollenmuster nicht entsprächen, hätten nur noch die Möglichkeit kulturell als illegitim definierte Mittel zu benutzen. Dies führe also in doppelter Hinsicht zu abweichendem Verhalten von Frauen: zum einen durch das nicht rollenkonforme Verhalten und zum anderen durch die Benutzung illegitimer Mittel. Barton stützte ihre Aussagen auf eine von ihr im Jahr 1965 veröffentlichte Studie zur selbstberichteten Delinquenz von Mädchen, deren Untersuchungsgegenstand eine nach Geschlechtszugehörigkeit differenzierte Ziel-Mittel-Diskrepanz war. ${ }^{262}$ Für die heutige Zeit können die Aussagen der befragten Mädchen zur traditionellen Rollenorientierung jedoch nicht mehr repräsentativ sein. ${ }^{263}$

Gipser264 ging in einer Studie, die die Ziel-Mittel-Diskrepanz der Anomietheorie mit sozialisationstheoretischen Bedingungen verknüpft, einen Schritt weiter und bezog das emanzipatorische Rollenbild mit ein. ${ }^{265}$ Sie ging von der Hypothese aus, abweichendes Verhalten entstehe, wenn es nicht möglich sei, die inhärenten Rollenziele zu erreichen oder wenn Rollenirritationen auftreten und zudem der $\mathrm{Zu}$ griff auf illegitime Mittel bestünde. ${ }^{260}$ Gipser versuchte ihre Hypothese durch eine Untersuchung zu belegen, in der neben einer Aktenanalyse 112 als delinquent bekannt gewordene Mädchen und 125 nicht durch Delinquenz aufgefallene Mädchen im Alter zwischen 16 und 21 Jahren befragt wurden. Sie kam u.a. zu dem Ergebnis, dass die Art des abweichenden Verhaltens von der Art des Rollenleitbildes geprägt wird, wobei die sozialstrukturell bedingte Einschränkung der Verfügbarkeit legitimer Mittel im Vergleich zur Erhöhung der Verfügbarkeit illegitimer Mittel entscheidend sei. ${ }^{267}$ Es ist jedoch zu kritisieren, dass sie in den Hypothesen und Ergebnissen Begriffe aus der Anomietheorie, kaum definierte sozialisationstheoretische Aspekte und nicht definierte Rolleninhalte nicht klar voneinander

\footnotetext{
260 Brökling, S. 41 ff; Funken, S. 28 f.; Franke, S. 98 f.

${ }^{261}$ Barton, Nachweis bei Brökling, S. $42 \mathrm{f}$.

262 Funken, S. 28 f., Brökling, S. 42 f.

263 So auch Franke, S. 99, 103; Lindner, S. 42.

264 Gipser, Mädchenkriminalität, 1975.

265 Siehe zu dieser Studie ebenfalls die Ausführungen unter Kap. 2, 2.3.2.

266 Gipser, S. 36 f.

267 Gipser, S. 123.
} 
abgrenzt, sodass die Studie nur ansatzweise zur Bestätigung der Anomietheorie herangezogen werden kann. ${ }^{268}$

Gegen die Anomietheorie lässt sich vorbringen, dass sie von einem einheitlichen Wert- und Normsystem in der Gesellschaft ausgeht, obwohl die Vielfalt verschiedenster Normsysteme dem entgegensteht. ${ }^{269}$ Ferner sind die damit verknüpften Ziele unpräzise umschrieben. Sie kann zudem nicht erklären, wann und unter welchen Voraussetzung es bei Personen mit gleicher Ausprägung der gesellschaftlichen Strukturen bei einigen zu Abweichung kommt und bei anderen nicht. ${ }^{270}$

Aber selbst wenn man eine grundsätzliche Anwendbarkeit der Anomietheorie bejahen würde, so sprechen doch die wenigen durchgeführten empirischen Untersuchungen dafür, dass die Spezifika weiblicher Kriminalität mit der Anomietheorie nicht eindeutig erklärt werden können. ${ }^{271}$ Die antiquierte Vorstellung, primäre Ziele von Frauen seien das Eingehen einer Ehe und die Gründung einer Familie, kann heutzutage nicht die Basis einer Begründung sein. Nach dem anomietheoretischen Konzept müsste die niedrigere Delinquenzbelastung von Frauen mit einer überproportional häufigen Wahl des Anpassungstypus der Konformität erklärt werden.

„Um die böhere weibliche Konformitätsrate $z_{u}$ begründen, sind Zusatzinformationen notwendig, aber diese scbließen sich gegenseitig aus. Entweder verfiggen Frauen über abweichende gesellschaftliche Wertvorstellungen, die nicht auf Woblstand und Erfolg ausgericbtet sind, oder sie stimmen mit den Wert- und Zielvorstellungen überein, baben aber nur begrenzten Zugang zu illegitimen Mitteln. '272

Die Frage lässt sich jedoch anhand der Anomietheorie nicht klären. ${ }^{273}$

\subsection{Kontrolltheorien}

2.4.1 Allgemeine Darstellung und Anwendbarkeit auf das weibliche Geschlecht

Kontrolltheorien thematisieren nicht die Gründe für sozial abweichendes, sondern für sozial konformes Verhalten. In seiner Halttheorie vertrat Reiss ${ }^{274}$ die Auffassung, sozial konformes Verhalten könne auf den Einfluss einer intakten Familie und Erziehung zurückgeführt werden. Kriminelles Verhalten dagegen sei die Konsequenz einer fehlgeschlagenen Erziehung oder zumindest des Misslingens der Vermittlung der sozialen Rolle sowie Unfähigkeit diese Rolle mit den Bedürf-

\footnotetext{
268 So auch Franke, S. 101; krit. auch Jacobsen, S. 204 ff.

269 Franke, S. 94.

270 Lamnek, 1996, S. 265; Schwind, \ 7, Rdn. 10.

271 So im Ergebnis auch Jacobsen, S. 228.

272 Franke, S. 104.

273 Brökling, S. 47; Franke, S. 104.

274 Reiss, in: ASR 1951, S. 196-207.
} 
nissen in Einklang zu bringen. Dies führe dazu, dass der innere Halt und die Immunisierung fehlen, die Grundlage für einen Widerstand gegen kriminelles Verhalten seien. ${ }^{275}$

Reckless ${ }^{276}$ erweiterte diese Theorie um den äußeren Halt. Der äußere und innere Halt eines Menschen bewahren diesen in Drucksituationen vor abweichendem Verhalten. Der äußere Halt hänge zusammen mit einem wirksamen Familienleben und haltgewährenden Gruppen. Ein wirksamer innerer Halt führe zu gelungener Selbstbeherrschung, einem guten Selbstkonzept und starkem Widerstand gegen Ablehnung. Gemeinsam verhinderten äußerer und innerer Halt die Entstehung von Kriminalität. Zu abweichendem Verhalten könne es kommen, wenn die schwache Ausprägung des einen Faktors nicht durch den anderen zu kompensieren sei. ${ }^{277}$

In seiner, zu den Kontrolltheorien zählenden, Bindungstheorie erläuterte Hirschi ${ }^{278}$ die Einflussfaktoren, welche für den äußeren und inneren Halt zumindest mitbestimmend sein könnten. Dies seien die emotionale Bindung an andere Menschen, Bindung an konventionelle Tätigkeitsmuster, Verpflichtung und Engagement im beruflichen Sektor und der Glaube an die Verbindlichkeit sozialer Normen. ${ }^{279}$

Die Kontrolltheorie wurde von Gottfredson/Hirschi280 um das Konzept der Selbstkontrolle erweitert. Kriminelle Handlungen dienten der unmittelbaren und sofortigen Bedürfnisbefriedigung und seien Folge einer geringen Selbstkontrolle. Menschen verhielten sich konform, weil sie die Langzeitfolgen ihres Handelns bedenken und eine hohe Selbstkontrolle besitzen würden. Dementsprechend führe mangelnde Selbstkontrolle zu non-konformen Verhalten. ${ }^{281}$

Bei Überprüfung der Anwendbarkeit der Kontrolltheorien für die Erklärung weiblicher Delinquenz, konnten Datesman, Scarpitti und Stephenson ${ }^{282}$ in ihrer Untersuchung bei Erforschung des Selbstbildes der Probanden eine für beide Geschlechter einheitliche Korrelation von negativen Selbstkonzept, welches zu einer schwachen Ausprägung des inneren Halts nach Reckless führt, und Delinquenz feststellen. ${ }^{283}$

Covington $^{284}$ ermittelte durch die Befragung von 170 weiblichen und 202 männlichen Heroinabhängigen, dass die Kontrolltheorie für Frauen sogar die im Vergleich zu Männern größere Aussagekraft besitzt. Bei den befragten Frauen zeigte

\footnotetext{
275 Reiss, in: ASR 1951, S. 196, 206 f.

276 Reckless, in: MschrKrim 1961, S. 1-14.

277 Reckless, in: MschrKrim 1961, S. 1, $11 \mathrm{f}$.

${ }^{278}$ Hirschi, Causes of delinquency.

${ }^{279}$ Hirschi, S. 16 ff.

280 Gottfredson/Hirschi, A general theory of crime.

281 Gottfredson/Hirschi, S. 119.

282 Datesman/Scarpitti/Stephenson, in: JResCrimDel 1975, S. 107-123 (Fn. 250).

283 Datesman/Scarpitti/Stephenson, in: JResCrimDel 1975, S. 107, 111.

${ }^{284}$ Covington, in: JResCrimDel 1985, S. 329-353.
} 
sich ein stärkerer Zusammenhang zwischen der Begehung von Eigentumsdelikten und der Trennung von Familie oder Schule als bei den Männern. ${ }^{285}$

Figueira-McDonough ${ }^{286} \mathrm{kam}$ in ihrer Studie zu dem Schluss, dass $49 \%$ der selbstberichteten Bagatellkriminalität der Mädchen und $42 \%$ der von den Jungen eingeräumten leichten Delikte mit den Aussagen der Kontrolltheorie begründet werden konnte und die Kontrolltheorie daher für beide Geschlechter eine vergleichbare Aussagekraft besitzt. ${ }^{287}$

Smith und Paternostere28 stellten bei ihrer Untersuchung eine Verbindung von verschiedenen Elementen der Kontrolltheorie und der Stärke des Marihuanakonsums fest. So kamen sie u.a. zu dem Ergebnis, dass die „elterliche Überwachung“ (,parental supervision") die Wahrscheinlichkeit eines Marihuanakonsums reduziert, die emotionale Bindung an Gleichaltrige (,attachment to peers") allerdings einen „positiven“ Einfluss, im Sinne eines stärkeren Konsums, besitzt. 289

Auch McGloin und ONeill Shermer290 konstatierten nach einer Befragung von Schülerinnen und Schülern der 7. bis 12. Jahrgangstufe in den Jahren 1994/95, dass eine geringe Selbstkontrolle die Wahrscheinlichkeit zukünftiger Delinquenz erhöhe. Die Straffälligkeit von Mädchen sinke, wenn sie gut in der Schule etabliert seien sowie ein gutes Elternverhältnis hätten. ${ }^{291}$

Diese Befunde sprechen in der Gesamtschau für eine Anwendbarkeit der Kontrolltheorien auf beide Geschlechter.

\subsubsection{Modifikation für frauenspezifische Belange}

Fraglich ist, ob die Kontrolltheorien dazu geeignet sind, die unterschiedliche Kriminalitätsbelastung der Geschlechter zu erklären. Man könnte vermuten, dass ein Erklärungsansatz die stärkere Ausprägung der Einbindung von Frauen in die Gesellschaft sein könnte. Allerdings wird dies von den Vertretern dieser Theorien nicht weiter thematisiert. Vielmehr wird versucht, die geringere Kriminalitätsbelastung der Frau auf eine genetisch bedingte stärkere Selbstkontrolle zurückzuführen. Diese Begründung nähert sich weit den biologischen Theorien, sodass auch hier zu kritisieren ist, dass die geschlechtsspezifische Sozialisation aus dem Blick verloren wird. ${ }^{292}$ Ferner sind keine empirisch gesicherten Erkenntnisse bekannt, die bestimmte genetische Veranlagungen lediglich einem Geschlecht zuschreiben, ${ }^{293}$ weshalb die Kontrolltheorien nicht dazu geeignet sind, die Spezifika weiblicher Kriminalität zu erklären.

\footnotetext{
285 Covington, in: JResCrimDel 1985, S. 329, 347 f.

286 Figueira-McDonough, in: CrimDel 1987, S. 403-424.

287 Figueira-McDonough, in: CrimDel 1987, S. 403, $410 \mathrm{ff}$.

288 Smith/Paternoster, in: JResCrimDel 1987, S. 140-172 (Fn. 256).

289 Smith/Paternoster, in: JResCrimDel 1987, S. 140, 153.

290 McGloin/ONeill Shermer, in: JResCrimDel 2009, S. 35-72.

291 McGloin/ONeill Shermer, in: JResCrimDel 2009, S. 35, 53.

292 Franke, S. $151 \mathrm{f}$.

293 Franke, S. 151 f.
} 


\subsection{Theorie der differentiellen Assoziation}

\subsubsection{Allgemeine Darstellung und Anwendbarkeit auf das weibliche Geschlecht}

Der Ansatz der differentiellen Assoziation wird auch Theorie der unterschiedlichen Kontakte genannt. Als Begründer kann Sutherland ${ }^{294}$ gesehen werden, der die Theorie später mit Cressey zusammen weiterentwickelte. Sutherland, der die Theorie in neun Thesen zusammenfasste, ging davon aus, dass kriminelles Verhalten erlerntes Verhalten sei, das in Interaktion mit anderen Personen in einem Kommunikationsprozess vermittelt werde, der sich primär in intimen, persönlichen Gruppen vollziehe. Das Erlernen kriminellen Verhaltens schließe das Lernen der Techniken zur Ausführung des Verbrechens, die manchmal sehr kompliziert, manchmal sehr einfach seien und die spezifische Richtung von Motiven, Trieben, Rationalisierung und Attitüden mit ein. Die spezifische Richtung von Motiven werde gelernt, indem Gesetze positiv oder negativ formuliert würden. Eine Person werde delinquent infolge eines Überwiegens der die Verletzung begünstigenden Einstellungen über jene, die Gesetzesverletzungen negativ beurteilten. Der Prozess, in dem kriminelles Verhalten durch Kontakte mit kriminellen und antikriminellen Verhaltensmustern gelernt werde, umfasse alle Mechanismen, die bei jedem anderen Lernprozess auch beteiligt sind. Obwohl kriminelles Verhalten ein Ausdruck von generellen Bedürfnissen und Werten sei, werde es nicht durch diese generellen Bedürfnisse und Werte erklärt, da nichtkriminelles Verhalten Ausdruck eben derselben Bedürfnisse und Werte sei. ${ }^{295}$

Wenige Untersuchungen haben sich explizit mit der Frage beschäftigt, ob die Theorie der differentiellen Assoziation auf Frauen übertragbar ist.

Dazu zählt die bereits erwähnte Studie von Simons et al. ${ }^{296}$, die auch die Anwendbarkeit der Theorie der differentiellen Assoziation überprüfte. Die Probanden wurden nach den Wertvorstellungen ihrer Freunde und deren hypothetischer Reaktion auf kriminelles Verhalten befragt. Für beide Geschlechter erwies sich der Zusammenhang von Kontaktpersonen, Einstellungen und selbstberichteter Delinquenz als gleich stark. ${ }^{297}$

Bei der Untersuchung von Smith und Paternoster298 zeigte sich, dass der vermehrte Kontakt mit Drogenkonsumenten bei Männern und Frauen die Konsumhäufigkeit steigerte. ${ }^{299}$

Haynie $^{300}$ kam nach einer Befragung von Schülern der 7. bis 12. Jahrgangsstufe in den Jahren 1994/95 sowie 1995/96 zu dem Ergebnis, dass delinquentes Verhal-

\footnotetext{
294 Sutherland, in: Sack/König (Hrsg.), Kriminalsoziologie, S. 395-399.

295 Sutherland, in: Sack/König (Hrsg.), Kriminalsoziologie, S. 395, 396 ff.

296 Simons/Miller/Aigner, in: JResCrimDel 1980, S. 42, 45 (Fn. 253).

297 Simons/Miller/Aigner, in: JResCrimDel 1980, S. 42, 46 f.

298 Smith/Paternoster, in: JResCrimDel 1987, S. 140-172 (Fn. 256).

299 Smith/Paternoster, in: JResCrimDel 1987, S. 140, 152, 155.

300 Haynie, in: AJS 2001, S. 1013-1057; Haynie, in: JQuantCrim 2002, S. 99-134.
} 
ten umso wahrscheinlicher ist, je dichter das Netzwerk von Freunden ist und je mehr delinquente Freunde sich darin befinden. Frauen hätten allerdings eher ein Netzwerk mit nichtstraffälligen Freunden. ${ }^{301}$

Die Ergebnisse der Untersuchungen sprechen in der Gesamtschau dafür, dass die Theorie der differentiellen Assoziation sowohl für Männer als auch für Frauen Anwendung findet, auch wenn nur Teilaspekte überprüft wurden.

\subsubsection{Modifikation für frauenspezifische Belange}

Nach Sutherland haben Männer und Frauen unterschiedliche soziale Positionen, weshalb auch die sozialen Determinanten zum Erlernen von kriminellen Verhaltensmustern verschieden seien. Die soziale Kontrolle bei Frauen sei innerhalb der Familie und gesellschaftlichen Institutionen stärker ausgeprägt, sodass Frauen und Mädchen einen geringen Kontakt zu kriminellen Verhaltensmustern hätten. Ursache hiefür sei die gesellschaftliche Sexualmoral. Das geringe Ausmaß der weiblichen Kriminalität erkläre sich mithin aus den durch die soziale Kontrolle bedingten, geringen Kontakten mit kriminellen Verhaltensmustern. ${ }^{302}$

Sutherlands Theorie ist grundsätzlich entgegenzuhalten, dass sie Trieb- und Affekttaten nicht erklären kann. ${ }^{303}$ Ferner bleibt die Frage unbeantwortet, warum es zur Bildung von Gruppen kommt, in denen abweichendes Verhalten erlernt wird. ${ }^{304}$ Erklärungsbedürftig bleibt insbesondere die Frage, warum das Prinzip der differentiellen Kontakte bei Frauen eine andere Ausprägung erfährt als bei Männern. Denn nach dieser Theorie fördert eine ineffektive Sozialisation den Anschluss an delinquente Jugendbanden ${ }^{305}$, obwohl zahlreiche Studien ${ }^{306}$ belegen, dass sich Frauen bei gleicher Umgebung und gleichen Erfahrungen seltener einer delinquenten Jugendbande anschließen. Schließlich wird die geschlechtsspezifische Sozialisation auch von der Theorie der differentiellen Assoziation nur unzureichend aufgegriffen, denn sie wird der gesellschaftlichen Komplexität nicht gerecht, die geringere Kriminalitätsbelastung von Frauen in der stärkeren sozialen Kontrolle aufgrund der gesellschaftlichen Sexualmoral zu sehen. Weitere Einflussfaktoren werden nicht weiter ausgeführt, sodass man zur Erklärung weitere Theoriekonzepte heranziehen muss. ${ }^{307}$

\footnotetext{
301 Haynie, in: JQuantCrim 2002, S. 99, 119.

302 Sutherland/Cressey, Principles of criminology, S. 142.

303 Göppinger 2008, J 9, Rdn. 4.

304 Göppinger 2008, J 9, Rdn. 4; Brökling, S. 49; Franke, S. 79 ff.

$305 \mathrm{Vgl}$. die Ausführungen in Kap. 2, 1.3.1.

306 Beispielsweise: Eckert/Reiss/Wetzstein, „Ich will halt anders sein wie die anderen”. Abgrenzung, Gewalt und Kreativität bei Gruppen Jugendlicher; Baier/Pfeiffer/Rabold, et al., Kinder und Jugendliche in Deutschland, 2010, S. 170.

307 So auch, Brökling, S, 49 f; Franke, S. 81 f.
} 


\subsection{Mehr-Faktoren-Ansätze}

In zeitlich jüngeren Untersuchungen wurde das pluralistische Konzept des MehrFaktoren-Ansatzes zugrunde gelegt. Vertreter ${ }^{308}$ dieses Ansatzes lehnen die Herausfilterung präziser Einzelursachen zur Erklärung der Kriminalität ab. Vielmehr wird versucht, verschiedenste Umwelteinflüsse, Anlagefaktoren und individuelle Persönlichkeitsmerkmale des Straftäters zu erfassen, um Kriminalität durch eine Kombination bestimmter Umstände zu erklären. Um den Blickwinkel nicht einzuengen, wird auf eine Hypothesenbildung verzichtet, sodass den Mehrfaktoren-Ansätzen oft „Theoriefreiheit“ vorgeworfen wird. ${ }^{309}$ Dabei wird jedoch außer Acht gelassen, dass bestimmte Vorstellungen der Untersucher zumindest über die Auswahl der zu erhebenden Faktoren entscheidet. ${ }^{310}$ Folglich steht die Empirie auf Kosten der Theorie im Vordergrund. ${ }^{311}$ Daher stellt sich an dieser Stelle, im Gegensatz zu den anderen Erklärungsansätzen, auch nicht die Frage, ob die theoretischen Ausgangsüberlegungen sowohl für Männer als auch für Frauen Anwendung finden. Es kann direkt geprüft werden, ob multifaktorielle Ansätze dazu geeignet sind, Frauenkriminalität zu erklären

Berühmtester Vertreter des Mehr-Faktoren-Ansatzes ist Pollak ${ }^{312}$. Nach Pollak führe die Beziehung von biologischen und sozialen Einflussfaktoren zu einer für Frauen besonderen Entwicklung krimineller Motive, vor allem im sexuellen Bereich, zu geschlechtsspezifisch unterschiedlichen Zugangsmöglichkeiten zu Objekten der kriminellen Handlung sowie zu Erschwernissen bei der Ermittlung weiblicher Delikte, da diese überwiegend im sozialen Nahraum ausgeübt würden. Er spricht in diesem Zusammenhang vom ,masked character of female crime "313.

Pollak berücksichtigte in seinen Untersuchungen zwar die soziale Lage von Frauen, allerdings begründete er die so entstandenen Lebensbedingungen mit der Biologie der Geschlechter. ${ }^{314}$ Sein Versuch die biologischen Faktoren in ihren sozialen Auswirkungen zu beschreiben, ist rein spekulativ.

Aussagekräftiger ist eine Studie von Glueck und Glueck ${ }^{315}$ aus den dreißiger Jahren. Das Ehepaar Glueck untersuchte im Rahmen des Mehr-Faktoren-Ansatzes den Zusammenhang zwischen Kriminalität und mehreren Faktoren u.a. den Familienverhältnissen, Kindheit, Jugend und der Sexualität krimineller Frauen. In ihrer Studie wurden 500 straffällige Frauen des „Massachusetts Reformatory of Women" befragt. Insgesamt wurden 402 Variablen erhoben. Aufgrund des erhebli-

\footnotetext{
308 Glueck/Glueck, Five hundred delinquent women; Pollak, 1961; West, in: Göppinger (Hrsg.), Angewandte Kriminologie, 1988, S. 21-29; Göppinger, Der Täter in seinen sozialen Bezügen.

${ }^{309}$ Moser, Jugendkriminalität und Gesellschaftsstruktur, S. 91; Göppinger 2008, § 2, Rdn. 49.

310 Kürzinger, Kriminologie, S. 88; Schwind, S 8, Rdn. 22.

311 Schneider, Kriminologie, S. 38; Schwind, \8, Rdn. 22.

312 Pollak, 1961.

313 Pollak, S. 8.

314 Vgl. zur Kritik an dieser Argumentation die Ausführungen unter Punkt Kap. 2, 2.1.

315 Glueck/Glueck, Five hundred delinquent women.
} 
Erklärungsansätze für das Phänomen der Frauenkriminalität

chen Umfangs der Untersuchung sollen hier nur einige Ergebnisse dargestellt werden:

Weniger als $10 \%$ der befragten Frauen berichteten aus intakten Familienverhältnissen zu stammen; 58,4\% wuchsen in sog. „broken-home“ Verhältnissen auf; 38,8 \% wiesen zumindest gestörte Familienverhältnisse auf. Mehr als die Hälfte der Frauen hatten in ihrer Kindheit und Jugend Erfahrungen mit Fürsorgeeinrichtungen gemacht und nur 5,7\% der befragten Frauen hatten eine abgeschlossene Berufsausbildung. ${ }^{316}$

Fazit der Glueckschen Untersuchung ist, dass kriminelle Frauen alle wesentlichen Merkmale individueller und sozialer Pathologien aufweisen. Die Ursache weiblicher Kriminalität liege in einer Kombination von Fakten, deren kriminogene Qualität im Einzelnen schwer zu erfassen sei. ${ }^{317}$

Die Ergebnisse der Studie lassen durchaus den Schluss zu, dass (Frauen-) Kriminalität auf multiple Faktoren zurückzuführen ist, wobei einige deutlicher ausgeprägt sind als andere.

Fischer-Jehle $e^{318}$ untersuchte im Jahr 1982/83 die Lebensentwicklung von insgesamt 416 weiblichen Strafgefangenen der Strafvollzugsanstalt Schwäbisch-Gmünd anhand von Aktenanalysen und Befragungen. Sie versuchte in umfassender Weise, den Werdegang weiblicher Straffälliger sowie ihre sozialen und persönlichen Verhältnisse zu erfassen. Fischer-Jeble kam zu dem Ergebnis, dass die Probandinnen unterschiedliche Lebensentwicklungen aufwiesen, die mit unterschiedlichen Lebensformen, Lebensumständen und Verhaltensweisen verknüpft waren und welche in jeweils besonderer Art mit Delinquenz zusammenhingen. ${ }^{319}$

Geiger-Battermann/Kreuzer ${ }^{320}$ führten in ihrer Gladbacher Gewaltstudie narrative Interviews mit zehn straffällig gewordenen Mädchen im Alter zwischen 15 und 24 Jahren durch. Alle befragten Täterinnen wiesen, singulär oder kumulativ auftretend, zahlreiche Sozialisationsdefizite wie geringe soziale Kompetenzen, fehlende Empathiefähigkeit, niedrige Frustrationstoleranz oder mangelnde Impulskontrolle auf. 321

Auch für männliche Täter wurde in zahlreichen Untersuchungen ${ }^{322}$ ein multifaktorieller Einfluss, beispielsweise von Familien mit niedrigem sozioökonomischen Status, gestörten Familienverhältnissen, Leistungsschwächen, Drogenund/oder Alkoholproblemen, auf Kriminalität festgestellt.

\footnotetext{
316 Glueck/Glueck, S. 64 ff.

317 Glueck/Glueck, S. 62.

318 Fischer-Jeble, Frauen im Strafvollzug.

319 Fischer-Jeble, S. 289 f.

320 Geiger-Battermann/Kreuzer, Gewalt ist auch weiblich, in: BewHi 2009, S. 15-31; Geiger-Battermann/ Kreuzer, Gewalt ist auch weiblich, Gladbacher Gewaltstudie 2008, Bd. 1 und Bd.2.

321 Geiger-Battermann/Kreuzer, in: BewHi 2009, S. 27.

322 Glueck/Glueck, Unraveling, juvenile delinquency; Göppinger, Der Täter in seinen sozialen Bezügen; West/Farrington, Who becomes delinquent?
} 
Den Mehr-Faktoren-Ansätzen ist grundsätzlich zugute zu halten, dass sie sich von der Einseitigkeit anderer Erklärungsansätze gelöst haben, indem sie eine Vielzahl von Faktoren in ihre Überlegungen mit einbeziehen. Kritisiert wird jedoch, dass das umfassende Datenmaterial, die Gefahr von „Datenfriedhöfen“ birgt, d.h. es würden zu viele überflüssige Daten erhoben. ${ }^{323}$ Ferner bestünde die Gefahr, dass Scheinzusammenhänge genauso behandelt würden wie die relevanten Ursachenfaktoren, die aufgrund exakt formulierter Thesen zustande gekommen sind. Dies könne wiederum dazu führen, zusammenhanglose Daten willkürlich miteinander in Verbindung zu setzen, wobei bedeutungslose Ergebnisse überbewertet werden könnten. ${ }^{324}$

Neben der generellen Kritik an den Mehr-Faktoren-Ansätzen ist festzustellen, dass sie zwar grundsätzlich dazu geeignet sind, Kriminalität zu erklären, jedoch können auch sie keine Begründung der frauenspezifischen Besonderheiten liefern, denn der Ansatz schließt die Vermutung ein, Männer würden aufgrund der höheren Kriminalitätsbelastung wesentlich häufiger in desolaten Verhältnissen aufwachsen. Es wird nicht erklärt, warum Frauen, oder auch Männer, die in schlechten Verhältnissen aufwachsen nicht straffällig werden, oder warum diejenigen, die in normalen Verhältnissen aufwachsen, trotz dessen abweichendes Verhalten zeigen. 325

\subsection{Labeling approach}

Der labeling approach oder Etikettierungsansatz ${ }^{326}$, hervorgegangen aus dem symbolischen Interaktionismus, analysiert nicht das kriminelle Verhalten an sich, sondern richtet den Blick auf den Prozess der Kriminalisierung. Nach den Vertre$\operatorname{tern}^{327}$ dieser Theorie ist Kriminalität ,ubiquitär“, also eine normale Erscheinung, die gleichmäßig über alle Schichten der Bevölkerung verteilt sei. Kriminelles Verhalten sei das, was andere als abweichend definieren. „Kriminell“ ist also keine Eigenschaft oder Merkmal, das dem Verhalten als solchem zukomme, sondern das an das jeweilige Verhalten herangetragen werde. ${ }^{328}$ Mithin bestimme die Gesellschaft bzw. der Gesetzgeber, wem das Etikett des Straftäters aufgedrückt werde. Durch diese Stigmatisierung des „Kriminellseins“ verändere sich die Verhaltensweise der Person, die eigene Identität werde neu definiert und die Konsequenz sei weiteres normabweichendes Verhalten. ${ }^{329}$ Lemert ${ }^{330}$ untersuchte die Sta-

\footnotetext{
${ }^{323}$ Kun₹, S 12, Rdn. 11, 12; Schwind, \ 8, Rdn. 27.

${ }^{324}$ Kürzinger, S. 89; Schwind, \ 8, Rdn. 27.

325 Franke, S. 70 f.

326 Ausführliche Darstellung und Diskussion der einzelnen Ansätze findet sich bei: Keckeisen, Die gesellschaftliche Definition abweichenden Verhaltens. Perspektiven und Grenzen des Labeling Approach; Rüther, Abweichendes Verhalten und Labeling Approach.

327 Vertreter u.a.: Tannenbaum, Crime and Community; Sack, in: KrimJ 1972, S. 3-31;

Lemert, Social pathology; Becker, Außenseiter.

328 Sack, in: Sack/König (Hrsg.), Kriminalsoziologie, S. 470.

${ }^{329}$ Göppinger 2008, \ 10, Rdn. 52.
} 
dien devianter Entwicklung der etikettierten Individuen und nahm eine Unterteilung in primäre und sekundäre Devianz vor. Primäre Devianz sei das erstmalige Auftreten einer Abweichung, die für die handelnde Person ungeahndet bleibe. Sekundäre Devianz meine das weitere deviante Verhalten, welches mit einer Stigmatisierung durch die sozialen Kontrollinstanzen ende. ${ }^{331}$ Der sekundären Devianz wird von den Vertreten des labeling approach die wesentlichere Bedeutung beigemessen, sodass Erklärungsansätze zur Entstehung der primären Devianz kaum diskutiert werden.

Daraus folgt, dass der Ansatz des labeling approach weder für Frauen noch für Männer eine Erklärung für das erstmalige Auftreten von abweichendem Verhalten liefert. Die Überlegungen setzen vielmehr erst bei der sozialen Reaktion auf deviantes Verhalten an. Bei Anwendung des labeling approach stellt sich folglich nicht die Frage nach den persönlichen und sozialen Bezügen der Täter, sondern nach dem Prozess der Kriminalisierung.

Da sich mit dem labeling approach vor allen Dingen die primäre Devianz nicht erklären lässt, kann dieser Ansatz auch zur Entstehung weiblicher Kriminalität nichts beitragen.

Es ist daher direkt danach zu fragen, inwieweit der Kriminalisierungsprozess bei Frauen unterschiedlich abläuft.

Die Vertreter des Etikettierungsansatzes erklären die geringere Kriminalitätsbelastung von Frauen gegenüber Männern unterschiedlich: Einige argumentieren, dass Rechtssystem sei für Männer geschaffen, sodass die antisozialen Handlungen die Frauen begingen, ignoriert würden. ${ }^{332}$ Hauptsächlich wird jedoch darauf abgestellt, Frauen würden von den offiziellen Sanktionsinstanzen weniger häufig kriminalisiert, da sie nachsichtiger behandelt würden. ${ }^{333}$ Wenn sie kriminalisiert würden, dann wegen weniger schwerwiegender Delikte, sodass auch das Umfeld weniger negativ reagiere und Frauen weniger etikettiert würden. ${ }^{334}$

Den Vertretern des Labeling approach ist insofern zuzustimmen, als sich in dem Selektionsprozess der Strafverfolgung in der Tat auch immer ein definitorischer Prozess vollzieht. ${ }^{335}$ Das sich in den amtlichen Statistiken widerspiegelnde Bild der Kriminalität ist als Tätigkeitsbericht der Kriminalisierungsinstanzen zu verstehen und beruht dementsprechend auch auf selektiver Wahrnehmung des jeweiligen Entscheidungsträgers. Die Begründungen vermögen jedoch nicht in Gänze zu überzeugen. Zwar sind Frauen in den kriminellen Gelegenheiten nach

\footnotetext{
${ }^{330}$ Lemert, in: Lüderssen/Sack (Hrsg.), Seminar. Abweichendes Verhalten I. Die selektiven Normen der Gesellschaft, S. 433-476.

${ }^{331}$ Lemert, in: Lüderssen/Sack (Hrsg.), Seminar. Abweichendes Verhalten I. Die selektiven Normen der Gesellschaft, S. 433.

332 Mannheim, Vergleichende Kriminologie, Bd. 2, S. 831 f.; Herz, in: KrimJ 1994, S. 296-309.

333 Pollak, S. 151; Geißler/Marißen, in: KZfSS 1988, S. 505-526; Schur, Labeling women deviant; Julian, in: Culliver (Hrsg.), Female criminality, S. 343-362.

334 Nowack,in: Albrecht/Brusten (Hrsg.), Soziale Probleme und soziale Kontrolle, 1982, S. 185, 188 f.

335 Vgl. hierzu auch die Ausführungen in Kap. 1, 3.
} 
wie vor durchaus eingeschränkter als Männer, da sie in der Erwerbstätigkeit noch nicht den gleichen Stand erreicht haben wie Männer, wenn sich auch die Verhältnisse zunehmend angeglichen haben. Auch ist die vollerwerbstätige Frau eher durch die Haushaltsführung, Kindererziehung und Pflege alter und kranker Verwandter eingebunden. Dies schränkt den Handlungsspielraum für Kriminalität jedoch nur für einige Bereiche, beispielsweise den Wirtschaftssektor, ein. Für andere Straftaten bestehen jedoch grundsätzlich die gleichen Begehungsmöglichkeiten wie für Männer. Trotzdem sind Frauen in fast allen Bereichen strafrechtlich deutlich seltener auffällig. Besonders sichtbar ist der Unterschied im Bereich der Gewaltkriminalität. Diese große Diskrepanz kann nicht allein dadurch erklärt werden, Frauen begingen Gewalt eher im sozialen Nahraum und es komme daher seltener zur Anzeige. Denn wie in Kapitel 1 festgestellt, besteht auch im Dunkelfeld ein großer Abstand zwischen weiblichen und männlichen Gewalttätern. Die in Kapitel 1 vorgestellten Dunkelfelduntersuchungen beziehen sich zudem hauptsächlich auf Schülerinnen, die in ihrem Handlungsspielraum eher selten durch Kindererziehung oder Pflege alter oder kranker Angehöriger eingeschränkt sind.

Bleibt zu klären, ob die geringere Kriminalitätsbelastung von Frauen tatsächlich mit einer nachsichtigeren Behandlung durch die Instanzen der sozialen Kontrolle, auch als „Frauenbonus“ bezeichnet, zu begründen ist. Die Beantwortung dieser Frage ist schwierig, da etliche Faktoren die Entscheidungen der einzelnen Entscheidungsträger beeinflussen können. Hierbei muss zwischen den unterschiedlichen Verfolgungsinstanzen differenziert werden, denn eine mildere Behandlung von Frauen könnte grundsätzlich bereits beim Anzeigeerstatter beginnen. Es existieren einige Studien ${ }^{336}$, die sich mit dieser Frage auseinandergesetzt haben, wobei zumeist ein Frauenbonus auf staatsanwaltlicher oder gerichtlicher Ebene zum Untersuchungsgegenstand gemacht wurde. Dabei wird in der Regel die Sanktionierung von Frauen und Männern unter Berücksichtigung verschiedener Variablen, wie beispielsweise der Vorstrafenbelastung oder Geständnisbereitschaft, einander gegenübergestellt. In der Tendenz weisen die Studien darauf hin, dass ein Frauenbonus nicht existieren dürfte. Wenn Frauen milder behandelt würden, dann sei dies gerechtfertigt, da sie in der Regel seltener vorbestraft seien und weniger schwerwiegendere Delikte begingen. ${ }^{337}$ Allerdings sind die bislang durchgeführten Untersuchungen regional begrenzt oder sie konnten nur auf eine kleine Datenbasis zurückgreifen, weshalb die Frage letztendlich noch nicht zufriedenstellend beantwortet werden konnte. Hieran knüpft die eigene Untersuchung in Kapitel 5 an.

336 Vgl. eine umfassende Zusammenstellung dieser Studien in Kap. 5, 1.2.

337 So beispielsweise Ludwig-Mayerbofer/Rzepka, in: KZfSS 1993, S. 542, 556. 


\subsection{Zusammenfassende Diskussion}

In den unterschiedlichen Kriminalitätstheorien lassen sich die Ursachen für weibliche Kriminalität oftmals nicht von denen für männliche unterscheiden. Die theoretischen Überlegungen der traditionellen Kriminalitätstheorien können auch der Frauenkriminalität zugrunde gelegt werden. Bei den Ansätzen, bei denen festgestellt wurde, dass sie sich nicht zur Erklärung der Kriminalitätsentstehung eignen, gilt dies für beide Geschlechter gleichermaßen. Der Aussage Smith/Paternosters „The fact that most theories of deviance were constructed to account for male deviance does not mean that they cannot account for female deviance" "338 ist daher zuzustimmen.

Die Spezifika der weiblichen Kriminalität machten es jedoch notwendig, die Theorien auch auf ihre Erklärungskraft für diese Besonderheiten hin zu überprüfen. Bei der Untersuchung zeigte sich, dass die dargestellten Theorien für frauenspezifische Belange nur unzureichend anwendbar sind. Jeder Ansatz weist für sich genommen gewisse Mängel auf.

Den biologischen und psychoanalytischen Erklärungsansätzen ist eine recht einseitige Sichtweise vorzuwerfen. Außerhalb dieser Erklärungsmodelle befindliche Einflussfaktoren werden nicht genügend berücksichtigt. Beide Modelle bieten aber durchaus interessante Ansätze, die weitere Forschung lohnenswert macht.

Der Anomietheorie ist entgegenzuhalten, dass sie sich, neben grundsätzlichen Bedenken, sowohl für Frauen als auch für Männer schwer empirisch bestätigen lässt. Dies dürfte vor allen Dingen damit zusammenhängen, dass das Anomiekonzept zentrale Begriffe wie kulturelle Ziele, soziale Schichten, Werte und Normen nicht klar definiert. Dadurch lassen sich auch die Besonderheiten weiblicher Kriminalität nicht eindeutig klären. Die Annahme, Frauen würden Ziele verfolgen, die einem traditionellen Rollenleitbild folgten, ist in der heutigen Zeit nicht mehr haltbar. Es müsste daher zunächst die grundsätzliche Frage beantwortet werden, welche gesellschaftlichen Ziele Frauen favorisieren.

Den Kontrolltheorien kommt mit ihrer Kernaussage, der Grad der Einbindung des Individuums in die Gesellschaft bestimme das Ausmaß abweichenden Verhaltens, ein größerer Erklärungsgehalt für Frauenkriminalität zu. Die Theorien sind mittlerweile genügend empirisch belegt. Jedoch können sie keine Erklärung für die unterschiedliche Kriminalitätsbelastung von Frauen und Männern liefern. Die Vermutung, Frauen verfügten über eine genetisch bedingte stärkere Selbstkontrolle ist empirisch nicht belegt und auch schwerlich nachprüfbar.

Die Theorie der differentiellen Assoziation kann zur Erklärung von kriminellem Verhalten herangezogen werden, jedoch gilt dies nicht für die Besonderheiten der weiblichen Kriminalität. Dieser Ansatz führt durch die Annahme, kriminelles Verhalten werde durch Interaktion mit anderen in einem Kommunikationsprozess erlernt, zu einer Reduzierung des Erklärungsgehalts. Weder kann zufriedenstellend erklärt werden, warum es überhaupt zu abweichendem Verhalten kommt, noch

338 Smith/Paternoster, in: JResCrimDel 1987, S. 141, S. 143. 
warum Frauen, auch unter den gleichen Voraussetzungen wie Männer, weniger kriminell werden.

Ähnliche Kritik ist den Mehr-Faktoren-Ansätzen entgegenzubringen. Zwar werden eine Vielzahl unterschiedlichster Einflussfaktoren untersucht. Allerdings kann dadurch alleine nicht die unterschiedliche Kriminalitätsbelastung der Geschlechter begründet werden. Die Mehr-Faktoren-Ansätze bieten mithin für sich genommen einen unzureichenden Rahmen für die Erklärung von weiblicher Kriminalität.

Der labeling approach kann das erstmalige Auftreten von Kriminalität nicht begründen. Die Annahme bezüglich der sekundären Devianz, Frauen würden weniger kriminell, da sie von den Instanzen der sozialen Kontrolle begünstigt behandelt würden, konnte bislang noch nicht zufriedenstellend geklärt werden. Ob ein Frauenbonus tatsächlich existiert, soll an späterer Stelle aufgegriffen und eingehend untersucht werden. ${ }^{339}$

Insgesamt ist daher festzustellen, dass die diskutierten Theorien zwar generell geeignet sind, um auch weibliche Kriminalität zu erklären. Jedoch ist ihre Begründung für die frauenspezifischen Besonderheiten unzureichend.

\section{Erklärungsansätze für die geringere Kriminalitätsbelastung von Frauen}

Es existieren nicht nur Erklärungsversuche, die sich ausgehend von den traditionellen Kriminalitätstheorien mit den Besonderheiten weiblicher Kriminalität auseinandersetzen, sondern auch eigenständige Theoriekonzepte für die geringere Kriminalitätsbelastung von Frauen im Vergleich zu Männern. Die Vertreter dieser Erklärungsansätze versuchen, dieses Phänomen zum einen damit zu begründen, dass Frauen gar nicht weniger kriminell werden (sog. Gleichverteilungsthese ${ }^{340}$ ). Zum anderen wird versucht, eine Erklärung aufgrund der spezifischen weiblichen Besonderheiten zu finden. Oftmals lassen sich diese zwei Grundpositionen nicht klar voneinander abgrenzen, da derselbe Autor Argumente sowohl für die eine als auch für die andere Position ergreift, ${ }^{341}$ sodass hier teilweise schwer zu differenzieren ist. Bei der folgenden Darstellung wird der Schwerpunkt innerhalb der einzelnen Ansätze nicht auf der Grundposition der Gleichverteilung liegen, denn gegen eine nahezu gleiche Verteilung der Kriminalitätsbelastung sprechen die in Kapitel 1 gewonnenen Ergebnisse. Nicht nur im Hellfeld, sondern auch im Dunkelfeld bestätigt sich der Geschlechterabstand. Zwar fehlt es an wiederholt repräsentativen Täterinnenbefragungen im Dunkelfeld, aber die bereits durchgeführten Un-

\footnotetext{
${ }^{339}$ Eine genauere Überprüfung findet in Kap. 5 statt.

340 Vertreter beispielsweise Leder, Frauen- und Mädchenkriminalität.

${ }^{341}$ Für eine differenzierte Betrachtung auch Schmölzẹr, in: MschrKrim 1995, S. 219, 262; Göppinger 2008, \24, Rdn. 148.
} 
tersuchungen lassen den Schluss einer geringeren Kriminalitätsbelastung von Frauen durchaus zu. Insbesondere die deutschlandweite Schüler- und Schülerinnenbefragung des KFN ist aufschlussreich. Es gibt jedoch Vertreter der Gleichverteilungsthese, die ihre Argumentation im Sinne des labeling approach auf eine geschlechtsspezifisch unterschiedliche Kriminalisierung stützen. Diese Position ist zum einen klar abgrenzbar und zum anderen deshalb nicht auszublenden, da auch mit den oben gewonnenen Ergebnissen nicht auszuschließen ist, dass eine etwaige geschlechtsspezifisch unterschiedliche Kriminalisierung den Geschlechterabstand zumindest vergrößert. Diese Argumentationsrichtung ist für die vorliegende Untersuchung der Sanktionierungspraxis besonders interessant und wird in Kapitel 5 aufgegriffen. Im Folgenden wird hierzu daher zunächst nur ein Überblick über den theoretischen Hintergrund geliefert.

Darüber hinaus haben die Ausführungen in Kapitel 1 deutlich gemacht, dass weibliche Kriminalität eine eigene Struktur aufweist. Frauen begehen in erster Linie einfachen Diebstahl und Betrug. Bei der Gewaltkriminalität sind sie erheblich unterrepräsentiert. Auch für diese besondere Deliktsstruktur versuchen einige Erklärungsansätze eine Begründung zu finden, worauf im Folgenden eingegangen werden soll.

\subsection{Kavalierstheorie}

Die sogenannte Kavalierstheorie geht von einer grundsätzlichen Gleichverteilung delinquenten Verhaltens auf beide Geschlechter aus. Als Begründer dieser Theorie kann Pollak $k^{342}$ angesehen werden, der die geringere Delinquenzbelastung mit einem „masked character" der Frauen erklärt. ${ }^{343}$ Frauen entgingen nur eher den Augen der Strafverfolgungsbehörden. Dementsprechend bestehe ein hohes Dunkelfeld und wenn es doch zur Anzeige komme, so werden Frauen seltener und milder bestraft. Dies sei auf die Ritterlichkeit der strafverfolgenden Männer zurückzuführen. ${ }^{344}$ Von Hentig ${ }^{345}$ schließt sich den Hypothesen Pollaks an. Auch er sieht den Grund für den geringeren Frauenanteil an der registrierten Kriminalität in der Fähigkeit der Frau zu täuschen. ${ }^{346}$

Die Aussagen bezüglich eines maskierten Charakters von Frauen und der besonderen Fähigkeit von Frauen zur Lüge stellen eine Herabwürdigung von Frauen dar ${ }^{347}$ und sind den im historischen Überblick dargestellten antiquierten Behauptungen zuzuordnen. Dem verbleibenden Ansatz eines ritterlichen Verhaltens

\footnotetext{
342 Pollak, 1961.

343 Pollak, S. 1 ff.

344 Pollak, S. 151.

345 von Hentig, Das Verbrechen, Bd. III, 1963.

346 von Hentig, S. 27

347 So auch der Kommentar Schneiders zu den älteren biologischen Theorien, vgl. Schneider, in: Schneider (Hrsg.), Internationales Handbuch der Kriminologie, Bd. 1, S. 435, 448.
} 
strafverfolgender Männer ist zu entgegnen, dass hier vorausgesetzt wird, die Strafverfolgung ginge nur von Männern aus, was ebenfalls nicht mehr zeitgemäß ist.

Die „Ritterlichkeitsthese“ ist wiederholt aufgegriffen und überprüft worden, 348 wobei es mehr um die Frage ging, ob Frauen von den Instanzen der Sozialkontrolle generell, und nicht nur durch strafverfolgende Männer, nachsichtiger behandelt werden als Männer. Es kommt hier folglich zu einer Überschneidung mit dem Etikettierungsansatz, sodass auf die dortigen Ausführungen verwiesen wird. ${ }^{349}$ Ferner wird dieser Frage noch im Rahmen der vorliegenden Untersuchung genauer nachgegangen. ${ }^{350}$

\subsection{Feministische Theorien}

Nach den sog. feministischen Theorien ${ }^{351}$ begehen Frauen deshalb weniger Straftaten, weil sie einer ,doppelten Unterdrückung durch kapitalistische und patriarchalische Strukturen unterlägen" 352 , wohingegen Männer nur durch kapitalistische Strukturen unterdrückt würden. Dies führe dazu, dass Frauen eher passive Problemlösungsstrategien, wie Alkohol oder Prostitution, anstelle von Kriminalität wählten. ${ }^{353}$ Je mehr Frauen ihre unterdrückte Stellung wahrnehmen würden, umso eher zeigten sie auch abweichendes Verhalten. ${ }^{354}$

Ein weiterer feministischer Ansatz stellt für die Erklärung der geringeren Kriminalitätsbelastung von Frauen darauf ab, dass das Strafrecht auf die Kontrolle von Männern zugeschnitten sei. Frauen treten vorwiegend in Bereichen wie beispielsweise Haushalt und Kindererziehung auf, sodass die Abweichungen von Frauen häufig in der Privatsphäre der Kontrolle der Ehemänner überlassen seien. ${ }^{355}$

Nach den Befürwortern der feministischen Theorien ist die spezielle Deliktsstruktur weiblicher Krimineller Folge ihrer gesellschaftlichen Position und Ausdruck der weiblichen Rollendefinition. ${ }^{356}$ Das weibliche Rollenbild, sowohl der Hausfrau als auch der berufstätigen Frau, sei auf Konsum ausgerichtet. Der von Frauen relativ häufig begangene Ladendiebstahl sei daher ein Versuch, trotz begrenzter Konsumchancen dem weiblichen Rollenbild durch den Erwerb von Sta-

\footnotetext{
348 Geißler/Marißen, in: KZfSS 1988, S. 505-526; Leder, Frauen- und Mädchenkriminalität.

${ }^{349} \mathrm{Vgl}$. Ausführungen unter Kap. 2, 2.7.

${ }^{350}$ Vgl. ausführlich unter Kap. 5, 1.

351 Vertreterinnen beispielsweise: Brökling, Frauenkriminalität; Gipser, in: Gipser/Stein-Hilbers (Hrsg.), Wenn Frauen aus der Rolle fallen, S. 169-182; Dürkop/Hardtmann, in: KJ 1974, S. 219, 236; Eisenbach-Stangl, Weiblicher Körper und männliche Vernunft. Abweichungen und Kontrolle von Frauen.

352 Brökling, S. 85, 95.

353 Dürkop/Hardtmann, in: KJ 1974, S. 219, 226 f.; Brökling, S. 85; Gipser, in: Gipser/Stein-Hilbers (Hrsg.), Wenn Frauen aus der Rolle fallen, S. 175.

354 Gipser, in: Gipser/Stein-Hilbers (Hrsg.), Wenn Frauen aus der Rolle fallen, S. 175.

355 Eisenbach-Stangl, S. 18; Smaus, in: KrimJ 1990, S. 266, 275.

356 Gipser, in: Gipser/Stein-Hilbers (Hrsg.), Wenn Frauen aus der Rolle fallen, S. 175.
} 
tussymbolen und Schönheitsattributen zu entsprechen. ${ }^{357}$ Gipser geht in ihrer Studie $^{358}$ u.a. davon aus, dass die Wahrscheinlichkeit, dass Mädchen, die ein eher traditionelles Rollenleitbild internalisiert haben, sich abweichend verhalten, umso größer sei, je weniger legitime und je mehr illegitime Mittel ihnen zur Erreichung der diesem Leitbild entsprechenden Ziele zur Verfügung stünden. Als rollenstützendes abweichendes Verhalten bezeichnet Gipser insbesondere Diebstähle von Attributen, die für eine Partnersuche als wichtig angesehen werden, da der weibliche Statuserwerb bei den Mädchen mit einem traditionellen Rollenbild immer noch überwiegend auf die Partnersuche gerichtet sei. ${ }^{359}$ Im Rahmen der Studie gaben 37 Mädchen an, Attribute die für eine Partnersuche bedeutsam sein könnten, wie Kosmetika oder Schmuck, gestohlen zu haben. Gipser sieht dadurch ihre Hypothese bestätigt. ${ }^{360}$ Beachtet werden muss allerdings, dass ebenso viele Mädchen angaben, Süßigkeiten, Spielwaren o.ä. gestohlen zu haben, mithin Dinge die nicht einem traditionellen Rollenverständnis zuzuordnen sind. Die Einstufung des Kaufhausdiebstahls als rollenstützendes abweichendes Verhalten lässt sich daher nicht ohne weiteres treffen. Die entwendeten Gegenstände drücken vielmehr das Konsumverhalten eines jeden einzelnen aus. Dies gilt im Übrigen nicht nur für Frauen sondern auch für Männer. 361

Der geringe Anteil an der Gewaltkriminalität wird von den Vertretern der feministischen Erklärungsversuche mit dem weiblichen Rollenverständnis erklärt. Physische Gewalt passe nicht in das traditionelle Rollenbild, dies sei eine „männliche Domäne“. .362 Begingen Frauen dennoch Gewaltdelikte, so richteten sich diese zumeist gegen Personen in ihrem sozialen Nahraum und seien als Aggressionsentladungen gegen die Unterdrücker zu interpretieren. ${ }^{363}$

Den Vertretern der feministischen Theorien ist entgegenzuhalten, dass sie versuchen, weibliche Kriminalität, ebenso wie die Vertreter biologischanthropologischer Ansätze, mit „Passivität“ zu begründen, mit dem Unterschied, dass sie diese Passivität als gesellschaftliches Produkt und nicht als biologische Determinante sehen. ${ }^{364}$ Die Annahme, Frauen könnten ohne die Unterdrückungsmechanismen ebenso kriminell sein wie Männer, kann von den Vertretern der feministischen Theorien nicht belegt werden. Die Kriminalitätsrate der Frauen ist zwar in den letzten Jahren deutlich angestiegen, ${ }^{365}$ hierbei ist jedoch zu berücksichtigen, dass Frauen nach wie vor im Vergleich zu den Männern bei der Ge-

\footnotetext{
${ }^{357}$ Gipser, in: Gipser/Stein-Hilbers (Hrsg.), Wenn Frauen aus der Rolle fallen, S. 175 f.; Brökling, S. 109.

358 Gipser, Mädchenkriminalität, 1975; zur Methodik siehe Ausführungen unter Kap. 2, 1.1.2.

359 Gipser 1975, S. 36 f; so auch Brökling, S. 109.

360 Gipser, 1975, S. 122.

${ }^{361}$ So auch Wagner, Ladendiebstahl - Wohlstands- oder Notstandskriminalität, S. 63.

362 Brökling, S. 119.

363 Dürkop/Hardtmann, in: KJ 1974, S. 219, 235 f.

364 Theurer, S. 63 ff.; Lindner, S. 33.

$365 \mathrm{Vgl}$. Ausführungen unter Kap. 1, 2.1.3, 2.3.3.
} 
samtkriminalität erheblich unterrepräsentiert sind. Die Teilnahme am Erwerbsleben und die rechtliche Gleichstellung von Frauen haben folglich nicht zu einer Gleichheit von Frauen- und Männerkriminalität geführt. 366

Auch die Hypothese, das Strafrecht sei auf Männer zugeschnitten, kann nicht überzeugen. Es stellt sich die Frage, wo genau die Strafbarkeitslücken im häuslichen Milieu zu sehen sind ${ }^{367}$ und inwiefern andere Straftatbestände nur auf die männliche Kontrolle zugeschnitten sein sollen. Diese Frage kann von den Vertretern dieses Erklärungsversuches nicht hinreichend beantwortet werden.

\subsection{Emanzipationstheorie}

Vertreter der Emanzipationstheorie ${ }^{368}$ gehen davon aus, dass die bislang geringere Kriminalitätsbelastung von Frauen ein Zeichen von Schwäche sei. Im Zuge der Frauenbewegung werde sich die weibliche Kriminalitätsrate der der männlichen angleichen, ${ }^{369}$ denn Frauen forderten auch im Bereich der Kriminalität gleiche Chancen. ${ }^{370}$ Durch die Bewusstseinsänderung im Zuge der Frauenbewegung würden vermehrt Frauen am Berufs- und Wirtschaftsleben teilnehmen und damit auch vermehrt mit dem Gesetz in Konflikt kommen. Denn sie strebten nun auf „männlichen“ Wegen nach Status, sodass sie den Versuchungen des Erwerbslebens in höherem Maße ausgesetzt seien. ${ }^{371}$ Nach Simon bezieht sich diese Zunahme jedoch hauptsächlich auf das ,white-collar crime“. Im Gegensatz dazu werde der Anteil der Frauen an den Gewaltdelikten sinken, da Gewaltkriminalität auslösende Gefühle, wie Frustration und Machtlosigkeit, sich durch die Teilnahme am Arbeitsleben verminderten. ${ }^{372}$

Adler versuchte, den von ihr vermuteten generellen Anstieg weiblicher Kriminalität durch eine Auswertung der Daten des Uniform Crime Report in der Zeit von 1960 bis 1972 zu belegen. Sie konzentrierte sich auf schwere Gewaltdelikte und kam zu dem Ergebnis, dass mit Ausnahme von Mord und schwerem tätlichem Angriff die Verhaftungszahlen der Frauen bei allen Straftaten prozentual vielfach schneller zunahmen als die der Männer. ${ }^{373}$

Diese hohen Zuwachsraten sind jedoch irreführend. Dies liegt daran, dass die zugrunde liegenden absoluten Zahlen sehr niedrig sind. ${ }^{374}$ Damit führt auch jede Verhaftung von Frauen zu einem höheren prozentualen Zuwachs als bei Män-

\footnotetext{
366 Schneider, in: Hirsch/Kaiser/Marquardt (Hrsg.), Gedächtnisschrift für Hilde Kaufmann, S. 267, 277.

367 So auch Theurer, S. 64.

368 Adler, Sisters of crime, 1976; Simon, Woman and crime, 1975.

369 Adler, S. 16 ff.

370 Adler, S. 13.

371 Adler, S. 16 ff.; Simon, S. 106 f.

372 Simon, S. 19.

373 Adler, S. 16.

374 Smart, in: BritJCrim 1979, S. 50, 57.
} 
Erklärungsansätze für das Phänomen der Frauenkriminalität

nern. ${ }^{375}$ Ferner kommen zahlreiche Untersuchungen, und auch der in Kapitel 1 durchgeführte Eckdatenvergleich auf Grundlage der Daten der PKS, ${ }^{376}$ zu dem Ergebnis, dass bei schweren Formen der Gewaltkriminalität für Frauen zumeist kein Anstieg verzeichnet werden kann. ${ }^{377}$ Abgesehen davon, wird die Frage eines Zusammenhangs zwischen Kriminalitätsanstieg und Emanzipation nicht zufriedenstellend beantwortet.

Interessant ist in diesem Zusammenhang eine Schülerinnenbefragung mittels Fragebögen von James/Thornton ${ }^{378}$. Sie befragten 287 Mädchen der 8. bis 12. Jahrgangsstufe und kamen zu dem Ergebnis, dass eine positive Einstellung zum Feminismus nicht mit einer erhöhten Delinquenz einhergeht. ${ }^{379}$ Allerdings ist die Methodik der Untersuchung zu kritisieren, da die Einstellung zum Feminismus nur anhand der persönlichen Einschätzung der Befragten von drei Aussagen ${ }^{380}$ erfasst wurde ${ }^{381}$ und daher nicht aussagekräftig genug ist.

Letztlich konnte ein Zusammenhang zwischen Emanzipation und Kriminalität nicht nachgewiesen.

Die weibliche Deliktsstruktur kann von den Vertretern der Emanzipationstheorie nicht erklärt werden. Der Aussagegehalt reduziert sich auf die Annahme, dass sich die Kriminalitätsrate der Frauen denen der Männer mit steigender Emanzipation angleichen wird. Konsequenz dieser Überlegungen dürfte sein, dass die bislang bestehenden Differenzen ein Ausdruck von „Schwäche“ der Frauen sind und dass ein struktureller Unterschied zwischen weiblicher und männlicher Kriminalität bei vollständiger Gleichberechtigung nicht bestehen dürfte.

Darüber hinaus ist einzuwenden, dass die Vertreter dieser Theorie Frauen nicht in ihrem sozialen Umfeld betrachten. Kriminelle Frauen und Männer kommen meist aus einem problematischen sozialen Umfeld ohne berufliche Perspektiven. Es ist fraglich, ob die Frauenbewegung auch diese Frauen erreicht. ${ }^{382} \mathrm{Zu}$ dem ist zu beachten, dass es, trotz vermehrter Teilnahme von Frauen am Erwerbs- und Wirtschaftsleben in den letzten Jahrzehnten, nicht zu der vorausgesagten „Angleichung“ an die Männerkriminalität gekommen ist. ${ }^{383}$

\footnotetext{
375 Smart, in: BritJCrim 1979, S. 50, 53; Crites, in: Crites (Hrsg.), The Female offender, S. 33-44.

376 Vgl. Kap. 1, 2.1.3.

377 Beispielsweise: Einsele, Wandelt sich die weibliche Kriminalität?, in: Haesler (Hrsg.), Weibliche und männliche Kriminalität, 1982, S. 53-80; Marshall, in: Barak-Glantz/Johnson (Hrsg.), Comparative criminology, 1983, S. 53-80.

378 James/Thornton, in: JResCrimDel 1980, S. 230-244.

379 James/Thornton, in: JResCrimDel 1980, S. 230, 242 f.

380 Folgende Aussagen wurden zur Erfassung der Variable „Einstellung zum Feminismus“ formuliert: 1) Frauen sollten für gleiche Rechte wie Männer kämpfen. 2) Es ist nicht natürlich, wenn einer Frau ihre Karriere so wichtig ist, wie ihr Mann und ihre Kinder. 3) Wenn sie sich danach fühlen, sollten Mädchen Jungs nach einer Verabredung fragen.

381 James/Thornton, in: JResCrimDel 1980, S. 230, 233.

382 So auch Crites, in: Crites (Hrsg.), The female offender, S. 33, $36 \mathrm{ff}$.

383 Smart, in: BritJCrim 1979, S. 50, 57.
} 
Es erscheint auch nicht plausibel, so wie Adler dies getan hat, aus Einzelbiographien weniger Frauen, die wegen Delikten auffielen die sie selten begehen, wie Mord oder Raub, irgendeinen Rückschluss auf „Emanzipation“ zu ziehen. 384 Bruhns $^{385} \mathrm{kam}$ in ihrer Studie über gewaltbereiten Mädchengruppen zu dem Ergebnis, dass die Übernahme männlicher Verhaltensweisen durch Frauen und Mädchen in Form der Begehung von Gewaltdelikten nicht zwangsläufig zu einem neuen Selbstbild von Weiblichkeit führt, sondern durchaus auch mit traditionellen geschlechterstereotypen Vorstellungen einhergehen kann. ${ }^{386}$

\subsection{Rollentheorie}

Aus sozialwissenschaftlichen Ansätzen zu Beginn des letzten Jahrhunderts, die bei der Erklärung weiblicher Kriminalität besonders die Rolle der Frau betonen, entwickelte sich die Rollentheorie. Popitz ${ }^{87}$ konkretisierte die soziale Rolle als Bündel von Verhaltensnormen, die eine Kategorie von Gesellschafts- bzw. Gruppenmitgliedern im Unterschied zu anderen Kategorien zu erfüllen habe. ${ }^{388}$ Als Ansammlung gleichförmiger Verhaltensweisen sei sie ein gesellschaftliches Konstrukt. Individuelle Personen würden in eine positionelle, gesellschaftlich verfestigte Kategorie eingeordnet. ${ }^{389}$ Rollenverhalten wird im Rahmen der Sozialisation vermittelt und sei eine Bedingung der Möglichkeit von Vergesellschaftung. ${ }^{390}$ Anhänger der Rollentheorie gehen von der Konzeption einer weitgehend geschlechtsspezifisch verlaufenden Sozialisation aus, wobei die Frau eine besondere Entwicklung durchlaufe und dabei geschlechtstypische Verhaltensweisen, Motive und Einstellungen von Geburt an lerne. ${ }^{391}$ Gipser bringt vor, die Tendenz der Frau zu abweichendem Verhalten, hänge davon ab, welches Leitbild internalisiert worden sei, d.h. also von der Stärke der Rollenidentifikation und dem in ihrem Werdegang vermittelten Handlungsmöglichkeiten. ${ }^{392}$ Regelmäßig seien Mittel verfügbar, die mit der gesellschaftlichen Rollendefinition in Einklang stehen. Parsons geht in seinem Rollenmodell davon aus, dass die Mutter bei der Erziehung als Rollenvorbild für das Mädchen fungiere und diesem das Erlernen der weiblichen Erwachsenenrolle ermögliche. Mädchen werde vermittelt, sie hätten nett und fügsam zu sein, wogegen Jungen Rauheit und Härte zu lernen hätten. ${ }^{393}$ Das von den Mädchen

\footnotetext{
384 Göppinger 2008, \24, Rdn. 162.

385 Brubns, in: Elz (Hrsg.), Täterinnen, S. 177-194.

386 Bruhns/Wittmann, 2002, S. 227; Bruhns, in: Elz (Hrsg.), S. 177, 185.

387 Popitr, Der Begriff der sozialen Rolle als Element der soziologischen Theorie.

388 Popity, S. 21.

389 Popitz, S. 21.

390 Popitz, S. 20, 36.

391 Kaiser, in: ZStW 1986, S. 658, 671 f.; Popp, in: Holtappels/Heitmeyer/Melzer/Tillmann (Hrsg.), Forschung über Gewalt an Schulen, S. 207, 209.

392 Gipser, S. 439.

393 Parsons, in: Parsons (Hrsg.), Essays in sociological theory, S. 298, 304 f.
} 
erlernte Verhalten stehe im Widerspruch zu vielen Formen der Kriminalitä̈. ${ }^{394}$ Zusätzlich sei mit der weiblichen Geschlechtsrolle eine stärkere soziale Kontrolle verbunden. Schon seit der Geburt sei das Mädchen in größerem Ausmaß als Jungen elterlicher Kontrolle unterworfen und ihre Handlungsspielräume stärker eingeschränkt. ${ }^{395}$ Letztlich wirke also die geschlechtsspezifische Sozialisation kriminalitätshemmend, indem die erfolgreiche Verinnerlichung geschlechtstypischer Werte und Verhaltensweisen die Verfügbarkeit über abweichende asoziale oder antisoziale Verhaltensformen begrenze. Misslinge diese Sozialisation, so entstehe eine Gefährdungslage, in der es zu abweichendem Verhalten der Frau kommen könne. ${ }^{396}$

Die Annahme der Rollentheorie, Frauen begingen aufgrund erlernter Verhaltensweisen und strenger Sozialkontrolle nur wenige Delikte, sodass Kriminalität entstehe, wenn die geschlechtstypische Sozialisation nicht gelinge und die geschlechtsspezifische soziale Kontrolle versage ${ }^{397}$, ist wegen ihrer Vielschichtigkeit nur schwer überprüfbar, weshalb Untersuchungen immer nur auf Teilaspekte bezogen sind. Untersuchungen zeigten, dass gerade bei Straftäterinnen Sozialisationsdefizite, schlechte Ausbildung und defizitäres Arbeitsverhalten gegeben waren. ${ }^{398}$ In der Verbindung mit der Behauptung, die festgestellten Sozialisationsstörungen seien Ausdruck fehlerhaften Erlernens weiblichen Rollenverhaltens, wurden jene Befunde als Bestätigung der Rollentheorie interpretiert. Tatsächlich weisen die Ergebnisse zwar auf eine gestörte Sozialisation, nicht jedoch speziell auf das fehlerhafte Erlernen weiblichen Rollenverhaltens hin. Sozialisationsdefizite treten auch bei männlichen Straftätern auf, so dass deren Vorliegen bei Straftäterinnen nicht als Beweis für die geschlechtsspezifischen Annahmen der Rollentheorie gewertet werden können. Untersuchungen, die umfassend den Zusammenhang von mangelhafter Internalisierung weiblicher Verhaltensweisen mit Kriminalität prüfen, sind nicht bekannt. Zahlreiche Studien ${ }^{399}$ untersuchen die Korrelation von als typisch männlich klassifizierten Charakterzügen und Kriminalität für beide Geschlechter. Sie gelangten zu dem Ergebnis, dass männliche Charaktereigenschaften geschlechtsunabhängig die Delinquenzneigung erhöhen. ${ }^{400}$ Frauen mit männlichen Charakteristika sind jedoch weniger häufig kriminell als Männer mit den selbigen. Die Rollentheorie kann dadurch nicht als bestätigt angesehen wer-

\footnotetext{
394 Schneider, in: Hirsch/Kaiser/Marquardt (Hrsg.), Gedächtnisschrift für Hilde Kaufmann, S. 267, 272

395 Eisenbach-Stangl, in: KB 1979, S. 4, 27; Schneider, in: Schneider (Hrsg.), Internationales Handbuch der Kriminologie, Bd. 1, S. 435, 442 f.

396 Keupp, in: MschrKrim 1982, S. 219, 225.

397 Keupp, in: MschrKrim 1982, S. 219, 227 f.

398 Glueck/Glueck, Five hundred delinquent women; Memminger, Untersuchungen zur weiblichen Frühkriminalität.

${ }^{399} \mathrm{Vgl}$. Zusammenstellungen bei Theurer, S. 85 f.

400 Beispielsweise: Cullen/Golden/Cullen, in: Crim 1979, S. 307, 305.
} 
den, da hierzu die Wirkung vergleichbarer Faktoren auf beide Geschlechter zu einer Kriminalitätsangleichung führen müsste.

Hengesch ${ }^{401}$ analysierte 1.134 forensische Gutachten und kam zu einem anderen Ergebnis. ${ }^{402}$ Die Selbstbeurteilung der Persönlichkeit des Probanden anhand des Freiburger Persönlichkeitsinventars ${ }^{403}$ zeigte, dass Frauen, die Kapitaldelikte verübt hatten, extrovertierter und kontaktfreudiger als Frauen waren, die andere Straftaten begangen hatten. Hengesch setzte Kontakthemmung und Introvertiertheit mit typisch weiblichen Charakterzügen gleich und zog daraus den Schluss, Frauen müssten „männlich“ werden, um schwere Formen der Delinquenz zu begehen. Bei der Aussagekraft der Studie ist allerdings zu beachten, dass die Stichprobe der Frauen, die Kapitaldelikte begangen hatten, lediglich 15 Personen umfasste. ${ }^{404}$

Funken $^{405}$ überprüfte die Auswirkung der Rolle auf Frauenkriminalität anhand der Geschlechtsrollenorientierung der einzelnen Frauen. Sie befragte 125 Frauen $\mathrm{zu}$ ihrer Geschlechtsrollenorientierung und setzte diese in Relation zu vier Deliktsgruppen. ${ }^{406}$ Sie kam zu dem Ergebnis, dass der Zusammenhang zwischen der Tat und dem sozialen Nahraum in Kombination mit der Variablen Rolle umso stärker ist, je stärker die traditionellen Rollenvorstellungen sind. ${ }^{407}$ Jedoch betrifft Funkens Untersuchung nur einen eingeschränkten Teilbereich, sodass eine verallgemeinerungsfähige Aussage über den Zusammenhang zwischen Geschlechtsrollenorientierung und Straffälligkeit wohl nicht getroffen werden kann. 408

Theurer ${ }^{409}$ untersuchte in ihrer Studie die Gültigkeit der Rollen- sowie auch der Emanzipationstheorie. Sie überprüfte den Zusammenhang zwischen Deliktsbegehung und dem Grad der Emanzipation. Den Grad der Emanzipation bestimmte sie nach dem Rollenbild der Frau von emanzipatorisch bis traditionell. Als Untersuchungsinstrument dienten ihr Interviews von insgesamt 105 Probandinnen im Alter von 25-60 Jahren mittels standardisierten Fragebögen. Theurer kam zu dem Ergebnis, dass , zwischen der Internalisierung eines fortschrittlichen Frauenbildes und der Kriminalitätsbelastung von Frauen" 410 ein eindeutiger Zusammenhang besteht, was für die Gültigkeit der Rollentheorie spräche. ${ }^{411}$

\footnotetext{
401 Hengesch, in: MschrKrim 1990, S. 331-335.

402 Hengesch, in: MschrKrim 1990, S. 331.

403 Dies ist ein psychologischer Persönlichkeitstest, bei dem die Antworten hinsichtlich zwölf Skalen (beispielsweise Lebenszufriedenheit, soziale Orientierung, Aggressivität, Gehemmtheit, Emotionalität) ausgewertet werden.

${ }^{404}$ Hengesch, in: MschrKrim 1990, S. 331, 334.

405 Funken, (Fn. 172).

406 Funken, S. $101 \mathrm{ff}$.

407 Funken, S. 194-199.

408 So auch Schmölzer, in: MschrKrim 1995, S. 219, 233.

409 Theurer, (Fn. 172).

410 Theurer, S. 152.

411 Theurer, S. 152.
} 
Die Autorin wendet allerdings selbst ein, bei der Interpretation der Ergebnisse sei zu beachten, dass lediglich ein Teilaspekt, nämlich die Geschlechtsrollenorientierung der Probandinnen, ermittelt wurde. Eine Überprüfung der Gültigkeit des rollentheoretischen Konzepts verlange aber eine Überprüfung des tatsächlichen Rollenverhaltens von Frauen. ${ }^{412}$

Vertreter des rollentheoretischen Ansatzes begreifen die unterschiedliche Deliktsstruktur bei Frauen und Männern als Ausdruck ihres Rollenmusters. ${ }^{413}$ Frauen begingen relativ häufig Beleidigungen, da sie gelernt hätten, ihre Aggressionen verbal und nicht physisch auszudrücken. ${ }^{414}$

Die geringe Gewaltkriminalität von Frauen und Mädchen sei darauf zurückzuführen, dass sie zu geringerer Aggressivität erzogen würden und dass sie lernten, ihren Aggressionen mehr mit Worten als mit Taten Ausdruck zu verleihen. Sie lernten mithin in ihrer geschlechtsspezifischen Sozialisation, dass aggressives Verhalten für Frauen nicht akzeptabel sei. ${ }^{415}$ Männer bekämen hingegen vermittelt, dass gewisse Verhaltensmuster, die in Begriffen wie Aggressivität, Impulsivität, Heldentat oder Wagemut zum Ausdruck kommen, typisch männliche seien und dem Beweis reiner Männlichkeit dienten. ${ }^{416}$ Schneider erklärt die relativ häufige Verübung von Gewaltdelikten im sozialen Nahraum durch Frauen dadurch, dass die Männer die Frauen in modernen Wohnhäusern mit ihrer „sozialen Isolation “ und ihrem „Kontaktmangel" allein ließen. 417

Insgesamt lässt sich konstatieren, dass die Behauptung, dass Erziehung und Kontrolle durch das Umfeld wichtige Faktoren bei der Entstehung von Devianz seien, zunächst plausibel erscheint, doch können diese stets nur einzelne Fälle und nicht das Gesamtphänomen erklären. Trotz gleicher Erziehung können sich Menschen in ihrem Legalverhalten unterscheiden, wie etwa die Adoptionsstudien gezeigt haben. Zudem gibt es Fälle, in denen Frauen männliche Charaktereigenschaften übernehmen und dennoch nicht straffällig werden. Die bereits durchgeführten Untersuchungen zeigen die Schwierigkeit bei der Überprüfung der Rollentheorie.

Abgesehen davon wird von den Vertretern der Rollentheorie das Handeln von Männern und Frauen als Ausdruck von geschlechtstypischen Rollenmustern charakterisiert, ohne diese zu erklären. Dies führt laut Kersten in eine „erkenntnistheoreti-

\footnotetext{
412 Theurer, S. 153.

413 Schneider, in: Hirsch/Kaiser/Marquardt (Hrsg.), Gedächtnisschrift für Hilde Kaufmann, S. 267, 274.

414 Schneider, in: Hirsch/Kaiser/Marquardt (Hrsg.), Gedächtnisschrift für Hilde Kaufmann, S. 267, 274.

415 Schneider, in: Hirsch/Kaiser/Marquardt (Hrsg.), Gedächtnisschrift für Hilde Kaufmann, S. 267, 274; Eisenbach-Stangl, in: KB 1979, S. 4, 27.

416 Cohen, Kriminelle Jugend, S. 104 ff.

417 Schneider, in: Hirsch/Kaiser/Marquardt (Hrsg.), Gedächtnisschrift für Hilde Kaufmann, S. 267, 274.
} 
sche Sackgasse".418 Schließlich scheint es fraglich, ob das traditionelle duale Rollenkonzept unkritisch zugrunde gelegt werden kann. Heutzutage gibt es eine Vielzahl von Verhaltensmustern, die nicht mehr mit den geschlechtsrollenspezifischen Erwartungen übereinstimmen. ${ }^{419}$

\subsection{Zusammenfassende Diskussion}

Betrachtet man die Erklärungsversuche für die geringere Delinquenzbelastung von Frauen, so ist auffällig, dass sowohl die Vertreter der emanzipatorischen als auch die der feministischen und rollentheoretischen Ansätze, Frauen oftmals als passiv, mit begrenzten Aktionsradius und daraus resultierender geringer Möglichkeit zur Deliktsbegehung beschreiben. ${ }^{420}$ Teilweise hat es den Anschein, als ob eher eine Erklärung dafür gesucht wird, warum ein Unterschied in der Kriminalitätsbelastung nicht bestehen dürfte. Davon ausgehend reichen die Begründungen von einer bevorzugten Behandlung durch die staatlichen Kontrollorgane, einer gesellschaftlichen Unterdrückung und damit einhergehender Passivität von Frauen bis hin zur Angleichung der Kriminalitätsraten im Zuge der Emanzipation.

Der Rollentheorie ist zugute zu halten, dass sie erstmals unterschiedliche geschlechtsspezifische Sozialisation und unterschiedliche Rollenerwartungen mit berücksichtigt. Keine der erörterten Theorien kann jedoch für sich allein eine befriedigende Begründung für die geringere und weniger schwerwiegende Delinquenz von Frauen liefern. Es kann nur weiterhin versucht werden, sich der Antwort mit fundierten empirischen Studien anzunähern, wobei die bislang durchgeführten Untersuchungen lediglich Teilaspekte erfassen konnten.

Schließlich muss man die hier erörterten Theorien in Zusammenhang mit den unter 2. behandelten Erklärungsansätzen betrachten. Schmölzer stellte fest:

„Erst wenn man auf verschiedene Fragen zur weiblichen Kriminalität dieselbe Antwort erhalten hat, könnte man das Gesamtphänomen ,Frauenkriminalität auf eine Theorie redurieren. "421

\footnotetext{
418 Kersten, in: Scarbath/Schlottau/Straub/Waldmann (Hrsg.), Geschlechter. Zur Kritik und Neubestimmung geschlechtsbezogener Sozialisation und Bildung, S. 77, 78.

${ }^{419}$ So auch Silkenbeumer, Im Spiegel ihrer Lebensgeschichten. Gewalttätiges Verhalten Jugendlicher und Geschlechtszugehörigkeit, S. 23.

420 So auch Theurer, S. 103.

421 Schmölzer, in: MschrKrim 1995, S. 219, 226.
} 



\section{Kapitel 3: Anlage der eigenen Untersuchung}

Die vorliegende Untersuchung, die sich sowohl der Sanktionierungspraxis der Gerichte als auch der weiblichen Rückfallkriminalität widmet, basiert auf den für die Rückfalluntersuchung 2004-2007422 erhobenen BZR-Daten.

Im folgenden Kapitel wird die Datenbasis vorgestellt und auf die Anlage der eigenen Untersuchung eingegangen, wobei zwischen der Sanktionierungspraxis und der Rückfälligkeit unterschieden wird. Dafür war eine Modifikation der Daten notwendig. Die sich aus dem Datenmaterial ergebenden Einschränkungen der Aussagekraft der Untersuchung werden abschließend diskutiert.

\section{Datenbasis}

\subsection{Rückfalluntersuchungen für das Basisjahr 2004}

Die vorliegende Untersuchung konnte auf die der Rückfalluntersuchung 20042007423 zugrunde liegenden Daten des BZR ${ }^{424}$ zurückgreifen. Diese Studie wurde

\footnotetext{
422 Jeble/Albrecht/Hohmann-Fricke/Tetal, Legalbewährung nach strafrechtlichen Sanktionen. Eine bundesweite Rückfalluntersuchung 2004-2007.

423 Jeble/Albrecht/Hohmann-Fricke/Tetal, Legalbewährung nach strafrechtlichen Sanktionen. Eine bundesweite Rückfalluntersuchung 2004-2007, 2010.
} 
vom Bundesministerium der Justiz bei der Abteilung für Kriminologie an der Universität Göttingen (Prof. Jehle) und dem Max-Planck-Institut für ausländisches und internationales Strafrecht in Freiburg (Prof. Albrecht) in Auftrag gegeben. Für die Erhebung wurden anhand der personenbezogenen Eintragungen im Bundeszentral- und Erziehungsregister alle im Basisjahr 2004 strafrechtlich Sanktionierten oder aus der Haft Entlassenen erfasst und während eines dreijährigen Rückfallzeitraumes bis 2007 weiterverfolgt, um zu erkennen, ob sie wieder straffällig geworden sind. Zudem konnten für diese Probanden sämtliche Voreintragungen erfasst werden, sofern die Abstände zwischen den Eintragungen nicht so groß waren, dass sie zwischenzeitlich getilgt wurden. Zuvor wurde bereits eine erste kommentierte Rückfallstatistik der Bundesrepublik Deutschland für das Basisjahr 1994 (Rückfallzeitraum bis 1998) veröffentlicht. ${ }^{425}$ Beiden Untersuchungen liegt ein überaus umfangreiches Datenmaterial zugrunde. Durch die einzigartige Datenquelle des BZR war es für die Basisjahre 1994 und 2004 möglich, umfassende Daten über Strafzumessung und Rückfallraten in Abhängigkeit von Sanktion, Delikt, Alter, Geschlecht, Nationalität und Vorstrafenbelastung der Sanktionierten zu erfassen. Dabei ging es den Autoren der Rückfalluntersuchung jedoch nicht darum, individuelle Rückfallverläufe abzubilden. Für die Zwecke der Studie musste die Vielfältigkeit der Daten auf wenige aussagekräftige Kriterien reduziert werden, sodass auch keine umfassende, nach Geschlechtern differenzierende, Auswertung erfolgte.

\subsection{Der Inhalt des BZR}

Das BZR besteht aus dem Zentral- und dem Erziehungsregister. Gem. \3 BZRG sind strafgerichtliche Verurteilungen, bestimmte Entscheidungen von Verwaltungsbehörden und Gerichten, Vermerke über Schuldunfähigkeit, nachträgliche Entscheidungen und Tatsachen, die sich auf die vorgenannten Tatsachen beziehen, sowie gerichtliche Feststellungen nach $\$ \$ 17$ II, 18 BZRG eintragungspflichtig. Der Begriff der Verurteilung wird in $\$ 4$ BZRG genauer definiert: Neben den rechtskräftigen Entscheidungen, die wegen einer rechtswidrigen Tat auf Strafe erkannt haben, sind danach auch Maßregeln der Besserung und Sicherung (vgl. \4 Nr. 2 BZRG) einzutragen. Nicht einzutragen sind hingegen alle informellen Sanktionen, also vor allem die Einstellung des Verfahrens gem. $\iint$ 153, 153a StPO.426

Weitere Eintragungspflichten ergeben sich aus $\iint 5$ Abs. 1 Nr. 2-7, Abs. 2, 7 , 10, 12-16, 19 BZRG. ${ }^{427}$

\footnotetext{
424 Zur rechtlichen Struktur des BZR siehe ausführlich: Harrendorf, S. 84 ff.

425 Jeble/Heinz/Sutterer, Legalbewährung nach strafrechtlichen Sanktionen, 2003.

426 Eine Ausnahme stellen $\$ 11$ Abs. 1 Nr. 1und 2 BZRG dar.

427 Vgl. ausführlich hierzu: Harrendorf, S. 84 ff.
} 
In das Erziehungsregister werden gem. $\int 60$ BZRG u.a. die Anordnung von Erziehungsmaßregeln und Zuchtmitteln nach JGG sowie die Verfahrenseinstellungen nach $\iint 45,47 \mathrm{JGG}$ eingetragen.

$\int 5$ I Nr. 1 BZRG sieht vor, die Personendaten des Verurteilten aufzunehmen. Hierzu zählen das Geburtsdatum, der Vor-, Familien- und Geburtsname, der Geburtsname der Mutter sowie etwaige Aliasnamen, der Geburtsort, die Staatsangehörigkeit und das Geschlecht. Für die Rückfalluntersuchungen wurden die Daten vollständig anonymisiert, sodass eine Identifikation der betroffenen Personen nicht möglich ist. ${ }^{428}$ Der hier verwendete Datensatz enthält noch Angaben zu Geburtsjahr und -monat, Nationalität und Geschlecht. Den Probanden wurden Personennummern gegeben, um gleichwohl eine eindeutige Zuordnung der Entscheidung zu bestimmten Personen, auch für Folgeuntersuchungen, zu ermöglichen. ${ }^{429}$ Die Daten des BZR bieten daher eine ausgezeichnete Grundlage für eine umfassende empirische, geschlechtsdifferenzierende bzw. frauenspezifische Überprüfung der Sanktionierungspraxis der Gerichte sowie der Rückfallkriminalität.

\section{Untersuchungsanlage}

Da die vorliegende Untersuchung neben der Rückfallkriminalität von Frauen auch die Sanktionierungspraxis analysieren will, musste mit zwei unterschiedlichen Datensätzen gearbeitet werden: Dem Rückfall- und dem Entscheidungsdatensatz, denen ein jeweils anderes Erfassungskonzept zugrunde liegt.

\subsection{Rückfalldatensatz}

Für die Analyse der Rückfallkriminalität wird der sog. Rückfalldatensatz verwendet, wie er auch der Rückfalluntersuchung für das Basisjahr 2004 zugrunde lag. Der Rückfalldatensatz ist als sog. Personendatensatz konzipiert. Er umfasst die Daten aller Personen, die im Bezugsjahr 2004 mit einer ambulanten Reaktion nach JGG belegt oder zu einer ambulanten Sanktion nach JGG oder StGB verurteilt wurden. Ferner werden die Personen erfasst, die nach einer stationären Strafe oder Maßregel entlassen worden sind. Insgesamt beinhaltet der Rückfalldatensatz 1.051.887430 Bezugsentscheidungen, für die sämtliche, mit der Sanktionierung verbundenen, Individualeintragungen berücksichtigt wurden. Von den so erfassten Personen waren 217.443 Frauen und 834.444 Männer.

\footnotetext{
428 Jeble/Albrecbt/Hohmann-Fricke/Tetal, Legalbewährung nach strafrechtlichen Sanktionen, 2010, S. 11; Harrendorf, S. 105.

${ }^{429}$ Harrendorf, S. 105.

430329 Fälle ohne Geschlechtsangabe wurden ausgeschlossen.
} 
Schaubild 3.1: Strukturmodell des Rückfalldatensatzes 2004-2007

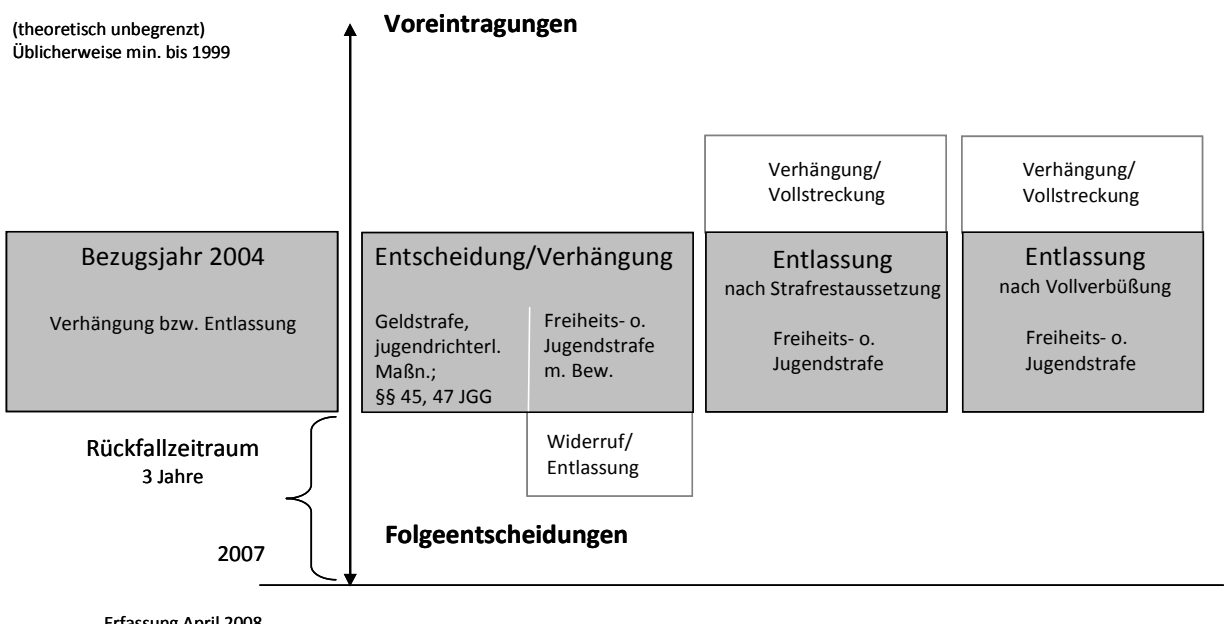

Quelle: Jehle/Albrecht/Hohmann-Fricke/Tetal, Legalbewährung nach strafrechtlichen Sanktionen, 2010, Abb. A 1.4, S. 11.

Schaubild 3.1 verdeutlicht die Struktur des Rückfalldatensatzes.

Stationäre Maßnahmen (Freiheits- und Jugendstrafen, Strafarreste, Maßregeln gem. $\iint 63,64,66 \mathrm{StGB}$ ) werden als Bezugsentscheidung registriert, wenn die durch Eintragung des Erledigungszeitpunkts im BZR vermerkte Haftentlassung im Bezugsjahr 2004 liegt.

Ambulante Sanktionen (zur Bewährung ausgesetzte Freiheits- und Jugendstrafen, Strafarreste und Maßregeln gem. $\iint 63$, 64 StGB, deren Vollstreckung zur Bewährung ausgesetzt wurde, Geldstrafen, Verwarnung mit Strafvorbehalt, Absehen von Strafverfolgung, Einstellungen nach $\int \S 45,47$ JGG, Erziehungsmaßregeln und Zuchtmittel einschließlich Jugendarrest ${ }^{431}$ sowie andere durch jugendrichterliches Urteil getroffene Entscheidungen ${ }^{432}$ ) werden erfasst, wenn das Entscheidungsdatum in 2004 liegt.

Bei Personen, die wegen einer Strafrestaussetzung in Freiheit entlassen wurden, musste an die dem BZR gemeldeten richterlichen Aussetzungsbeschlüsse angeknüpft werden, da das BZR kein Entlassungsdatum enthält. Die Meldung erfolgt jedoch in der Regel nicht zeitgleich mit der Aussetzung, sondern um einige Monate verzögert, sodass Personen, die gegen Ende des Bezugsjahres mit einem

431 Auch beim Jugendarrest wurde der Zeitpunkt der Verhängung als Anknüpfungspunkt gewählt, obwohl er stationär ist. Dies scheint gerechtfertigt, da der Jugendarrest zumeist von sehr kurzer Dauer und zudem der Vollstreckungszeitpunkt nicht eingetragen ist.

432 Dazu zählen: jugendrichterliche Reaktion bei mangelnder Reife $\ 3$ S. 2 JGG, Aussetzung der Verhängung der Jugendstrafe gem. \27 JGG, Überweisung an den Vormundschaftsrichter gem. $\int 53$ JGG. 
zur Bewährung ausgesetzten Strafrest in die Freiheit entlassen werden, bei alleiniger Betrachtung des Bezugsjahres nicht als solche erfasst würden. Um dies zu vermeiden, wurde der einjährige Erfassungszeitraum für solche Fälle um vier Monate ins Folgejahr verschoben. ${ }^{433}$

Bei mehreren potentiellen Bezugsentscheidungen wurde immer die zeitlich erste gezählt. Jede weitere Entscheidung im Bezugsjahr wird als Rückfalltat registriert. Auch später einbezogene Entscheidungen werden als Bezugsentscheidung erfasst. Die nachfolgenden (auch einbeziehenden) Entscheidungen gelten jedoch nur dann als Folgeentscheidung, wenn das Tatdatum nach der Bezugsentscheidung liegt. Gem. \55 StGB ist Voraussetzung für eine Einbeziehung, dass das Tatdatum vor der einbezogenen Entscheidung liegt, sodass letztendlich alle einbeziehenden Entscheidungen nach allgemeinem Strafrecht als Folgeentscheidung ausgeschlossen werden. Anderes gilt hingegen für einbeziehende jugendstrafrechtliche Verurteilungen nach $\int 31$ JGG, bei denen eine erneute Tat im Risikozeitraum begangen wurde. ${ }^{434}$

Die so erfassten Personen wurden über einen Zeitraum von 3 Jahren bis 2007 weiterfolgt, um zu erkennen, ob sie wieder straffällig geworden sind oder nicht. Der Beginn des Beobachtungszeitraums orientiert sich bei ambulanten Sanktionen am Entscheidungszeitpunkt, im Übrigen an der Strafrestaussetzung bzw. am Vollstreckungsende.

Der Rückfallzeitraum wurde im Hinblick auf die Tilgungsvorschriften des BZRG gewählt. Gem. \47 III BZRG können Entscheidungen nur getilgt werden, wenn auch die letzte Entscheidung tilgungsreif geworden ist, sodass Informationen über die gesamte kriminelle Karriere der Probanden zur Verfügung stehen.

\subsection{Entscheidungsdatensatz}

Der Rückfalldatensatz musste allerdings für die Untersuchung der Deliktsstruktur (Kapitel 4) und der Sanktionierungspraxis (Kapitel 5) modifiziert werden. Problematisch ist, dass der Rückfalldatensatz bei den stationären Strafen an den Zeitpunkt der Haftentlassung anknüpft. Würde man auch die Analyse der Deliktsstruktur und der Sanktionierungspraxis anhand des Rückfalldatensatzes vornehmen, so würde dies dazu führen, dass der Entscheidungszeitpunkt bei den stationären Strafen in den meisten Fällen vor dem Bezugsjahr 2004 liegt und für die Haftstrafen keine Aussagen für das Bezugsjahr getroffen werden könnten. Es wurde daher ein sog. Entscheidungsdatensatz konzipiert, der zwar nicht jede Entscheidung im Bezugsjahr zählt, sondern, wie der Rückfalldatensatz, für jede Person nur die zeit-

$433 \mathrm{Jeble} /$ Albrecbt/Hohmann-Fricke/Tetal, Legalbewährung nach strafrechtlichen Sanktionen, 2010, S. 12.

434 Jeble/Albrecbt/Hohmann-Fricke/Tetal, Legalbewährung nach strafrechtlichen Sanktionen, 2010, S. 13. 
lich erste. Dafür wurde jedoch auch bei den stationären Strafen auf das Entscheidungs- und nicht auf das Haftentlassungsdatum abgestellt.

$\mathrm{Zu}$ berücksichtigen ist folglich, dass es durch die Zählung lediglich der zeitlich ersten Entscheidung im Bezugsjahr zu einer Reduzierung der Fälle kommen kann. Zwar könnte mit den zugrunde liegenden Daten des BZR grundsätzlich auch ein Datensatz konzipiert werden, der sich am Erfassungskonzept der Strafverfolgungsstatistik orientiert, und alle Verurteilungen für eine Person im Bezugsjahr zählt. Dies würde allerdings zu unterschiedlichen Ergebnissen für die Voreintragungen im so konzipierten Datensatz und im Rückfalldatensatz führen. Ferner hätte die Konzeption eines solchen, der Strafverfolgungsstatistik entsprechenden, Datensatzes zur Konsequenz, dass die betrachteten Entscheidungen nicht mehr denen, die für die Auswertung der Rückfälligkeit zugrunde gelegt werden müssen, entsprechen würden. Bei der Rückfälligkeit (Kapitel O) soll jedoch sowohl auf die deliktsspezifischen Auswertungen (Kapitel 4) als auch auf die sanktionsspezifische Auswertungen unter Berücksichtigung der Voreintragungen (Kapitel 5) zurückgegriffen und Bezug genommen werden. Zum Zwecke der Vergleichbarkeit mit den unter Kapitel 6 folgenden Ergebnissen zur Rückfälligkeit wurde daher der soeben vorgestellte Entscheidungsdatensatz erstellt, der nur bei den stationären Strafen zu anderen Ergebnissen als der Rückfalldatensatz kommt. Der Datensatz enthält 1.086.303 Bezugsentscheidungen: 221.008 für Frauen und 865.295 für Männer.

\subsection{Gang der eigenen Untersuchung}

Aus der vorgestellten Datenbasis kann mit Hilfe einer Querschnittsanalyse aller im Jahr 2004 verurteilten Straftäterinnen und Straftäter ein Überblick über Umfang und Struktur der Frauenkriminalität und deren Sanktionierung gegeben werden. Dabei ist es möglich, detailliert die Sanktionierungspraxis der Gerichte nach Geschlecht, Alter, Nationalität, Delikt und Vorstrafenbelastung abzubilden.

Zunächst erfolgt eine Untersuchung der Struktur der Frauenkriminalität im Querschnitt. Dabei wird die Deliktsstruktur analysiert, wobei sich darin die Ergebnisse, die bereits in Kapitel 1 für das Jahr 2009 dargestellt wurden, widerspiegeln dürften. Es findet allerdings eine differenziertere Betrachtung statt. Als nächstes werden die neben dem Geschlecht im BZR erfassten demographischen Variablen Alter und Nationalität in die Untersuchung mit einbezogen.

Ebenfalls im Querschnitt wird in Kapitel 5 eine Untersuchung der Sanktionierung von Frauenkriminalität im Vergleich zur Männerkriminalität erfolgen. Dabei wird zwischen der Sanktionierung nach Jugend- und der nach Erwachsenenstrafrecht differenziert. Es ist anzunehmen, dass Frauen insgesamt milder bestraft werden als Männer: Der Anteil von weiblichen Tätern dürfte bei den weniger schwerwiegenden Sanktionen besonders hoch und im Umkehrschluss bei den schwerwiegenden Sanktionen besonders niedrig sein. Die Tendenz der milderen Sanktionierung dürfte auch bei differenzierter Betrachtung der einzelnen Sanktionen nach Dauer und Anzahl der Tagessätze noch erhalten bleiben. Dass diese 
Ergebnisse jedoch nichts mit einem „Frauenbonus“ zu tun haben, sondern vielmehr durch eine geringere Vorstrafenbelastung und eine andere Deliktsstruktur erklärbar sein dürften, wird herauszuarbeiten sein. Hierzu soll die Sanktionierung von Frauen und Männern im Rahmen einer multifaktoriellen Analyse miteinander verglichen werden. Es ist anzunehmen, dass ein etwaiger „Geschlechterbonus“ bei simultaner Berücksichtigung mehrerer Variablen nicht besteht. Ferner ist zu vermuten, dass bei heranwachsenden Täterinnen eher Verurteilungen nach Erwachsenstrafrecht erfolgen als bei männlichen Tätern.

Mit Hilfe einer Längsschnittanalyse der zugrunde liegenden Daten soll die Rückfallkriminalität der Frauen differenziert nach Deliktsgruppen dargestellt werden. Dabei wird auch die Rückfallgeschwindigkeit sowie die Art und Schwere des Rückfalls analysiert. Später sollen auch Voreintragungen in die Untersuchung miteinbezogen werden, sodass die gesamte kriminelle Karriere der Täterinnen untersucht werden kann.

Dass Frauen seltener rückfällig werden als Männer, ist bereits bekannt. ${ }^{435}$ Die Rückfallrate dürfte jedoch, wie zu untersuchen sein wird, auch von der Art des begangenen Delikts abhängen. Je höher die Zahl der Voreintragungen, desto höher dürfte die Rückfallquote sein. Darüber hinaus ist zu vermuten, dass die Täterinnen, die bisher häufig ein bestimmtes Delikt begangen haben, auch eher wegen dieses Delikts rückfällig werden, sodass mit einer gewissen Spezialisierung zu rechnen ist. Dies dürfte insbesondere für die Delikte gelten, die relativ häufig von Frauen begangen werden. Junge Täterinnen dürften häufiger rückfällig werden. Schließlich ist zu vermuten, dass Frauen im Falle eines Rückfalls zwar grundsätzlich mildere Sanktionen erhalten als Männer. Eine geschlechtervergleichende Analyse der Sanktionsart der Folgeeintragungen unter simultaner Berücksichtigung mehrerer Variablen dürfte jedoch, ebenso wie bei Analyse der Bezugssanktion, eine mildere Sanktionierung nicht mehr erkennen lassen.

\section{Einschränkungen}

Die Auswertung des umfangreichen BZR-Datenmaterials ist mit Einschränkungen verbunden. Wie bereits in Kapitel 1 diskutiert, können die BZR-Daten kein getreues Abbild der Kriminalitätswirklichkeit bieten, da das wirkliche Ausmaß von Kriminalität im schwer einschätzbaren Dunkelfeld verbleibt. Ferner sind Einschränkungen zu beachten, die sowohl auf die Datenbasis selbst als auch auf qualitative Einbußen zurückzuführen sind.

435 Vgl. Jeble/Heinz/Sutterer, Legalbewährung nach strafrechtlichen Sanktionen, 2003, S. 47;

Jeble/Albrecbt/Hohmann-Fricke/Tetal, Legalbewährung nach strafrechtlichen Sanktionen, 2010,

S. 49. 


\subsection{Nichtberücksichtigung strafprozessualer Verfahrenseinstellungen}

Im Gegensatz zu den Diversionsregelungen im Jugendstrafrecht ( $\$ \$$ 45, 47 JGG) sind Verfahrenseinstellungen nach dem Opportunitätsprinzip nach allgemeinem Strafprozessrecht (insbesondere $\$ \$ 153,153$ a StPO) - ob mit oder ohne Beteiligung des Gerichts, ob vor oder in der Hauptverhandlung - nicht erfasst. Dies führt zu einem Verlust derartiger Entscheidungen, insbesondere im Bereich der Bagatellkriminalität, der umso schwerer wiegt, als ein großer Anteil der Verfahren heutzutage auf informellem Wege erledigt wird.

Ferner wird dadurch die Vergleichbarkeit der nach JGG Sanktionierten einerseits und der nach allgemeinem Strafrecht Sanktionierten andererseits beeinträchtigt. ${ }^{436}$ Sowohl die verfahrensrechtlichen Einstellungen gem. $\$ \int$ 153, 153a StPO als auch die im Jugendstrafrecht einschlägigen Vorschriften der $\iint 45$, 47 JGG finden auf leichtere Fälle mit eher günstiger Prognose Anwendung. Folglich führt das Fehlen der Einstellungen gem. $\iint$ 153, 153a StPO bei den Bezugsentscheidung dazu, dass die Rückfallraten hinsichtlich der Sanktionen nach allgemeinem Strafrecht eher zu hoch und bei den Folgeentscheidungen eher zu niedrig ausgewiesen sind. 437 Allerdings würde auch die Nichtberücksichtigung der Entscheidungen nach $\iint 45,47 \mathrm{JGG}$ zu keiner befriedigenden Lösung führen, da die Einstellungspraxis im Jugendstrafrecht mit der im Erwachsenenstrafrecht nicht übereinstimmt. Daher wurden die Entscheidungen nach $\$ ₫ 45,47$ JGG grundsätzlich mitberücksichtigt und nur an einigen Stellen der Übersicht halber herausgerechnet.

\subsection{Meldemoral}

Darüber hinaus ist die Meldemoral der an das BZR meldenden Stellen problematisch. Zwar sind im BZR Warnfunktionen eingebaut, die gegenüber der fehlerhaft meldenden Stelle eine Art Mahnverfahren auslösen, letztlich fehlt es jedoch an einer effektiven Handlungsgrundlage, wenn die Informationen dennoch ausbleiben. ${ }^{438}$ So können beispielsweise Informationen über die Anzahl der Tagessätze, das Alter zum Tatzeitpunkt oder auch über das Geschlecht fehlen.439 Derartige Fälle konnten sowohl hier als auch in den Rückfalluntersuchungen für die Basisjahre 1994 und 2004 nur in der Gesamtbetrachtung berücksichtigt werden. Ferner ist teilweise, insbesondere bei kurzen vollstreckten Freiheitsstrafen, kein Vollstreckungsende mitgeteilt.

\footnotetext{
436 Jehle/Heinz/ Sutterer, Legalbewährung nach strafrechtlichen Sanktionen, 2003, S. 22 f.;

Jeble/Albrecht/Hohmann-Fricke/Tetal, Legalbewährung nach strafrechtlichen Sanktionen, 2010, S. 18 f.; Hein₹, in: ZJJ 2004, S. 35, 38.

${ }^{437}$ Heinr, in: ZJJ 2004, S. 35, 39.

438 Jeble/Heinz/Sutterer, Legalbewährung nach strafrechtlichen Sanktionen, 2003, S. 23.

439 Jeble/Heinz/Sutterer, Legalbewährung nach strafrechtlichen Sanktionen, 2003, S. 23.

Jeble/Albrecht/Hohmann-Fricke/Tetal, Legalbewährung nach strafrechtlichen Sanktionen, 2010, S. 19.
} 
Für die vorliegende Untersuchung mussten gerade die Fälle, in denen kein Geschlecht mitgeteilt wurde, unberücksichtigt bleiben. Dies waren jedoch nur 329 Personen, sodass es hierdurch nicht zu einem großen Datenverlust gekommen ist.

\subsection{Fehlerhafte Eintragungen}

Ferner treten zum Teil fehlerhafte oder unvollständige Eintragungen auf. So sind bereits in der ersten kommentierten Rückfallstatistik vereinzelt Fälle jugendlicher Probanden aufgefallen, die mit einer Sanktion des allgemeinen Strafrechts registriert wurden. ${ }^{440}$ Harrendorf wies zudem in seiner Untersuchung zur Rückfälligkeit von Gewalttätern darauf hin, dass es zu Fehleintragungen durch Schreibfehler gekommen sein dürfte. Dies konnte er für die $\iint 315$ c, 316 c StGB konkret belegen. ${ }^{441}$ Diese Probleme sind auch in dem dieser Untersuchung zugrunde liegenden Datensatz für das Bezugsjahr 2004 aufgetaucht. Offensichtlich fehlerhafte und nicht zuzuordnende Fälle mussten aussortiert werden. So sind beispielsweise 68 Fälle von \315c I Nr. a StGB enthalten. Damit könnten sowohl Fälle von \315c I Nr. 1a StGB als auch von $\int 315$ c I Nr. 2a StGB gemeint sein. Diese Fälle sind daher bei der deliktsspezifischen Betrachtung unberücksichtigt geblieben.

Ein weiteres Problem betrifft die Nichteintragung und Zuordnung der Vorschriften des Allgemeinen Teils des Strafrechts.

Mit der Textkennziffer (TKZ) 4422013 sollen zwar auch diese Vorschriften zum BZR gemeldet werden, jedoch ist davon auszugehen, dass dies in der Regel nicht konsequent geschieht. So hat Harrendorf diesbezüglich festgestellt, dass bei der Maßregel des $\int 63$ StGB, nur in etwa vier Fünftel der Fälle eine der beiden Vorschriften SS 20, 21 StGB eingetragen wurde, obwohl die Annahme einer Schuldunfähigkeit oder verminderten Schuldunfähigkeit Voraussetzung für die Verhängung dieser Maßregel ist. ${ }^{443}$

Aber auch wenn die Vorschriften des allgemeinen Teils eingetragen sind, so sind diese nicht immer richtig zuzuordnen. Die Meldung zum BZR sieht keine bestimmte Reihenfolge vor und das Hauptdelikt wird als Freitext auf dem Meldebogen eingetragen, ${ }^{444}$ sodass bei mehreren Straftatbeständen in einer Entscheidung eine Zuordnung kaum möglich ist. ${ }^{445}$ Es kann daher u.a. nicht geklärt werden, welche von mehreren gleichzeitig abgeurteilten Delikten in Mittäterschaft

\footnotetext{
440 Jeble/Hein₹/Sutterer, Legalbewährung nach strafrechtlichen Sanktionen, 2003, S. 24;

Jeble/Albrecht/Hohmann-Fricke/Tetal, Legalbewährung nach strafrechtlichen Sanktionen, 2010,

S. $19 \mathrm{f}$.

${ }^{441}$ Harrendorf, S. 129 f.

${ }^{442}$ Die abgesammelten Datensätze enthalten Textkennziffern (TKZ) entsprechend der Verwaltungsvorschriften zum BZR, die bestimmte Informationen eindeutig kodieren, vgl. hierzu ausführlich Harrendorf, S. 105.

${ }^{443}$ Vgl. Harrendorf, S. 130.

${ }^{444}$ Vgl. den Musterauszug zum BZR bei Ublig, 1985, S. 111; auch abgedruckt bei Harrendorf, 2007, S. 106.

${ }^{445}$ Harrendorf, S. 130; Weigelt, S. 80.
} 
begangen wurden oder bezüglich welchen Delikts eine Teilnahme vorlag. Auch hinsichtlich der Konkurrenzen $\left(\$ \int 52,53\right.$ StGB) kann häufig nicht sicher geklärt werden, welche Delikte in Ideal- und welche in Realkonkurrenz zueinander stehen, da die Vorschriften im Datensatz zum Teil alleine, zum Teil aber auch zusammen mit anderen Vorschriften auftauchen. Eine Analyse der eingetragenen Vorschriften des allgemeinen Teils konnte daher nicht erfolgen. ${ }^{446}$

Schließlich ist zu berücksichtigen, dass im Rückfalldatensatz nur rückfallfähige Personen, d.h. diejenigen die im Rückfallzeitraum überhaupt rückfällig und im BZR mit Folgeentscheidungen eingetragen werden können, enthalten sein sollten. Als nicht rückfallfähig in diesem Sinne sind aber Personen zu betrachten, die im Untersuchungszeitraum verstorben, ausgewandert oder abgeschoben worden sind. Das BZR enthält diese Informationen nur teilweise, sodass es zu einer Überschätzung des Anteils der Nichtrückfälligen, insbesondere bei den Nichtdeutschen, kommen kann. ${ }^{447}$

\subsection{Tilgungs- und Löschvorschriften}

Ein Problem besonderer Art können die Tilgungs- und Löschvorschriften des BZRG darstellen. Nach dem Verstreichen einer bestimmten Tilgungsfrist, welche abhängig ist von der Schwere der verhängten Sanktion, werden die registrierten Straftaten tilgungsreif und sodann, ein Jahr nach Eintritt der Tilgungsreife, aus dem Register auch physikalisch gelöscht (vgl. $\iint 45$ ff. BZRG). Die kürzeste Tilgungsfrist beträgt fünf, die längste fünfzehn Jahre. Lebenslange Freiheitsstrafen sowie bestimmte stationäre Maßregeln unterliegen keiner Tilgung. Im Hinblick auf die kürzeste, fünfjährige Tilgungsfrist, wurde in der ersten Rückfalluntersuchung der Rückfallzeitraum auf vier Jahre festgelegt, um somit Tilgungsverluste der Bezugsentscheidung für Erwachsene zu minimieren. ${ }^{448}$ Dies stellte sich jedoch aufgrund der Tilgungsvorschrift des $₫ 63$ BZRG als problematisch heraus, wonach alle Eintragungen im Erziehungsregister beim Erreichen des 24. Lebensjahres entfernt werden, wenn zwischenzeitlich keine Eintragung im BZR mit einer Verurteilung zu Freiheits- oder Jugendstrafe, Strafarrest oder einer freiheitsentziehenden Maßregel der Besserung und Sicherung erfolgt ist. Dies betrifft alle Erziehungsmaßregeln ( $\int \mathbb{S} 9$ ff. JGG), Zuchtmittel (\$S 13 ff. JGG), das Absehen von Verfolgung und die Verfahrenseinstellung nach $\int \$ 45,47$ JGG sowie die seltenen

\footnotetext{
${ }^{446}$ Hiervon wurde eine Ausnahme gemacht, vgl. Kap. 5,2.2.2: Da dort nur 6 Fälle betrachtet wurden, konnte die ausführliche, im BZR dokumentierte, Deliktsbeschreibung, gelesen werden. Zuordnungsprobleme bestanden nicht.

447 Jeble/Heinz/Sutterer, Legalbewährung nach strafrechtlichen Sanktionen, 2003, S. 24; Jeble/Albrecbt/Hobmann-Fricke/Tetal, Legalbewährung nach strafrechtlichen Sanktionen, 2010, S. 19 f; Heinz in: ZJJ 2004, S. 35, 40.

448 Jeble/Hein₹/Sutterer, Legalbewährung nach strafrechtlichen Sanktionen, 2003, S. 25; Jeble/Albrecht/Hobmann-Fricke/Tetal, Legalbewährung nach strafrechtlichen Sanktionen, 2010, S. $19 \mathrm{f}$.
} 
Fälle des $₫ 30$ JGG, nicht jedoch die Jugendstrafe ( $\$ 17$ JGG ggf. i.V.m. $₫ 21$ JGG) und den Schuldspruch (\$27 JGG), die gem. \4 BZRG ins BZR aufzunehmen sind. Durch diese Tilgungsvorschrift gingen der Rückfalluntersuchung für das Basisjahr 1994 insbesondere all diejenigen nichtrückfälligen 20-jährigen, die nur Eintragungen im Erziehungsregister aufwiesen, verloren. ${ }^{449}$

Daher wurde der Rückfallzeitraum für die Legalbewährungsstudie für das Bezugsjahr 2004 auf drei Jahre verkürzt. ${ }^{450}$

Tabelle 3.1: Entfernungs- und endgültiger Löschzeitpunkt für verschiedene Geburtsjahrgänge

\begin{tabular}{|c|c|c|c|}
\hline & & \multicolumn{2}{|c|}{$\begin{array}{c}\text { nach JGG Sanktionierte; } \\
\text { Geburtsjahrgang }\end{array}$} \\
\hline & & 1982 & 1983 \\
\hline \multirow{6}{*}{ 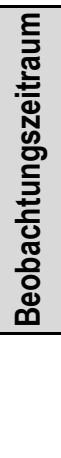 } & 2004 & Alter $=22$ & Alter $=21$ \\
\hline & 2005 & Alter $=23$ & Alter $=22$ \\
\hline & 2006 & $\begin{array}{l}\text { Alter }=24 \\
\text { Entfernung }\end{array}$ & Alter $=23$ \\
\hline & 2007 & $\begin{array}{l}\text { Alter }=25 \\
\text { Löschung }\end{array}$ & $\begin{array}{l}\text { Alter }=24 \\
\text { Entfernung }\end{array}$ \\
\hline & 2008 & & $\begin{array}{l}\text { Alter }=25 \\
\text { Löschung }\end{array}$ \\
\hline & 2009 & & \\
\hline
\end{tabular}

Datenabsammlung

April 2008

Quelle: Jehle/Albrecht/Hohmann-Fricke/Tetal, Legalbewährung nach strafrechtlichen Sanktionen, 2010, Tab. A 2.2.1, S. 24.

Wie Tabelle 3.1 zeigt, sind nunmehr, durch die Verkürzung des Rückfallzeitraums, allenfalls für die Personen die im Jahr 1982 geboren sind, Tilgungsverluste zu erwarten. Da gem. \ 105 Abs. 1 S. 1 JGG das Alter des Täters zum Tatzeitpunkt ausschlaggebend für die Anwendung von JGG oder StGB ist, können für diese Personen noch erziehungsregisterpflichtige Entscheidungen eingetragen werden. Gem. \63 StGB tritt für diese Fälle 2006 die Entfernung aus dem Register und 2007 die Löschung ein (vgl. Tabelle 3.1).451

Nicht erfasst werden können jedoch die Verwarnung mit Strafvorbehalt gem. \59 StGB sowie die Aussetzung der Verhängung der Jugendstrafe gem. \ 27

449 Jeble/Heinz/ Sutterer, Legalbewährung nach strafrechtlichen Sanktionen, 2003, S. 25;

Jeble/Albrecht/Hohmann-Fricke/Tetal, Legalbewährung nach strafrechtlichen Sanktionen, 2010, S. $19 \mathrm{f}$.

$450 \mathrm{Jeble} /$ Albrecbt/Hohmann-Fricke/Tetal, Legalbewährung nach strafrechtlichen Sanktionen, 2010, S. $23 \mathrm{f}$.

451 Näher dazu: Jehle/Albrecbt/Hobmann-Fricke/Tetal, Legalbewährung nach strafrechtlichen Sanktionen, 2010, S. 24. 
JGG. Dies liegt im Fall des $\int 59$ StGB daran, dass die Eintragung gem. \12 II BZRG sofort entfernt wird, wenn das Gericht feststellt, dass es bei der Verwarnung sein Bewenden hat. Im Fall des $₫ 27$ JGG kommt es im Erfolgsfall zu einer Tilgung des Schuldspruchs ( $\$ 30$ II JGG) und auch hier wird die Eintragung gem. $\int 13$ II S. 2 BZRG sofort entfernt. ${ }^{452}$

\subsection{Gesetzesänderungen und zeitliche Rahmenbedingungen}

Beachtet werden muss, dass das Datenmaterial aus dem Bezugsjahr 2004 stammt und dementsprechend auch auf der damaligen Gesetzeslage beruht. Da auch die Voreintragungen einer Person Berücksichtigung finden, können selbst lange zurückliegende Gesetzesfassungen Bedeutung haben.

Darüber hinaus ist eine Veränderung der zeitlichen Rahmenbedingungen zu beachten. Die Annahme einer allgemeinen Gültigkeit der ermittelten Ergebnisse ist nur möglich, wenn man unterstellt, die gesellschaftlichen Verhältnisse seien über die Zeit konstant geblieben. 453

\subsection{Begrenzung auf Geschlecht, Alter und Nationalität}

Besonders bedauerlich ist, dass die Daten keinerlei Informationen zur Sozialisation der Probanden enthalten. Über die zur Verfügung stehenden soziodemographischen Daten Geschlecht, Alter und Nationalität hinaus, kann daher keine Aussage über die Verurteilten getroffen werden.

\subsection{Namensänderungen}

Schließlich ist zu vermuten, dass insbesondere einige Frauen im Falle einer Eheschließung den Nachnamen des Ehepartners annehmen, und dass es durch die Namensänderung zu Zuordnungsproblemen im Rückfalldatensatz kommt. Sollte also eine Frau im Risikozeitraum rückfällig werden und erfolgte in dieser Zeit ein Namenswechsel, kann nicht ausgeschlossen werden, dass diese Tat nicht als Rückfall, sondern vielmehr als erste Tat für die Täterin mit dem neuen Nachnamen registriert wurde und es dadurch zu einer leichten Reduzierung der Rückfälle kommt.

452 Jehle/Hein₹/Sutterer, Legalbewährung nach strafrechtlichen Sanktionen, 2003, S. 25; Weigelt, S. 78.

${ }^{453}$ Harrendorf, S. 126; Weigelt, S. 81. 


\section{Kapitel 4: Frauenkriminalität im Querschnitt}

Zwischen der Straffälligkeit von Frauen und Männern besteht nicht nur eine große zahlenmäßige Differenz, sondern auch ein beachtenswerter qualitativer Unterschied. Kapitel 1 hat bereits einen ersten groben Überblick geboten. Die Tatsache, dass Frauen weitaus weniger und zudem weniger schwerwiegende Delikte begehen als Männer, lässt sich für die Ebene der Tatverdächtigen, Verurteilten und Inhaftierten nachweisen und für das Dunkelfeld vermuten. ${ }^{454}$ Aber ist deshalb bereits der Feststellung Ritters: „Das Weib ist gut; der Mann allein hat das Böse zu überwinden." 455 zuzustimmen? Die vorliegende Arbeit konzentriert sich auf die Ebene der Verurteilten und kann mit den zugrundeliegenden Daten des BZR einen detaillierten Überblick über die von Frauen im Bezugsjahr 2004 begangene Kriminalität im Querschnitt geben. Zwar können auch aus der StVS Informationen über die in diesem Kapitel im Fokus stehenden Variablen Geschlecht, Alter, Delikt und Nationalität der Verurteilten entnommen werden. Allerdings stößt die StVS aufgrund ihrer Konzeption an gewisse Grenzen: So liegen für das vorliegend untersuchte Bezugsjahr 2004 keine Daten für Gesamtdeutschland, sondern nur für die alten Bundesländer und Gesamtberlin vor. ${ }^{456}$ Darüber hinaus lässt der feste Tabel-

\footnotetext{
454 Vgl. hierzu ausführlich Kap. 1.

455 Ritter, S. 481.

456 Seit 2007 weist die StVS die Zahlen für Gesamtdeutschland aus.
} 
lenanhang keine differenzierteren Analysen zu. ${ }^{457}$ Letztlich wird durch die Darstellung des Umfangs und der Struktur von Frauenkriminalität mit den BZR-Daten auch Vergleichbarkeit zu den Kapiteln 5 und 6 hergestellt, da auf den folgenden deliktsspezifischen Auswertungen aufgebaut werden kann. ${ }^{458}$

Für die Untersuchung wurde auf Grundlage der Daten des BZR ein Entscheidungsdatensatz, konzipiert. Dieser zählt für jede Person die jeweils zeitlich erste rechtskräftig gewordene Entscheidung im Bezugsjahr 2004.459 Der verwendete Datensatz erfasst für jede Bezugsentscheidung bis zu fünf Straftaten, wobei die abstrakt schwersten ${ }^{460}$ der verwirklichten Straftaten gezählt werden. Bei allen ambulanten und stationären Entscheidungen wurde auf den Entscheidungszeitpunkt abgestellt. Das Erfassungskonzept ähnelt mithin dem in der StVS mit dem Unterschied, dass nicht jede Entscheidung, die im Bezugsjahr für eine Person ergangen ist, sondern nur die jeweils zeitlich erste gezählt wird. ${ }^{461}$ Insgesamt beinhaltet der Entscheidungsdatensatz 1.086.303 Bezugsentscheidungen.

Anhand der den Bezugsentscheidungen zugrundeliegenden Straftaten wird in diesem Kapitel anfangs auf die Deliktstruktur von Frauen im Vergleich zu den Männern eingegangen. Ferner werden die Delikte kategorisiert, um ihre Handhabung für die vorliegende Untersuchung, insbesondere für die noch folgenden Auswertungen zur Sanktionierungspraxis (Kapitel 5) und Rückfälligkeit (Kapitel O), zu vereinfachen. Sodann werden die in Deliktsgruppen zusammengefassten Straftaten deliktsgruppenspezifisch ausgewertet. Um ein vertieftes Bild zu gewinnen, werden die gebildeten Deliktsgruppen in einigen Bereichen untergliedert und noch differenzierter betrachtet.

In einem zweiten Schritt werden die weiteren zur Verfügung stehenden soziodemographischen Daten zum Alter und zur Nationalität analysiert.

\section{Deliktsstruktur}

\section{1 Überblick}

Von den insgesamt 1.086.303 Bezugsentscheidungen sind 221.008 gegenüber Frauen ergangen. Daraus ergibt sich ein prozentualer Anteil der Frauen an den Verurteilten im Bezugsjahr 2004 von $20 \%$. Ob außer dieser Unterrepräsentation die Kriminalität von Frauen spezifische Züge aufweist, wird im Folgenden untersucht.

\footnotetext{
${ }^{457}$ Zwar stehen bei den Forschungsdatenzentren der Länder die unaufbereiteten Rohdaten für weitergehende Auswertungen zur Verfügung, vgl. www.forschungsdatenzentrum.de, jedoch besteht weiterhin die Grenze der kategorisierten Datenerhebung.

${ }^{458}$ Vgl. auch Kap. 3, 2.3.

${ }^{459} \mathrm{Vgl}$. zum hier verwendeten Entscheidungsdatensatz ausführlich unter Kap. 3, 2.2.

${ }^{460}$ Die Einteilung wurde nach dem Strafrahmen vorgenommen.

461 Vgl. hierzu auch ausführlich unter Kap. 3, 2.2.
} 


\section{Schaubild 4.1: Deliketsstruktur von Frauen nach Deliktsgruppe*}

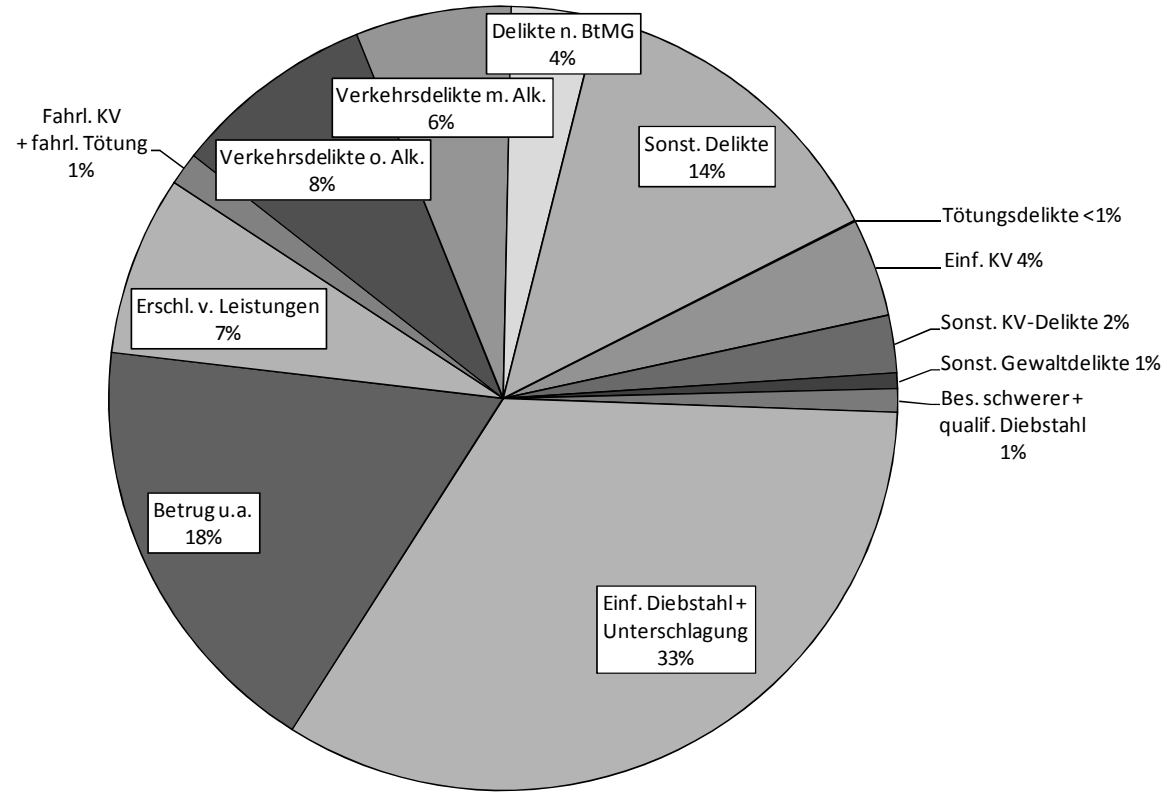

* Absolutrablen siebe Tab. 4.1 a im Anhang

Schaubild 4.1 zeigt die Verteilung aller registrierten Straftaten für Frauen nach Deliktsgruppen. ${ }^{462}$ Es wird deutlich, dass auch die der Bezugsentscheidung zugrunde liegenden Delikte das bereits in Kapitel 1 gewonnene Bild über die Deliktsstruktur von Frauen bestätigen.

Frauen haben im Bezugsjahr am häufigsten den einfachen Diebstahl und die Unterschlagung mit zusammen $33 \%$ begangen, gefolgt von der Gruppe der Betrugs-, Untreue- und Urkundendelikte mit $18 \%$ sowie den Verkehrsdelikten ohne Alkoholeinfluss mit $8 \%$ und dem Erschleichen von Leistungen mit $7 \%$. Die Verkehrsdelikte unter Alkoholeinfluss machen immerhin noch einen Anteil von $6 \%$ aus, gefolgt von den Delikten nach dem BtMG mit $4 \%$. Lediglich in jeweils $1 \%$ der Fälle liegt eine fahrlässige Tötung oder Körperverletzung bzw. ein besonders schwerer und qualifizierter Diebstahl vor. Betrachtet man die den Gewaltdelikten zuzuordnenden Delikte insgesamt (Tötungsdelikte, einfache Körperverletzung, sonstige Körperverletzungs- und sonstige Gewaltdelikte $\left.{ }^{463}\right)$, so stellt man fest, dass diese zusammen einen Anteil von $7 \%$ an der Gesamtkriminalität im Bezugsjahr 2004 ausmachen, wobei von den insgesamt $7 \%$ allein $6 \%$ auf die Körperverletzungsdelikte entfallen. Zudem existiert noch eine, mit $14 \%$ recht große, Kategorie für die sonstigen Delikte. Bei differenzierter Betrachtung weisen

462 Zur Einteilung der Deliktsgruppen siehe sogleich unter Kap. 4, 1.2-1.4.

$463 \mathrm{Zu}$ den Gründen dieser Gruppierung siehe sogleich unter Kap. 4, 1.2. 
die in dieser Kategorie zusammengefassten Delikte jedoch jeweils einen prozentualen Anteil von unter $5 \%$ auf, sodass eine Zusammenfassung in einer Kategorie „Sonstige Delikte“ hier sinnvoll erscheint.

Wenn Frauen verurteilt werden, dann also zumeist wegen leichterer Eigentums- oder Vermögenskriminalität. Dies wird noch einmal besonders deutlich, wenn man die grobe Deliktsstruktur von Frauen und Männern im Vergleich betrachtet (vgl. Schaubilder 4.2 und 4.3).

\section{Schaubild 4.2: Grobe Deliktsstruktur von Franen*}

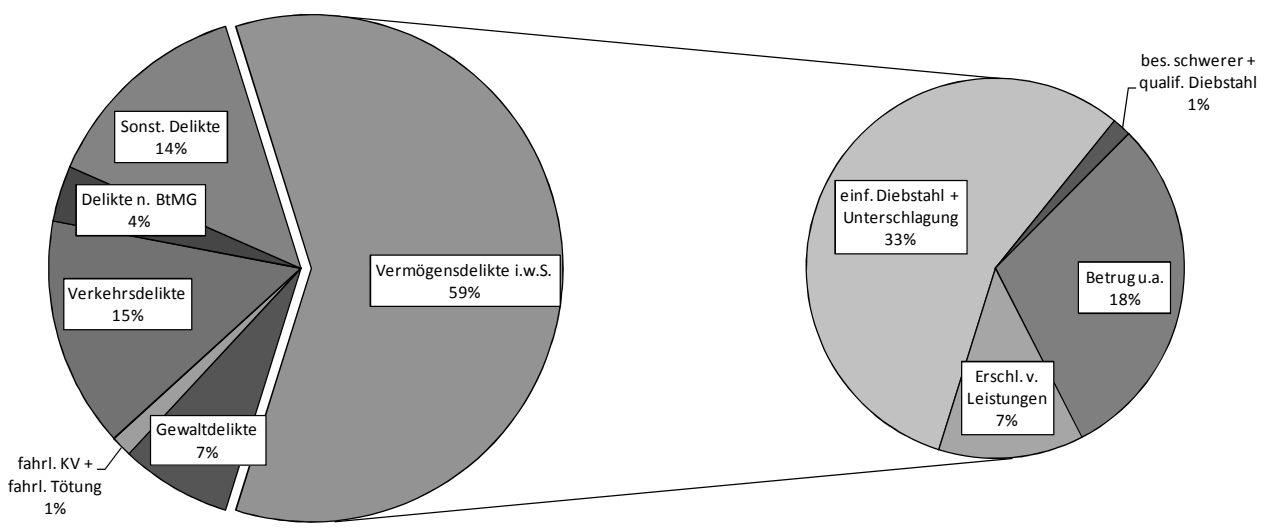

* Absolutzablen siehe Tab. 4.1 a im Anhang

\section{Schaubild 4.3: Grobe Deliktsstruktur von Männern*}

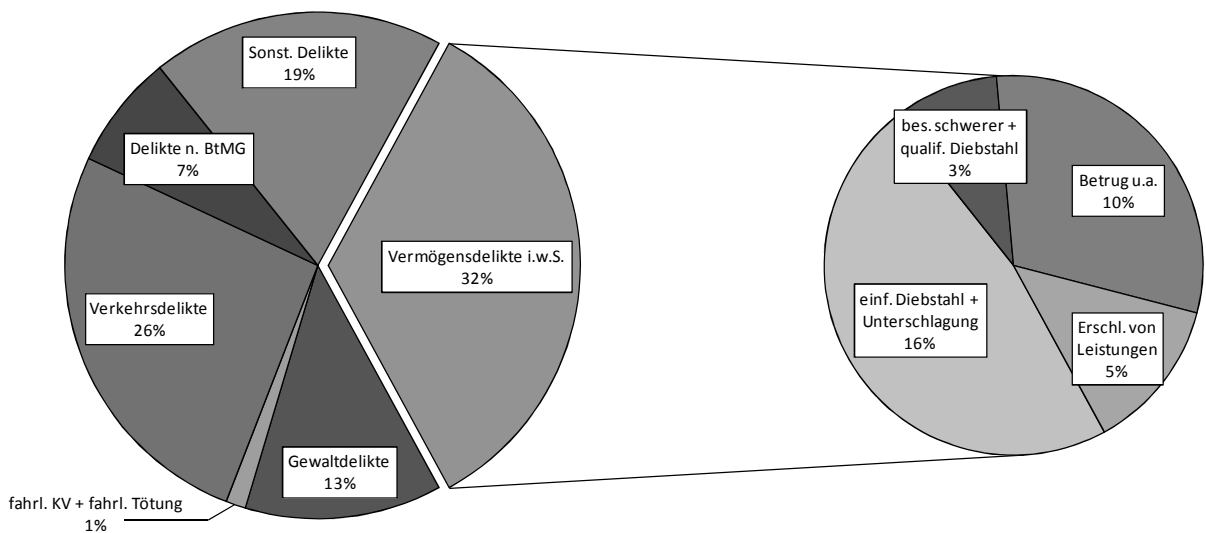

* Absolutzablen siehe Tab. 4.1 a im Anhang

Die Schaubilder 4.2 und 4.3 bieten einen groben Überblick über die Struktur der im Bezugsjahr begangenen Delikte für Frauen und Männer, die der Bezugsentscheidung zugrunde lagen. Die Eigentums-, Vermögens- und Urkundendelikte machen 
bei den Frauen über die Hälfte der gesamten Deliktsstruktur aus, während diese bei den Männern nur 1/3 ausmachen. Bei den Männern sind dafür die anderen Deliktsbereiche deutlicher ausgeprägt als bei den Frauen. So hat die Gewaltkriminalität einen Anteil von $13 \%$ an der gesamten Deliktsstruktur; bei den Frauen sind dies nur $7 \%$. Auch bei den Delikten nach dem BtMG weisen die Männer mit $7 \%$ gegenüber $4 \%$ einen fast doppelt so hohen Anteil auf. Die Verkehrsdelikte übertreffen mit $26 \%$ ebenfalls den Anteil, der für die Frauen innerhalb ihrer Deliktsstruktur für diese Gruppe zu verzeichnen ist (15\%). Die Gruppe der Eigentums-, Vermögens- und Urkundendelikte wird bei den Männern nicht so stark vom einfachen Diebstahl dominiert wie bei den Frauen.

\section{Schaubild 4.4: Anteil von Frauen und Männern an Deliktsgruppen*}

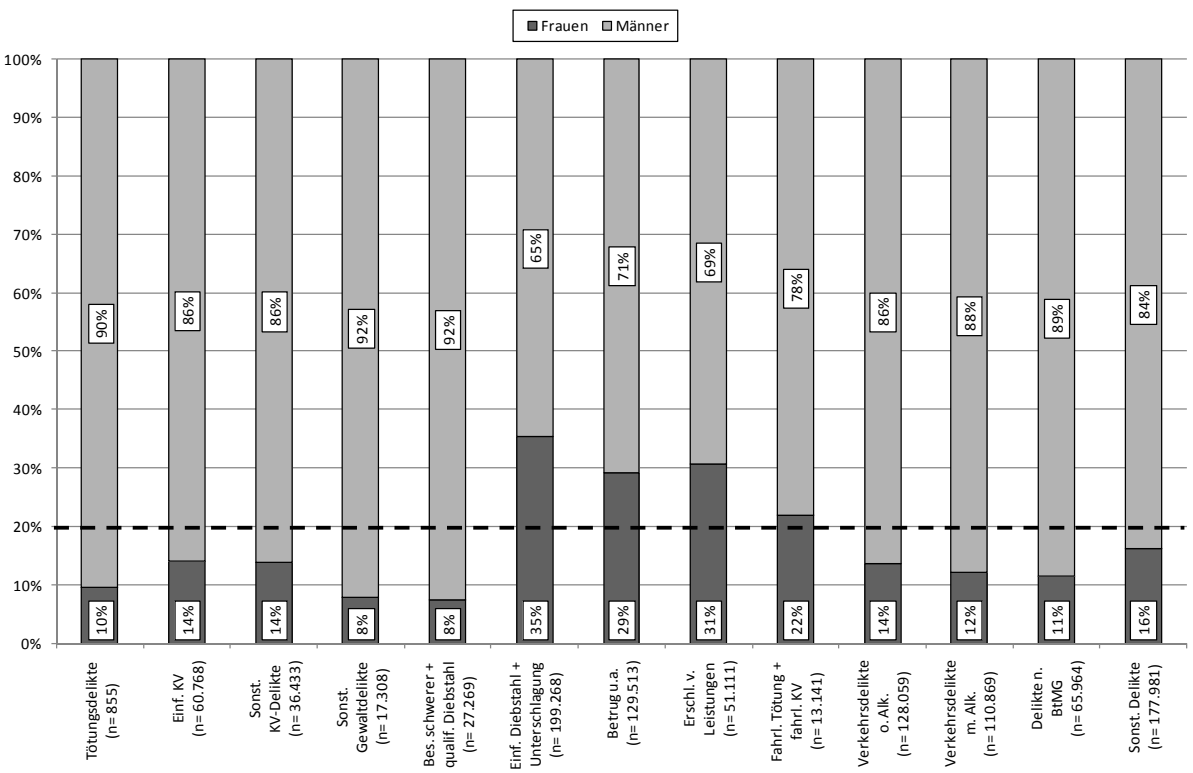

* Absolutrablen siebe Tab. 4.1 a im Anbang

Schaubild 4.4 zeigt die Beteiligung von Frauen und Männern an den ausgewählten Deliktskategorien (s. Schaubild 4.1). Der knapp 20\%ige Anteil der Frauen an der Kriminalität insgesamt ist mittels der gestrichelten Linie hervorgehoben worden. Es wird deutlich, dass $35 \%$ aller Diebstähle und Unterschlagungen von Frauen begangen wurden. Einen relativ großen, über ihrem Durchschnittswert liegenden Anteil haben Frauen außerdem mit $31 \%$ am Erschleichen von Leistungen, mit $29 \%$ an den Betrugs-, Untreue- und Urkundendelikten und mit $22 \%$ an der fahrlässigen Tötung bzw. Körperverletzung. 
Deutlich unter dem durchschnittlichen Frauenanteil an der Kriminalität insgesamt liegen mit jeweils $14 \%$ die Körperverletzungsdelikte und die Verkehrsdelikte ohne Alkoholeinfluss sowie mit einem jeweiligen Anteil zwischen 10-12 \% die Tötungsdelikte, Delikte nach dem BtMG und die Verkehrsdelikte unter Alkoholeinfluss (vgl. Schaubild 4.4).

Bei lediglich $8 \%$ der besonders schweren und qualifizierten Diebstähle sowie der sonstigen Gewaltdelikte waren die Täter weiblich. Dies war zu erwarten, da Frauen, wie bereits ausgeführt, in der Regel sehr viel seltener schwerwiegende Delikte und dabei vor allen Dingen seltener Delikte, die ein hohes Maß an offener Aggressivität erfordern, begehen.

Ein genauerer Blick auf einzelne Delikte mit vergleichsweise starker Frauenbeteiligung kann Aufschluss darüber geben, ob sog. „frauentypische“ Delikte, also solche, die Frauen häufiger begehen als Männern, existieren. ${ }^{464}$

\section{Schaubild 4.5: Anteil von Frauen und Männern an ausgewäblten Deliketen ${ }^{465}$}

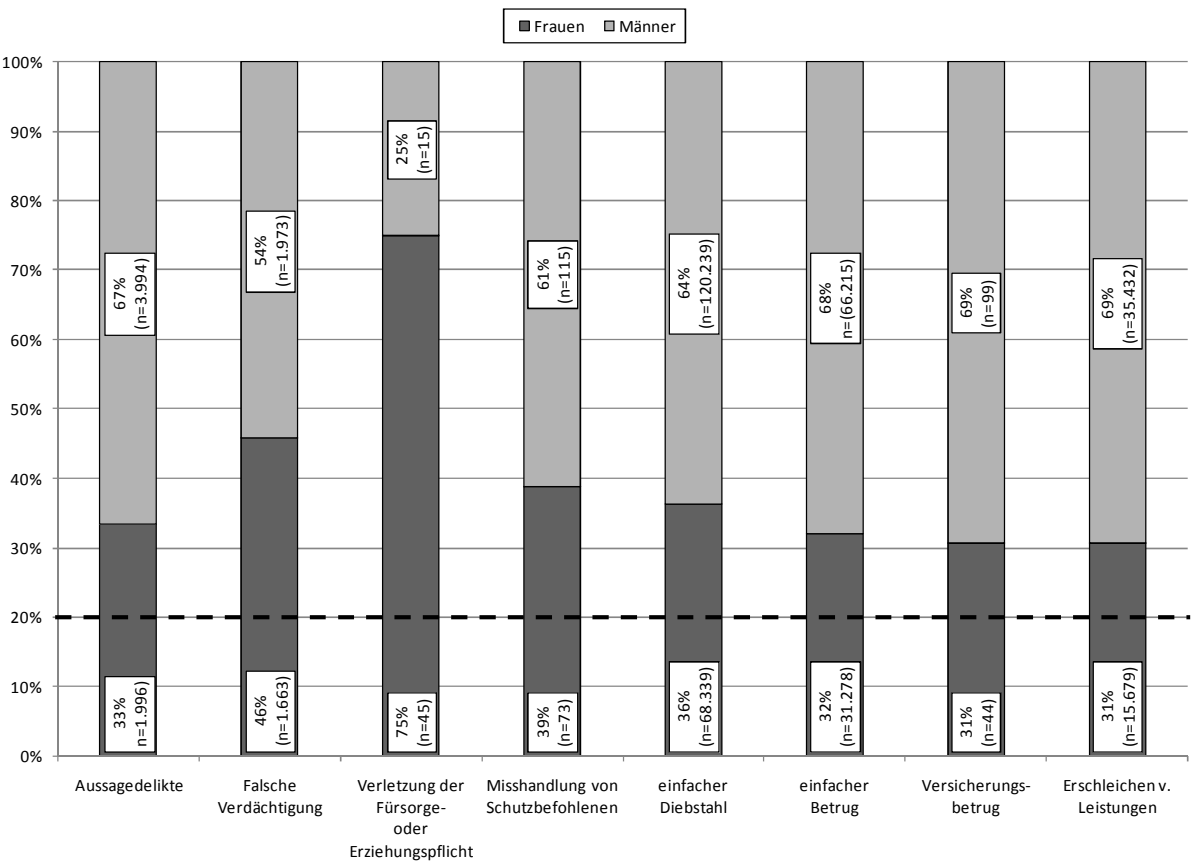

464 Vgl. hierzu Ausführungen unter Kap. 1, 2.4.

465 Nicht mit aufgenommen wurde hier der Schwangerschaftsabbruch gem. \$S 218, 218b StGB. Hier konnten im Bezugsjahr nur 2 Fälle registriert werden, wobei der Täter in beiden Fällen männlich war. Die Zahlen sind daher zu niedrig, um sie zu interpretieren. 
Schaubild 4.5 zeigt wieder den jeweiligen Anteil von Frauen und Männern an einem Delikt, jedoch handelt es sich hier um Delikte, bei denen der Frauenanteil sich dem der Männer annähert. ${ }^{466}$ Hier liegen zum Teil sehr geringe Personenzahlen zugrunde, die daher an dieser Stelle im Schaubild mit genannt sind (vgl. Schaubild 4.5 sowie auch Tab. 4.1d im Anhang). Der durchschnittliche Anteil der weiblichen Straffälligen wurde erneut mit einer Linie kenntlich gemacht.

Auf den ersten Blick zeigt sich, dass auch im Bezugsjahr 2004 die Verletzung der Fürsorge- und Erziehungspflicht gem. \171 StGB das einzige Delikt darstellt, bei dem der Anteil der Frauen den der Männer deutlich überwiegt. Dies bestätigt mithin die Ergebnisse nach den Daten der PKS für das Berichtsjahr 2009.467 Zu berücksichtigen ist aber die sehr niedrige Personenzahl: Nur 45 Frauen und 15 Männer wurden wegen Verletzung der Fürsorge- oder Erziehungspflicht verurteilt. Ferner dürfte eine Erklärung darin zu sehen sein, dass Frauen in erster Linie mit der konkreten Umsetzung von Fürsorge- und Erziehungspflichten betraut sind und Männer daher weniger Gelegenheiten zur Tatbegehung haben dürften. ${ }^{468}$

Auch der Frauenanteil an der Misshandlung von Schutzbefohlenen, der im Übrigen vermutlich oftmals mit der Verletzung der Fürsorge- und Erziehungspflicht gem. \171 StGB einhergehen wird, ${ }^{469}$ ist mit $39 \%$ verhältnismäßig hoch. Der erhöhte Frauenanteil dürfte hier, ähnlich wie bei Verletzung der Fürsorgeoder Erziehungspflicht, mit der großen Einwirkungsmöglichkeit der Frauen auf ihre Kinder zu tun haben. Zu beachten sind allerdings wieder die geringen absoluten Zahlen. Gerade im Bereich der Misshandlung von Schutzbefohlenen ist jedoch, wie im übrigen ebenfalls bei der Verletzung der Fürsorge- und Erziehungspflicht, aufgrund der hilflosen Lage der Opfer und des Abhängigkeitsverhältnisses zwischen Täter und Opfer von einer hohen Dunkelziffer auszugehen. ${ }^{470}$ Ferner führt die Tatsache, dass sich die Misshandlungen zumeist im sozialen Nahraum ${ }^{471}$ ereignen, dazu, dass die Außenwelt die Tat häufig nicht wahrnimmt oder als private Angelegenheit betrachtet. Als Anzeigeerstatter kommen ferner zumeist kenntniserlangende Personen aus dem privaten Umfeld in Betracht, denen es allerdings,

\footnotetext{
466 Hier wurden Delikte gewählt, bei denen der Anteil der Frauen über $30 \%$ beträgt.

467 Vgl. hierzu Ausführungen unter Kap. 1, 2.4.

468 Vgl. hierzu Ausführungen unter Kap. 1, 2.4.

${ }^{469}$ Fischer, $\$ 225, \mathrm{Rdn} .21, \rrbracket 171, \mathrm{Rdn} .11$.

470 Jehle, Schutz kindlicher Opfer im Strafverfahren, in: Kindesmisshandlung und -vernachlässigung, Jahrg. 11, Heft 2/2008, S. 20-40; Vgl. eine Zusammenstellung einiger Studien zum Dunkelfeld bei der Misshandlung von Schutzbefohlenen: BMI/ BMJ (Hrsg.), PSB I, S. 494 ff.

${ }^{471}$ Vgl. hierzu beispielsweise Jeble, Schutz kindlicher Opfer im Strafverfahren, in: Kindesmisshandlung und -vernachlässigung, Jahrg. 11, Heft 2/2008, S. 20-40: Jeble stellte einen Zusammenhang zwischen dem Rückgang der Körperverletzungen mit kindlichen Opfern unter 6 Jahren im Zeitraum 2005-2007 und dem gleichzeitigen Anstieg der Misshandlungen von Schutzbefohlenen fest. Da Kinder unter 6 Jahren sich fast ausschließlich im privaten Umfeld bewegen, liegt die Vermutung nahe, dass die Misshandlungen zumeist im sozialen Nahraum erfolgen.
} 
z.B. wegen eines verwandtschaftlichen oder freundschaftlichen Verhältnisses zum Täter, schwer fällt, ein Strafverfahren in Gang zu setzen. ${ }^{472}$

Darüber hinaus zeigt sich, dass die falsche Verdächtigung fast genauso häufig von Frauen begangen wird wie von Männern, nämlich in $46 \%$ der Fälle.

Der Anteil der weiblichen Verurteilten am einfachen Betrug ${ }^{473}$ liegt mit $32 \%$ deutlich unter dem der Männer, aber ebenfalls deutlich über dem Frauenanteil an der Gesamtkriminalität. Dies schließt zwar nicht aus, dass bestimmte Betrugsformen, z.B. der Betrug zum Nachteil von Sozialversicherungen ${ }^{474}$, häufiger von Frauen begangen werden. Eine solche Differenzierung ist aber mit den vorliegenden Daten nicht möglich. Allerdings können Betrugsformen, die als eigener Tatbestand formuliert sind, gesondert betrachtet werden: Schaubild 4.5 zeigt, dass ebenfalls der Versicherungsbetrug gem. \265 StGB mit $31 \%$ relativ häufig vorkommt. Das betrugsähnliche Erschleichen von Leistungen gem. \265a StGB 475 wird ebenfalls in $31 \%$ der Fälle von Frauen begangen.

Zudem ist der Frauenanteil an den Aussagedelikten gem. $\$ \int$ 153, 154, 156, 159, 160, 163 StGB mit $33 \%$ relativ hoch, wobei diese Gruppe stark von der uneidlichen Falschaussage gem. $\int 153$ StGB dominiert wird. ${ }^{476}$ Die wenigen Studien ${ }^{477}$, die sich mit der weiblichen Aussagekriminalität beschäftigen, kommen zu dem Ergebnis, dass ein Schwerpunkt bei Falschangaben im Rahmen von gerichtlichen Ehescheidungs- und Unterhaltsprozessen liegt. ${ }^{478}$ Danach sollen Frauen häufig aus Sorge um das Wohl des Kindes ${ }^{479}$ oder auch aus anderen uneigennützigen Moti$v^{2} n^{480}$ falsch aussagen. Anzumerken ist jedoch, dass die Aussagekraft dieser Studien fraglich ist, da sie durchweg relativ alt sind und ihnen wenig Untersuchungsmaterial zugrunde lag. 481

Schließlich hat der einfache Diebstah ${ }^{482}$ nicht nur, wie bereits festgestellt, einen hohen Anteil an den von Frauen begangenen Delikten (vgl. Schaubild 4.1 und 4.2), sondern Schaubild 4.5 macht deutlich, dass der Anteil von Täterinnen bei diesem Delikt zudem mit $36 \%$ verhältnismäßig stark ins Gewicht fällt.

\footnotetext{
472 Trube-Becker, S. 15; Joest, S. 38.

473 Vgl. zu den Begehungsformen ausführlich unter Kap. 5, 2.6.2.

474 Vgl. hierzu Ausführungen unter Kap. 1, 2.4.

475 Vgl. hierzu auch Ausführungen unter Kap. 4, 1.3.1.4.

4761.394 Fällen von insgesamt 1.996 registrierten Aussagedelikten lag eine Verurteilung wegen \153 StGB zugrunde.

477 Wille/Schwary, in: MSchrKrim 1966, S. 263-273; Mumm, Zum Wesen der Aussagedelikte; Cremer, Untersuchungen zur Kriminalität der Frau.

478 Wille/Schwary, in: MSchrKrim 1966, S. 263, 265; Mumm, Zum Wesen der Aussagedelikte, S. 17; Cremer, S. 40.

${ }^{479}$ Mumm, Zum Wesen der Aussagedelikte, S. 51.

480 Wille/Schwary, in: MSchrKrim 1966, S. 263, 264.

481 So auch Cremer, S. 509 und Lindner, S. 256.

$482 \mathrm{Vgl}$. zu den Begehungsformen ausführlich unter Kap. 5, 2.6.1.
} 


\subsection{Gewaltdelikte}

\subsubsection{Gruppierung der Gewaltdelikte}

Der Begriff der Gewalt umfasst ein weites Spektrum an Bedeutungen. So hat sich beispielsweise der sog. strukturelle Gewaltbegriff herausgebildet, wonach bereits die vermeidbare Beeinträchtigung grundlegender menschlicher Bedürfnisse als Gewalt eingestuft wird. ${ }^{483}$ Der Terminus erfährt, je nach dem aus welcher wissenschaftlichen Perspektive man ihn betrachtet, eine andere Ausprägung. ${ }^{484}$ Aber auch bei der für die vorliegende Untersuchung notwendigen strafrechtlichen Interpretation existieren noch die verschiedensten Verständnismöglichkeiten. Das Strafgesetzbuch verwendet zwar vereinzelt den Begriff der Gewalt, definiert diesen jedoch nicht. 485 Ein Minimalkonsens herrscht darüber, dass darunter jede „zielgerichtete, direkte physische Schädigung von Menschen durch Menschen“"486 zu fassen ist. Was darüber hinaus unter Gewalt zu subsumieren ist, ist streitig. Teilweise werden auch das Zerstören von Sachen im Sinne einer Sachbeschädigung ${ }^{487}$ oder verbale Aggressionen im Sinne einer Beleidigung in den Terminus mit einbezogen. ${ }^{488}$ Aufgrund der fehlenden klaren Abgrenzung ist der strafrechtliche Gewaltbegriff in der Rechtsprechung seit je her einem starken Wandel unterzogen, wobei die Diskussion zumeist anhand des $\ 240$ StGB erfolgt: Zunächst vertrat das RG eine enge Definition und verstand unter Gewalt die Anwendung physischer Kraft zur Überwindung eines geleisteten oder erwarteten Widerstandes. ${ }^{489}$ Sodann hatte eine Verlagerung vom physischen auf den psychischen Bereich, die sog. „Vergeistigung“ des Gewaltbegriffs ${ }^{490}$, stattgefunden. Der BGH hat anlässlich der strafrechtlichen Beurteilung einer Blockade einer Straßenbahn durch einen auf den Gleiskörper getretenen Demonstranten festgestellt, dass bereits unwiderstehlicher, psychisch wirkender Zwang auf das Opfer unter den Gewaltbegriff zu subsumieren ist. ${ }^{491}$ Diese Rechtsprechung wurde vom BVerfG zunächst bestätigt, ${ }^{492}$ später jedoch als unvereinbar mit Art. 103 II GG angesehen, soweit keinerlei physische Zwangswirkung beim Opfer festzustellen sei.493 Daran zeigt sich, dass die ver-

483 Galtung, in: Funke (Hrsg.): Friedensforschung, S. 99, 101; Schwind/Baumann/Schneider/Winter, in: Schwind/Baumann u.a. (Hrsg.), Ursachen, Prävention und Kontrolle von Gewalt, S. 36; Walter, Rdn. 30a, 57; Weiß, S. 10.

$484 \mathrm{Wahl}, \mathrm{S} .6$.

485 Geiger-Battermann, in: Kreuzer/Geiger-Battermann (Hrsg.), Gewalt ist auch weiblich, Bd. 2, S. 9.

486 Schwind/Baumann/Schneider/Winter, in: Schwind/Baumann u.a. (Hrsg.), Ursachen, Prävention und Kontrolle von Gewalt, S. 36.

487 So Schneider, Kriminologie der Gewalt, S. 14.

488 Bock, J 22, Rdn. 950.

${ }^{489}$ RGSt 64, 113, 115; RGSt 73, 343, 344.

490 Von der sog. Vergeistigung des Gewaltbegriffs ist seit der Laepple-Entscheidung des BGH die Rede, vgl. BGHSt 23, 46.

491 BGHSt 23, 46, 54.

492 BVerfGE 73, 206.

493 BVerfGE 92, 1, 18. 
schiedenen Interpretationsmöglichkeiten dieses Begriffs zu Abgrenzungsschwierigkeiten führen. ${ }^{494}$ Nach der wohl heutzutage herrschenden Definition ist Gewalt ,jede körperliche Tätigkeit, durch die körperlich wirkender Zwang ausgeïbt wird, um geleisteten oder erwarteten Widerstand zu überwinden. "495 Ferner ist die bloße Drohung mit der Herbeiführung der Zwangswirkung mit ihrer Herbeiführung an sich gleichzusetzen. 496

Die PKS subsumiert nur mittelschwere bis schwerste Straftaten unter den Begriff der Gewaltkriminalität und lässt leichtere Formen wie die einfache Körperverletzung gem. \223 StGB oder die Nötigung gem. \240 StGB in dieser Kategorie unberücksichtigt. ${ }^{497}$

In der vorliegenden Untersuchung wurde für die Gruppierung der Gewaltdelikte, ähnlich wie in der PKS, eine pragmatische Lösung gewählt, um eine uferlose Ausweitung auf Tatbestände mit fraglichem Gewaltgehalt zu vermeiden. ${ }^{498}$ Dementsprechend werden Gewalt gegen Sachen, verbale Gewalt sowie die Nötigung gem. $\int 240 \mathrm{StGB}$, trotz kriminologisch interessanter Fragestellung, nicht zu den Gewaltdelikten gezählt. ${ }^{499}$

\subsubsection{Tötungsdelikte}

Danach sind Tötungsdelikte unproblematisch als Gewaltdelikte einzustufen. $\mathrm{Zu}$ dieser Gruppe werden vorliegend die $\$ \$ 211,212,213$ StGB sowie $\$ 227$ StGB gezählt.

Es wäre zwar auch denkbar die Körperverletzung mit Todesfolge gem. \227 StGB in der Kategorie der sonstigen Körperverletzungsdelikte zu berücksichtigen, jedoch ist zu beachten, dass in den Fällen des $₫ 227$ StGB der Vorsatz des Täters schwer zu ermitteln ist, sodass eine Abgrenzung zur Tötung schwer möglich ist. Die Bewertung des Vorsatzes ist hier weitgehend eine Ermessensfrage. 500 TrubeBecker führte hierzu aus: „Häufig wird wegen Mordes ermittelt und dann die Anklage wegen Totschlags erboben und schließlich wegen Körperverletzung mit Todesfolge verurteilt. Es kann auch das Umgekehrte der Fall sein. "501

Sessar stellte bei Betrachtung der Tötungskriminalität anhand der Daten der PKS und StVS einen Zusammenhang zwischen der Abnahme der Körperverlet-

\footnotetext{
${ }^{494}$ Vgl. ausführlich zum Gewaltbegriff: Harrendorf, S. 9 ff.

495 Rengier, BT II, \23, Rdn. 23.

496 Harrendorf, S. 19.

${ }^{497}$ Die PKS fasst unter Gewaltkriminalität Mord, Totschlag, Tötung auf Verlangen, Vergewaltigung und sexuelle Nötigung, Raub, räuberische Erpressung, räuberischer Angriff auf Kraftfahrer, Körperverletzung mit Todesfolge, gefährliche und schwere Körperverletzung, erpresserischer Menschenraub, Geiselnahme und Angriff auf den Luft- und Seeverkehr zusammen.

498 So auch Göppinger, \28, Rdn. 5; Bock, \22, Rdn. 953.

499 Ähnlich Göppinger, \28, Rdn. 5,6, sowie Bock, $\ 22$ Rdn. 953, wobei beide Autoren die Nötigung zu den Gewaltdelikten zählen.

500 So auch Trube-Becker, S. 20; Sessar, S. 6 m.w.N.

501 Trube-Becker, S. 20.
} 
zungen mit Todesfolge in den Jahren 1971 bis 1979 und der Zunahme der vollendeten Mord- und Totschlagsdelikte fest. ${ }^{502}$ Er führte dieses Ergebnis auf eine Umdefinition der Körperverletzung mit Todesfolge zu vorsätzlichen Tötungsdelikten zurück. .03

Die Tötung auf Verlangen gem. $\int 216$ StGB wird hingegen nicht in der Gruppe der Tötungsdelikte berücksichtigt. Bei Fällen, in denen das Opfer in die Rechtsgutsverletzung eingewilligt hat, sollte nicht von Gewalt gesprochen werden. ${ }^{504}$

\subsubsection{Einfache Körperverletzung}

Anders als in der PKS wird in der vorliegenden Untersuchung die einfache Körperverletzung gem. \223 StGB berücksichtigt. Es handelt sich um das quantitativ bedeutsamste Delikt, das mit physischer Gewalt gegen Personen einhergeht. ${ }^{505}$ Eine getrennte Betrachtung der einfachen Körperverletzung von den sonstigen Körperverletzungsdelikten bietet sich hier an, da letztere einen wesentlich höheren Handlungsunrechtsgehalt aufweisen. Zwar ist dies nicht für jedes sonstige Körperverletzungsdelikt zwingend, z.B. liegt auf der einen Seite gem. \224 I Nr. 4 StGB bereits bei gemeinschaftlicher Tatbegehung eine gefährliche Körperverletzung vor. Auf der anderen Seite ist eine solche gem. \ 224 I Nr. 5 StGB gleichfalls bei einer das Leben gefährdenden Behandlung gegeben. Die Nummern des $\ 224$ Abs. 1 StGB sind jedoch selten genau im BZR aufgeführt und lassen sich daher nicht differenzieren. Folglich wird die einfache Körperverletzung von den sonstigen Körperverletzungsdelikten getrennt betrachtet.

\subsubsection{Sonstige Körperverletzungsdelikte}

In der Gruppe der sonstigen Körperverletzungsdelikte werden die $\$ \$ 224,225$ sowie $226 \mathrm{StGB}$ zusammengefasst. Zwar ist $\ 225 \mathrm{StGB}$ insofern nicht mit den

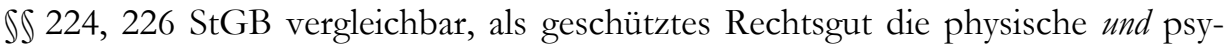
chische Unversehrtheit des dort genannten Personenkreises ist. ${ }^{506}$ Allerdings ist eine eigene Gruppe für $\ 225$ StGB aufgrund der wenigen Fälle im Bezugsjahr nicht sinnvoll. Auch von einer Berücksichtigung des $₫ 225$ StGB in der Kategorie der einfachen Körperverletzung wurde abgesehen, denn bei der Tathandlung der rohen Misshandlung, der Gesundheitsschädigung durch böswillige Vernachlässigung sowie des Quälens in Form der körperlichen Integritätsverletzung handelt es sich um eine Qualifikation der Körperverletzung. Soweit sich das Quälen als die

\footnotetext{
502 Sessar, S. $70 \mathrm{ff}$.

503 Sessar, S. 79.

504 So auch Harrendorf, S. 20 f.

505 Göppinger, \28, Rdn. 5.

506 Stree/Sternberg-Lieben, in: Schönke/Schröder, $₫ 225$, Rdn. 1.
} 
Verursachung seelische Leiden darstellt handelt es sich um einen eigenen Tatbestand. .07

Ferner ist die Beteiligung an einer Schlägerei gem. $\int 231$ StGB in dieser Kategorie zu berücksichtigen. Im Entscheidungsdatensatz finden sich hierzu für das Bezugsjahr 2004 jedoch keine Fälle für weibliche und nur 5 für männliche Verurteilte. 508

\subsubsection{Sonstige Gewaltdelikte}

In dieser Kategorie werden $\$ ₫ 113,177,178,239 a, 239 b, 249-252,255$ StGB sowie $₫ 316$ a StGB zusammengefasst.

Die $\iint 113,177,178,249-252,255$ StGB erfordern tatbestandlich entweder die Anwendung von Gewalt, die Drohung mit Gewalt oder mit gegenwärtiger Gefahr für Leib oder Leben. Dabei handelt es sich auch bei der Drohung mit gegenwärtiger Gefahr für Leib oder Leben um eine sog. Gewaltdrohung, die der Gewaltausübung gleichsteht.509 Auch die $\int \mathbb{1 1 3}, 177$ StGB haben eine hinreichend qualifizierte Drohungsalternative, so dass sie, im Gegensatz zu $₫ 240$ StGB, zu berücksichtigen sind. ${ }^{110}$ Somit unterfallen die $\$ \$ 113,177,178,249-252,255$ StGB der Gruppe der sonstigen Gewaltdelikte.

Die Tathandlung des erpresserischen Menschenraubs gem. \239a StGB und der Geiselnahme gem. \239b StGB erfordern das Entführen, also das Verbringen des Opfers an einen anderen Ort, an welchem es dem ungehemmten Einfluss des Täters ausgesetzt ist, ${ }^{511}$ oder das Sich-Bemächtigen durch Erlangung anhaltender physischer Gewalt über das Opfer. ${ }^{512}$ Das Sich-Bemächtigen geschieht mithin gegen den (mutmaßlichen) Willen des Opfers, sodass in diesen Fällen Gewalt vorliegen dürfte. Das Entführen unterscheidet sich vom Sich-Bemächtigen nur darin, dass eine Ortsänderung zur Ermöglichung des Sich-Bemächtigens herbeizuführen ist; die Begriffe überschneiden sich. ${ }^{513}$ Das Entführen erfordert folglich zumindest die Absicht der späteren Gewaltausübung oder -drohung. Diese Konstellation ist folglich vergleichbar mit einem versuchten typischen Gewaltdelikt, wie z.B. Raub, wo es auch noch nicht zur Anwendung von Gewalt gekommen ist, der Täter jedoch zumindest aufgrund seines Vorsatzes als Gewalttäter einzustufen ist. ${ }^{514}$ Damit sind auch die $\$ \$ 239 \mathrm{a}, 239 \mathrm{~b}$ StGB den sonstigen Gewaltdelikten zuzuordnen.

\footnotetext{
${ }^{507}$ So die h.M., vgl. z.B.: Stree/Sternberg-Lieben, in: Schönke/Schröder, $\ 225$, Rdn. 1; Kübl, $\ 225$,

Rdn. 1; Fischer, $₫ 225 \mathrm{Rdn} .2$.

$508 \mathrm{Vgl}$. auch Tab. $4.1 \mathrm{~b}$ im Anhang.

${ }^{509} \mathrm{Vgl}$. Ausführungen unter Kap. 4, 1.2.1.

510 So auch Harrendorf, S. 24.

511 BGHSt 22, 178; 24, 90; 39, 350.

512 BGHSt 26, 70.

513 Fischer, $\$ 239$ a, Rdn. 4.

${ }^{514}$ So auch Harrendorf, S. 22.
} 
Der räuberische Angriff auf Kraftfahrer gem. \ 316a StGB setzt „einen Angriff auf Leib oder Leben oder die Entschlussfreiheit des Führers eines Kraftfahrzeugs oder eines Mitfahrers" voraus. Problematisch ist nur, ob die Alternative „Angriff auf die Entschlussfreiheit des Führers eines Kraftfahrzeugs oder eines Mitfahrers" unter den Gewaltbegriff zu subsumieren ist, da hierfür grundsätzlich jede Form der Nötigung, also auch die Drohung mit einem empfindlichen Übel, genügt. ${ }^{515}$ Allerdings beabsichtigt der Täter zumindest für die Zukunft die Ausübung von oder Drohung mit Gewalt, sodass hier die Vergleichbarkeit mit einem versuchten typischen Gewaltdelikt gegeben ist, und der $\$ 316 a \mathrm{StGB}$ in die Gruppe der sonstigen Gewaltdelikte aufzunehmen ist.

Auch der Angriff auf den Luft- und Seeverkehr gem. \316c I Nr. 1a und b StGB enthält eine Gewaltkomponente, ${ }^{516}$ jedoch wurden im Bezugsjahr keine Fälle mit weiblichen Tätern registriert, weshalb diese Norm unberücksichtigt bleibt.

\subsubsection{Ergebnisse}

Die Schaubilder 4.6 und 4.7 verdeutlichen die Struktur der Gewaltdelikte jeweils für Frauen und Männer. Die Kategorie der sonstigen Gewaltdelikte wurde dabei in weitere Untergruppen geteilt, sodass die jeweiligen Anteile für Raubdelikte, sexuelle Gewaltdelikte sowie für den Widerstand gegen Vollstreckungsbeamte deutlich werden.

Beide Geschlechter begehen am häufigsten die einfache Körperverletzung (57\% Frauen und $52 \%$ Männer), gefolgt von den sonstigen Körperverletzungsdelikten (33\% Frauen und $31 \%$ Männer). Allein diese beiden Deliktsgruppen machen folglich bei den Frauen einen Anteil von $90 \%$ an ihrer gesamten Gewaltkriminalität aus. Bei den Männern sind es $83 \%$. Bei den einfachen Körperverletzungen mit weiblichen Tätern dürften oftmals Kinder die Opfer sein und somit ein Zusammenhang zur Misshandlung von Schutzbefohlenen bestehen. Jehle517 stellte hierzu anhand der Daten der PKS fest, dass ein Rückgang der Körperverletzungen mit kindlichen Opfern unter 6 Jahren im Zeitraum 2005-2007 gleichzeitig zu einem Anstieg der Misshandlungen von Schutzbefohlenen führte. Eine Zusammenbetrachtung der Delikte ließ den Anstieg der Körperverletzungen verschwinden, sodass davon ausgegangen werden kann, dass hier eine Umdefinition von Körperverletzungen hin zu einer Misshandlung stattgefunden hat.

\footnotetext{
515 Fischer, $₫ 316 a$, Rdn. 6.

516 Vgl den Wortlaut des $₫ 316$ c I StGB: „Mit Freiheitsstrafe nicht unter fünf Jahren wird bestraft, wer 1. Gewalt anwendet (...)“.

517 Jehle, Schutz kindlicher Opfer im Strafverfahren, in: Kindesmisshandlung und -vernachlässigung, Jahrg. 11, Heft 2/2008, S. 20, 25 f.
} 
Schaubild 4.6: Gewaltdelikte von Frauen*

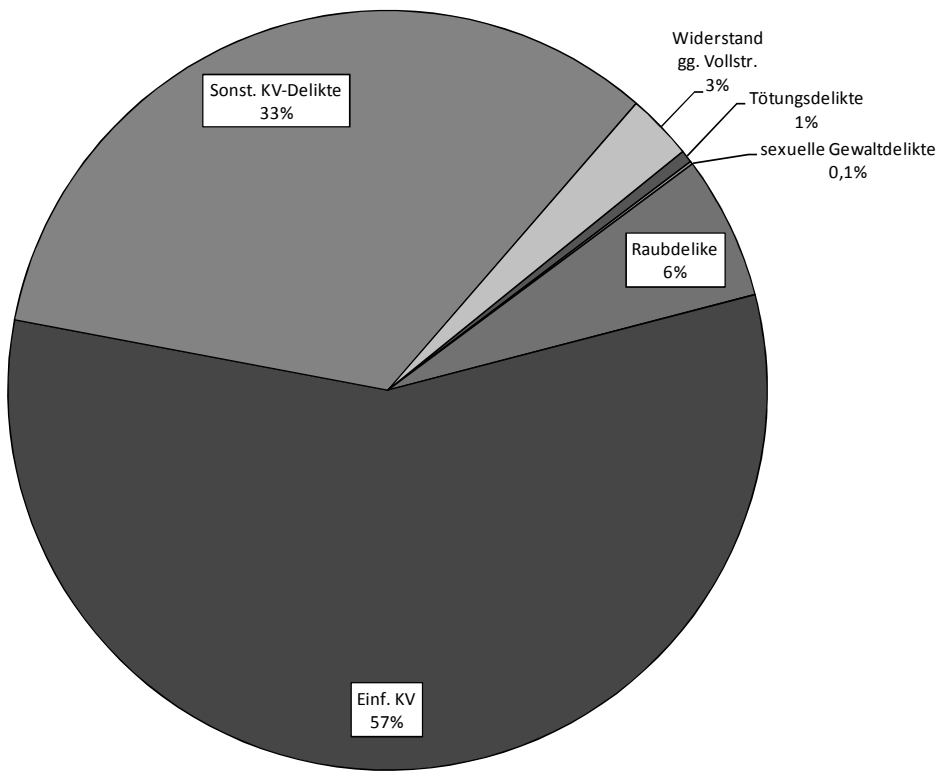

* Absolutzablen siehe Tab. 4.1b im Anhang

Schaubild 4.7: Gewaltdelikte von Männern*

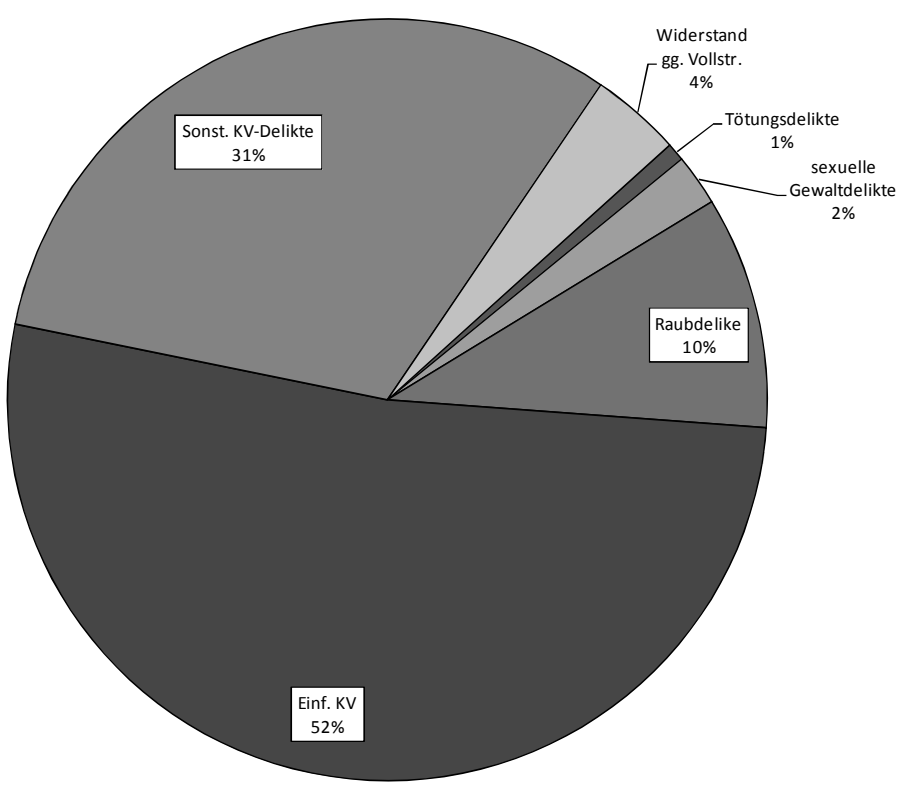

* Absolutzablen siehe Tab. 4.1b im Anbang 
Einzelfallstudien ${ }^{518}$ kommen ebenfalls zu dem Ergebnis, dass Frauen sich bevorzugt Schwächere und dabei insbesondere Kinder als Opfer wählen.

In der Kategorie der sonstigen Körperverletzungsdelikte ist ferner zu berücksichtigen, dass diese stark von der gefährlichen Körperverletzung dominiert wird. Die schwere Körperverletzung und die Misshandlung von Schutzbefohlenen spielen kaum eine Rolle. ${ }^{519}$ Folglich begehen sowohl Frauen als auch Männer in erster Linie leichtere Gewaltdelikte. Mit Ausnahme der Körperverletzungs- (einfache Körperverletzung, Misshandlung von Schutzbefohlenen sowie sonstige Körperverletzungsdelikte) und Tötungsdelikte überwiegt der Anteil der übrigen Delikte innerhalb dieser Deliktsgruppe an der gesamten Gewaltkriminalität bei den Männern die jeweiligen Anteile bei den Frauen: So sind 2\% der von Männern begangenen Gewaltstraftaten sexuelle Gewaltdelikte ${ }^{520}$. Bei den Frauen sind dies lediglich 0,1\%. Männliche Gewalttäter begehen in $10 \%$ der Fälle ein Raubdelikt ${ }^{521}$, bei den weiblichen Gewalttätern sind es $6 \%$. Auch der Anteil für Widerstand gegen Vollstreckungsbeamte überwiegt bei den Männern mit $4 \%$ den bei den Frauen mit $3 \%$.

Die Tötungsdelikte stellen für beide Geschlechter nur einen kleinen Teil der Gewaltkriminalität dar und werden im Übrigen vom Totschlag gem. \212 StGB dominiert. 522

Bei der Interpretation dieser Ergebnisse darf jedoch nicht vergessen werden, dass die Anzahl der weiblichen Verurteilten, gerade im Bereich der Gewaltdelikte, deutlich niedriger ist als die der männlichen Verurteilten. Dies veranschaulicht Schaubild 4.8.

Neben der Kategorie für die sonstigen Gewaltdelikte wurde für Schaubild 4.8 auch die Kategorie der sonstigen Körperverletzungsdelikte differenzierter, nämlich nach der Misshandlung von Schutzbefohlenen sowie der gefährlichen bzw. schweren Körperverletzung, betrachtet. So zeigt sich, dass die Frauen von allen Gewaltdelikten am stärksten bei der Misshandlung von Schutzbefohlenen mit $39 \%$, gefolgt von der einfachen und gefährlichen bzw. schweren Körperverletzung mit jeweils $14 \%$ repräsentiert sind.

\footnotetext{
518 Versen, Erscheinungsformen und Strafzumessung bei der Körperverletzung; Scholz, Motive und Ursachen bei Körperverletzungen im Landgerichtsbezirk Bonn (1945-1955); Joerss, Die gefährliche Körperverletzung - eine strafrechtliche kriminologische Untersuchung unter Berücksichtigung einer Aktenuntersuchung im Landgerichtsbezirk Kiel, 1959-1961.

519 Lediglich 11 Frauen und 95 Männer wurden wegen schwerer Körperverletzung verurteilt; vgl. zu den Absolutzahlen auch Tab. $4.1 \mathrm{~b}$ im Anhang.

${ }^{520}$ Hierunter wurden die $\iint$ 177, 178 StGB gefasst; vgl. auch Ausführungen unter Kap. 4, 1.2.1.4.

${ }^{521}$ Hierunter wurden die $\$ \int 249-252,255,316 \mathrm{a}, 239 \mathrm{a}, 239 \mathrm{~g}$ gefasst; vgl. auch Ausführungen unter Kap. 4, 1.2.1.4.

522 Vgl. Tab. $4.1 b$ im Anhang.
} 


\section{Schaubild 4.8: Anteil von Frauen und Männern an Gewaltdelikten*}

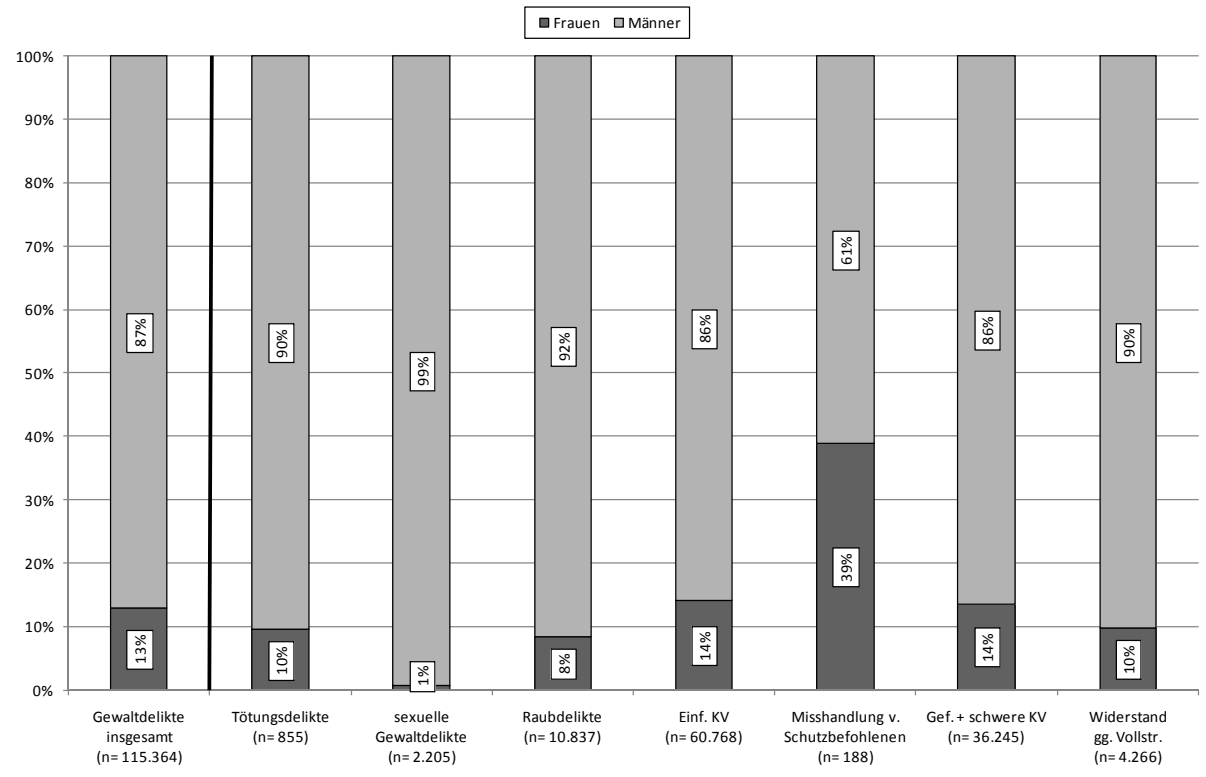

\section{* Absolutzablen siehe Tab. $4.1 \mathrm{~b}$ im Anbang}

Die Tatsache, dass es sich bei der Misshandlung von Schutzbefohlenen gem. $\ 225$ StGB vornehmlich um innerfamiliäre Gewalt von Eltern an ihren Kindern handelt, dürfte zu dem recht hohen Frauenanteil führen. 523

Erstaunlich könnte auf den ersten Blick sein, dass der Anteil der weiblichen Täter bei den schwersten Gewalttaten, den Tötungsdelikten, immerhin $10 \%$ beträgt. Jedoch lässt sich auch dieser relativ hohe Anteil dadurch erklären, dass sich diese Taten zumeist im sozialen Nahraum abspielen und auf Konflikten beruhen. ${ }^{224}$ In diesem Zusammenhang kam Trube-Becker ${ }^{25}$ nach einer Analyse von Tötungsdelikten mit 86 Täterinnen zu dem Ergebnis, dass 70 der 94 Opfer in einer Angehörigenbeziehung zu den Täterinnen standen. ${ }^{526}$ Außerdem untersuchte Oberlies ${ }^{527} 93$ wegen Tötungsdelikten verurteilte Frauen. Ihre Auswertung ergab, dass 2/3 der Mordverurteilungen auf den Partnerschaftsbereich entfielen. Den meisten der Taten waren Misshandlungen durch die späteren Opfer vorausgegan-

\footnotetext{
523 Vgl. auch Ausführungen unter Kap. 4, 1.1.

524 Oberlies, in: KJ 1990, S. 318, 320; Burgheim, in: MschrKrim 1994, S. 232, 234; vgl. zum Dunkelfeld bei Tötungsdelikten naher Angehöriger: Rückert, Tote habe keine Lobby: Die Dunkelziffer der vertuschten Morde; Brinkmann/Du Chesne, Tötungsdelikte/Suizide/Unfälle, in: Brinkmann/

Madea (Hrsg.), Handbuch gerichtlicher Medizin, S. 229 ff.

525 Trube-Becker, S. 49 f.

526 Trube-Becker, S. 50, 77.

527 Oberlies, Tötungsdelikte zwischen Männern und Frauen; Oberlies, in: MschrKrim 1997, S. 133-147.
} 
gen. ${ }^{528}$ Solche Konflikttäter zeigen in der Regel ein unauffälliges Sozialverhalten. Göppinger spricht in diesem Zusammenhang von einem sog. „kriminellen Übersprung “"529. Konflikttäter sind mithin nicht mit den typischen Gewalttätern zu vergleichen. ${ }^{530}$ Es überrascht daher nicht, dass der Frauenanteil an den Tötungsdelikten zunächst verhältnismäßig hoch ist.

Bei der weiblichen Tötungskriminalität dürfte ferner die Tötung des eigenen Kindes vor allen Dingen in Form von Neonatiziden eine größere Rolle spielen als bei männlichen Tätern, denn die Frau ist dem Opfer nach der Geburt besonders nah und befindet sich zudem in einer psychischen Ausnahmesituation. ${ }^{531}$ Auch hier ist im Übrigen von einer nicht unerheblichen Dunkelziffer auszugehen, da die Schwangerschaft in solchen Fällen teils unbemerkt bleibt und ein Säugling im Vergleich zu einem Erwachsenen leichter zu töten und die Tat zudem einfacher zu verdecken ist. ${ }^{532}$ Bis zum 31.03.1998 existierte noch der Tatbestand der Kindstötung (\$ 217 a.F. StGB), der aber im Zuge der 6. Strafrechtsreform aufgehoben wurde. Der Gesetzgeber führte zur Begründung an, der Ausnahmesituation einer Mutter könne mit der Anwendung des $₫ 213$ StGB genügend Rechnung getragen werden. ${ }^{533} \mathrm{Da}$ der vorliegenden Untersuchung das Bezugsjahr 2004 zugrunde liegt kann der $\int 217$ a.F. StGB nicht gesondert betrachtet werden. Eine genauere Analyse der Tötungsdelikte hat ergeben, dass bei den 51 für Frauen im BZR registrierten Totschlagstaten in 19 Fällen $\int 213$ StGB mit aufgeführt ist. In fast $40 \%$ der registrierten Totschlagsdelikte wurde bei den Frauen also ein minderschwerer Fall angenommen. Die Daten des BZRs lassen allerdings keine Feststellungen zu, aus welchen Gründen ein minderschwerer Fall angenommen wurde.

Besonders niedrig ausgeprägt ist der weibliche Anteil an den sexuellen Gewaltdelikten $(1 \%)$. Dass Frauen selten Sexualstraftaten begehen, ist hinlänglich bekannt. ${ }^{534}$ Dies bezieht sich vor allen Dingen auf die hier betrachteten sexuellen Gewaltdelikte gem. $\iint 177,178$ StGB. ${ }^{535}$ Die Verbindung von Sexualität und Aggression bei Frauen scheint eine andere Ausdrucksform zu erfahren. Becker spricht von „perverser Mütterlichkeit“, die in besonders erregtem Schlagen des eigenen Kindes oder in Übergriffen bei der Körperpflege zum Ausdruck kommt, wobei

\footnotetext{
528 Oberlies, in: MschrKrim 1997, S. 133, 135 f.

529 Göppinger 1997, S. 428 f.

530 So auch Harrendorf, S. 149.

531 Saimeh, „Mein eigen Fleisch und Blut“ - Mütter, die töten, in: Greuel/Petermann (Hrsg.), Macht - Nähe - Gewalt (?), S. 55, 57; vgl. ferner zur Kindstötung: Bauermeister, Die Tötung Neugeborener unter der Geburt (Kindstötung \ 217 StGB); Wandiger, Tötungsdelikte an Neugeborenen und älteren Kindern zwischen 1969 und 1982.

532 So auch Kroetsch, Tötungsdelikte an Kindern unter 6 Jahren, S. 11.

533 BT-Drucks. 13/8587, S. 34.

534 Eisenberg, \45, Rdn. 67; Lindner, S. 235 ff.

535 Göppinger, \29, Rdn. 41; Eisenberg, \ 45, Rdn. 67.
} 
letzteres nicht unbedingt von der Umgebung als pervers identifiziert werden muss. .336

Betrachtet man neben den $\iint 177,178$ StGB auch die anderen Sexualdelikte für das Bezugsjahr mit weiblichen Täterinnen, so ist festzustellen, dass sie am häufigsten wegen sexuellen Missbrauchs von Kindern gem. \176 StGB verurteilt wurden. ${ }^{537}$ Im Hinblick auf die Gesamtkriminalität nimmt der sexuelle Kindesmissbrauch jedoch keine beachtenswerte Stellung ein. Auch wenn man nur die Bezugsentscheidungen wegen sexuellen Missbrauchs betrachtet, kommt man zu dem Ergebnis, dass die Täter in $98 \%$ der Fälle männlich sind. Ferner wird vermutet, dass die weiblichen Täter selbst in den wenigen Fällen oftmals nicht als Alleintäter gehandelt haben, sondern vielmehr unter männlichem Einfluss standen. ${ }^{538}$ Eine Überprüfung dieser These ist hier allerdings nicht möglich, da die Daten des BZR keine zuverlässigen Angaben zu den Vorschriften des Allgemeinen Teils des StGB enthalten. ${ }^{539}$ Zudem dürfte hier - ebenso wie bei den anderen Delikten, die sich zumeist im sozialen Nahraum ereignen - ein nicht unerhebliches Dunkelfeld existieren. ${ }^{540}$

Schaubild 4.8 verdeutlicht weiterhin, dass der Anteil an Raubdelikten und Widerstand gegen Vollstreckungsbeamte unter dem durchschnittlichen Anteil der Frauen an den Gewaltdelikten liegen. Dies dürfte daran liegen, dass es sich hierbei gerade nicht um Taten handelt, die sich im sozialen Nahraum abspielen, ${ }^{541}$ sondern um solche, bei denen zumeist die Erlangung eines Vermögensvorteils im Vordergrund steht. ${ }^{52}$ Vermutlich sind Frauen, insbesondere bei den Raubdelikten, oftmals als Mittäterinnen oder Gehilfinnen beteiligt. Anhaltspunkte hierfür finden sich z.B. bei Müller-Engelmann $n^{543}$, der feststellte, dass Frauen häufig die gewaltlose Lockvogelrolle übernehmen. 544

Insgesamt zeigt Schaubild 4.8, dass der Anteil der Frauen an den jeweiligen Gewaltdelikten deutlich niedriger ist als der der Männer und - mit Ausnahme der Misshandlung von Schutzbefohlenen - auch deutlich niedriger als der Frauenanteil an der Kriminalität insgesamt.

\footnotetext{
536 Becker, in: Forum der Psychoanalyse 2005, S. 242, 244; Pfäfflin, in: Venzlaff/Foerster (Hrsg.), Psychiatrische Begutachtung, S. 329, 341.

${ }^{537}$ Im Bezugsjahr sind 53 Frauen wegen sexuellen Kindesmissbrauchs verurteilt worden.

538 Vgl. beispielsweise Kavemann, in: Wodtke-Werner (Hrsg.): „Nicht wegschauen!“, Vom Umgang mit Sexual(straf)tätern, S. 31, 39.

${ }^{539}$ Vgl. hierzu Ausführungen unter Kap. 3, 3.3, aber ausnahmsweise Kap. 5, 2.2.2.

540 Kavemann, in: Wodtke/Mähne (Hrsg.), „Nicht wegschauen!“, Vom Umgang mit Sexual(straf)tätern, S. 31, 37; Gerber, S. 5 ff.; vgl. zum Dunkelfeld: Bange/Deegener, Sexueller Missbrauch an Kindern.

541 So auch Harrendorf, S. 149.

542 Harrendorf, S. 37 f.

543 Müller-Engelmann, Der Raub.

${ }^{544}$ Müller-Engelmann, S. 133.
} 


\subsection{Eigentums-, Vermögens- und Urkundendelikte}

\subsubsection{Gruppierung der Eigentums-, Vermögens- und Urkundendelikte}

Eine weitere größere Kategorie bilden die Eigentums-, Vermögens- und Urkundendelikte ${ }^{545}$, die sich wiederum aus mehreren Gruppen zusammensetzen. Diese Kategorie ist für die weiblichen Verurteilten von besonderem Gewicht, da sie immerhin einen Anteil von $59 \%$ an der gesamten im Bezugsjahr 2004 für sie gemessenen Kriminalität ausmacht (vgl. Schaubild 4.2).

\subsubsection{Besonders schwerer und qualifizierter Diebstabl}

Der besonders schwere Diebstahl gem. $₫ 243$ StGB und der qualifizierte Diebstahl gem. $\iint 244$, 244a StGB sollen vom einfachen Diebstahl getrennt betrachtet werden. Dies ist für eine genauere Untersuchung der Frauenkriminalität notwendig, da der einfache Diebstahl zusammen mit der Unterschlagung mit 33\%546 das von Frauen am häufigsten begangene Delikt darstellt. Das Regelbeispiel des \243 StGB und die Qualifikationen gem. S\$ 244, 244a StGB machen mit lediglich 1.653 bzw. 396 im Bezugsjahr verwirklichten Fällen zusammengerechnet einen prozentualen Anteil von $1 \%{ }^{547}$ aus. Hier bestätigt sich wieder, dass Frauen eher leichtere Delikte verwirklichen.

\subsubsection{Einfacher Diebstabl und Unterschlagung}

Wie bereits erwähnt, stellt der einfache Diebstahl das von Frauen am häufigsten begangene Delikt dar und ist daher sinnvollerweise von dem besonders schweren und qualifizierten Diebstahl getrennt zu betrachten. Ferner wurde die Unterschlagung gem. \246 StGB in dieser Kategorie mitberücksichtigt. Zwar fehlt es bei $\$ 246$ StGB an der Wegnahmehandlung, jedoch muss zumindest eine nach außen erkennbare Manifestation der Zueignung vorliegen. Die Abgrenzung dürfte nicht immer eindeutig sein, sodass eine gemeinsame Betrachtung von einfachem Diebstahl und Unterschlagung sinnvoll erscheint. Die sog. veruntreuende Unterschlagung gem. \246 II StGB wurde gleichfalls hier und nicht in der Gruppe der Betrugs-, Untreue- und Urkundendelikte berücksichtigt. Ein Treueverhältnis i.S.v. \266 StGB ist für $\$ 246$ II StGB nicht erforderlich ${ }^{548}$, sodass eine Berücksichtigung in dieser Gruppe erfolgt.

\footnotetext{
545 Im Folgenden wird diese Gruppe mit „Vermögensdelikte i.w.S.“ abgekürzt.

${ }^{546}$ Vgl. Schaubilder 4.1 und 4.2 sowie Tab. 4.1a, 4.1d im Anhang.

547 Vgl. Schaubilder 4.1 und 4.2 sowie Tab. 4.1a, 4.1d im Anhang.

${ }^{548}$ Fischer, $\$ 246$, Rdn. 17.
} 


\subsubsection{Betrug, Untreue und Urkundendelikte549}

Zudem soll aus den $\$$ \$263-281 StGB eine Deliktsgruppe gebildet werden. Den Tatbeständen ist gemeinsam, dass sie ein Täuschungselement enthalten.

Für eine Zusammenfassung der Betrugs- und Urkundendelikte spricht ferner, dass diese häufig gemeinsam begangen werden. Da bis zu fünf Strafnormen erfasst werden, erlauben die Rückfalldaten auch eine Auswertung von Entscheidungen nach Deliktskombinationen. Eine Auswertung der BZR-Daten bezüglich des Zusammenhangs der Delikte Betrug gem. \$263 StGB und Urkundenfälschung gem. $\$ 267$ StGB hat ergeben, dass der $\$ 267$ StGB das Delikt ist, welches am häufigsten mit $\ 263$ StGB im Zusammenhang steht. Daher soll für die vorliegende Untersuchung die Zusammenfassung dieser Delikte in einer Gruppe erfolgen.

\subsubsection{Erschleichen von Leistungen}

\265a StGB ist gesondert zu betrachten. Zwar wäre es durchaus vertretbar, den Straftatbestand in die Kategorie der Betrug-, Untreue und Urkundendelikte zu verschieben, da auch $\$ 265$ a StGB eine täuschungsähnliche Handlung voraussetzt. Jedoch dürfte der Unrechtsgehalt dieses Straftatbestandes in der Regel nicht mit dem der $\$ \int 263-281$ StGB vergleichbar sein, denn von $\$ 265$ a StGB wird vor allen Dingen die typische Beförderungserschleichung erfasst. Dies schlägt sich auch in den Zahlen wieder: $\int 265 \mathrm{a}$ StGB macht immerhin einen Anteil von $7 \% 550$ an der weiblichen Gesamtkriminalität aus und ist damit das von Frauen am dritthäufigsten begangene Delikt, weshalb dieser Straftatbestand eine eigene Gruppe bilden soll.

\subsubsection{Ergebnisse}

Schaubilder 4.9 und 4.10 verdeutlichen zunächst wieder den Anteil an den jeweiligen Straftatbeständen der Deliktsgruppe der Vermögensdelikte i.w.S. sowohl für Frauen als auch für Männer.

Der einfache Diebstahl macht bei den Frauen über die Hälfte der gesamten Deliktsgruppe aus, wohingegen auf den besonders schweren und qualifizierten Diebstahl insgesamt nur 1\% entfallen. Dies stellt sich bei den Männern anders dar: Der einfache Diebstahl ist zwar auch das am häufigsten begangene Delikt dieser Tätergruppe, liegt aber mit $42 \%$ deutlich unter dem Anteil bei den Frauen. Dafür begehen Männer in insgesamt $8 \%$ der Fälle eine der schwereren Diebstahlsformen. Sowohl bei den Frauen als auch bei den Männern stellt der Betrug mit $23 \%$ (Männer) bzw. $24 \%$ (Frauen) die zweitgrößte Gruppe dar, gefolgt vom Erschleichen von Leistungen mit einem jeweils 12\%igen Anteil.

\footnotetext{
${ }^{549}$ Diese Gruppe wird im Folgenden mit „Betrug u.a.“ abgekürzt.

550 Vgl. Schaubilder 4.1 und 4.4 sowie Tab. 4.1d im Anhang.
} 
Schaubild 4.9: Vermögensdelikte i.w.S. von Frauen*

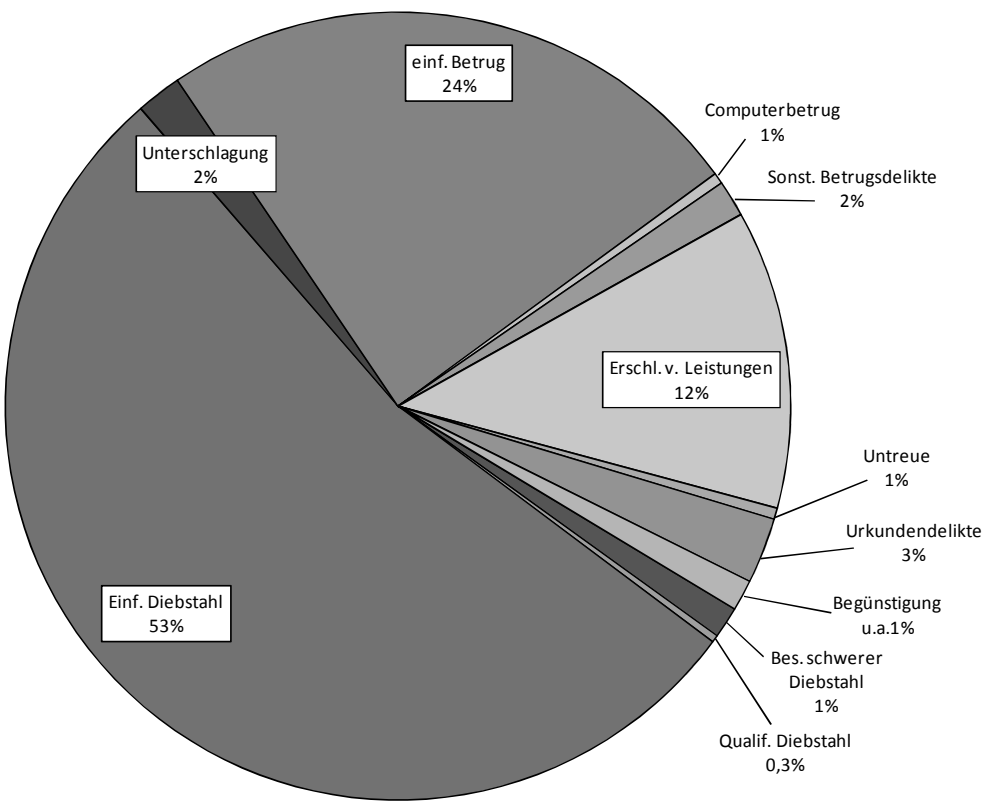

* Absolutzablen siehe Tab. 4.1c im Anhang

Schaubild 4.10: Vermögensdelikte i.w.S. von Männern*

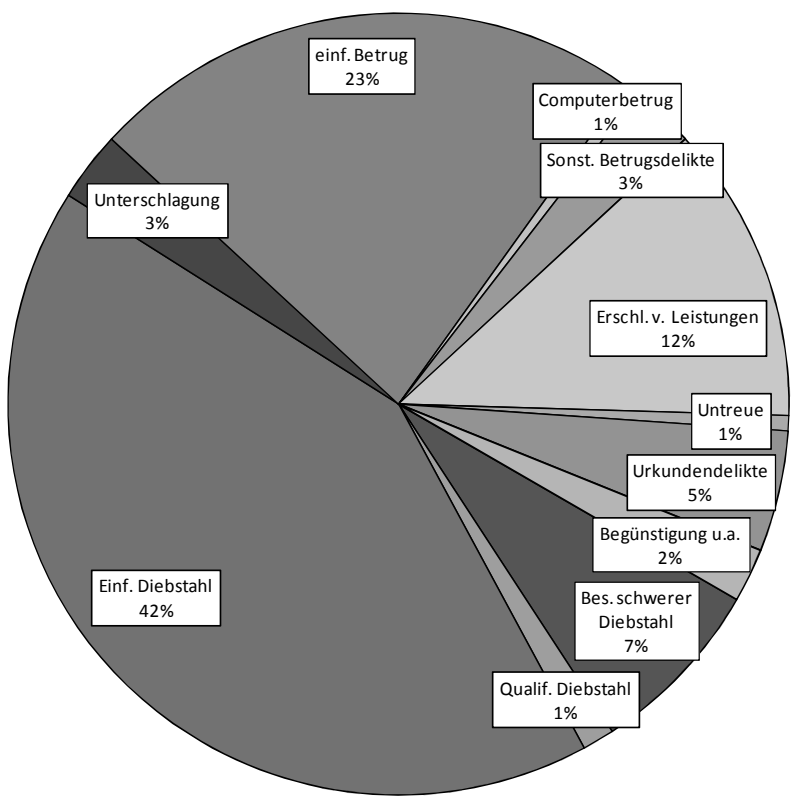

* Absolutzablen siehe Tab. 4.1c im Anhang 
Die Urkundendelikte spielen bei den Männern mit $5 \%$ eine etwas größere Rolle innerhalb der betrachteten Gruppe der Vermögensdelikte i.w.S. als bei den Frauen mit nur 3\%. Bei den anderen Straftatbeständen bestehen keine großen Unterschiede zwischen den Geschlechtern. Im Übrigen spielen die Delikte Begünstigung, Hehlerei und Geldwäsche sowohl für Männer (2\%) als auch für Frauen $(1 \%)$ kaum eine Rolle. ${ }^{551}$

Schaubild 4.11: Anteil von Frauen und Männern an Vermögensdelikten i.w.S.*

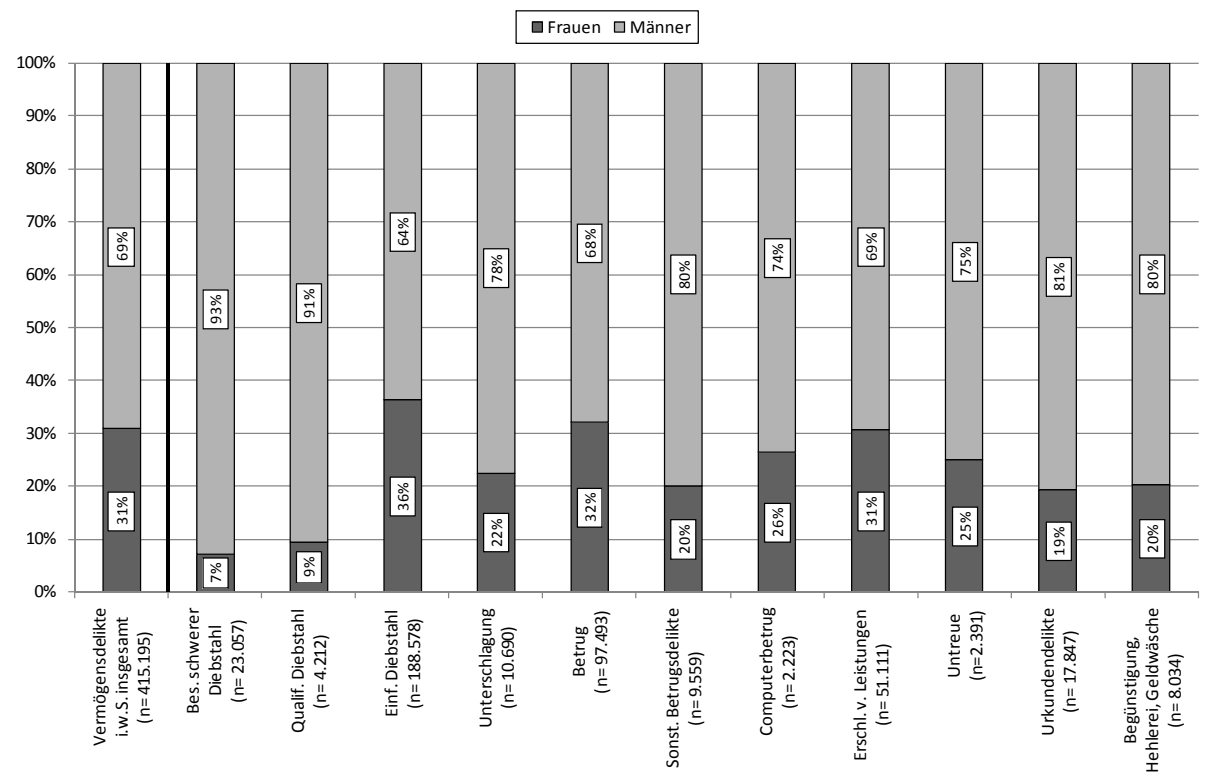

* Absolutzablen siehe Tab. 4.1c im Anhang

Der Gesamtanteil der Täterinnen an der Eigentums-, Vermögens- und Urkundenkriminalität liegt bei $31 \%$ (vgl. Schaubild 4.11). Am stärksten sind die Frauen beim einfachen Diebstahl (36\%), Betrug (32\%) sowie beim Erschleichen von Leistungen $(31 \%)$ repräsentiert. Der Frauenanteil am Computerbetrug und an der Untreue liegt mit $26 \%$ und $25 \%$ zwar über ihrem Anteil an der Gesamtkriminalität (20\%), jedoch unter ihrem Anteil an den Vermögensdelikten i.w.S. insgesamt (31\%). Gleiches gilt für die Unterschlagung mit $22 \%$. Ein besonders niedriger Frauenanteil ist schließlich beim qualifizierten $(9 \%)$ und besonders schweren Diebstahl (7\%) zu verzeichnen.

${ }^{551}$ Daher wird für diese Delikte auch keine eigene Kategorie gebildet. Sie werden im Folgenden bei den „sonstigen Delikten“ berücksichtigt. 


\subsection{Sonstige Deliktsgruppen}

\subsubsection{Gruppierung der sonstigen Deliktsgruppen}

Aus pragmatischen Gründen, insbesondere aufgrund der kleinen Fallzahlen, werden die übrigen Delikte im Allgemeinen zu einer Großgruppe „sonstige Deliktsgruppen“ zusammengefasst, obwohl sie inhaltlich heterogen sind. Um deutlich zu machen, welche unterschiedlichen Delikte mit je spezifischer Eigenart darunter fallen, werden sie im Folgenden kurz analysiert.

\subsubsection{Fahrlässige Körperverletzung und fahrlässige Tötung}

Die fahrlässige Körperverletzung gem. \229 StGB sowie die fahrlässige Tötung gem. \ 222 StGB wurden nicht mit den Körperverletzungs- bzw. Tötungsdelikten zusammengefasst, da das Handlungsunrecht bei den Fahrlässigkeitsdelikten weniger schwer wiegt als bei den vorsätzlichen Körperverletzungs- und Tötungsdelikten und es sich nicht um Gewaltdelikte handelt.

Fraglich ist jedoch, ob die beiden Tatbestände im Rahmen der Verkehrsdelikte zu berücksichtigen sind. Sie können tatbestandlich zwar auch auf andere Weise als im Verkehr verwirklicht werden, spielen aber besonders dort eine bedeutsame Rolle. Dies wird deutlich, wenn man die Zahlen der StVS heranzieht, die die $\iint 222,229$ StGB von vorneherein in zwei Kategorien einteilt, nämlich ,im Verkehr“ und „außerhalb des Verkehrs“: So wurden im Jahr 2009 insgesamt 3.993 Frauen wegen fahrlässiger Körperverletzung verurteilt, wovon 2.946 der Fälle im Verkehr und lediglich 1.047 außerhalb des Verkehrs erfolgten.552 Der StVS liegt jedoch eine andere Datenerhebungsmethode zugrunde. Sie beruht auf den Verwaltungsdaten der Strafverfolgungsbehörden, die wiederum auf den Verfahrensakten beruhen. ${ }^{553}$ Für die vorliegende Untersuchung kann nur versucht werden, durch bestimmte Deliktskombinationen ${ }^{554}$, die Deliktsbeschreibung ${ }^{555}$ oder eine verkehrsspezifische Sanktion ${ }^{556}$ einen Zusammenhang zum Verkehr zu ermitteln. Allerdings können so nicht alle Fälle mit straßenverkehrsrechtlichem Bezug ermittelt werden. ${ }^{557}$ Ein solcher verkehrsrechtlicher Zusammenhang ist nicht zwingend im BZR einzutragen. Auch ein Vergleich mit den Daten der StVS aus dem Bezugsjahr 2004 zeigt, dass für die vorliegende Untersuchung viele fahrlässige Tötungen und Körperverletzungen, die im Straßenverkehr begangen wurden, nicht

\footnotetext{
552 StatB A (Hrsg.), StVS 2009, Tab. 2.1.

$553 \mathrm{Vgl}$. StatB $A$ (Hrsg), StVS 2009, S. 6.

554 So wäre beispielsweise die Kombination von \229 StGB und \315 c I Nr. 1a StGB ein Indiz für eine im Straßenverkehr verwirklichte fahrlässige Körperverletzung.

555 Manchmal findet sich der Zusatz „im Straßenverkehr“ o.ä. in der Deliktsbeschreibung im Datensatz wieder.

556 So wäre z.B. eine neben $\iint 222,229$ StGB im Urteilstenor genannte Entziehung der Fahrerlaubnis gem. \69 StGB ein verhältnismäßig sicheres Indiz für einen verkehrsrechtlichen Bezug.

557 So auch bereits Kirchner, in: Heinz/Jehle (Hrsg.), Rückfallforschung, S. 263 f.
} 
erfasst werden können: So lässt sich nach den oben genannten Kriterien im Datensatz des BZR für $\$ 229$ StGB nur in 260 Fällen ein verkehrsrechtlicher Bezug herstellen, wohingegen nach der StVS 3.445 der insgesamt 4.376 Fälle des $\ 229$ StGB im Verkehr verwirklicht wurden. ${ }^{558}$ Folglich ist eine klare Abgrenzung nicht möglich, weshalb die $\int \$ 222,229$ StGB für die vorliegende Untersuchung gesondert betrachtet werden.

\subsubsection{Verkehrsdelikte ohne und unter Alkoholeinfluss}

Die Straßenverkehrsdelikte sollen in zwei Gruppen betrachtet werden, nämlich einmal ohne und zum anderen unter Alkoholeinfluss.

In der Kategorie der Verkehrsdelikte unter Alkoholeinfluss werden die $\$ \int 315 \mathrm{c}$ Abs. 1 Nr. 1a, 316 StGB zusammengefasst.

Bei den Verkehrsdelikten ohne Alkoholeinfluss werden die $\$ ₫ 315 \mathrm{~b}$, die restlichen Fälle des $₫ 315$ c StGB ${ }^{559}, \rrbracket 142$ StGB sowie Verstöße gegen das StVG ${ }^{560}$ berücksichtigt.

\subsubsection{Delikte nach dem BtMG}

Die Daten des BZR geben auch Auskunft über Verstöße gegen das BtMG, sodass diese in einer Gruppe dargestellt werden können.

\subsubsection{Sonstige Delikte}

Letztendlich sind sämtliche Delikte, die nicht bereits einer anderen Gruppe hinzugerechnet wurden, in einer Kategorie für sonstige Delikte zu berücksichtigen.

\subsubsection{Ergebnisse}

Die sonstigen Deliktsgruppen, also die fahrlässige Körperverletzung und fahrlässige Tötung, die Verkehrsdelikte mit und unter Alkoholeinfluss, die Delikte nach dem BtMG sowie die sonstigen Delikte, sind aufgrund ihrer Heterogenität größtenteils nicht miteinander vergleichbar. Ein Vergleich der einzelnen Gruppen dieser Kategorie, entsprechend dem Vorgehen bei den zuvor dargestellten Ergebnissen zu den Gewaltdelikten ${ }^{561}$ sowie den Vermögensdelikten i.w.S562, wird daher nicht angestellt. Vergleichbar sind allerdings die jeweiligen Anteile an der Gesamtkriminalität von Frauen und Männern. Diese ergeben sich für die Frauen bereits aus Schaubild 4.2 und für die Männer aus Schaubild 4.3. Es zeigt sich, dass Männer innerhalb der sonstigen Deliktsgruppen mit 26\% (davon sind 14\% Verkehrsdelikte ohne Alkoholeinfluss und $12 \%$ solche mit Alkoholeinfluss) sowie $7 \%$ häufi-

\footnotetext{
558 Vgl. StatBA (Hrsg.), StVS 2004, Tab. 2.1.

${ }^{559}$ Gemeint sind die Fälle, die nicht unter $\$ 315$ c I Nr. 1a fallen.

${ }^{560}$ Dies sind insbesondere Verstöße gegen $\iint 21$, 22, 22a, 24a StVG.

561 Vgl. Kap. 4, 1.2.2.

562 Vgl. Kap. 4, 1.3.2.
} 
ger Verkehrsdelikte und Delikte nach dem BtMG begehen als Frauen. Frauen fallen mit $14 \%$ bei den Verkehrsdelikten (6\% unter und $8 \%$ ohne Alkoholeinfluss) und $4 \%$ bei den Delikten nach dem BtMG auf. Der Anteil für fahrlässige Tötungen bzw. fahrlässige Körperverletzungen an der jeweiligen Gesamtkriminalität ist für beide Geschlechter mit $1 \%$ niedrig. Der Anteil für die sonstigen Delikte beträgt für die Frauen $14 \%$ und für die Männer $19 \%$. Betrachtet man die große Gruppe der sonstigen Delikte noch einmal detaillierter, ${ }^{563}$ so zeigt sich, dass hiervon sowohl bei den Frauen als auch bei den Männern $3 \%$ auf Verstöße gegen das AuslG ${ }^{564}$ bzw. AsylverfG entfallen. In $2 \%$ der Fälle sind Frauen und auch Männer wegen Beleidigung aufgefallen. Bei den Frauen erfolgte ferner eine Verurteilung wegen Aussagedelikten, falscher Verdächtigung, Nötigung bzw. Bedrohung, Aussagedelikten, Hausfriedensbruch und Sachbeschädigung in jeweils $1 \%$ der Fälle. Bei den Männern macht die Sachbeschädigung hingegen immerhin einen Anteil von $4 \%$ an ihrer Gesamtkriminalität aus. Auf den Hausfriedensbruch sowie die Nötigung bzw. Bedrohung entfällt auch bei den Männern lediglich ein 1\%iger Anteil. Eine Verurteilung wegen falscher Verdächtigung und Aussagedelikten nimmt bei den Männern hingegen einen kaum messbaren Anteil von unter $1 \%$ ein.

Bei der Bagatellkriminalität, beispielsweise bei Beleidigung und Sachbeschädigung, ist von einem recht großen Selektionsprozess durch die Anwendung der $\iint 153,153$ a StPO sowie durch die Verweisung auf den Privatklageweg 565 auszugehen. Auf der Ebene der polizeilich bekannt gewordenen Kriminalität machen diese beiden Bereiche noch einen Anteil von $8 \%$ (Beleidigung) und $4 \%$ (Sachbeschädigung) an der gesamten von Frauen im Jahr 2004 begangenen Kriminalität aus. ${ }^{566}$ Betrachtet man sämtliche gegen Frauen im Bezugsjahr 2004 ergangenen Verurteilungen wegen Beleidigung oder Sachbeschädigung, so ergibt sich, wie festgestellt, jeweils nur ein Anteil von $1 \%$ an allen gegen Frauen ergangenen Verurteilungen. Insgesamt sind die Anteile der Delikte, die in der Gruppe der sonstigen Delikte zusammengefasst sind, recht niedrig, weshalb diese Delikte auch in der Gesamtbetrachtung (vgl. Schaubild 4.1) keine Erwähnung finden.

563 Vgl. zu den Absolutzahlen Tab. 4.1dim Anhang.

${ }^{564}$ Das AuslG ist am 31.12.2004 außer Kraft getreten und wurde durch das Aufenthaltsgesetz abgelöst.

565 Nur soweit das Delikt im Katalog des $₫ 374$ StPO Erwähnung findet.

566 BKA (Hrsg.), PKS 2004, berechnet nach Tab. 48; vgl. auch Schaubild 1.2 welches sich allerdings auf die Zahlen aus dem Jahr 2009 bezieht; vgl. generell zu den Problemen der Vergleichbarkeit Kap. 1, 1.4 und 3.2. 
Schaubild 4.12: Anteil von Frauen und Männern an sonstigen Deliktsgruppen*

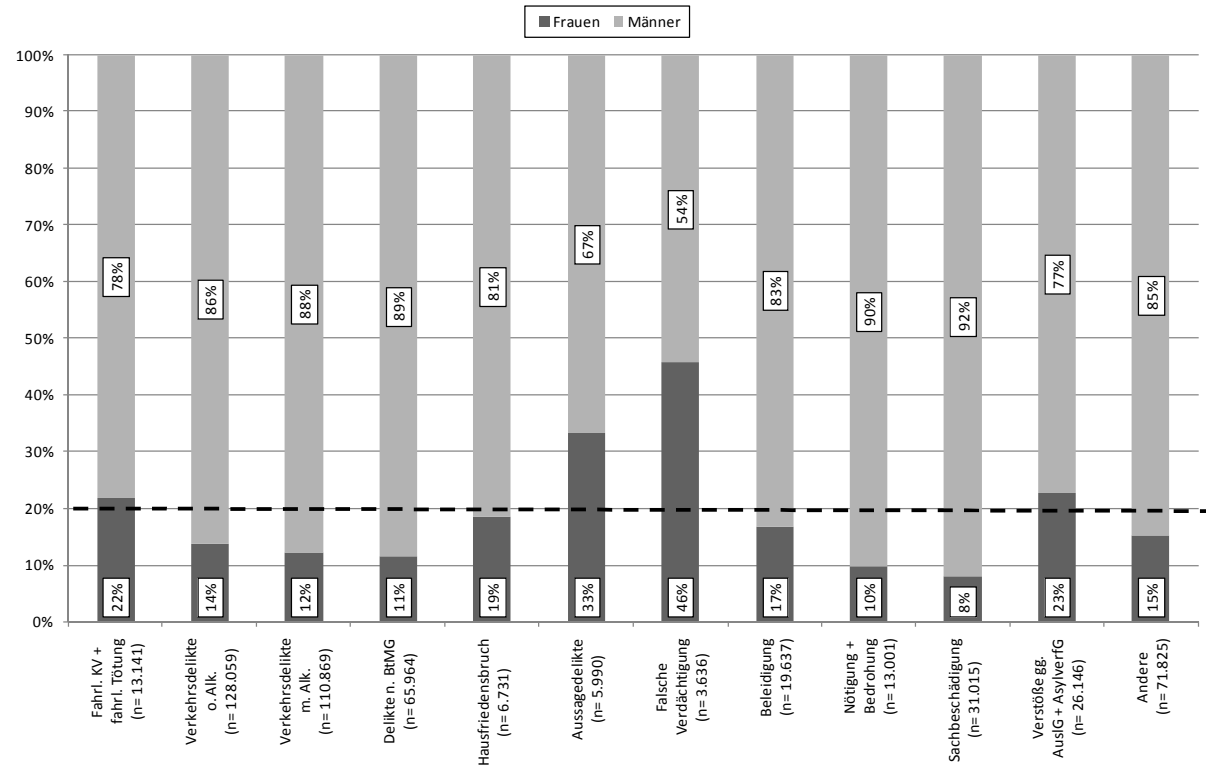

* Absolutrablen siebe Tab. 4.1d im Anhang

Schaubild 4.12 orientiert sich an den Schaubildern 4.8 sowie 4.11 und verdeutlicht den Anteil von Frauen und Männern an den sonstigen Deliktsgruppen, also an der fahrlässigen Körperverletzung und fahrlässigen Tötung, den Verkehrsdelikten mit und ohne Alkoholeinfluss, den Delikten nach dem BtMG sowie den sonstigen Delikten. Die Kategorie der sonstigen Delikte wurde für Schaubild 4.12 detaillierter betrachtet.

Die differenziertere Darstellung zeigt, dass der durchschnittliche Anteil von Frauen an der Gesamtkriminalität von $20 \%$ (vgl. gestrichelte Linie) vor allem von ihrem Anteil an der falschen Verdächtigung und den Aussagedelikten übertroffen wird (vgl. hierzu auch Schaubild 4.5). Etwas höher als der Durchschnitt ist ferner der Frauenanteil an den Verstößen gegen das AuslG und AsylverfG (23\%) sowie an der fahrlässigen Körperverletzung und Tötung $(22 \%)$. Auf den Hausfriedensbruch und die Beleidigung entfallen immerhin noch $19 \%$ bzw. $17 \%$. Besonders niedrig ist der Anteil der Frauen an den Delikten nach dem BtMG (11\%), der Nötigung und Bedrohung (10 \%) sowie der Sachbeschädigung mit $8 \%$. 


\section{Soziodemographische Daten}

\subsection{Alter}

Neben dem Geschlecht und der Nationalität geben die Daten des BZR auch Auskunft über das Alter der Täterinnen und Täter. Alter im Sinne der vorliegenden Untersuchung bedeutet die Differenz in Jahren zwischen dem Geburtsdatum und dem Zeitpunkt der der Bezugsentscheidung zugrunde liegenden Tat. ${ }^{567}$

Bei der Darstellung der Altersstruktur nach den vorliegenden Daten ist immer zu beachten, dass sämtliche verfahrenserledigenden Einstellungen auf der Grundlage der StPO, also vor allen Dingen auch die $\iint 153,153$ a StPO, mangels Eintragung in das BZR nicht bei der Auswertung berücksichtigt werden können. Die $\iint 45,47$ JGG sind hingegen in das Erziehungsregister einzutragen und können daher mit analysiert werden. ${ }^{568}$ Dies kann zu einer Verzerrung der Altersstruktur führen, da der Anteil der Bezugsentscheidungen im Jugend- und Heranwachsendenalter im Vergleich zum Erwachsenenalter deutlich erhöht erscheint.

Um dies zu verdeutlichen, gibt Schaubild 4.13 die Altersstruktur der weiblichen im Vergleich zu den männlichen Tätern zur Tatzeit, zum einen ohne und zum anderen unter Berücksichtigung der Eintragungen nach $\iint$ 45, 47 JGG, wieder.

Betrachtet man die Alterskurven ohne die Entscheidungen nach SS 45 , $47 \mathrm{JGG}$, so wird deutlich, dass beide Geschlechter am häufigsten im Heranwachsendenalter (Höhepunkt liegt im Alter von 21 Jahren) mit einer strafrechtlichen Verurteilung registriert werden. Mit zunehmenden Lebensjahren sinken die Zahlen zunächst steil, dann immer weiter abflachend ab.

Im Vergleich dazu findet sich bei Berücksichtigung der Entscheidungen nach $\iint 45,47$ JGG auf den ersten Blick eine deutliche Erhöhung der Zahlen jugendlicher und heranwachsender Täter. Diese Erhöhung ist allerdings auf das bereits erwähnte unterschiedliche Spektrum eintragungspflichtiger Entscheidungen nach Jugendstrafrecht zurückzuführen.

Ferner zeigt der Vergleich der Alterskurven mit den Entscheidungen nach $\iint$ 45, 47 JGG, dass Frauen mit 14 Jahren den Höchstwert früher als Männer mit 17 Jahren erreichen. Darüber hinaus nimmt die Alterskurve beider Geschlechter mit zunehmendem Lebensalter immer weiter ab und tendiert schließlich gegen Null.

\footnotetext{
567 Vgl. auch Jeble/Hobmann-Fricke/Albrecht/Tetal, Legalbewährung nach strafrechtlichen Sanktionen, 2010, S. 41.

568 Vgl. auch Ausführungen unter Kap. 3, 3.1.
} 
Schaubild 4.13: Bezugsentscheidung nach Alter und Geschlecht*

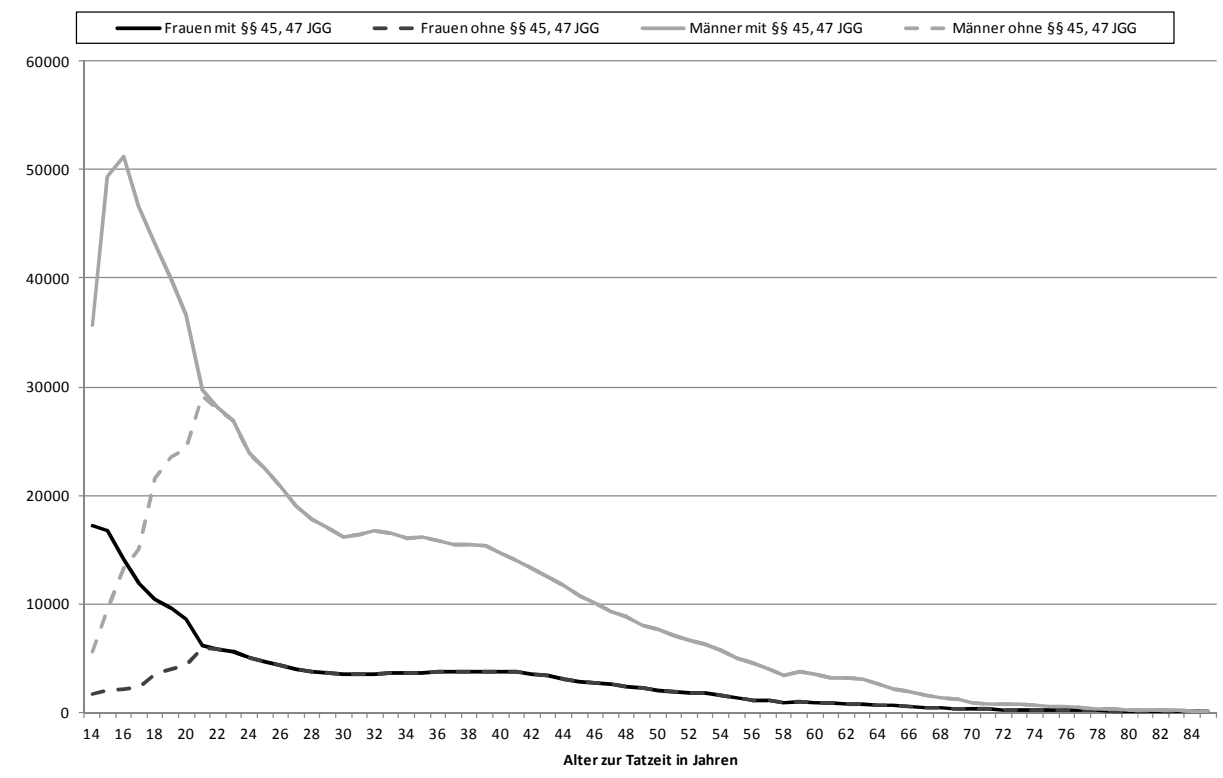

* Absolutzablen siehe Tab. $4.2 \mathrm{a}$ im Anhang

Nachdem der Unterschied zwischen der Berücksichtigung und Ausklammerung der Einstellungen gem. $\iint 45,47$ JGG verdeutlicht wurde, werden diese im Folgenden aus zwei Gründen immer mitberücksichtigt:569 Zum einen stellen sie den größten Teil der jugendrechtlichen Verfahrenserledigungen dar und ihre Berücksichtigung führt zu einem erheblichen Informationsgewinn. Zum anderen ist die Einstellungspraxis im Erwachsenenstrafrecht nicht mit der im Jugendstrafrecht zu vergleichen, sodass man auch ohne Berücksichtigung der $\$ \int 45,47$ JGG keine wirkliche Gleichstellung erreichen würde. ${ }^{570}$

Schließlich ist $\mathrm{zu}$ beachten, dass mit demographischen Schwankungen zu rechnen ist, da sich die Werte nicht auf die deutsche Wohnbevölkerung beziehen.

Eine Analyse des relativen Anteils der jeweiligen Altersstufe an der Gesamtzahl der Straftaten für die gebildeten Gewaltdeliktsgruppen im Vergleich nur für die Frauen, ergibt folgendes Bild: ${ }^{571}$ Bei allen Deliktsgruppen - mit Ausnahme der Tötungsdelikte - zeigt sich ein deutlicher Höchstwert für die 14- und 15-jährigen Mädchen. Bis zum Ende des Heranwachsendenalters mit 21 Jahren sinken die

${ }^{569}$ Eine Differenzierung findet sich aber der Übersicht halber in den Tabellen im Anhang.

570 So auch die Jeble/Albrecht/Hohmann-Fricke/Tetal, Legalbewährung nach strafrechtlichen Sanktionen, 2010, S. 37.

571 Vgl. zu den Zahlen Tab. 4.3a im Anhang; auf eine graphische Darstellung wurde an dieser Stelle aufgrund der teilweise sehr niedrigen Zahlen in den jeweiligen Gewaltdeliktsgruppen verzichtet. 
Zahlen erwartungsgemäß drastisch ab. Es wird deutlich, dass fast $60 \%$ der einfachen Körperverletzungen und $62 \%$ der sonstigen Gewaltdelikte von Frauen in der Altersphase von 14 bis unter 21 Jahren begangen werden. Bei den sonstigen Körperverletzungsdelikten sind es sogar $80 \%$. Bis zum 25. Lebensjahr fällt die Alterskurve für die Körperverletzungs- und sonstigen Gewaltdelikte konstant ab. Danach sind die Zahlen sehr schwankend: Die Anzahl der einfachen Körperverletzungen steigt mit Erreichen des 30. bis zum 36. Lebensjahr noch einmal leicht an, um dann wieder konstant abzufallen. Auch die Anzahl der sonstigen Körperverletzungsdelikte nimmt ab dem 30. bis zum 33. Lebensjahr noch einmal kurzfristig zu. Der leichte Anstieg dürfte auf die geburtenstarken Jahrgänge in Deutschland zurückzuführen sein. Für die sonstigen Gewaltdelikte ist eine solche Tendenz kaum auszumachen, da die absoluten Zahlen durchweg sehr niedrig sind.

Bei Auswertung der Altersstruktur für die Tötungsdelikte ergibt sich ein uneinheitlicher, schwankender Verlauf auf, der allerdings gleichfalls auf die geringen Fallzahlen zurückzuführen ist. Dennoch zeigt sich, dass die Altersstruktur bei den Tötungsdelikten von Anfang an relativ konstant bleibt: Die Zahlen bleiben durchweg auf sehr niedrigem Niveau und finden nicht, etwa wie bei den anderen Gewaltdeliktsgruppen, einen deutlichen Höhepunkt in den Jugendjahren. Gut ein Drittel der Tötungsdelikte (37\%) findet in der Altersphase von 30 bis 43 Jahren statt.

Schaubild 4.14 verdeutlicht den relativen Anteil der jeweiligen Altersstufe an den verschiedenen Vermögensdeliktsgruppen. Auffällig ist zunächst der einfache Diebstahl, bei dem gegen die 14-jährigen Mädchen am häufigsten eine Entscheidung ergeht und der Rückgang mit zunehmendem Alter zunächst besonders deutlich ist, um dann ab dem 21. Lebensjahr in einen nur noch gemächlichen Rückgang überzugehen. Der Höchstwert liegt auch in der Gruppe des besonders schweren und qualifizierten Diebstahls bei den 14-jährigen. Ähnlich wie bei der einfachen Körperverletzung (vgl. Tab. 4.3a im Anhang) nimmt die Anzahl der Entscheidungen in den Diebstahlsgruppen bis zum Beginn des Erwachsenenalters stark ab. Ca. $60 \%$ der einfachen, besonders schweren und qualifizierten Diebstähle werden in der Altersphase 14 bis unter 21 Jahre begangen.

Bei den anderen Delikten innerhalb dieser Gruppe ist das Maximum nicht bereits in der Altersgruppe der 14-jährigen zu verzeichnen. Beim Erschleichen von Leistungen liegt es vielmehr bei den 19-jährigen Frauen. Gleichwohl werden auch hier knapp $60 \%$ der Delikte im Alter von 14 bis unter 21 begangen. Zu berücksichtigen ist aber, dass, wie anfangs erwähnt, insbesondere im Bereich der leichteren Kriminalität mit einer vermehrten Anwendung der $\iint 45,47$ JGG zu rechnen ist. ${ }^{572}$

Eine andere Altersverteilung ergibt sich allerdings bei Betrachtung der Deliktsgruppe Betrug u.a.

572 Vgl. zu einem Vergleich der absoluten Zahlen mit und ohne $\iint 45,47$ JGG Tab. $4.3 b$ im Anhang. 
Schaubild 4.14: Anteil der jeweiligen Altersstufe an verschiedenen Vermögensdelikten i.w.S. von Frauen*

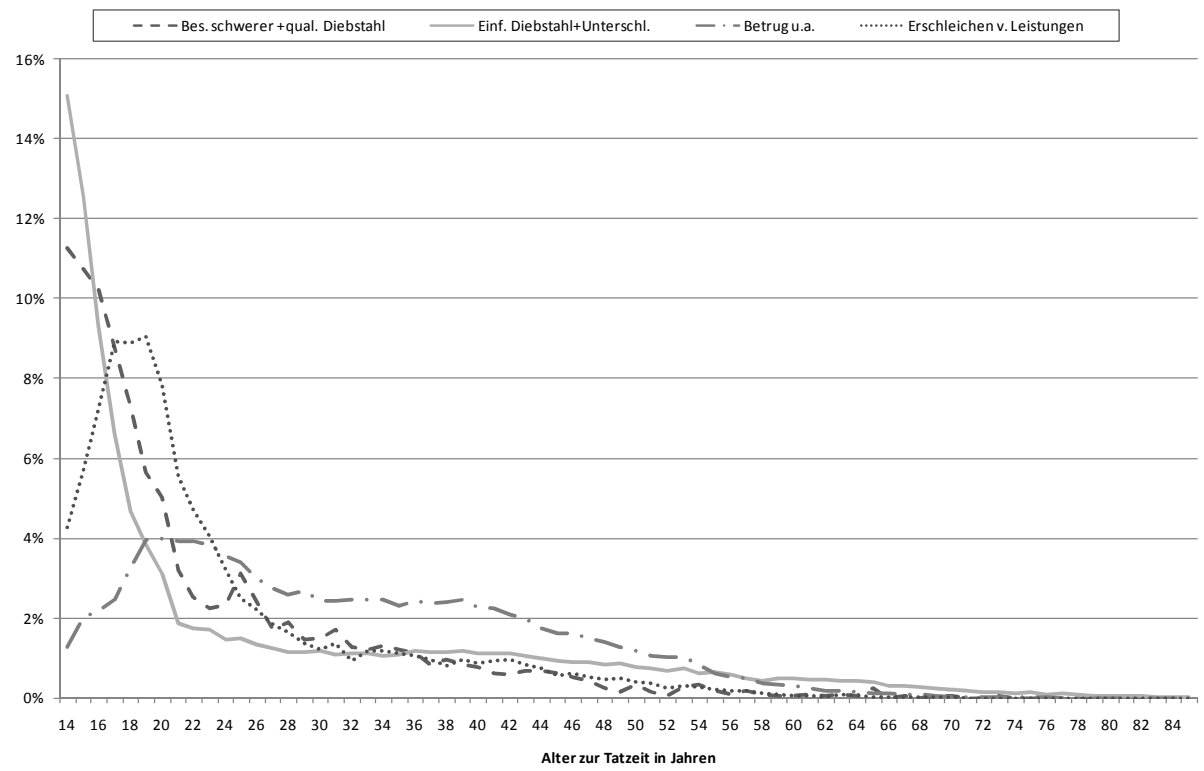

\section{* Absolutrablen siehe Tab. 4.36 im Anhang}

Schaubild 4.14 verdeutlicht, dass die Alterskurve mit zunehmendem Alter nicht so drastisch absinkt wie bei den anderen Deliktsgruppen. Der Höchstwert liegt hier in der Gruppe der 20-jährigen; lediglich $22 \%$ der Betrügereien finden im Alter von 14 bis unter 21 Jahren statt. Die Betrügerinnen sind mithin älter als die „durchschnittliche“ Täterin, die zumeist im Alter von 14 Jahren verurteilt wird (vgl. Schaubild 4.14).

Schaubild 4.15 zeigt nunmehr den relativen Anteil der jeweiligen Altersstufe an den Verkehrsdelikten ohne und unter Alkoholeinfluss, Delikten nach dem BtMG sowie den fahrlässigen Körperverletzungen und Tötungen.

Der starke Anstieg der Verkehrsdelikte und der fahrlässigen Körperverletzungen und Tötungen bis zum Alter von 18 Jahren ist auf den Erwerb der Fahrerlaubnis zurückzuführen.

Für die Verkehrsdelikte ohne Alkoholeinfluss liegt der Höchstwert bei den 18jährigen. Auch fahrlässige Körperverletzungen und Tötungen werden am häufigsten von 18-jährigen Täterinnen begangen. Dies verwundert nicht, da diese Delikte vermutlich zumeist im Zusammenhang mit dem Straßenverkehr stehen. ${ }^{573}$ Sodann sinkt die Alterskurve stark ab. Ab dem Alter von 34 Jahren steigt der Anteil der

573 Vgl. Ausführungen unter Kap. 4, 1.4.1.1. 
jeweiligen Altersstufe an den Verkehrsdelikten ohne Alkoholeinfluss noch einmal kurzfristig an.

Schaubild 4.15: Anteil der jeweiligen Altersstufe an den sonstigen Deliktsgruppen für Frauen*

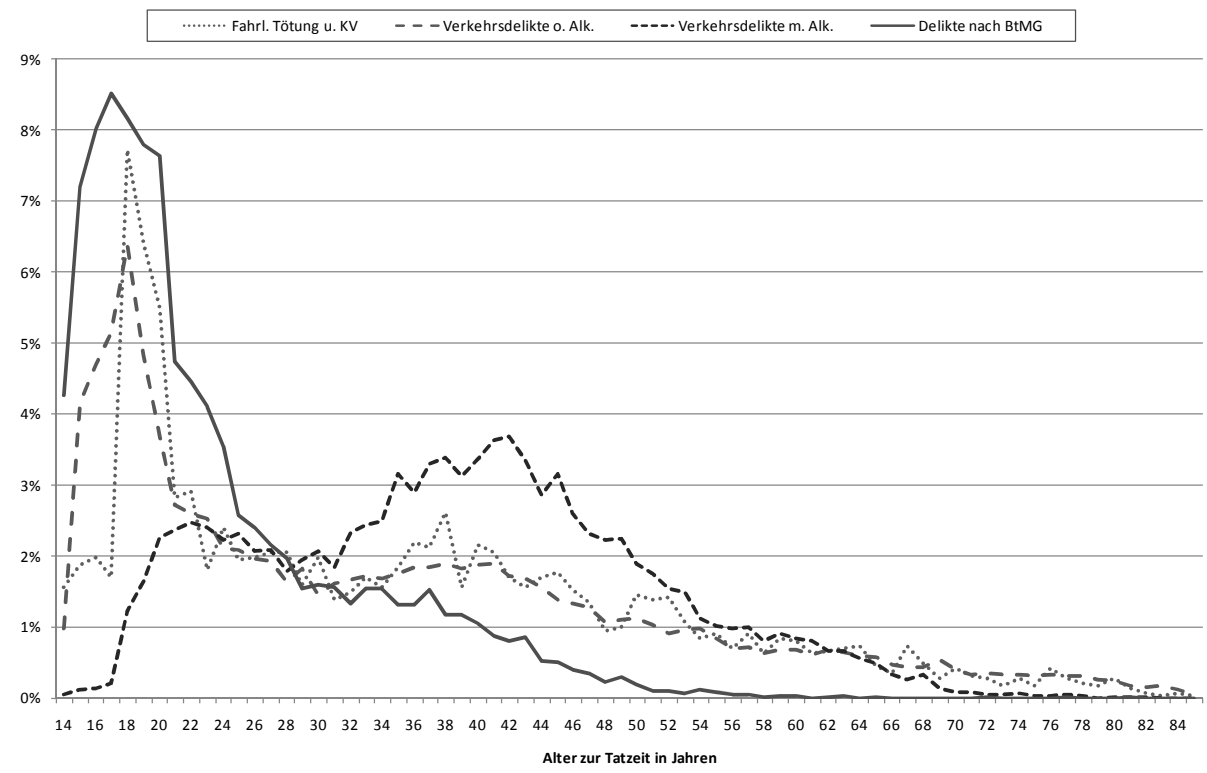

* Absolutzablen siehe Tab. $4.3 \mathrm{c} \mathrm{im} \mathrm{Anhang}$

Bei den Verkehrsdelikten unter Alkoholeinfluss liegt der Höchstwert hingegen bei den 40-42-jährigen Frauen. Nur 7 \% der Täterinnen innerhalb dieser Deliktsgruppe sind unter 21 Jahre. Der Anteil der 21-34-jährigen ist relativ gleichbleibend. Ab 34 bis 42 Jahren steigt die Alterskurve noch einmal an, um dann wieder konstant $\mathrm{zu}$ sinken. Folglich unterscheidet sich die Altersverteilung bei den Täterinnen eines Verkehrsdelikts unter Alkoholeinfluss erheblich von der Altersverteilung bei den anderen Deliktsgruppen.

Betrachtet man den Verlauf der Altersverteilung bei den Delikten nach dem BtMG, so fällt auf, dass die Alterskurve mit zunehmendem Alter sehr stark abnimmt. Das Maximum ist hier bei den 18-jährigen Täterinnen auszumachen. 60 \% der wegen eines BtMG-Delikts verurteilten Frauen sind 14 bis unter 21 Jahre. Der Verlauf der Alterskurve entspricht hier mithin der der meisten anderen Deliktsgruppen, wie z.B. der beim einfachen Diebstahl oder bei der einfachen Körperverletzung (vgl. Schaubild 4.14 und Tab. 4.3a, 4.3b im Anhang). 


\subsection{Nationalität}

Ein weiteres personenbezogenes Merkmal ist die Nationalität. Von den straffälligen Frauen sind insgesamt $17 \%$ nichtdeutsch. Bei den straffälligen Männern ist der Anteil von Nichtdeutschen mit $19 \%$ etwas höher.

Schaubild 4.16574 zeigt den Anteil von Nichtdeutschen an den verurteilten Frauen sowie den Anteil von Nichtdeutschen an den verurteilten Männern differenziert nach den ausgewählten Deliktsgruppen (vgl. Schaubild 4.1).

Schaubild 4.16: Anteil von Nichtdeutschen an verurteilten Frauen und Männern insgesamt differenziert nach Deliktsgruppen*

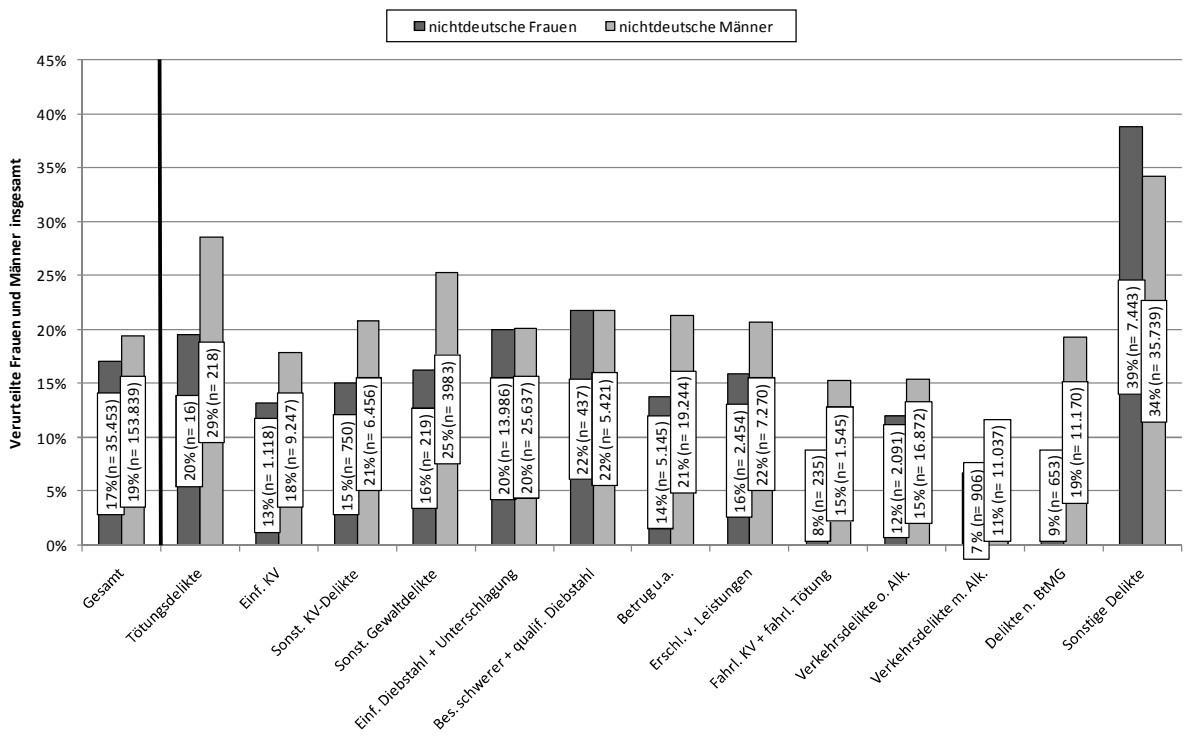

* Absolutzablen siebe Tab. $4.4 a$ im Anhang

Es zeigt sich zunächst, dass der Anteil von Nichtdeutschen an der Gesamtzahl der Verurteilten sowohl bei den Frauen als auch bei den Männern mit 39 \% (Frauen) bzw. $34 \%$ (Männer) am höchsten in der Kategorie der sonstigen Delikte ist. Grund dafür ist, dass in dieser Kategorie die Verstöße gegen das AuslG und AsylverfG erfasst werden. Hohe Anteile sind ferner für die Diebstahlsdelikte mit $22 \%$ beim besonders schweren und qualifizierten Diebstahl sowie $20 \%$ beim einfachen Diebstahl zu verzeichnen. In diesen Kategorien ist der Anteil von nichtdeutschen Frauen an der Gesamtzahl der verurteilten Frauen im Übrigen genauso hoch wie der Anteil von nichtdeutschen Männern an den verurteilten Männern insgesamt.

${ }^{574}$ Die Fälle, für die keine Nationalität ermittelt werden konnte, wurden ausgeschlossen. 
Aber auch bei den Tötungsdelikten übersteigt der Anteil von nichtdeutschen Täterinnen mit knapp $20 \%$ ihren Anteil an der Gesamtkriminalität von Frauen, der, wie festgestellt, bei $17 \%$ liegt. Zudem fällt auf, dass bei den Gewaltdeliktsgruppen und den Delikten nach BtMG die Kluft zwischen dem Anteil von Nichtdeutschen bei den Frauen und dem der Nichtdeutschen bei den Männern besonders groß ist. Der Anteil von Nichtdeutschen an straffälligen Männern insgesamt ist bei den Tötungsdelikten mit $29 \%$ besonders hoch. Vermutlich werden die hier und die bei sonstigen schwereren Gewaltdelikten registrierten nichtdeutschen Täter häufig als Folge ausgewiesen (vgl. den im Bezugsjahr geltenden $\ 47$ AuslG). Dafür spricht auch ein Vergleich mit den Daten des Rückfalldatensatzes, der nicht auf den Zeitpunkt der Verurteilung, sondern auf die Haftentlassung abstellt: Eine vergleichende Berechnung hat ergeben, dass in diesem Fall der Anteil von Nichtdeutschen sowohl bei den straffälligen Frauen als auch bei den straffälligen Männern nur noch $16 \%$ beträgt. Die Differenz zu den auf dem Entscheidungsdatensatz beruhenden Daten dürfte durch Ausweisung oder Abschiebung zu erklären sein. In diesen Fällen wird im BZR kein Erledigungszeitpunkt eingetragen.

Besonders niedrig ist der Anteil von Nichtdeutschen an den verurteilten Frauen bei den Delikten nach dem BtMG (9\%), den Verkehrsdelikten (12\% für die Verkehrsdelikte ohne und $7 \%$ für die unter Alkoholeinfluss) sowie der vermutlich überwiegend mit letzteren im Zusammenhang stehenden fahrlässigen Tötung und fahrlässigen Körperverletzung (8 \%).

Der Anteil von Nichtdeutschen an den Täterinnen und Tätern übersteigt über alle Deliktsgruppen hinweg deutlich ihren Anteil an der Wohnbevölkerung. Tab. 4.1 macht dies noch einmal deutlich.

Tabelle 4.1: Anteil der Nichtdeutschen an der weiblichen bzw. männlichen Wobnbevölkerung und den weiblichen bzw. männlichen Verurteilten im Jabr 2004

\begin{tabular}{|c|c|c|c|c|}
\hline & \multicolumn{2}{|c|}{$\begin{array}{c}\text { Anteil an der weiblichen } \\
\text { bzw. männlichen Wohnbe- } \\
\text { völkerung }\end{array}$} & \multicolumn{2}{|c|}{$\begin{array}{c}\text { Anteil an den weiblichen } \\
\text { bzw. männlichen Verurteil- } \\
\text { ten }\end{array}$} \\
\hline & abs. & in $\%$ & abs. & in $\%$ \\
\hline $\begin{array}{l}\text { Nichtdeutsche } \\
\text { Frauen }\end{array}$ & 3.501 .524 & $8 \%$ & 38.093 & $17 \%$ \\
\hline Nichtdeutsche Männer & 3.786 .456 & $9 \%$ & 173.304 & $20 \%$ \\
\hline
\end{tabular}

Quelle: StBA (Hrsg.), Fachserie 1, Reihe 1.3: Bevölkerungsfortschreibung 2004, Tab. 1.2 sowie eigene Daten.

Im Bezugsjahr 2004 haben nichtdeutsche Frauen einen Anteil von $8 \%$ an der weiblichen Wohnbevölkerung und nichtdeutsche Männer einen Anteil von 9\% an der männlichen Wohnbevölkerung ausgemacht. Die durchschnittlichen Anteile an den weiblichen von $17 \%$ bzw. an den männlichen Verurteilten von $19 \%$ sind 
sehr viel höher. Hierbei muss jedoch berücksichtigt werden, dass im BZR auch Ausländer registriert werden, die nicht zur Wohnbevölkerung hinzugerechnet werden, wie beispielsweise Touristen, illegale Einwanderer, Durchreisende, Stationierte oder Studenten. Zudem gibt es Straftatbestände, die in der Regel nur von Ausländern verwirklicht werden können, nämlich die Straftaten nach dem AuslG und AsylverfG. Ferner muss relativierend festgestellt werden, dass der Anteil der jüngeren Personen sowie Angehörigen der niedrigeren sozialen Schichten bei den Nichtdeutschen höher ist als bei den Deutschen, sodass die Bedeutung des relativ hohen Anteils an den Verurteilten im Vergleich zur Wohnbevölkerung nicht überschätzt werden darf. Aus diesen Gründen kann auch keine aussagekräftige Belastungszahl für Nichtdeutsche berechnet werden. ${ }^{575}$

Schaubild 4.16 lässt jedoch keine Aussage über die Deliktsstruktur der Nichtdeutschen zu, die daher in Schaubilder 4.17 gesondert betrachtet werden soll.

\section{Schaubild 4.17: Deliktsstruktur von nichtdeutschen Frauen*}

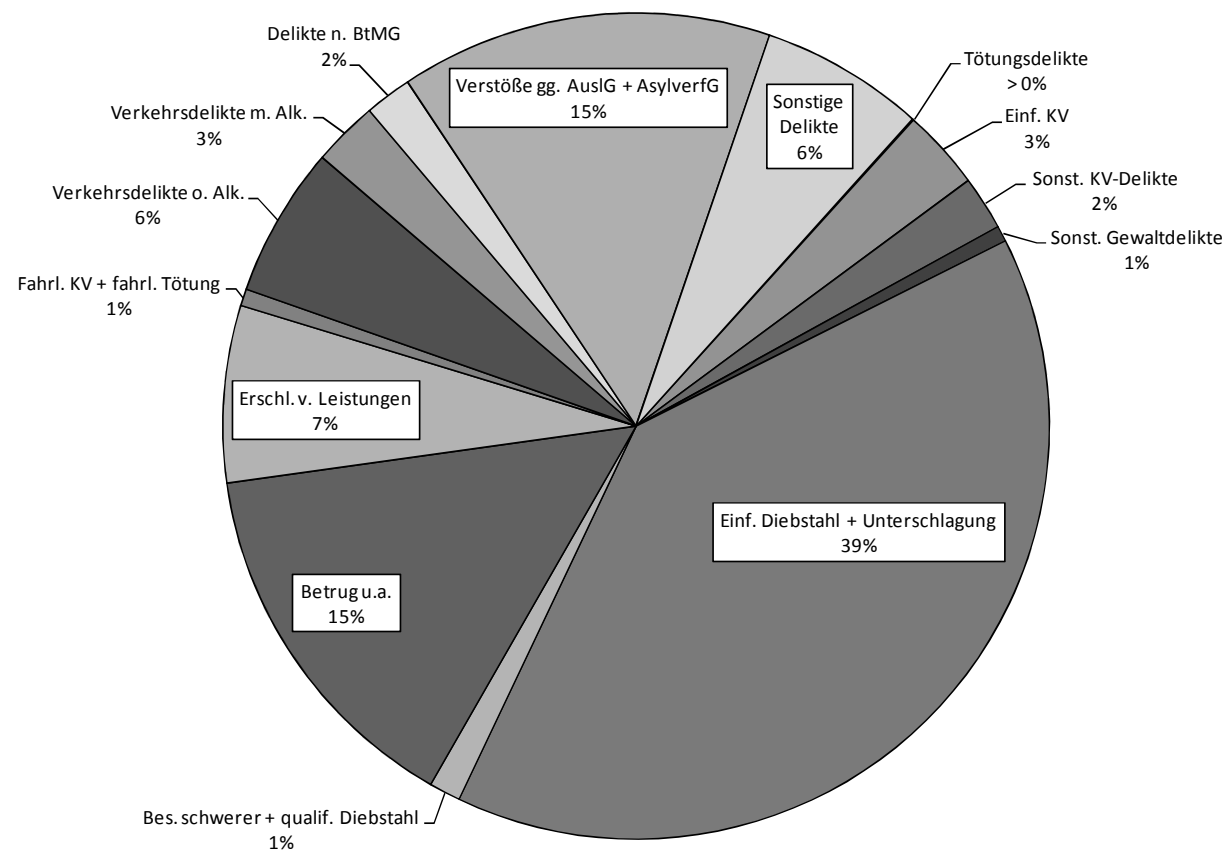

* Absolutzablen siebe Tab. 4.4a im Anhang

Schaubild 4.17 bietet einen Überblick über die von nichtdeutschen Frauen begangene Kriminalität. Es zeigt sich, dass sich die Deliktsstruktur der nichtdeutschen kaum von der der deutschen Frauen unterscheidet. Auch die nichtdeutschen Täte-

575 Hierzu bereits Kap. 1, 2.1.1. 
rinnen begehen in erster Linie Diebstähle und Unterschlagungen (39\%). Der einfache Betrug u.a. sowie das Erschleichen von Leistungen machen immerhin noch Anteile von $15 \%$ bzw. $7 \%$ aus, sodass auf die Vermögenskriminalität i.w.S. über $50 \%$ der Gesamtkriminalität entfällt. Der Anteil von nichtdeutschen Frauen an der Gesamtzahl von Frauen ist bei den schwereren Diebstahlsformen zwar relativ hoch (vgl. Schaubild 4.16), gleichwohl spielt der besonders schwere und qualifizierte Diebstahl in der Gesamtstruktur mit $1 \%$ nur eine geringe Rolle. Erwartungsgemäß werden hingegen Verstöße gegen das AuslG und AsylverfG, gemeinsam mit der Deliktsgruppe „Betrug u.a.“, am zweithäufigsten begangen.

Der Anteil der Deliktsgruppen, die der Gewaltkriminalität zuzuordnen sind, ist wie bei den deutschen Frauen recht klein.

Ein deutlicher Unterschied besteht aber bei der Begehung von Verkehrsdelikten und Delikten nach dem BtMG: Nichtdeutsche Frauen fallen hier im Gegensatz zu deutschen Frauen recht selten auf, was auf kulturelle Unterschiede im Umgang mit Alkohol und Drogen zurückführbar sein könnte.

Schaubild 4.18: Altersverteilung von deutschen und nichtdeutschen Frauen mit und obne $\iint$ 45, $47 \mathrm{JGG}^{*}$

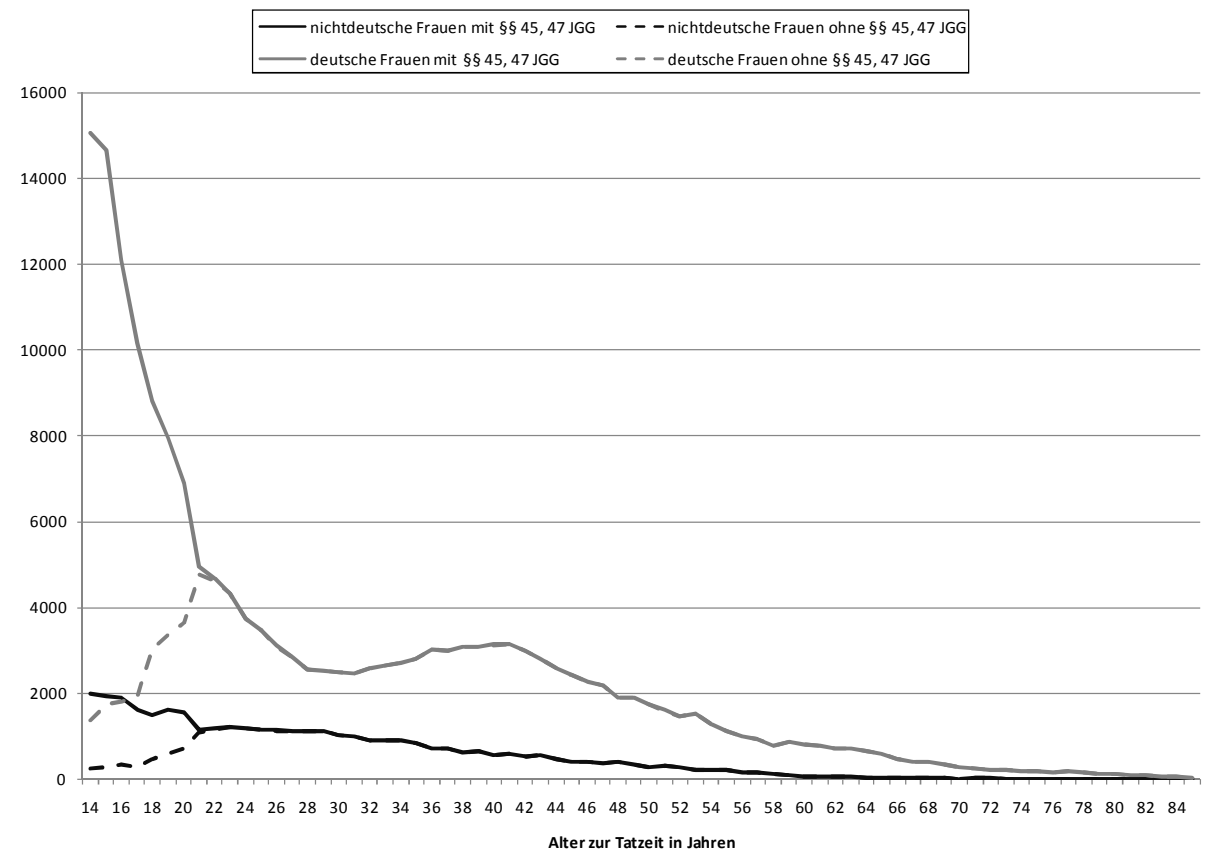

* Absolutzablen siehe Tab. 4.5 a im Anhang 
In Schaubild 4.18 ist die Altersverteilung für deutsche und nichtdeutsche Frauen dargestellt. An dieser Stelle soll, angelehnt an Schaubild 4.13, auch eine Betrachtung ohne die $\$ \int 45,47$ JGG erfolgen. Wie zu erkennen ist, stellen sowohl bei den nichtdeutschen als auch bei den deutschen Frauen die 14-jährigen die größte Gruppe dar, wenn man die $\iint 45,47$ JGG mitberücksichtigt. Ohne die informellen Reaktionen ist die Kriminalitätsbelastung bei den 15- (nichtdeutsche Frauen) und 16-jährigen (deutsche Frauen) am höchsten. Die Kurve der Nichtdeutschen sinkt danach stetig ab. Im Gegensatz dazu steigt die der Deutschen im Alter von 32-41 Jahren noch einmal leicht an. Diese in Schaubild 4.18 deutlich sichtbare „Ausbuchtung“ dürfte auf die geburtenstarken Jahrgänge in Deutschland zurückzuführen sein. Der sog. „Baby-Boom“ dauerte von Mitte der 1950er bis Mitte der 1960er Jahre. ${ }^{576}$ Dementsprechend müsste die Anzahl der 30-40-jährigen deutschen Verurteilten höher sein, was auch der Fall ist. Da hier die absoluten Zahlen zugrunde liegen, ist diese demographische Veränderung sichtbar. Darüber hinaus besteht bei den deutschen Frauen eine größere Kluft zwischen den Entscheidungen mit und denen ohne $\$ \int 45,47$ JGG. Dabei ist jedoch zu berücksichtigen, dass die nichtdeutschen Frauen insgesamt nur einen Anteil von knapp 17\% der verurteilten Frauen ausmachen.

576 StatBA (Hrsg.), Geburten in Deutschland, 2007, S. 8. 


\section{Kapitel 5: Sanktionierung der Frauenkriminalität}

Im Wortlaut des Strafgesetzbuches existieren kaum noch geschlechtsspezifische Differenzierungen. Die verbleibenden Ausnahmen, insbesondere die Nichtpönalisierung des weiblichen Exhibitionismus und die Privilegierung der Frau beim Schwangerschaftsabbruch, sind sachlich gerechtfertigt. ${ }^{577}$ Folglich dürfte allein die Zugehörigkeit zu einem bestimmten Geschlecht keinen Einfluss auf die Sanktionierung und damit auf die Art der Bezugsentscheidung haben. Gleichwohl wird das Bestehen eines sogenannten Frauenbonus, also einer nachsichtigeren Behandlung von Frauen gegenüber Männern, diskutiert. ${ }^{578}$ Aber gibt es wirklich einen Frauenbonus in der Justiz? Die Frage konnte aufgrund weniger Untersuchungen, die zumeist auf kleinen Stichproben mit uneinheitlichen Prüfkriterien beruhen, bislang nicht zufriedenstellend beantwortet werden. Es wird daher überprüft, ob sich bei einer bundesweiten Analyse eines ganzen Verurteilungsjahrgangs Unterschiede bei der Sanktionierung von Männern und Frauen finden, d.h. ob und wenn ja inwieweit eine geschlechtsspezifische Differenzierung auf justizieller Ebene stattfindet.

Anfangs wird die theoretische Grundlage dieser Problematik erörtert, wobei auf die bereits in Kapitel 2 gewonnenen Erkenntnisse zum labeling approach zu-

\footnotetext{
577 Hilgendorf, in: Frauen im Recht, S. 130.

578 Vgl. beispielsweise eine durch Geißler/Marißen, in: KZfSS 1988, S. 505-526 ausgelöste Diskussion zum Thema eines etwaigen Frauenbonus.
} 
rückgegriffen werden kann. Im weiteren Verlauf wird sodann der Forschungsstand aufgearbeitet.

Schließlich werden die eigenen Ergebnisse auf der Grundlage der Daten des BZR vorgestellt. Anhand der Bezugsentscheidung für das Jahr 2004 wird die Sanktionierung der Kriminalität von Frauen im Vergleich zu der Kriminalität von Männern umfassend dargestellt. Die zugrunde liegenden Daten des BZR erlauben hier eine detaillierte Überprüfung der rechtlichen Reaktionen gegenüber Frauen und Männern in Abhängigkeit von Alter, Nationalität, Vorstrafenbelastung und Delikt. Wie bereits im vorangegangenen Kapitel wird für diese Untersuchung der eigens hierfür konzipierte Entscheidungsdatensatz verwendet. Dieser zählt für jede Person die jeweils zeitlich erste rechtskräftig gewordene Entscheidung im Bezugsjahr 2004.579 Der verwendete Datensatz erfasst für jede Bezugsentscheidung bis zu fünf Straftaten, wobei die abstrakt schwersten ${ }^{580}$ der verwirklichten Straftaten gezählt werden. Bei allen ambulanten und stationären Entscheidungen wurde wie in Kapitel 4 - auf den Urteilszeitpunkt abgestellt.

\section{Existiert ein „Frauenbonus“?}

Die Darstellung des Umfangs der weiblichen Kriminalität (vgl. Kapitel 1) hat bereits ergeben, dass Frauen nicht nur seltener straffällig werden, sondern auch, dass der strafrechtliche Selektionsprozess bei Frauen noch ausgeprägter ist als bei Männern (vgl. Schaubilder 1.11 und 1.12). Dieses Phänomen sorgt schon seit langer Zeit für Diskussionsstoff. Im Mittelpunkt der Diskussionen steht die Frage, ob das Geschlecht ausschlaggebend für Qualität und Quantität der Reaktionen durch die entsprechende strafverfolgende oder Sanktionen aussprechende Instanz ist. Es stellt sich folglich die Frage, ob tatverdächtige Frauen aufgrund eines Frauenbonus milder bestraft werden.

\subsection{Theoretische Grundlage}

Die selektive Sanktionierung hat insbesondere bei Autoren älterer kriminologischer Literatur ${ }^{581}$ zu der Vermutung geführt, dass Frauen im Selektionsprozess der Strafverfolgung gegenüber Männern begünstigt werden. Im Sinne des labeling approach $^{582}$ gehen sie davon aus, dass Frauen in der Realität grundsätzlich nicht seltener straffällig werden als Männer; ihre Straffälligkeit werde lediglich seltener entdeckt, seltener angezeigt und im Falle einer Anzeige milder bestraft. ${ }^{583}$ Dieses

\footnotetext{
${ }^{579}$ Vgl. zum hier verwendeten Entscheidungsdatensatz ausführlich unter Kap. 3, 2.2.

580 Die Einteilung wurde nach dem Strafrahmen vorgenommen.

581 Pollak, The criminality of women, 1961; Leder, Frauen- und Mädchenkriminalität, 1997;

Geißler/Marißen, in: KZfSS 1988, S. 505-526.

$582 \mathrm{Vgl}$ die Ausführungen unter Kap. 2, 2.7.

583 Pollak, S. 44 ff.; Leder, S. 153; Geißler/Marißen, in: KZfSS 1988, S. 505, 509 ff.
} 
Phänomen soll mit der „ritterlichen“ Einstellung der strafverfolgenden Männer zu tun haben, weshalb dieser Erklärungsversuch als Kavalierstheorie bezeichnet wird.

Schon Pollak führte in diesem Zusammenhang aus: „One of the outstanding concomitants of the existing inequality between the sexes is chivalry and the general protective attitude of man toward woman. This attitude exists on the part of the male victim of crime as well as on the part of the officers of the law, who are still largely male in our society. Men hate to accuse women and thus indirectly to send them to their punishment, police officers dislike to arrest them, judges and juries to find them guilty, and so on. "584

Das Verhalten von Frauen werde seltener als strafrechtlich relevant definiert, da sie aufgrund ihres Mitgefühls und sozialen Denkens in der Regel kein strafrechtlich relevantes Motiv verfolgten. Ferner würden Frauen deshalb in geringerem Maße kontrolliert. 585

Der Anstieg registrierter weiblicher Kriminalität wird von den Vertretern der Kavalierstheorie mit der Emanzipation begründet, die dazu führe, dass die Strafverfolgungsorgane sich weniger ,ritterlich“ verhalten und die ,privilegierte“ Position der Frau abgeschwächt werde. ${ }^{586}$

\subsection{Bisherige deutsche Forschungsergebnisse zur geschlechtsspezifischen Bevorzugung}

Nach Darlegung der theoretischen Ausgangslage stellt sich die Frage, ob sich eine etwaige geschlechtsspezifische Bevorzugung bzw. die Existenz eines Frauenbonus empirisch belegen lässt. Hierzu sollen im Folgenden einige ausgewählte Studien ${ }^{587}$ vorgestellt werden, wobei unterschiedliche Fragestellungen differenziert werden müssen: Ist die Anzeigebereitschaft gegenüber Frauen geringer? Werden Frauen nachsichtiger behandelt, wenn sie den jeweiligen Strafverfolgungsbehörden als Täterin bekannt geworden sind?

\subsubsection{Mildere Behandlung durch die Anzeigeerstatter}

Zunächst führen die Vertreter der Kavalierstheorie an, die Kriminalität der Geschlechter sei im Dunkelfeld gleich verteilt. Die Anzeigebereitschaft gegenüber Frauen sei gering. Dass dies nicht der Fall ist, konnte bereits unter Kap. 1, 2.2 festgestellt werden: Zahlreiche Studien belegen, dass auch im Dunkelfeld ein Abstand zwischen den Kriminalitätsanteilen der Geschlechter besteht; je nach Delikt ist

\footnotetext{
584 Pollak, , S. 151.

585 Keupp, in: MschrKrim 1982, S. 219, 222 f.; Mansel, in: Lamnek/Boatca (Hrsg.), Geschlecht, Gewalt, Gesellschaft, S. 384, 385.

586 Geißler/Marißen, in: KZfSS 1988, S. 505, 524.

587 Dabei werden im Folgenden aufgrund der unterschiedlichen Rechtsanwendungsprinzipien nur deutsche Untersuchungen berücksichtigt. Vgl. eine Zusammenstellung ausländischer Untersuchungen bei Raab, Männliche Richter - weibliche Angeklagte, S. 17 ff. sowie Legnaro/Aengenheister, Schuld und Strafe, S. 5 ff.
} 
dieser mehr oder weniger ausgeprägt. Die seltene Registrierung dürfte daher auf eine tatsächlich geringere Delinquenzbelastung zurückzuführen sein. ${ }^{588}$

Manse ${ }^{589}$ stellte sogar eine gesteigerte Anzeigebereitschaft von männlichen Opfern gegenüber weiblichen Tätern fest. ${ }^{590}$ Er kam allerdings auch zu dem Ergebnis, dass Straftaten von Frauen insgesamt seltener angezeigt werden, wenn man das Geschlecht des Opfers unberücksichtigt lässt.591 Dieser geschlechtsspezifische Unterschied bei der Anzeigeerstattung vergrößere sich mit steigender Schadenshöhe. Anders verhalte es sich bei den Bagatelldelikten: Hier werde eher gegenüber Frauen Anzeige erstattet. 592

Auch im Bereich des häuslichen Milieus gibt es Anzeichen dafür, dass gegenüber weiblichen Tätern eher von einer Anzeige abgesehen wird. ${ }^{593}$ Ein Grund dafür könnte fehlendes Unrechtsempfinden gegenüber leichten Körperverletzungen, die von Frauen ausgeübt werden, sein. Vielleicht werden Handlungen von Männern eher unter den Tatbestand der Körperverletzung subsumiert als vergleichbare Handlungen von Frauen. ${ }^{594}$ Dabei ist jedoch zum einen zu berücksichtigen, dass ein solch unterschiedlicher Definitionsprozess nicht unbedingt mit einer nachsichtigeren Behandlung gleichzusetzen ist. Zum anderen ist hier ein spezifischer Kriminalitätsbereich betroffen, bei dem das Absehen von einer Anzeige zahlreiche Gründe, wie z.B. Schamgefühl männlicher Opfer, haben kann, welche im Übrigen auch nicht auf andere Kriminalitätsbereiche übertragbar sind.

\subsubsection{Mildere Behandlung durch die Strafverfolgungsbehörden und Gerichte}

Ferner führen die Vertreter der Kavalierstheorie an, dass Frauen auch im Falle einer Entdeckung durch die Strafverfolgungsbehörden milder behandelt werden. Es lassen sich hier folglich verschiedene Ebenen unterscheiden, auf denen es zu einer nachsichtigeren Behandlung bzw. Sanktionierung kommen könnte: die Polizei, die Staatsanwaltschaft und die Justiz.

\subsubsection{Polizei}

Horntha ${ }^{595}$ untersuchte durch schriftliche Befragung von Hamburger Polizeibeamten die Ausübung des Ermessens hinsichtlich der Sanktionierung von Ordnungswidrigkeiten im Straßenverkehr. Die Auswertung der Fragebögen ergab, dass sich die Variable Geschlecht je nach Art der Ordnungswidrigkeit unterschiedlich aus-

\footnotetext{
588 So auch bereits Stein-Hilbers, in: KrimJ 1978, S. 281, 284.

589 Mansel, in: Lamnek/Boatca (Hrsg.), Geschlecht, Gewalt, Gesellschaft, S. 384-406.

$590 \mathrm{Vgl}$. ausführlich unter Kap. 1, 1.5; zu beachten ist ferner, dass hier geringe Fallzahlen zugrunde lagen.

591 Mansel, in: Lamnek/Boatca (Hrsg.), Geschlecht, Gewalt, Gesellschaft, S. 384, 392.

592 Mansel, in: Lamnek/Boatca (Hrsg.), Geschlecht, Gewalt, Gesellschaft, S. 384, 392.

$593 \mathrm{Vgl}$. ausführlich unter Kap. 1, 1.5.

594 Walter/Lenz/Puchert, in: Gewalt gegen Männer - Personale Gewaltwiderfahrnisse von Männern in Deutschland. Pilotstudie, BMFSFJ (Hrsg.), S. 192 ff.; vgl. ausführlich unter Kap. 1, 1.5.

595 Hornthal, Analyse psychologischer Merkmale im Ermessen von Polizeibeamten, 1975.
} 
wirkte. Bei „,verbotenem Halten in zweiter Reihe“ verhängten die Polizisten häufiger bei Frauen ein Verwarnungsgeld, beim Einfahren in eine verstopfte Kreuzung bei Männern. ${ }^{596}$ Hornthal erklärt dies mit der Berufstätigkeit: Dem typischerweise berufstätigen Mann sehe man ein Halten in zweiter Reihe eher nach als der Frau, von der eher erwartet werde, dass sie sich einen Parkplatz suche, wenn sie Besorgungen zu erledigen habe. Beim Einfahren in eine verstopfte Straßenkreuzung verhalte es sich umgekehrt, da die Beamten bei den Männern eine größere Fahrpraxis voraussetzen. ${ }^{597}$ Darüber hinaus stellte der Autor fest, dass bei einsichtigen Frauen öfter auf die Verhängung eines Verwarnungsgeldes verzichtet wurde als bei einsichtigen Männern. Gegen uneinsichtige Frauen wurde dagegen häufiger ein Verwarnungs- oder Bußgeld verhängt als gegen uneinsichtige Männer, woraus Hornthal den Schluss zieht „(...) - Widerstand des Mannes und Unterwerfung der Frau bewirken also Milde. "598

In den Jahren 1973-1975 wurde von Steffen ${ }^{599}$ im Rahmen eines durch das BKA finanzierten Forschungsprojektes eine deliktsspezifische Analyse des polizeilichen Ermittlungsverfahrens aus der Sicht des späteren Strafverfahrens durchgeführt. Es wurde versucht, insbesondere anhand von Aktenanalysen ${ }^{600}$, empirisch begründete Antworten auf die Frage nach den Faktoren zu geben, die das polizeiliche Kontrollverhalten bei der Strafverfolgung im Gesamtzusammenhang des strafrechtlichen Selektionsprozesses beeinflussen und bestimmen. Hierbei fand eine Beschränkung auf die Delikte Ladendiebstahl, Betrug im Geschäftsverkehr, Unterschlagung und Einbruch statt. In diesem Rahmen wurde auch der Einfluss des Geschlechts der Tatverdächtigen auf das Kontrollhandeln von Polizei und Justiz untersucht. ${ }^{601}$ Die Forschungsgruppe kam zu dem Ergebnis, dass die These, Frauen würden von den Instanzen der Kriminalitätskontrolle besser behandelt, als widerlegt angesehen werden könne. Denn die Datenanalyse, insbesondere ein Vergleich der ermittelten und verurteilten Männer mit den Frauen, habe ergeben, dass das polizeiliche Ermittlungs- und das justizielle Erledigungsverfahren gegenüber männlichen und weiblichen Tatverdächtigen deliktsspezifisch unterschiedlich sei: Beim Ladendiebstahl und beim Betrug im Geschäftsverkehr - also bei den Delikten, bei denen Frauen einen relativ hohen Anteil der Tatverdächtigen stellen - werde eher gegenüber Frauen aufgeklärt; beim Einbruch und bei der Unterschlagung eher gegenüber männlichen Tatverdächtigen. Ein Grund dafür wurde in der unterschiedlichen Geständnisbereitschaft gesehen, die als weitere Variable bei der Datenauswertung hinzugenommen wurde: Verfahren wurden danach als auf-

\footnotetext{
${ }^{596}$ Hornthal, S. 78 f.

597 Hornthal, S. 79.

598 Hornthal, S. 82.

599 Steffen, Analyse polizeilicher Ermittlungstätigkeit aus der Sicht des späteren Strafverfahrens. 600 Steffen, S. 87 ff.

601 Steffen, S. 223. Die Akten wurden stichprobenartig aus den Landgerichtsbezirken Coburg, Regensburg, Hechingen, Arnsberg, Duisburg, Itzehoe, Darmstadt und Hamburg analysiert, wobei pro Bezirk nicht mehr als 700 Strafakten gezogen wurden.
} 
geklärt bezeichnet, wenn die Tatverdächtigen ein Geständnis abgelegt hatten, was bei tatverdächtigen Frauen eher beim Ladendiebstahl und beim Betrug, bei tatverdächtigen Männern hingegen eher beim Einbruch und bei der Unterschlagung der Fall war. ${ }^{602}$ Darüber hinaus wurde unter Einbeziehung der Variablen „Vorstrafenbelastung" festgestellt, dass die unterschiedliche Vorstrafenbelastung sich nicht auswirkt: Obwohl die Frauen in geringerem Maße vorbelastet waren, wurden sie nicht seltener angeklagt und verurteilt. ${ }^{603}$ Dies führe letztendlich sogar zu einer „Benachteiligung“ von Frauen. ${ }^{604}$

Im Rahmen seiner seit 1973 kontinuierlich durchgeführten Delinquenzbefragungen ${ }^{605}$ widmete sich auch Krenzer der Frage, warum ein Unterschied bei der Geschlechterbelastung mit Kriminalität besteht. Für den Autor sind die Deliktshäufigkeit und -schwere die ausschlaggebenden Kriterien für die Entdeckungs-, Verfolgungs- und Verurteilungswahrscheinlichkeit. Er stellte die These auf, je schwerer ein Delikt sei und je häufiger jemand delinquent werde, desto wahrscheinlicher seien Entdeckung und Strafverfolgung. Da Männer öfter und schwerere Delikte begehen, würden sie stärker verfolgt und bestraft. Kreuzer untersuchte daraufhin die Variablen Delinquenzbelastung und Polizeiauffälligkeit. Danach zeigte sich, dass zwar die meisten männlichen und weiblichen Probanden, die als „stark delinquenzbelastet“ eingestuft wurden, nie polizeiauffällig waren, dass sich aber - geschlechtergleich - mit wachsender Häufigkeit und Schwere tatsächlicher Delinquenz die Wahrscheinlichkeit polizeilich aufzufallen erhöht. Da weibliche Befragte unter den stark Delinquenzbelasteten unterrepräsentiert waren, war entsprechend ihr Anteil unter Polizeiauffälligen geringer. ${ }^{606}$

\subsubsection{Staatsanwaltschaften}

Im Rahmen des soeben unter 1.2.2.1 erwähnten Forschungsprojektes des BKA wurde für das Untersuchungsjahr 1970 von Blankenburg/Sessar/Steffen ${ }^{607}$ auch eine Analyse entscheidungsrelevanter Kriterien (Geständnisbereitschaft, Vorbelastung, Schaden, Deliktshäufigkeit, Tatgenossenschaft) für die staatsanwaltliche Erledigung im Vergleich zwischen Frauen und Männern vorgenommen. Die Überprüfung des Zusammenhangs zwischen dem Geschlecht der Tatverdächtigen und dem weiteren Verlauf der Strafverfolgung durch den Staatsanwalt kam zu einem entsprechenden Ergebnis wie die oben erwähnte Untersuchung von Steffen. Die

\footnotetext{
${ }^{602} \mathrm{Zu}$ einem anderen Ergebnis ist Legnaro für die Hauptverhandlung gekommen: Er stellte in einer Studie zwar auch fest, dass Frauen geständnisbereiter sind, jedoch wirkte sich dies kaum entlastend für die geständigen Täterinnen aus, vgl. Legnaro, in: ZfRSoz 1987, S. 231-152.

603 Steffen, S. 235.

604 Steffen, S. 235.

605 Vgl. hierzu ausführlich unter Kap. 1, 2.2.1.

${ }^{606}$ Krenzer, in: Hirsch/Kaiser/Marquart (Hrsg.), Gedächtnisschrift für Hilde Kaufman, S. 291, 301 ff.

${ }^{607}$ Blankenburg/Sessar/Steffen, Die Staatsanwaltschaft im Prozess strafrechtlicher Sozialkontrolle.
} 
Staatsanwaltschaft klagt danach Frauen und Männer delikts- und nicht geschlechtsspezifisch unterschiedlich häufig an. ${ }^{608}$

Ludwig-Mayerhofer ${ }^{609}$ untersuchte zusammen mit Rzepka die staatsanwaltliche Entscheidung zwischen Anklageerhebung und Verfahrenseinstellung nach \ 45 JGG a.F. ${ }^{610}$ Er stellte fest, dass Verfahren gegen Mädchen bzw. junge Frauen signifikant häufiger mit einer Informalisierung statt mit einer Anklage beendet werden als die Verfahren gegen junge Männer. ${ }^{611}$ Um der Frage des Frauenbonus genauer nachgehen zu können, hatte der Autor eine multivariate Analyse angeschlossen, d.h. es wurden sämtliche potentiell entscheidungsrelevanten Variablen - soweit sie erhoben werden konnten - simultan berücksichtigt. Danach kam Ludwig-Mayerhofer zu dem Ergebnis, dass das Geschlecht bei der „Alltagskriminalität“, wie Sachbeschädigung und leichteren Diebstahlsformen, für die Anklagebereitschaft der Jugendstaatsanwaltschaft keine Rolle spiele. Ein deutlicher Unterschied in der Anklagewahrscheinlichkeit zwischen weiblichen und männlichen Jugendlichen bzw. Heranwachsenden konnte nur bei Delikten festgestellt werden, bei denen es sich quantitativ gesehen um einen Ausnahmefall handelte. So zeigte sich eine mildere Behandlung bei schwereren Diebstahlsdelikten, welche vor dem Jugendschöffengericht angeklagt wurden, und bei Körperverletzungen, bei denen weibliche Beschuldigte männliche Geschädigte verletzt hatten. ${ }^{612}$ Diese etwaige Bevorzugung wird von Ludwig-Mayerhofer/Rzepka allerdings im Wesentlichen als „Artefakt, resultierend aus der unzureichenden Berücksichtigung anderer entscheidungsrelevanter Faktoren" 613 verstanden.

Schließlich widmen sich einige Untersuchungen ${ }^{614}$, die sich mit der Reaktionspraxis der Staatsanwaltschaft beschäftigen, am Rande der Frage, ob das Geschlecht der straffälligen Person Einfluss auf die Reaktion des Staatsanwalts hat. So stellten beispielsweise Gréus ${ }^{615}$ oder Kotz ${ }^{16}$ fest, dass ein solcher Einfluss nicht bestehe. ${ }^{617}$

${ }_{008}$ Blankenburg/Sessar/Steffen, S. $193 \mathrm{ff}$.

${ }^{609}$ Ludwig-Mayerhofer, in: Albrecht (Hrsg.), Informalisierung des Rechts, S. 47-225; LudwigMayerbofer/Rzepka, in: KZfSS 1993, S. 542-557.

${ }^{610}$ Die Untersuchung bezog sich auf die bis zum 30.11 .1990 gültige Fassung.

${ }^{611}$ Ludwig-Mayerhofer, in: Albrecht (Hrsg.), Informalisierung des Rechts, S. 47, 135.

${ }^{612}$ Ludwig-Mayerhofer/Rzepka, in: KZfSS 1993, S. 542, 554.

${ }^{613}$ Ludwig-Mayerbofer/Rzepka, in: KZfSS 1993, S. 542, 556.

${ }^{614}$ Gréus, Das Absehen von der Verfolgung jugendlicher Straftäter in der Praxis; Kotz, Die Wahl der Verfahrensart durch den Staatsanwalt; Stor: Jugendstrafrechtliche Reaktionen und Legalbewährung in: BMJ (Hrsg.), Diversion im Jugendstrafverfahren der Bundesrepublik Deutschland; Herbort, Wer kommt vor das Gericht.

${ }^{615}$ Gréus, S. 144 f.; Gréus analysierte den Anwendungsbereich der Vorschrift $₫ 45$ JGG durch Auswertung von insgesamt 540 Ermittlungsakten der Staatsanwaltschaften Tübingen, Mosbach, Heilbronn und Mannheim aus dem Jahr 1973.

616 Kotz, S. 110 ff.; Kotz untersuchte die Faktoren, die die Erhebung der öffentlichen Klage, den Antrag auf Erlass eines Strafbefehls und die vorläufige Verfahrenseinstellung unter Anordnung von Auflagen und Weisungen beeinflussen. Hierfür analysierte er im Wege der Stichprobenzie- 


\subsubsection{Gerichte}

Rolinski $i^{618}$ untersuchte 350 Urteile, die im Landgerichtsbezirk Wiesbaden in den Jahren 1959 und 1960 gefällt wurden. Sämtlichen Urteilen lagen Vermögensdelikte zugrunde, nämlich die $\iint 242,243,244,246,263$ und 264 StGB. Seine Auswertung ergab eine gleichmäßige Verteilung von hohen und niedrigen Strafen auf die Geschlechter. ${ }^{619}$ Rolinski zog daher den Schluss, bei der Behauptung, Frauen werden milder bestraft als Männer, handele es sich um ein veraltetes Vorurteil aus der Zeit ,als die Frau zu einer passiven und schutzerbeischenden Rolle, der Mann aber zur korrespondierenden Stellung, zur Aktivität schlechthin, verpflichtet waren".620 Dies gelte zumindest für die von ihm untersuchten Delikte. Auch bezüglich der zur Bewährung ausgesetzten Strafen zeigten die Stichproben eine gleichmäßige Verteilung auf beide Geschlechter. ${ }^{621}$

In ihrer Arbeit „Tötungsdelikte zwischen Männern und Frauen“ untersuchte Oberlies622 BGH-Urteile zu gegengeschlechtlichen Tötungsdelikten aus dem Zeitraum 1975-1985. Sie nahm hierzu anhand der Daten eine Fallrekonstruktion aus der Urteilsbegründung sowie eine multivariate Analyse vor. Oberlies kam zu dem Ergebnis, dass sich die Lebenssachverhalte der Tötungsdelikte von Frauen deutlich von denen der Männer unterschieden. ${ }^{623}$ Unterschiedliche Lebenssachverhalte führten bei identischen Regeln der Rechtsanwendung zu unterschiedlicher Behandlung. Deshalb verliere die Variable Geschlecht in einer multivariaten Regressionsanalyse bei Einbeziehung entsprechender strafzumessungsrelevanter Variablen ihre Bedeutung. ${ }^{624}$ Die Autorin resümierte, dass die unterschiedlichen Lebenssachverhalte (bei den Taten handelte es sich oftmals um Tötungsdelikte misshandelter Frauen an ihren misshandelnden Partnern) vor Gericht nicht genügend Berücksichtigung fänden und es dadurch sogar zu einer Benachteiligung weiblicher gegenüber männlichen Tätern kommen könne. ${ }^{625}$

Vor allem Geißler/Marißen sorgten mit ihrer Veröffentlichung zu dem Thema

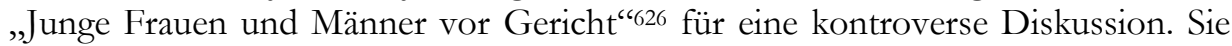
werteten ca. 7.000 statistische Zählblätter der Jugendgerichtshilfe der Stadt Stutt-

hung Strafakten der Staatsanwaltschaften des Landgerichtbezirks Augsburg der Jahrgänge 1975 und 1978.

${ }^{617} \mathrm{Zu}$ einem anderen Ergebnis kommt Herbort: Sie stellt fest, dass Verfahren gegen weibliche Jugendliche wegen Diebstahls gem. IS 242, 243, 244 StGB sowie Körperverletzung gem. IS 223, 223a, 230 a.F. StGB eher informalisierend erledigt wird, nicht jedoch bei Sachbeschädigung; vgl. Herbort, S. 153 f., Tab. 28, 29, 30.

618 Rolinski, Die Prägnanztendenz im Strafurteil.

${ }^{619}$ Rolinski, S. 54.

620 Rolinski, S. 54.

621 Rolinski, S. 75.

622 Oberlies, Tötungsdelikte zwischen Männern und Frauen.

${ }^{623}$ Oberlies, S. $148 \mathrm{ff}$.

624 Oberlies, S. 183.

625 Oberlies, S. 194 ff.

${ }^{626}$ Geißler/Marißen, in: KZfSS 1988, S. 505-526. 
gart aus den Jahren 1983 bis 1985 aus und kamen zu dem Ergebnis, dass Frauen durch Kriminalität und Kriminalisierung durch mildere Behandlung in doppelter Weise „privilegiert“ und Männer in doppelter Weise „benachteiligt" sind.627 Die Straftaten junger Frauen entgingen eher den Augen der Polizei, den Anklagen der Staatsanwaltschaft, den Urteilen der Richter und vor Gericht den harten Bestrafungen. Ihre Behauptung eines „geschlechtsspezifischen Selektionsfilters“ versuchen sie zu belegen, indem sie die relativen Anteile von Männern und Frauen auf den verschiedenen Verfolgungsebenen vergleichen. ${ }^{628}$

Diese Behauptung wurde insbesondere von Ludwig-Mayerhofer/Rzepka ${ }^{629}$ und Oberlies $^{630}$ stark kritisiert: Sie vertreten die Auffassung, Aussagen über geschlechtsspezifische Selektionen bei der registrierten Strafverfolgung würden voraussetzen, dass die Zahl der Tatverdächtigen zu der Zahl der Angeklagten, Verurteilten und Inhaftierten getrennt nach Geschlechtern in Bezug gesetzt wird. ${ }^{631}$ Ferner komme den Ergebnissen nur eine eingeschränkte Aussagekraft zu, da man mehrere der erhobenen Variablen durch multivariate Analyse simultan hätte berücksichtigen müssen. Dies führe zu dem Ergebnis, dass die mildere Bestrafung von Frauen nicht aus dem Merkmal Geschlecht, sondern ganz im Sinne des rechtlichen Programms, aus den besonderen Merkmalen der Tat und der Täterinnen resultiere. Die Signifikanz der Variable Geschlecht wäre sonst verschwunden und die aufgeklärte Varianz angestiegen. ${ }^{632}$

Auch Körner633 wertete, ebenso wie Oberlies, die Rechtsprechung des BGH zu Tötungsdelikten aus. Besonderes Augenmerk richtete er auf den Einfluss des Rollenverhaltens der Frau auf die Entscheidung. Er kam zu dem Ergebnis, die Behandlung der Frauen durch das Gericht hänge davon ab, ob sie sich geschlechtsrollenkonform verhalten habe. ${ }^{634}$ Die Rollenerwartung an Frauen sei insbesondere die Rolle als Hausfrau, Ehefrau und Mutter. ${ }^{635}$ Rollenkonformes Verhalten wirke sich strafmildernd aus, wohingegen rollendiskonformes Verhalten zu einer Benachteiligung der Täterinnen im Rahmen der Strafzumessung und der Anwendung der Mordmerkmale führe. ${ }^{636}$ Ein solches rollendiskonformes Verhalten sei

${ }^{627}$ Geißler/Marißen, in: KZfSS 1988, S. 505; zur Kritik an dem Begriff der „Privilegierung“ bzw.

„Benachteiligung“ in diesem Zusammenhang vgl. Oberlies, in: KZfSS 1990, S. 129, 142 sowie

Replik von Geißler/Marißen, in: KZfSS 1990, S. 144, 148.

${ }^{628}$ Geißler/Marißen, in: KZfSS 1988, S. 505, 513 ff.

${ }^{629}$ Ludwig-Mayerhofer, in: Albrecht (Hrsg.), Informalisierung des Rechts, S. 47-225.

630 Oberlies, in: KZfSS 1990, S. 129-143; Oberlies, Tötungsdelikte zwischen Männern und Frauen, S. 182.

631 Oberlies, in: KZfSS 1990, S. 129, 136.

${ }^{632}$ Ludwig-Mayerhofer, in: Albrecht (Hrsg.), Informalisierung des Rechts, S. 134 f.; LudwigMayerbofer/Rzepka, in: KZfSS 1993, S. 542, S. 543; Oberlies, in: KZfSS 1990, S. 129, 139.

633 Körner, Das soziale Machtgefälle zwischen Mann und Frau als gesellschaftlicher Hintergrund der Kriminalisierung.

${ }^{634}$ Körner, S. 188.

${ }^{635}$ Körner, S. 22 ff.

636 Körner, S. 89 ff. 
beispielsweise dann gegeben, wenn die Frau als Mittäterin bei der Tötung ihres Mannes mitwirke. Hier werde über den Totschlag hinaus auch der Rollenbruch sanktioniert. ${ }^{637}$

Hartmann ${ }^{638}$ untersuchte den sozialen Bonus im Jugendstrafverfahren mittels eines standardisierten Fragekatalogs, basierend auf den Zählblättern der Jugendgerichtshilfe. Sie stellte die Hypothese auf, junge Mädchen hätten von Seiten männlicher Richter eher „väterliches“ Verständnis zu erwarten und würden daher milder verurteilt als Jungen. ${ }^{639}$ Sie spricht in diesem Zusammenhang von einer ,unbewussten ,Lolita'-Projektion der Richter' ${ }^{\text {' } 40}$. Um die Einflussgröße mehrerer unabhängiger Variablen auf die Beurteilung der Tat zu überprüfen, verwendete Hartmann ein log-lineares Rechenmodell. Danach kam sie zu dem Ergebnis, dass sich ihre Hypothese nicht bestätigen lässt. ${ }^{641}$

Albrecht642 führte eine empirische Studie zur Strafzumessung bei schwerer Kriminalität durch. Er wertete 2.183 Akten aus fünf Landgerichtsbezirken des Bundeslandes Baden-Württemberg im Hinblick auf die Deliktsgruppen Raub, Vergewaltigung und Einbruchdiebstahl aus. ${ }^{643}$ Weibliche Verurteilte tauchten in den Deliktsgruppen Raub und Einbruchdiebstahl auf. Albrecht kam u.a. zu dem Ergebnis, dass der Mittelwert bei wegen Raubes verurteilten weiblichen Straftätern bei 16 Monate Freiheitsstrafe lag, wohingegen der Mittelwert bei Männern mit 31 Monaten fast doppelt so groß war. ${ }^{644}$ Auch im Falle des Einbruchdiebstahls ergab sich eine erhebliche Differenz: Die durchschnittliche Strafe bei weiblichen Verurteilten lag hier bei fünf Monaten, bei männlichen Verurteilten dagegen bei 11 Monaten. ${ }^{645}$ Albrecht resümierte, dass dieser Unterschied nicht unbegründet sein dürfte: So dominierte bei den weiblichen Verurteilten die Beteiligung an männlichen Straftaten. Nur ein knappes Fünftel der Raubdelikte weiblicher Personen und ein Drittel der ihnen zugerechneten Einbruchdiebstähle begingen Frauen in Alleintäterschaft. Weibliche Verurteilte wiesen zudem eine geringere Vorstrafenbelastung und die von ihnen begangenen Delikte eine geringere Schadenshöhe auf. ${ }^{646}$

Die Untersuchungen von Sauer-Burghard/Zill und Raab basieren, anders als die bislang diskutierten Studien, auf der Beobachtung von Hauptverhandlungen und der Befragung von Richtern.

\footnotetext{
${ }^{637}$ Körner, S. 88 f.

${ }^{638}$ Hartmann, Der soziale Bonus im Jugendstrafverfahren, 1994.

${ }^{639}$ Hartmann, S. 71.

640 Hartmann, S. 71.

641 Hartmann, S. 135.

642 Albrecht, Strafzumessung bei schwerer Kriminalität, 1994.

643 Albrecht, S. 235.

644 Albrecht, S. 345.

645 Albrecht, S. 345.

646 Albrecht, S. 346.
} 
Sauer-Burghard/Zill647 untersuchten, welches die maßgeblichen Bedingungen für die unterschiedliche Einschätzung von männlichen und weiblichen Angeklagten waren, und die Auswirkungen auf die angeklagten Frauen. Es wurden im Zeitraum September 1981 bis Februar 1982 insgesamt 79 Strafprozesse vor dem Amts- oder Landgericht in Köln besucht. Die Autoren vermuten, dass kriminelles Verhalten von Frauen vergleichsweise häufiger pathologisiert oder relativ härter bestraft werde als das von Männern, da Kriminalität ein Verhaltensmuster sei, das von Frauen gewöhnlich nicht erwartet werde. Eine Regressionsanalyse ergab jedoch keine Signifikanz des Faktors Geschlecht. Ferner kamen sie zu dem Ergebnis, dass sich die geringere Vorbelastung der Frauen kaum strafmildernd auswirke. ${ }^{648}$

In einer von Raab649 im Zeitraum September 1986 bis Februar 1987 durchgeführten explorativen Studie geht es um die Alltagstheorien, die Richterinnen und Richter beim Urteilen über Frauen anwenden. Ziel der Untersuchung war es, die Einstellungen und Alltagstheorien von Strafrichtern zu erkunden und zu analysieren sowie deren Wirksamkeit im konkreten Strafverfahren gegen Frauen nachzuvollziehen. ${ }^{650}$ Insgesamt wurden 32 Hauptverhandlungen beobachtet und anschließend im Interview mit den Richtern besprochen. Raabs Untersuchung kommt zu dem Ergebnis, dass die Richter die Rollenkonformität der angeklagten Frauen durch ihre Reaktion unterstützen bzw. rollendiskonfirmes Verhalten bestrafen oder pathologisieren. So neigten die befragten Richter dazu, bei Müttern betreuungsbedürftiger Kinder Freiheitsstrafen zur Bewährung auszusetzen sowie die Taten als krankheitsbedingt zu bewerten. Raab stellte hierzu abschließend fest: „Ob der Rollenbruch bestraft oder pathologisiert wird, die Rollenkonformität belohnt oder die Sanktion im Hinblick auf die Sicherstellung der zukïnftigen Rollenerfuillung ausgewäblt wird, stets trägt die strafrechtliche Reaktion zur Aufrechterbaltung der Geschlecbtsrolle bei. "851

Dennoch zieht die Autorin nicht den Schluss, Frauen würden milder bestraft als Männer. Zwar handele es sich bei der Freiheitsstrafe zur Bewährung und der Annahme eines Schuldminderungsgrundes um Privilegierungen im strafrechtlichen Sinn. Allerdings wirke sich die Anwendung des $₫ 21$ StGB nicht immer günstig für die Angeklagten aus, da ihnen vermittelt werde, dass sie psychisch krank und dass ihre Probleme auf die Krankheit zurückzuführen seien. ${ }^{652}$

Auch Legnaro/Aengenheister ${ }^{63}$ beobachteten 47 Hauptverhandlungen mit insgesamt 56 Angeklagten (28 weibliche und 28 männliche) in acht Bundesländern. 32 Verhandlungen fanden vor der Schwurgerichtskammer und fünf vor der Jugendkammer satt. ${ }^{654}$ Die Autoren widmeten sich in ihrer Untersuchung u.a. der Frage

\footnotetext{
647 Sauer-Burghard/Zill, Frauen in der Rechtsprechung, 1984.

${ }^{648}$ Saner-Burghard/Zill, S. 59.

${ }^{649}$ Raab, Männliche Richter - weibliche Angeklagte, 1992.

${ }^{650}$ Raab, S. 41.

651 Raab, S. 123.

652 Raab, S. 121.

${ }^{653}$ Legnaro/Aengenheister, Schuld und Strafe, 1999.

${ }^{654}$ Legnaro/Aengenheister, S. 35.
} 
des unterschiedlichen Umgangs mit Frauen und Männern im Rahmen der Strafzumessung. Sie kamen zu dem Ergebnis, dass bei Frauen eher als bei Männern die Kriterien eines minder schweren Falles angenommen würden ${ }^{655}$ und die Strafe entsprechend häufiger zur Bewährung ausgesetzt werde. ${ }^{656}$ Ferner werde der Strafrahmen bei Frauen bei gleicher Subsumtion tendenziell weniger ausgeschöpft als bei Männern. ${ }^{657}$ Als Grund für diese ,vermeintlich ritterliche oder paternalistische Strafzumessung " führen die Autoren an, dass bei Frauen heteronome Verhaltensweisen deutlicher rekonstruiert werden konnten, sodass sie oft als "bilflos Ausgelieferte" erscheinen. ${ }^{658}$

Schließlich sollen noch einmal die bereits unter 1.2.1 dargestellten Ergebnisse von Mansel aufgegriffen werden. Mansel ging nicht nur der Frage nach, inwiefern das Anzeigeverhalten von Opfern und Zeugen zu unterschiedlichen Kriminalitätsraten der Geschlechter führen. Er versuchte ferner, die gewonnenen Ergebnisse zur Anzeigebereitschaft in den Selektionsprozess bis hin zu den gerichtlich Abgeurteilten einzubetten. Hierfür setzte er die Daten der Dunkelfeldstudie mit denen aus dem Hellfeld in Beziehung. ${ }^{659}$

Mansel kam zu dem Ergebnis, dass der Selektionsprozess für Frauen deutlich intensiver ausfällt als für Männer: Nur jeder vierte Tatverdächtige ist eine Frau, wobei die Differenzen in den Belastungsziffern nicht unerheblich von der Deliktsgruppe abhängig sind. Hingegen ist nur jeder sechste Abgeurteilte weiblich, wobei auch hier deliktsgruppenbezogene Unterschiede bestehen. Dieser deutliche geschlechtsspezifische Unterschied bei den Tatverdächtigen und gerichtlich Abgeurteilten sei darauf zurückzuführen, dass die Staatsanwaltschaft seltener Anklage erhebe und die von der Polizei eingeleiteten Ermittlungsverfahren eher einstelle. ${ }^{660}$ Er konstatierte, dass der unterschiedliche Selektionsprozess nichts mit einem Frauenbonus zu tun haben dürfte, sondern eher damit, dass Männer in der Regel strafrechtlich stärker vorbelastet seien und die den Männern zur Last gelegten Straftaten häufiger schwerwiegende Schäden herbeiführten. ${ }^{661}$

\subsubsection{Zwischenfarit}

Die dargestellten Untersuchungen zeigen, dass sich der vieldiskutierte Frauenbonus, also eine Bevorzugung krimineller Frauen nur aufgrund ihres Geschlechts, bisher nicht nachweisen ließ.

Auf der Ebene der Anzeigeerstatter fehlt es an repräsentativen Studien. Mansel stellte zwar grundsätzlich eine gesteigerte Anzeigebereitschaft gegenüber Männern

\footnotetext{
655 Legnaro/Aengenheister, S. 126.

${ }^{656}$ Legnaro/Aengenheister, S. $44 \mathrm{f}$.

657 Legnaro/Aengenheister, S. 45 ff.

${ }^{658}$ Legnaro/Aengenheister, S. 149.

${ }^{659}$ Mansel, in: Lamnek/Boatca (Hrsg.), Geschlecht, Gewalt, Gesellschaft, S. 384, 402; zu den Problemen der Vergleichbarkeit der Daten vgl. Kap. 1, 3.2.

${ }^{660}$ Mansel, in: Lamnek/Boatca (Hrsg.), Geschlecht, Gewalt, Gesellschaft, S. 384, 388 f.

661 Mansel, in: Lamnek/Boatca (Hrsg.), Geschlecht, Gewalt, Gesellschaft, S. 384, 389.
} 
fest, allerdings änderte sich dies, wenn das Geschlecht des Opfers männlich oder die Schadenshöhe gering war. Studien zur Anzeigebereitschaft bei Straftaten im privaten Nahraum weisen darauf hin, dass gegenüber Frauen seltener Anzeige erstattet wird. Dennoch ist zu beachten, dass dies nichts mit einer nachsichtigeren Behandlung zu tun haben dürfte. ${ }^{662}$

Hornthal kam auf der Ebene der Polizei für den Bereich der Ordnungswidrigkeiten im Straßenverkehr zu dem Ergebnis, dass Polizeibeamte von ihrem Ermessen gegenüber Frauen und Männern in unterschiedlicher Weise Gebrauch machen. Ein genereller Frauenbonus offenbarte sich folglich nicht. Auch Steffen resümierte, die Variable Geschlecht verliere unter Berücksichtigung weiterer Variablen, wie Delikt und Geständnisbereitschaft, ihre Bedeutung. Die unterschiedliche Vorstrafenbelastung wirke sich hingegen nicht sanktionsschärfend aus.

Zum gleichen Ergebnis kommen Blankenburg/Sessar/Steffen für die Ebene der Staatsanwaltschaft. Ludwig-Mayerhofer/Rzepka bestätigen nach einer multivariaten Analyse ebenfalls, dass dem Faktor Geschlecht bei den Delikten, denen sich das Gros der weiblichen Delinquenz zuordnen lässt, keine Bedeutung beizumessen ist. Eine Bevorzugung von Frauen wurde aber bei schwererer Delinquenz festgestellt.

Auf der Ebene des Gerichts kommen die meisten der Untersuchungen zu dem Ergebnis, dass eine unterschiedliche Sanktionierung der Geschlechter bei einer multivariaten Analyse für leichtere Delikte nicht zu verzeichnen sei. Lediglich Geißler/Marißen halten an der These einer milderen Bestrafung von Frauen fest. Den Autoren ist aber vorzuhalten, dass sie trotz Erhebung mehrerer Variablen lediglich jeweils eines dieser Merkmale kontrolliert haben. Die Möglichkeit eines anderen Ergebnisses durch die simultane Berücksichtigung mehrerer Merkmale wurde außer Acht gelassen. Für Tötungsdelikte konnte Oberlies gleichfalls keine Bevorzugung von Frauen feststellen. Körner, Raab und Sauer-Burghardt/Zill vermuten, dass eine etwaige Bevorzugung nur bei rollenkonformen Verhalten von Frauen stattfindet. Legnaro/Aegenheister konstatieren zwar eine Stereotypisierung bei der Wahrnehmung und Beurteilung von weiblichen und männlichen Angeklagten, insgesamt beschreiben sie die Strafzumessung aber als überraschend regelhaft und regelmäßig. ${ }^{663}$

Zusammenfassend lässt sich feststellen, dass die Ergebnisse der Studien darauf hinweisen, dass unterschiedliche Sanktionierung nichts mit einem Frauenbonus zu tun haben dürfte. Vor allen Dingen die Berücksichtigung des Delikts führte dazu, dass eine geschlechtsspezifisch unterschiedliche Sanktionierung kaum mehr auszumachen war. Für die schwereren Delikte, bei denen eine Bevorzugung von Frauen teils festgestellt wurde, wurde von den Autoren zumeist selbst eingeräumt, dass entweder die Stichprobe nur noch sehr klein war oder nicht genügend beeinflussende Faktoren berücksichtigt werden konnten. Die Thesen der Vertreter der Kavalierstheorie finden mithin keine hinreichende Stütze in den dargestellten

$662 \mathrm{Vgl}$. Ausführungen unter Kap. 5, 1.2.1.

${ }^{663}$ Legnaro/Aengenheister, S. 165. 
Ergebnissen. Die Studien beziehen sich allerdings überwiegend auf eine geringe Anzahl von Probanden oder sind regional begrenzt und haben daher nur eine eingeschränkte Aussagekraft. Mit der vorliegenden Untersuchung kann der Einfluss, einiger der in den hier diskutierten Studien festgestellten strafzumessungsrelevanter Faktoren, auf der Basis eines gesamten Verurteilungsjahrgangs analysiert werden.

\section{Eigene Forschungsergebnisse auf der Grundlage der Daten des Bundeszentralregisters}

Der Überblick über den Forschungsstand zur nachsichtigen Behandlung von Frauen hat aufgezeigt, dass umfangreiche und repräsentative Untersuchungen zur Thematik selten sind. Mit den der vorliegenden Studie zugrunde liegenden Daten des BZR wird nunmehr eine bundesweite Analyse der Sanktionierungspraxis der Gerichte gegenüber Frauen und Männern nach Alter, Delikt und Vorstrafenbelastung für das Bezugsjahr 2004 durchgeführt. Dabei wird die Frage einer etwaigen Bevorzugung von Frauen bei der Strafzumessung der Gerichte einer genaueren Betrachtung unterzogen.

Freilich können viele Faktoren, die bei der Strafzumessung eine Rolle spielen, nicht berücksichtigt werden. So kann beispielsweise nicht überprüft werden, ob geschlechtsrollenkonformes bzw. - diskonformes Verhalten die Strafzumessung beeinflussen, worauf die Ergebnisse einiger der soeben dargestellten Studien hindeuten. $\mathrm{Zu}$ berücksichtigen ist ferner, dass nach der gesetzlichen Konzeption härtere Sanktionen für Täter mit einer ungünstigen Prognose vorgesehen sind. Dabei können die unterschiedlichsten Faktoren in die Prognose mit einfließen.664 Die genauen Tat- und Lebensumstände der registrierten Personen sind jedoch nicht bekannt. Darüber hinaus dürfte auch die hier nicht berücksichtigungsfähige Strafeinstellung des Richters eine Rolle spielen. Oswald ${ }^{665}$ stellte hierzu fest, dass eine hohe „Täter-Gesellschafts-Orientierung ${ }^{\text {“666 }}$ von Richtern mit der Tendenz zu härteren Strafen einhergeht:667 „Je mehr sich der Richter von einer Täterorientierung abund zu einer Gesellschaftsorientierung binwendet, umso positiver ist seine Einstellung gegenüber barten Strafen. "668 Drewniak ${ }^{669}$ bestätigte dieses Ergebnis noch einmal mit dem $\mathrm{Zu}$ -

\footnotetext{
${ }^{664}$ So hat beispielsweise Künそ̨l festgestellt, dass ein erlittenes Trauma bei Täterinnen die Wahrheit verschleiern könne und dadurch die Erzählweise beeinflusse. Damit bestehe die Gefahr, dass die Täterinnen als unglaubwürdig eingestuft würden, vgl. Künzel, in: Seidler/Eckart (Hrsg.), Verletzte Seelen: Möglichkeiten und Perspektiven einer historischen Traumaforschung, S. 213-228.

665 Oswald, Psychologie des richterlichen Strafens.

${ }^{666}$ Hierunter fasst die Autorin die Konfliktlage strafender Personen, die bei der Strafzumessung nicht nur Belange der Täter, sondern auch der „Nichttäter“ (insbesondere der Opfer) im Auge haben, vgl. Oswald, S. 188.

667 Oswald, S. $194 \mathrm{ff}$.

668 Oswald, S. 189.
} 
satz, dass dies auch unabhängig vom Geschlecht des Richters gelte. ${ }^{670}$ Darüber hinaus hat u.a. die bereits vorgestellte Untersuchung von Raab Anhaltspunkte dafür geliefert, dass die Sanktionierung durch den Richter von Geschlechtsrollenerwartungen beeinflusst wird. ${ }^{671}$ Laut Stammermann/Gransee ${ }^{672}$ diene als Normalitätsgrundlage für eine Beurteilung von Frauen das Bild einer ,asexuellen (reinen) Mutter. "צ73 Insbesondere die plakative und emotionalisierte Kriminalitätsberichterstattung führe zur (Re-)Produktion normativer Geschlechterkonstruktionen. ${ }^{674}$

Allerdings ist es möglich, eine umfangreiche Analyse der Sanktionierungspraxis gegenüber Frauen und Männern, unter Berücksichtigung der eingangs erwähnten Variablen, durchzuführen und diese einander gegenüberzustellen.

Die Überprüfung einer etwaigen geschlechtsdifferenzierenden Sanktionierung bringt es mit sich, dass Frauen im Vergleich zu den Männern betrachtet werden müssen. Dabei ist immer zu berücksichtigen, dass Frauen generell seltener straffällig werden (vgl. auch die Ergebnisse unter Kapitel 4).

Ausgehend von dem soeben gelieferten Überblick über die Untersuchungen zur Behandlung von Frauen durch die strafrechtlichen Kontrollinstanzen wird vorliegend vermutet, dass Frauen in der Justiz nicht aufgrund ihres Geschlechts bevorzugt behandelt werden. Die „mildere“ Bestrafung von Frauen dürfte an Signifikanz verlieren, wenn man weitere Variablen, wie das Delikt und die Vorstrafenbelastung, mit einbezieht. Das Geschlecht dürfte kein einflussreicher Faktor für die besondere Schwere oder Milde der Sanktionierung sein. Darauf weisen die unter 1.2.2.3 diskutierten Studien hin.

Für die hier zugrunde liegende Bewertung einer Sanktion als schwer oder mild musste eine Rangskalierung vorgenommen werden, die sich an den gesetzlichen Vorgaben orientiert. Die Sanktionen nach Jugendstrafrecht und allgemeinem Strafrecht werden grundsätzlich getrennt betrachtet: Eine Jugendstrafe ohne Bewährung wiegt danach schwerer als eine solche mit Bewährung. ${ }^{675}$ Die Jugendstrafen insgesamt wiegen schwerer als die sonstigen Entscheidungen nach JGG. Hierunter befinden sich Erziehungsmaßregeln, Zuchtmittel (einschließlich Jugendarrest) sowie andere durch jugendrichterliches Urteil getroffene eintragungspflichti-

${ }^{669}$ Drewniak, Strafrichterinnen als Hoffnungsträgerinnen? Eine vergleichende Analyse strafrechtlicher Orientierungen von Richterinnen und Richtern.

${ }^{670}$ Drewniak, S. 88 ff., 114.

671 Raab, S. $122 \mathrm{f}$.

672 Stammermann/Gransee, in: Frehsee/Löschper/Smaus (Hrsg.), Konstruktion der Wirklichkeit durch Kriminalität und Strafe, S. 435-455.

673 Stammermann/Gransee, in: Frehsee/Löschper/Smaus (Hrsg.), Konstruktion der Wirklichkeit durch Kriminalität und Strafe, S. 435, 449.

674 Stammermann/Gransee, in: Frehsee/Löschper/Smaus (Hrsg.), Konstruktion der Wirklichkeit durch Kriminalität und Strafe, S, 435, 453.

${ }^{675} \mathrm{Zu}$ beachten ist aber, dass die Entscheidung darüber, ob eine Jugend- oder Freiheitsstrafe zur Bewährung ausgesetzt wird, von den in $\ 56$ StGB genannten Kriterien abhängt. Dies wird bei der Interpretation der Ergebnisse zu berücksichtigen sein. 
ge Entscheidungen. 676 Die mildeste Sanktion des JGG sind die Einstellungen gem. $\int \$ 45,47$ JGG. Bei den Sanktionen nach allgemeinem Strafrecht wiegen die Freiheitsstrafen ohne Bewährung am schwersten, gefolgt von den Freiheitsstrafen mit Bewährung. Die mildeste Sanktion des StGB ist die Geldstrafe, auch wenn dies im Einzelfall von dem Verurteilten anders bewertet werden kann. So ist es denkbar, dass eine Geldstrafe eine finanziell schlecht gestellte Person, trotz Berücksichtigung der wirtschaftlichen Verhältnisse des Täters im Tagessatzsystem, ${ }^{677}$ härter treffen kann als eine Freiheitsstrafe, die zur Bewährung ausgesetzt wird. Gleiches kann für eine Jugendstrafe mit Bewährung im Vergleich zu einer sonstigen Entscheidung nach dem JGG, z.B. Jugendarrest gelten. Ferner kann auch eine Einstellung nach den $\iint 45,47 \mathrm{JGG}$ mit Auflagen verbunden werden und daher im Einzelfall schwer wiegen. ${ }^{678}$ Solche Einzelfallumstände können jedoch mit den zugrunde liegenden Daten nicht berücksichtigt werden.

Wie eingangs erwähnt, knüpft die Bezugsentscheidung auch für die Analyse der Sanktionierung im Querschnitt bei stationären Sanktionen am Urteilszeitpunkt an. Die Verwendung des Entscheidungsdatensatze 6 $^{679}$ hat den Vorteil, dass die Sanktionierungspraxis voll umfänglich für das zugrunde liegende Bezugsjahr 2004 abgebildet werden kann. Würde man auch an dieser Stelle den Rückfalldatensatž 60 heranziehen und folglich nur bei ambulanten Sanktionen das Urteil in 2004, bei stationären hingegen den Entlassungszeitpunkt in 2004 als Bezugsentscheidung zugrunde legen, so könnte dies zu Verzerrungen bei der Verteilung der Sanktionen durch etwaige Änderung in der Sanktionierungspraxis führen.

Im Folgenden wird sowohl die Sanktionierung nach Jugendstrafrecht als auch die Sanktionierung nach allgemeinem Strafrecht detailliert abgebildet. Diese Einteilung führt dazu, dass sich die Altersgruppe der 18-21-jährigen Heranwachsenden sowohl bei den Sanktionen nach Jugendstrafrecht als auch bei den Sanktionen nach allgemeinem Strafrecht befindet, je nachdem, ob gem. \105 JGG Jugendstrafrecht angewandt wurde oder nicht.

Im weiteren Verlauf werden die in Kapitel 4 gebildeten Deliktsgruppen sowie die Voreintragungen miteinbezogen.

\subsection{Anteil der Geschlechter an der Art der Bezugsentscheidung}

Bevor die Sanktionierung nur für die Gruppe der Frauen im Vergleich zu der Gruppe der Männern betrachtet wird, gibt Schaubild 5.1 zunächst einen Überblick über die Arten der Bezugsentscheidungen und den Anteil der Geschlechter an der jeweiligen Art der Bezugsentscheidung nach dem Jugend- und dem allgemeinem Strafrecht.

\footnotetext{
${ }^{676} \mathrm{Vgl}$. hierzu ausführlich unter Kap. 3, 2.1.

677 Vgl. ausführlich zur Geldstrafe Schäfer/Sander/van Gemmen, S. 23 ff.

${ }^{678}$ Kritisch zu der hier gewählten Rangskalierung wohl Oberlies, in: KZfSS 1990, S. 129, 139.

${ }^{679}$ Vgl. hierzu auch Ausführungen unter Kap. 3, 2.2.

${ }^{680}$ Vgl. hierzu auch Ausführungen unter Kap., 3.2.1.
} 


\section{Schaubild 5.1: Anteil von Frauen und Männern an der Art der Bezugsentscheidung681*}

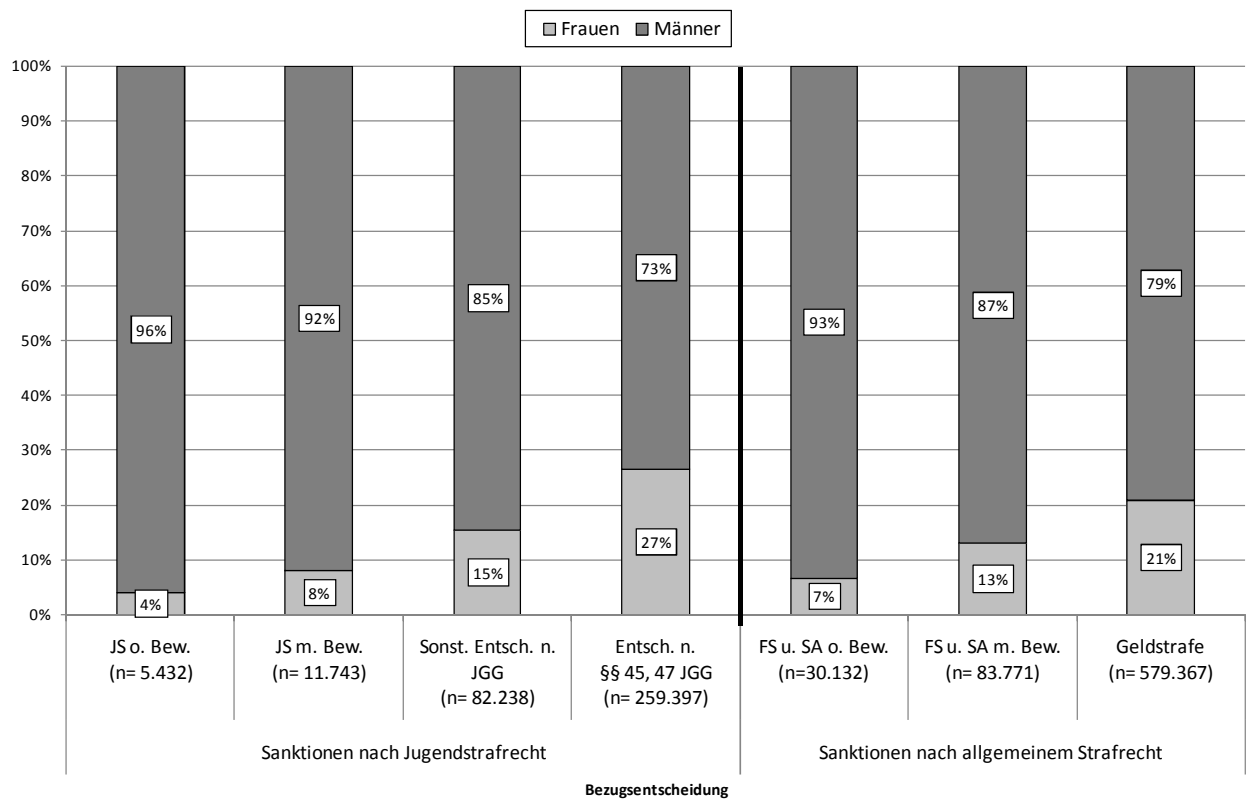

* Absolutzablen siehe Tab. 5.1 a im Anhang

Es zeigt sich, dass Frauen über alle Sanktionsgruppen hinweg einen deutlich niedrigeren Anteil an der jeweiligen Art der Bezugsentscheidung haben. Das überrascht angesichts des Geschlechterunterschieds im Datensatz nicht.

Für die Sanktionierung nach Jugendstrafrecht kann zwischen der Jugendstrafe mit und ohne Bewährung, den sonstigen jugendrichterlichen Entscheidungen ${ }^{682}$

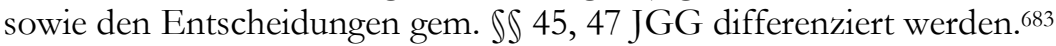

Betrachtet man diese jugendstrafrechtlichen Sanktionen, so fällt auf, dass sich hier sowohl die Sanktion mit dem niedrigsten als auch die mit dem höchsten Frauenanteil findet: bei den Jugendstrafen ohne Bewährung beträgt der Frauenanteil nur $4 \%$, wohingegen ihr Anteil an den Entscheidungen nach $\iint 45,47 \mathrm{JGG}$ bei $27 \%$ liegt. $15 \%$ der sonstigen Entscheidungen nach dem JGG und $8 \%$ der bedingten Jugendstrafen ergehen gegen Frauen. Der Anteil von Frauen an der Art

${ }^{681}$ Hier wurden nur Entscheidungen erfasst, die einer der dargestellten Theorien zuzuordnen sind.

Nicht enthalten sind daher sonstige Entscheidungen (Maßregeln gem. SS 63, 64, 66 StGB sowie

Nebenstrafen nach dem StGB, wie das Berufsverbot, die Entziehung der Fahrerlaubnis oder das Fahrverbot). Allerdings wird in Kap. 5, 2.3.5 eine Betrachtung der verkehrsrechtlichen Sanktionen (Entziehung der Fahrerlaubnis und Fahrverbot) erfolgen.

${ }^{682}$ Hierunter befinden sich Erziehungsmaßregeln, Zuchtmittel (einschließlich Jugendarrest) sowie andere durch jugendrichterliches Urteil getroffene eintragungspflichtige Entscheidungen.

683 Vgl. hierzu ausführlich Kap. 3, 2.1. 
der Bezugsentscheidung nach dem JGG nimmt folglich mit steigender Schwere der Sanktionsart ab.

Dieser Trend zeigt sich auch bei den Reaktionen nach allgemeinem Strafrecht. Für das allgemeine Strafrecht werden die Sanktionsarten differenziert nach Freiheitsstrafe ohne und mit Bewährung sowie Geldstrafe dargestellt. Bei den Freiheitsstrafen ist der militärische Strafarrest, der nach dem Wehrstrafgesetz verhängt wird, miterfasst. Dieser spielt jedoch zahlenmäßig keine Rolle. ${ }^{684}$

Der Anteil der Frauen innerhalb der einzelnen Sanktionsgruppen nach dem StGB variiert zwischen $7 \%$ bei der unbedingten Freiheitsstrafe und $21 \%$ bei der Geldstrafe. Der Frauenanteil an den bedingten Freiheitsstrafen beträgt 13\%.

Insgesamt lässt sich konstatieren, dass Frauen über alle Arten von Bezugsentscheidungen hinweg seltener vertreten sind und ihr Anteil mit steigender Sanktionsschwere kleiner wird.

\subsection{Sanktionierung nach Jugendstrafrecht}

Im Folgenden wird zunächst die Bezugsentscheidung unter Berücksichtigung der zur Verfügung stehenden Variablen umfassend deskriptiv dargestellt.

\subsubsection{Verteilung der jugendstrafrechtlichen Reaktionen}

Schaubild 5.2 gibt einen Überblick über die jugendstrafrechtlichen Reaktionen in der Bezugsentscheidung. Im Gegensatz zu Schaubild 5.1 wird hier jedoch nicht der jeweilige Anteil von Frauen und Männern an der Sanktionsart der Bezugsentscheidung betrachtet, sondern vielmehr die Verteilung sämtlicher jugendstrafrechtlicher Reaktionen, die im Bezugsjahr 2004 für Frauen ergangen sind. Als Vergleichsgruppe werden die Männer mit betrachtet. Darüber hinaus wird für Schaubild 5.2 der Jugendarrest separat ausgewiesen.

$0,3 \%$ der Frauen erhielten im Bezugsjahr Jugendstrafe ohne und $1 \%$ Jugendstrafe mit Bewährung. Bei den Männern liegen die Anteile hingegen bei $2 \%$ (Jugendstrafe ohne Bewährung) und $4 \%$ (Jugendstrafe mit Bewährung). $2 \%$ der Frauen und $4 \%$ der Männer wurden im Bezugsjahr zu Jugendarrest verurteilt. Bei den sonstigen Entscheidungen nach dem JGG stehen sich Anteile von 13\% (Frauen) und $20 \%$ (Männern) gegenüber. Bei Frauen werden nur die Einstellungen gem. $\iint 45,47$ JGG mit $83 \%$ im Vergleich zu den Männern häufiger angewandt $(69 \%)$.

Betrachtet man alle jugendstrafrechtlichen Bezugsentscheidungen, so lässt sich feststellen, dass sowohl Frauen als auch Männer am seltensten zu einer Jugendstrafe ohne Bewährung verurteilt werden und am häufigsten eine Entscheidung nach den $\iint 45,47$ JGG erhalten.

${ }^{684}$ Daher wird in den folgenden Schaubildern nur noch mit „FS“ für Freiheitsstrafe abgekürzt und auf den Zusatz „SA“ für Strafarrest verzichtet. 


\section{Schaubild 5.2: Jugendstrafrechtliche Reaktionen nach Geschlecht*}

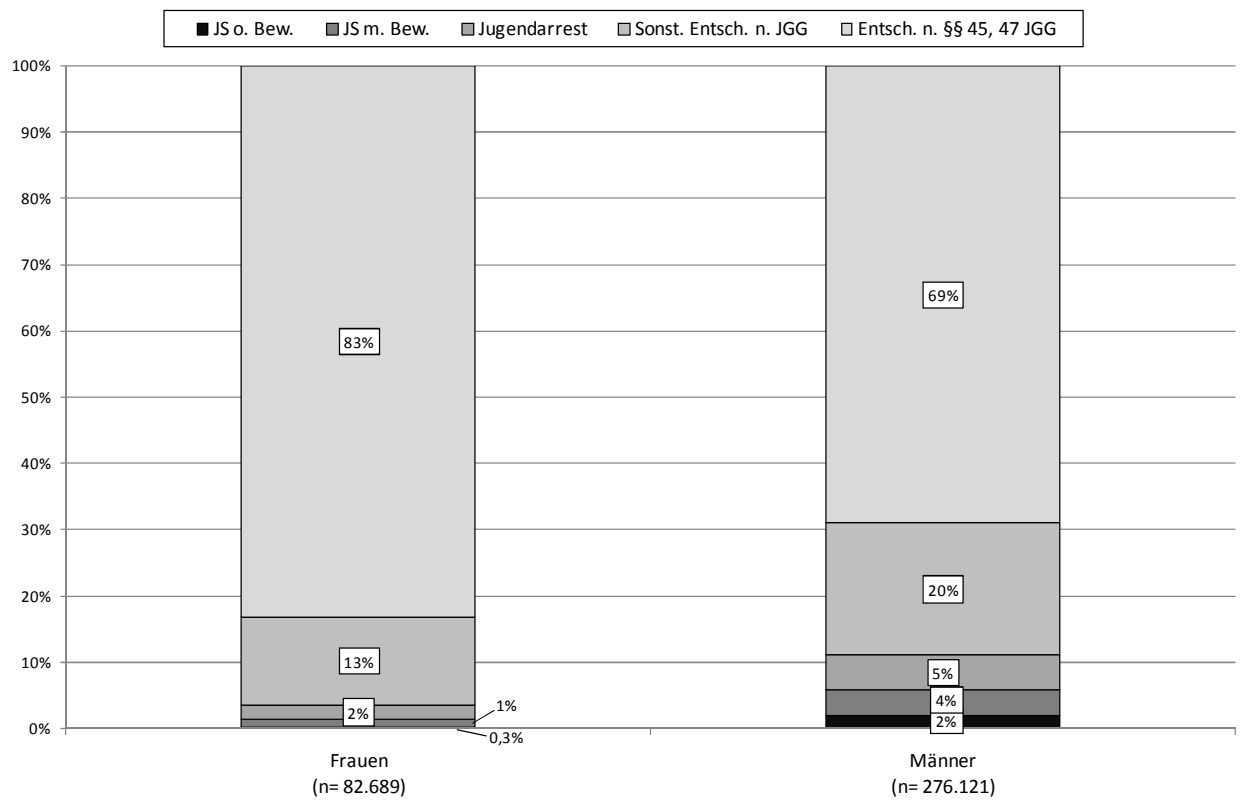

* Absolutrablen siebe Tab. 5.2a im Anhang

Frauen erhalten allerdings seltener schwerwiegende jugendstrafrechtliche Sanktionen, dafür häufiger eine Einstellung nach den $\iint 45,47$ JGG.

\subsubsection{Dauer der Jugendstrafen ohne Bewährung}

Schaubild 5.3 verdeutlicht die Verteilung der Dauer der Jugendstrafen ohne Bewährung für Frauen und Männer im Vergleich. Angesichts der geringen Anzahl von Frauen, müssen die Ergebnisse vorsichtig betrachtet werden.

Es zeigt sich, dass bei beiden Geschlechtern mit $41 \%$ am häufigsten eine Jugendstrafe von ein bis zwei Jahren verhängt wird. Bei den Frauen folgt sogleich die Gruppe der Jugendstrafen von sechs Monaten bis zu einem Jahr mit 33\%, sodass die Jugendstrafen von sechs Monaten bis zu zwei Jahren bei den Frauen zusammen einen Anteil von $74 \%$ ausmachen. Auch bei den Männern ist der Anteil von Jugendstrafen von bis zu zwei Jahren mit insgesamt $61 \%$ recht hoch, allerdings stehen die kürzeren Jugendstrafen bis zu zwölf Monaten, anders als bei den Frauen, erst an dritter Stelle. Sie bekommen mit $25 \%$ am zweithäufigsten eine Jugendstrafe von zwei bis zu drei Jahren. Bei den Frauen stehen die Jugendstrafen von zwei bis zu drei Jahren erst an dritter Stelle. Der Anteil von Jugendstrafen über fünf Jahren bei den Täterinnen übersteigt mit 3\% zwar den Anteil bei den Tätern mit $2 \%$. Hier ist aber zu berücksichtigen, dass lediglich sechs Frauen eine solche Jugendstrafe erhielten. 


\section{Schaubild 5.3: Dauer der Jugendstrafe obne Bewäbrung nach Geschlecht*}

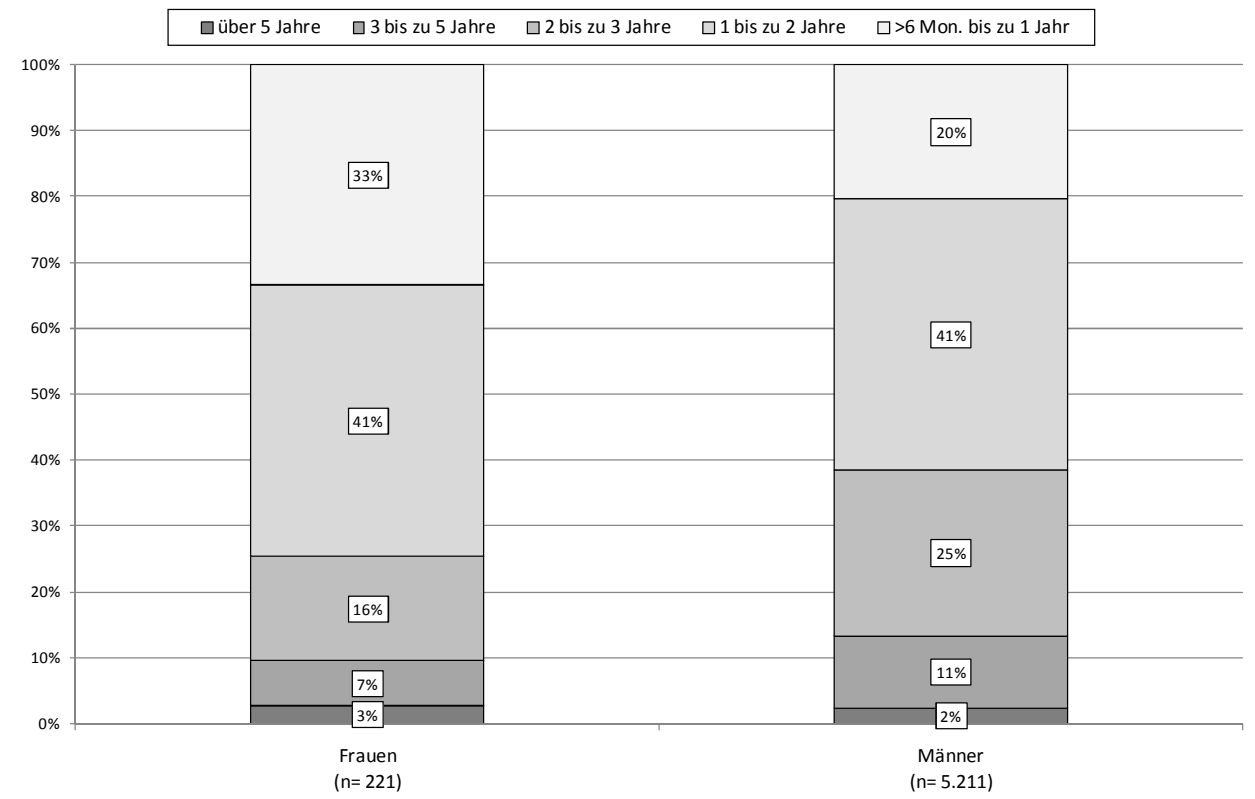

* Absolutrablen siehe Tab. 5.3 a im Anbang

Eine genauere Analyse dieser Fälle mit Hilfe der Deliktsbeschreibung, die im BZR dokumentiert wird, hat ergeben, dass drei dieser sechs Verurteilungen ein gemeinschaftlicher Mord zugrunde lag. ${ }^{685}$ In einem weiteren Fall wurde Beihilfe zum Mord begangen. ${ }^{686}$ Dies spricht für die Annahme, dass Täterinnen schwere Straftaten häufig nicht in Alleintäterschaft begehen. ${ }^{687}$

Insgesamt lässt sich feststellen, dass Männer vergleichsweise länger andauernde Jugendstrafen erhalten. Dies bestätigt auch der Mittelwert, welcher bei den Frauen 652 Tage und bei den Männern 745 Tage beträgt.

${ }^{685}$ Hierbei ist zu berücksichtigen, dass grundsätzlich von einer Analyse der Vorschriften des Allgemeinen Teils des StGB abgesehen wurde, da Zuordnungsprobleme bestehen, vgl. auch Kap. 3, 3.3. An dieser Stelle konnte dieses Problem jedoch ausgeschlossen werden, da für diese kleine Stichprobe die ausführliche Deliktsbeschreibung im BZR betrachtet wurde. Da $\ 211 \mathrm{StGB}$ das einzige eingetragene Delikt war, konnten die Vorschriften des Allgemeinen Teils zugeordnet werden.

${ }^{686}$ Bei den anderen zwei Fällen handelte es sich zum einen um mehrfaches unerlaubtes

Handeltreiben und Erwerben von Betäubungsmitteln in nicht geringen Mengen und zum anderen um eine einfache Körperverletzung. Bei letzterer dürfte es sich um eine Fehleintragung handeln, da eine einfache Körperverletzung nicht zu einer solch langen Jugendstrafe führen kann.

${ }^{687}$ So auch Albrecht für die Delikte Raub und Einbruchdiebstahl, siehe auch Kap. 5, 1.2.2.3. 


\subsubsection{Strafaussetzung zur Bewährung}

Nunmehr wird überprüft, wie häufig eine grundsätzlich aussetzungsfähige Jugendstrafe auch tatsächlich ausgesetzt wird. Zu beachten ist dabei, dass die Aussetzung der Verhängung der Jugendstrafe gem. \27 JGG hier aufgrund der Tilgungsvorschriften des BZR nicht mehr enthalten ist. 688

\section{Schaubild 5.4: Aussetrungsquote bei Jugendstrafe nach Geschlecht*}

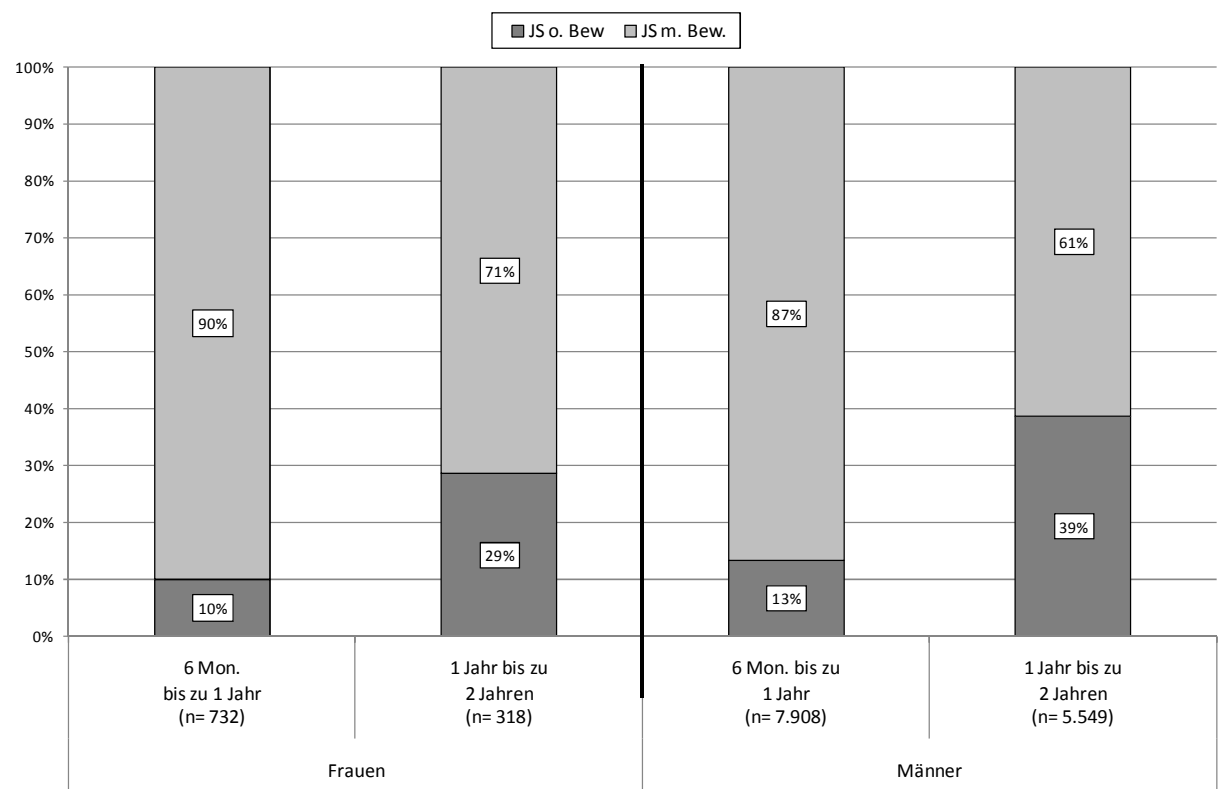

*Absolutzablen siebe Tab. 5.4a im Anhang

Aus Schaubild 5.4 geht hervor, dass sowohl bei den Tätern als auch bei den Täterinnen eine Jugendstrafe von sechs Monaten bis zu einem Jahr zumeist zur Bewährung ausgesetzt wird. Bei den Frauen ist der Anteil mit $90 \%$ allerdings größer als bei den Männern mit $87 \%$. Auch die Jugendstrafen von einem Jahr bis zu zwei Jahren werden bei den Frauen mit einer Quote von 71 \% (Frauen) häufiger zur Bewährung ausgesetzt als bei den Männern (61 \%), mit dem Unterschied, dass die Differenz zwischen den Anteilen der Geschlechter hier größer ist.

Das Ergebnis, wonach bei Frauen Jugendstrafen tendenziell häufiger zur Bewährung ausgesetzt werden, besagt noch nichts darüber, dass dies Folge einer nachsichtigeren Behandlung von Frauen ist. Dies spricht vielmehr dafür, dass die gem. \56 StGB durchzuführende Sozialprognose für Frauen in der Regel günstiger ausfällt als für Männer.

${ }^{688} \mathrm{Vgl}$. hierzu auch Kap. 3, 3.4. 
Die Frage bezüglich einer Unterstellung unter die Bewährungsaufsicht (vgl. Kap. 5, 2.4) stellt sich bei Jugendstrafen nicht, da diese hier immer angeordnet werden muss (vgl. \$24 JGG). Zwar ist dies nach dem Entscheidungsdatensatz des BZR im Basisjahr in nur $24 \%$ der ausgesetzten Jugendstrafen für Frauen und $25 \%$ der ausgesetzten Jugendstrafen für Männer geschehen. Dies dürfte jedoch auf unvollständige Eintragungen zurückzuführen sein, da eine Unterstellung für die Jugendgerichte selbstverständlich ist.

\subsubsection{Anwendung des $\$ 105$ I JGG}

Gem. \105 I JGG können auf Heranwachsende bestimmte für Jugendliche geltende Vorschriften angewandt werden, wenn die Gesamtwürdigung der Persönlichkeit des Täters bei der Berücksichtigung auch der Umweltbedingungen ergibt, dass er zur Zeit der Tat nach seiner sittlichen und geistlichen Entwicklung noch einem Jugendlichen gleichstand ( $\$ 105$ I Nr. 1 JGG) oder wenn es sich nach der Art, den Umständen oder den Beweggründen der Tat um eine Jugendverfehlung handelt (\$ 105 I Nr. 2 JGG). Fraglich ist, ob sich ein Unterschied bei der Anwendung des \105 I JGG auf Männer und Frauen ergibt. Für weibliche Heranwachsende könnten die Voraussetzungen des $₫ 105$ I JGG eher verneint werden, da sie in ihrer Entwicklung in der Regel weiter fortgeschritten sind als das andere Geschlecht. Um dieser Frage nachzugehen, wird nunmehr die Art der Bezugsentscheidung nach dem JGG und dem StGB nur für die Altersgruppe der heranwachsenden Frauen und Männern betrachtet.

Tabelle 5.1: Anwendung des JGG oder StGB auf heranwachsende Frauen und Männer

\begin{tabular}{|l|r|r|r|r|}
\hline \multirow{2}{*}{} & \multicolumn{2}{|c|}{ Frauen } & \multicolumn{2}{c|}{ Männer } \\
& \multicolumn{1}{|c|}{ abs. } & \multicolumn{1}{c|}{ in $\%$} & \multicolumn{1}{c|}{ abs. } & \multicolumn{1}{c|}{ in $\%$} \\
\hline JGG & 22.601 & $80 \%$ & 92.112 & $78 \%$ \\
\hline StGB & 5.729 & $20 \%$ & 26.205 & $22 \%$ \\
\hline Gesamt & 28.330 & $100 \%$ & 118.317 & $100 \%$ \\
\hline
\end{tabular}

Tabelle 5.1 verdeutlicht jedoch, dass bei der Anwendung von $\ 105$ I JGG zwischen den Geschlechtern kaum ein Unterschied besteht. In der Altersgruppe der Heranwachsenden werden sowohl für Frauen (mit $80 \%$ ) als auch für Männer (mit $78 \%$ ) die Voraussetzungen des $\$ 105$ I JGG meistens bejaht; für Frauen sogar minimal häufiger. Die in Kapitel 3 aufgestellte Hypothese, ${ }^{689}$ dass bei heranwachsenden Täterinnen eher Verurteilungen nach Erwachsenenstrafrecht erfolgen als bei heranwachsenden Tätern, kann mithin nicht bestätigt werden. Zudem verdeut-

${ }^{689} \mathrm{Vgl}$. Kap. 3, 2.3. 
licht dieses Ergebnis noch einmal die Tatsache, dass auf Heranwachsende, entgegen dem Wortlaut des $\ 105$ I JGG, in der Regel Jugendstrafrecht angewendet wird.

In diesem Zusammenhang kann außerdem die These überprüft werden, die Anwendungswahrscheinlichkeit des $\int 105$ I JGG steige mit der Schwere des Delikts. ${ }^{690}$ Dabei stellt sich ferner die Frage, ob bei einer deliktsdifferenzierenden Betrachtung Unterschiede bei den Geschlechtern zu erkennen sind.

Schaubild 5.5 veranschaulicht den Anteil jugendstrafrechtlicher Sanktionen an allen Bezugsentscheidungen für heranwachsende Frauen und Männer für die verschiedenen Deliktsgruppen.

Es zeigt sich, dass eine Jugendverfehlung oder Reifeverzögerung besonders häufig in der Gruppe der Gewaltdelikte angenommen wird und dort vor allen Dingen bei den sonstigen Körperverletzungs- und Gewaltdelikten. Hier wird in 93-95 \% der Fälle für beide Geschlechter von \105 I JGG Gebrauch gemacht. Bei den Tötungsdelikten werden immerhin noch $90 \%$ der Männer nach Jugendstrafrecht verurteilt. Für die Frauen ergibt sich hier sogar ein Wert von $100 \%$. Alle heranwachsenden Frauen, die im Bezugsjahr wegen eines Tötungsdelikts verurteilt wurden, wurden mithin nach Jugendstrafrecht verurteilt. Dabei ist allerdings zu beachten, dass dies nur acht Frauen waren.

Lediglich die einfache Körperverletzung sticht aus der Gruppe der Gewaltdelikte heraus: Hier findet $\int 105$ I JGG nur in $74 \%$ (Frauen) bzw. $79 \%$ (Männer) der Fälle Anwendung.

Es bestätigt sich folglich, dass der Anteil jugendstrafrechtlicher Sanktionen bei schwereren Delikten, wie den Gewaltdelikten, besonders hoch ist. Dies wird u.a. damit begründet, dass es bei schwersten Delikten regelmäßig zu einer genaueren Persönlichkeitserforschung unter Einholung von Sachverständigengutachten kommt, wodurch Reifeverzögerungen besser entdeckt werden können. ${ }^{691}$ Ferner soll vermutlich das flexiblere Sanktionssystem des JGG genutzt werden, auch um den teilweise als unangemessen hoch bewerteten Strafrahmen aus dem Weg zu gehen. ${ }^{692}$

Betrachtet man die Anwendungshäufigkeit bei den Vermögensdelikten i.w.S., zeigt sich auch hier, dass für beide Geschlechter die schwereren Diebstahlsformen eher nach Jugendstrafrecht sanktioniert werden: Der Anteil beträgt hier $92 \%$ für beide Geschlechter. Bei den anderen Deliktsgruppen in dieser Kategorie wird \105 I JGG etwas häufiger bei Frauen als bei Männern angewendet. Verhältnismäßig selten finden jugendstrafrechtliche Sanktionen für die Deliktsgruppe Betrug u.a. mit $72 \%$ (Frauen) und $71 \%$ (Männer) Anwendung.

\footnotetext{
${ }^{690}$ Schaffstein/Beulke, \8 III.

691 Streng, \5, Rdn. 5; Eisenberg, \105, Rdn. 5; Goerdeler, in: Ostendorf, Grdl. z. \\ 105 und 106, Rdn. 6.

692 Streng, $\int 5$, Rdn. $79 \mathrm{ff}$.
} 
Schaubild 5.5: Anwendungshäufigkeit des \105 JGG nach Deliktsgruppen und Geschlecht*

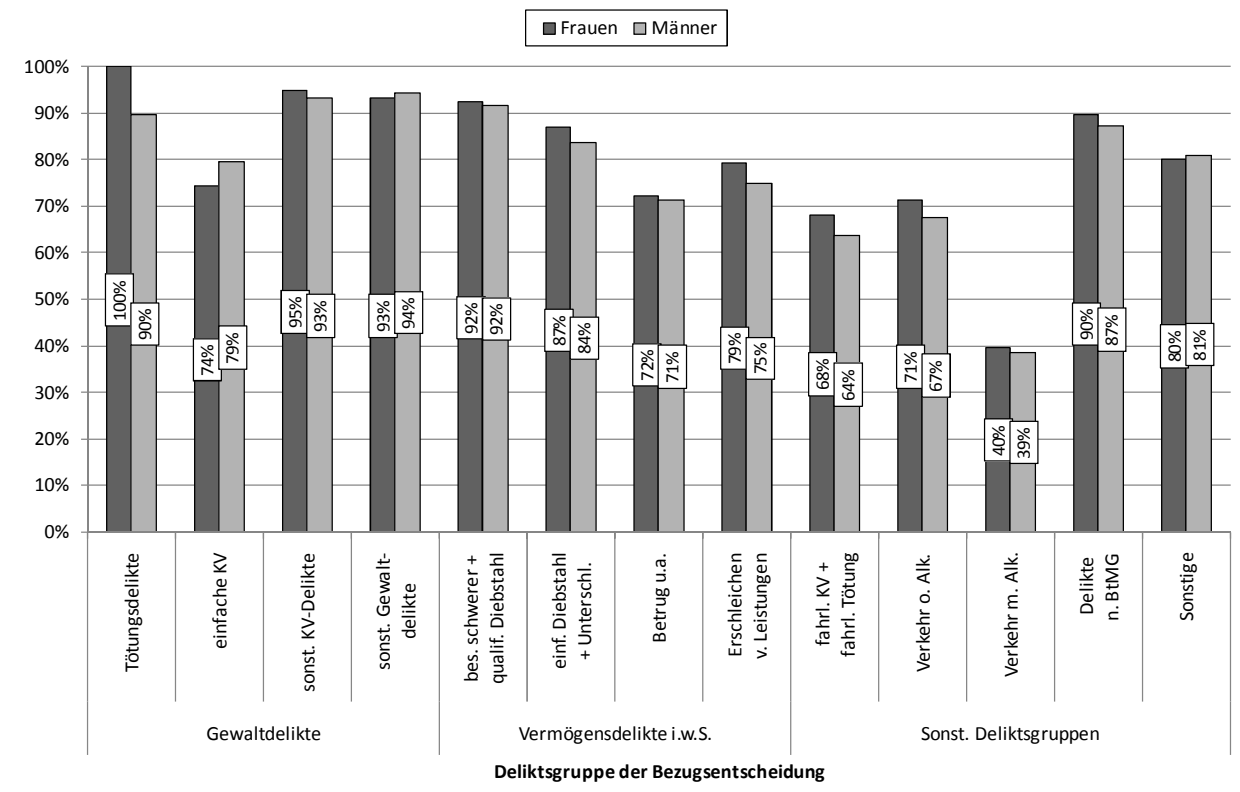

* Absolutrablen siebe Tab. $5.5 a$ und $5.5 b$ im Anbang

Ferner verdeutlicht Schaubild 5.5 eindrucksvoll die altbekannte Tatsache, dass für die Gruppe der Verkehrsstraftäter am häufigsten Erwachsenenstrafrecht Anwendung findet. ${ }^{693}$ Bei den weiblichen und männlichen Verkehrsstraftätern unter Alkoholeinfluss liegt nur $39 \%$ (Frauen) bzw. $40 \%$ (Männer) aller Bezugsentscheidungen eine Verurteilung nach dem JGG zugrunde. Dies ist die einzige Deliktsgruppe, in der eine Anwendung des $\$ 105$ I JGG für heranwachsende Frauen und Männer in der Mehrzahl der Fälle verneint wird. Auch bei den Verkehrsdelikten ohne Alkoholeinfluss und der vermutlich damit im Zusammenhang stehenden fahrlässigen Körperverletzung und fahrlässigen Tötung ist die Anwendungshäufigkeit des $\$ 105$ I JGG mit $71 \%$ und $67 \%$ (Frauen und Männer für Verkehrsdelikte ohne Alkoholeinfluss) bzw. $68 \%$ und $64 \%$ (Frauen und Männer für fahrlässige Körperverletzung und fahrlässige Tötung) nicht so hoch wie bei den anderen Delikten. Die relativ häufige Anwendung des allgemeinen Strafrechts auf Ver-

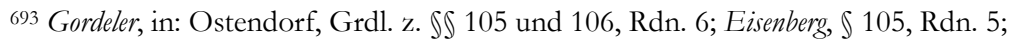

Laubenthal/Nestler, in: Dollinger/Schmidt-Semisch (Hrsg.), Handbuch der Jugendkriminalität, S. 475, 477; Streng, \5, Rdn. 85. 
kehrsdelikte hängt vermutlich mit der aufgrund von $\$ \int 109$ I S. 1, II S. 1, 79 I JGG nur dann gegebenen Möglichkeit eines Strafbefehlsverfahrens zusammen. ${ }^{694}$

Bei den Delikten nach dem BtMG $(90 \%$ bei den Frauen und $87 \%$ bei den Männern) und den sonstigen Delikten (80\% für Frauen und $81 \%$ für Männer) finden wieder vermehrt die Sanktionen des JGG Anwendung.

Zusammenfassend lässt sich feststellen, dass auch bei einer deliktsspezifischen Betrachtung der Anwendungshäufigkeit des \105 I JGG keine großen Unterschiede zwischen Frauen und Männern zu finden sind. Tendenziell wird für Frauen noch etwas häufiger das Jugendstrafrecht angewandt. Die Differenzen sind jedoch minimal. Lediglich bei der einfachen Körperverletzung und den sonstigen Gewaltdelikten findet $\$ 105$ I JGG eher bei Männern Anwendung. Der größte Unterschied zwischen den Geschlechtern findet sich bei Tötungsdelikten. Diese große Differenz ist aber aufgrund der geringen Zahl wegen vorsätzlicher Tötungsdelikte verurteilter Frauen nicht aussagekräftig. Bei der einfachen Körperverletzung besteht immerhin noch ein 5\%iger Unterschied. Bei den Verkehrsdelikten ohne Alkoholeinfluss, der fahrlässigen Körperverletzung und fahrlässigen Tötung sowie dem Erschleichen von Leistungen übersteigen die Anwendungsquoten für \105 I JGG bei den Frauen die bei den Männern um jeweils $4 \%$.

\subsection{Sanktionierung nach allgemeinem Strafrecht}

Als Nächstes werden die Bezugsentscheidungen nach dem StGB unter Berücksichtigung der zur Verfügung stehenden Variablen umfassend deskriptiv dargestellt.

Hierbei ist zu berücksichtigen, dass die Einstellungen nach der StPO und dem BtMG, vor allen Dingen die $\$ \int 153$, 153a StPO, nicht mit abgebildet werden können. Wie bereits ausgeführt, ${ }^{695}$ sind diese nicht eintragungspflichtig. Fraglich ist, ob dies zu einer Verzerrung der Sanktionsstruktur, insbesondere für die Täterinnen, führt. Schaubild 5.2 hat bereits verdeutlicht, dass Frauen häufiger eine jugendrichterliche Reaktion nach den $\iint 45,47$ JGG erhalten als Männer. Dies lässt vermuten, dass auch die $\$ \mathbb{S} 153$, 153a StPO häufiger für Frauen ergehen. Dies könnte wiederum dazu führen, dass, bei Nichtberücksichtigung der $\$ \int 153$, 153a StPO, der Frauenanteil an den anderen Sanktionen (Freiheitsstrafe mit und ohne Bewährung sowie Geldstrafe) sogar noch überschätzt wird. Die Daten der StVS, ${ }^{696}$ die

\footnotetext{
${ }^{694}$ Goerdeler, in: Ostendorf, Grdl. z. $\iint 105$ und 106, Rdn. 6; Eisenberg, \105, Rdn. 5;

Laubenthal/Nestler, in: Dollinger/Schmidt-Semisch (Hrsg.), Handbuch der Jugendkriminalität, S. $475,477$.

${ }^{695} \mathrm{Vgl}$. Ausführungen unter Kap. 3, 3.1.

${ }^{696}$ Dass ein Vergleich der Daten des BZR mit denen der StVS möglich ist, wurde bereits für die Rückfalluntersuchungen der Bezugsjahre 1994 und 2004 untersucht: Zwischen den Hauptstrafen des StGB und des JGG haben sich kaum Abweichungen ergeben, vgl.: Jeble/Hein₹/Sutterer, Legalbewährung nach strafrechtlichen Sanktionen 2003, S. 22; Jeble/Albrecbt/Hohmann-Fricke/Tetal, Legalbewährung nach strafrechtlichen Sanktionen 2010, S. 22.
} 
die Zahlen für die gerichtlichen Einstellungen gem. \$S 153, 153a StPO enthält, zeigen jedoch, dass sowohl bei Frauen als auch bei Männern der Anteil von gerichtlichen Einstellungen an allen Aburteilungen ${ }^{697}$ nach allgemeinem Strafrecht im Jahr 2004 bei $14 \%$ liegt. 698 Daraus folgt für die vorliegende Untersuchung, dass die Nichtberücksichtigung der gerichtlichen strafprozessualen Verfahrenseinstellungen insgesamt gesehen nicht zu einer größeren Verzerrung der Sanktionsstruktur führen dürfte. ${ }^{699} \mathrm{Zu}$ beachten ist aber, dass ein Großteil der Einstellungen auf staatsanwaltlicher Ebene, insbesondere für Bagatellkriminalität, ergeht. Vermutlich dürfe bei weiblichen Tätern häufig von den staatsanwaltlichen Opportunitätsvorschriften Gebrauch gemacht werden, da Frauen gerade in diesem Bereich relativ häufig straffällig werden. ${ }^{700}$ Dementsprechend ist Ludwig-Mayerhofer in einer Untersuchung zu staatsanwaltlichen Entscheidungen zwischen Anklageerhebung und Verfahrenseinstellung zu dem Ergebnis gekommen, dass Verfahren gegen junge Frauen signifikant häufiger mit einer Informalisierung statt mit einer Anklage beendet werden, als Verfahren gegen junge Männern. ${ }^{701}$ Informationen über staatsanwaltliche Einstellungen lassen sich zwar grundsätzlich der Statistik der Gerichte und Staatsanwaltschaften entnehmen. Ein sinnvoller Vergleich ist allerdings nicht möglich, da diese sich in erster Linie auf Verfahren bezieht und daher keine Angaben zum Tätergeschlecht enthält. ${ }^{702}$

\subsubsection{Verteilung der Sanktionen des StGB}

Schaubild 5.6 gibt nunmehr einen Überblick über den Anteil unterschiedlicher Sanktionsarten des StGB bei Bezugsentscheidungen aus dem Jahr 2004 für Frauen und Männer im Vergleich.

Das Ergebnis der milderen Sanktionierung von Frauen bei den jugendstrafrechtlichen Reaktionen bestätigt sich auch im Hinblick auf die Sanktionen nach dem StGB. So werden Frauen im Vergleich zu Männern seltener zu einer Freiheitsstrafe mit oder ohne Bewährung verurteilt. Sie erhalten häufiger die mildere Sanktion der Geldstrafe: Lediglich $1 \%$ der Frauen wird zu einer Freiheitsstrafe ohne Bewährung und nur $9 \%$ werden zu einer Freiheitsstrafe mit Bewährung verurteilt. Die Übrigen (90 \%) erhalten eine Geldstrafe. Betrachtet man die Gruppe der Männer, so wird deutlich, dass 3\% der verurteilten Männer mit einer Freiheitsstrafe ohne und $15 \%$ mit einer Freiheitsstrafe mit Bewährung sanktioniert

\footnotetext{
${ }^{697}$ Die Freisprüche wurden für diese Berechnung nicht mit zu den Aburteilungen gezählt.

698 StatBA (Hrsg.), StVS 2004, Tab. 2.2; Informationen zu den staatsanwaltlichen Einstellungen lassen sich jedoch auch der StVS nicht entnehmen.

${ }^{699} \mathrm{Zu}$ beachten ist aber, dass hier keine differenzierte Betrachtung vorgenommen wurde. Die Größe des Anteils von strafprozessualen Einstellungen ist noch von zahlreichen anderen Faktoren, z.B. dem zugrundeliegenden Delikt, abhängig.

${ }^{700}$ Vgl. hierzu Ausführungen unter Kap. 4.

${ }^{701}$ Ludwig-Mayerhofer, in: Albrecht (Hrsg.), Informalisierung des Rechts, S. 47, S. 135; vgl. hierzu auch die Ausführungen unter Kap. 5, 1.2.2.2.

702 Vgl. hierzu auch Ausführungen unter Kap. 1, 1.2 sowie Kap. 3, 3.1.
} 
werden. Dementsprechend liegt auch der Anteil der Männer, die eine Geldstrafe erhalten haben, mit $82 \%$, unter dem der Frauen mit $90 \%$.

Schaubild 5.6: Sanktionen des StGB nach Geschlecht*

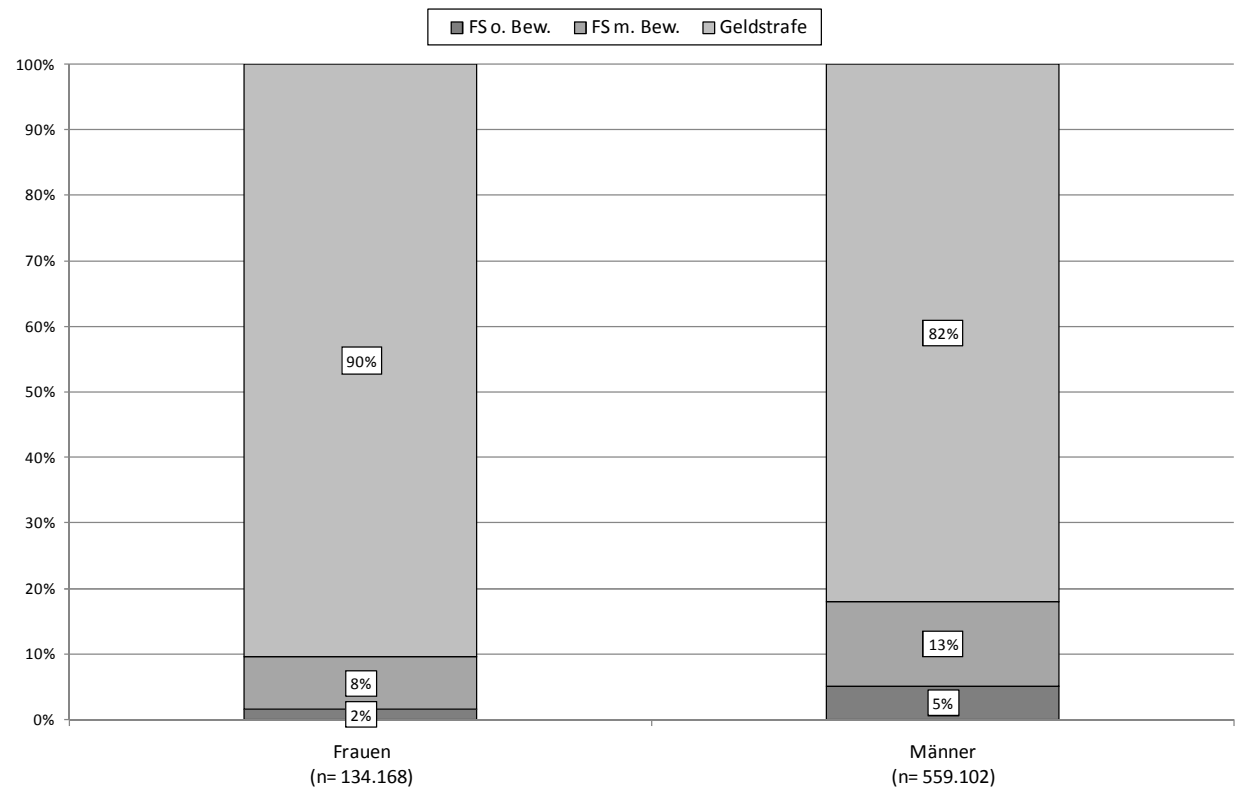

* Absolutrablen siebe Tab. 5.6a im Anhang

\subsubsection{Dauer der Freiheitsstrafe ohne Bewährung}

Der Trend, dass Frauen mit milderen Sanktionen belegt werden setzt sich auch fort, wenn man die Abstufungen der einzelnen Sanktionsarten betrachtet. Aus Schaubild 5.7 geht die Verteilung der Dauer der Freiheitsstrafen ohne Bewährung für Frauen und Männer im Vergleich hervor.

Aus Schaubild 5.7 ergibt sich ein ähnlicher Verlauf wie bei den Jugendstrafen ohne Bewährung, allerdings sind hier noch die kurzen und lebenslangen Freiheitsstrafen zu berücksichtigen: Die meisten Frauen erhalten eine Freiheitsstrafe bis zu sechs Monaten. Dies ist zunächst erstaunlich, da kurze Freiheitsstrafen unter sechs Monaten gem. \47 StGB nur in Ausnahmefällen verhängt werden sollen. Mit zunehmender Dauer nehmen die Anteile bei den Frauen sodann kontinuierlich ab. Freiheitsstrafen bis zu zwei Jahren nehmen einen Anteil von insgesamt $77 \%$ ein. Lediglich fünf Frauen erhielten im Bezugsjahr eine lebenslange Freiheitsstrafe, sodass der Wert hier nur $0,2 \%$ beträgt.

Der Anteil von kurzen Freiheitsstrafen unter sechs Monaten ist bei den Männern mit $24 \%$ wesentlich geringer als bei den Frauen mit 36\%. Darüber hinaus 
ist der Anteil von Freiheitsstrafen von sechs Monaten bis zu einem Jahr bei den Männern, anders als bei den Frauen, größer als der von kurzen Freiheitsstrafen.

Schaubild 5.7: Dauer der Freiheitsstrafe obne Bewäbrung nach Geschlecht*

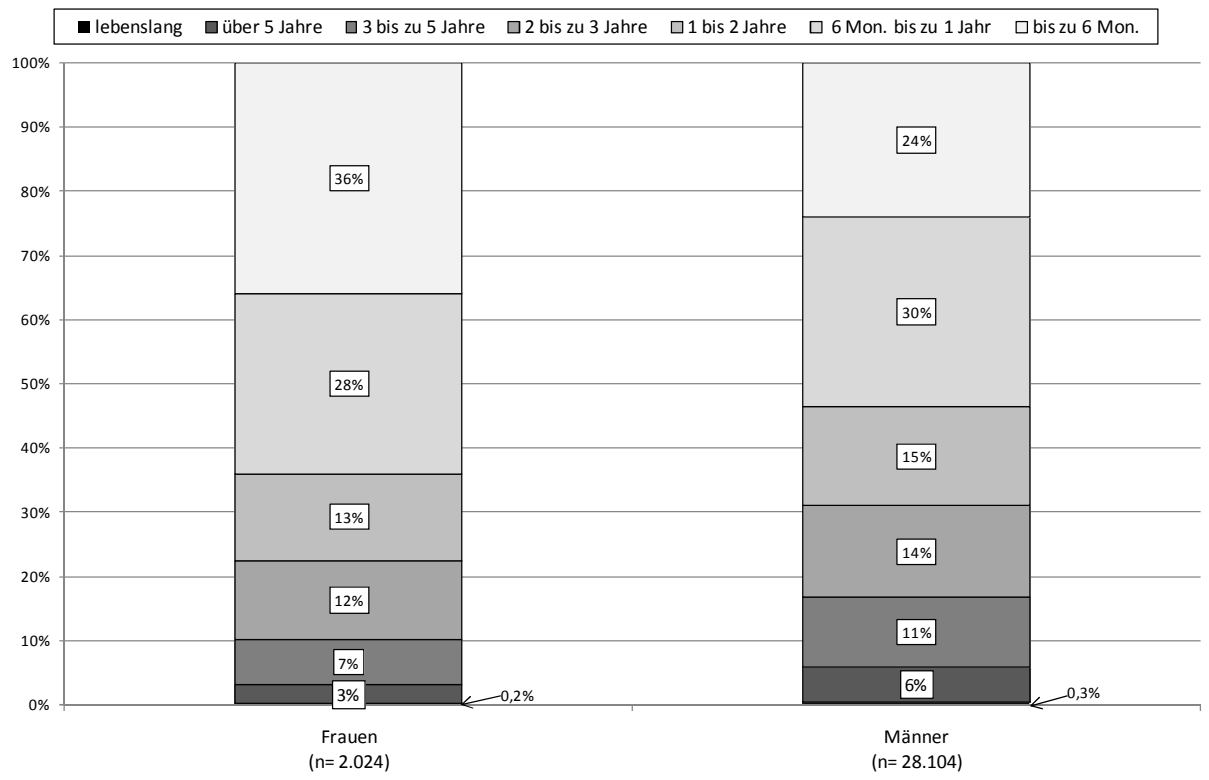

* Absolutzablen siebe Tab. 5.7a im Anbang

Ein Absinken mit steigender Dauer der Freiheitsstrafe findet erst ab dieser Gruppe statt, was dem Ausnahmecharakter des $₫ 47$ StGB zuzuschreiben sein dürfte. Mit Ausnahme der Freiheitsstrafen bis zu sechs Monaten übersteigen die Anteile für die gebildeten Dauergruppen bei den Männern die der Frauen.

Es kann also festgestellt werden, dass Frauen in der Regel kürzere Freiheitsstrafen erhalten als Männer. Die Mittelwerte ${ }^{703}$ betragen 466 Tage bei den Frauen und 633 bei den Männern. Von der Ausnahmevorschrift des $₫ 47$ StGB wird bei Täterinnen öfter Gebrauch gemacht.

\subsubsection{Strafaussetzung zur Bewährung}

Auch für die Freiheitsstrafen wird im Folgenden überprüft, wie häufig grundsätzlich aussetzungsfähige Freiheitsstrafen bis zu zwei Jahren auch tatsächlich zur Bewährung ausgesetzt werden.

Schaubild 5.8 zeigt, dass die Aussetzungsquote je nach Dauer unterschiedlich ist: Sowohl bei den Tätern als auch bei den Täterinnen wird die Freiheitsstrafe von

${ }^{703}$ Für die Berechnung des Mittelwertes wurden die lebenslangen Freiheitsstrafen nicht mit berücksichtigt. 
sechs Monaten bis zu einem Jahr am häufigsten zur Bewährung ausgesetzt. Bei den Frauen ist der Anteil jedoch mit 89 \% größer als bei den Männern mit 81 \%.

Schaubild 5.8: Aussetzungsquote bei Freiheitsstrafe nach Geschlecht*

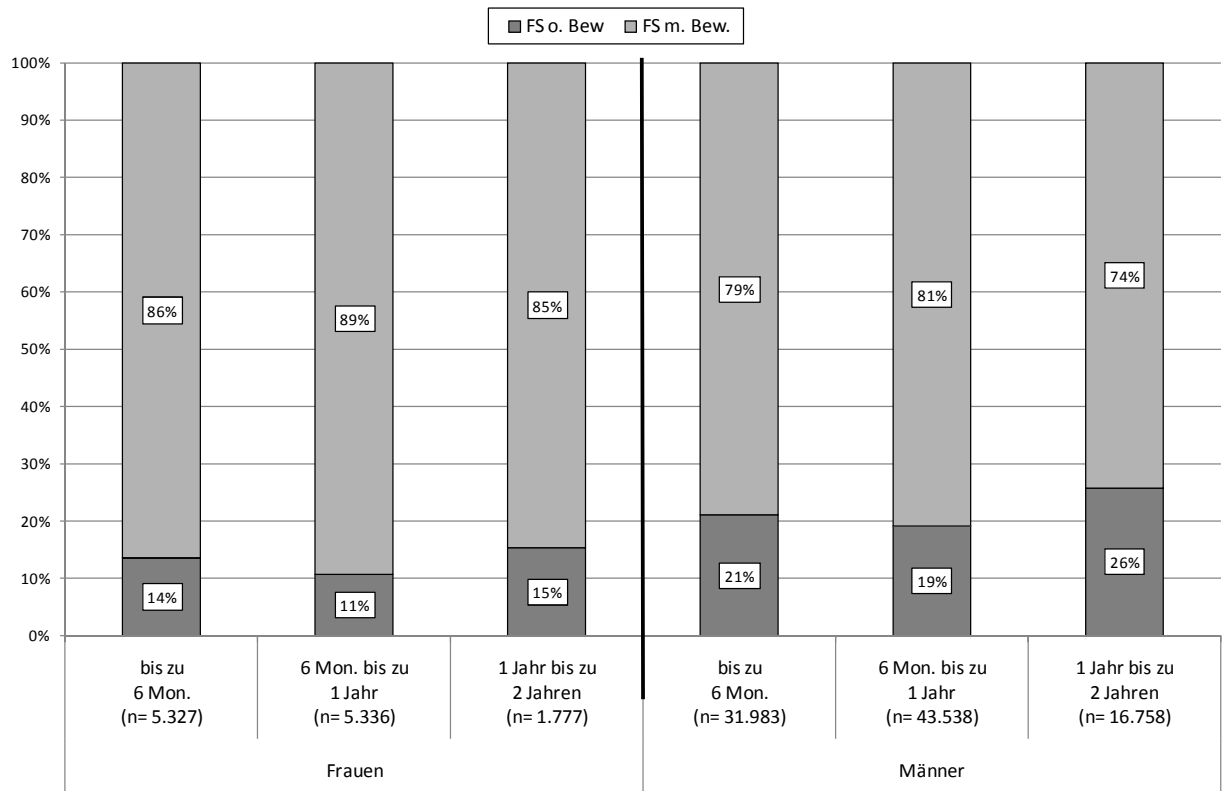

* Absolutrablen siehe Tab. 5.8a im Anhang

Die Freiheitsstrafen von einem Jahr bis zu zwei Jahren werden bei beiden Geschlechtern am seltensten ausgesetzt: Die Aussetzungsquoten betragen hier $85 \%$ (Frauen) zu 74 \% (Männer). Bei den kurzen Freiheitsstrafen bekommen Frauen in $86 \%$ und Männer in $79 \%$ der Fälle eine Freiheitsstrafe mit Bewährung. Folglich wird über alle Dauergruppen hinweg bei Frauen die Freiheitsstrafe eher zur Bewährung ausgesetzt als bei Männern. Auch hier muss jedoch noch darauf hingewiesen werden, dass dies auf zahlreiche Gründe zurückzuführen sein kann und das Ergebnis für sich genommen noch nicht für eine mildere Behandlung von Frauen spricht.

Gem. \56d I StGB kann das Gericht die verurteilte Person für die Dauer oder einen Teil der Bewährungszeit der Aufsicht und Leitung einer Bewährungshelferin oder eines Bewährungshelfers unterstellen, wenn dies angezeigt ist, um sie von Straftaten abzuhalten.

Für die primär ausgesetzten Freiheitsstrafen ergibt sich bezüglich der Unterstellung unter die Bewährungsaufsicht aus Tabelle 5.2, dass Frauen (29,9\%) etwa ebenso häufig der Bewährungsaufsicht unterstellt werden wie Männer (29,8 \%). 
Tabelle 5.2: Bewährungsunterstellung nach Geschlecht

\begin{tabular}{|c|c|c|c|c|c|c|c|}
\hline & \multicolumn{2}{|c|}{ Frauen } & \multicolumn{2}{|c|}{ Männer } & \multicolumn{2}{|c|}{ Gesamt } \\
\hline & & abs. & $\%$ & abs. & $\%$ & abs. & $\%$ \\
\hline \multirow{2}{*}{$\begin{array}{l}\text { Ausgesetzte } \\
\text { Freiheitsstrafen } \\
\text { bis einschließ- } \\
\text { lich zwei Jahre }\end{array}$} & Bewährungsaufsicht & 3.254 & $29,9 \%$ & 21.703 & $29,8 \%$ & 24.957 & $30 \%$ \\
\hline & $\begin{array}{l}\text { Keine Bewährungsauf- } \\
\text { sicht }\end{array}$ & 7.618 & $70,1 \%$ & 51.196 & $70,2 \%$ & 58.814 & $70 \%$ \\
\hline & Gesamt & \multicolumn{2}{|c|}{10.872} & \multicolumn{2}{|c|}{72.899} & \multicolumn{2}{|c|}{83.771} \\
\hline
\end{tabular}

Betrachtet man darüber hinaus die Unterstellung unter die Bewährungsaufsicht differenziert nach der jeweiligen Dauer der Freiheitsstrafe (Tabelle 5.3), so wird deutlich, dass die Wahrscheinlichkeit der Anordnung von Bewährungsaufsicht mit zunehmender Dauer der Freiheitsstrafe steigt.

Tabelle 5.3: Bewährungsunterstellung nach Dauer der bedingten Freiheitsstrafe und Geschlecht

\begin{tabular}{|c|c|c|c|c|c|c|c|c|}
\hline & \multicolumn{4}{|c|}{ Frauen } & \multicolumn{4}{|c|}{ Männer } \\
\hline & \multicolumn{2}{|c|}{$\begin{array}{l}\text { Bewährungs- } \\
\text { aufsicht }\end{array}$} & \multicolumn{2}{|c|}{$\begin{array}{c}\text { Keine Bewährungs- } \\
\text { aufsicht }\end{array}$} & \multicolumn{2}{|c|}{$\begin{array}{l}\text { Bewährungs- } \\
\text { aufsicht }\end{array}$} & \multicolumn{2}{|c|}{$\begin{array}{c}\text { Keine Bewährungs- } \\
\text { aufsicht }\end{array}$} \\
\hline & abs. & $\%$ & abs. & $\%$ & abs. & $\%$ & abs. & $\%$ \\
\hline \begin{tabular}{|l|} 
Bis zu 6 \\
Mon. \\
\end{tabular} & 1.830 & $29 \%$ & 4.562 & $71 \%$ & 10.150 & $27 \%$ & 27.582 & $73 \%$ \\
\hline $\begin{array}{l}\text { Über } 6 \text { Mon. } \\
\text { bis zu } 9 \\
\text { Mon }\end{array}$ & 464 & $29 \%$ & 1.161 & $71 \%$ & 3.733 & $30 \%$ & 8.715 & $70 \%$ \\
\hline $\begin{array}{l}\text { Über } 9 \text { Mon. } \\
\text { bis zu } 12 \\
\text { Mon. }\end{array}$ & 403 & $30 \%$ & 948 & $70 \%$ & 3.391 & $33 \%$ & 6.904 & $67 \%$ \\
\hline $\begin{array}{l}\text { Über } 12 \\
\text { Mon. bis zu } \\
18 \text { Mon. }\end{array}$ & 283 & $36 \%$ & 510 & $64 \%$ & 2.080 & $35 \%$ & 3.833 & $65 \%$ \\
\hline $\begin{array}{l}\text { Über } 18 \\
\text { Mon. bis zu } \\
24 \text { Mon. } \\
\end{array}$ & 270 & $38 \%$ & 435 & $62 \%$ & 2.321 & $36 \%$ & 4.114 & $64 \%$ \\
\hline Gesamt $^{704}$ & \multicolumn{4}{|c|}{10.866} & \multicolumn{4}{|c|}{72.823} \\
\hline
\end{tabular}

${ }^{704}$ Die Gesamtzahlen stimmen nicht mit denen in Tabelle 5.2 überein, da hier die Fälle ausgeschlossen wurden, die keiner der gebildeten Dauergruppen zugeordnet werden konnten, weil beispielsweise eine Fehl- oder unvollständige Eintragung vorlag. 
Dies gilt sowohl für Frauen als auch für Männer. Die Unterschiede sind minimal: ${ }^{705}$ So bekommen Frauen im Vergleich zu den Männern eher einen Bewährungshelfer bei den ausgesetzten Freiheitsstrafen über 12 Monate zur Seite gestellt. Dafür wird bei den Freiheitsstrafen unter 12 Monaten häufiger bei den Männern eine Bewährungsaufsicht angeordnet.

\subsubsection{Geldstrafe}

Wie unter Punkt 3.3.1 festgestellt, werden Frauen mit $90 \%$ und Männer mit $82 \%$ jeweils am häufigsten zu einer Geldstrafe verurteilt. In einem weiteren Schritt wird überprüft, ob sich die Anzahl der verhängten Tagessätze bei Frauen und Männern unterscheidet. Schaubild 5.9 zeigt die im Bezugsjahr für Frauen und Männer ergangenen Geldstrafen und differenziert diese nach der Anzahl der Tagessätze.

\section{Schaubild 5.9: Anzahl der Tagessätre bei Geldstrafe nach Geschlecht*}

$\square>=90 \quad \square 51-90 \quad \square 31-50 \quad \square 16-30 \quad \square 1-15$

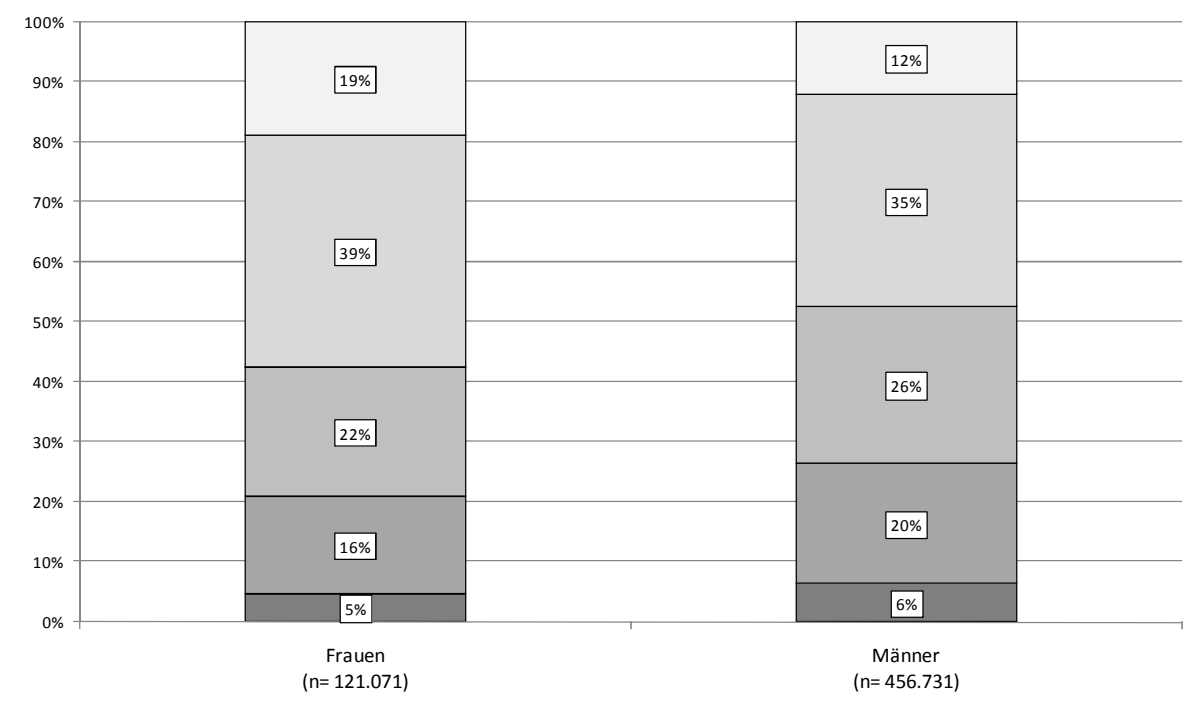

* Absolutzablen siehe Tab. 5.9 a im Anhang

Bei Betrachtung der Anzahl der Tagessätze, lässt sich zunächst feststellen, dass sowohl Frauen als auch Männer am häufigsten zu einer Geldstrafe von 16-30 Tagessätzen (39\% der mit Geldstrafe sanktionierten Frauen und 35\% der mit Geldstrafe sanktionierten Männer) und am seltensten zu einer Geldstrafe von über 90 Tagessätzen (5\% der Frauen und 6\% der Männer) verurteilt werden. Aller-

${ }^{705} \mathrm{Der} \mathrm{chi}^{2}$-Test hat ergeben, dass die Unterschiede gleichwohl signifikant sind. Dies dürfte vor allen Dingen auf die große Stichprobe zurückzuführen sein. 
dings zeigt ein Vergleich der Gruppe der mit Geldstrafe sanktionierten Männer, mit der entsprechenden Gruppe der Frauen, dass die Anteile der Gruppe mit höheren Tagessatz-Anzahlen bei den Männern größer sind: 20 \% der Männer werden zu einer Geldstrafe von 51-90 Tagessätzen verurteilt, bei den Frauen sind dies nur 16\%. $26 \%$ der Täter und $22 \%$ der Täterinnen erhalten 31-50 Tagessätze. Dagegen übersteigt der Anteil der Gruppe mit den wenigsten Tagessätzen (1-15) bei den Frauen mit $19 \%$, den Anteil bei den Männern mit nur $12 \%$.

Folglich erhalten Frauen nicht nur häufiger die mildere Sanktion der Geldstrafe (vgl. Schaubild 5.0), sondern sie werden auch bei Erhalt einer Geldstrafe zu weniger Tagessätzen verurteilt. $\mathrm{Ob}$ dieser Unterschied sich bei deliktsspezifischer Betrachtung relativiert, wird an späterer Stelle noch geprüft. ${ }^{706}$

\subsubsection{Verkehrsrechtliche Sanktionen}

Neben der Hauptsanktion können in den Bezugsentscheidungen auch Nebenstrafen sowie Maßregeln der Besserung und Sicherung ${ }^{707}$ angeordnet werden. Im Folgenden sollen die Entziehung der Fahrerlaubnis gem. \$S 69, 69a StGB sowie das Fahrverbot gem. $\int 44$ StGB einer kurzen Betrachtung unterzogen werden. Beide Sanktionen wurden für die Darstellung als „,verkehrsrechtliche Sanktion“ zusammengefasst.

Tabelle 5.4: Verkehrsrechtliche Sanktion nach Geschlecht für Verkehrsdelikte obne sowie unter Alkoboleinfluss 708

\begin{tabular}{|l|c|c|c|c|c|c|c|c||}
\hline \multirow{2}{*}{} & \multicolumn{4}{|c|}{$\begin{array}{c}\text { Verkehrsdelikte ohne Alkoholein- } \\
\text { fluss }\end{array}$} & \multicolumn{4}{c|}{ Verkehrsdelikte unter Alkoholein- } \\
& \multicolumn{2}{|c|}{ Frauen } & \multicolumn{2}{c|}{ Männer } & \multicolumn{2}{c|}{ Frauen } & \multicolumn{2}{c|}{ Männer } \\
\cline { 2 - 9 } & abs. & in \% & abs. & in \% & abs. & in \% & abs. & in \% \\
\hline $\begin{array}{l}\text { Keine vekehrs- } \\
\text { rechtliche } \\
\text { Sanktion }\end{array}$ & 10.755 & $61 \%$ & 71.674 & $65 \%$ & 787 & $6 \%$ & 11.056 & $11 \%$ \\
\hline $\begin{array}{l}\text { Verkehrsrecht- } \\
\text { liche Sanktion }\end{array}$ & 6.819 & $39 \%$ & 38.811 & $35 \%$ & 12.726 & $94 \%$ & 86.300 & $89 \%$ \\
\hline Gesamt & 17.574 & $100 \%$ & 110.485 & $100 \%$ & 13.513 & $100 \%$ & 97.356 & $100 \%$ \\
\hline
\end{tabular}

Tabelle 5.4 verdeutlicht wie häufig die Gerichte eine verkehrsrechtliche Sanktion (Entziehung der Fahrerlaubnis oder Fahrverbot) verhängt haben und zwar differenziert nach Verkehrsdelikten ohne und unter Alkoholeinfluss sowie Geschlecht.

Betrachtet man zunächst die Verkehrsdelikte ohne Alkoholeinfluss so zeigt sich, dass Frauen in $39 \%$ und Männer in $35 \%$ der Fälle eine verkehrsrechtliche

706 Vgl. Kap. 5, 2.6.1.2 sowie Kap. 5, 2.6.2.2.

707 Letztere können überwiegend auch isoliert angeordnet werden: $\int 71$ StGB.

708 Der chi ${ }^{2}$-Test hat ergeben, dass die Unterschiede in der Tabelle signifikant sind. 
Sanktion erhalten. Gegen Frauen wird folglich eher eine verkehrsrechtliche Sanktion verhängt als gegen Männer, wobei der Unterschied gering ist. Dieses Bild bestätigt sich bei Überprüfung der Verkehrsdelikte unter Alkoholeinfluss: Auch hier erhalten Frauen mit $94 \%$ anteilsmäßig häufiger eine verkehrsrechtliche Sanktion als Männer mit $89 \%$. Der hohe Anteil für beide Geschlechter dürfte damit zu erklären sein, dass in der Gruppe der Verkehrsdelikte unter Alkoholeinfluss die $\iint 315$ c I Nr. 1a, 316 StGB berücksichtigt wurden, welche beide zu den in $\iint 44$, 69 StGB genannten Tatbeständen zählen, bei denen in der Regel ein Fahrverbot verhängt wird bzw. die Fahrerlaubnis zu entziehen ist. Die Gruppe der Verkehrsdelikte ohne Alkoholeinfluss beinhaltet zwar den restlichen \315c StGB sowie \142 StGB als Regeltatbestände i.S.d. \69 StGB. Dabei handelt es sich jedoch zum einen nicht um Regeltatbestände i.S.d. \ 44 StGB. Zum anderen sind in dieser Deliktsgruppe zusätzlich der \315b StGB sowie die Verstöße gegen das StVG erfasst, welche weder in $\int 44 \mathrm{StGB}$ noch in $\int 69 \mathrm{StGB}$ genannt sind.

Schließlich ist zu beachten, dass Frauen insgesamt seltener Verkehrsdelikte begehen als Männer: Die Ausführungen in Kapitel 4 haben bereits ergeben, dass der Frauenanteil an den Verkehrsdelikten ohne Alkoholeinfluss $14 \%$ und bei den Verkehrsdelikten unter Alkoholeinfluss nur $12 \%$ beträgt. ${ }^{709}$

\subsection{Sanktionierung und Voreintragungen}

Als weitere Variable werden nun die Voreintragungen mitberücksichtigt. Dabei wird untersucht, inwieweit sich eine aus dem Zentralregister ersichtliche Vorbelastung weiblicher und männlicher Täter auf die Sanktionierungspraxis auswirkt. Es ist zu vermuten, dass Frauen grundsätzlich weniger Voreintragungen zu verzeichnen haben und dass eine zunehmende Anzahl von Voreintragungen zu schärferen Sanktionen führt, denn gem. \46 II StGB berücksichtigt das Gericht bei der Strafzumessung u.a. das Vorleben des Täters, wozu insbesondere auch die Vorstrafen zählen. ${ }^{710}$ Eine strafschärfende Wirkung von Vorstrafen wird jedenfalls dann bejaht, wenn sie einschlägig sind und erkennen lassen, dass der Täter sich über frühere Warnungen hinweggesetzt hat ${ }^{711}$ oder wenn sich aus ihnen eine erhöhte Schuld des Täters und die gesteigerte Notwendigkeit ergeben auf ihn einzuwirken. ${ }^{712}$ Daher werden in einem weiteren Schritt (vgl. Kap. 5, 2.5.2) ebenfalls die einschlägigen Voreintragungen in die Untersuchung miteinbezogen.

\subsubsection{Begriff der Voreintragung}

Als Voreintragungen zu berücksichtigen sind solche Entscheidungen, die mit dem Entscheidungs- und Rechtskraftdatum zeitlich vor dem Datum der Bezugsent-

\footnotetext{
709 Vgl. Kap. 4, 1.4.1.2 sowie Tab. 4.1d im Anhang.

710 Fischer, \46, Rdn. $37 \mathrm{ff}$.

711 BGHSt 24, 198.

712 BGH, in: NStZ 1992, 327; Fischer, \ 46, Rdn. 38.
} 
scheidung liegen und zum Entscheidungszeitpunkt im Register erfasst sind. Erfasst werden dabei nicht nur solche Voreintragungen, bei denen das Tatdatum vor dem der Bezugsentscheidung liegt, sondern auch solche, bei denen es nach dem Tatdatum der Bezugsentscheidung liegt, die spätere Tat jedoch zügiger von der Justiz verfolgt wurde und dementsprechend schon eine Eintragung dieser zeitlich späteren Tat im BZR vorlag, als die Sanktionsentscheidung getroffen wurde. Grund hierfür ist, dass auch diese Taten im Wege der nachträglichen Gesamtstrafenbildung gem. $\ 55$ StGB oder durch Bildung einer Einheitsstrafe gem. \31 II JGG bei der Urteilsfindung der Bezugsentscheidung durch den Richter berücksichtigt worden sein dürften.

Erfasst werden können vorliegend alle im BZR (einschließlich des Erziehungsregisters) eingetragenen strafrechtlichen Sanktionen, also Haupt- und Nebenstrafen des Erwachsenen- und Jugendstrafrechts, Maßregeln der Besserung und Sicherung sowie die jugendstrafrechtlichen Diversionsentscheidungen gem. $\int \mathbb{S} 45$, 47 JGG. Letztere werden erneut mitberücksichtigt, um einen umfassenden Eindruck über das strafrechtliche Vorleben eines Verurteilten gewinnen zu können. ${ }^{713}$ $\mathrm{Zu}$ beachten ist jedoch, dass sich dadurch die Vorstrafenbelastung bei Jugendlichen und Heranwachsenden als überhöht darstellen kann.

Dieses Problem verschärft sich zunächst noch, wenn man bedenkt, dass aufgrund der Vorschrift des $₫ 63$ BZRG bei der Mehrzahl der über 24-jährigen Verurteilten die Eintragungen aus dem Erziehungsregister (neben den Einstellungen gem. $\iint 45,47$ JGG insbesondere auch die Erziehungsmaßregeln und Zuchtmittel) nicht mehr vorhanden sind. Andererseits können derartige Eintragungen, soweit sie schon bei der Sanktionsentscheidung nicht mehr im Register vorhanden waren, auch vom Gericht bei der Strafzumessung nicht strafschärfend berücksichtigt werden ( $\$ S 63$ Abs. 4, 51 Abs. 1 BZRG).

Darüber hinaus können ganz generell bereits getilgte Voreintragungen nicht berücksichtigt werden. Erneut gilt jedoch, dass auch das Gericht insofern an einer Verwertung gehindert war, wenn die Voreintragung bereits zum Urteilszeitpunkt getilgt war (vgl. \51 Abs. 1 BZRG). Angesichts des Grundsatzes der Einheit des Registers ( $₫ 47$ Abs. 3 BZRG) ist es dabei plausibel, dass zum Zeitpunkt der Untersuchung nicht mehr im Register vorhandene Eintragungen in aller Regel auch zum Zeitpunkt der Bezugsentscheidung nicht mehr im Register eingetragen waren. ${ }^{714}$ Schließlich muss auch beachtet werden, dass es vom Lebensalter der Täterinnen und Täter abhängt, wie lange der Zeitraum zwischen Strafreife und Bezugsentscheidung ist. Junge Täterinnen und Täter, die durch Erreichung des 14. Lebensjahres gerade erst strafrechtlich verantwortlich geworden sind, können naturgemäß noch keine Voreintragungen aufweisen.

\footnotetext{
${ }^{713}$ So auch Harrendorf, S. 252; Weigelt, S. 116.

${ }^{714}$ Vgl. zur Tilgung Kap. 3, 3.4.
} 


\subsubsection{Anzahl und Art der schwersten Voreintragungen}

Die Voreintragungen werden nach Häufigkeit sowie nach Art der schwersten Sanktion erfasst. Bei der Häufigkeit werden alle Eintragungen - einschließlich der später einbezogenen Entscheidungen (s.o.) - gezählt.

\section{Schaubild 5.10: Anzabl der Voreintragungen nach Gescblecht*}

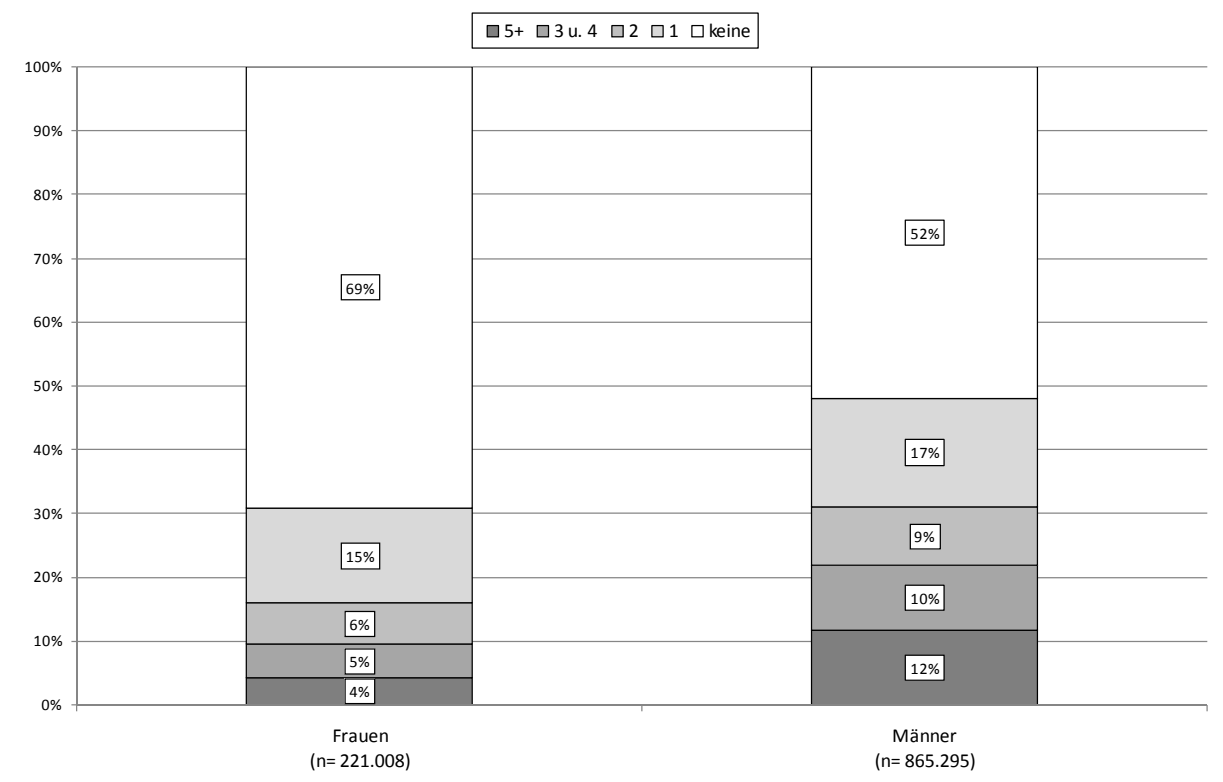

* Absolutzablen siebe Tab. 5.10a im Anbang

Schaubild 5.10 gibt einen Überblick über die Anzahl von Voreintragungen differenziert nach den Geschlechtern.

$69 \%$ der Frauen und $52 \%$ der Männer weisen keine Voreintragungen auf. Der Anteil von Personen mit Voreintragungen sinkt bei den Frauen ab der Gruppe mit einer Voreintragung kontinuierlich ab, wohingegen der Anteil bei den Männern nur bis zu der Gruppe mit zwei Voreintragungen sinkt und sodann wieder steigt.

Ein deutlicher Unterschied besteht insbesondere zwischen dem Anteil der Frauen und dem der Männer in den Kategorien keine sowie mehr als fünf Voreintragungen: Frauen weisen seltener Voreintragungen auf; auch wenn sie strafrechtlich bereits aufgefallen sind, so ist dies relativ selten vorgekommen. Die Männer haben hingegen fast genauso häufig eine $(17 \%)$ wie mehr als fünf Voreintragungen $(12 \%)$ aufzuweisen (vgl. Schaubild 5.10); allerdings ist auch bei ihnen die Mehrzahl nicht mit Voreintragungen belastet.

Schaubild 5.11 zeigt die Art der schwersten Voreintragung für Frauen und Männer im Vergleich. Betrachtet werden nur die Personen mit mindestens einer 
Voreintragung. Der Übersicht halber wurde die Gruppe der Jugend- und Freiheitsstrafen hier zusammengefasst.

Schaubild 5.11: Art der schwersten Voreintragung nach Gescblecbt*

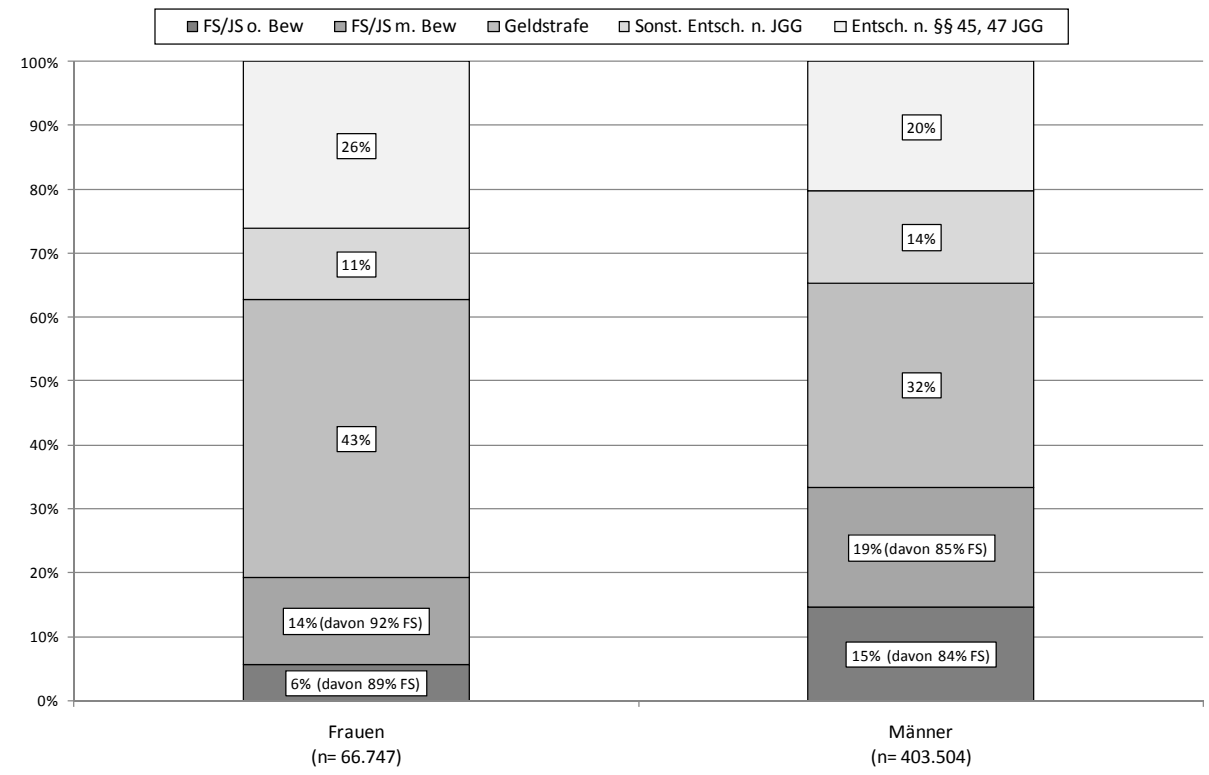

* Absolutzablen siebe Tab. 5.11a im Anbang

Es zeigt sich auch hier, wie schon bei der Anzahl der Voreintragungen (Schaubild 5.10), ein deutlicher Unterschied zwischen den Geschlechtern: Nur $6 \%$ der Frauen, für die eine Voreintragung registriert werden konnte, erhielten als schwerste Sanktion eine stationäre Freiheits- oder Jugendstrafe. Bei den Männern ist der Anteil mit $15 \%$ mehr als doppelt so groß. Auch ist der Anteil der Freiheits- und Jugendstrafen mit Bewährung als schwerste Voreintragung bei den männlichen Tätern mit $19 \%$ größer als der bei den Frauen mit 14 \%. Im Übrigen werden die Anteile der zusammengefassten Gruppen der Freiheits- und Jugendstrafe mit und ohne Bewährung stark von den Freiheitsstrafen bestimmt (vgl. Schaubild 5.11), was nicht verwundert, da sich bei den Jugendlichen eine kriminelle Karriere in der Regel noch nicht verfestigt haben kann. Erwartungsgemäß wurde für die Frauen $(43 \%)$ im Bezugsjahr anteilsmäßig häufiger als bei den Männern (32\%) eine Geldstrafe als schwerste Voreintragung registriert. Auch überwiegt der Anteil von Einstellungen gem. $\iint 45,47$ JGG bei den Frauen $(26 \%)$ den Anteil für diese Entscheidungen bei den Männern (20 \%), wohingegen für Männer mit $14 \%$ häufiger eine sonstige Entscheidung nach dem JGG als schwerste Voreintragung erging als bei den Frauen mit 11 \%. Frauen, die im Bezugsjahr 2004 verurteilt oder 
mit einer jugendstrafrechtlichen Reaktion belegt wurden, haben folglich nicht nur weniger Voreintragungen, sondern auch im Falle einer Voreintragung eine weniger schwerwiegende Sanktion erhalten als Männer.

\subsubsection{Sanktionierung nach Jugendstrafrecht und Voreintragungen}

Nach diesem allgemeinen Überblick wird im Folgenden die Art der Bezugsentscheidung nach dem JGG in Abhängigkeit von der Anzahl der Voreintragungen für Frauen und Männer betrachtet (vgl. Schaubild 5.12).

\section{Schaubild 5.12: Jugendstrafrechtliche Reaktionen nach Anzabl der Voreintragungen und Ge schlecht}

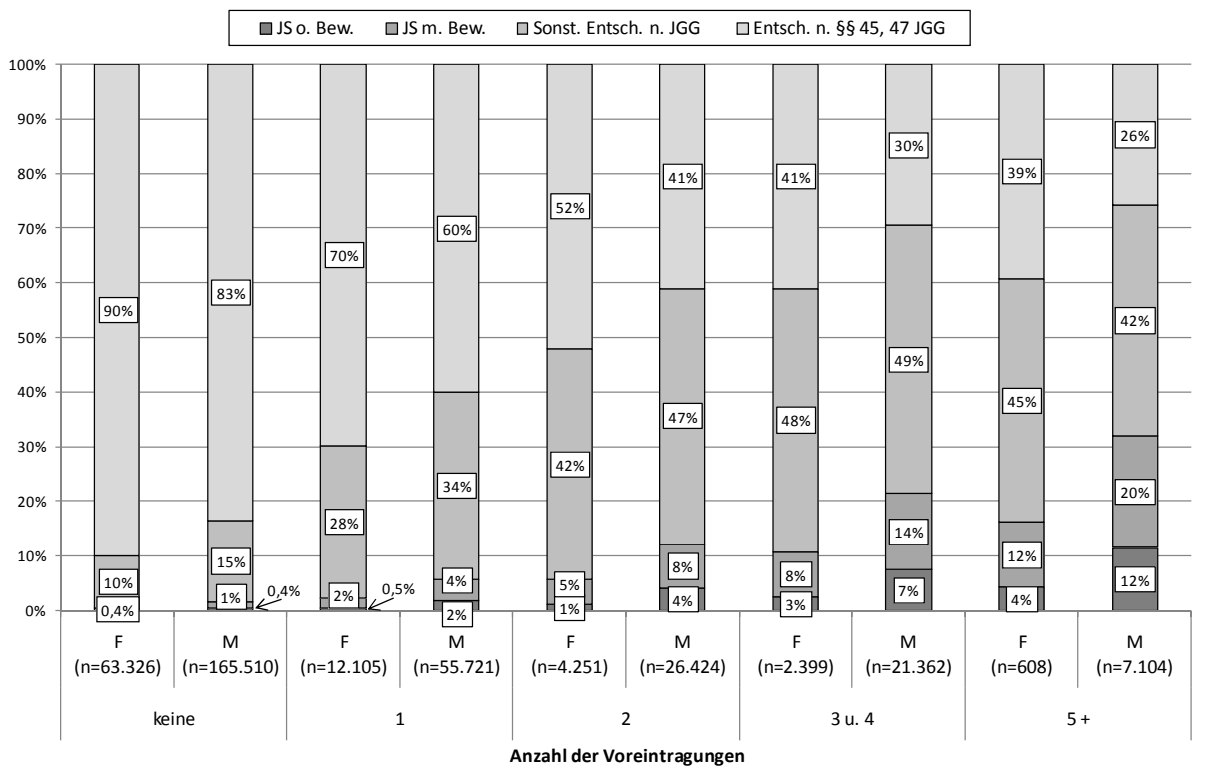

* Absolutrablen siehe Tab. 5.12 a im Anhang

Für die nach Jugendstrafrecht sanktionierten Täterinnen und Täter zeigt sich eine Beziehung zwischen der Anzahl der Voreintragungen und der Art der Bezugsentscheidung nach dem JGG. Während bei denjenigen, die keinerlei Voreintragungen aufweisen, der überwiegende Teil eine informelle Reaktion nach den $\int \$ 45,47$ JGG erhält ( $90 \%$ der Frauen und $83 \%$ der Männer), erhalten diejenigen mit fünf und mehr Voreintragungen nur noch in 39\% (Frauen) bzw. 26\% (Männer) der Fälle eine Entscheidung nach den $\iint 45,47$ JGG. Der Anteil von informellen Reaktionen nimmt folglich für beide Geschlechter mit steigender Anzahl der Voreintragungen annähernd kontinuierlich ab. Dementsprechend nimmt der Anteil von sonstigen Entscheidungen nach dem JGG bis zu einer Anzahl von drei bis 
vier Voreintragungen zu, um dann bei fünf und mehr Voreintragungen zu sinken, da dort vermehrt Jugendstrafen ausgesprochen werden. Sowohl der Anteil von Jugendstrafen mit als auch der von Jugendstrafen ohne Bewährung steigt entsprechend an: bei den Frauen steigen die Jugendstrafen ohne Bewährung von $0 \%$ auf $4 \%$ und die Jugendstrafen mit Bewährung von $0,4 \%$ auf $12 \%$ an; bei den Männern ist eine Steigerung von 0,4 \% auf $12 \%$ (Jugendstrafe ohne Bewährung) sowie von $1 \%$ auf $20 \%$ (Jugendstrafen mit Bewährung) zu verzeichnen. Der Verlauf stellt sich folglich für beide Geschlechter gleich dar. Allerdings sind die Anteile der schwerwiegenderen Sanktionen der Jugendstrafe mit und ohne Bewährung bei den Frauen durchweg niedriger als bei den Männern. Auch strafrechtlich häufig in Erscheinung getretene Täterinnen mit fünf und mehr Voreintragungen erhalten nur in $4 \%$ der Fälle als Bezugssanktion eine Jugendstrafe ohne Bewährung, wohingegen der Anteil der Männer in dieser Kategorie mit $12 \%$ dreimal so groß ist.

Auch dies dürfte jedoch kein Zeichen einer bevorzugten Behandlung von Frauen sein, sondern mit der unterschiedlichen Deliktsstruktur von Frauen und Männern zusammenhängen. Dies wird noch zu prüfen sein.

Als nächstes wird die Art der Bezugsentscheidung nach Jugendstrafrecht nach Art der schwersten Voreintragung betrachtet. Obwohl hier die Bezugsentscheidungen nach Jugendstrafrecht untersucht werden, werden bei den Voreintragungen auch solche nach allgemeinem Strafrecht berücksichtigt. Es sind Konstellationen denkbar, bei denen eine heranwachsende Person eine Bezugsentscheidung nach dem JGG erhält, jedoch bereits eine Voreintragung nach allgemeinem Strafrecht aufweist, weil zu diesem Zeitpunkt die Voraussetzungen des \105 I JGG verneint wurden. Ebenso können auch gegen Erwachsene wegen im Jugend- oder Heranwachsendenalter begangener Taten noch Sanktionen nach Jugendstrafrecht ergehen. Da bei einer Bezugsentscheidung nach Jugendstrafrecht sehr selten eine Freiheitsstrafe mit oder ohne Bewährung als Voreintragung gegeben ist, wurde diese mit der Gruppe der Jugendstrafen mit und ohne Bewährung zusammengefasst. Eine Geldstrafe taucht hingegen im Datensatz verhältnismäßig häufig als schwerste Voreintragung auf, sodass diese eine eigene Kategorie bildet. ${ }^{715}$ Darüber hinaus wurden die Einstellungen nach $\$ \int 45,47$ JGG und die sonstigen Entscheidungen nach dem JGG zur Gruppe ambulante Reaktionen nach dem JGG zusammengefasst. Hierbei ist jedoch zu berücksichtigen, dass auch der Jugendarrest hinzugezählt wurde.

715 Vgl. zu den absoluten Zahlen Tab. 5.14a im Anhang. 
Schaubild 5.13: Jugendstrafrechtliche Reaktionen nach Art der schwersten Voreintragung und Geschlecht*

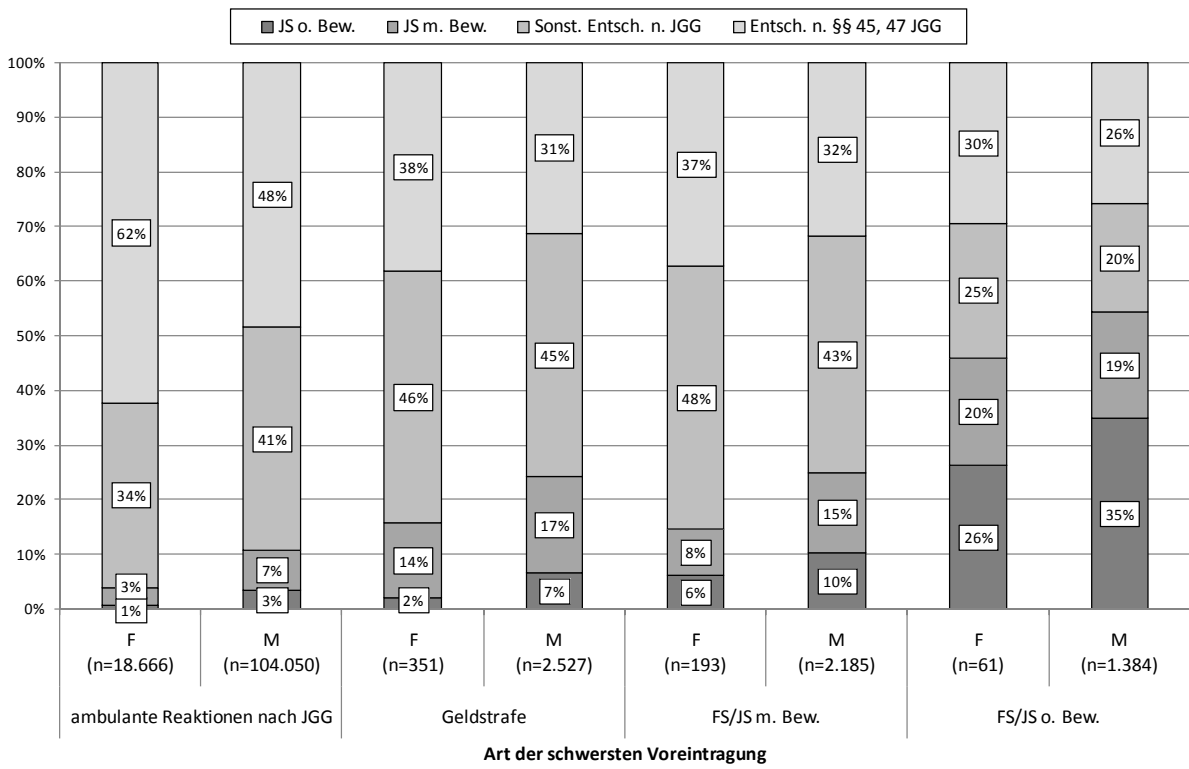

* Absolutzablen siehe Tab. 5.13 a im Anhang

Schaubild 5.13 bildet die jugendstrafrechtlichen Reaktionen nach Art der schwersten Voreintragung für Frauen und Männer im Vergleich ab.

Hier offenbart sich eine ähnliche Beziehung wie zwischen der Anzahl der Voreintragungen und der Art der Bezugsentscheidung nach dem JGG: Je schwerer die Sanktion der Voreintragung, desto schwerer auch die Sanktion der Bezugsentscheidung nach Jugendstrafrecht. Nur $1 \%$ der Täterinnen sowie $3 \%$ der Täter haben als Bezugssanktion eine Jugendstrafe ohne Bewährung erhalten, wenn die schwerste Voreintragung eine ambulante Sanktion nach dem JGG war. Dieser Anteil steigert sich kontinuierlich bis hin zu $26 \%$ (Frauen) bzw. $35 \%$ (Männer) für diejenigen Verurteilten, die als schwerste Voreintragung eine stationäre Sanktion erhalten haben.

Obwohl das Abhängigkeitsverhältnis der Bezugssanktion von der Art der schwersten Voreintragung für beide Geschlechter besteht, werden die Täterinnen, auch noch unter Berücksichtigung der Art der schwersten Voreintragung, eher milder sanktioniert als Männer.

\subsubsection{Sanktionierung nach allgemeinem Strafrecht und Voreintragungen}

Schaubild 5.14 stellt die Art der Bezugsentscheidung nunmehr nach allgemeinem Strafrecht zunächst wieder nach Anzahl der Voreintragungen und Geschlecht dar. 
Schaubild 5.14: Sanktionen des StGB nach Anzabl der Voreintragungen und Geschlecht*

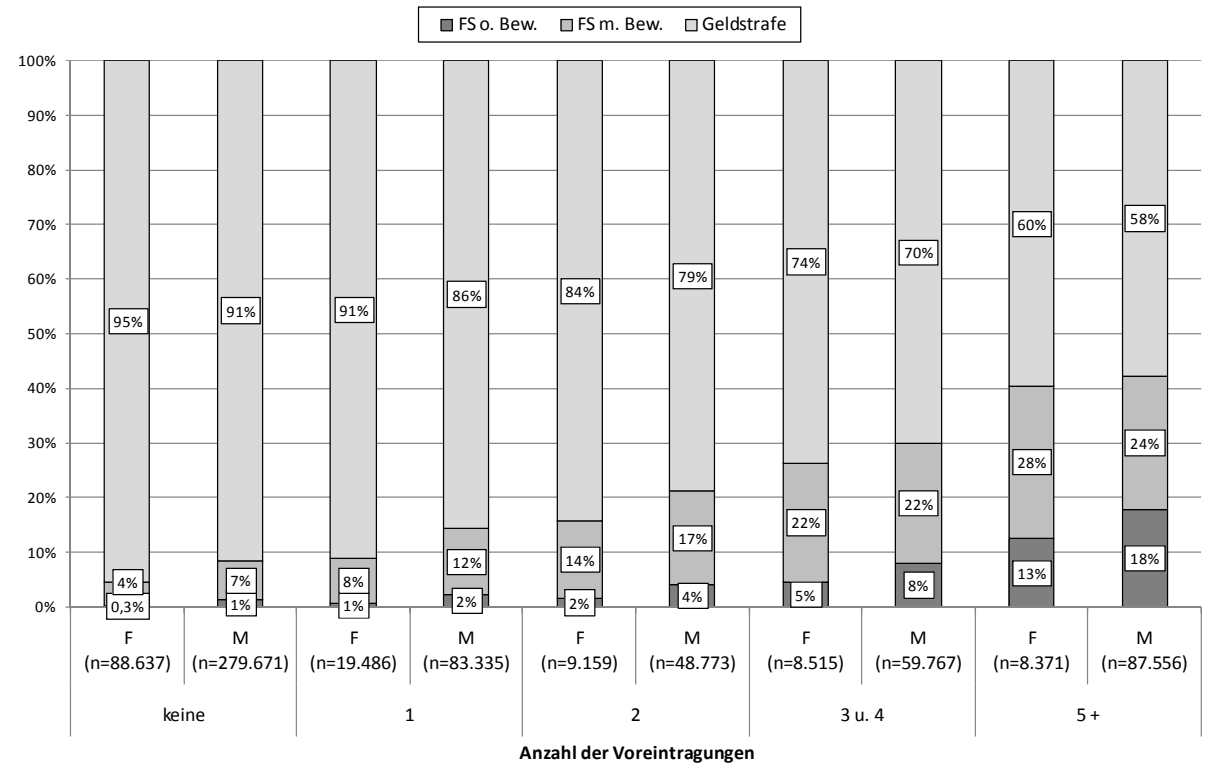

* Absolutzablen siehe Tab. 5.14 a im Anhang

Aus Schaubild 5.14 geht hervor, dass mit zunehmender Anzahl von Voreintragungen auch die Wahrscheinlichkeit steigt, zu einer Freiheitsstrafe mit oder ohne Bewährung verurteilt zu werden. Die nach allgemeinem Strafrecht verurteilten Frauen und Männer ohne Voreintragungen erhalten als Sanktion in der Bezugsentscheidung ganz überwiegend Geldstrafen (95\% der Frauen und $91 \%$ der Männer). Bei fünf und mehr Voreintragungen sind es hingegen nur $60 \%$ der Frauen und $58 \%$ der Männer. Zu einer Freiheitsstrafe mit Bewährung werden in diesem Fall immerhin noch 28 \% Frauen und $24 \%$ Männer verurteilt. Der Vergleich der beiden Geschlechter zeigt, dass Frauen also nicht nur weniger Voreintragungen aufweisen (vgl. Schaubild 5.10), sondern auch unter Berücksichtigung der Anzahl der Voreintragungen weniger schwerwiegende Sanktionen nach dem StGB erhalten. Zwar steigt auch bei den Frauen mit zunehmender Anzahl der Voreintragungen die Wahrscheinlichkeit, eine Freiheitsstrafe - mit oder ohne Bewährung - zu bekommen, jedoch nicht in dem Maße wie bei den Männern. Dies dürfte mit der anderen Struktur der von Frauen begangenen Delikte zusammenhängen. An späterer Stelle wird die Art des begangenen Delikts noch mit zu berücksichtigen sein.

Auffällig ist allerdings, dass der Unterschied zwischen den Geschlechtern hier nicht so ausgeprägt ist wie bei den Sanktionen in der Bezugsentscheidung nach Jugendstrafrecht. Dies wird besonders deutlich, wenn man die Personen mit fünf 
und mehr Voreintragungen betrachtet: $12 \%$ der Männer und lediglich $4 \%$ der Frauen erhalten als Bezugssanktion eine Jugendstrafe ohne Bewährung (vgl. Schaubild 5.12). Im Vergleich zum allgemeinen Strafrecht, wo der Unterschied $13 \%$ (Frauen) zu $18 \%$ (Männer) beträgt (vgl. Schaubild 5.14), ist die Differenz bei Bezugsentscheidungen nach Jugendstrafrecht mithin fast doppelt so groß.

Eine ähnliche Beziehung zeigt sich auch zwischen der Schwere der Voreintragung und der Bezugsentscheidung nach allgemeinem Strafrecht (vgl. Schaubild 5.15).

Schaubild 5.15: Sanktionen des StGB nach Art der schwersten Voreintragung und Geschlecht*

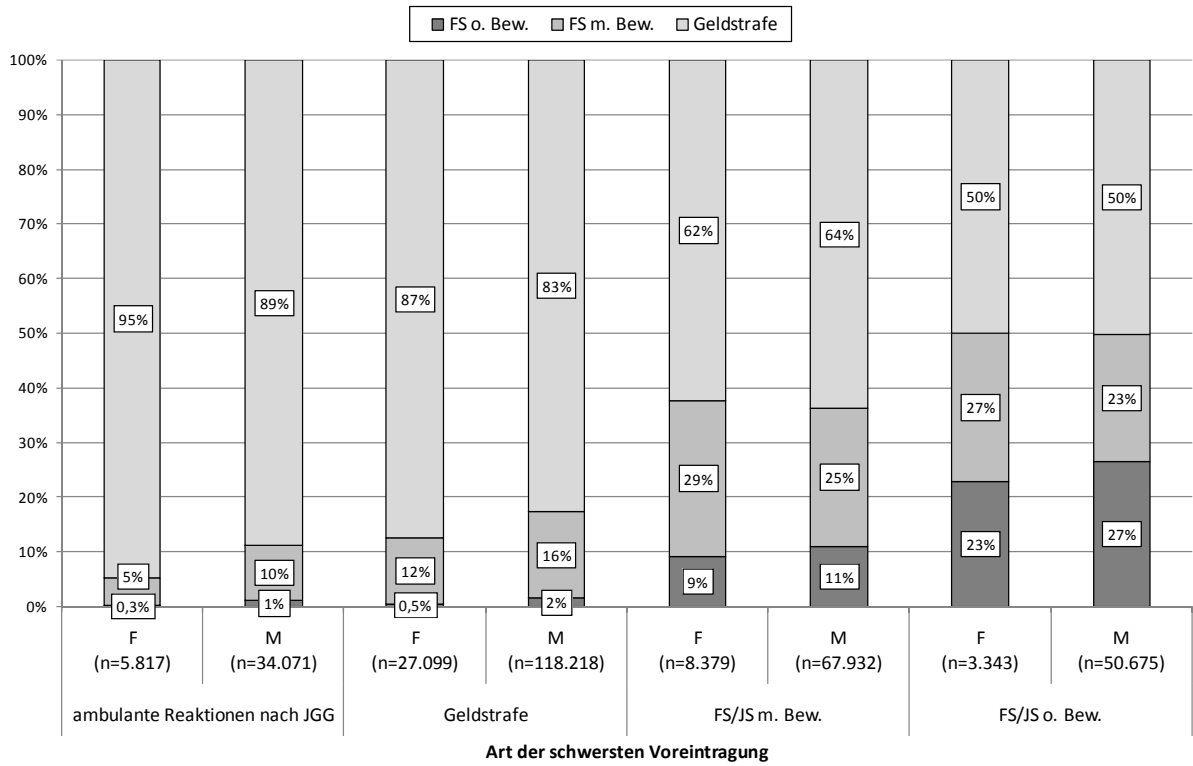

* Absolutrablen siehe Tab. 5.15 a im Anhang

Je schwerer die Art der Voreintragung, desto schwerer ist die Bezugssanktion. Dies gilt an dieser Stelle sowohl für weibliche als auch für männliche Verurteilte. War die Art der schwersten Voreintragung eine Geldstrafe oder eine ambulante Reaktion nach dem JGG, so erhalten Männer häufiger als Frauen Freiheitsstrafen mit oder ohne Bewährung als Bezugssanktion. Dementsprechend übersteigt in dieser Kategorie der Anteil von Geldstrafen bei den Frauen den entsprechenden Anteil bei den Männern. Frauen erhalten insgesamt wieder seltener eine stationäre Sanktion in der Bezugsentscheidung, auch wenn die Voreintragung bereits eine solche enthielt: in diesem Fall werden 27 \% der Männer, aber nur 23 \% der Frauen erneut zu einer Freiheitsstrafe ohne Bewährung verurteilt. Bei Frauen wird die Freiheitsstrafe häufiger zur Bewährung ausgesetzt. Der Anteil zur Bewährung 
ausgesetzter Freiheitsstrafen in der Bezugsentscheidung ist bei ihnen mit $27 \%$ größer als bei den Männern mit $23 \%$, sodass der Anteil von Freiheitsstrafen insgesamt bei Frauen und Männern mit jeweils $50 \%$ gleich groß ist. Ein ähnliches Bild ergibt sich bei Voreintragungen mit Freiheits- oder Jugendstrafen mit Bewährung: Der Anteil von freiheitsentziehenden Bezugssanktionen ist bei den Frauen mit $9 \%$ zwar geringer als bei den Männern mit $11 \%$, allerdings ist der Anteil von Freiheitsstrafen mit Bewährung bei den Frauen mit 29 \% größer als bei den Männern mit $25 \%$. Dies führt letztlich dazu, dass der Anteil von Freiheitsstrafen insgesamt bei den Frauen (38\%) sogar größer ist als bei den Männern (36\%).

Eine mildere Behandlung von Frauen ist folglich mit Ausnahme der Aussetzung von Freiheitsstrafen zur Bewährung ${ }^{716}$ nicht erkennbar. Vielmehr zeigt sich, dass die Sanktionsart der Voreintragung bei den Frauen die Sanktionsart der Bezugsentscheidung mindestens genauso stark beeinflusst wie bei den Männern.

\subsection{Sanktionierung nach Deliktsgruppen}

Die Untersuchung beschränkte sich bislang darauf, sowohl die Bezugsentscheidungen als auch die Voreintragungen unabhängig von dem zugrunde liegenden Delikt zu betrachten. Im Folgenden wird nunmehr als weitere Variable das Delikt mit einbezogen. Dabei wird zunächst die Art der Bezugsentscheidung nach jugendstrafrechtlichen Reaktionen und nach allgemeinem Strafrecht von Frauen und Männern für bestimmte Delikte dargestellt. In einem zweiten Schritt wird geprüft, ob sich die Sanktionierung bei Einschlägigkeit einer Voreintragung ändert, und ob eine etwaige Änderung für Frauen und Männer gleichermaßen zu verzeichnen ist.

\subsubsection{Art der Bezugsentscheidung nach Deliktsgruppen}

Schaubild 5.16 bezieht sich auf die Art der Bezugsentscheidung nach Jugendstrafrecht für jugendliche und heranwachsende Frauen.

\footnotetext{
716 Die häufigere Aussetzung von Freiheitsstrafen zur Bewährung hat jedoch nichts mit einem „Frauenbonus“ zu tun hat, vgl. dazu die Ausführungen unter Kap. 5, 2.6.4, Kap. 5, 3 sowie Kap. 6, 5.6.
} 


\section{Schaubild 5.16: Jugendstrafrechtliche Reaktionen nach Deliktsgruppe von Frauen*}

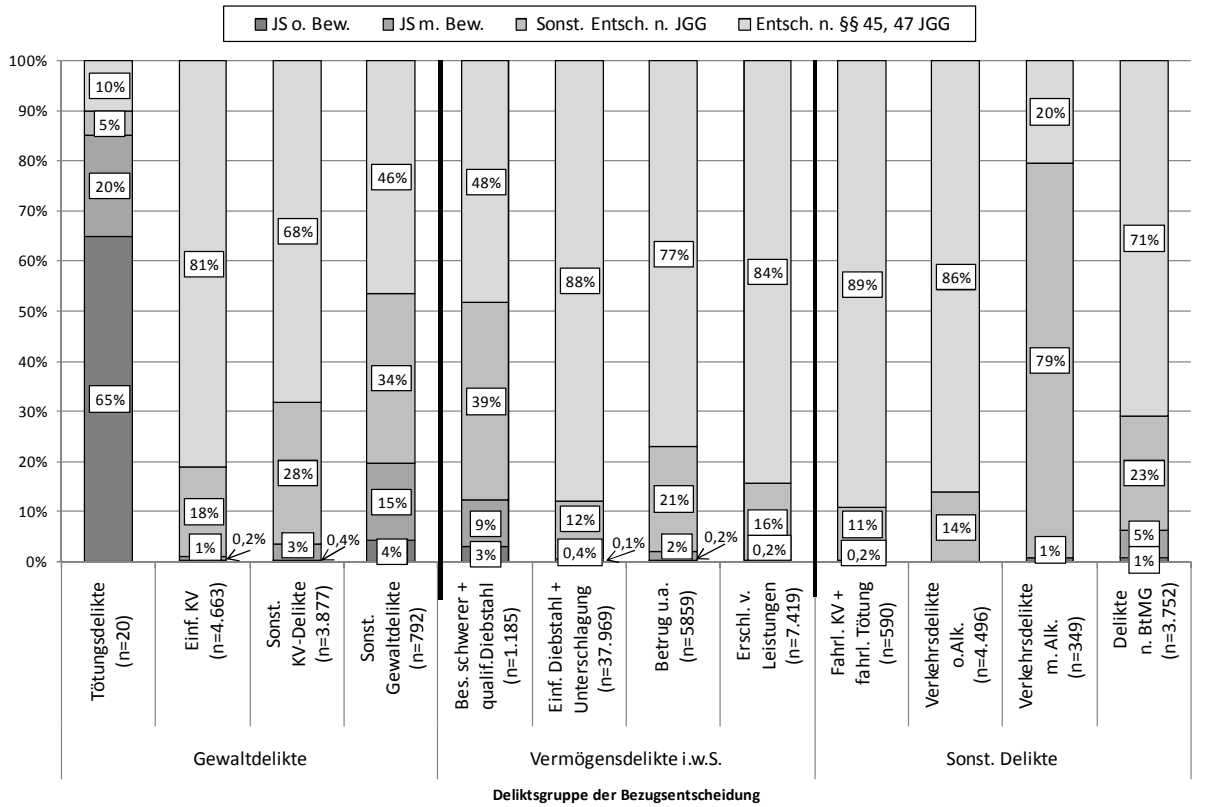

* Absolutzablen siehe Tab. 5.16 a im Anhang

Es zeigt sich, dass die Jugendstrafe ohne Bewährung lediglich in der Deliktsgruppe der Tötungsdelikte mit $65 \%$ eine Rolle spielt. In allen anderen Deliktsgruppen schwankt der Anteil der Jugendstrafen ohne Bewährung zwischen $0 \%$ und $4 \%$ (letzteres bei den sonstigen Gewaltdelikten). Auch die Jugendstrafe mit Bewährung fällt nur bei den Tötungsdelikten mit $20 \%$, den sonstigen Gewaltdelikten mit $15 \%$ und den schweren Diebstahlsdelikten mit 9\% ins Gewicht. Ausgenommen bei den Verkehrsdelikten unter Alkoholeinfluss überwiegen ansonsten bei allen

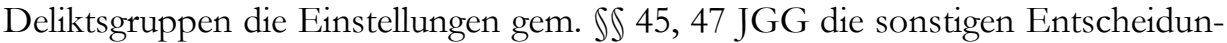
gen nach JGG. Die Täterinnen eines Verkehrsdelikts unter Alkohol erhalten mit $79 \%$ am häufigsten eine sonstige Entscheidung nach dem JGG. 
Schaubild 5.17: Jugendstrafrechtliche Reaktionen nach Deliktsgruppe von Männern*

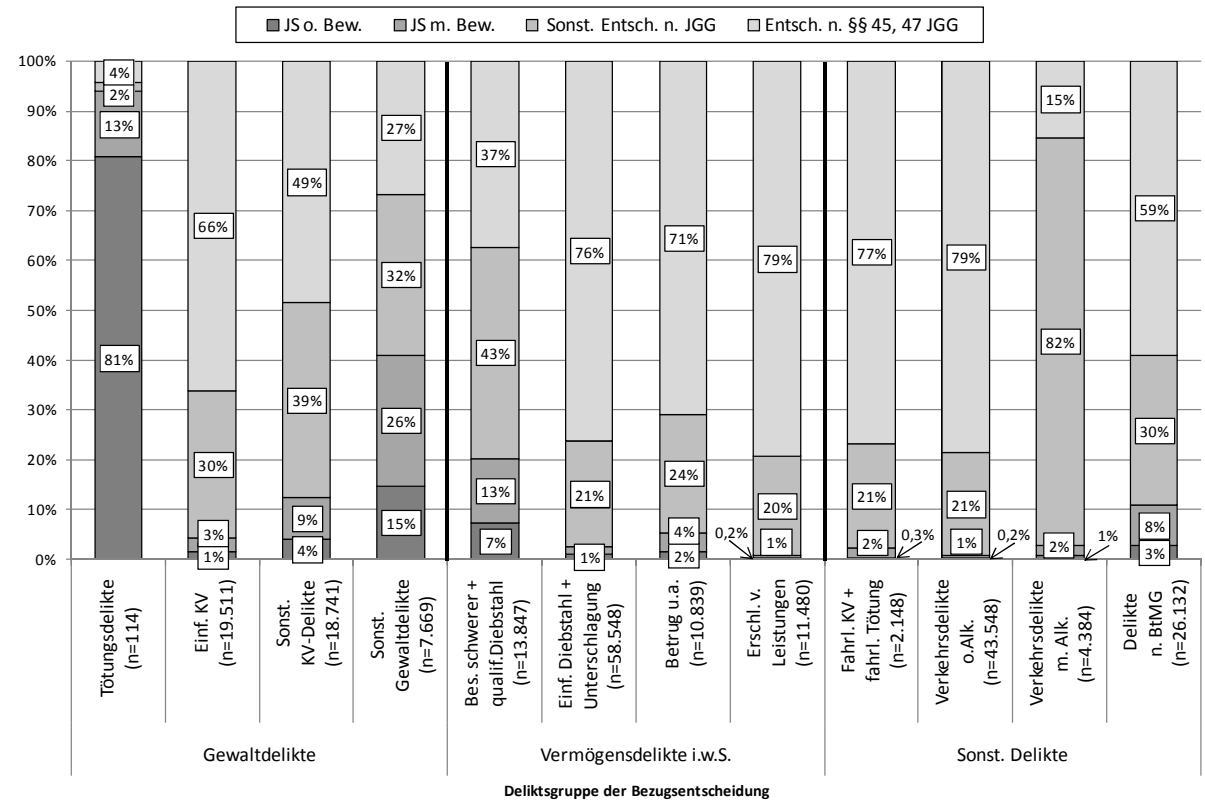

* Absolutzablen siehe Tab. 5.17a im Anhang

Bei den jugendlichen und heranwachsenden Männern ergibt sich ein ähnliches Bild: Auch bei den Männern ist die Gruppe der Tötungsdelikte von den Jugendstrafen ohne Bewährung dominiert (81\%). Der Anteil von Jugendstrafen ohne Bewährung ist bei den Männern allerdings um 16 Prozentpunkte höher als bei den Frauen. Bei den sonstigen Gewaltdelikten erhalten jugendliche und heranwachsende Männer in $15 \%$, bei schweren Diebstahlsformen in $7 \%$ der Fälle eine unbedingte Jugendstrafe. Auch hier überwiegen die Anteile bei den Männern deutlich die bei den Frauen. Es gibt keine Deliktsgruppe, bei der die Anteile der Jugendstrafen ohne oder mit Bewährung bei den Frauen die bei den Männern übersteigen. Bei den Männern fällt ebenfalls auf, dass die Täter eines Verkehrsdelikts unter Alkoholeinfluss mit $82 \%$ am häufigsten wegen sonstiger Entscheidungen nach dem JGG registriert sind.

Schaubild 5.18 veranschaulicht nunmehr die Art der Bezugsentscheidung nach allgemeinem Strafrecht von Frauen. Hierbei ist zu berücksichtigen, dass die Größe der Anteile der einzelnen Sanktionsarten von der jeweiligen gesetzlichen Strafandrohung abhängig sind. 


\section{Schaubild 5.18: Sanktionen des StGB nach Deliktsgruppe von Frauen*}

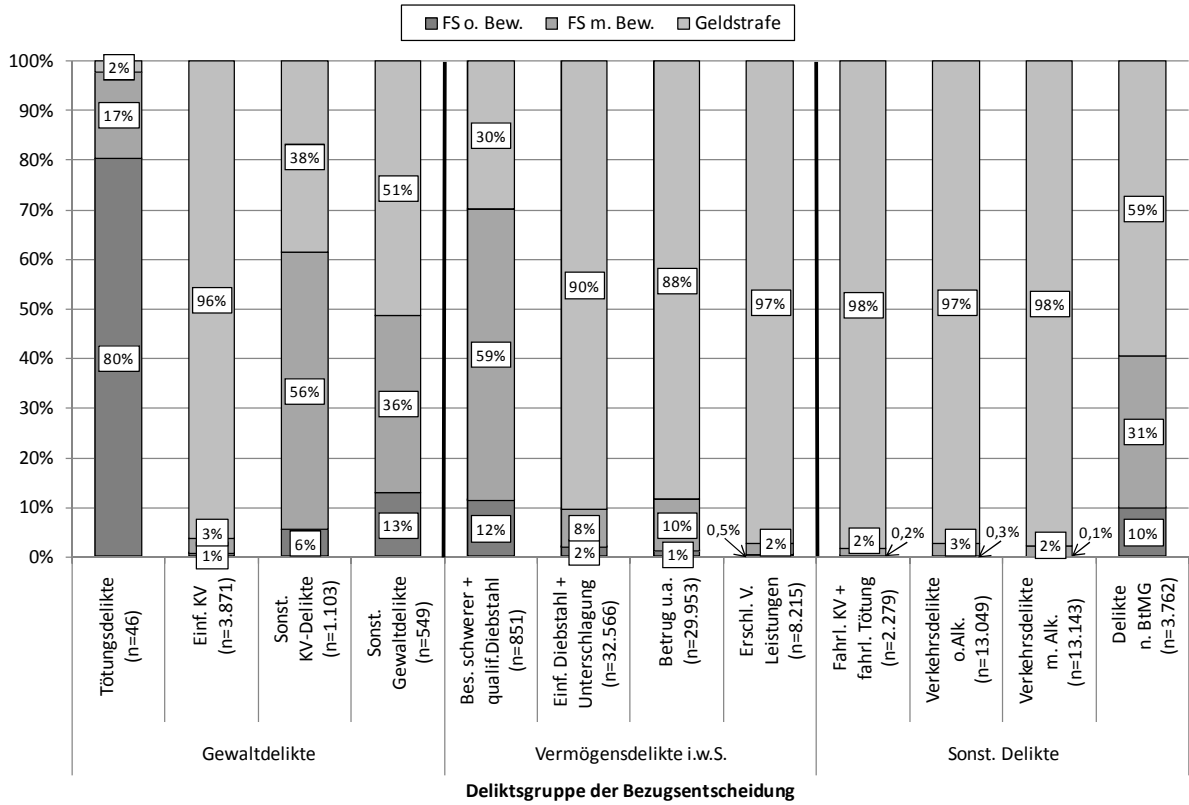

* Absolutzablen siehe Tab. 5.18 a im Anbang

Frauen bekommen häufiger Freiheitsstrafen ohne Bewährung als Jugendstrafen ohne Bewährung. Dies trägt der Tatsache Rechnung, dass der Erziehungsgedanke des JGG nicht gilt. Ferner dürfte sich bei einigen Täterinnen bereits ein kriminelles Vorleben entwickelt haben, welches bei der Strafzumessung zu berücksichtigen ist. Bei dem Bagatelldelikt Erschleichen von Leistungen, den Verkehrsdelikten und der fahrlässigen Tötung und Körperverletzung bleibt der Anteil von Freiheitsstrafen unter oder genau 0,5\%. Am härtesten werden auch hier wieder die Tötungsdelikte, sonstigen Gewaltdelikte und schweren Diebstahlsformen bestraft, was aufgrund der hohen Strafandrohungen kaum verwundert.

Vergleicht man die Art der Sanktionierung von Frauen nach dem StGB differenziert nach Deliktsgruppen nun mit der der Männer, so stellt man fest, dass auch hier deutliche Unterschiede zwischen den Geschlechtern bestehen.

Die Anteile von Freiheitsstrafen ohne Bewährung bei den Männern überwiegen die Anteile bei den Frauen deutlich: So erhalten Männer beispielsweise bei $33 \%$ aller Verurteilungen wegen sonstiger Gewaltdelikte und bei $28 \%$ aller Verurteilungen wegen schweren Diebstahlsformen eine Freiheitsstrafe ohne Bewährung. 
Schaubild 5.19: Sanktionen des StGB nach Deliktsgruppe von Männern*

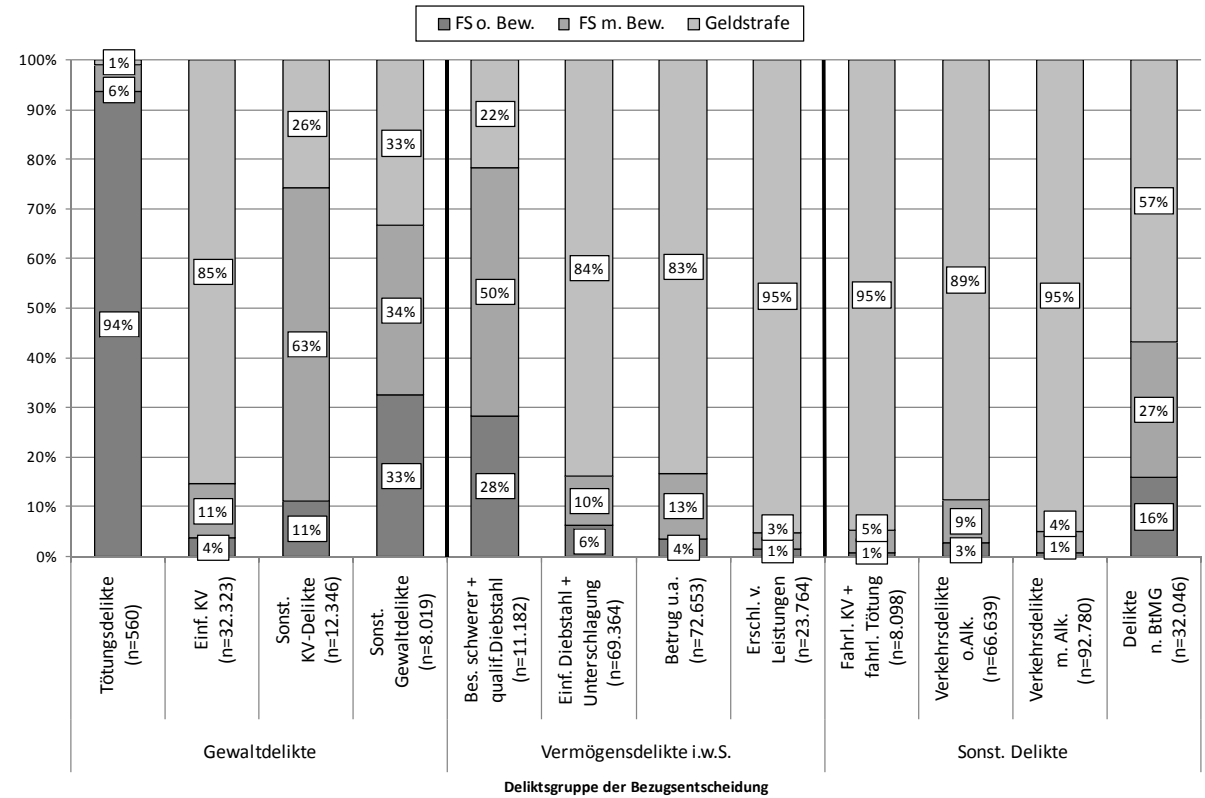

* Absolutzablen siehe Tab. 5.19a im Anbang

Bei den Frauen betragen die entsprechenden Anteile $13 \%$ bei den sonstigen Gewaltdelikten und $12 \%$ bei den schweren Diebstahlsformen (vgl. Schaubild 5.18). Auch bei Delikten nach dem BtMG beträgt der Anteil von stationären Sanktionen $16 \%$, bei den sonstigen Körperverletzungsdelikten immerhin noch $11 \%$. Im Vergleich dazu erhalten Frauen nur in $10 \%$ (Delikte nach dem BtMG) bzw. $6 \%$ (sonstige Körperverletzungsdelikte) der Fälle eine solche Sanktion. Mit Ausnahme der Delikte nach dem BtMG, den sonstigen Gewaltdelikten und den schweren Diebstahlsformen werden Frauen über alle Deliktsbereiche hinweg auch seltener mit einer Freiheitsstrafe mit Bewährung als Bezugssanktion registriert als Männer. Auffällig sind zudem die Unterschiede bei der Sanktionierung von Verkehrsdelikten und dort besonders bei den Verkehrsdelikten ohne Alkoholeinfluss: Hier beträgt der Anteil der Freiheitsstrafen mit Bewährung bei den Männern 9\%, bei den Frauen hingegen nur 3\%. Im Vergleich zu den Männern erhalten Frauen in allen Deliktskategorien häufiger eine Geldstrafe als Bezugssanktion. Besonders groß ist der Unterschied zwischen den Geschlechtern bei der Sanktionierung nach Gewaltdelikten und bei schweren Diebstahlsformen. Aber auch bei leichteren Delikten, wie z.B. dem einfachen Diebstahl, erhalten Männer härtere Sanktionen.

Die deliktsspezifische Betrachtung bestätigt noch einmal die bereits unter 3.2 gewonnenen Ergebnisse. 


\subsubsection{Art der Bezugsentscheidung und einschlägige Voreintragungen}

Voreintragungen haben insbesondere dann eine strafschärfende Wirkung, wenn sie einschlägig sind. ${ }^{17}$ Daher wird überprüft, wie sich die Einschlägigkeit der Voreintragung(en) in unterschiedlichen Deliktsgruppen bei Frauen und Männern auf die Sanktionierung auswirkt.

Dabei wird differenziert zwischen keinen Voreintragungen, nur Voreintragungen mit einem anderen Delikt, (auch) Voreintragungen mit einem Delikt einer verwandten Deliktsgruppe und (auch) einschlägigen Voreintragungen. Die nachfolgende Darstellung weist zwar die den Voreintragungen zugrunde liegenden Delikte nicht aus, allerdings wird die Berechnung so vorgenommen, dass die jeweiligen Delikte der Voreintragungen in der entsprechenden Gruppe den jeweiligen Bezugsentscheidungen zugeordnet werden. Hier soll die bereits in Kapitel 4 vorgestellte Deliktsgruppierung verwendet werden. Es gilt zunächst zu klären, welche Definition den vorliegend gebildeten Gruppen zur Einschlägigkeit zugrunde liegt bzw. wie die Zuordnung der Voreintragungen in die entsprechende Gruppe erfolgen soll. In der Gruppe „keine Voreintragung(en)“ sind alle Bezugsentscheidungen zusammengefasst, für die keine Voreintragung registriert ist. In der Gruppe „nur Voreintragungen mit einem anderen Delikt“ sind die Personen berücksichtigt, die eine oder mehrere Voreintragungen aufweisen, bei denen das zugrunde liegende Delikt weder einschlägig ist noch einer dem Bezugsdelikt verwandten Deliktsgruppe angehört. In der Gruppe der (auch) einschlägigen Voreintragungen wurden die Personen berücksichtigt, die eine Voreintragung wegen desselben Delikts oder derselben Deliktsgruppe der Bezugsentscheidung erhalten haben. Der Begriff der Einschlägigkeit ist folglich etwas weiter zu fassen, wie Tabelle 5.5 verdeutlicht.

Tabelle 5.5 veranschaulicht, welche Einteilung bezüglich der Einschlägigkeit vorgenommen wird: Wer beispielsweise eine Bezugsentscheidung wegen Diebstahls und eine Voreintragung wegen Unterschlagung aufweist, wird in der Gruppe der (auch) einschlägigen Voreintragungen berücksichtigt. Gleiches gilt für die Personen, die eine Bezugsentscheidung wegen gefährlicher Körperverletzung gem. \224 StGB und eine Voreintragung wegen schwerer Körperverletzung gem. \226 StGB erhalten haben, da beide Delikte zu den sonstigen Körperverletzungsdelikten zählen.

In der Gruppe der Personen, für die (auch) Voreintragungen mit Delikten einer verwandten Deliktsgruppe verzeichnet sind, wird der Kreis der berücksichtigten Delikte vergrößert: Wer z.B. eine Bezugsentscheidung wegen einfachen Diebstahls und eine Voreintragung wegen besonders schweren Diebstahls erhalten hat, wird zu dieser Gruppe gezählt.

${ }^{717}$ BGHSt 24, 198. 
Tabelle 5.5: Bestimmung der einschlägigen Voreintragungen

\begin{tabular}{|c|c|c|c|}
\hline & & $\begin{array}{c}\text { (Auch) Voreintra- } \\
\text { gung(en) mit Delikten } \\
\text { einer verwandten De- } \\
\text { liktsgruppe }\end{array}$ & $\begin{array}{l}\text { (Auch) einschlägige } \\
\text { Voreintragung(en) }\end{array}$ \\
\hline \multirow{4}{*}{ Gewaltdelikte } & Tötungsdelikte & $\begin{array}{l}\text { Einf. KV, } \\
\text { sonst. KV-Delikte, } \\
\text { sonst. Gewaltdelikte }\end{array}$ & Tötungsdelikte \\
\hline & Einf. KV & \begin{tabular}{|l|} 
Tötungsdelikte, \\
sonst. KV-Delikte, sonst. \\
Gewaltdelikte \\
\end{tabular} & Einf. KV \\
\hline & $\begin{array}{l}\text { Sonst. } \\
\text { KV-Delikte }\end{array}$ & $\begin{array}{l}\text { Tötungsdelikte, } \\
\text { einf. KV, } \\
\text { sonst. Gewaltdelikte, }\end{array}$ & Sonst. KV-Delikte \\
\hline & $\begin{array}{l}\text { Sonst. } \\
\text { Gewaltdelikte }\end{array}$ & $\begin{array}{l}\text { Tötungsdelikte, } \\
\text { einf. KV, } \\
\text { sonst. KV-Delikte }\end{array}$ & Sonst. Gewaltdelikte \\
\hline \multirow{4}{*}{$\begin{array}{l}\text { Vermögens- } \\
\text { delikte i.w.S. }\end{array}$} & $\begin{array}{l}\text { Bes. schwerer und } \\
\text { qualif. Diebstahl }\end{array}$ & $\begin{array}{l}\text { Einf. Diebstahl und Un- } \\
\text { terschlagung }\end{array}$ & $\begin{array}{l}\text { Bes. schwerer + qualif. } \\
\text { Diebstahl }\end{array}$ \\
\hline & $\begin{array}{l}\text { Einf. Diebstahl und } \\
\text { Unterschlagung }\end{array}$ & $\begin{array}{l}\text { Bes. schwerer und qualif. } \\
\text { Diebstahl }\end{array}$ & $\begin{array}{l}\text { Einf. Diebstahl + Unter- } \\
\text { schlagung }\end{array}$ \\
\hline & Betrug u.a. & Erschl. von Leistungen & Betrug u.a. \\
\hline & $\begin{array}{l}\text { Erschl. von } \\
\text { Leistungen }\end{array}$ & Betrug u.a. & Erschl. von Leistungen \\
\hline \multirow{4}{*}{ Sonst. Delikte } & $\begin{array}{l}\text { Fahrl. KV und } \\
\text { fahrl. Tötung }\end{array}$ & $\begin{array}{l}\text { Verkehrsdelikte o. Alk., } \\
\text { Verkehrsdelikte m. Alk. }\end{array}$ & $\begin{array}{l}\text { Fahrl. KV + fahrl. Tö- } \\
\text { tung }\end{array}$ \\
\hline & $\begin{array}{l}\text { Verkehrsdelikte } \\
\text { o. Alk. }\end{array}$ & $\begin{array}{l}\text { Verkehrsdelikte m. Alk., } \\
\text { fahrl. KV und fahrl. Tö- } \\
\text { tung }\end{array}$ & Verkehrsdelikte ०. Alk. \\
\hline & $\begin{array}{l}\text { Verkehrsdelikte } \\
\text { m. Alk. }\end{array}$ & $\begin{array}{l}\text { Verkehrsdelikte o. Alk., } \\
\text { fahrl. KV und fahrl. Tö- } \\
\text { tung }\end{array}$ & Verkehrsdelikte m. Alk. \\
\hline & $\begin{array}{l}\text { Delikte } \\
\text { n. BtMG }\end{array}$ & $\begin{array}{l}\text { Einf. Diebstahl, } \\
\text { bes. schwerer und qualif. } \\
\text { Diebstahl }\end{array}$ & Delikte n. BtMG \\
\hline
\end{tabular}

Eine Person, die eine Voreintragung wegen einfacher Körperverletzung und eine Bezugsentscheidung wegen eines Tötungsdelikts bekommen hat, wird gleichfalls in der Gruppe (auch) Voreintragung wegen eines Delikts einer verwandten Deliktsgruppe berücksichtigt. Wer als Bezugsentscheidung ein Verkehrsdelikt ohne Alkoholeinfluss und als Voreintragung ein Verkehrsdelikt unter Alkoholeinfluss 
oder eine fahrlässige Körperverletzung bzw. fahrlässige Tötung aufweist, wird ebenfalls in der Gruppe (Voreintragung wegen eines Delikts einer verwandten Deliktsgruppe) gezählt. Für die Verkehrsdelikte unter Alkoholeinfluss und die fahrlässige Körperverletzung/ fahrlässige Tötung wird umgekehrt genauso verfahren. Für die BtMG-Delikte sind hingegen in diesem Fall die Diebstahlsdelikte als verwandte Deliktsgruppe zu werten. Grund hierfür ist, dass Betäubungsmittelkriminalität häufig mit sog. Beschaffungstaten zusammenhängt. ${ }^{718}$ So hat eine Überprüfung der eigenen Daten ergeben, dass der einfache Diebstahl gem. \242 StGB das Delikt ist, welches am häufigsten mit einer Bezugsentscheidung wegen eines BtMG-Delikts zusammenhängt. Kreuzer ${ }^{719}$ führte in diesem Zusammenhang in den Jahren 1988/1989 insgesamt 100 Intensiv-Interviews mit Drogenabhängigen in Hessen durch. Danach nahm, sowohl für Männer als auch für Frauen, nach dem Drogenhandel und der Drogenvermittlung sowie dem Schwarzfahren, der Ladendiebstahl die wichtigste Position bei der Delinquenzbelastung von Drogenabhängigen ein. ${ }^{720}$

Auch Erhardt ${ }^{721}$ befragte 100 Drogenabhängige im Rhein-Main-Gebiet und im Großraum Gießen, die sich in einer öffentlichen oder privaten Entzugseinrichtung bzw. Institutionen zur Entgiftungsbehandlung befanden. Die Auswertung der Interviews ergab, dass der Ladendiebstahl das mit Abstand am häufigsten begangene indirekte Beschaffungsdelikt ${ }^{722}$ ist. ${ }^{723}$

Schaubild 5.20 zeigt nunmehr die Art der Bezugsentscheidung nach Jugendstrafrecht und Einschlägigkeit der Voreintragung von Frauen und Männern im Vergleich.

Es zeigt sich, dass der Anteil der Jugendstrafen für beide Geschlechter stets dann am niedrigsten ist, wenn keine Voreintragung vorhanden ist. Der Anteil erhöht sich für beide Geschlechter, wenn Voreintragungen vorliegen. Dies entspricht auch den bereits unter 2.4.3 gewonnenen Ergebnissen. Am häufigsten erhalten Frauen und Männer eine Jugendstrafe ohne Bewährung, wenn für sie auch eine Voreintragung wegen eines Delikts einer verwandten Deliktsgruppe vorliegt (Frauen: $3 \%$, Männer: $8 \%$ ). Jedoch sind auch hier Unterschiede zwischen den Geschlechtern erkennbar: Während der Anteil von Jugendstrafen ohne Bewäh-

718 Kreuzer, in: Kreuzer (Hrsg.), Handbuch des Betäubungsmittelstrafrechts, S. 170 ff.; Kreuzer, Drogen und Delinquenz, S. 379 ff.

719 Kreuzer/Römer-Klees/Schneider, Beschaffungskriminalität Drogenabhängiger; Kreuzer, in: Kreuzer (Hrsg.), Handbuch des Betäubungsmittelstrafrechts.

720 Kreuzer, in: Kreuzer (Hrsg.), Handbuch des Betäubungsmittelstrafrechts, S. 173; Dieses Ergebnis deckt sich im Übrigen mit Erkenntnissen aus amerikanischen Untersuchungen, vgl. eine Zusammenstellung dieser Untersuchungen bei Krenzer/Römer-Klees/Schneider, S. 234 ff.; Zurbold, S. 72 ff. sowie Rautenberg, S. $41 \mathrm{ff}$.

${ }^{721}$ Erhardt, Drogenabhängigkeit und Beschaffungskriminalität, 1991.

${ }^{722}$ Vgl. zum Begriff der indirekten bzw. mittelbaren Beschaffungskriminalität sowie zur Systematik der Drogendelinquenz: Kreuzer/Römer-Klees/Schneider, S. 8 ff.

723 Erhardt, S. 32. 
rung bei den Frauen mit einschlägigen Voreintragungen genauso hoch ist wie bei den Frauen, die nur Voreintragungen wegen anderer Delikte aufweisen, überwiegt der Anteil von Jugendstrafen ohne Bewährung bei den Männern mit einschlägigen Voreintragungen den von Männern mit nur Voreintragungen wegen anderer Delikte um zwei Prozentpunkte. Bei einschlägigen Voreintragungen sind die Anteile der einzelnen jugendstrafrechtlichen Reaktionen bei beiden Geschlechtern wieder etwas niedriger.

\section{Schaubild 5.20: Jugendstrafrechtliche Reaktionen nach Einschlägigkeit der Voreintragungen und Geschlecht*}

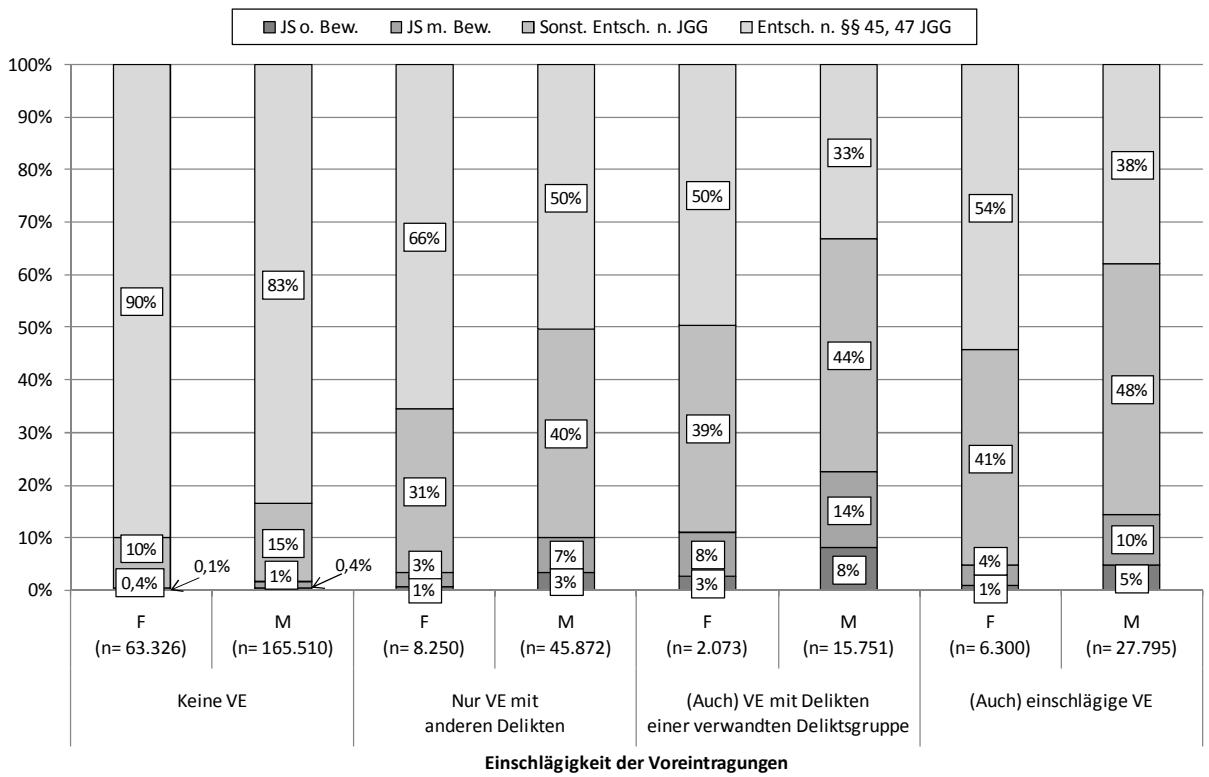

\section{* Absolutzablen siehe Tab. 5.20a im Anhang}

Schaubild 5.21 macht deutlich, dass sich für die Bezugsentscheidungen nach allgemeinem Strafrecht ein ähnlicher Verlauf ergibt.

Die niedrigsten Anteile von Freiheitsstrafen weisen wieder die Personen ohne Voreintragungen auf. Bei den Frauen steigt der Anteil bis zu den Voreintragungen wegen eines Delikts einer verwandten Deliktsgruppe an und stagniert bei den Freiheitsstrafen ohne Bewährung dann auf dem Anteil von $5 \%$. Der Anteil von Freiheitsstrafen mit Bewährung sinkt von $21 \%$ bei den Frauen mit Voreintragungen wegen eines Delikts einer verwandten Deliktsgruppe auf $19 \%$ bei den Frauen mit einschlägigen Voreintragungen ab. Bei den Männern steigt der Anteil von Freiheitsstrafen ohne Bewährung kontinuierlich an. Im Übrigen wird auch die Differenz zu den Frauen immer größer: Anfangs ist der Anteil noch ca. doppelt so 
groß, bei den einschlägigen Voreintragungen ist der Anteil von Freiheitsstrafen mit Bewährung bei den Männern sogar dreimal größer als bei den Frauen.

Schaubild 5.21: Sanktionen des StGB nach Einschlägigkeit der Voreintragungen und Geschlecht*

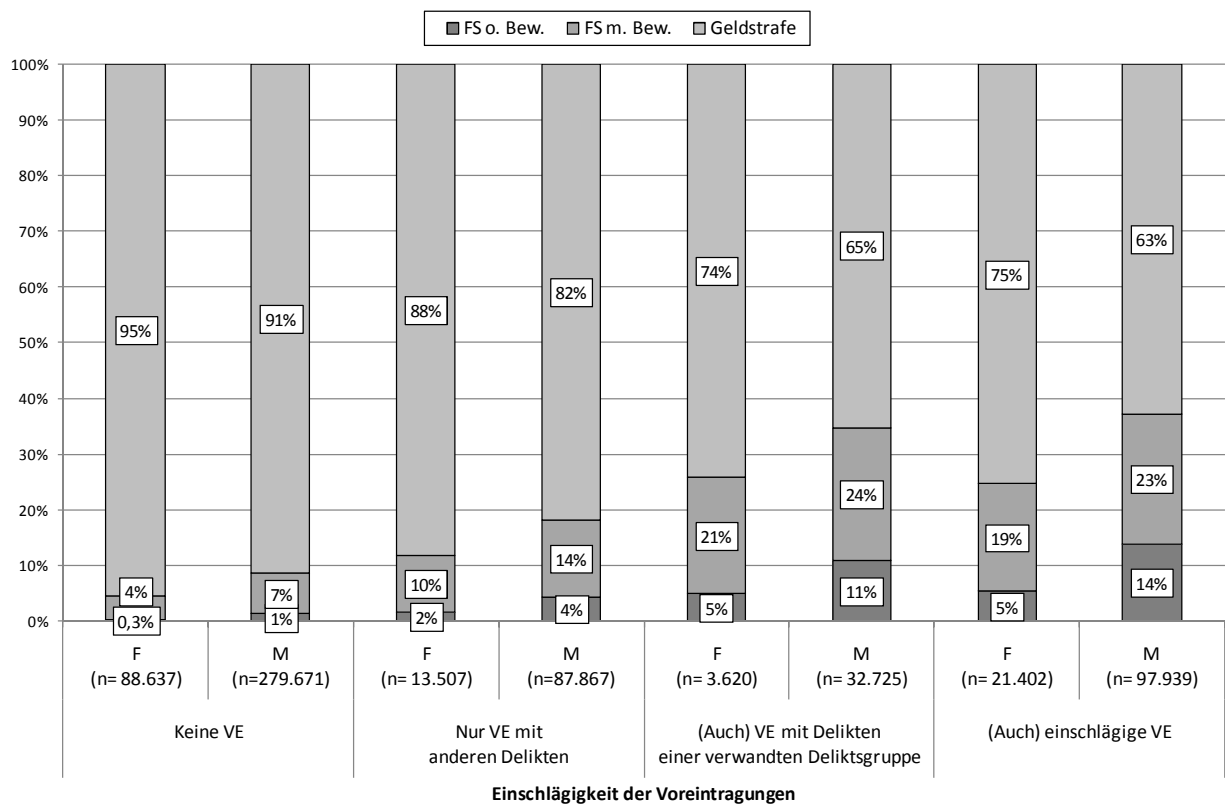

* Absolutrablen siehe Tab. 5.21a im Anbang

Insgesamt lässt sich feststellen, dass sich die Einschlägigkeit der Voreintragungen bei beiden Geschlechtern sanktionsschärfend auswirkt, bei den Frauen jedoch nicht in dem Maße wie bei den Männern. Bei den Frauen macht es für die Sanktionierung kaum einen Unterschied, ob Voreintragungen wegen eines Delikts einer verwandten Deliktsgruppe oder Voreintragungen wegen eines einschlägigen Delikts vorliegen. Bei letzeren fällt die Sanktionierung in der Bezugsentscheidung sogar minimal milder aus. Bei den Männern lässt sich diese Aussage nur auf die Bezugssanktionen nach Jugendstrafrecht übertragen. Bei den Sanktionen nach allgemeinem Strafrecht wirkt sich die Einschlägigkeit der Voreintragungen hingegen minimal stärker aus als eine Voreintragung wegen eines Delikts einer verwandten Deliktsgruppe.

\subsection{Sanktionierung bei Diebstahl gem. $\ 242$ StGB}

Bislang konnten für Frauen grundsätzlich mildere Sanktionen verzeichnet werden als für Männer. Diese Praxis setzt sich auch unter Berücksichtigung der Anzahl der Voreintragungen, Art der schwersten Voreintragung, einschlägigen Voreintra- 
gungen und Deliktsgruppen fort. Hierbei muss aber immer berücksichtigt werden, dass Frauen eine andere Deliktsstruktur aufweisen und eine grobe Kategorisierung in Deliktsgruppen nicht ausreichend Aufschluss darüber gibt, ob wirklich das Merkmal Geschlecht den Ausschlag für die mildere Sanktionierung gibt. Es stellt sich daher die Frage, ob die unterschiedliche Sanktionierungspraxis von Frauen und Männern immer noch gegeben ist, wenn man anhand ausgewählter Delikte mehrere Variablen simultan berücksichtigt.

Im nächsten Abschnitt wird daher die Sanktionierung von Frauen und Männern bei einer Bezugsentscheidung aufgrund von Diebstahl gem. \242 StGB und im Anschluss daran aufgrund von Betrug gem. \263 StGB (Kap. 5, 2.7) detailliert überprüft. Diese beiden Delikte bieten sich für eine tiefergehende Analyse an, da es sich hierbei sowohl um Delikte handelt, bei denen sich die Häufigkeit der Verurteilungen von Frauen der der Männer zumindest annähert, ${ }^{724}$ als auch um Delikte, welche innerhalb der Deliktsstruktur der Frauen eine große Rolle spielen. ${ }^{725}$

Für das Bezugsjahr konnten insgesamt 188.578 Verurteilungen wegen einfachen Diebstahls gem. \242 StGB gezählt werden, wobei 120.239 (64\%) Täter männlich und die restlichen 68.339 (36\%) Täter weiblich waren. ${ }^{726}$ Auch der einfache Diebstahl wird folglich, wie auch schon in Kapitel 4 festgestellt, häufiger von Männern begangen. Betrachtet man jedoch die Frauenkriminalität für sich, so stellt der einfache Diebstahl mit $31 \%$ das von Frauen am häufigsten begangene Delikt dar (vgl. Schaubild 4.1727).

Die Diebstahlskriminalität von Frauen wurde daher in der Literatur verhältnismäßig oft thematisiert. Die genauen Tatumstände und Erscheinungsformen des Diebstahls können mit den dieser Untersuchung zugrunde liegenden Daten leider nicht rekonstruiert werden. Aus diesem Grund wird an dieser Stelle kurz auf den Forschungsstand eingegangen.

Mehrere Studien ${ }^{728}$ belegen, dass Frauen einfache Diebstähle insbesondere in Form des Ladendiebstahls begehen. Die Autoren begründen den hohen Anteil der Frauen an dieser Erscheinungsform des Diebstahls vor allen Dingen mit ihrem erheblichen Kundenanteil in Kaufhäusern und mit der wenig risikoreichen Begehungsweise. ${ }^{729}$ Die Hemmschwelle sei hier geringer als bei anderen Delikten, da weder ein hohes Maß an körperlicher Anstrengung erforderlich sei noch Hindernisse überwunden werden müssten. Ferner werde durch die Warenpräsentation

\footnotetext{
724 Vgl. Schaubild 4.4.

$725 \mathrm{Vgl}$. Schaubilder 4.1 und 4.2.

${ }^{726} \mathrm{Vgl}$. Schaubild 4.4 sowie Tab. $4.1 \mathrm{c}$ im Anhang.

727 Dort ist der Diebstahl mit der Unterschlagung zusammengerechnet, sodass ein Anteil von $32 \%$ zustande gekommen ist. Alleine der einfache Diebstahl macht einen 31\%igen Anteil an der Frauenkriminalität insgesamt aus.

728 Bethge, Der Ladendiebstahl unter besonderer Berücksichtigung des Diebstahls in Selbstbedienungsläden, 1996; Ochmann, Diebstahlsdelikte von Frauen, 1965; Wocher, Die Entwicklung der weiblichen Kriminalität von 1912-1948, 1951.

${ }^{729}$ Bethge, S. $45 \mathrm{ff}$.
} 
mit dem Ziel der Selbstbedienung eine Situation geschaffen, welche zum Diebstahl verführe. ${ }^{730}$

Die PKS bestätigt dieses, durch die oben erwähnten Untersuchungen gewonnene, Bild. Wie in Kapitel 1 aufgeführt, dominiert der Ladendiebstahl bei den Diebstahlsformen. ${ }^{731} \mathrm{Zu}$ berücksichtigen ist jedoch, dass auch der Ladendiebstahl kein „frauentypisches“ Delikt im engeren Sinne ist. Zunächst einmal ist diese Diebstahlsform nur eine Ausprägung des \242 StGB und kein eigenständiges Delikt. Diese Form des Diebstahls wird außerdem ebenfalls häufiger von Männern als von Frauen begangen. Auswertungen von Grützediek ${ }^{732}$ und Lindner ${ }^{733}$ haben im Übrigen ergeben, dass die Anzahl der männlichen Ladendiebe seit 1990 im Vergleich zur Anzahl der weiblichen Ladendiebe überproportional angestiegen ist. ${ }^{734}$ Zur Begründung wird auf die Auflockerung der traditionellen Rollenaufteilung und den damit einhergehenden vermehrten Anteil von Männern unter den Konsumenten hingewiesen. ${ }^{735}$

Mit den Daten des BZR kann lediglich versucht werden, die Schwere des Diebstahls anhand des $\int 248$ a StGB festzumachen. Danach bedarf der Diebstahl geringwertiger Sachen eines Strafantrags. Wie bereits erwähnt besteht die Möglichkeit, Deliktskombinationen auszuwerten, da im Datensatz die fünf schwersten Delikte erfasst sind. Eine Überprüfung der Bezugsentscheidungen wegen Diebstahls und der jeweils vier weiteren daneben erfassten Delikte hat ergeben, dass $\operatorname{der} \int 248 \mathrm{a}$ StGB nur in insgesamt 108 Entscheidungen mit eingetragen wurde. Dies verwundert nicht, da bezüglich der Vorschriften für Strafanträge keine Eintragungspflicht besteht. Vermutlich dürfte aber die Anzahl der Diebstähle geringwertiger Sachen sehr viel höher sein. Daher kann hier durch die Ausfilterung des \248a StGB leider kein Rückschluss auf die Schwere des begangenen Diebstahls gezogen werden.

Schließlich wurde in der Literatur die Frage diskutiert, ob Frauen, die Ladendiebstähle begehen, häufiger psychisch krank sind. In diesem Fall müsste an die verminderte oder volle Schuldunfähigkeit gem. $\iint 20,21$ StGB gedacht werden. Früher wurde oftmals behauptet, Frauen stehlen um des Stehlens willen. Dies erfülle das Krankheitsbild der Kleptomanie. Heute ist man sich jedoch weitgehend einig darüber, dass es sich bei Kleptomanie nicht um eine eigenständige Krankheit handelt, sondern vielmehr um ein Symptom für eine der in \20 StGB aufgezählten Grunderkrankungen. ${ }^{736}$ In der neueren Literatur taucht dafür nun der Begriff des „pathologischen Stehlens“ auf. ${ }^{737}$ Dies liege in Abgrenzung zum „,normalen“

\footnotetext{
${ }^{730}$ Kürzinger, S. 284; Michaelis, S. 220 f.

731 Vgl. Ausführungen unter Kap. 1, 2.1.2.

732 Grützediek, Intensivtäterinnen beim Diebstahl, 2001.

${ }^{733}$ Linder, 100 Jahre Frauenkriminalität, 2005.

734 Grützediek, S. 35; Linder, S. 190 f.

735 Michaelis, S. 36 f.; Lindner, S. 191.

736 Grützediek, S. 71; Schorsch, in: Venzlaff, Psychiatrische Begutachtung, 1986, S. 279, 308.

737 Michaelis, S. 86; Floru, in: MschrKrim 1974, S. 72, 76; Grützediek, S. 47.
} 
Diebstahl dann vor, wenn mangelnde Vorsicht bei der Tatausführung, fehlende Bereicherungsabsicht, geringer Wert der gestohlenen Sache sowie eine fehlende Erklärbarkeit der Tat gegeben seien. ${ }^{738}$ Diese Merkmale sind jedoch schwierig nachzuweisen und treten auch bei „normalen“ Diebstählen auf, sodass auch der Begriff des „pathologischen Stehlens“ zu Recht in die Kritik geraten ist. ${ }^{739}$ Insgesamt ist der Anteil unter den Diebinnen, bei denen rechtsrelevante psychische Auffälligkeiten i.S.d. \$S 20, 21 StGB angenommen werden, gering. ${ }^{740} \mathrm{Da}$ die Vorschriften des Allgemeinen Teils im BZR nicht konsequent eingetragen werden und zudem Zuordnungsprobleme bestehen, ${ }^{741}$ wurde auf eine Analyse der $\iint 5$, $21 \mathrm{StGB}$ in Verbindung mit \242 StGB verzichtet.

\subsubsection{Sanktionierung nach Jugendstrafrecht}

Schaubild 5.22 stellt jugendrichterlichen Reaktionen in der Bezugsentscheidung differenziert nach Geschlecht dar.

Schaubild 5.22: Jugendstrafrechtliche Reaktionen aufgrund von Diebstabl nach Geschlecht*

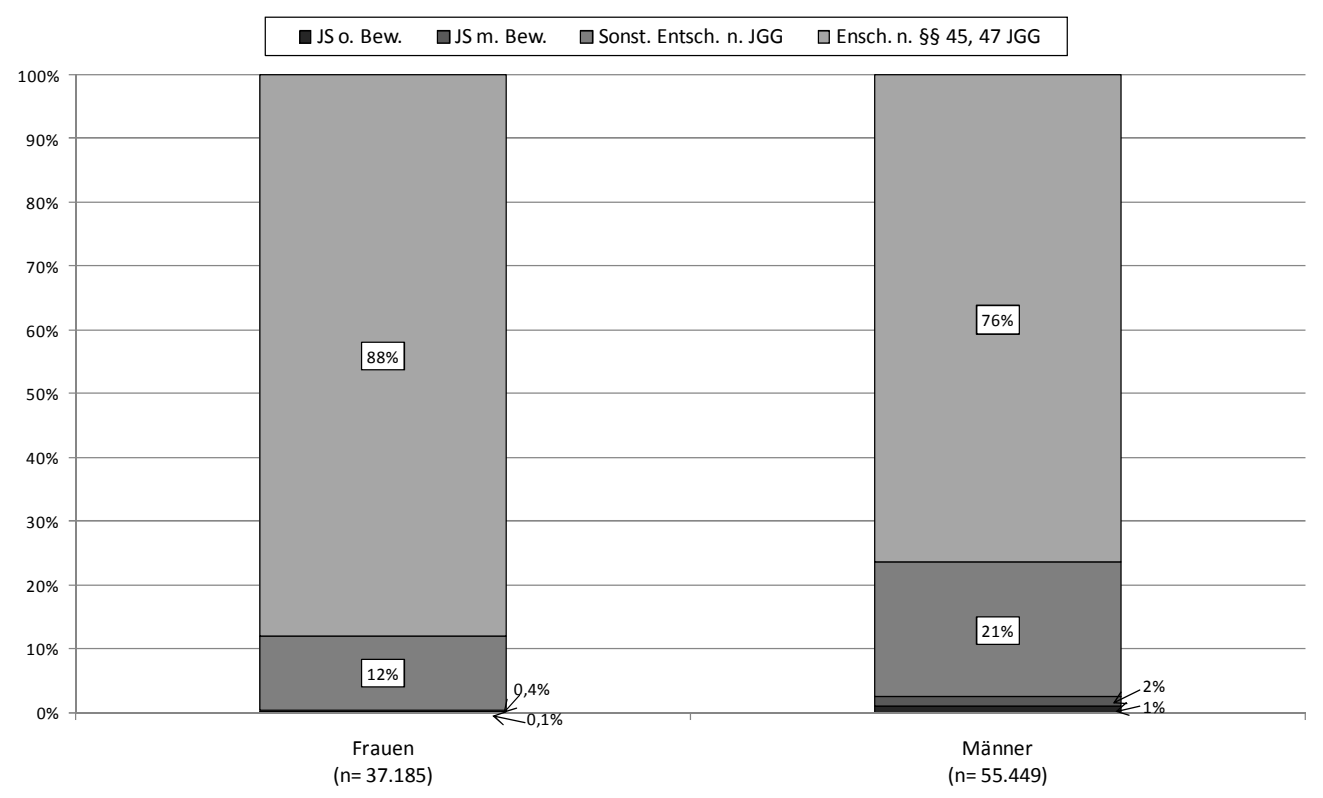

* Absolutzablen siebe Tab. 5.22a im Anbang

\footnotetext{
738 Floru, in: MschrKrim 1974, S. 72, 76; Grütrediek, S. 47 f.

${ }^{739}$ Knöllinger/Förster, in: BewHi 2000, S. 43, 45 ff.; Grützediek, S. 65 f.

740 Osburg, in: MschrKrim 1992, S. 10; Wagner, S. 243; Grützediek, S. 70 f.

741 Vgl. zu dieser Problematik ausführlich unter Kap. 3, 3.3.
} 
Bei den jugendstrafrechtlichen Reaktionen überwiegen, sowohl bei Frauen $(88 \%)$ als auch bei Männern (76\%), die Diversionsentscheidungen nach $\$ \int 45,47$ JGG, gefolgt von den sonstigen Entscheidungen nach JGG mit $12 \%$ (Frauen) und $21 \%$ (Männer).

Von den insgesamt 37.185 Täterinnen eines Diebstahls, die eine jugendrichterliche Reaktion erhalten haben, sind nur $47(0,1 \%) \mathrm{zu}$ einer Jugendstrafe ohne Bewährung und $145(0,4 \%)$ zu einer Jugendstrafe mit Bewährung verurteilt worden. Auch von den männlichen Tätern wurden nur insgesamt $1 \%$ zu einer Jugendstrafe mit und $2 \%$ zu einer Jugendstrafe ohne Bewährung verurteilt. ${ }^{742}$

Insgesamt ist bei dieser deliktsspezifischen Betrachtung immer noch eine mildere Sanktionierung von Frauen zu verzeichnen.

Fraglich ist ferner, ob diese Tendenz noch bei Betrachtung der Aussetzungsquoten zu erkennen ist. Unter 2.2.3 wurde festgestellt, dass Jugendstrafen bei Frauen häufiger zur Bewährung ausgesetzt werden (vgl. Schaubild 5.4). Dieses Ergebnis dürfte sich vermutlich für den Diebstahl nicht anders darstellen, da nicht das Delikt, sondern vielmehr die in $\int 56$ StGB genannten Prognose-Gesichtspunkte für die Entscheidung über eine Aussetzung von Bedeutung sind.

\section{Schaubild 5.23: Aussetzungsquote bei Jugendstrafe aufgrund von Diebstabl nach Geschlecht*}

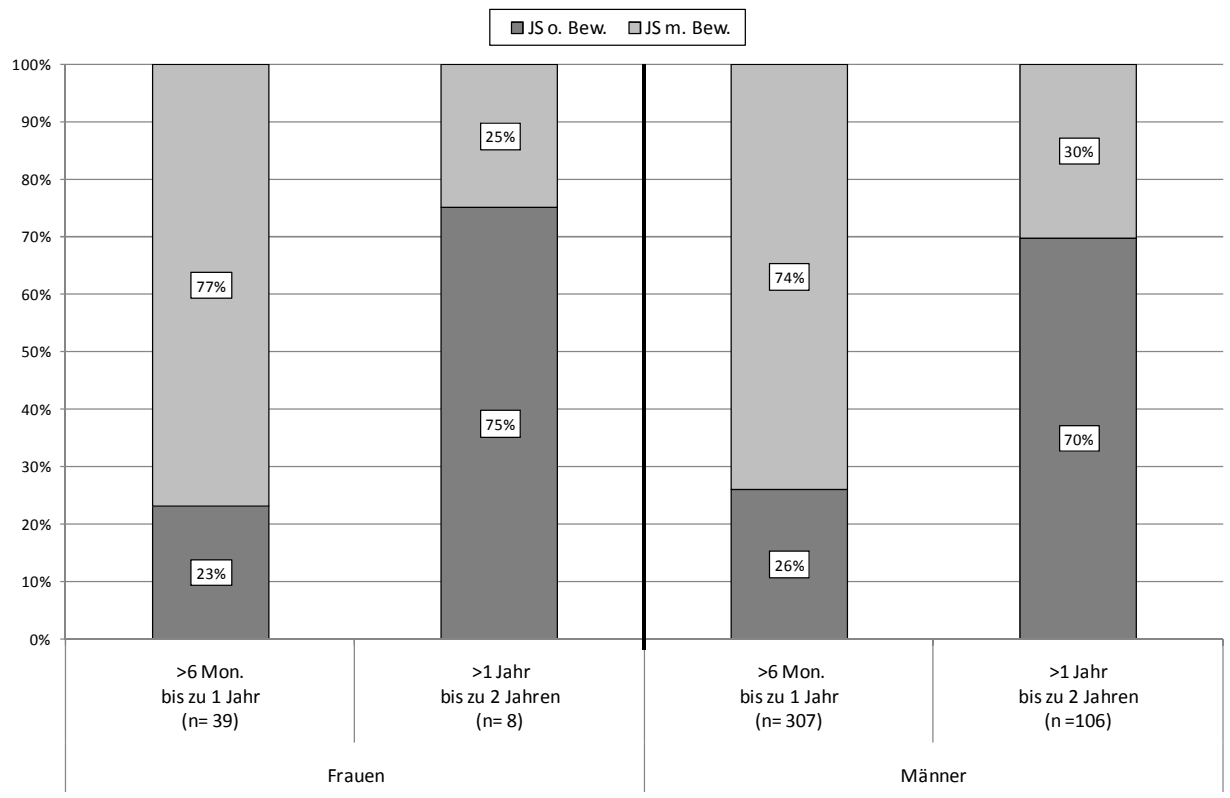

* Absolutrablen siehe Tab. 5.23 a im Anhang

${ }^{742}$ Vgl. zu den absoluten Zahlen Tab. 5.22a im Anhang. 
Schaubild 5.23 zeigt nunmehr die Aussetzungsquoten nur für die Frauen und Männer, die als Bezugssanktion eine Jugendstrafe wegen Diebstahls erhalten haben.

Bei deliktsspezifischer Betrachtung werden Jugendstrafen von sechs Monaten bis zu einem Jahr mit $77 \%$ bei Frauen und $74 \%$ bei Männern in etwa gleich häufig zur Bewährung ausgesetzt. Bei den Jugendstrafen von einem bis zu zwei Jahren stellt sich die Verteilung anders dar: Im Vergleich zu Schaubild 5.4, wo der Anteil von Jugendstrafen mit Bewährung bei den Frauen den der Männer um zehn Prozentpunkte übersteigt, zeigt sich hier, dass bei $25 \%$ der Frauen und bei $30 \%$ der Männer eine Aussetzung der Jugendstrafe erfolgt.

Hierbei ist allerdings zu beachten, dass nur acht Frauen im Bezugsjahr eine Jugendstrafe von einem bis zu zwei Jahren aufgrund von Diebstahl erhalten haben, weshalb die Verteilung letztlich nicht aussagekräftig ist, der Vollständigkeit halber jedoch dargestellt wurde.

2.6.2 Sanktionierung nach allgemeinem Strafrecht

Schaubild 5.24: Sanktionen des StGB aufgrund von Diebstabl nach Geschlecht*

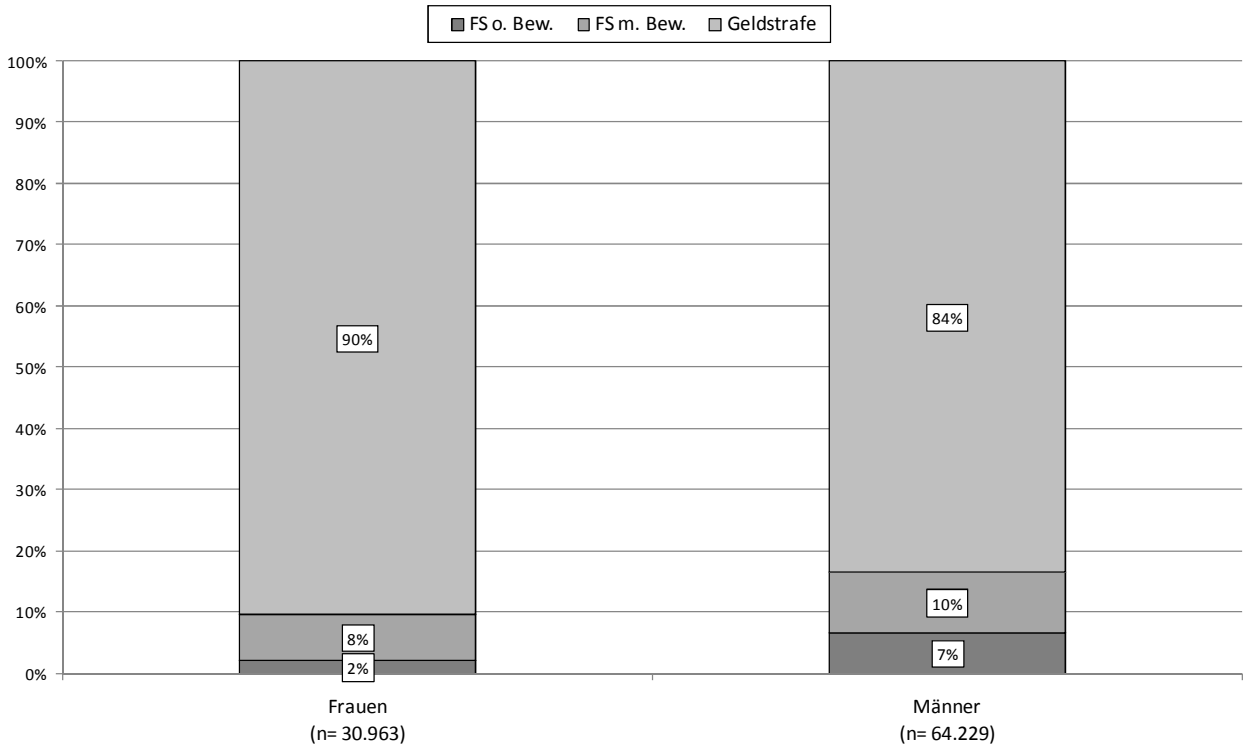

* Absolutzablen siehe Tab. 5.24a im Anhang

Bei der Sanktionierung nach allgemeinem Strafrecht dominiert die Verhängung der Geldstrafe mit $90 \%$ bei den Frauen und $84 \%$ bei den Männern (Schaubild 5.24). Frauen erhalten mithin im Vergleich zu den Männern bei Diebstahl häufiger eine Geldstrafe als Sanktion. Bei den Sanktionen Freiheitsstrafe mit und ohne 
Bewährung dominieren wieder die Männer mit insgesamt $17 \%$. Für weibliche Täter ist hingegen nur in 10\% aller Bezugssanktionen wegen Diebstahls eine Freiheitsstrafe registriert. Besonders groß ist die Differenz erneut zwischen den Anteilen der Freiheitsstrafe ohne Bewährung, die lediglich für $2 \%$ der Frauen, aber für $7 \%$ der Männer ausgesprochen wird. Die Sanktionierung des einfachen Diebstahls stellt sich folglich in der Tendenz so dar, wie die Sanktionierung aller Straftaten zusammen (vgl. Schaubild 5.6).

Darüber hinaus sollen auch für die Freiheitsstrafen aufgrund von Diebstahl die Aussetzungsquoten überprüft werden (Schaubild 5.25).

Schaubild 5.25: Aussetzungsquote bei Freiheitsstrafe aufgrund von Diebstahl nach Geschlecht*

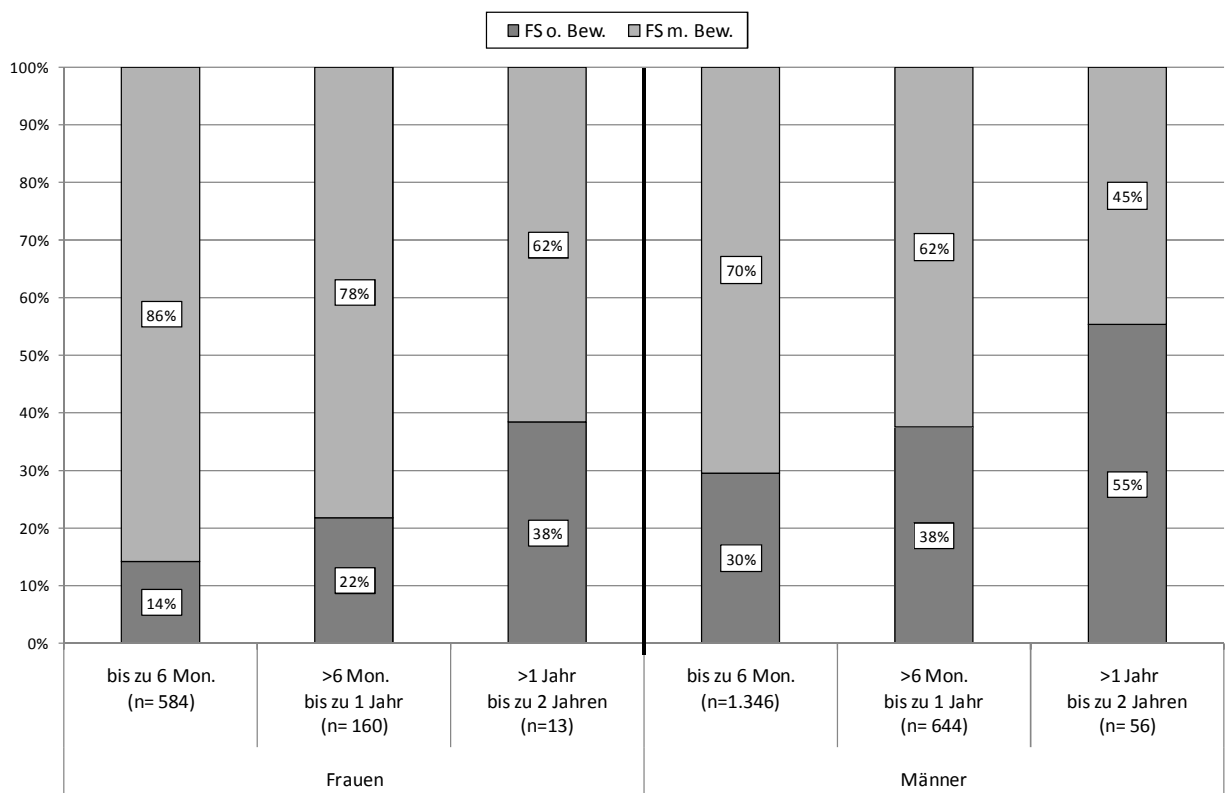

* Absolutzablen siehe Tab. 5.25 a im Anhang

Es wird nochmals deutlich, dass der Anteil von Freiheitsstrafen mit Bewährung bei den Frauen den der Männer überwiegt. Bei den hier betrachteten Freiheitsstrafen aufgrund von Diebstahl stellt sich der Unterschied besonders deutlich dar: Bei $86 \%$ der Frauen und bei lediglich $70 \%$ der Männer wird eine kurze Freiheitsstrafe bis zu sechs Monaten zur Bewährung ausgesetzt. Bei den Freiheitsstrafen von sechs Monaten bis zu einem Jahr stehen sich Anteile von $78 \%$ (Frauen) und 62\% (Männer) und bei den Freiheitsstrafen von einem bis zu zwei Jahren von $62 \%$ (Frauen) zu $45 \%$ (Männer) gegenüber. Wie bereits erwähnt, sind dies die Ergebnisse einer Gesamtwürdigung nach $\int 56$ I S. 2, II S. 1 StGB. Erneut ist jedoch die 
geringe Anzahl der Täterinnen in der Gruppe der Freiheitsstrafen von einem bis zu zwei Jahren zu berücksichtigen.

Da ein Großteil der Diebe und Diebinnen ${ }^{743}$ als Sanktion in der Bezugsentscheidung eine Geldstrafe erhalten, wird nun ferner die Anzahl der Tagessätze genauer betrachtet (Schaubild 5.26).

\section{Schaubild 5.26: Anzabl der Tagessätze bei Geldstrafe aufgrund von Diebstabl nach Geschlecht*}

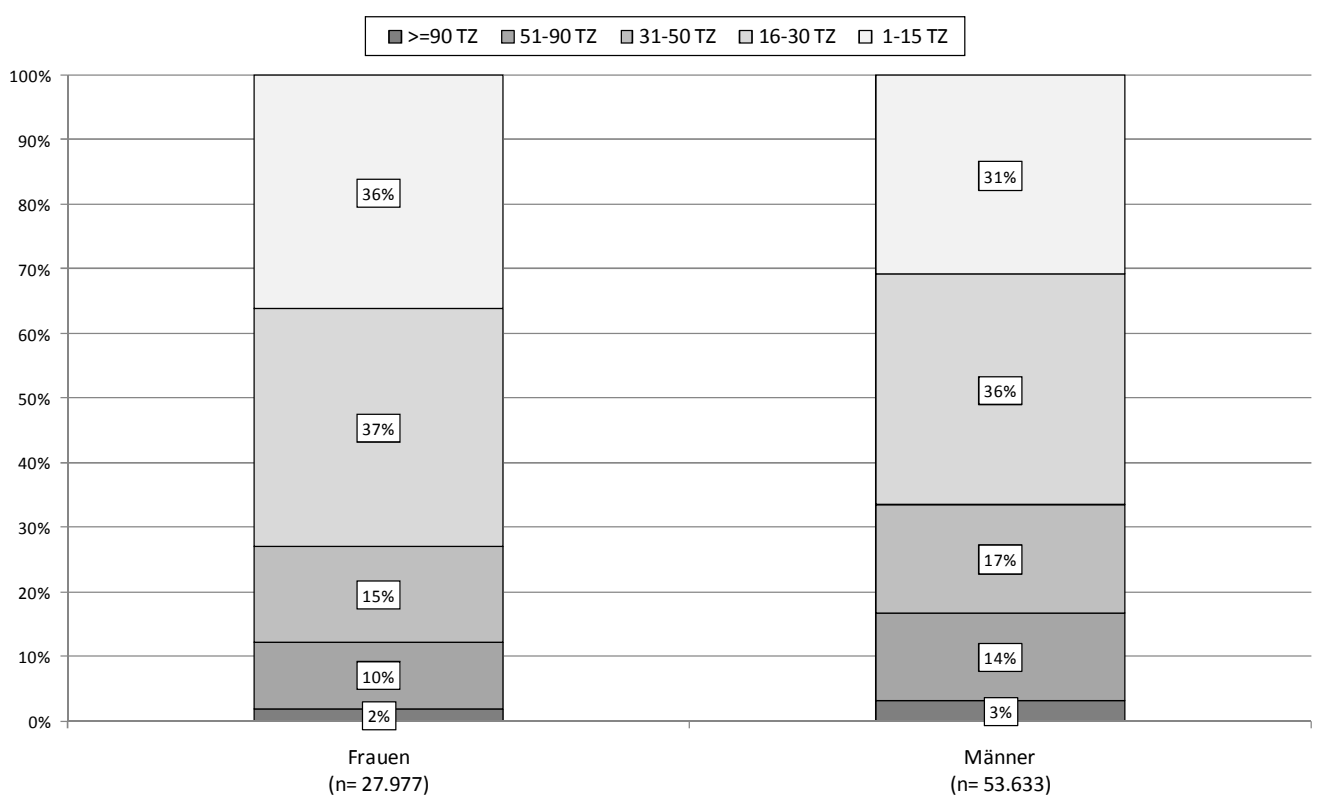

\section{* Absolutzablen siehe Tab. 5.26a im Anbang}

Für Frauen und Männer zeigt sich eine ähnliche Verteilung: Beide Geschlechter erhalten am häufigsten 16-30 Tagessätze, gefolgt von 1-15 Tagessätzen. Ab der Gruppe 31-50 Tagessätze nehmen die Anteile kontinuierlich ab. Insgesamt wird bei den Diebinnen etwas häufiger die geringere Anzahl von 1-15 Tagessätzen (36 \% der Frauen und $31 \%$ der Männer) verhängt. Diebe sind dafür häufiger in den Tagessatzgruppen 31-50, 51-90 und über 90 registriert.

Die Tendenz der milderen Sanktionierung wird also auch bei Geldstrafen wegen Diebstahls deutlich. Insgesamt sind die Unterschiede aber recht gering. Die Ergebnisse ähneln im Übrigen denen, die bei der Betrachtung der Anzahl der Tagessätze für alle Delikte erzielt wurden (vgl. Schaubild 5.9).

\footnotetext{
${ }^{743}$ Im Folgenden werden mit den Begriffen Dieb bzw. Diebin die Täter bzw. Täterinnen eines einfachen Diebstahls gem. $\$ 242$ StGB bezeichnet.
} 


\subsubsection{Sanktionierung und Voreintragungen}

\subsubsection{Anzabl und Art der schwersten Voreintragungen}

Zunächst wird ein allgemeiner Überblick über die Anzahl (vgl. Schaubild 5.27) und Art der schwersten Voreintragungen (vgl. Schaubild 5.28) für das Delikt des einfachen Diebstahls gegeben.

Schaubild 5.27: Bezugsentscheidungen aufgrund von Diebstabl nach Anzahl der Voreintragungen und Geschlecht*

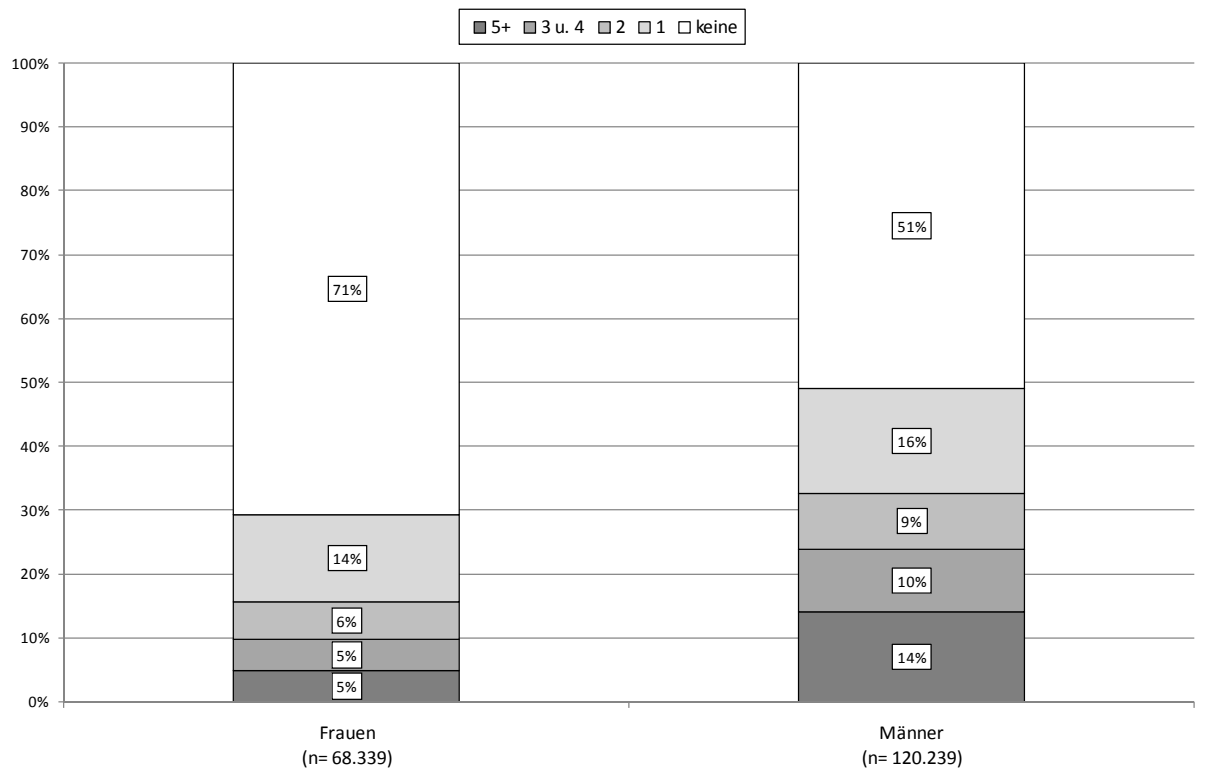

* Absolutzablen siehe Tab. 5.27a im Anbang

Aus Schaubild 5.27 geht hervor, dass wegen Diebstahls sanktionierte Frauen deutlich seltener vorbestraft sind als Männer. Mit steigender Anzahl der Voreintragungen wird auch der Abstand zwischen den Geschlechtern größer. So haben $5 \%$ der Diebinnen fünf und mehr Voreintragungen. Bei den Männern ist der Anteil hingegen dreimal so groß; er beträgt $15 \%$.

Schaubild 5.28 stellt die Art der schwersten Voreintragung beim Diebstahl für beide Geschlechter dar. Betrachtet werden nur die Personen mit mindestens einer Voreintragung. Die Freiheits- und Jugendstrafen mit und ohne Bewährung wurden zu jeweils einer Gruppe zusammengefasst. Wie bei der Anzahl der Voreintragungen (Schaubild 5.28) zeigt sich ein deutlicher Unterschied zwischen den Geschlechtern: Nur $7 \%$ der Frauen, für die eine Voreintragung registriert wurde, erhielten als schwerste Sanktion eine nicht ausgesetzte Freiheits- oder Jugendstra- 
fe. Bei den Männern ist der Anteil mit 17\% mehr als doppelt so groß. Auch ist der Anteil von Freiheits- und Jugendstrafen mit Bewährung als schwerste Voreintragung bei den Männern mit $17 \%$ größer als der bei den Frauen mit $14 \%$. Die Anteile der zusammengefassten Gruppen der Freiheits- und Jugendstrafe mit und ohne Bewährung werden stark von den Freiheitsstrafen bestimmt (vgl. Schaubild 5.28). Erwartungsgemäß wurde für die Frauen (44\%) im Bezugsjahr häufiger als bei den Männern (30 \%) eine Geldstrafe als schwerste Voreintragung registriert. Auch bei den jugendstrafrechtlichen Reaktionen überwiegt der Anteil von Einstellungen gem. $\iint 45,47$ JGG bei den Frauen $(26 \%)$ den bei den Männern (22\%), wohingegen für Männer mit $14 \%$ häufiger eine sonstige Entscheidung nach dem JGG als schwerste Voreintragung erging als bei den Frauen mit 10\%.

Diese Ergebnisse entsprechen denen, die bereits für die nicht deliktsdifferenzierende Darstellung gewonnen wurden (vgl. Schaubild 5.11).

Im Ergebnis weisen Frauen auch beim Diebstahl nicht nur weniger Voreintragungen als Männer auf, sondern sie erhalten zudem im Fall einer Voreintragung eine weniger schwerwiegende Sanktion. Die deliktsspezifische Betrachtung kommt folglich zu keinem anderen Ergebnis als die Betrachtung aller Bezugsentscheidungen (vgl. Schaubilder 5.10 und 5.11).

Schaubild 5.28: Bezugsentscheidungen aufgrund von Diebstabl nach Art der schwersten Voreintragung und Geschlecht*

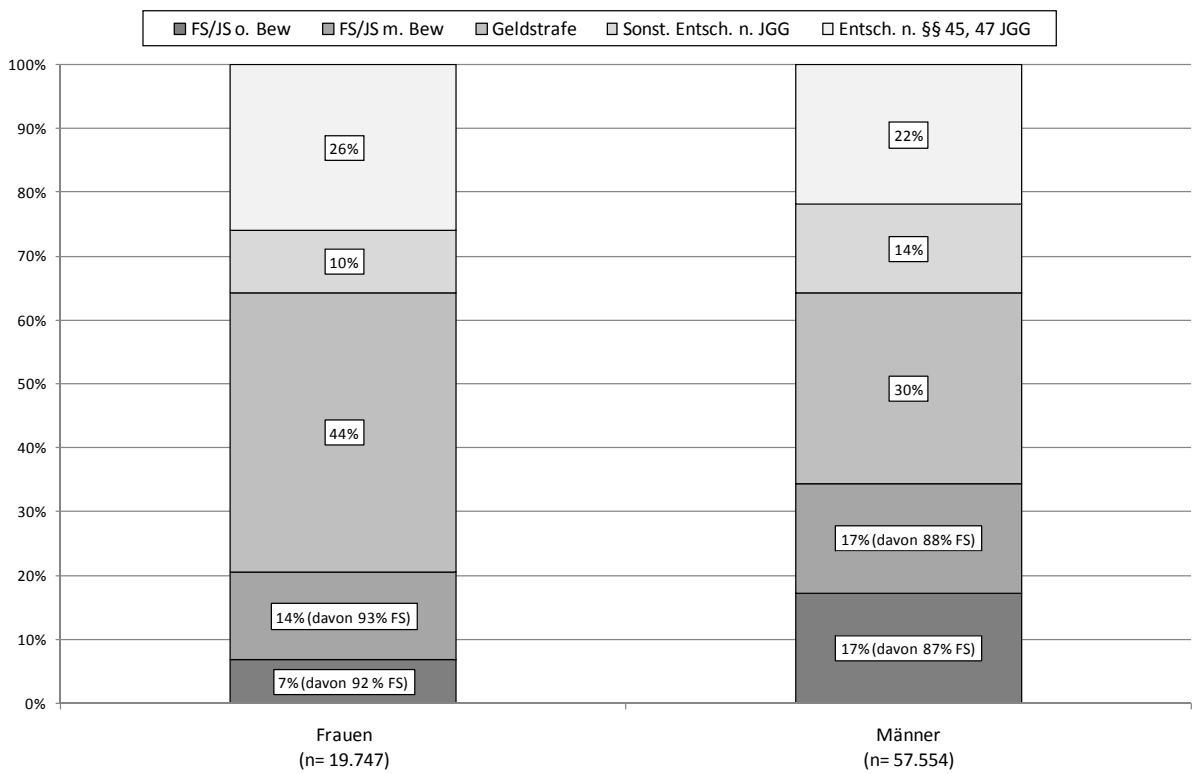

* Absolutzablen siebe Tab. 5.28a im Anbang 


\subsubsection{Sanktionierung nach Jugendstrafrecht und Voreintragungen}

Nach dem allgemeinen Überblick wird als weitere Variable die Bezugssanktion nach dem JGG und zwar in Abhängigkeit von Anzahl und Art der schwersten Voreintragungen für Frauen und Männer betrachtet (vgl. Schaubild 5.29). Es ist zu vermuten, dass sich der Unterschied bei der Sanktionierungspraxis der Geschlechter bei alleiniger Betrachtung des Delikts Diebstahl im Vergleich zur Betrachtung aller Delikte reduziert. Daher wird an dieser Stelle ein Vergleich zu den diesbezüglichen Schaubildern 5.12 und 5.13 erfolgen.

In Schaubild 5.29 ist die jugendstrafrechtliche Sanktionierung in der Bezugsentscheidung differenziert nach Anzahl der Voreintragungen von Frauen und Männern für das Delikt Diebstahl dargestellt. Es wird deutlich, dass auch hier die Schwere der Sanktion mit steigender Anzahl der Voreintragungen zunimmt. Auffällig ist, dass der Unterschied zwischen den Geschlechtern, wie vermutet, nicht mehr so ausgeprägt ist, wie bei der Darstellung über alle Delikte hinweg (vgl. Schaubild 5.12): Der Anteil der schwersten Sanktion, der Jugendstrafe ohne Bewährung, ist bei den Personen ohne Voreintragungen noch für beide Geschlechter mit $0 \%$ und $0,2 \%$ in etwa gleich gering.

\section{Schaubild 5.29: Jugendstrafrechtliche Reaktionen aufgrund von Diebstabl nach An₹abl der Voreintragungen und Geschlecht*}

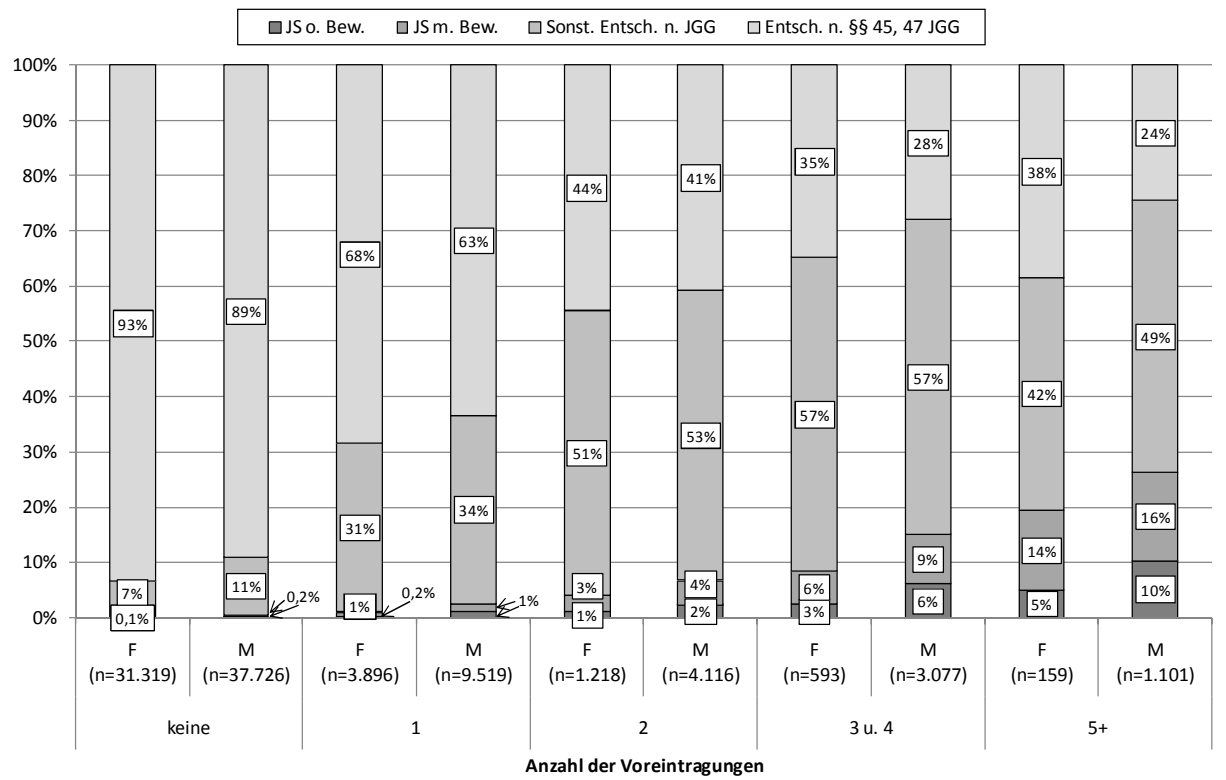

* Absolutrablen siebe Tab. 5.29a im Anbang 
Erst ab einer und mehr Voreintragungen werden bei den Anteilen von Jugendstrafe ohne Bewährung wieder deutlichere Unterschiede bei der der Sanktionierung von Frauen und Männern sichtbar, jedoch in reduzierterem Maß: Während in Schaubild 5.12 der Anteil von stationären Sanktionen bei den Männer zumeist dreimal so groß war wie bei den Frauen, ist dies hier nicht mehr der Fall. Vielmehr ist der Anteil immer genau doppelt so groß. So erhalten beispielsweise die Diebinnen und Diebe mit fünf und mehr Voreintragungen in $5 \%$ (Frauen) bzw. 10\% (Männer) der Fälle eine Jugendstrafe ohne Bewährung und nicht mehr, wie bei der Betrachtung sämtlicher jugendstrafrechtlicher Bezugsentscheidungen (vgl. Schaubild 5.12), 4 \% (Frauen) zu $12 \%$ (Männer). Diese Angleichung der Sanktionsraten wird auch sichtbar, wenn man sich den Jugendstrafen mit Bewährung zuwendet: Beim hier betrachteten Diebstahl beträgt der Unterschied zwischen den Geschlechtern höchstens drei Prozentpunkte und zwar bei den Verurteilten mit drei bis vier Voreintragungen. Aus Schaubild 5.12 ergab sich noch eine größere Differenz, die bis zu acht Prozentpunkte betrug (bei fünf und mehr Voreintragungen). Frauen erhalten jedoch auch hier insgesamt häufiger Entscheidungen nach den $\iint 45,47$ JGG als Männer.

Schaubild 5.30 differenziert nunmehr die Bezugssanktionen des JGG nach Art der schwersten Voreintragung und Geschlecht.

Schaubild 5.30: Jugendstrafrechtliche Reaktionen aufgrund von Diebstabl nach Art der schwersten Voreintragung und Gescblecbt*

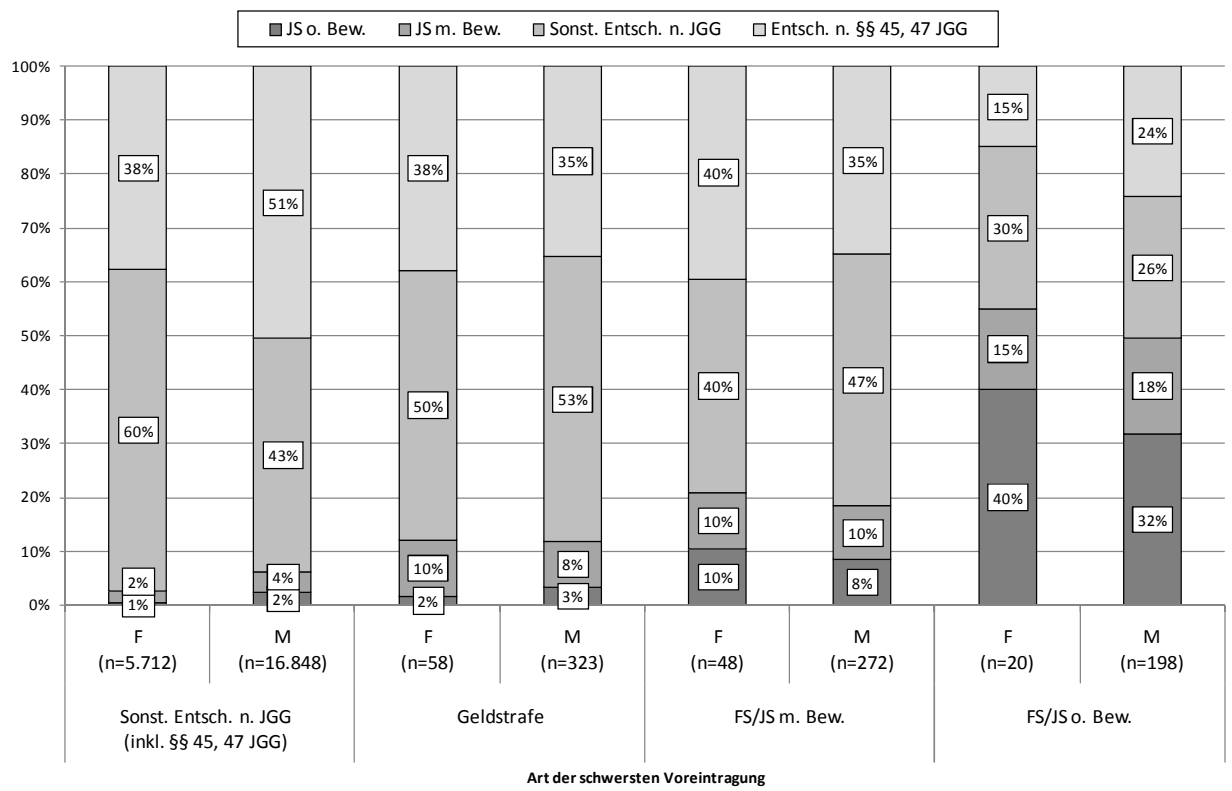

Absolutzablen siebe Tab. 5.30a im Anhang* 
Es ist anzunehmen, dass der Unterschied hier ebenfalls weniger ausgeprägt ist als bei Schaubild 5.13. Hier übersteigt der Anteil von Jugendstrafen ohne Bewährung der Diebinnen, die als schwerste Voreintragung eine Jugend- oder Freiheitsstrafe mit oder ohne Bewährung erhalten haben, mit $40 \%$ sogar den Anteil bei den Männern, der nur $32 \%$ beträgt. Allerdings ist bei der Interpretation dieses Ergebnisses zu beachten, dass es sich auf lediglich 20 Diebinnen bezieht. Auch bei den ausgesetzten Jugend- oder Freiheitsstrafen findet sich eine härtere Sanktionierung der Frauen; hier sind indes ebenfalls nur wenige Frauen $(n=48)$ betroffen. In der Tendenz wirkt sich die Art der Voreintragung bei Frauen mindestens genauso stark aus wie bei den Männern.

\subsubsection{Sanktionierung nach allgemeinem Strafrecht und Voreintragungen}

Nunmehr wird auch eine Analyse der Bezugsentscheidungen nach allgemeinem Strafrecht für das Delikt Diebstahl unter Berücksichtigung der Anzahl und Art der schwersten Voreintragungen von Frauen und Männern erfolgen.

Aus Schaubild 5.31 geht hervor, dass mit zunehmender Anzahl an Voreintragungen die Schwere der Sanktion nach allgemeinem Strafrecht wegen Diebstahls zunimmt.

Schaubild 5.31: Sanktionen des StGB aufgrund von Diebstabl nach Anzabl der Voreintragungen und Gescblecht*

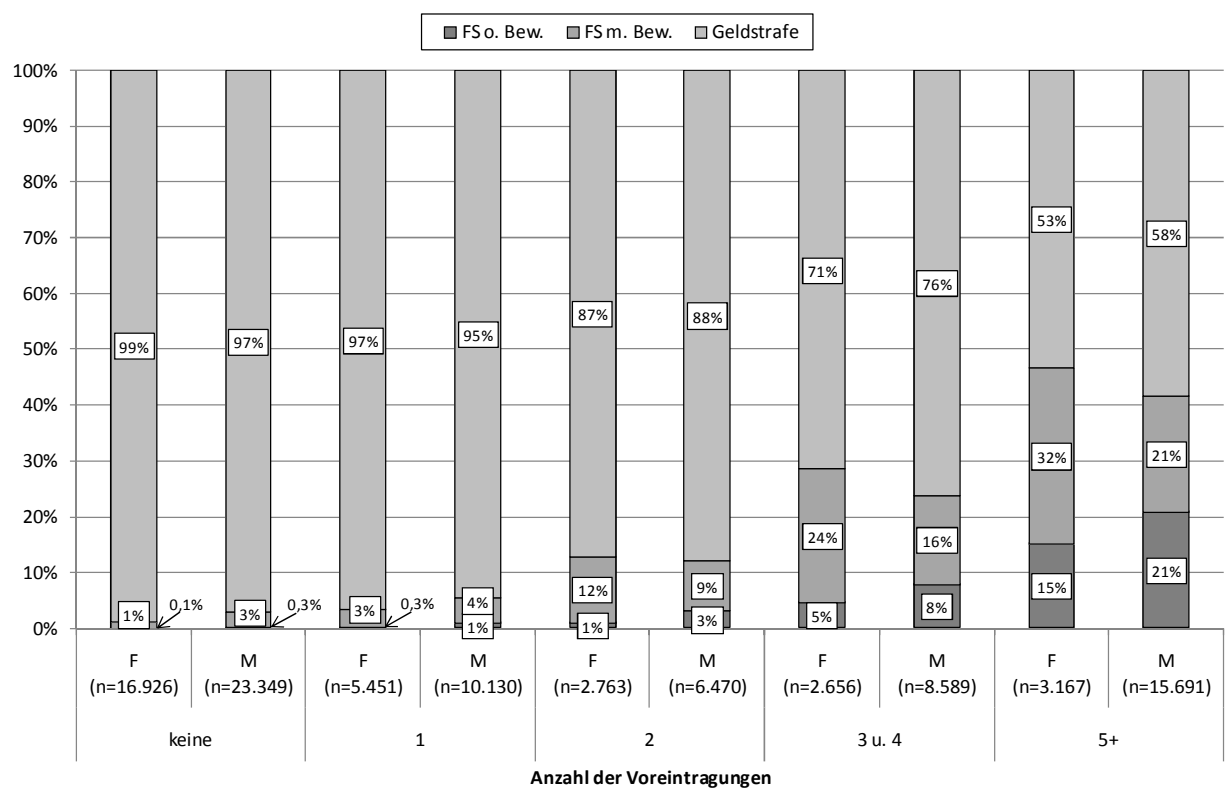

* Absolutzablen siehe Tab. 5.31a im Anbang 
Männer erhalten über alle Kategorien der Voreintragungen hinweg häufiger Freiheitsstrafen ohne Bewährung. Der Unterschied ist bei den Sanktionen nach dem StGB nicht mehr so groß wie bei den Sanktionen nach dem JGG. Die Anteile bei den Frauen nähern sich hier denen der Männer weiter an (vgl. Schaubild 5.31). Auch zeigen sich wieder Unterschiede zu der Sanktionierung für alle Straftaten zusammen (Schaubild 5.14): Der Anteil von Freiheitsstrafen mit Bewährung bei den Frauen ist hier deutlich höher als noch bei Schaubild 5.14 und im Übrigen bei mehreren Voreintragungen auch höher als der jeweilige Anteil bei den Männern: So erhalten Frauen mit zwei Voreintragungen in $12 \%$ der Fälle eine Freiheitsstrafe mit Bewährung, bei den Männern sind es nur $9 \%$. Frauen mit drei bis vier Voreintragungen werden mit $24 \%$ gleichfalls häufiger als Männer mit $16 \%$ zu einer Freiheitstrafe mit Bewährung wegen Diebstahls verurteilt, wohingegen Männer mit $8 \%$ zu $5 \%$ öfter eine Freiheitsstrafe ohne Bewährung erhalten. Auch Frauen mit mindestens fünf Voreintragungen erhalten mit 32\% häufiger eine Freiheitsstrafe mit Bewährung. Bei den Männern sind es lediglich $21 \%$. Schaubild 5.14 zeigte hingegen, dass der Anteil von Freiheitsstrafen mit Bewährung bei den Frauen den der Männer nur bei fünf und mehr Voreintragungen leicht übersteigt. Bei den Anteilen von Freiheitsstrafen ohne Bewährung zeigt sich zwar kaum ein Unterschied zu Schaubild 5.14, bemerkenswert ist allerdings, dass Frauen bei zwei und mehr Voreintragungen häufiger Freiheitsstrafen insgesamt (d.h. bei Addition der Anteile von Freiheitsstrafen mit und ohne Bewährung) erhalten als Männer.

Als nächstes veranschaulicht Schaubild 5.32 die Sanktionierung nach allgemeinem Strafrecht in Abhängigkeit von der Art der schwersten Voreintragung.

Es wird deutlich, dass hier ebenfalls keine mildere Sanktionierung von Frauen zu erkennen ist: Zwar überwiegen die Anteile von Freiheitsstrafen ohne Bewährung als Bezugssanktion bei den Männern nach wie vor die bei den Frauen über alle Arten der Voreintragung hinweg, allerdings ist der Unterschied minimal: So erhalten $11 \%$ der Frauen und $12 \%$ der Männer, mit einer Freiheits- oder Jugendstrafe ohne Bewährung als schwerste Voreintragung, eine stationäre Bezugssanktion. $26 \%$ der Frauen und $28 \%$ der Männer, für die eine Freiheits- oder Jugendstrafe als schwerste Voreintragung registriert ist, haben als Sanktion in der Bezugsentscheidung eine Freiheitsstrafe ohne Bewährung erhalten. Da der Unterschied zwischen den Geschlechtern im Bereich der stationären Strafen diesmal so gering ist, müssten die Männer im Falle einer milderen Sanktionierung der Frauen als Bezugssanktion häufiger Freiheitsstrafen mit Bewährung erhalten. Dies ist jedoch nicht der Fall. Vielmehr werden Frauen bei schwereren Voreintragungen anteilsmäßig häufiger zu einer Bewährungsstrafe verurteilt: Frauen, für die als schwerste Voreintragung eine Freiheits- oder Jugendstrafe mit Bewährung verzeichnet ist, erhalten in $31 \%$ der Fälle eine Freiheitsstrafe mit Bewährung. Bei den Männern sind es in dieser Konstellation hingegen nur $19 \%$, und das, obwohl der Unterschied bei den Freiheitsstrafen ohne Bewährung als Bezugssanktion nur einen Prozentpunkt beträgt. 
Schaubild 5.32: Sanktionen des StGB aufgrund von Diebstabl nach Art der schwersten Voreintragung und Geschlecht*

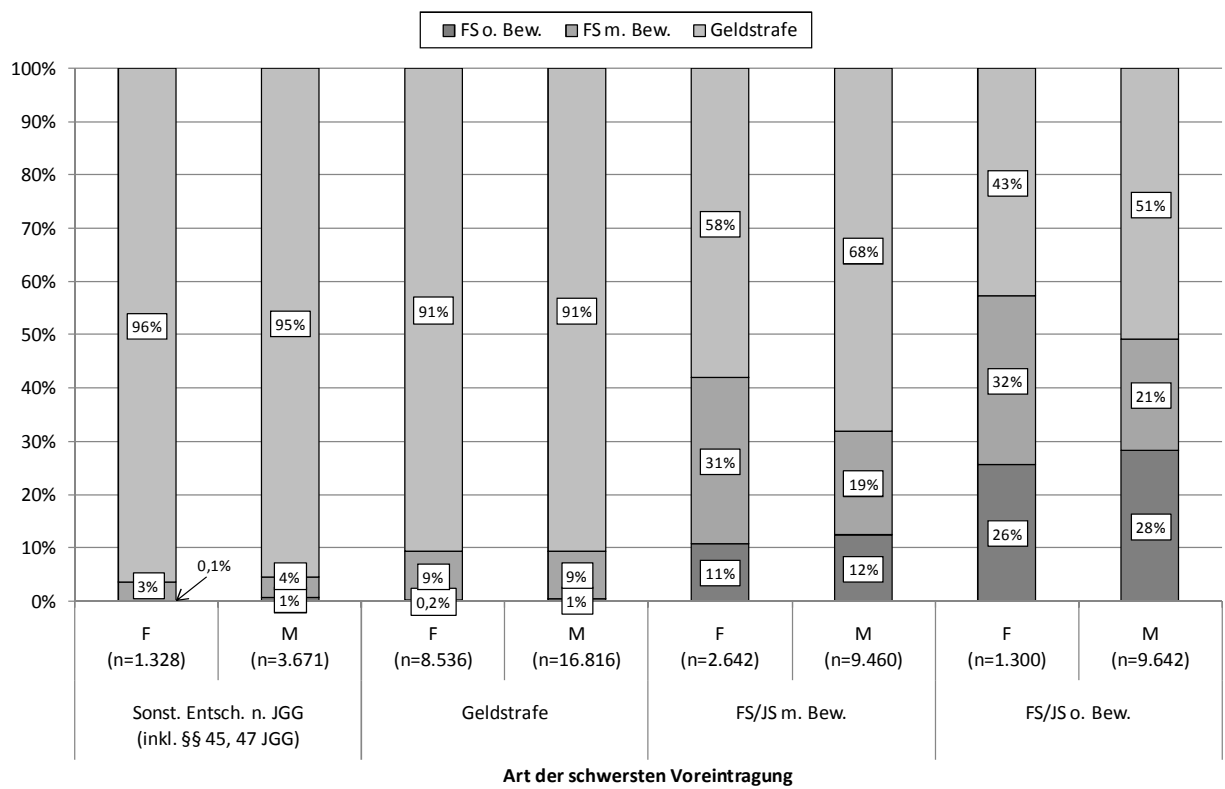

* Absolutrablen siehe Tab. 5.32 a im Anhang

Gleiches ergibt sich bei Betrachtung der Freiheits- oder Jugendstrafe ohne Bewährung als schwerste Voreintragung: Hier sind Frauen in $32 \%$ und Männer lediglich in $21 \%$ der Fälle im Bezugsjahr zu einer Freiheitsstrafe mit Bewährung verurteilt worden. Männer werden in diesen Fällen dafür häufiger mit Geldstrafen sanktioniert als Frauen. Man kann hier also schon von einer milderen Sanktionierung der Männer sprechen. Die schwer interpretierbaren Ergebnisse bezüglich der Bezugssanktionen nach Jugendstrafrecht deuteten auch bereits darauf hin.

Da es sich bei den Diebstählen oftmals um Beschaffungskriminalität Drogenabhängiger handelt, könnte ein Grund für die schärfere Sanktionierung von Frauen die höhere Rate von weiblichen Drogenkonsumenten im Strafvollzug sein. Die Arbeitsgruppe Kriminologischer Dienst des Landes Nordrhein-Westfalen führte im Jahr 1997 in Zusammenarbeit mit den Anstaltsärzten mehrerer Justizvollzugsanstalten eine Untersuchung über ,Drogenerfahrung und Suchtproblematik bei Neuzugängen im Justizvollzug des Landes Nordrhein-Westfalen“ durch. Besonders auffällig war der vergleichsweise hohe Anteil drogenabhängiger Frauen mit knapp $50 \%$ im Vergleich zum Gesamtwert von ca. $33 \%{ }^{744}$ Auch wenn man nur die Gruppe der weiblichen Inhaftierten betrachtet, so zählt ein Großteil der Frau-

744 Wirth, in: BewHi 2002, S. 104-122; Zu beachten ist, dass die Ergebnisse nicht ohne weiteres für Gesamtdeutschland verallgemeinert werden können. 
en zu den Drogengebraucherinnen; ${ }^{745}$ schätzungsweise beträgt der Anteil ca. 75 $\%{ }^{746}$ Für diese Frauen dürfte daher in der Regel keine günstige Legalprognose erfolgen. Schließlich wiesen Kreyssig/Kurth auf eine destruktive Wirkung des Strafvollzugs auf Drogenkonsumentinnen hin. ${ }^{747}$

\subsubsection{Einschlägige Voreintragungen}

Schaubild 5.33 weist nunmehr einschlägige Voreintragungen und deren Einfluss auf die Sanktionierung von Diebinnen und Dieben nach Jugendstrafrecht aus. In der Gruppe der einschlägigen Voreintragungen wird diesmal nur der einfache Diebstahl gem. I 242 StGB berücksichtigt und nicht wie zuvor (vgl. Tab. 5.5) auch die Unterschlagung gem. \246 StGB, um eine rein deliktsspezifische Analyse vornehmen zu können. Die Unterschlagung fällt in die Gruppe der Voreintragungen wegen eines anderen Diebstahldelikts.

\section{Schaubild 5.33: Jugendstrafrechtliche Reaktionen aufgrund von Diebstabl nach Einschlägigkeit der Voreintragungen und Geschlecht*}

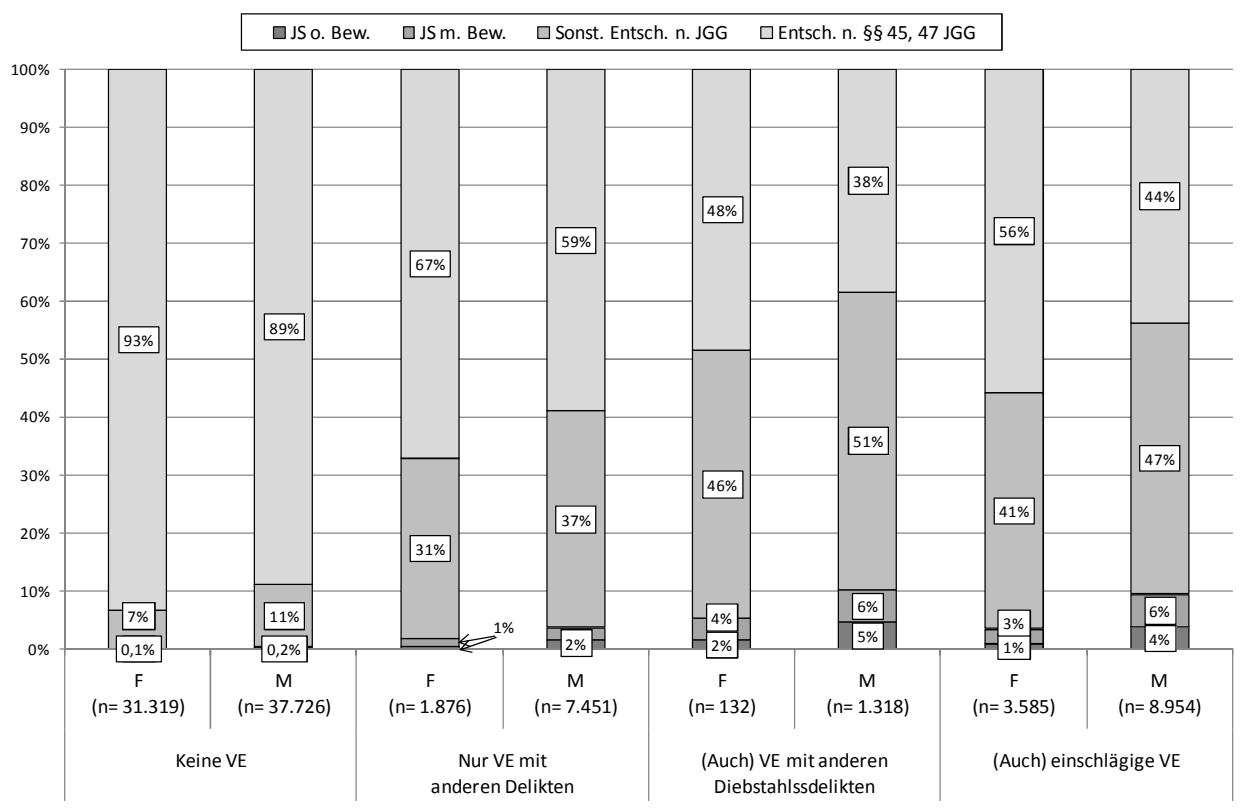

* Absolutzablen siehe Tab. 5.33 a im Anhang

\footnotetext{
745 Zurhold, Kriminalität und Kriminalisierung drogengebrauchender Frauen, S. 93.

746 WHO (Hrsg.), Gesundheit von Frauen im Strafvollzug, 2009, S. 29.

${ }^{747}$ Kreyssig/Kurth, in: Sachverständigenkommission Sechster Jugendbericht (Hrsg.), Alltag und Biographie von Mädchen, 1984, S. 49-102.
} 
Es zeigt sich, dass sich die Einschlägigkeit der Voreintragung auch bei der hier erfolgten deliktsspezifischen Betrachtung eher negativ auf die Sanktionierung von Männern als von Frauen auswirkt. So haben $4 \%$ der männlichen Täter mit einschlägigen Voreintragungen wegen Diebstahls eine Jugendstrafe ohne Bewährung erhalten, bei den Frauen war es lediglich $1 \%$. Auch erhalten Männer in diesem Fall verhältnismäßig häufiger Jugendstrafen mit Bewährung $(6 \%)$ und sonstige Entscheidungen nach dem JGG (47\%). Die gleiche Tendenz ergibt sich bei Betrachtung der Sanktionierung von Frauen und Männern ohne Voreintragungen sowie mit Voreintragungen mit anderen Delikten und anderen Diebstahlsdelikten. Ferner werden beide Geschlechter am häufigsten bei Voreintragungen wegen eines anderen Diebstahldelikts zu einer Jugendstrafe ohne Bewährung verurteilt. Dies dürfte damit zusammenhängen, dass in dieser Gruppe die schwerwiegende-

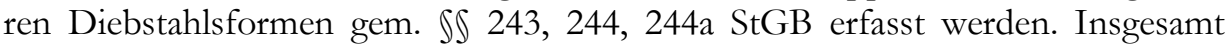
bestehen keine großen Unterschiede zu den Ergebnissen der Betrachtung sämtlicher Delikte (vgl. Schaubild 5.20).

Schaubild 5.34 verdeutlicht den Zusammenhang zwischen der Einschlägigkeit der Voreintragungen und den Bezugssanktionen nach dem StGB für beide Geschlechter im Vergleich.

Schaubild 5.34: Sanktionen des StGB aufgrund von Diebstabl nach Einschlägigkeit der Voreintragungen und Geschlecht*

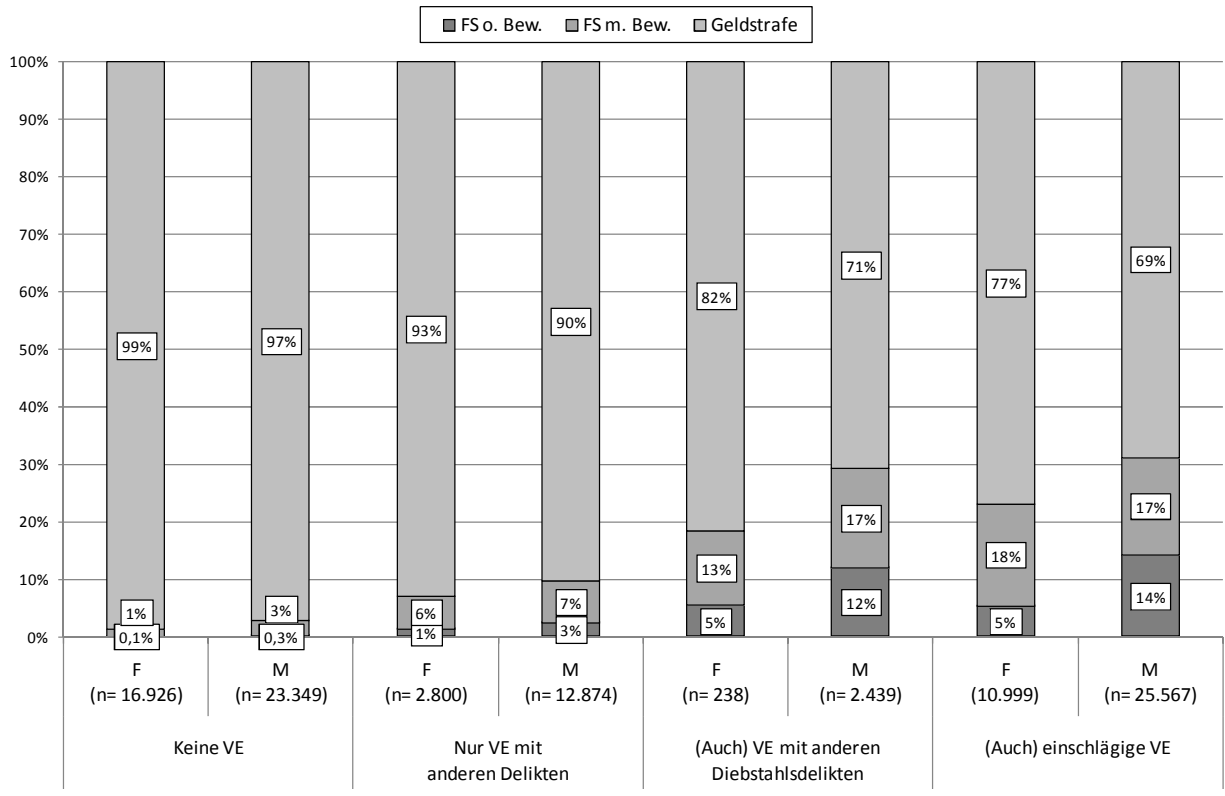

* Absolutzablen siebe Tab. 5.34a im Anhang 
Erwartungsgemäß ist der Einfluss der Einschlägigkeit auf die Sanktionen nach allgemeinem Strafrecht für beide Geschlechter größer als auf die zuvor dargestellten jugendstrafrechtlichen Reaktionen. Hier führen einschlägige Voreintragungen allerdings häufiger zu Freiheitsstrafen als Voreintragungen mit anderen Diebstahlsdelikten. Insgesamt führt die deliktsspezifische Betrachtung jedoch zu keinen anderen Ergebnissen als sie bereits für Schaubild 5.21 festgestellt wurden, sodass auf die Ausführungen an dieser Stelle verwiesen wird.

Die zugrundeliegenden absoluten Zahlen machen im Übrigen sowohl für die Sanktionen nach Jugendstrafrecht als auch für die nach allgemeinem Strafrecht für beide Geschlechter deutlich, dass Diebe viel häufiger Voreintragungen wegen desselben Delikts, als Voreintragungen wegen eines anderen Diebstahldelikts aufweisen.

\subsubsection{Multifaktorielle Analyse}

Die deliktsspezifische Betrachtung für den einfachen Diebstahl hat anfangs ergeben, dass grundsätzlich immer noch eine leichte Tendenz zur milderen Behandlung von Frauen erkennbar ist. Allerdings ist der Unterschied nicht mehr so ausgeprägt wie bei der Betrachtung aller Straftaten zusammen. Nach Hinzunahme der Anzahl und Art der Voreintragungen war eine mildere Sanktionierung von Frauen nicht mehr zu erkennen. Bei Berücksichtigung der Art der schwersten Voreintragung zeigte sich sogar eine „härtere“ Sanktionierung von Frauen, für die als Voreintragung eine Freiheits- und Jugendstrafen ohne Bewährung registriert wurde. Auch bei Freiheits- und Jugendstrafen mit Bewährung als schwerste Voreintragung übersteigt der kumulierte Anteil von Freiheitsstrafen mit und ohne Bewährung bei den Frauen den Anteil bei den Männern. Gleiches konnte für den Anteil von Freiheitsstrafen in Abhängigkeit von mehr als zwei Voreintragungen festgestellt werden. Doch im Verlauf der bisherigen Analyse wurde die Sanktionierung jeweils nur in Abhängigkeit von bis zu drei ausgewählten Merkmalen untersucht. Es ist anzunehmen, dass zwischen mehreren Merkmalen Abhängigkeiten bestehen, deshalb wird im Folgenden eine multifaktorielle Analyse ${ }^{78}$ durchgeführt. Hierzu werden so viele Variablen wie möglich simultan berücksichtigt. Da sich die Datenbasis dadurch sehr stark reduziert, bietet sich dieses Verfahren für den einfachen Diebstahl gut an, denn dieser wird, wie bereits festgestellt, auch von Frauen verhältnismäßig häufig begangen.

$\mathrm{Zu}$ diesem Zweck wird analysiert, wie sich die Sanktionierung von Frauen und Männern beim Diebstahl nur unter Berücksichtigung von deutschen Erwachsenen, die mindestens fünf Voreintragungen aufweisen, von denen mindestens eine

\footnotetext{
748 Von der Durchführung einer logistischen Regression wurde hier abgesehen, da etliche Merkmale, die Einfluss auf die Strafzumessung haben, nicht erhoben werden können. Eine logistische Regression hätte daher nur eine geringe Varianzaufklärung und keine größere Aussagekraft als die vorliegend gewählte Methode.
} 
einschlägig ist und mindestens eine entweder eine Jugend-/Freiheitsstrafe ohne Bewährung oder eine Jugend-/Freiheitsstrafe mit Bewährung ist, darstellt.

Schaubild 5.35: Sanktionen des StGB aufgrund von Diebstabl unter Berücksichtigung multipler Faktoren nach Geschlecht*

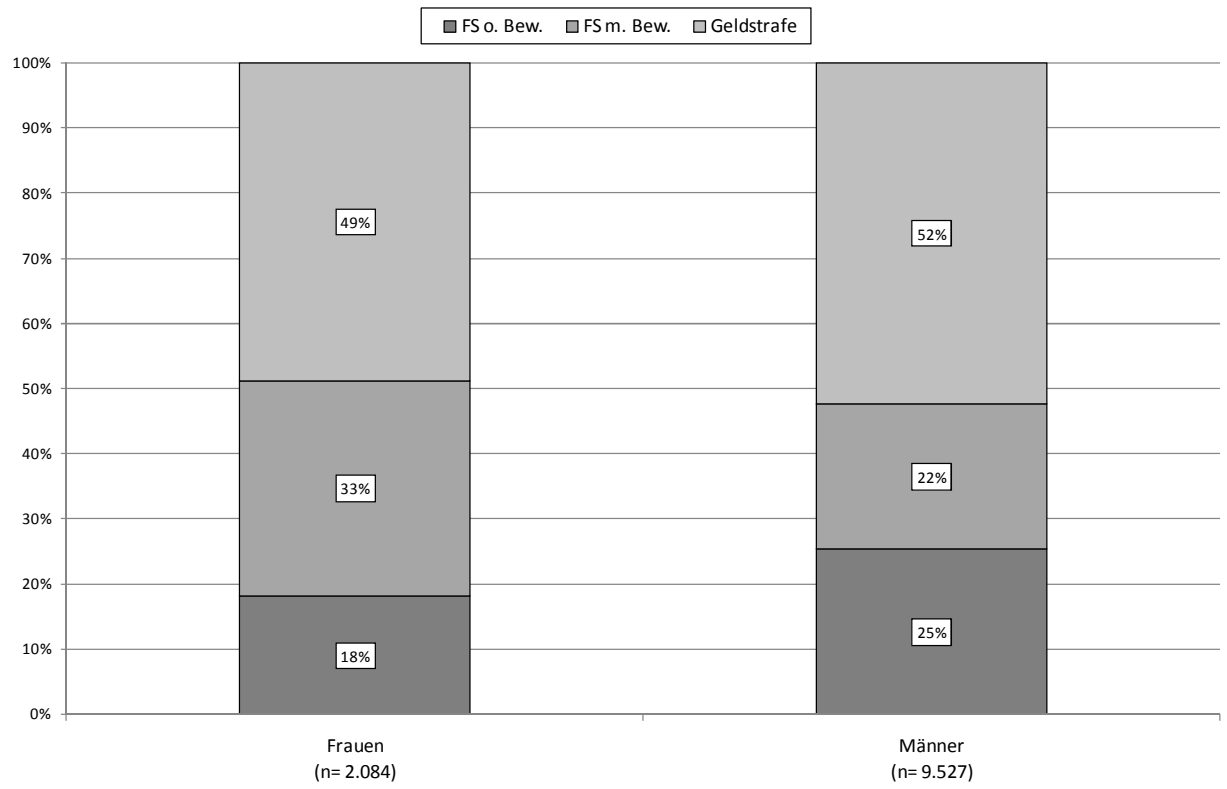

* Absolutzablen siehe Tab. 5.35 a im Anhang

Schaubild 5.35 gibt das Ergebnis der multifaktoriellen Analyse wieder: Zwar werden die hier betrachteten Männer mit $25 \%$ immer noch häufiger zu einer Freiheitsstrafe ohne Bewährung verurteilt als die betrachteten Frauen mit 18 \%. Vergleicht man dieses Ergebnis allerdings mit den Anteilen, die sich aus Schaubild 5.24 ergeben haben, so stellt man fest, dass der Anteil bei den Männern hier nicht länger dreimal so groß ist. Die Frauen erhalten nunmehr sogar verhältnismäßig häufiger Freiheitsstrafen insgesamt als Bezugssanktion: Addiert man die Anteile von Freiheitsstrafen mit und ohne Bewährung, so machen diese beiden Sanktionen knapp über $50 \%$ der im Bezugsjahr für die nach den oben genannten Kriterien ermittelten verurteilten Frauen aus. Bei den Männern sind es hingegen knapp unter $50 \%$. Folglich ist eine Tendenz zur milderen Sanktionierung von Frauen nicht auszumachen. Frauen erhalten aber selbst bei dieser ausgelesenen Gruppe häufiger Bewährungsstrafen, was auf eine positivere Legalprognose zurückzuführen ist (vgl. \56 StGB). Es darf nicht außer Acht gelassen werden, dass die Entscheidung über die Aussetzung einer Freiheits- oder Jugendstrafe zur Bewährung das Ergebnis einer Gesamtwürdigung der Täterpersönlichkeit und der Tatumstän- 
de ist, sodass auch viele andere Faktoren, wie beispielsweise die Lebensverhältnisse der Täter und Täterinnen im Hinblick auf die Familie, eine gewichtige Rolle spielen. Die Annahme eines Frauenbonus bei der Sanktionierung durch die Gerichte ist daher in diesen Fällen nicht plausibel. Zu bedenken ist ferner, dass weitere wichtige Faktoren, die für die Strafzumessung eine Rolle spielen, nicht berücksichtigt werden können. Einige Studien weisen darauf hin, dass bei den Diebinnen der verursachte Schaden in der Regel weniger hoch ist ${ }^{749}$ als bei den Dieben. Ferner seien Frauen beim Diebstahl geständnisbereiter als Männer, ${ }^{750}$ um nur einige wenige strafzumessungsrelevante Faktoren zu benennen. Fraglich ist allerdings, ob eine etwaige geringere Schadenshöhe oder größere Geständnisbereitschaft auch noch bei den vorliegend untersuchten Täterinnen gegeben ist. Da nur solche mit mindestens fünf u.a. einschlägigen Voreintragungen, wovon mindestens eine mit Freiheits- oder Jugendstrafe mit oder ohne Bewährung bestraft wurde, untersucht wurden, liegt der Fokus auf Frauen mit gesteigertem kriminellem Potenzial.

\subsection{Sanktionierung bei Betrug gem. \263 StGB}

Für Betrug wurden im Bezugsjahr insgesamt 97.493 Entscheidungen registriert; davon entfallen ca. 2/3 (66.215) auf männliche und 1/3 (31.278) ${ }^{751}$ auf weibliche Personen. Folglich werden Männer zwar häufiger wegen Betrugs verurteilt als Frauen, betrachtet man jedoch die Gruppe der Frauen an sich, so macht der Betrug über $14 \%$ der weiblichen Gesamtkriminalität aus und ist mithin nach dem einfachen Diebstahl das von Frauen am zweithäufigsten begangene Delikt. Daher wird die Sanktionierung des Betrugs ebenfalls einer genaueren Betrachtung unterzogen. Um Wiederholungen zu vermeiden, soll jedoch ein Schwerpunkt auf der Betrachtung von Unterschieden zu den vorab bereits gewonnenen Ergebnissen liegen. Soweit sich keine wesentlichen Veränderungen ergeben wird daher auf eine graphische Darstellung verzichtet. ${ }^{752}$

Informationen über die Erscheinungsform des Betrugs oder die Schadenshöhe sind leider auch hier den Daten nicht zu entnehmen. Möglich ist eine Schwereeinteilung dieses Delikts anhand der Verwirklichung des Regelbeispiels gem. Absatz 3 oder der Qualifikation gem. Absatz 5. Allerdings ergibt die Auswertung, dass ca. 2/3 der Fälle des $₫ 263$ StGB den Absatz 1 betreffen. Auch das restliche Drittel beinhaltet keine Fälle der Absätze 3 und 5. Die übrigen Fälle können vielmehr nicht zugeordnet werden, da kein Absatz eingetragen wurde. Hier kann nur vermutet werden, dass dies zumeist auch Fälle des $\int 263$ Abs. 1 StGB sind, bei denen

\footnotetext{
${ }^{749}$ Vgl. beispielsweise Albrecht (Fn. 66), S. 346.

750 Steffen (Fn. 599); Blankenburg/Sessar/Steffen (Fn. 607); Zu einem anderen Ergebnis ist Legnaro gekommen: Er stellte zwar eine größere Geständnisbereitschaft von Frauen fest, diese wirkte sich jedoch kaum entlastend aus, vgl. Legnaro, in: ZfRSoz 1987, S. 231, 238 ff.

$751 \mathrm{Zu}$ den Absolutzahlen vgl. Tab. 4.1c im Anhang.

752 Die Absolutzahlen sind allerdings im Anhang abgebildet.
} 
der Absatz nicht gemeldet wurde. ${ }^{753} \mathrm{Da}$ sich den Daten leider keine weiteren Informationen entnehmen lassen, müssen andere Quellen herangezogen werden.

Schulte 754 analysierte die Betrugskriminalität von 180 Heranwachsenden anhand von Akten des Landgerichtsbezirks Mannheim aus den Jahren 1960 und 1961. Er nannte in seiner Untersuchung den Berechtigungsbetrug (Fälle in denen der Täter zur Erlangung des erstrebten Vorteils über eine Berechtigung täuscht, die ihm nicht oder nicht in der vorgespiegelten Weise zusteht) als dominierende Erscheinungsform des Betrugs bei den Frauen. Der Berechtigungsbetrug entspreche der weiblichen Eigenart; die von einer Frau vorgetragene Hilfsbedürftigkeit finde eher Anklang, als wenn sie von einem männlichen Täter vorgebracht werden würde. Einen kleinen Anteil hatten die weiblichen Täter auch am Gegenleistungsbetrug (Fälle, in denen der Täter für eine Leistung eine gleichwertige Gegenleistung verspricht, aber von vorneherein nicht beabsichtigt, diese Gegenleistung zu erbringen) in Form des Abzahlungskaufs, wobei es hier nicht wie bei den männlichen Tätern zu einer Weiterveräußerung kam. ${ }^{755}$

Auch Einsele 756 und Cremer ${ }^{757}$ kamen in ihren Untersuchungen zu dem Ergebnis, dass ein Schwerpunkt weiblicher Betrugskriminalität beim Abzahlungsbetrug liegt. ${ }^{758}$

$H_{a a g}{ }^{759}$ stellte auf der Grundlage einer Literaturrecherche fest, dass die weiblichen Betrugsaktivitäten in einem engen Zusammenhang mit ihrem eher häuslichen Wirkungskreis, beispielsweise Mitleidsschwindel (Vorspiegeln von Hilfsbedürftigkeit), liegen. ${ }^{760}$ Auch nach Zirpins ${ }^{761}$ fallen Frauen häufig durch Schwindel auf, indem sie versuchen beim Opfer Mitleid zu erregen..$^{762}$

Die Untersuchungen sind allerdings vor dem Hintergrund ihrer zeitlichen Entstehung zu betrachten. Die aufgeführten Aussagen machen deutlich, dass zumeist noch ein antiquiertes Geschlechtsrollenbild vorherrschte, sodass die Interpretation der Ergebnisse in der Form nicht mehr auf die heutige Zeit anwendbar ist.

Neuere Erkenntnisse bieten die Daten der PKS, die bei einzelnen Delikten, u.a. beim Betrug, weitere Differenzierungen nach Art der Begehung aus kriminologischen Gesichtspunkten zulassen. Die aktuellsten Zahlen aus dem Jahr 2009 zeigen, dass Frauen in erster Linie Waren- und Warenkreditbetrug (32\%) (63 $^{76}$ bege-

\footnotetext{
${ }^{753}$ Lediglich für 19 dieser Fälle ist ein Versuch gem. \263 Abs. 2 StGB eingetragen; vgl. zu den Schwierigkeiten fehlerhafter Eintragungen Kap. 3, 3.3.

754 Schulte, Betrugskriminalität Heranwachsender, 1967.

755 Schulte, S. 138.

756 Einsele, in: MschrKrim 1986, S. 28-79.

757 Cremer, Untersuchungen zur Kriminalität der Frau, 1972.

758 Einsele, in: MschrKrim, 1986, S. 28, 39; Cremer, S. 98 ff.

759 Haag, Betrügerische Hochstapelei und Schwindel, 1977.

${ }^{760}$ Haag, S. 142 f.

761 Zirpins, Der Betrug, in: Sieverts (Hrsg.), HwbKrim, Bd. 1, S. 81-95.

762 Zirpins, in Sieverts (Hrsg.), HwbKrim, Bd. 1, S. 81, 90.

763 Vgl. BKA (Hrsg.), PKS 2009, Tab. 20 im Anhang.
} 
hen. Auch im Jahr 2004, dem Bezugsjahr der vorliegenden Untersuchung, machte diese Kategorie mit $24 \% \%^{764}$ den Hauptanteil der Betrugstaten von Frauen aus.

Betrachtet man die weibliche Betrugskriminalität nach den Daten der PKS wieder im Vergleich zur männlichen, so stellt man fest, dass Frauen mit $42 \%$ (2009) bzw. $29 \%$ (2004) beim Betrug zum Nachteil von Sozialversicherungsnehmern sowie mit $46 \%$ (2009) bzw. $43 \%(2004)^{765}$ beim sonstigen Sozialleistungsbetrug annähernd so häufig tatverdächtig sind wie die Männer.

\subsubsection{Sanktionierung nach Jugendstrafrecht}

Bei der Sanktionierung nach Jugendstrafrecht für das Delikt Betrug zeigt sich wieder, dass sowohl bei Frauen als auch bei Männer die Einstellung nach den $\$ ₫ 45,47$ JGG als jugendstrafrechtlichen Reaktionen überwiegen; bei weiblichen Tätern sind sie mit $76 \%$ etwas häufiger als bei den männlichen mit ca. $71 \%$. Männer werden dagegen häufiger zu Erziehungsmaßregeln und Zuchtmitteln sowie zu Jugendstrafen mit und ohne Bewährung verurteilt. Auffällig ist, dass beim Betrug der Unterschied zwischen den Geschlechtern beim Anteil der Entscheidungen nach $\int \$ 45,47$ JGG sowie der sonstigen Entscheidungen nach JGG geringer ausgeprägt ist als beim Diebstahl. Dort beträgt der Unterschied der Anteile bei $\$ \int 45,47$ JGG noch zwölf Prozentpunkte, hier sind es nur noch fünf Prozentpunkte. Bei den sonstigen Entscheidungen nach JGG ist die Differenz von neun auf einen Prozentpunkt geschrumpft.766

Eine genauere Betrachtung der Aussetzungsquoten für die Jugendstrafen bestätigt das bereits für den Diebstahl (vgl. Schaubild 5.23) und die sich auf alle Delikte beziehende Auswertung (vgl. Schaubild 5.4) gewonnene Bild: Gegenüber Betrügerinnen erfolgt eher eine Aussetzung zur Bewährung als gegenüber Betrügern.767

\subsubsection{Sanktionierung nach allgemeinem Strafrecht}

Die Analyse der Sanktionierung aufgrund von Betrug zeigt erneut, dass Männer häufiger Freiheitsstrafen und Frauen im Vergleich zu den Männern häufiger Geldstrafen erhalten: Weibliche Täter erhalten eine Geldstrafe in $89 \%$ der Fälle, männliche Täter hingegen in lediglich $84 \%$. Männer werden in $13 \%$ der Fälle zu einer Freiheitsstrafe mit und in $4 \%$ zu einer solchen ohne Bewährung verurteilt, während die entsprechenden Quoten bei den Frauen nur $10 \%$ bzw. $1 \%$ betragen. ${ }^{768}$

Bei Betrachtung der Aussetzungsquoten ist erwähnenswert, dass bei Frauen, die als Sanktion in der Bezugsentscheidung eine Freiheitsstrafe von sechs Mona-

\footnotetext{
764 Vgl. BKA (Hrsg.), PKS 2004, Tab. 20 im Anhang.

765 Vgl. BKA (Hrsg.), PKS des jeweiligen Jahrgangs, Tab. 168.

766 Siehe zu den Ergebnissen Tab. 5.36a im Anhang.

767 Siehe zu den Ergebnissen Tab. 5.37a im Anhang; im Folgenden werden mit den Begriffen Betrüger bzw. Betrügerin die Täter bzw. Täterinnen eines Betrugs gem. \263 StGB bezeichnet.

768 Siehe zu den Ergebnissen Tab. 5.38 im Anhang.
} 
ten bis zu einem Jahr aufgrund von Betrug erhalten haben, mit $81 \%$ in etwa gleich oft eine Aussetzung zur Bewährung erfolgt wie bei Männern mit $82 \%$. Ansonsten unterscheiden sich die Ergebnisse in der Tendenz nicht von den für den Diebstahl (vgl. Schaubild 5.25) und für alle Delikte (vgl. Schaubild 5.8) bereits dargestellten Ergebnissen. ${ }^{769}$

Eine genauere Analyse der Sanktionsgruppe Geldstrafe macht deutlich, dass Frauen zwar auch beim Betrug häufiger eine niedrigere Anzahl von Tagessätzen erhalten: So werden sie häufiger zu 1-30 und seltener zu 31 bis über 90 Tagessätzen verurteilt. Insgesamt ist jedoch bezüglich der Höhe von Geldstrafen nur eine leichte Tendenz zur milderen Behandlung erkennbar. Die Unterschiede sind hier noch weniger ausgeprägt als beim Diebstahl: $6 \%$ der Frauen und $8 \%$ der Männer erhalten über 90 Tagessätze. Bei 51-90 Tagessätzen stehen sich Anteile von $23 \%$ (Frauen) zu $25 \%$ (Männer), bei 31-50 Tagessätzen $22 \%$ (Frauen) zu 23 \% (Männer) gegenüber. $36 \%$ der Frauen und $34 \%$ der Männer werden zu 16-30 und $13 \%$ der Frauen sowie $10 \%$ der Männer zu 1-15 Tagessätzen verurteilt.. ${ }^{70}$

\subsubsection{Sanktionierung und Voreintragungen}

\subsubsection{Anzahl und Art der schwersten Voreintragungen}

Die Belastung mit Voreintragungen stellt sich so dar wie in der Gesamtstichprobe und wie beim Diebstahl: Männliche Täter sind häufiger vorbestraft als weibliche und weisen auch häufiger schwerere Voreintragungen auf. 771

\subsubsection{Sanktionierung nach Jugendstrafrecht und Voreintragungen}

Betrachtet man die Anzahl der Voreintragungen im Zusammenhang mit der Sanktionierung nach dem JGG, so stellt man zunächst wieder fest, dass die Sanktionsschwere grundsätzlich mit steigender Anzahl der Voreintragungen zunimmt. Bei den Frauen sinkt der Anteil von Verurteilungen zu Jugendstrafen ohne Bewährung allerdings von $2 \%$, bei den Frauen mit drei bis vier Voreintragungen, auf $0 \%$, bei den Frauen mit fünf und mehr Voreintragungen. Hierbei ist zu beachten, dass die Gruppe der Betrügerinnen mit fünf und mehr Voreintragungen mit insgesamt 43 Personen sehr klein ist und die Ergebnisse daher auf Zufall beruhen dürften. Insgesamt sind die Unterschiede zwischen den Geschlechtern wieder etwas größer als beim Diebstahl (vgl. Schaubild 5.29), sodass eher eine Vergleichbarkeit mit den Ergebnissen zur nicht deliktsdifferenzierenden Gesamtstichprobe besteht (vgl. Schaubild 5.12). ${ }^{772}$

Die Ergebnisse zu der Art der schwersten Voreintragung im Zusammenhang mit den Bezugssanktionen nach JGG lassen sich für den Betrug nicht mehr inter-

\footnotetext{
${ }^{769}$ Siehe zu den Ergebnissen Tab. 5.39a im Anhang.

770 Siehe zu den Ergebnissen Tab. 5.40a im Anhang.

771 Siehe zu den Ergebnissen Tab. 5.41a, 5.42a im Anhang.

772 Siehe zu den Ergebnissen Tab. 5.43a im Anhang.
} 
pretieren: Nur fünf Betrügerinnen, die eine Sanktion nach dem JGG erhalten haben, weisen für das Bezugsjahr 2004 als schwerste Voreintragung eine Freiheitsoder Jugendstrafe ohne Bewährung auf. Auch bei einer ausgesetzten Freiheitsoder Jugendstrafe als schwerste Voreintragung beträgt die Anzahl der Frauen nur 14, sodass auf den Zusammenhang zwischen der Art der schwersten Voreintragung und der Bezugsentscheidung nach JGG im Geschlechtervergleich nicht weiter eingegangen wird. ${ }^{773}$

\subsubsection{Sanktionierung nach allgemeinem Strafrecht und Voreintragungen}

Für die Sanktionen in der Bezugsentscheidung nach allgemeinem Strafrecht besteht jedoch wieder eine solide Datenbasis. Betrachtet man diese zunächst in Abhängigkeit von der Anzahl der Voreintragungen für beide Geschlechter, so zeigt sich eine etwas andere Verteilung als beim Delikt Diebstahl (vgl. Schaubild 5.31), die sich nachfolgend aus Schaubild 5.36 ergibt.

Sowohl für Frauen als auch für Männer nimmt mit steigender Anzahl der Voreintragungen die Schwere der Bezugssanktion zu. Eine Tendenz zu einer milderen

\section{Schaubild 5.36: Sanktionen des StGB aufgrund von Betrug nach Anzabl der Voreintragungen und Geschlecht*}

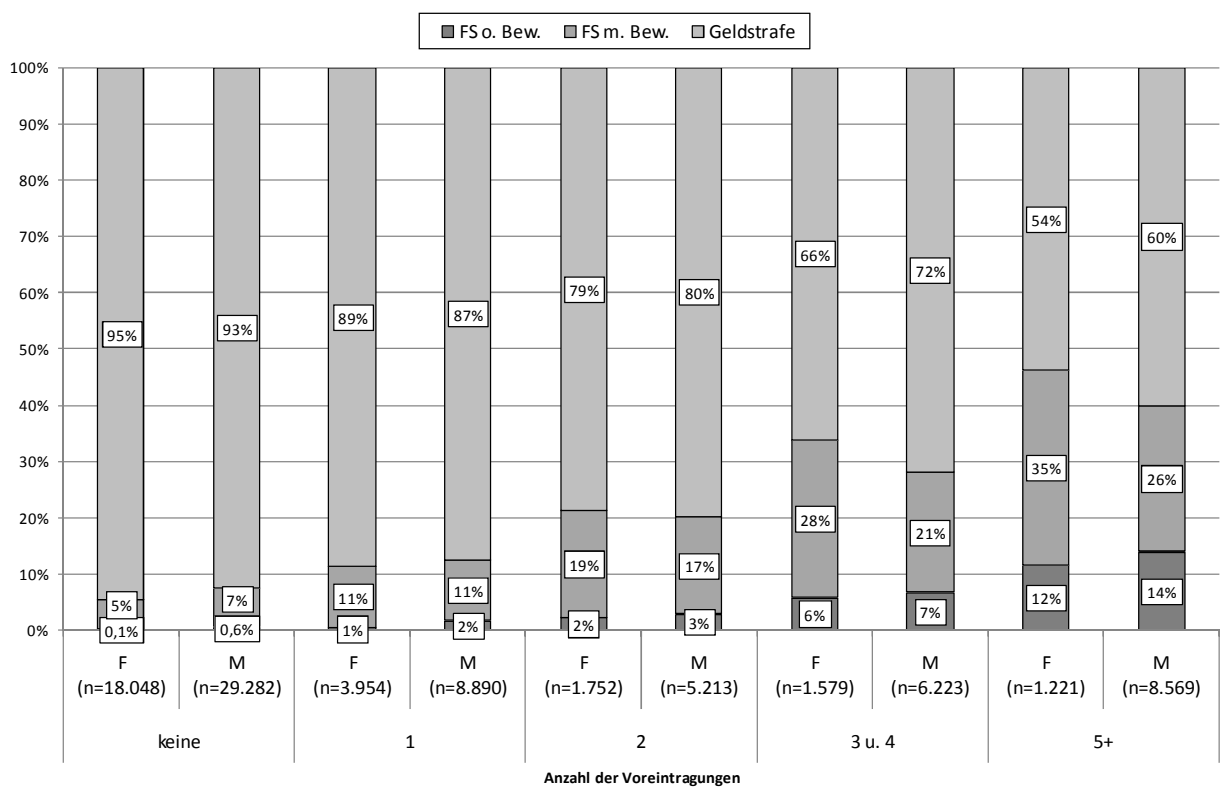

* Absolutzablen siehe Tab. 5.45a im Anhang

${ }^{773}$ Siehe zu den Ergebnissen Tab. 5.44a im Anhang. 
Behandlung von Frauen ist nicht erkennbar. Für die Frauen ist in fast allen Gruppen ein höherer Anteil von Freiheitsstrafen mit Bewährung sowie der Gesamtzahl der Freiheitsstrafen zu verzeichnen. Lediglich bei den Personen mit nur einer Voreintragung ist der Anteil von Verurteilungen zu Freiheitsstrafe mit Bewährung bei Frauen und Männern mit 11 \% gleich groß. Im Falle einer milderen Sanktionierung von Frauen müssten die Anteile von Freiheitsstrafen ohne Bewährung bei den Männern entsprechend höher sein. Dies ist jedoch nicht der Fall. Der Anteil von Freiheitsstrafen ohne Bewährung ist zwar bei den Männern über alle Kategorien höher als bei den Frauen, die Differenz beträgt jedoch lediglich bis zu einem Prozentpunkt und bei den Personen mit fünf und mehr Voreintragungen zwei Prozentpunkte. Im Gegensatz dazu übersteigt der Anteil von Freiheitsstrafen mit Bewährung bei den Frauen den bei den Männern um bis zu neun Prozentpunkte

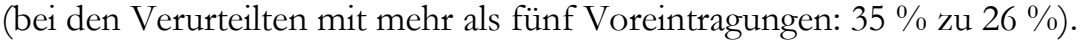

Betrachtet man die Bezugssanktionen nach dem StGB nach Art der schwersten Voreintragung für beide Geschlechter im Vergleich, so lassen sich auch hier keine Anhaltspunkte für einen Frauenbonus bei der Sanktionierung nach Betrugsdelikten erkennen.

\section{Schaubild 5.37: Sanktionen des StGB aufgrund von Betrug nach Art der schwersten Vorein- tragung und Geschlecht*}

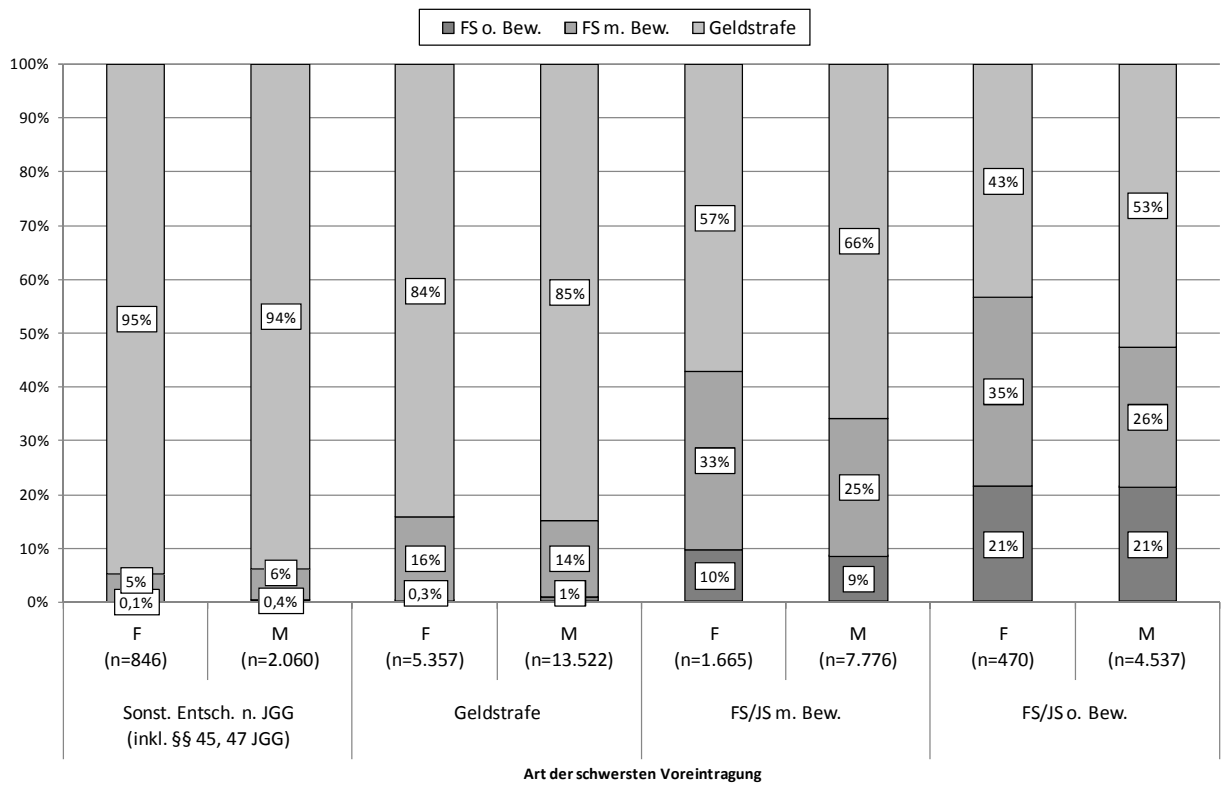

* Absolutzablen siehe Tab. 5.46 a im Anhang 
Mit Ausnahme der Personen, die als Voreintragungen lediglich Entscheidung nach den $\iint 45,47 \mathrm{JGG}$ erhalten haben, ist der Anteil der ausgesetzten Freiheitsstrafen bei den Frauen wieder höher als bei den Männern. Darüber hinaus erhalten Frauen, die als schwerste Voreintragung eine Freiheits- oder Jugendstrafe mit Bewährung erhalten haben, mit 10\% sogar anteilsmäßig häufiger Freiheitsstrafen ohne Bewährung als Männer mit $9 \%$. War die schwerste Voreintragung eine stationäre Sanktion, so haben jeweils $21 \%$ der verurteilten Frauen und Männer eine Freiheitsstrafe ohne Bewährung als Bezugssanktion erhalten. 35\% der Frauen und $26 \%$ der Männer wurden in diesem Fall zu einer Freiheitstrafe mit Bewährung verurteilt.

Betrügerinnen mit vielen oder schweren Voreintragungen werden folglich nicht nachsichtiger sanktioniert. Eher das Gegenteil scheint der Fall zu sein.

\subsubsection{Einschlägige Voreintragungen}

Die Analyse des Einflusses der Einschlägigkeit der Voreintragungen ergibt, dass das Vorhandensein einer einschlägigen Voreintragung oder einer Voreintragung wegen eines anderen Täuschungsdelikts, entsprechend den Ergebnissen beim Diebstahl, für beide Geschlechter zu schärferen Sanktionen führt.

Schaubild 5.38: Jugendstrafrechtliche Reaktionen aufgrund von Betrug nach Einschlägigkeit der Voreintragungen und Geschlecht*

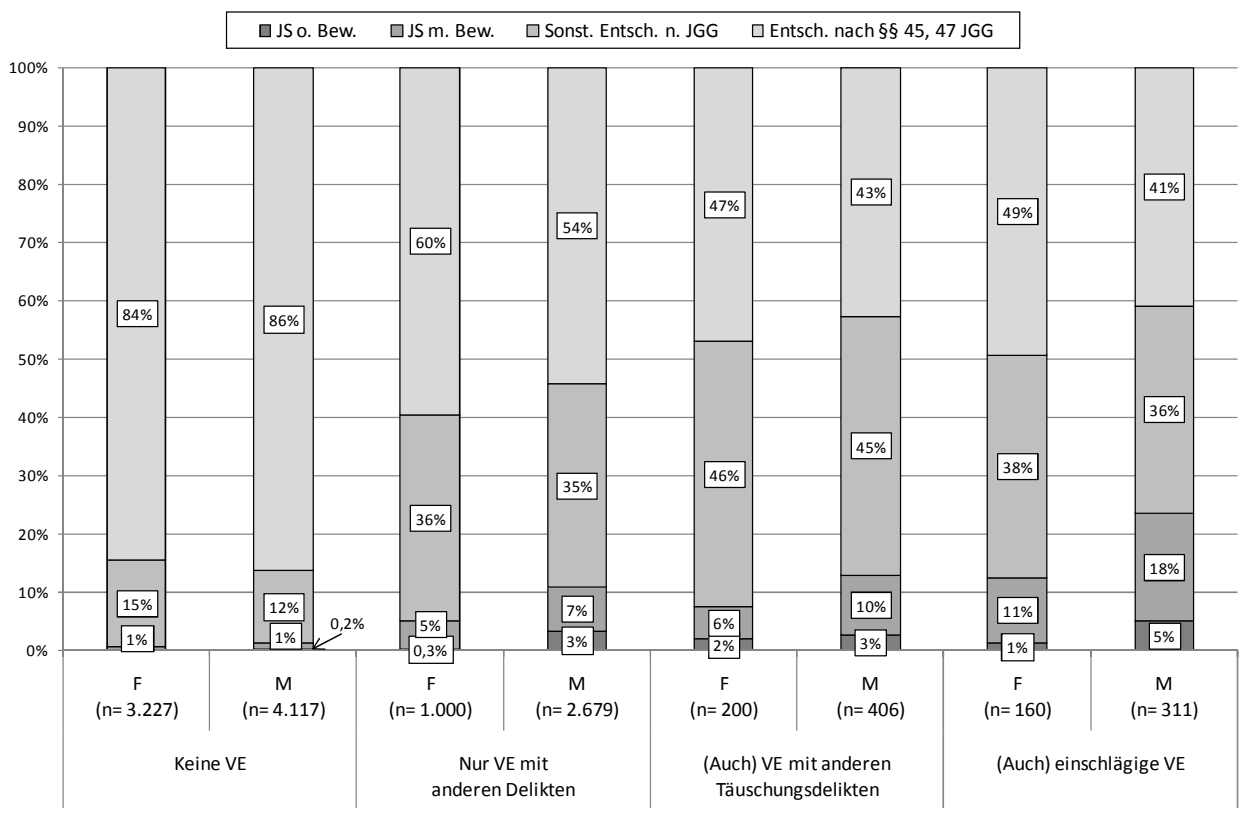

* Absolutzablen siehe Tab. 5.47 a im Anhang 
In der Gruppe der einschlägigen Voreintragungen wird diesmal nur der einfache Betrug gem. \263 StGB berücksichtigt und nicht wie zuvor (vgl. Tabelle 5.5) auch Untreue und Urkundendelikte. ${ }^{774}$ Diese Delikte werden nunmehr in die Gruppe der Voreintragungen wegen eines anderen Täuschungsdelikts erfasst, um eine rein deliktsspezifische Analyse zu ermöglichen. Der Anteil von Jugendstrafen ohne Bewährung ist bei den Männern in allen Gruppen (keine Voreintragung, nur Voreintragungen mit anderen Delikten, auch Voreintragungen mit anderen Täuschungsdelikten sowie auch einschlägige Voreintragungen) größer als der Anteil bei den Frauen. Es ergeben sich jedoch auch einige Unterschiede zum Diebstahl: Männer erhalten hier am häufigsten eine Jugendstrafe ohne Bewährung, wenn für sie eine einschlägige Voreintragung registriert ist. Bei den Frauen ist der Anteil von Jugendstrafen ohne Bewährung, wie beim Diebstahl, bei Voreintragungen mit anderen Täuschungsdelikten größer als bei einschlägigen Voreintragungen. Hingegen führt die Einschlägigkeit einer Voreintragung bei Betrügerinnen häufiger zu einer Jugendstrafe mit Bewährung als bei den Diebinnen. Dies könnte damit zusammenhängen, dass es sich bei den einfachen Diebstählen noch häufiger als beim einfachen Betrug um Bagatelldelikte mit niedrigem Schaden handelt. Laut PKS für das Berichtsjahr 2004, waren ein Drittel der Diebstähle Ladendiebstähle. Von den registrierten Ladendiebstählen betrug die Schadenshöhe in ca. der Hälfte der Fälle unter $15 €$. $^{775}$

Auch bei den Bezugssanktionen nach allgemeinem Strafrecht ist der Anteil von Freiheitsstrafen ohne Bewährung bei den Männern in allen Gruppen mindestens doppelt so groß (vgl. Schaubild 5.39). Wie beim Diebstahl führt das Vorhandensein einschlägiger Voreintragungen bei Männern häufiger zu einer Verurteilung zu unbedingter Freiheitsstrafe. Die Differenz ist beim Betrug jedoch weniger ausgeprägt. Die Einschlägigkeit der Voreintragungen führt bei den Betrügerinnen häufiger als bei den Diebinnen zu Freiheitsstrafen mit $(26 \%)$ und ohne $(6 \%)$ Bewährung. Bei den Diebinnen waren Anteile von $18 \%$ (Freiheitsstrafe mit Bewährung) und $5 \%$ (Freiheitsstrafe ohne Bewährung) zu verzeichnen (vgl. Schaubild 5.21). Dieser Effekt kehrt sich allerdings für den Anteil von unbedingten Freiheitsstrafen bei Voreintragungen mit anderen Täuschungsdelikten um: Das Vorhandensein von Voreintragungen wegen eines anderen Diebstahldelikts führt bei den Diebinnen und Diebin häufiger zu unbedingten Freiheitsstrafen, was wahrscheinlich mit der Berücksichtigung der schweren Diebstahlsformen in dieser Kategorie zusammenhängt.

\footnotetext{
${ }^{774}$ Diese Gruppe wurde mit Betrug u.a. abgekürzt.

775 BKA (Hrsg.), PKS 2004, S. 165; vgl. ferner zu dem Problem der Vergleichbarkeit der Statistiken: Kap. 1, 3.2.
} 
Schaubild 5.39: Sanktionen des StGB aufgrund von Betrug nach Einschlägigkeit der Voreintragungen und Geschlecht*

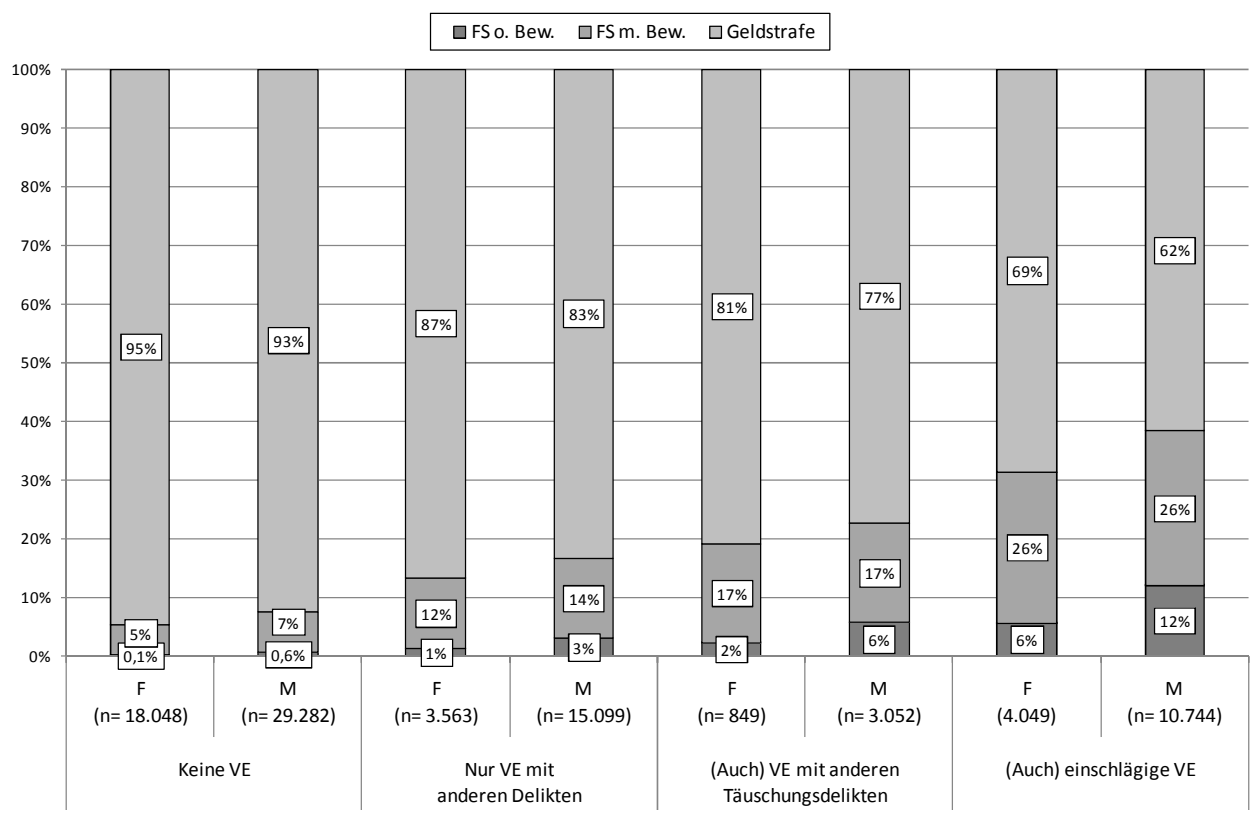

*Absolutzablen siehe Tab. 5.48a im Anbang

Darüber hinaus ist der Anteil der Freiheitsstrafen mit Bewährung bei den Betrügerinnen über alle Gruppen hinweg größer als bei den Diebinnen. Ferner zeigt sich wieder, dass für beide Geschlechter sehr viel häufiger einschlägige Voreintragungen als Voreintragungen wegen eines anderen Täuschungsdelikts zu verzeichnen sind.

\subsubsection{Multifaktorielle Analyse}

Nunmehr wird für den Betrug überprüft, ob ein Unterschied in der Sanktionierung der Geschlechter bei simultaner Berücksichtigung mehrerer Variablen bestehen bleibt. Es wurde wieder die Gruppe der deutschen, erwachsenen Frauen und Männer betrachtet, die mindestens fünf Voreintragungen aufweisen, von denen mindestens eine einschlägig ist und mit einer Freiheits- oder Jugendstrafe mit oder ohne Bewährung sanktioniert wurde. Wie beim Diebstahl (Schaubild 5.35) erhalten wieder weniger Frauen (16\%) als Männer $(20 \%)$ als Bezugssanktion eine Freiheitsstrafe ohne Bewährung. Die Differenz beträgt hier aber nur noch vier Prozentpunkte, während sie beim Diebstahl noch sieben Prozentpunkte betrug. Dafür übersteigt der Anteil der Freiheitsstrafen mit Bewährung bei den Frauen den bei den Männern mit 39 \% zu $31 \%$ deutlich. Dies führt wiederum dazu, dass die untersuchten Frauen zusammen betrachtet häufiger Freiheitsstrafen erhalten als 
die männliche Vergleichsgruppe. Männer erhalten zwar in der überprüften Konstellation häufiger Freiheitsstrafen ohne Bewährung als Frauen. Dieses Ergebnis dokumentiert jedoch lediglich, dass für Frauen häufiger eine günstige Legalprognose gestellt wird. Insgesamt lässt sich eine mildere Sanktionierung aufgrund des Geschlechts daher nicht feststellen.

Schaubild 5.40: Sanktionen des StGB aufgrund von Betrug unter Berücksichtigung multipler Faktoren nach Geschlecht*

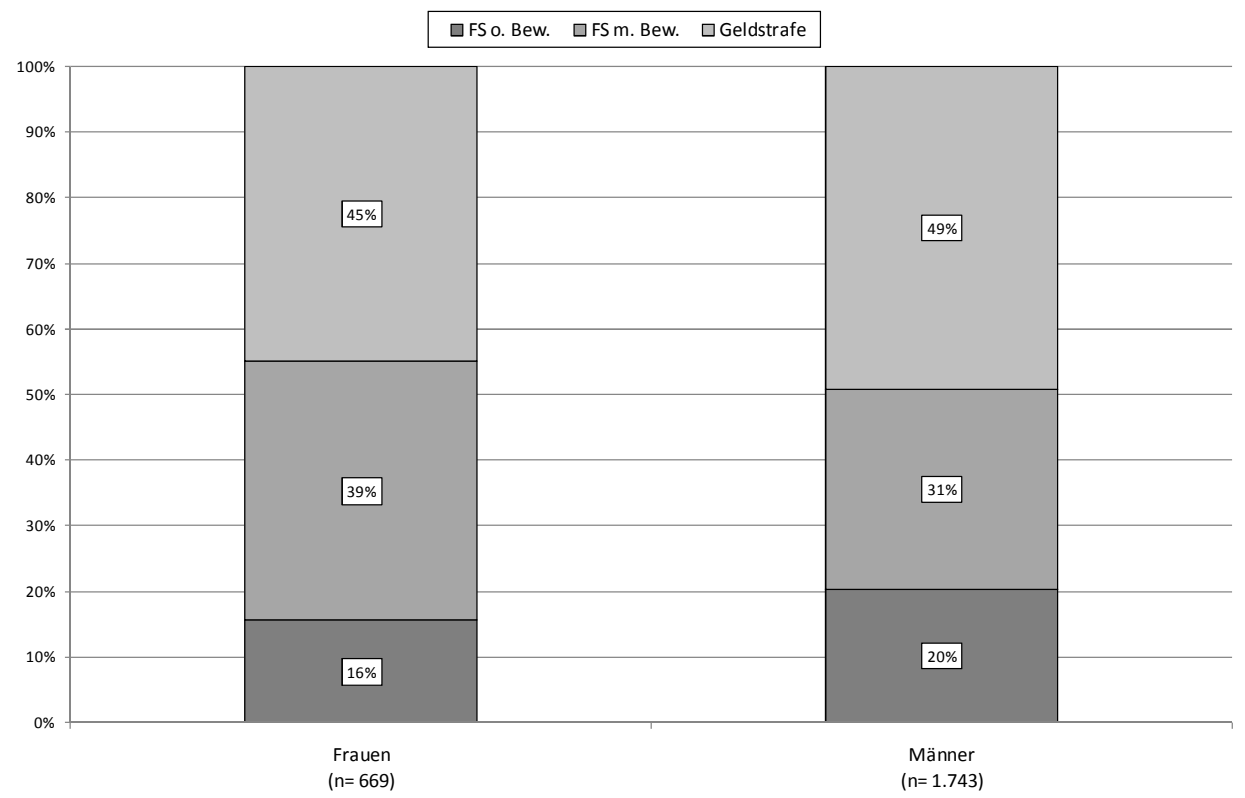

* Absolutzablen siehe Tab. 5.49 a im Anhang

\section{Bewertung der Ergebnisse: „Frauenbonus“ oder nicht?}

Die vorstehenden Ausführungen haben deutlich gemacht, dass sich die Annahme eines Frauenbonus auf der Ebene der Gerichte nicht halten lässt.

Bei Betrachtung der Gesamtstichprobe nur nach Art der Bezugsentscheidung nach Jugendstrafrecht und allgemeinem Strafrecht ergibt sich in der Tat zunächst eine deutlich mildere Sanktionierung von Frauen: Bei den schwereren Sanktionen sind sie unter- bei den milderen hingegen überrepräsentiert. Bereits die detaillierte Betrachtung unter Hinzunahme der Anzahl bzw. Art der schwersten Voreintragung zeigte aber, dass die Differenz zwischen den Geschlechtern mit steigender Anzahl und Schwere der Voreintragungen abnimmt, obwohl ein Unterschied immer noch erkennbar war. Hierbei muss man jedoch berücksichtigen, dass Frauen, wie in Kapitel 1 und 4 festgestellt, eine andere Deliktsstruktur aufweisen als 
Männer. Sie begehen in erster Linie Straftaten, die einen verhältnismäßig niedrigen Strafrahmen aufweisen. Straftaten, für die hohe Strafen angedroht sind, werden selten von Frauen begangen. Daher wurde vorliegend zudem eine deliktsspezifische Betrachtung durchgeführt, wobei der einfache Diebstahl und der einfache Betrug als häufig von Frauen begangene Delikte für eine entsprechende Analyse ausgewählt wurden. Die Auswertung hat sowohl für Diebstahl als auch für Betrug ergeben, dass ein „Geschlechterbonus“ nicht nachgewiesen werden kann.

Die Analyse der Anzahl der Voreintragungen für die Delikte Diebstahl und Betrug hat zwar keine gleichhohen oder gar höheren Anteile von stationären Strafen bei den Frauen ergeben, allerdings erhalten Frauen, wenn man die Anteile der Freiheitsstrafen mit und ohne Bewährung addiert, ab einer Anzahl von zwei Voreintragungen häufiger Freiheitsstrafen als Männer. Allein die Tatsache, dass Frauen in den überprüften Konstellationen seltener unbedingte Freiheitsstrafen erhalten, ist nicht mit einer milderen Behandlung gleichzusetzen, sondern spricht vielmehr dafür, dass für Frauen häufiger die Voraussetzungen des $\ 56$ StGB bejaht wurden. Sie scheinen daher günstigere Legalprognosen zu erhalten.

Betrachtet man die Art der schwersten Voreintragung, so kann man eine Tendenz zur milderen Behandlung von Männern erkennen. Beim Diebstahl übersteigt der Anteil von Freiheitsstrafen bei den Frauen, die als schwerste Voreintragung Freiheits- oder Jugendstrafen mit oder ohne Bewährung erhalten haben, den Anteil bei den Männern. Der Anteil von unbedingten Freiheitsstrafen ist bei den Männern nur noch minimal höher. Bei Betrachtung des Delikts Betrug zeigt sich, dass Frauen sogar minimal häufiger unbedingte Freiheitsstrafen erhalten als Männer, wenn für sie die schwerste Voreintragung mit Freiheits- oder Jugendstrafe mit Bewährung sanktioniert wurde. Bei stationären Freiheits- und Jugendstrafen als schwerste Voreintragung, ist der Anteil von Freiheitsstrafen ohne Bewährung bei den Frauen genauso hoch wie bei den Männern, wobei der Anteil von Freiheitsstrafen mit Bewährung wieder größer ist als bei den Männern.

Die Einschlägigkeit von Voreintragungen hat hingegen für Männer einen stärkeren Einfluss auf die Sanktionierung als dies bei Frauen der Fall ist. Dieses Ergebnis konnte sowohl für die Betrachtung über alle Delikte hinweg als auch für die spezifisch analysierten Delikte Diebstahl und Betrug festgestellt werden.

Die multifaktorielle Analyse für die beiden Delikte Diebstahl und Betrug bestätigt schließlich noch einmal, dass sich ein etwaiger Frauenbonus nicht in den Ergebnissen wiederspiegelt. Die eingangs auf Grundlage der bereits existierenden Untersuchungen aufgestellten Hypothesen haben sich mithin anhand der Analyse aller im Jahr 2004 in Deutschland verurteilten Straftäter bestätigt. 


\section{Kapitel 6: Rückfallkriminalität von Frauen}

Wenn man sich in der kriminologischen Literatur auf die Suche nach empirisch gesicherten Informationen zur Rückfallkriminalität von Frauen begibt, so wird man feststellen, dass diese Thematik bislang nicht im Mittelpunkt des Forschungsinteresses stand, und dies obwohl die Rückfallkriminalität zu den ,kelassischen Forschungsgegenständen von Kriminologie, Strafrechtswissenschaft und Kriminalpolitik" "776 zählt. Eine Erklärung hierfür dürfte sein, dass Frauen seltener und weniger schwerwiegende Straftaten begehen. Dies ist jedoch kein hinreichender Grund dafür, die Frauen aus dem Blick zu verlieren. Denn es gibt durchaus viele Frauen, die straffällig werden und dementsprechend besteht hier in gleicher Weise ein Informationsbedürfnis.

In diesem Kapitel erfolgt daher eine bundesweite empirische Untersuchung der Rückfallkriminalität von Frauen für das Bezugsjahr 2004. Im Gegensatz zu den vorangegangenen Kapiteln wird für die folgende Analyse der Rückfalldatensatz. auf Grundlage der BZR-Daten verwendet. Der Rückfalldatensatz umfasst die Daten aller Personen, die im Bezugsjahr 2004 mit einer ambulanten Reaktion nach \S 45, 47 JGG belegt oder zu einer ambulanten Sanktion nach JGG oder StGB verurteilt wurden. Ferner werden die Personen erfasst, die nach einer stationären Strafe oder Maßregel entlassen worden sind. Insgesamt beinhaltet der Rückfallda-

\footnotetext{
776 Heinz, in: Heinz/Jehle (Hrsg.), Rückfallforschung, S. 12.
} 
tensatz 1.051.887777 Bezugsentscheidungen, für die sämtliche, mit der Sanktionierung verbundenen Individualeintragungen berücksichtigt wurden. Von den so erfassten Personen waren 217.443 Frauen und 834.444 Männer. Diese wurden über einen Zeitraum von drei Jahren bis 2007 weiterfolgt, um zu erkennen, ob sie wieder straffällig geworden sind oder nicht. Der Beginn des Beobachtungszeitraums orientiert sich bei ambulanten Sanktionen am Entscheidungszeitpunkt, im Übrigen an der Strafrestaussetzung bzw. am Vollstreckungsende. 778

Anfangs wird ein kurzer Überblick über die Bedeutung von Rückfälligkeit und die geschichtliche Entwicklung der Rückfallstatistiken gegeben. Anschließend wird der Forschungsstand zur Rückfälligkeit von Frauen aufgearbeitet. Sodann erfolgt die Darstellung der eigenen Ergebnisse, wobei zunächst der verwendete Rückfallbegriff erläutert wird. Anders als im vorangegangenen Kapitel erfolgt zu Beginn eine rein frauenspezifische Analyse, da es sinnvoll ist, Frauenkriminalität in ihrer Eigenständigkeit zu untersuchen und nicht nur im Geschlechtervergleich. ${ }^{779}$ Gleichwohl soll am Ende des Kapitels eine Gegenüberstellung der Rückfallkriminalität der Geschlechter erfolgen, um anknüpfend an Kapitel 5 herauszuarbeiten, ob sich im Falle eines Rückfalls eine andere Sanktionierung von Frauen ergibt und ob insgesamt Unterschiede zwischen den Geschlechtern bei der Rückfälligkeit zu verzeichnen sind.

\section{Die Bedeutung der Rückfälligkeit und der Rückfallstatistik}

Die Bedeutung der Rückfälligkeit für die Strafrechtspolitik bestimmt sich maßgeblich nach den Aufgaben des Strafrechts. Es besteht heute weitgehend Einigkeit darüber, dass die Aufgabe des Strafrechts nicht nur darin zu sehen ist, einen Ausgleich der geschehenen Rechtsverletzung herbeizuführen, um dem Vergeltungsgedanken Rechnung zu tragen (absolute Straftheorie). Vielmehr verhalfen von Liszt und die sogenannte moderne Schule zum Ende des 19. Jahrhunderts wieder zur Sichtweise eines präventiven Rechtsgüterschutzes (relative Straftheorien). ${ }^{780} \mathrm{Da}$ nach kann die von der Strafe erwartete Wirkung auf der Ebene des Täters (Spezialprävention) oder auf der Ebene der Allgemeinheit wirken (Generalprävention). Dies bedeutet konkret für die spezialpräventive Ebene, dass der Täter entweder resozialisiert (positive Spezialprävention) oder von weiteren Straftaten abgeschreckt bzw. gesichert werden soll, um weitere Straftaten zu verhindern (negative Spezialprävention). Auf generalpräventiver Ebene lässt sich zwischen der Ab-

\footnotetext{
777329 Fälle ohne Geschlechtsangabe wurden ausgeschlossen.

778 Vgl. ausführlich zum Rückfalldatensatz Kap. 3, 2.1.

${ }^{779}$ So auch Schmölzzer 2003, S. 16.

780 Jehle, in: Heinz/Jehle (Hrsg.), Rückfallforschung, S. 145, S. 148; Heinz, Kriminalprävention auf justizieller Ebene: Hilft weniger mehr?, S. 3; Fischer, \46 StGB, Rdn. 2; Kunz \9, Rdn. 13 ff.
} 
schreckungswirkung der Strafe (negative Generalprävention) sowie der Stabilisierung des Normbewusstseins der Bevölkerung (positive Generalprävention) unterscheiden. ${ }^{781}$

Rückfallverhinderung zählt mithin zu den wichtigsten Aufgaben des Strafrechts. ${ }^{782}$ Die Frage des Rückfalls ist wiederum eng mit der strafrechtlichen Sanktionierung verknüpft. Denn bei der Strafzumessung ist der Rückfall bzw. die Rückfallgefahr entscheidend für die Sanktionsart, beispielsweise für die Aussetzung der Freiheitsstrafe zur Bewährung oder für andere Maßnahmen, die der Sozialisierung oder Resozialisierung des Täters dienen. ${ }^{783} \mathrm{In}$ einem folgenorientierten System ist Strafe nur dann gerechtfertigt, wenn sie dazu geeignet ist, die genannten Präventionsziele zu erreichen. Eine Überprüfung setzt empirische Erkenntnisse voraus. ${ }^{784}$ Das empirisch festgestellte Ausmaß der Rückfälligkeit ist der zentrale Indikator für den Grad der Realisierung von Rückfallvermeidung. ${ }^{785}$ Es ist daher wichtig, der Rechtspraxis und Gesetzgebung gesichertes Wissen über die Effizienz strafrechtlicher Sanktionen zur Verfügung zu stellen. ${ }^{786}$

Das Ausmaß der Rückfälligkeit konnte in Deutschland lange Zeit nur durch regional und zeitlich beschränkte empirische Einzelfallstudien gemessen werden, da die existierenden Rechtpflegestatistiken keine Überprüfung der Rückfälligkeit ${ }^{787}$ gewährleisteten. ${ }^{788}$ Dem wurde mit der im Jahr 2003 erstmals erschienenen und mittlerweile zum zweiten Mal herausgegebenen Legalbewährungsstudie für Deutschland abgeholfen und damit eine zentrale Lücke im bisherigen System der Rechtspflegestatistiken geschlossen.

Jedoch muss bei der Aussagekraft der Legalbewährungsstudie beachtet werden, dass sie als Bezugstat und Rückfall nur registrierte und sanktionierte Straftaten erfasst und nicht etwa auch Straftaten im Dunkelfeld oder polizeilich registrierte Tatverdächtige, ${ }^{789}$ sodass mit Verzerrungseffekten zu rechnen ist.

Ferner bleibt der kausale Zusammenhang zwischen Sanktion und Rückfall problematisch. Eine niedrige Rückfallquote bei einer bestimmten Sanktion gegenüber einer höheren bei einer anderen Sanktion muss nicht unweigerlich bedeuten,

${ }^{781}$ Heinz, Kriminalprävention auf justizieller Ebene: Hilft weniger mehr?, S. 3 ff.; Kun₹, \9, Rdn. 16 ff.

782 Heinz, in: Heinz/Jehle (Hrsg.), Rückfallforschung, S. 11, 19.

783 Blath, in: Heinz/Jehle (Hrsg.), Rückfallforschung, S. 133 f.; Jeble, in: Heinz/Jehle (Hrsg.), Rückfallforschung, S. 145, $148 \mathrm{f}$.

${ }^{784}$ Heinz, Kriminalprävention auf justizieller Ebene: Hilft weniger mehr?, S. 3.

785 Blath, in: Heinz/Jehle (Hrsg.), Rückfallforschung, S. 133, 134; Heinz, in: ZJJ 2004, S. 35.

786 BMI/BMJ (Hrsg.), PSB I, S. 444.

${ }^{787}$ Lediglich die Bewährungshilfestatistik liefert u.a. Informationen darüber, ob die Bewährung „,nur oder auch wegen einer Straftat" widerrufen wurde. Da jedoch nicht jede Straftat einen Widerruf nach sich zieht (vgl. $\int 56 \mathrm{f} \mathrm{StGB}$ ) und die Ergebnisse nur für diejenigen gelten, die einem hauptamtlichen Bewährungshelfer unterstellt wurden, bietet die Bewährungshilfestatistik keine ausreichende Grundlage für die Messung der Legalbewährung.

788 BMI/BMJ, (Hrsg.), PSB I, S. 448 f.; Heinr, in: ZJJ 2004, S. 35.

789 Vgl. zum Rückfallbegriff ausführlich unter Kap. 6, 4.1. 
die Sanktion mit der niedrigeren Rückfallquote sei spezialpräventiv wirksamer. Unterschiede in den Rückfallquoten können auch auf Selektionseffekte zurückzuführen sein, da härtere Sanktionen in der Regel gegenüber Personen ergehen, die eine negative Sozialprognose aufweisen. ${ }^{790}$

Gleichwohl ist die Erhebung offizieller Rückfallraten, sowohl im Rahmen einer auf wenige handhabbare und aussagekräftige Kriterien beschränkten Statistik, als auch im Rahmen detaillierter Einzelfallstudien von großer Bedeutung. ${ }^{791}$

\section{Die Entwicklung der Rückfallstatistik}

\subsection{Die Rückfalldaten in der Kriminalstatistik des Deutschen Reiches}

Bereits vor mehr als einem Jahrhundert wurden Stimmen laut, die die Einführung einer Rückfallstatistik als materiell wichtigsten und zugleich methodologisch schwierigsten Teil der Kriminalstatistik forderten. ${ }^{792}$ Schon seit 1882 gibt es eine Statistik, in der die Zahl der jährlich Verurteilten nach verschiedenen Kriterien aufgeschlüsselt dargestellt wird. Es war zunächst gängige Praxis, aus den Vorbestraftenquoten auf die Rückfälligkeit zu schließen. Köbner kritisierte in einem grundlegenden Gutachten für die IV. Hauptversammlung der Internationalen Kriminalistischen Vereinigung diese Praxis. ${ }^{793}$ Lediglich einige Informationen zur Vorbelastung der Tatverdächtigen, Verurteilten, Strafgefangenen und Bewährungshilfeprobanden standen zur Verfügung. Vorbestrafte sind jedoch nicht identisch mit Rückfälligen, weshalb die Strafverfolgungsstatistik zur Rückfallmessung völlig ungeeignet ist. Die Frage nach der Rückfälligkeit bedarf einer prospektiven Betrachtungsweise, bei der zu ermitteln ist, wieviele rückfallfähige Personen innerhalb eines bestimmten Zeitraums erneut justiziell in Erscheinung treten. ${ }^{794}$ Die Strafverfolgungsstatistik ist hingegen retrospektiv aufgebaut, d.h. ihr Blick ist in die Vergangenheit gerichtet und erlaubt daher keinen Rückschluss auf die weitere Entwicklung registrierter Straftäter. ${ }^{795}$ Ein Schluss von der Vorbestraften- auf die Rückfallquote ist auch deshalb unzulässig, weil man bei alleiniger Betrachtung der Vorbestraftenanteile, die Rückfälligen nicht auf die Zahl der Rückfallfähigen beziehen kann. ${ }^{796}$ Köbner führte hierzu aus, richtiger Ansatz für eine Rückfallstatistik sei die Bezugnahme der Rückfälligen auf die Rückfallfähigen, d.h. die Personen die mindestens einmal bestraft und zudem nicht außerstande sind, ein neues Delikt zu

\footnotetext{
${ }^{790}$ BMI/BMJ (Hrsg.), PSB I, S. 445 f.; Niggli, Kriminologische Überlegungen zur Strafzumessung, S. 13.

791 So auch Jehle, in: Heinz/Jehle (Hrsg.), Rückfallforschung, S. 145, $170 \mathrm{f}$.

792 Köbner, in: ZStW 1893, S. 615, 738; Harrendorf, S. 93.

793 Köbner, in: ZStW 1893, S. 615, 668 ff.

${ }^{794}$ Heinz, in: Heinz/Jehle (Hrsg.), Rückfallforschung, S. 11, S. 20; Harrendorf, S. 94.

795 Heinz, in: Heinz/Jehle (Hrsg.), Rückfallforschung, S. 11, S. 20; Harrendorf, S. 94.

796 Harrendorf, S. 94.
} 
begehen. ${ }^{797}$ Ausgeschlossen werden müssten danach die Personen, die entweder endgültig (z.B. durch Tod) oder vorübergehend (z.B. durch eine zeitige Freiheitsstrafe) nicht dazu imstande sind eine erneute Straftat zu begehen. ${ }^{798}$

Wohl angestoßen durch Köbners Artikel, wurde im Jahr 1894 mit der Erhebung einer Rückfallstatistik für das Deutsche Reich ${ }^{799}$ begonnen. Diese kam jedoch den Forderungen insoweit nicht nach, als sie nicht auf strafrechtlichen Registereinträgen, sondern auf einer besonderen zusätzlichen Auswertung der Zählerkarten beruhte. Ausgehend von den in einem Jahr verurteilten Personen wurde im Rahmen einer sog. vorblickenden Statistik die Häufigkeit des Rückfalls, d.h. eine erneute Verurteilung dieser Person in den auf das Kalenderjahr folgenden 10 Jahren untersucht. Mangels entsprechender statistischer Unterlagen konnten weder die Dauer der Strafverbüßung noch die Zahl der Personen berücksichtigt werden, die wegen Todes oder Auswanderung nicht zu den Rückfälligen zählten. ${ }^{800}$ Die Kriminalstatistik des Deutschen Reiches konnte daher die von Köbner angesprochenen Kritikpunkte nicht ausräumen. Sie wurde - wohl aufgrund des Kriegsausbruchs zum letzten Mal 1914 für den Zeitraum bis 1912 herausgegeben. 801

\subsection{Die Rückfallstatistiken auf der Grundlage der Daten des Bundeszentral- registers}

\subsubsection{Die Rückfallstatistik der Dienststelle Bundeszentralregister des Generalbun- desanwalts}

In den Jahren 1986 bis 1990 publizierte die Dienststelle Bundeszentralregister des Generalbundesanwaltes eine Rückfallstatistik für die Bezugsjahre 1980 bis 1984 auf Basis der Bundeszentralregisterdaten. ${ }^{802}$ Untersucht wurde die Rückfälligkeit nach freiheitsentziehenden Sanktionen differenziert nach Bezugsentscheidung, Folgeverurteilung, Geschlecht und Alter, wobei ein Rückfallzeitraum von fünf Jahren betrachtet wurde. 803

Allerdings wies auch diese Statistik gravierende Mängel auf. So blieben durch die alleinige Betrachtung der freiheitsentziehenden Sanktionen die Geldstrafe sowie die meisten jugendstrafrechtlichen Sanktionen, ${ }^{804}$ die Erziehungsmaßregeln und Zuchtmittel nach JGG unberücksichtigt. Diese Begrenzung war darauf zurückzuführen, dass als Beginn des Rückfallzeitraums das Vollstreckungsende gewählt wurde, welches nicht für jede Sanktion im BZR eingetragen wird. Daraus

\footnotetext{
797 Köbner, in: ZStW 1893, S. 615, 620 f.; Heinz, in: ZJJ 2004, S. 35, 36.

798 Köbner, in: ZStW 1893, S. 615, 628; Heinz, in: ZJJ 2004, S. 35, 36; Harrendorf, S. 96.

${ }^{799}$ Kaiserliches Statistisches Amt (Hrsg.), Kriminalstatistik für das Deutsche Reich.

800 Köbner, in: ZStW 1893 S. 615, 623 ff.

801 Heinz, in: Heinz/Jehle (Hrsg.), Rückfallforschung, S. 11, 31.

802 Generalbundesanwalt (Hrsg.), Rückfallstatistik.

803 Generalbundesanwalt (Hrsg.), Rückfallstatistik `90 für das Basisjahr 1984 aus den Eintragungen des Bundeszentralregister, 1990, S. 1 f.

804 Mit Ausnahme der Jugendstrafe als freiheitsentziehende Sanktion.
} 
resultierte als weiteres Problem, dass nicht alle Rückfälle während der Bewährungszeit bei ausgesetzten Freiheitsstrafen und Strafrestaussetzung erfasst wurden. In diesen Fällen befinden sich die Probanden schon vor dem Erledigungszeitpunkt in Freiheit und können rückfällig werden. Ferner wurde kritisiert, dass die Statistik keine Angaben zu den Vorstrafen der Probanden enthielt. 805

Aufgrund dieser noch bestehenden Kritikpunkte erschien 1990 der letzte Band. Eine Neustrukturierung war notwendig. Jeble, der damalige Direktor der Kriminologischen Zentralstelle in Wiesbaden (KrimZ), erstellte daher auf Veranlassung der Registerbehörde ein Gutachten mit Verbesserungsvorschlägen zur Rückfallstatistik.

\subsubsection{Die neu konzipierte Rückfalluntersuchung}

Das Bundesministerium der Justiz beauftragte die KrimZ sodann mit einer Neukonzeption der Rückfallstatistik, in der versucht wurde, die Verbesserungsvorschläge zur alten Rückfallstatistik aufzugreifen und umzusetzen. Nunmehr sollten sämtliche im BZR eingetragenen Sanktionen für ein bestimmtes Bezugsjahr erfasst werden. Rückfallbeginn sollte bei freiheitsentziehenden Maßnahmen weiter das Vollstreckungsende, bei ambulanten Sanktionen das Urteilsdatum und bei Strafrestaussetzung zur Bewährung ein fiktives Entlassungsdatum sein. Auch sollte eine Differenzierung nach Delikten erfolgen. 806

Das Bundesjustizministerium beauftragte 1995 das Statistische Bundesamt mit der Umsetzung der Neukonzeption einer regelmäßigen Rückfallstatistik. Mit der Durchsetzung wurden in einer ersten Machbarkeitsstudie Jeble und Heinz beauftragt, die zunächst eine exemplarische Rückfallstatistik für das Basisjahr 1991 erstellten, welche noch einige Mängel aufwies. ${ }^{807}$

\subsubsection{Die Rückfalluntersuchung für das Berugsjabr 1994}

Im Jahr 2003 wurde schließlich die Legalbewährungsstudie für das Bezugsjahr 1994 veröffentlicht. ${ }^{808}$ In der ersten Legalbewährungsstudie für Deutschland wurden alle in dem Bezugsjahr strafrechtlich Sanktionierten oder aus der Haft Entlassenen während eines vierjährigen Rückfallzeitraums weiterverfolgt, um zu erkennen, ob sie wieder straffällig werden. Insgesamt wurden rund 947.000 Entscheidungen erfasst. Für ambulante Sanktionen - einschließlich Strafrestaussetzung zur Bewährung - wurde als Bezugsentscheidung das Entscheidungsdatum und bei freiheitsentziehenden Sanktionen das Vollstreckungsende bzw. der Entlassungszeitpunkt zugrunde gelegt. Falls für einen so erfassten Probanden im Bezugsjahr

\footnotetext{
805 Ublig, in: Generalbundesanwalt (Hrsg.), Rückfallstatistik, S. 2; Harrendorf, S. 97; vgl. ausführlicher zu den Mängeln, Harrendorf, S. 97 f.

${ }^{806}$ Jeble/ Brings, Zur Messung der Rückfälligkeit von Straftätern, Wirtschaft und Statistik 1999, S. 498, 502 f.; Heinø, in: Jehle/Heinz (Hrsg.), Rückfallforschung, S. 11, 36.

807 Harrendorf, S. 98 f.

808 Jehle/Hein₹/Sutterer, Legalbewährung nach strafrechtlichen Sanktionen, 2003.
} 
mehrere Entscheidungen vorlagen, wurde nur die zeitlich erste Entscheidung gezählt. Die darauf folgende Entscheidung wurde bereits als Folgeentscheidung gewertet. 809

\subsubsection{Die ₹weite Rückefalluntersuchung für das Bezugsjahr 2004}

Darauf folgend wurde im Auftrag des Bundesministeriums der Justiz eine zweite Studie für das Bezugsjahr 2004 mit einem neuen Design angeschlossen. Es sind weitere Erhebungswellen von jeweils drei Jahren vorgesehen, wovon die erste Erhebungswelle mittlerweile ausgewertet ist.

Für diese Studie wurden alle im Bezugsjahr 2004 aus der Haft Entlassenen und strafrechtlich Sanktionierten während eines dreijährigen Rückfallzeitraums weiterfolgt, um zu untersuchen, ob es zu einer erneuten Sanktionierung gekommen ist. Im Vergleich zur ersten Rückfalluntersuchung wurde der Rückfallzeitraum also auf drei Jahre verkürzt, um weitere Tilgungsverluste zu vermeiden. ${ }^{810}$ Mit der anschließenden zweiten Erhebungswelle soll dem Ziel einer periodischen Legalbewährungsstudie näher gekommen werden. Daher waren auch Veränderungen im Absammelkonzept nötig. Für die Legalbewährungsstudie für das Bezugsjahr 1994 wurden alle Personen abgesammelt, deren letztes Bearbeitungsdatum nicht vor dem 01.01.1994 lag. Nicht abgesammelt wurden hingegen Personen, deren erste Entscheidung nach Ablauf des Bezugsjahres ergangen war. Im Hinblick auf die geplante Periodizität verzichtet die aktuelle Legalbewährungsstudie auf die zuletzt genannte Einschränkung. ${ }^{811}$

\section{Bisherige deutsche Forschungsergebnisse zur Rückfallkriminalität von Frauen}

Die Rückfallkriminalität von Frauen war bisher kaum Gegenstand von Untersuchungen. Grund dafür dürfte das bislang unzureichende Datenmaterial gewesen sein, welches eine prospektive Betrachtung ausschloss. Daher knüpfen die wenigen Studien zumeist an die Daten zu den Vorbestraften an und wollen daraus Aussagen zur Rückfälligkeit herleiten. ${ }^{812}$ Aber auch Einzelfallstudien zu dieser Thematik sind selten. Die meisten Studien beziehen sich nur auf männliche Probanden ${ }^{813}$ oder differenzieren nicht zwischen den Geschlechtern ${ }^{814}$ und wenn sie

${ }^{809}$ Vgl. hierzu auch ausführlich unter Kap. 3, 2.1.

810 Jeble/Albrecbt/Hohmann-Fricke/Tetal, Legalbewährung nach strafrechtlichen Sanktionen, 2010, S. 28 ff., 33.

811 Jeble/Albrecht/Hohmann-Fricke/Tetal, Legalbewährung nach strafrechtlichen Sanktionen, 2010, S. 15,33 .

812 Z.B. Lauritzen, Die Kriminalität der Frau; Cremer, Untersuchungen zur Kriminalität der Frau; Schmitz, Die Kriminalität der Frau.

813 Z.B. Lassen, Rückfälligkeit und Bewährung von 200 Probanden, die nach Widerruf einer Strafaussetzung zur Bewährung in der Strafanstalt Wolfenbüttel Freiheitsstrafen verbüßten, unter beson- 
es doch tun, dann wird den Frauen in der Regel nur ein kleiner Abschnitt gewidmet. ${ }^{815}$

Im Folgenden werden wesentliche Ergebnisse aus der Rückfallforschung, soweit sie sich auf Frauen beziehen, erörtert.

Schmitz ${ }^{816}$ stellt fest, dass ,die Frau als Rück.fallverbrecherin im Vergleich zum Manne nur ganz selten vor dem Richter steht. "1817 Hierbei bezog er sich auf Exner818 der wiederum durch die Auswertung der Daten der heutigen Strafverfolgungsstatistik für die Jahre 1935/36 zu dem Ergebnis kam, dass unter den weiblichen Verurteilten wesentlich weniger Vorbestrafte sind als unter den männlichen Verurteilten. ${ }^{819}$

Lauritzen $^{820}$ untersuchte zum einen den Anteil der Frauen an den damals geltenden sondergesetzlichen Rückfallbestimmungen, Rückfallbetrug und Rückfalldiebstahl, und zum anderen den deliktsspezifischen Anteil der Vorbestraften unter den verurteilten Frauen. Einen besonders hohen Vorstrafenanteil wiesen Frauen bei der Kuppelei, Gewalt und Drohung gegen Beamte sowie Eigentums- und Vermögensdelikten auf. ${ }^{821}$

Einsele822 führte im Jahr 1963 eine umfangreiche Untersuchung von Frauen, die in den Jahren 1956/57 aus der Frauenstrafanstalt Frankfurt/Main entlassen worden waren, mit Hilfe der Strafvollzugsakten durch. Der Autorin war es so möglich auch die konkreten Lebensumstände der Probandinnen in die Studie einzubeziehen. 305 erwachsene Frauen wurden nach Haftentlassung über einen Zeitraum von 6-7 Jahren weiterverfolgt. $45 \%$ der Probandinnen wurden rückfällig, davon $13 \%$ einmal und $32 \%$ mehrfach. Mehr als die Hälfte der Rückfälle erfolgten im ersten Jahr nach Haftentlassung. Zudem waren die Rückfallquoten der bedingt entlassenen niedriger als die der regulär entlassenen Frauen. 823

In gleicher Weise überprüfte Einsele ${ }^{824}$ die Rückfälligkeit von 69 haftentlassenen minderjährigen Mädchen. Für diese Altersgruppe betrug die Rückfallquote

derer Berücksichtigung ihres Anstaltsverhaltens; Morning, Symptome schwerer Rückfälligkeit bei jungen Vermögenstätern; Albrecht, Legalbewährung bei zu Geldstrafe und Freiheitsstrafe Verurteilten; Rotermann/Köbler/Hinrichs, Legalbewährung jugendlicher und heranwachsender Sexualund Gewaltstraftäter.

814 Z.B. Graalmann, Die Rückfälligkeit von Drogenstraftätern; Böhm, Hauptverhandlung und Legalbewährung; Quenžer, Jugendliche und heranwachsende Sexualstraftäter.

815 Z.B. Kin₹ig, Die Sicherungsverwahrung auf dem Prüfstand, S. 173 ff., wobei hier eine ausführlichere Berücksichtigung des Geschlechts aufgrund der niedrigen Anzahl von Frauen nicht möglich war; Storz, in: Bundesministerium der Justiz (Hrsg.), Diversion im Jugendstrafverfahren der Bundesrepublik Deutschland, S. 133, 169.

816 Schmitr, Die Kriminalität der Frau.

817 Schmitr, S. 6.

818 Exner, Kriminologie.

${ }^{819}$ Exner, S. 268.

${ }^{820}$ Lauritzen, Die Kriminalität der Frau, 1972.

821 Lauritzen, S. 155.

822 Einsele, in: MschrKrim 1968, S. 28-79.

${ }^{823}$ Einsele, in: MschrKrim 1968, S. 28, 76 f.

${ }^{824}$ Einsele, in: MschrKrim 1968, S. 334-362. 
$64 \%$. Von den 44 Mädchen wurden 35 mehrfach rückfällig. $61 \%$ der Rückfälle ereigneten sich im ersten Jahr nach Haftentlassung. Die Rückfallraten der bedingt und regulär entlassenen Mädchen unterschieden sich kaum voneinander. ${ }^{825}$

Ferner stellte die Autorin sowohl für die erwachsenen als auch für die minderjährigen Täterinnen die kriminelle Entwicklung dar, indem sie die ersten und letzten Straftaten betrachtete. Für die Erwachsenen kam Einsele zu dem Ergebnis, dass der Diebstahl mit 50\% am Anfang der kriminellen Karriere am häufigsten begangenen wurde. Der Anteil schrumpfte allerdings auf $37 \%$ bei der letzten Verurteilung. Betrug, Kuppelei, Meineid und Untreue nahmen hingegen im Verlauf der kriminellen Karriere zu. Bei den Minderjährigen war letzteres allerdings nicht der Fall. Einsele begründete dies damit, dass es sich hierbei um Delikte handele, bei denen ,größere Routine, kriminelle Aktivität oder berufliche Stellung'"826 erforderlich seien. Bei den Minderjährigen nahm der Diebstahl hingegen geringfügig zu, wohingegen Betrug, Kuppelei, Meineid und Untreue kaum eine Rolle spielten. ${ }^{827}$

Auch Memminger ${ }^{828}$ analysierte die Rückfälligkeit von Frauen nach Haftentlassung. Sie bezog 219 Frauen, die in der Zeit 1958/59 aus der Frauenhaftanstalt Gotteszell in Schwäbisch Gmünd entlassen worden waren, in ihre Studie ein und beobachtete diese über einen längeren Bewährungszeitraum von 5 bis 7 Jahren. ${ }^{829}$ Nur für $28 \%$ der Probandinnen wurde kein Rückfall in dieser Zeit registriert. ${ }^{830}$ Die Autorin ordnete die Probandinnen in Erfolgsgruppen ein, die sich an der Schwere der Sanktion in der Folgeentscheidung orientierten. Die Auswertung ergab, dass $39 \%$ der Frauen entweder nicht oder nur unerheblich rückfällig 831 wurden. Jeweils $22 \%$ wurden nicht ganz unerheblich ${ }^{832}$ sowie erheblich rückfäl$\operatorname{lig}^{833}$ und schließlich war für $11 \%$ ein schwerer Rückfall ${ }^{834}$ zu verzeichnen. ${ }^{835}$ Diese recht hohen Rückfallraten dürften damit zusammenhängen, dass sich die Studie auf Frauen bezog, die bereits eine stationäre Sanktion erhalten hatten und dementsprechend zu den besonders rückfallgefährdeten Personen zählen, wie auch im Folgenden noch zu untersuchen sein wird.

\footnotetext{
825 Einsele, in: MschrKrim 1968, S. 334, 358 f.

826 Einsele, in: MschrKrim 1968, S. 28, 34.

827 Einsele, in: MschrKrim 1968, S. 334, 338.

828 Memminger, Untersuchungen zur weiblichen Frühkriminalität.

${ }^{829}$ Memminger, S. 9.

830 Memminger, S. 179.

$831 \mathrm{Zu}$ dieser Gruppe wurden Neueintragungen wegen Geldstrafe oder wegen Freiheitsstrafen von nicht mehr als zwei Monaten sowie Widerruf des ausgesetzten Strafvollzugs gezählt; vgl. zu der Einteilung der Erfolgsgruppen: Memminger, S. $181 \mathrm{f}$.

832 Dazu zählten Freiheitsstrafen von insgesamt nicht mehr als neun Monaten.

${ }^{833}$ Hierunter fasste die Autorin Freiheitsstrafen von insgesamt nicht mehr als drei Jahren.

$834 \mathrm{Zu}$ dieser Gruppe wurden Freiheitsstrafen von insgesamt über drei Jahren gezählt.

835 Die restlichen $5 \%$ wurden nicht gewertet, weil sie z.B. verstorben waren.
} 
Loos ${ }^{836}$ untersuchte die Rückfallkriminalität von 83 heranwachsenden Frauen in den Jahren 1970 bis 1975 im Landgerichtsbezirk Koblenz anhand von Strafakten. Bei den Probanden handelte es sich nur um Rückfalltäterinnen. ${ }^{837}$ Schwerpunkt der Untersuchung war die Fragestellung, ob bei heranwachsenden Rückfalltäterinnen besondere soziale oder psychiatrische Auffälligkeiten zu finden sind, die sie speziell von männlichen Rückfalltätern unterscheiden. Hierzu stellte Loos fest, dass zwar sowohl Rückfalltäter als auch Rückfalltäterinnen überwiegend aus gestörten Familienverhältnissen kamen sowie psychische Auffälligkeiten und Intelligenzmängel aufwiesen. Die weiblichen Probanden waren jedoch einer Mehrzahl dieser negativen Einflüsse ausgesetzt. ${ }^{838}$ Der Autor zog aus diesem Ergebnis sowie aus einer ergänzend herangezogenen Analyse der Erklärungsansätze zur Entstehung weiblicher Kriminalität den Schluss, dass bei Frauen negative Einflüsse deutlich stärker oder aber vermehrt auftreten müssen, ehe sie straffällig werden. ${ }^{839}$ Darüber hinaus überprüfte Loos die Rückfallintervalle und stellte fest, dass sich $65 \%$ Rückfälle in den ersten zwölf Monaten ereigneten.

Bietsch ${ }^{840}$ untersuchte die Rückfälligkeit nach abgeschlossener Bewährungszeit. Hierzu befragte sie im Jahr 198288 Männer und 84 Frauen, deren Bewährungszeit im Jahr 1979 endete. Die Untersuchung ergab, dass 18\% der befragten Frauen und $48 \%$ der befragten Männer in der Folgezeit erneut straffällig geworden waren. ${ }^{841}$

Zu dem Ergebnis einer selteneren Rückfälligkeit von Frauen im Vergleich zu Männern kamen auch Pongrat₹/Jürgensen ${ }^{842}$. Sie führten eine Nachuntersuchung delinquenter Kinder im Erwachsenenalter durch. Dabei stellten sie für die 175 weiblichen Probanden eine Rückfallquote in Höhe von $10 \%$ und für die 1.107 männlichen Probanden eine 31\%ige Rückfallrate fest..$^{843}$

Eine aktuellere Untersuchung führte Miller ${ }^{844}$ durch. Anhand eines Datenerhebungsbogens wertete sie 88 Gutachten (44 Mädchen, 44 Jungen), die in der Abteilung Psychiatrie und Psychotherapie im Kindes- und Jugendalter in Tübingen im Zeitraum zwischen 1980 und 1997 begutachtet wurden, aus. Ergänzend wurden Auszüge des Bundeszentralregisters herangezogen, um das Rückfallverhalten mit zu analysieren. Ihre Auswertungen zur Rückfälligkeit der Probanden ergaben, dass

\footnotetext{
836 Loos, Rückfallkriminalität bei heranwachsenden Frauen in den Jahren 1970-1975 im Landgerichtsbezirk Koblenz.

${ }^{837}$ Dies entsprach einer Rückfallquote von 16,5 \% (83 von insgesamt 502 Täterinnen).

838 Loos, S. $120 \mathrm{f}$.

839 Loos, S. 144.

840 Bietsch, in: Kerner/Kury/Sessar (Hrsg.), Deutsche Forschungen zur Kriminalitätsentstehung und Kriminalitätskontrolle, S. 1591-1612.

841 Bietsch, in: Kerner/Kury/Sessar (Hrsg.), Deutsche Forschungen zur Kriminalitätsentstehung und Kriminalitätskontrolle, S. 1591, S. 1605.

842 Pongratz/Jürgensen, Kinderdelinquenz und kriminelle Karrieren, 1990.

843 Pongratz/Jürgensen, S. 176 f.

${ }^{844}$ Miller, Jugendliche Straftäterinnen - unterscheiden sie sich von delinquenten Jungen?, 2009.
} 
Jungen häufiger als Mehrfachtäter in Erscheinung treten als Mädchen und zudem mit $48 \%$ zu $26 \%$ eine deutlich höhere Rückfallquote aufweisen. Darüber hinaus stellte die Autorin fest, dass Mädchen häufiger einschlägig rückfällig werden als Jungen. ${ }^{845}$

Schließlich existieren einige Auswertungen, die wie die vorliegende Arbeit ausschließlich auf den Daten des BZR basieren.

Storz $\$ 46$ untersuchte den vollständigen Geburtenjahrgang 1961 auf seine Eintragungen im Zentral- und Erziehungsregister. Da die Daten 1984 gezogen wurden, war es möglich, die weiteren Eintragungen für die im Jugendalter Sanktionierten bis einschließlich des 22. Lebensjahres zu verfolgen, sodass auch Aussagen zu den Rückfallraten getroffen werden konnten. ${ }^{847}$ Nach Auswertung der Daten kam Storz zu dem Ergebnis, dass die Nachentscheidungsraten nach erstmaliger Sanktionierung innerhalb der untersuchten Delikts- und Altersgruppen von der informellen über die formelle ambulante Sanktionierung bis zu Arrest und Jugendstrafe als Sanktionsart im ersten Verfahren kontinuierlich ansteigen. Um die Frage zu beantworten, ob dieser Unterschied auch bei einer Differenzierung nach dem Merkmal Geschlecht erhalten bleibt, überprüfte Storz den Rückfall innerhalb von vier Jahren nach der Art der erstmaligen Sanktionierung bei einfachem Diebstahl und Fahren ohne Fahrerlaubnis bei Jugendlichen nach Geschlecht. Sie kam zu dem Ergebnis, dass von den wegen einfachen Diebstahls sanktionierten Frauen 15,8 \% mindestens eine Nachentscheidung aufwiesen. Für das Fahren ohne Fahrerlaubnis wiesen 8,5\% der Frauen mindestens eine Nachentscheidung auf. Ferner steigen auch bei den Frauen die Rückfallraten nach erstmaliger Sanktionierung, mit der Schwere der Sanktion an. ${ }^{848}$

Harrendorf ${ }^{849}$ stellt auf der Grundlage der Daten des BZR für das Jahr 1994 für die Gruppe der Gewalttäter fest, dass Frauen eine deutlich geringere Rückfälligkeit aufweisen und Serientäterschaften bei ihnen kaum vorkommen. ${ }^{850}$

Kirchner ${ }^{851}$ überprüfte ebenfalls die BZR-Daten für das Jahr 1994, allerdings für die Gruppe der Verkehrsstraftäter. Er kam zu dem Ergebnis, dass auch die Verkehrsstraftäterinnen seltener rückfällig werden. Im Falle eines Rückfalls werden sie allerdings anteilsmäßig häufiger verkehrsspezifisch rückfällig als Männer. ${ }^{852}$

\footnotetext{
845 Miller, S. $81 \mathrm{ff}$.

846 Storz, Jugendstrafrechtliche Reaktionen und Legalbewährung, in: Bundesministerium der Justiz (Hrsg.), Diversion im Jugendstrafrecht der Bundesrepublik Deutschland, S. 133-220.

847 Story, in: Bundesministerium der Justiz (Hrsg.), Diversion im Jugendstrafrecht der Bundesrepublik Deutschland, S. 133, 135.

848 Stor, in: Bundesministerium der Justiz (Hrsg.), Diversion im Jugendstrafrecht der Bundesrepublik Deutschland, S. 133, 169 f.

${ }^{849}$ Harrendorf, Rückfälligkeit und kriminelle Karrieren von Gewalttätern, 2007.

850 Harrendorf, S. 389.

${ }^{851}$ Kirchner, in: Heinz/Jehle (Hrsg.), Rückfallforschung, S. 261-288.

852 Kirchner, in: Heinz/Jehle (Hrsg.), Rückfallforschung, S. 261, 268 f.
} 
Weigelt 553 stellte auf Grundlage der Daten des BZR für das Bezugsjahr 1994 fest, dass Frauen nach Bewährungsstrafen seltener wiederverurteilt werden als Männer. ${ }^{854}$

Schließlich ergeben sich bereits aus der Rückfallstatistik der Dienststelle des BZR für die Jahre 1986-1990855 sowie aus den Legalbewährungsstudien für die Bezugsjahre 1994 und 2004,856 niedrigere Rückfallquoten für Frauen im Vergleich zu Männern.

Zusammenfassend lässt sich konstatieren, dass der Forschungsstand zur Rückfälligkeit von Frauen ausfüllungsbedürftig ist. Den Untersuchungen, die von dem Anteil an Vorstrafen der verurteilten Straftäterinnen auf die Rückfälligkeit schlieBen wollen, ist vorzuhalten, dass für die Bestimmung der Rückfälligkeit, wie bereits ausgeführt, eine prospektive Betrachtungsweise notwendig ist. Dies ist teilweise auch den Autoren bewusst. So merkt Lauritzen an, dass eine Rückfallstatistik die Frage beantworten müsste, welcher Prozentsatz der in einem bestimmten Zeitraum Verurteilten später wieder verurteilt worden ist. ${ }^{857}$ Darüber hinaus sind die meisten Untersuchungen relativ alt oder ihnen lag nur eine geringe Probandenzahl zugrunde. Die Untersuchung von Einsele ist hier allerdings hervorzuheben: Die Autorin hat umfangreiche Ergebnisse zu straffälligen Frauen und in diesem Zusammenhang auch einige interessante Ergebnisse zur weiblichen Rückfallkriminalität erzielt, die teils mit dem dieser Untersuchung zugrunde liegenden Datenmaterial überprüft werden können. Die neueren Studien, die bereits auf die Daten des BZR zurückgreifen, beschäftigen sich lediglich am Rande mit dem weiblichen Geschlecht. Kaum eine Untersuchung trifft über die allgemeine Feststellung, dass Frauen seltener rückfällig werden als Männern, hinaus Aussagen über ihre Rückfallkriminalität, sodass eine detaillierte Untersuchung mit einer breiten Datenbasis noch aussteht.

\section{Die Rückfallkriminalität von Frauen auf der Grundlage der Daten des Bundeszentralregisters}

Im Folgenden werden nunmehr die eigenen Ergebnisse zur Rückfallkriminalität von Frauen vorgestellt. Hierfür wird auf den bereits eingangs und in Kapitel 3 vorgestellten Rückfalldatensatz, der aus den Daten des BZR konzipiert wurde, zurückgegriffen. ${ }^{858}$

\footnotetext{
${ }^{853}$ Weigelt, Bewähren sich Bewährungsstrafen, 2008.

854 Weigelt, S. 196; so auch Bietsch, in: Kerner/Kury/Sessar (Hrsg.), S. 1605.

855 Vgl. Tab. aus Göppinger, 1997, S. 702, basierend auf den Daten der Rückfallstatistik der Dienststelle des BZR von 1986-1990.

856 Jeble/Heinz/Sutterer, Legalbewährung nach strafrechtlichen Sanktionen, 2003, S. 47; Jeble/Albrecht/

Hohmann-Fricke/Tetal, Legalbewährung nach strafrechtlichen Sanktionen, 2010, S. 49.

${ }^{857}$ Lauritzen, S. 157 f.

${ }^{858}$ Vgl. ausführlich unter Kap. 3, 2.1.
} 
Anders als im vorangegangenen Kapitel werden hier zunächst nur die Frauen betrachtet. Eine umfangreiche, frauenspezifische Analyse der Rückfallkriminalität wird erfolgen. Anschließend wird unter 5. an die Ergebnisse aus Kapitel 5 angeknüpft, um zu überprüfen, wie Frauen im Vergleich zu Männern im Falle eines Rückfalls sanktioniert werden. An dieser Stelle soll, im Unterschied zu Kapitel 5, nicht nur die Ebene der Bezugs-, sondern insbesondere die der Folgeentscheidung in die Auswertungen mit einbezogen werden.

Wie bereits erwähnt, muss bei der Analyse der Rückfälligkeit beachtet werden, dass unterschiedliche Rückfallraten nach den verschiedenen Sanktionen der Bezugsentscheidung keinen Rückschluss auf die Sanktionseffizienz zulassen. ${ }^{859}$ Vielmehr könnten die Unterschiede auf einer zutreffenden richterlichen Einschätzung der Täterpersönlichkeit beruhen, denn das Gesetz sieht schärfere Sanktionen vor allem für die Täter mit ungünstiger Prognose vor. ${ }^{860}$

\subsection{Der Rückfallbegriff}

Bevor die Rückfallkriminalität weiblicher Straftäter und später auch der Vergleich zu männlichen Straftätern (vgl. 5) eingehend untersucht werden, ist zu klären, was unter dem Begriff des Rückfalls bzw. der Rückfälligkeit zu verstehen ist. Der kriminologische Rückfallbegriff versteht unter Rückfall jede erneute Begehung von Straftaten, also auch die im Dunkelfeld verbliebenen Straftaten. ${ }^{861}$ Eine derartig weite Auffassung des Rückfallbegriffs kann der vorliegenden Untersuchung jedoch nicht zugrunde gelegt werden, da nur die im Datensatz registrierten und sanktionierten Straftaten ausgewertet werden können. Rückfall kann hier dementsprechend nur als jede erneute justiziell registrierte Straftat verstanden werden. ${ }^{862}$ Hierbei ist wiederum nur jede rechtskräftige Verurteilung als Rückfalltat zu berücksichtigen und nicht bereits ein polizeilicher Tatverdacht. Ein polizeilicher Tatverdacht scheidet schon deshalb aus, weil es kein bundesweites Register polizeilicher Tatverdächtiger gibt, mit dem eine Zuordnung zu den später Sanktionierten erfolgen könnte. ${ }^{863}$ Im BZR sind hingegen sämtliche rechtskräftigen strafgerichtlichen Verurteilungen durch ein deutsches Gericht enthalten (vgl. $\iint 3$ ff. BZRG). Daher bilden die dortigen Eintragungen die Grundlage für die Legalbewährungsstudien und für die vorliegende Untersuchung.

Bei ambulanten Sanktionen bildet das Urteil die Bezugsentscheidung. Damit ist der Tag der erstinstanzlichen Verurteilung der früheste Rückfallzeitpunkt, der späteste liegt drei Jahre danach. Bei verbüßten stationären Sanktionen, ist das Entlassungsdatum als Bezugsentscheidung zugrunde zu legen. Eine Person ist

\footnotetext{
${ }^{859}$ BMI/BMJ (Hrsg.), PSB I, S. 452; Harrendorf, S. 218.

${ }^{860}$ BMI/BMJ (Hrsg.), PSB I, S. 452; Harrendorf, S. 218; vgl. hierzu auch unter Kap. 5, 2.

${ }^{861}$ Mannheim 1974, S. 51; Heinz, in: ZJJ 2004, S. 35, 37.

862 Sog. strafrechtlicher Rückfallbegriff; vgl. hierzu auch Hein₹, in: ZJJ 2004, S. $35,37$.

863 Heinz, in: ZJJ 2004, S. 35, 37.
} 
rückfällig, wenn sie im dreijährigen Risikozeitraum eine im BZR registrierte weitere Straftat begangen hat (sog. allgemeiner Rückfallbegriff). 864

Neben diesem allgemeinen Rückfall soll auch der sog. einschlägige Rückfall untersucht werden. Der einschlägige Rückfall bezeichnet jede erneute Verurteilung wegen einer Straftat einer verwandten Deliktsgruppe oder desselben Delikts. ${ }^{865}$

\subsection{Folgeentscheidungen im Verhältnis zu den Bezugsentscheidungen}

Zunächst gibt Schaubild 6.1 einen Überblick über die Art der Bezugs- und Folgeentscheidungen, die Frauen im Bezugsjahr 2004 erhalten haben.

Schaubild 6.1: Art der Bezugsentscheidung und Art der Folgeentscheidung innerhalb von 3 Jabren von Frauen $(n=216.993866) *$

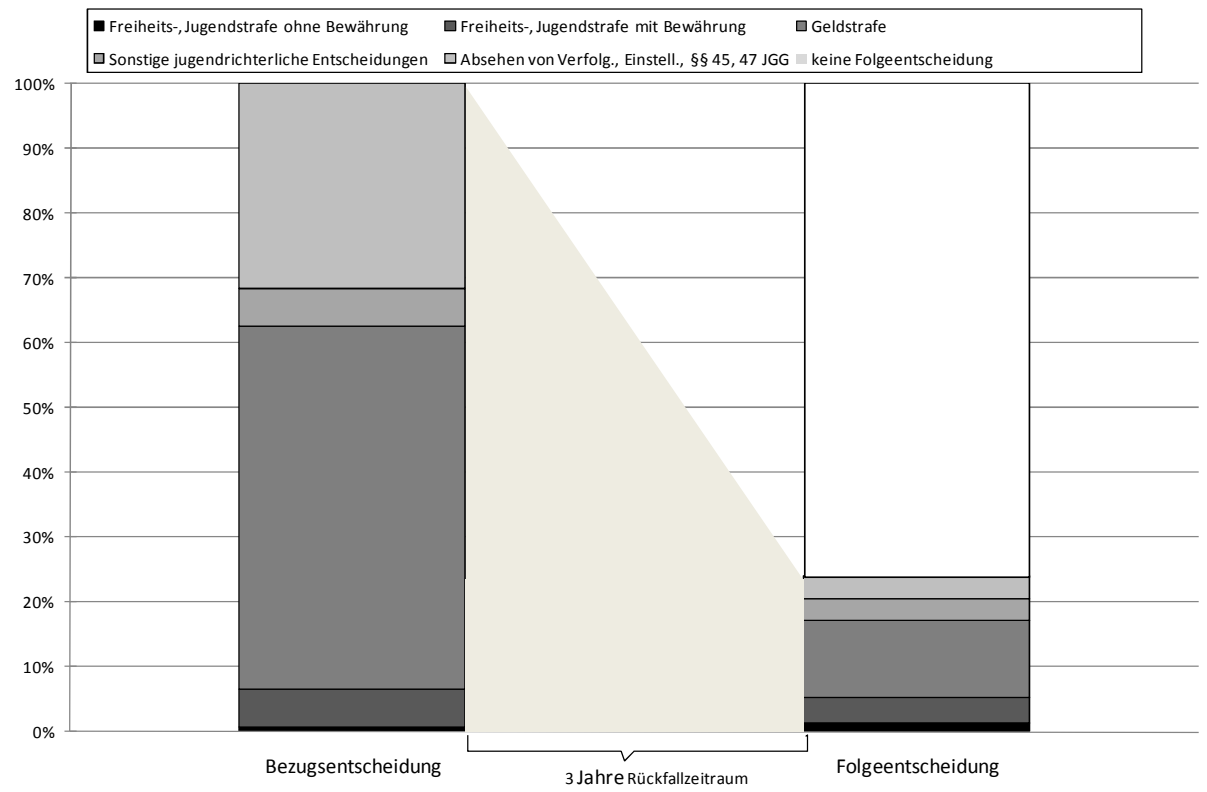

* Absolutzablen siebe Tab. 6.1 a im Anbang

Es wird deutlich, dass die meisten Frauen im Risikozeitraum von drei Jahren nicht erneut straffällig werden. Rund $24 \%$ werden wieder registriert. Betrachtet man die Art der Folgeeintragung genauer, zeigt sich, dass im Falle eines Rückfalls die Sanktion der Geldstrafe mit $12 \%$ der Ausgangspopulation dominiert, gefolgt von den Freiheitsstrafen mit Bewährung mit 4\%. Die Reaktionen gem. $\int S$ 45, 47 JGG sowie die sonstigen jugendrichterlichen Entscheidungen machen jeweils noch

${ }^{864}$ So auch der von Harrendorf zugrunde gelegte Rückfallbegriff, vgl. Harrendorf, S. 187.

865 Vgl. hierzu näher unter Kap. 6, 4.6 sowie auch unter Kap. 6, 5.4.4 und 5.5.4

866 Nicht enthalten sind 14 Fälle, die sich nicht den dargestellten Kategorien zuordnen lassen 
einen Anteil von 3\% aus. Die stationären Sanktionen spielen mit rund $1 \%$ kaum eine Rolle. ${ }^{867}$ Gleichwohl wird deutlich, dass die stationären Strafen im Verhältnis zu denen in der Bezugsentscheidung deutlich angewachsen sind: 0,7\% der Frauen haben als Sanktion in der Bezugsentscheidung eine Jugend- oder Freiheitsstrafe ohne Bewährung erhalten, wohingegen fast doppelt so viele, nämlich 1,3\%, eine stationäre Sanktion als Folgeeintragung aufweisen.

\subsection{Art der Folgeentscheidung nach Sanktionsart der Bezugsentscheidung}

\subsection{1 Überblick}

Als nächstes wird die Rückfallrate in Abhängigkeit von der Sanktionsart der Bezugsentscheidung betrachtet. Schaubild 6.2 differenziert die Rückfallrate sowohl für die Sanktionsarten der Bezugsentscheidungen nach Jugendstrafrecht (linke Seite) als auch für die Sanktionsarten der Bezugsentscheidungen nach allgemeinem Strafrecht (rechte Seite), wobei die bereits für Kapitel 5 gebildeten Sanktionsgruppen verwendet wurden. Der Jugendarrest wurde aus den sonstigen Entscheidungen nach JGG heraus gerechnet und stellt eine eigenständige Gruppe dar. Für die Folgeentscheidungen wurden hingegen der Übersicht halber die stationären Sanktionen (Freiheits- und Jugendstrafe ohne Bewährung), die ausgesetzten Strafen (Freiheits- und Jugendstrafen mit Bewährung) sowie die sonstigen ambulanten Sanktionen (Geldstrafe sowie alle jugendrichterlichen Reaktionen, die nicht eine Jugendstrafe betreffen) zu drei Gruppen zusammengefasst. Ferner wurde eine Gruppe für „keine Folgeentscheidung“ gebildet. Diese Einteilung auf der Ebene der Folgeentscheidung wird auch im weiteren Verlauf der Untersuchung zugrunde gelegt.

Die höchste Rückfallrate ist nach Jugendstrafen ohne Bewährung mit $58 \% \mathrm{zu}$ verzeichnen. Der Jugendarrest $(51 \%)$ und die Jugendstrafen mit Bewährung (49\%) besitzen gleichfalls hohe Rückfallquoten. Bei den Bezugssanktionen nach Jugendstrafrecht besitzen die Entscheidungen gem. $\iint 45,47$ JGG die niedrigsten Rückfallraten. Auch bei Betrachtung der Sanktionsart der Bezugsentscheidungen nach allgemeinem Strafrecht ist nach stationären Sanktionen die höchste Rückfallrate zu verzeichnen. Sie liegt aber mit $41 \%$ unter den Rückfallraten nach Jugendstrafen mit und ohne Bewährung sowie nach Jugendarrest. Die Rückfallrate nach Geldstrafe liegt vergleichsweise niedrig bei $23 \%$.

Wenn man die Sanktionsart der Folgeentscheidung mit betrachtet ergibt sich, dass nach den schwereren Sanktionen der Bezugsentscheidung auch die größten Anteile für stationäre Sanktionen als Folgeeintragungen vorliegen: So erhalten $23 \%$ der Frauen, die als Bezugssanktion eine Jugendstrafe ohne Bewährung und $17 \%$ der Frauen, die als Bezugssanktion eine Freiheitsstrafe ohne Bewährung er-

${ }^{867}$ Vgl. Zu den Absolutzahlen Tab. 6.1 im Anhang. 
Schaubild 6.2: Art der Folgeentscheidung nach Sanktionsart der Bezugsentscheidung*

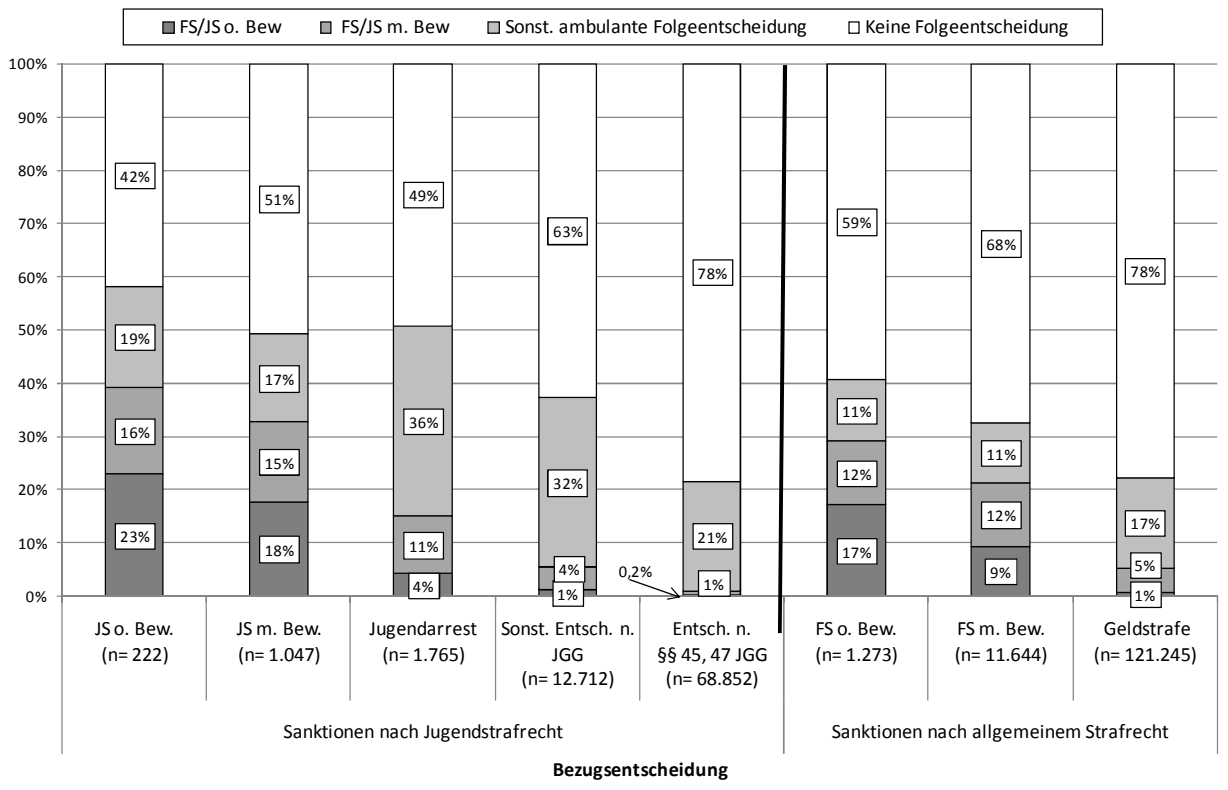

* Absolutrablen siebe Tab. 6.2a im Anhang

halten haben, gleichfalls eine Freiheits- oder Jugendstrafe ohne Bewährung als Folgesanktion.

Zudem ist die Rückfallwahrscheinlichkeit bei jungen Frauen, die in der Bezugsentscheidung eine Sanktion nach Jugendstrafrecht erhalten haben höher als bei denjenigen, die nach allgemeinem Strafrecht verurteilt wurden.

Insgesamt lässt sich konstatieren, dass ein deutlicher Zusammenhang zwischen der Schwere der Bezugssanktion und der Legalbewährung besteht: Je schwerer die Sanktionsart der Bezugsentscheidung, desto höher und schwerer ist auch der Rückfall.

\subsubsection{Art der Folgeentscheidung nach Geldstrafe}

Im Folgenden wird die Art der Folgeentscheidung nach Geldstrafe als Sanktion in der Bezugsentscheidung noch differenzierter nach Anzahl der Tagessätze betrachtet.

Schaubild 6.3 vergleicht die Sanktionsart der Folgeeintragung nach verschiedenen Tagessatzanzahlen der Geldstrafe in der Bezugsentscheidung. Insgesamt betrachtet ist die Rückfallrate nach Erhalt einer Geldstrafe mit $23 \%$ besonders niedrig. Auch im Falle eines Rückfalls werden die Frauen in erster Linie wegen sonstiger ambulanter Sanktionen wieder registriert. 


\section{Schaubild 6.3: Art der Folgeentscheidung nach Geldstrafe*}

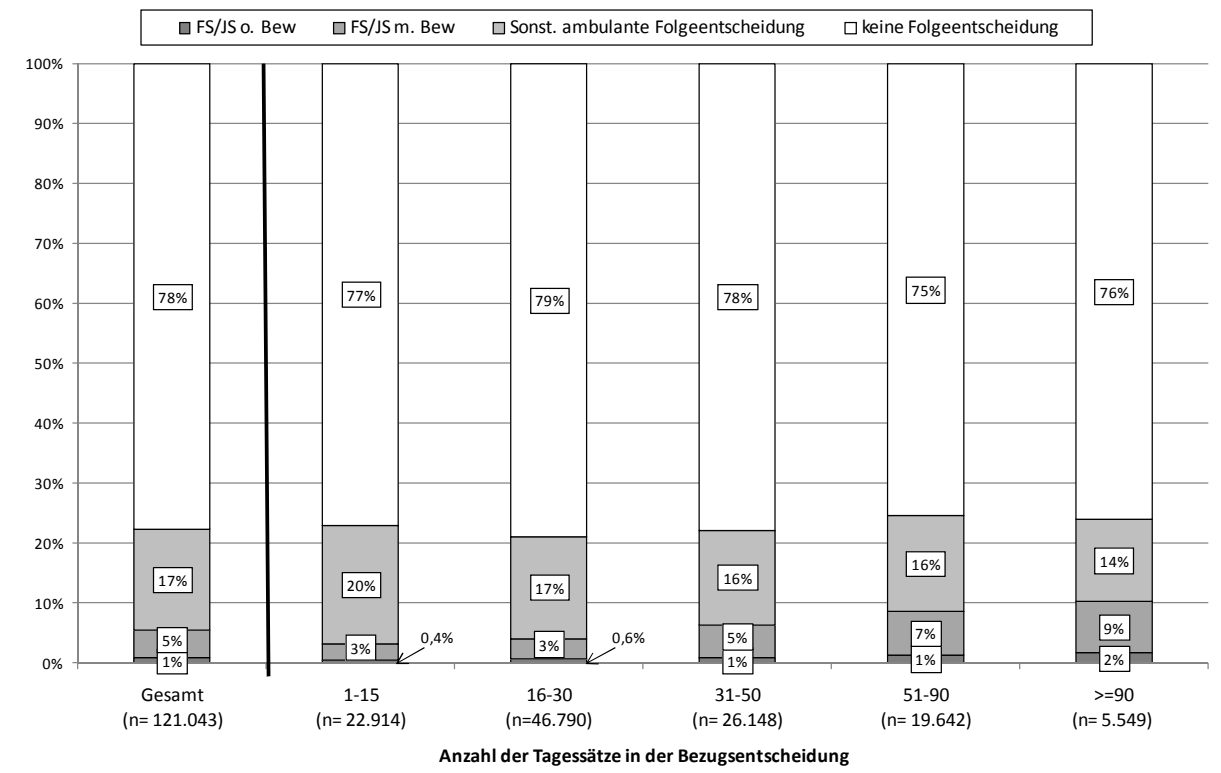

* Absolutzablen siehe Tab. 6.3 a im Anbang

Die Wahrscheinlichkeit, nach Geldstrafe eine stationäre Folgesanktion zu bekommen, steigt mit zunehmender Anzahl der Tagessätze leicht an. Aber auch für die Frauen, die als Sanktionsart in der Bezugsentscheidung eine Geldstrafe über 90 Tagessätze erhalten haben, wurde nur in $2 \%$ der Fälle als Folgeeintragung eine Jugend- oder Freiheitsstrafe ohne Bewährung registriert.

\subsubsection{Art der Folgeentscheidung nach freiheitsentziehenden Sanktionen}

Nach der differenzierten Darstellung der Rückfallraten nach Geldstrafen, wird nunmehr die Art der Folgeentscheidung nach freiheitsentziehenden Sanktionen, zunächst nach Jugend- und sodann nach Freiheitsstrafen betrachtet.

Schaubild 6.4 gibt die Ergebnisse einer Analyse der Rückfallraten nach freiheitsentziehenden Sanktionen wieder. Auf der linken Seite sind die Rückfallraten nach Jugendstrafen bis zu zwei Jahren abgebildet, wobei die Jugendstrafen mit und ohne Bewährung für diese Gruppe miteinander verglichen werden. Auf der rechten Seite werden die Rückfallraten aller vollstreckten Jugendstrafen nach Haftentlassung wegen Strafrestaussetzung und nach Vollverbüßung einander gegenüber gestellt. Der Vergleich ergibt, dass nach bedingten Jugendstrafen bis zu zwei Jahren eine niedrigere Rückfallrate zu verzeichnen ist als für die unbedingten Jugendstrafen bis zu zwei Jahren. 
Schaubild 6.4: Art der Folgeentscheidung nach Jugendstrafe*

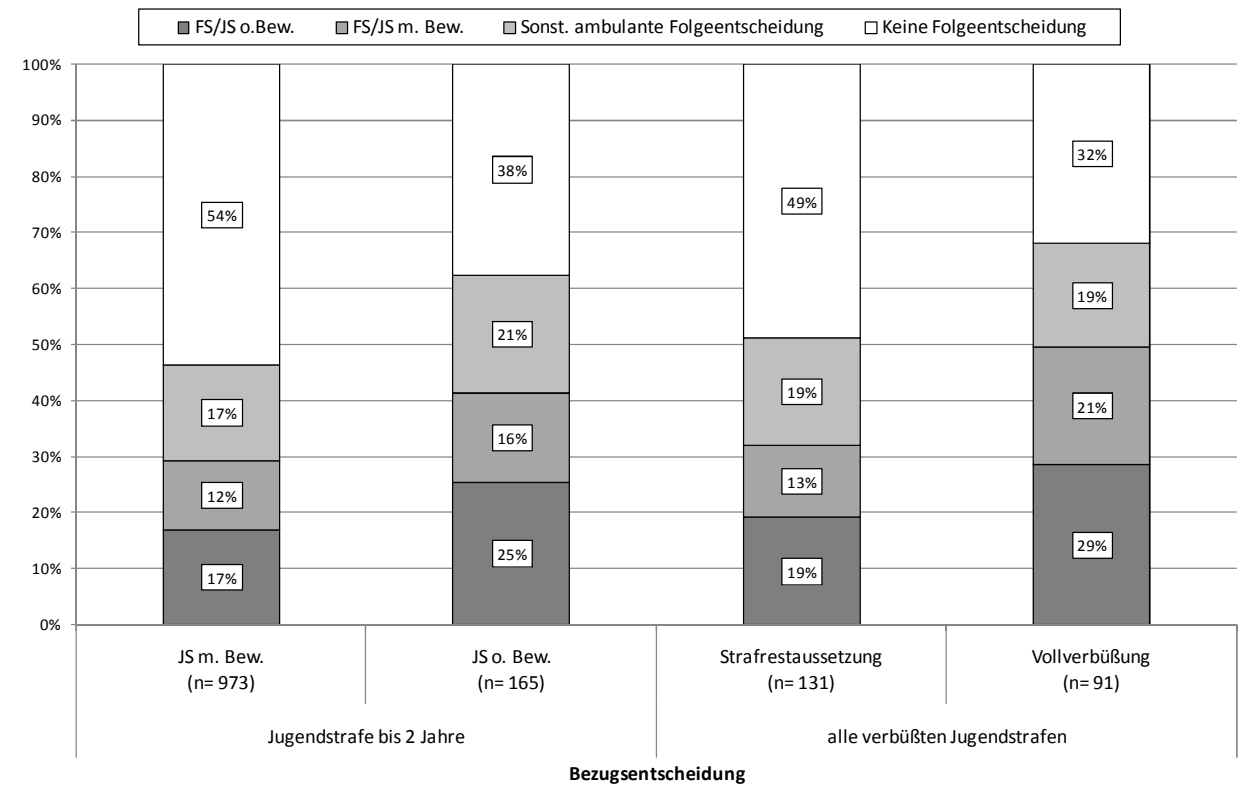

* Absolutrablen siebe Tab. 6.4a im Anhang

Auch im Falle eines Rückfalls ist die Sanktionsart der Folgeeintragung bei den bedingten Jugendstrafen weniger schwer als bei den unbedingten: So erhalten $25 \%$ der Frauen, die als Sanktion in der Bezugsentscheidung eine Jugendstrafe ohne Bewährung bis zu zwei Jahre erhalten haben, eine erneute stationäre Sanktion, wohingegen dieser Anteil bei den Jugendstrafen mit Bewährung nur $17 \%$ beträgt. Die gleiche Tendenz ergibt sich, wenn man die Rückfallraten der haftentlassenen Frauen nach Strafrestaussetzung und Vollverbüßung miteinander vergleicht: Im Falle der Strafrestaussetzung erhalten $19 \%$ der Frauen als Folgesanktion eine Freiheits- und Jugendstrafe ohne Bewährung, bei den Vollverbüßerinnen sind es hingegen $29 \%$. Nach Strafrestaussetzung wurde für die Täterinnen häufiger keine Folgeentscheidung (49\%) registriert als bei den Vollverbüßerinnen $(32 \%) .868$

Wie Schaubild 6.5 zeigt, sind die Unterschiede zwischen den Rückfallraten nach bedingten und unbedingten Freiheitsstrafen bis zu zwei Jahren noch deutlicher ausgeprägt als bei den Jugendstrafen: $9 \%$ der Frauen, die als Sanktion in der Bezugsentscheidung eine Freiheitsstrafe mit Bewährung erhalten haben, erhalten als

\footnotetext{
868 Anders Einsele, die zwischen den Rückfallraten minderjähriger Täterinnen nach bedingter und regulärer Entlassung nur einen Unterschied in Höhe von zwei Prozentpunkten feststellte, vgl. Einsele, in: MschrKrim 1968, S. 334, 359. Dieses Ergebnis dürfte jedoch allein schon aufgrund des Zeitablaufs nicht vergleichbar sein.
} 
Folgeentscheidung wieder eine stationäre Sanktion. Bei den Frauen, bei denen die Freiheitsstrafe bis zu zwei Jahren nicht zur Bewährung ausgesetzt wurde, sind es hingegen $22 \%$.

\section{Schaubild 6.5: Art der Folgeentscheidung nach Freiheitsstrafe*}

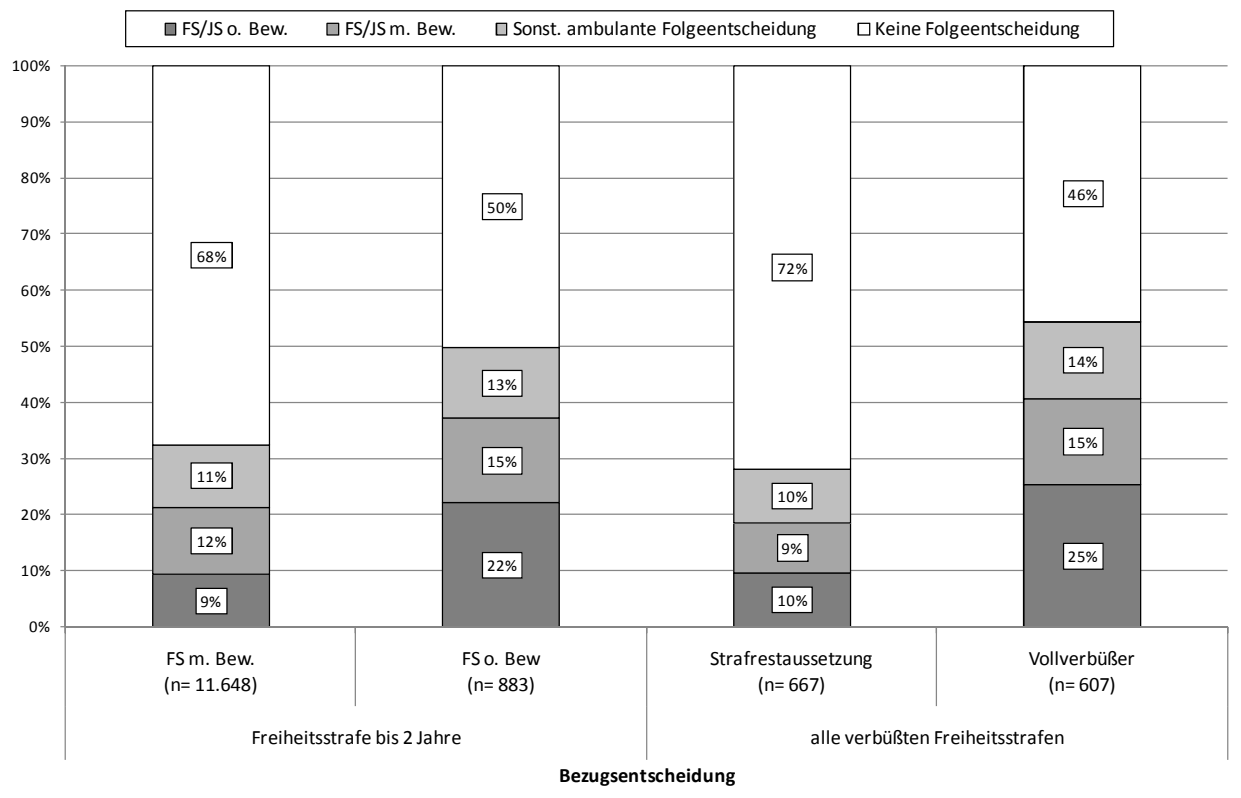

* Absolutrablen siehe Tab. 6.5a im Anhang

Der große Unterschied bei der Rückfälligkeit findet sich auch bei einem Vergleich der Strafrestaussetzungen mit den Vollverbüßungen wieder: $10 \%$ der Frauen, bei denen eine Haftentlassung nach Strafrestaussetzung erfolgte und $25 \%$ der Frauen, die ihre Haftstrafe voll verbüßen mussten, wurden erneut mit einer Jugend- oder Freiheitsstrafe ohne Bewährung registriert. ${ }^{869}$ Hierbei darf allerdings nicht außer Acht gelassen werden, dass den Fällen der Straf- und Strafrestaussetzung eine günstigere Prognose zugrunde liegt. 870

Schaubild 6.6 vergleicht die Rückfallrate nach stationären Jugend- und Freiheitsstrafen miteinander, wobei nach Dauer der Freiheitsentziehung in der Bezugssanktion differenziert wird. Zunächst werden wieder die insgesamt höheren Rückfallraten nach Jugendstrafen deutlich. Bei den Jugendstrafen zeigt sich, dass

${ }^{869}$ Einsele konnte für die Altersgruppe der Erwachsenen ebenfalls feststellen, dass bedingt entlassene seltener rückfällig wurden als regulär entlassene Täterinnen, vgl. Einsele, in: MschrKrim 1968, S. 28, 77; zur Problematik der Vergleichbarkeit der Ergebnisse vgl. Fn. 868.

870 Jeble/Albrecht/Hohmann-Fricke/Tetal, Legalbewährung nach strafrechtlichen Sanktionen, 2010, S. 65. 
die Rückfallrate von Frauen nach den kürzeren Jugendstrafen von sechs Monaten bis zu einem Jahr am höchsten ist $(68 \%)$ und dann stetig sinkt.

Schaubild 6.6: Rückfallrate nach Dauer der unbedingten Jugend-und Freiheitsstrafen der Bezugsentscheidung

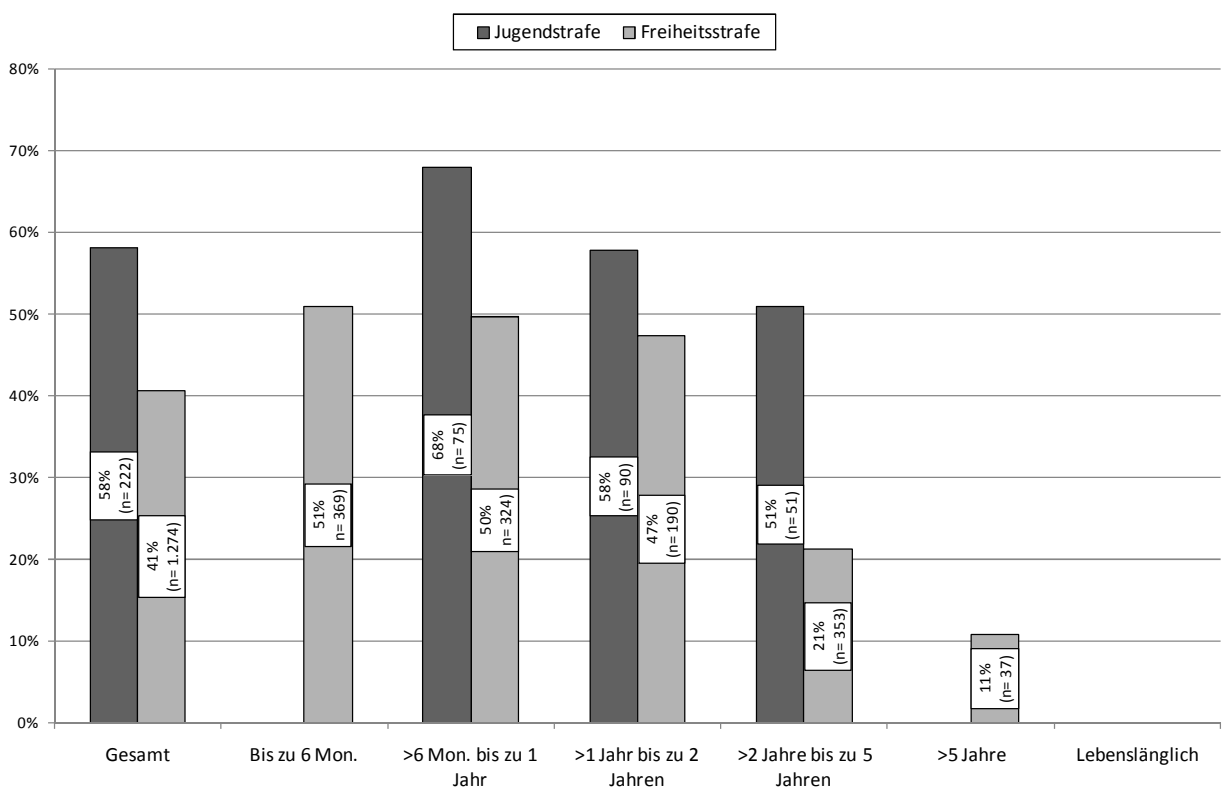

Von den sechs im Rückfalldatensatz registrierten Frauen, die als Bezugssanktion eine Jugendstrafe über fünf Jahre bekommen haben, ist keine Folgeentscheidung im Risikozeitraum registriert, sodass dort auch kein Rückfall zu verzeichnen ist.

Betrachtet man die Rückfälle nach Freiheitsstrafen, so lassen sich die höchsten Rückfallquoten für die kurzen Freiheitsstrafen (51\%), gefolgt von den Freiheitsstrafen von sechs Monaten bis zu einem Jahr (50\%) und ein bis zu zwei Jahren (47\%) feststellen. Ab den Freiheitsstrafen von sechs Monaten bis zu einem Jahr ist ein stetiger Rückgang der Rückfälligkeit zu verzeichnen. Nur eine Frau ist in der Dauergruppe der Lebenslänglichen registriert und danach nicht mehr rückfällig geworden, sodass sie Quote hier bei $0 \%$ liegt.

Die unterschiedlichen Raten können auf verschiedene Gründe zurückführbar sein: Die verschiedenen Muster krimineller Karrieren bei kürzer oder länger Inhaftierten, Alterungs- und Reifeprozesse sowie die Tatsache, dass Freiheitsstrafen bis zu zwei Jahren bei guter Prognose zur Bewährung ausgesetzt werden, dürften hier eine Rolle spielen. ${ }^{871}$

871 Jeble/Albrecht/Hobmann-Fricke/Tetal, Legalbewährung nach strafrechtlichen Sanktionen, 2010, S. 62. 


\subsection{Folgeentscheidungen und Voreintragungen}

In Kapitel 5 wurde bereits festgestellt, dass die Anzahl und Art der Voreintragungen Einfluss auf die Sanktion in der Bezugsentscheidung haben. Wie zu überprüfen sein wird, dürfte sich dieser Einfluss auch bei den Folgesanktionen wiederfinden. Folglich wird nunmehr der Zeitraum vor der Bezugsentscheidung mit betrachtet. Bereits getilgte Voreintragungen sind dabei nicht mehr erfassbar. Bei der Anzahl der Voreintragungen werden alle, auch die später einbezogenen, Entscheidungen gezählt. Die Differenzierung nach Art der Voreintragungen berücksichtigt die Art der schwersten Sanktion. ${ }^{872}$

4.4.1 Art der Folgeentscheidung nach Anzahl und Art der schwersten Voreintragungen bei jugendlichen und heranwachsenden Frauen

Aus Schaubild 6.7 ergibt sich die Art der Folgeentscheidung nach Anzahl der Voreintragungen für die Altersgruppe der jugendlichen und heranwachsenden Frauen.

Schaubild 6.7: Art der Folgeentscheidung nach Anzabl der Voreintragungen für jugendliche und heranwachsende Frauen*

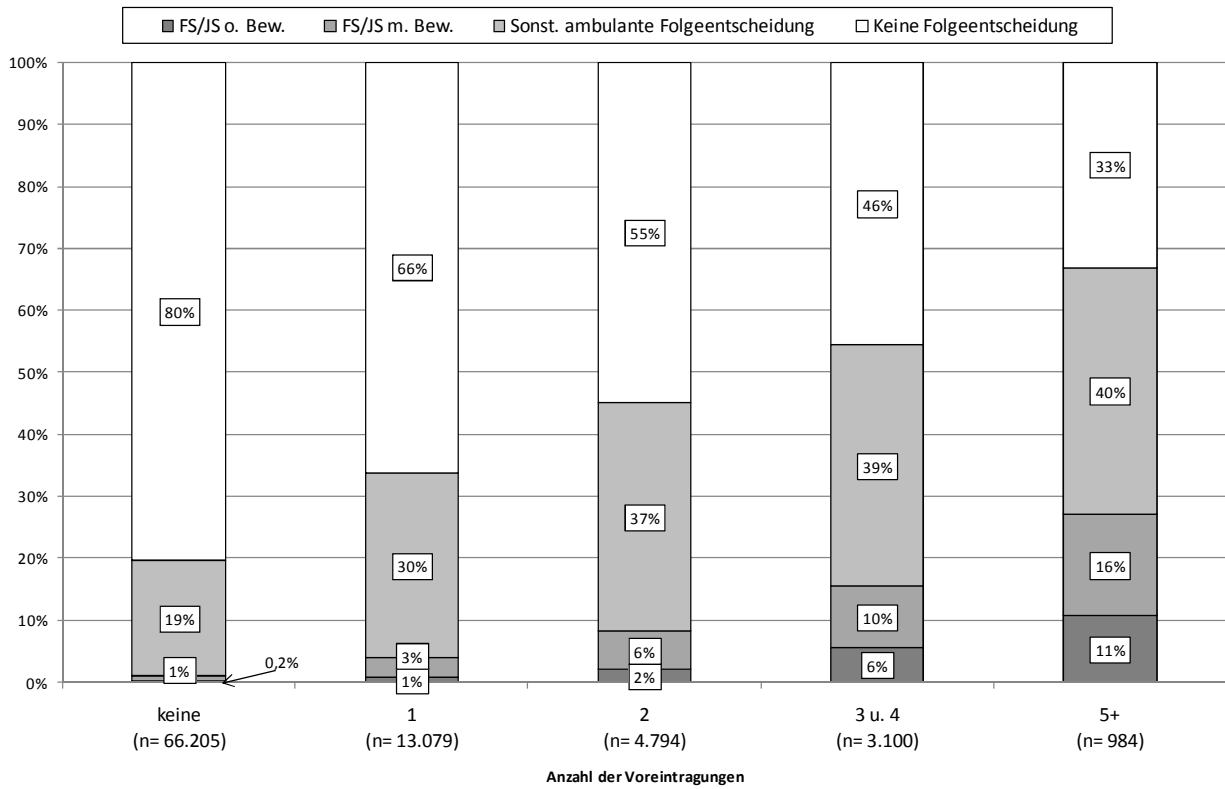

*Absolutrablen siehe Tab. 6.6a im Anbang.

Es wird deutlich, dass, wie vermutet, zwischen der Anzahl der Voreintragungen und der Rückfallwahrscheinlichkeit sowie der Art der Folgeentscheidung ein ein-

872 So auch die Zählung in Kap. 5. 
deutiger Zusammenhang besteht: Mit steigender Anzahl der Voreintragungen nimmt die allgemeine Rückfallquote zu.

Betrachtet man nur die Rückfälligen, so zeigt sich, dass der Anteil von stationären Folgesanktionen mit zunehmender Anzahl von Voreintragungen steigt. Bei den Frauen, für die keine Voreintragungen registriert wurden, beträgt der Anteil für Freiheits- bzw. Jugendstrafen ohne Bewährung 0,2 \%, wohingegen Frauen mit fünf und mehr Voreintragungen in $11 \%$ der Fälle eine Freiheits- oder Jugendstrafe ohne Bewährung als Folgesanktion erhalten. Dementsprechend werden $80 \%$ der Frauen, für die keine Voreintragungen registriert wurden, nicht wieder straffällig. Dieser Anteil reduziert sich auf $33 \%$ bei den Frauen mit 5 und mehr Voreintragungen.

Schaubild 6.8 widmet sich der Art der Folgeentscheidung nach Art der schwersten Voreintragung. Hier wurden auf Ebene der Voreintragungen die Freiheitsund Jugendstrafen zusammengefasst.

Schaubild 6.8: Art der Folgeentscheidung nach Art der schwersten Voreintragung für jugendliche und heranwachsende Frauen*

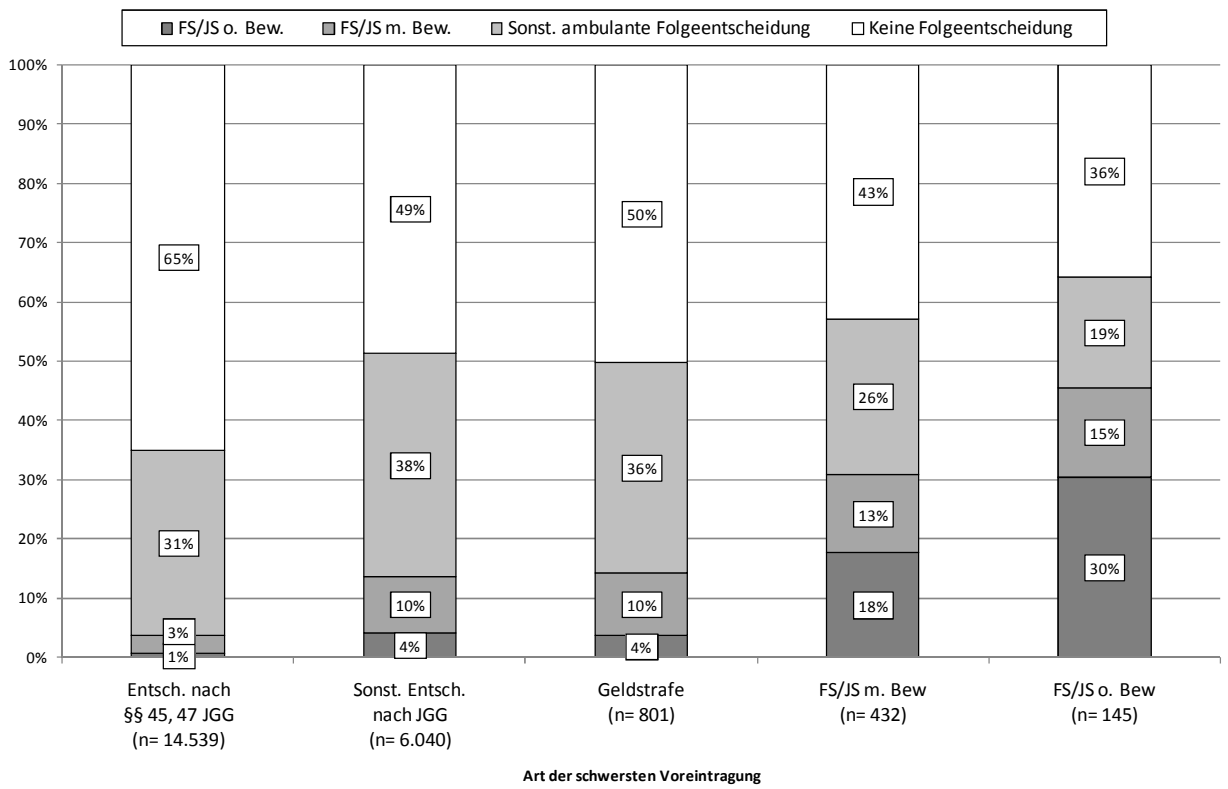

* Absolutzablen siehe Tab. 6.7a im Anhang 
Da vorliegend die jugendlichen und heranwachsenden Frauen betrachtet werden, ist es theoretisch möglich, dass auch Freiheitsstrafen als Voreintragung auftauchen. ${ }^{873}$ Als weitere Kategorien werden die Entscheidungen nach $\iint 45,47$ JGG, die sonstigen Entscheidungen nach JGG sowie die Geldstrafe miteinander verglichen. Der oben festgestellte Zusammenhang zwischen Sanktionsart der Folgeentscheidung und Anzahl der Voreintragungen bestätigt sich ebenso zwischen der Sanktionsart der Folgeentscheidung und der Art der schwersten Voreintragung (vgl. Schaubild 6.8): Frauen, für die als Voreintragung eine ambulante Entscheidung nach JGG oder StGB registriert ist, erhalten als Folgesanktion relativ selten eine

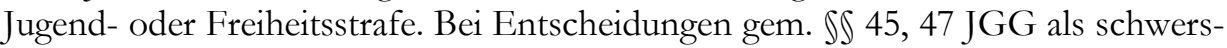
te Voreintragung sind es beispielsweise nur $1 \%$. Der Anteil steigt mit der Schwere der Voreintragung. Besonders hoch sind die Rückfallraten nach Freiheits- und Jugendstrafen mit und ohne Bewährung als schwerste Voreintragung: Hier erhalten $18 \%$ (Freiheits- und Jugendstrafe mit Bewährung) bzw. $30 \%$ (Freiheits- und Jugendstrafe ohne Bewährung) der Frauen eine stationäre Sanktion als Folgeeintragung. Insgesamt zeigen sich sehr hohe Rückfallraten, was aber damit zusammenhängt, dass hier die jüngeren, rückfallgefährdeteren Straftäterinnen ausgewählt wurden, für die im Übrigen auch mindestens schon zwei Entscheidungen registriert sind (die Voreintragung und die Bezugsentscheidung).

4.4.2 Art der Folgeentscheidung nach Anzahl und Art der schwersten Voreintragungen für erwachsene Frauen

Aus Schaubild 6.9 geht hervor, dass auch bei den erwachsenen Frauen die Rückfallwahrscheinlichkeit sowie die Sanktionsart der Folgeentscheidung von der Anzahl der Voreintragungen abhängen. Die Frauen ohne registrierte Voreintragungen, erhalten lediglich in 0,2\% der Fälle eine stationäre Sanktion als Folgeentscheidung. Demgegenüber wurden $11 \%$ der Frauen mit fünf und mehr Voreintragungen mit einer Freiheits- oder Jugendstrafe ohne Bewährung wieder registriert. Diese Ergebnisse entsprechen denen für die Gruppe der Jugendlichen und Heranwachsenden (vgl. Schaubild 6.7). Im Vergleich zu Schaubild 6.7 sind die Rückfallraten für die hier betrachtete Altersgruppe insgesamt etwas niedriger. Betrachtet man aber die Art der Folgeentscheidung, so sind bei den erwachsenen Frauen die Anteile für Jugend- und Freiheitsstrafen mit Bewährung höher, wohingegen jugendliche und heranwachsende Frauen häufiger sonstige ambulante Folgesanktionen erhalten.

${ }^{873}$ Hier wurde nur eine Freiheitsstrafe ohne Bewährung und 11 Freiheitsstrafen mit Bewährung als schwerste Voreintragung registriert. 
Schaubild 6.9: Art der Folgeentscheidung nach Anzahl der Voreintragungen für erwachsene Frauen*

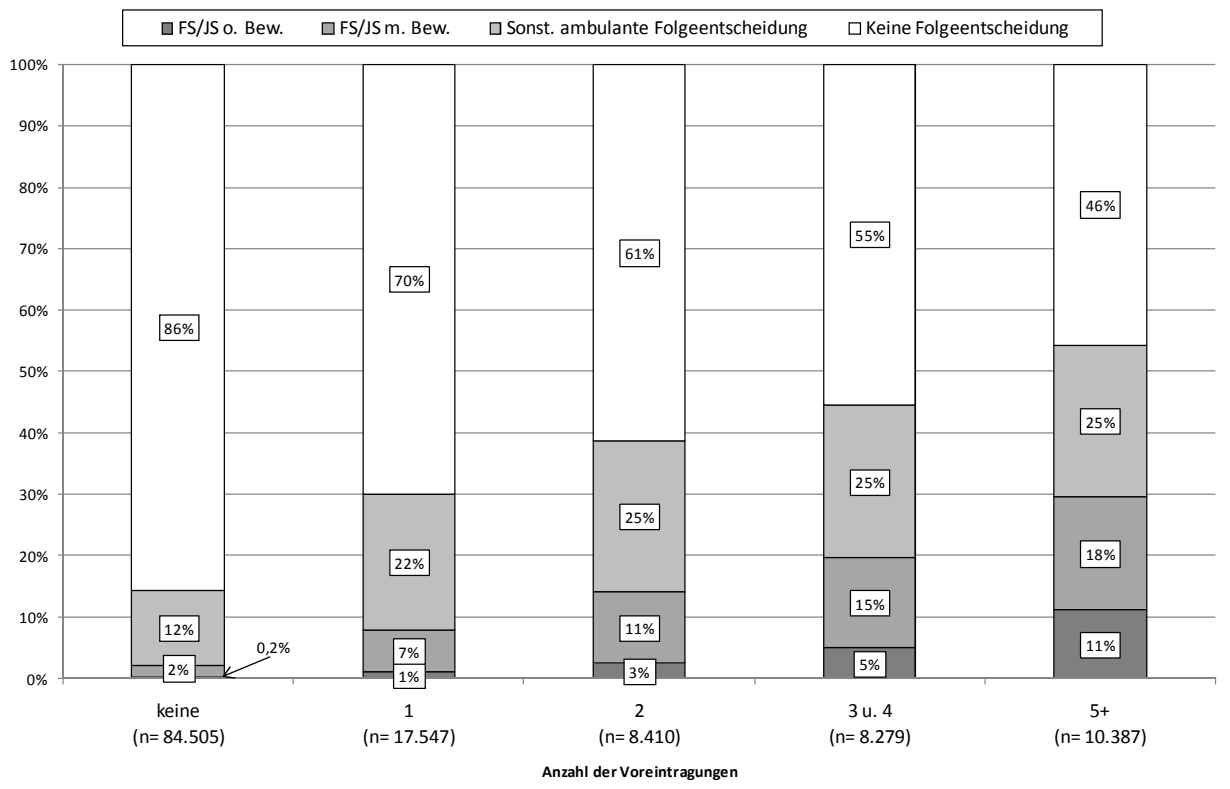

* Absolutzablen siehe Tab. 6.8 a im Anhang.

Schaubild 6.10 verdeutlicht die Folgesanktion nach der schwersten Sanktionsart in der Voreintragung für erwachsene Frauen. Wie bei den jugendlichen und heranwachsenden zeigt sich ebenfalls für die Gruppe der erwachsenen Frauen, dass die Rückfallraten für Freiheits- und Jugendstrafen ohne Bewährung bei den Frauen mit stationären Voreintragungen mit $17 \%$ am höchsten sind, gefolgt von den bedingten Freiheits- und Jugendstrafen mit $8 \%$ (vgl. Schaubild 6.10). Insgesamt sind die Rückfallraten niedriger als in der Gruppe der Jugendlichen und Heranwachsenden. Die niedrigsten Rückfallraten sind nach Entscheidungen gem. $\iint 45$, 47 JGG, gefolgt von Geldstrafen als schwerste Voreintragung zu verzeichnen. 
Schaubild 6.10: Art der Folgeentscheidung nach Art der schwersten Voreintragung für erwachsene Frauen*

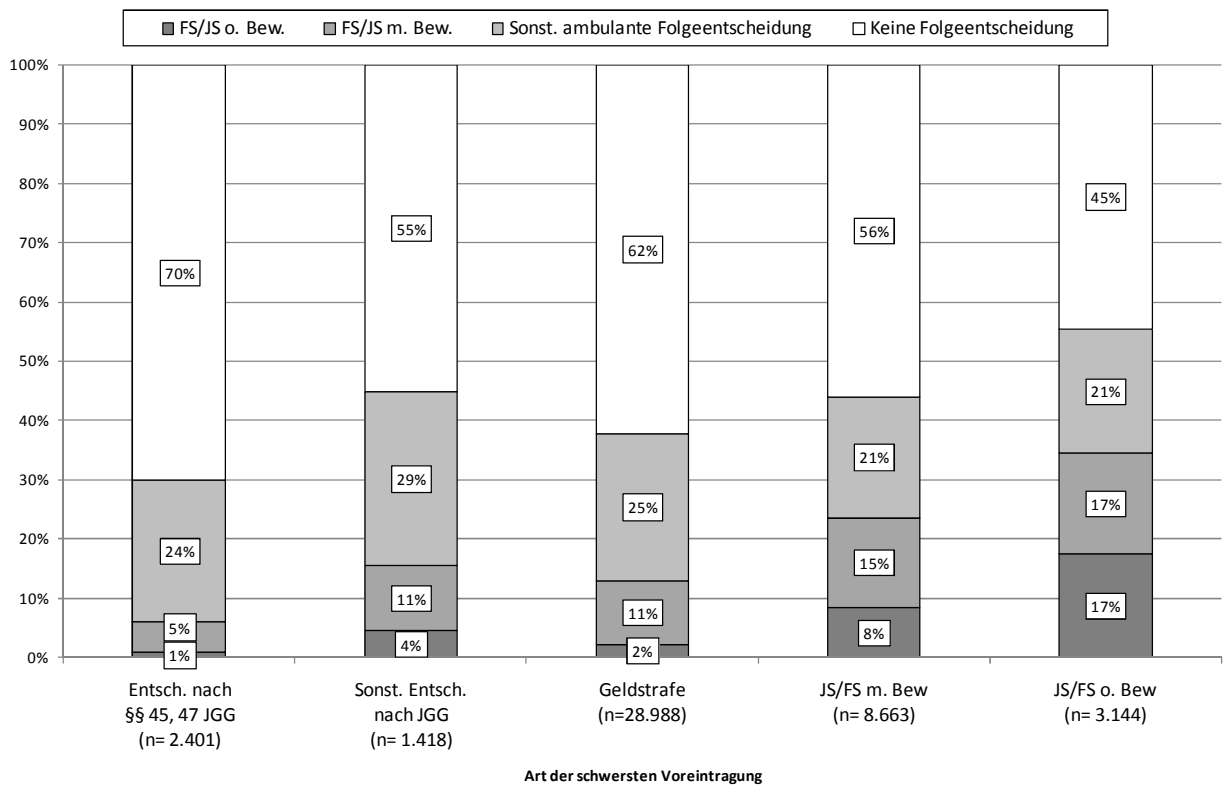

* Absolutrablen siebe Tab. 6.9a im Anhang.

\subsection{Folgeentscheidung nach Deliktsgruppen}

Vermutlich ist das der Bezugsentscheidung zugrunde liegende Delikt ein weiterer bedeutsamer Faktor für die Rückfälligkeit von Frauen. Im Folgenden wird daher die Art der Folgeentscheidung in Abhängigkeit vom Delikt analysiert, wobei die Deliktsgruppenbildung aus Kapitel 4 aufgegriffen wird. Zunächst wird ein grober Überblick gegeben. In einem zweiten Schritt wird ferner die Art der Bezugsentscheidung mit in die Untersuchung einbezogen.

\subsubsection{Art der Folgeentscheidung und Deliktsgruppen}

Bevor eine detaillierte Rückfallbetrachtung nach den einzelnen Deliktsgruppen und nach Art der Bezugsentscheidung erfolgt, vergleicht Schaubild 6.11 die Rückfallraten nach Sanktionsart der Folgeentscheidung für die unterschiedlichen Deliktsgruppen miteinander.

Die zwölf betrachteten Deliktsgruppen wurden wiederum in drei Großgruppen kategorisiert, nämlich die Gruppe der Gewalt-, Vermögensdelikte i.w.S. 874 sowie die Gruppe der sonstigen Delikte.

\footnotetext{
${ }^{874}$ Hier sind Eigentums-, Vermögens- und Urkundendelikte verzeichnet, sodass die Gruppe im Folgenden mit „Vermögensdelikte i.w.S“. abgekürzt wird. Vgl. hierzu auch unter Kap. 4, 1.3.
} 
Schaubild 6.11: Art der Folgeentscheidungen nach Deliktsgruppen*

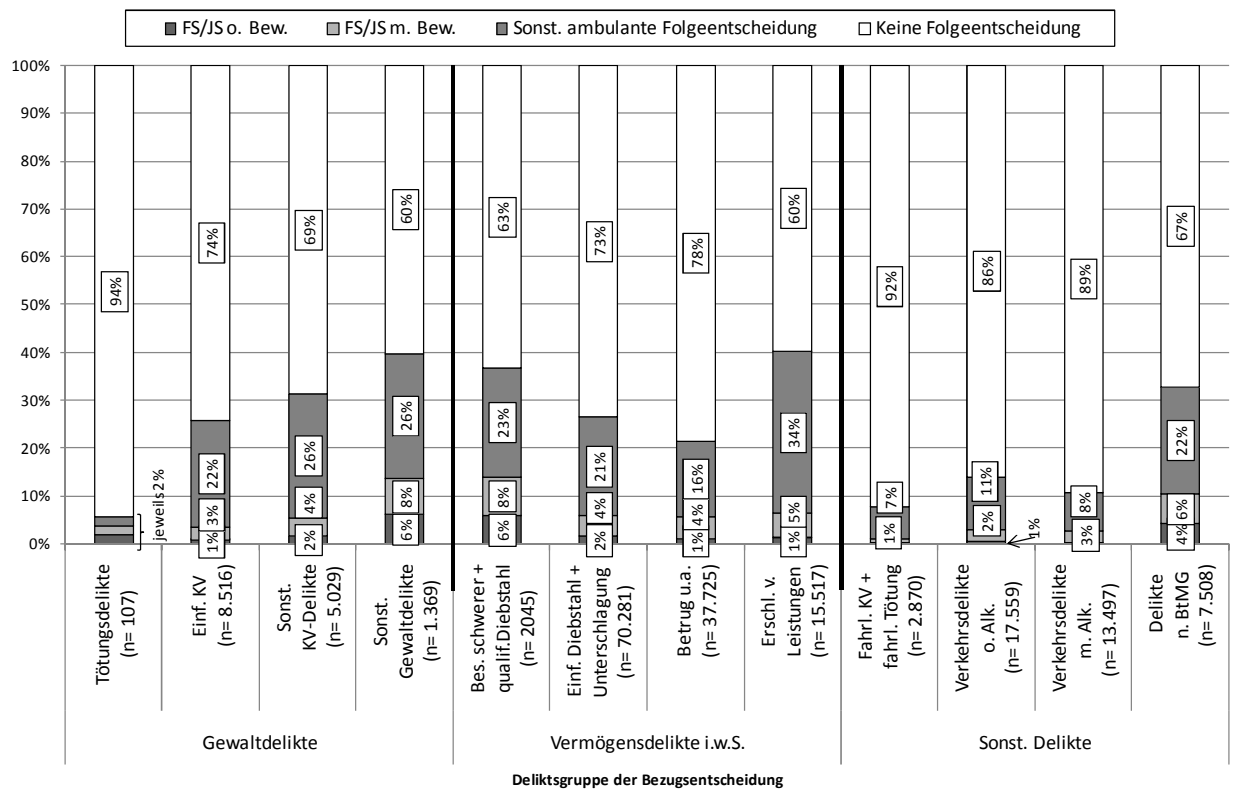

* Absolutrablen siehe Tab. 6.10a im Anhang

Betrachtet man zunächst die große Gruppe der Gewaltdelikte, so fällt auf, dass für Tötungsdelikte mit $6 \%$ die niedrigste Rückfallrate, auch im Vergleich zu den Nicht-Gewaltdelikten, besteht. Dies dürfte damit zusammenhängen, dass Frauen die töten, in der Regel nicht mit den anderen Gewalttäterinnen zu vergleichen sind. Es handelt sich vielmehr zumeist um Beziehungstaten aus dem sozialen Nahraum. ${ }^{875} \mathrm{Im}$ Falle eines Rückfalls ist der Anteil für Freiheits- und Jugendstrafen ohne Bewährung jedoch verhältnismäßig hoch und übersteigt vorliegend auch den Anteil der stationären Folgesanktionen bei den Täterinnen einer Körperverletzung um einen Prozentpunkt. Zu beachten ist jedoch, dass hier nur sehr geringe Fallzahlen zugrunde liegen: Nur zwei Täterinnen, die eine Bezugsentscheidung wegen eines Tötungsdelikts erhalten haben, wurden mit einer stationären Sanktion erneut registriert. Auffällig ist die hohe Rückfallquote für die Täterinnen sonstiger Gewaltdelikte mit $40 \%$. Nur für die Deliktsgruppe Erschleichen von Leistungen ist eine ebenso hohe Rückfälligkeit zu verzeichnen. Im Übrigen ist bei den Täterinnen eines sonstigen Gewaltdelikts auch der Anteil für stationäre Folgeeintragungen mit $6 \%$ verhältnismäßig hoch.

Diese Ergebnisse bestätigen auch die Auswertungen der Daten des BZR für das Bezugsjahr 1994 durch Harrendorf für die spezielle Gruppe der Gewalttäter.

$875 \mathrm{Vgl}$. hierzu ausführlich unter Kap. 4, 1.2.2. 
Für Frauen stellte der Autor eine besonders niedrige Rückfallrate bei Tötungsdelikten sowie eine besonders hohe bei Raubdelikten und Widerstand gegen Vollstreckungsbeamte fest. ${ }^{876}$ Die beiden letztgenannten Deliktsgruppen wurden vorliegend in der Gruppe der sonstigen Gewaltdelikte berücksichtigt, für die sich, wie bereits festgestellt, gleichfalls eine besonders hohe Rückfallquote ergibt.

In der großen Gruppe der Vermögensdelikte i.w.S. weisen neben dem Erschleichen von Leistungen die Täterinnen einer schweren Diebstahlsform mit $37 \%$ eine hohe Rückfallrate auf, wobei für $6 \%$ dieser Täterinnen eine Freiheitsoder Jugendstrafe als Folgesanktion registriert wurde. Niedriger sind die Rückfallraten der Diebinnen und Betrügerinnen. Diese erhalten ferner selten stationäre Folgeeintragungen.

Bei den Verkehrsstraftäterinnen fällt die Rückfallrate verhältnismäßig gering aus. Lediglich vier Täterinnen einer fahrlässigen Tötung oder fahrlässigen Körperverletzung $(0 \%)$ erhielten eine stationäre Folgesanktion. $92 \%$ der Täterinnen dieser Deliktsgruppe sind nicht rückfällig geworden. Der Anteil von Freiheits- und Jugendstrafen bei den Verkehrsstraftäterinnen unter Alkoholeinfluss liegt ebenfalls bei $0 \%$. Die Rückfallraten für die Verkehrsstraftäterinnen sind mit insgesamt $14 \%$ bei den Verkehrsdelikten ohne Alkoholeinfluss und 11\% bei den Verkehrsdelikten mit Alkoholeinfluss recht niedrig. Schließlich ist für die Gruppe der Drogendelinquenten eine hohe Rückfallrate zu verzeichnen. $4 \%$ der Täterinnen erhalten als Folgesanktion eine Freiheits- oder Jugendstrafe ohne Bewährung. Dies bestätigt im Übrigen die Ergebnisse Kreuzers, der u.a. feststellte, dass Drogenabhängigkeit bei Frauen einen großen Einfluss auf ihre Kriminalität hat. ${ }^{877}$

\subsubsection{Art der Folgeentscheidung nach Art der Bezugsentscheidung und De-}

liktsgruppe

Als nächstes soll für einige Deliktsgruppen die Art der Folgeentscheidung differenziert nach Art der Bezugsentscheidung dargestellt werden. Hierbei werden nur ausgewählte Deliktsgruppen mit hohen Rückfallraten betrachtet. Für die nicht dargestellten Deliktsgruppen erfolgt eine tabellarische Darstellung im Anhang. ${ }^{878}$

Für die Gruppe der Gewaltdelikte werden die sonstigen Gewaltdelikte analysiert. Für die Gruppe der Vermögensdelikte i.w.S. wird die Art der Folgeentscheidung nach Art der Bezugsentscheidung aufgrund von \$S 243, 244, 244a StGB dargestellt. Zwar ist in der großen Kategorie der Vermögensdelikte i.w.S. die allgemeine Rückfallrate für das Erschleichen von Leistungen am höchsten, allerdings sind für dieses Delikt als Folgeeintragungen und auch als Bezugsentscheidungen hauptsächlich sonstige ambulante Sanktionen registriert. ${ }^{879}$ Es liegen kaum stationäre Entscheidungen vor, sodass die schwereren Diebstahlsformen eine differen-

\footnotetext{
876 Harrendorf, S. 214.

877 Kreuzer, in: Kreuzer (Hrsg.), Handbuch des Betäubungsmittelstrafrechts, S. 167 ff.

${ }^{878} \mathrm{Vgl}$. Tab. 6.12a-d, 6.13a-d, 6.14a-d im Anhang.

${ }^{879}$ Vgl. Tab. 6.13a im Anhang.
} 
ziertere Analyse zulässt. Schließlich wird noch die Rückfälligkeit nach BtMGDelikten betrachtet.

\subsubsection{Sonstige Gewaltdelikete}

Aus Schaubild 6.12 ergibt sich die Art der Folgeentscheidung nach Sanktionierung aufgrund von sonstigen Gewaltdelikten. In dieser Kategorie werden \$S 113, 177 , 178, 239a, 239b, 249-252, 255 sowie \ 316a StGB berücksichtigt. ${ }^{880}$

Schaubild 6.12: Art der Folgeentscheidung nach Art der Bezugsentscheidung aufgrund von sonstigen Gewaltdelikten*

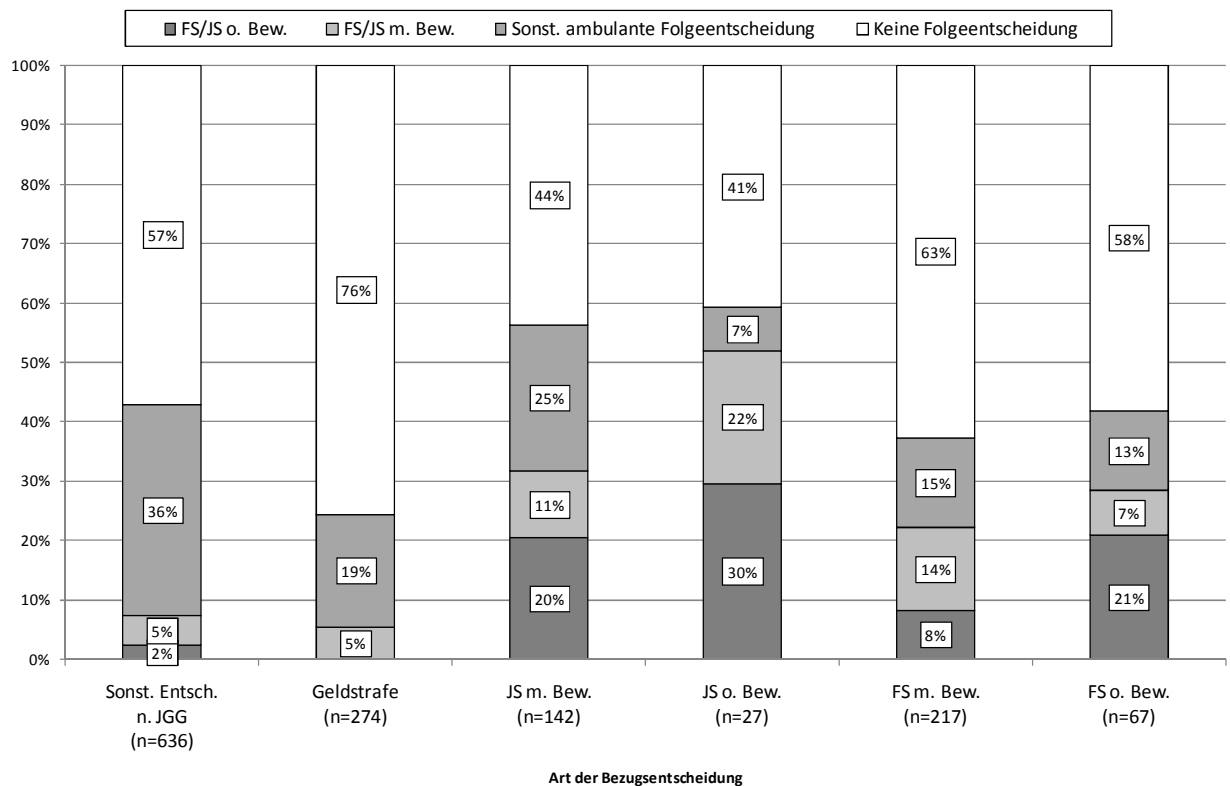

* Absolutzablen siehe Tab. 6.11d im Anhang

Die höchsten Legalbewährungsraten sind für die zu Geldstrafe (76\%) und zu Freiheitsstrafe mit Bewährung (63\%) verurteilten Frauen, gefolgt von den sonstigen Entscheidungen nach JGG (57\%) zu verzeichnen. Für keine Täterin ist nach einer Geldstrafe als Bezugssanktion eine stationäre Folgeeintragung registriert. Obwohl nach Freiheitsstrafen mit Bewährung verhältnismäßig niedrige Rückfallraten vorliegen, erhalten die Täterinnen hier im Falle eines Rückfalls immerhin in $8 \%$ der Fälle eine stationäre Sanktion als Folgeeintragung. Besonders hoch sind die Rückfallraten nach Jugendstrafen mit (56\%) und ohne Bewährung (59\%). $20 \%$ der Frauen, für die als Bezugsentscheidung eine Jugendstrafe mit Bewährung

880 Vgl. näher zu der Kategorisierung Kap. 4, 1.2.1.4. 
und $30 \%$ der Frauen, für die eine solche ohne Bewährung registriert wurde, haben eine stationäre Folgesanktion erhalten.

\subsubsection{Besonders schwerer und qualifizierter Diebstabl}

Schaubild 6.13 zeigt die Folgeentscheidungen nach Sanktionierung wegen SS 243, 244, 244a StGB.

Schaubild 6.13: Art der Folgeentscheidung nach Art der Bezugsentscheidung aufgrund von besonders schwerem und qualifiziertem Diebstahl*

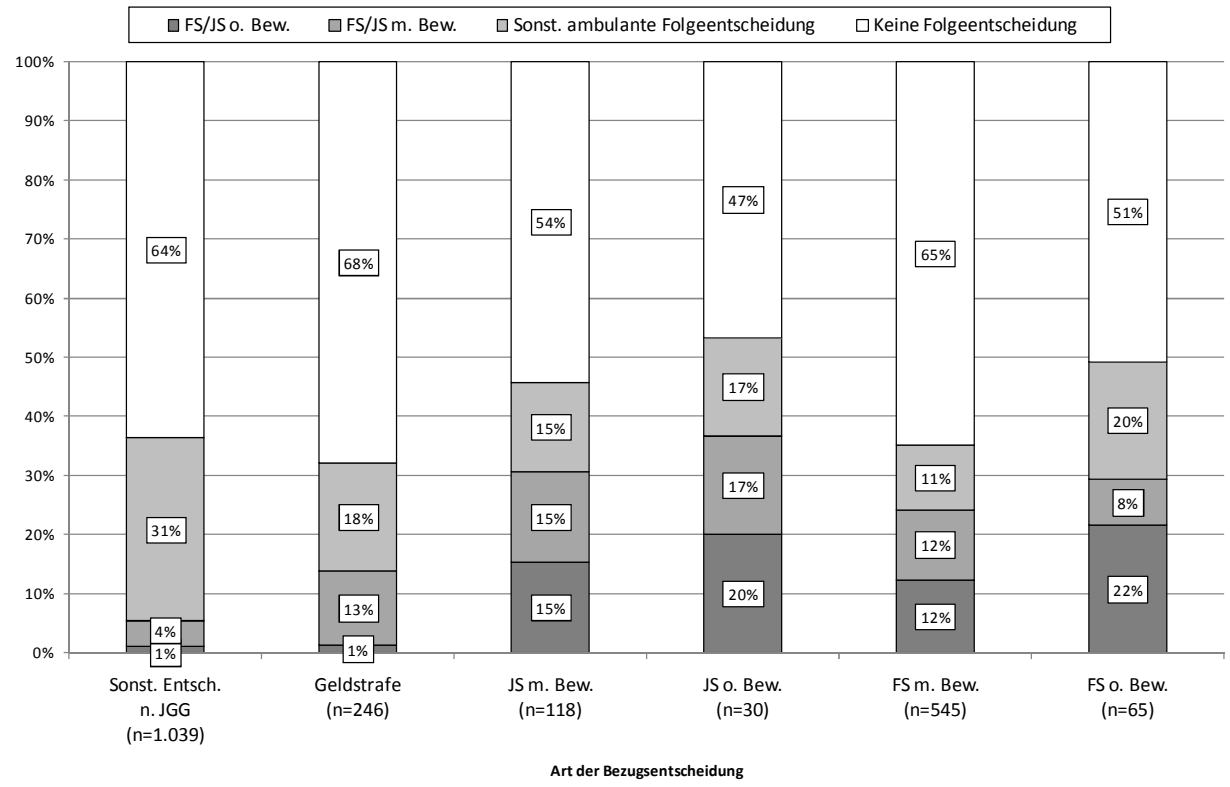

* Absolutzablen siebe Tab. 6.12b im Anhang.

Am höchsten sind die allgemeinen Rückfallraten nach Freiheits- und Jugendstrafen ohne Bewährung. Dort ist auch der Anteil von stationären Folgesanktionen mit $22 \%$ (nach Freiheitsstrafe ohne Bewährung) sowie $20 \%$ (nach Jugendstrafe ohne Bewährung) sehr ausgeprägt. Besonders gering sind die Rückfallraten nach Geldstrafen und sonstigen ambulanten Sanktionen. Im Vergleich zu Schaubild 6.12 zeigt sich insgesamt, außer nach Geldstrafen und Freiheitsstrafen ohne Bewährung, eine niedrigere allgemeine Rückfallrate.

\subsubsection{Delikte nach BtMG}

Wie schon in Schaubildern 6.12 und 6.13 zeigt sich auch bei den Delikten nach dem BtMG (Schaubild 6.14), dass die höchste allgemeine Rückfallrate mit $59 \%$ nach Jugendstrafen ohne Bewährung zu verzeichnen ist. 
Schaubild 6.14: Art der Folgeentscheidung nach Art der Bezugsentscheidung aufgrund von Deliketen nach BtMG*

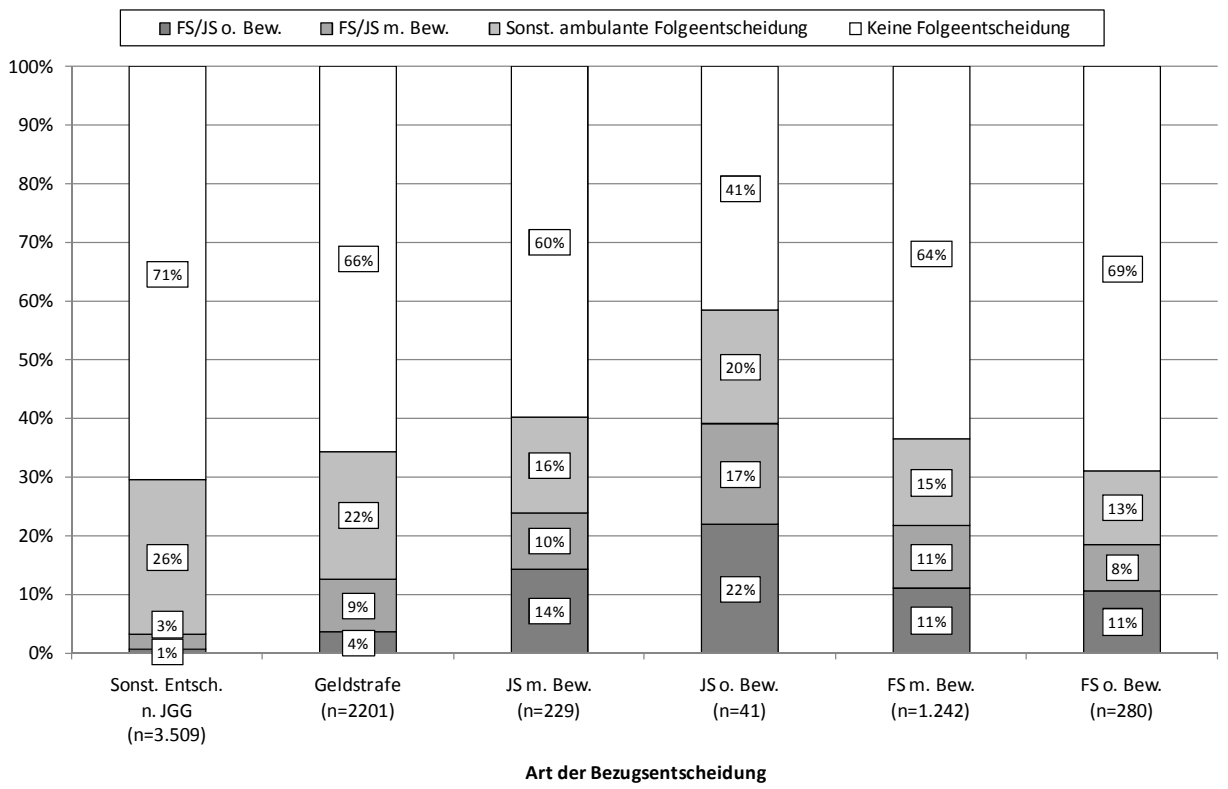

* Absolutzablen siehe Tab. 6.13d im Anbang

Die Rückfallrate ist damit genauso hoch wie bei den sonstigen Gewaltdelikten. Anders als bei den schwereren Diebstahlsformen (Schaubild 6.13) ist bei den Delikten nach dem BtMG die Rückfälligkeit nach Bewährungsstrafen (40\% nach Jugendstrafen und $37 \%$ nach Freiheitsstrafen mit Bewährung) höher als nach Freiheitsstrafen ohne Bewährung (31\%). Dieser Trend war auch schon für die sonstigen Gewaltdelikte (Schaubild 6.12), bei den Jugendstrafen mit Bewährung als Bezugssanktion, zu verzeichnen. Gleichwohl lag dort die allgemeine Rückfallrate nach Freiheitsstrafen ohne Bewährung bei $42 \%$ und damit höher als bei den vorliegend betrachteten BtMG-Delikten.

Insgesamt wird für alle drei betrachteten Deliktsgruppen deutlich, dass die hohen Rückfallquoten vor allen Dingen nach Jugendstrafen zu verzeichnen sind.

\subsection{Einschlägige Voreintragung, Bezugsentscheidung und einschlägiger Rückfall}

Die Untersuchung der Rückfälligkeit hat bislang nach Sanktionsart der Folgeentscheidung differenziert. Hierbei lag der allgemeine Rückfallbegriff zugrunde, d.h. als Rückfall wurde jede erneute im BZR registrierte Tat nach der Bezugsentscheidung gezählt. Als nächstes soll auch die Einschlägigkeit des Rückfalls eine Rolle spielen. Dabei wird zunächst die Art des Rückfalls nach Einschlägigkeit für die 
gebildeten Deliktsgruppen der Bezugsentscheidung überprüft. Nach einem Überblick über alle Deliktsgruppen hinweg wird zudem die Einschlägigkeit der Voreintragung mitberücksichtigt, sodass die kriminelle Karriere von Täterinnen abgebildet werden kann.

\subsubsection{Bezugsentscheidung und einschlägiger Rückfall}

Bei der Art des Rückfalls wird vorliegend nach den Gruppen „kein Rückfall“, „auch Rückfall wegen eines anderen Delikts“, ,auch Rückfall wegen eines Delikts einer verwandten Deliktsgruppe“ und dem „einschlägigen Rückfall“ differenziert. Die in den einzelnen Gruppen berücksichtigten Delikte ergeben sich aus Tabelle 6.1.

Die Bestimmung der Einschlägigkeit des Rückfalls erfolgt nach denselben Kriterien wie in Kapitel 5 zur Einschlägigkeit der Voreintragungen. ${ }^{881}$ Auch hier erfasst der „einschlägige Rückfall“ im engeren Sinne nicht immer nur ein Delikt wie beispielsweise bei der einfachen Körperverletzung oder dem Erschleichen von Leistungen. Als einschlägig gilt ein Delikt auch, wenn sich die erneute Straftat auf ein vergleichbares Delikt derselben Deliktsgruppe bezieht, wie etwa bei Diebstahl und Unterschlagung. Die Gruppe „(auch) Rückfall wegen eines Delikts einer verwandten Deliktsgruppe“ ist hingegen noch weiter gefasst, beinhaltet aber gleichwohl Delikte die mit dem Bezugsdelikt verwandt sind bzw. in Zusammenhang stehen: So werden hier z.B. Körperverletzungsdelikte erfasst, wenn der Bezugstat ein Tötungsdelikt zugrunde lag, denn beide Deliktsgruppen sind nach der vorliegenden Gruppierung 882 den Gewaltdelikten zuzuordnen, sodass ein Zusammenhang besteht. Die Gruppe „(auch) Rückfall wegen eines anderen Delikts“ erfasst dementsprechend alle weiteren Delikte, die nicht bereits als einschlägig oder verwandt berücksichtigt wurden.

${ }^{881}$ Vgl. daher ausführlich zur Einteilung unter Kapitel 5, 2.5.2.

882 Vgl. zur Gruppierung ausführlich Kap. 4. 
Tabelle 6.1: Bestimmung des einschlägigen Rückfalls

\begin{tabular}{|c|c|c|c|}
\hline & & $\begin{array}{l}\text { (Auch) Rückfall mit } \\
\text { Delikten einer } \\
\text { verwandten De- } \\
\text { liktsgruppe }\end{array}$ & $\begin{array}{l}\text { (Auch) } \\
\text { einschlägiger } \\
\text { Rückfall }\end{array}$ \\
\hline \multirow{4}{*}{ Gewaltdelikte } & Tötungsdelikte & $\begin{array}{l}\text { Einf. KV, } \\
\text { sonst. KV-Delikte, } \\
\text { sonst. Gewaltdelikte }\end{array}$ & Tötungsdelikte \\
\hline & Einf. KV & \begin{tabular}{|l|} 
Tötungsdelikte, \\
sonst. KV-Delikte, \\
sonst. Gewaltdelikte
\end{tabular} & Einf. KV \\
\hline & $\begin{array}{l}\text { Sonst. } \\
\text { KV-Delikte }\end{array}$ & $\begin{array}{l}\text { Tötungsdelikte, } \\
\text { einf. KV, } \\
\text { sonst. Gewaltdelikte, }\end{array}$ & Sonst. KV-Delikte \\
\hline & $\begin{array}{l}\text { Sonst. } \\
\text { Gewaltdelikte }\end{array}$ & \begin{tabular}{|l|} 
Tötungsdelikte, \\
einf. KV, \\
sonst. KV-Delikte \\
\end{tabular} & Sonst. Gewaltdelikte \\
\hline \multirow{4}{*}{$\begin{array}{l}\text { Vermögensdelikte } \\
\text { i.w.S. }\end{array}$} & $\begin{array}{l}\text { Bes. schwerer und } \\
\text { qualif. Diebstahl }\end{array}$ & $\begin{array}{l}\text { Einf. Diebstahl und } \\
\text { Unterschlagung }\end{array}$ & $\begin{array}{l}\text { Bes. schwerer + } \\
\text { qualif. Diebstahl }\end{array}$ \\
\hline & $\begin{array}{l}\text { Einf. Diebstahl und } \\
\text { Unterschlagung }\end{array}$ & $\begin{array}{l}\text { Bes. schwerer und } \\
\text { qualif. Diebstahl }\end{array}$ & $\begin{array}{l}\text { Einf. Diebstahl + } \\
\text { Unterschlagung }\end{array}$ \\
\hline & Betrug u.a. & Erschl. von Leistungen & Betrug u.a. \\
\hline & $\begin{array}{l}\text { Erschl. von } \\
\text { Leistungen }\end{array}$ & Betrug u.a. & $\begin{array}{l}\text { Erschl. von } \\
\text { Leistungen }\end{array}$ \\
\hline \multirow{4}{*}{ Sonst. Delikte } & $\begin{array}{l}\text { Fahrl. KV und } \\
\text { fahrl. Tötung }\end{array}$ & $\begin{array}{l}\text { Verkehrsdelikte o. Alk., } \\
\text { Verkehrsdelikte m. Alk. }\end{array}$ & $\begin{array}{l}\text { Fahrl. KV + fahrl. } \\
\text { Tötung }\end{array}$ \\
\hline & $\begin{array}{l}\text { Verkehrsdelikte } \\
\text { o. Alk. }\end{array}$ & $\begin{array}{l}\text { Verkehrsdelikte m. } \\
\text { Alk., } \\
\text { fahrl. KV und fahrl. } \\
\text { Tötung }\end{array}$ & $\begin{array}{l}\text { Verkehrsdelikte } 0 . \\
\text { Alk. }\end{array}$ \\
\hline & $\begin{array}{l}\text { Verkehrsdelikte } \\
\text { m. Alk. }\end{array}$ & $\begin{array}{l}\text { Verkehrsdelikte } 0 . \\
\text { Alk., } \\
\text { fahrl. KV und fahrl. } \\
\text { Tötung } \\
\end{array}$ & $\begin{array}{l}\text { Verkehrsdelikte m. } \\
\text { Alk. }\end{array}$ \\
\hline & $\begin{array}{l}\text { Delikte } \\
\text { n. BtMG }\end{array}$ & \begin{tabular}{|l|} 
Einf. Diebstahl, \\
bes. schwerer und \\
qualif. Diebstahl
\end{tabular} & Delikte n. BtMG \\
\hline
\end{tabular}

Schaubild 6.15 veranschaulicht die Art des Rückfalls für verschiedene Deliktsgruppen. Es zeigt sich, dass bei den den Vermögensdelikten i.w.S. zuzuordnenden Delikten die Einschlägigkeit besonders ausgeprägt ist: 


\section{Schaubild 6.15: Art des Rückfalls nach Deliktsgruppen der Bezugsentscheidung*}

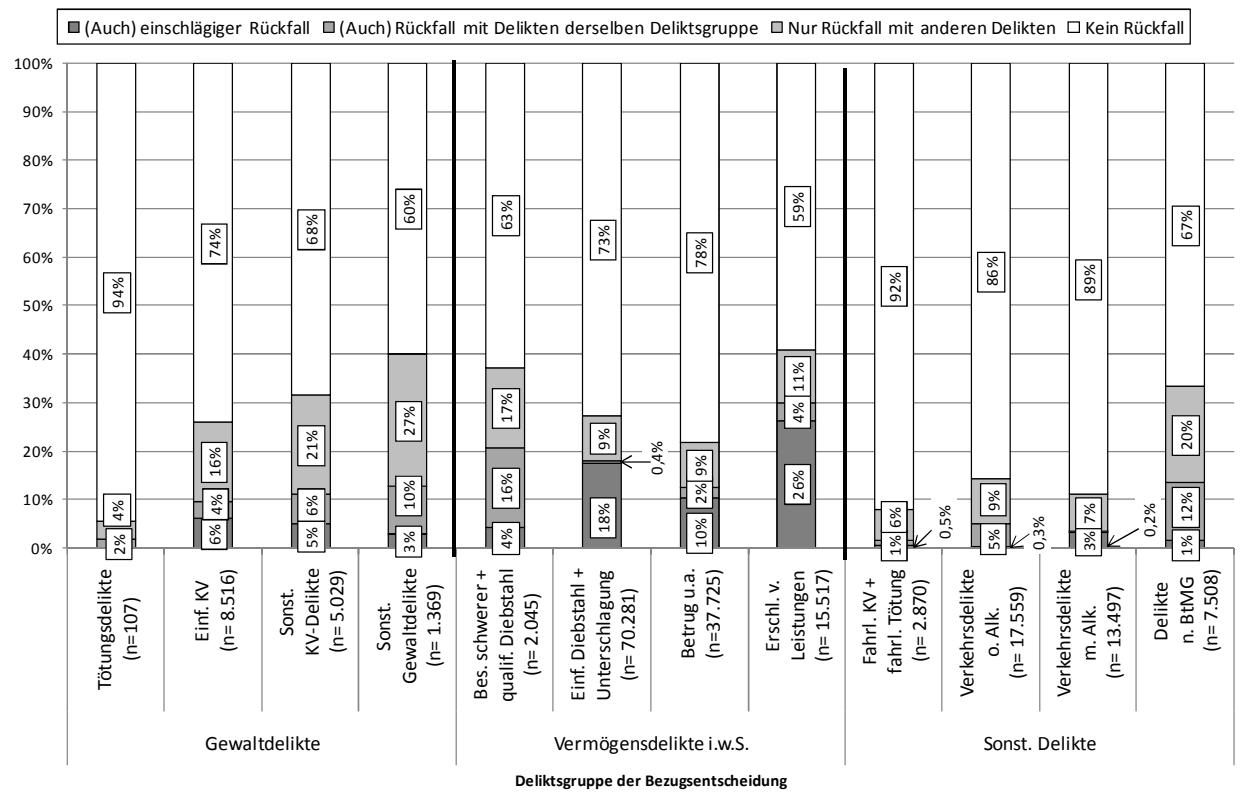

* Absolutzablen siebe Tab. 6.14a im Anhang

So weisen $26 \%$ der Frauen, die eine Bezugsentscheidung wegen Erschleichen von Leistungen erhalten haben, eine einschlägige Rückfalltat auf. Auch bei Diebstahl und Unterschlagung (18\%) sowie der Gruppe Betrug u.a. (11\%) ist der Anteil von einschlägigen Rückfällen recht hoch. Hingegen weist die Gruppe der schwereren Diebstahlsdelikte zwar insgesamt gesehen die dritthöchste Rückfallrate auf, allerdings nimmt der einschlägige Rückfall nur einen 4\%igen Anteil ein. Gleiches gilt für die Gruppe der Gewaltdelikte: Die Rückfallraten sind hier mit am höchsten, aber wenn Frauen nach einem Gewaltdelikt rückfällig werden, dann hauptsächlich wegen eines anderen Delikts. $27 \%$ der Frauen, die als Bezugsentscheidung ein sonstiges Gewaltdelikt erhalten haben, werden wegen eines Nichtgewaltdelikts erneut registriert. Bei der einfachen Körperverletzung ist der einschlägige Rückfall mit $6 \%$ im Vergleich zu den anderen Gewaltdelikten noch am höchsten. Betrachtet man die übrigen Deliktsgruppen, wird deutlich, dass die Rückfallrate für die Verkehrsstraftäterinnen und die Täterinnen einer fahrlässigen Körperverletzung oder fahrlässigen Tötung recht niedrig ist. Der einschlägige Rückfall spielt mit 3\% lediglich bei den Verkehrstäterinnen unter Alkoholeinfluss eine Rolle. Dies gilt nicht für die Frauen, die wegen eines Drogendelikts aufgefallen sind: Hier 
ist zum einem die Rückfallrate mit $33 \%$ verhältnismäßig hoch. Zum anderen ist auffällig, dass der Rückfall mit $20 \%$ hauptsächlich auf andere Delikte entfällt. 883

\subsubsection{Einschlägige Voreintragung, Bezugsentscheidung und einschlägiger Rückfall}

Die vorangegangenen Ausführungen zur Einschlägigkeit des Rückfalls beruhten bislang von der Bezugsentscheidung aus gesehen nur auf einer prospektiven Betrachtungsweise. Nun wird zusätzlich die Einschlägigkeit der Voreintragungen für einzelne Deliktsgruppen mit berücksichtigt, sodass auch eine retrospektive Betrachtung erfolgen und somit die kriminelle Karriere von Täterinnen analysiert werden kann.

\subsubsection{Gewaltdelikte}

Zunächst wird die einschlägige Rückfälligkeit von Gewalttäterinnen überprüft. Schaubild 6.11 hat bereits ergeben, dass Gewalttäterinnen verhältnismäßig häufig rückfällig werden, wobei es sich hauptsächlich nicht um Gewaltrückfälle handelt (vgl. Schaubild 6.15). Es stellt sich die Frage, welche Ergebnisse sich bei Einbeziehung einschlägiger Voreintragungen erzielen lassen. Die Bestimmung der Kategorien der Einschlägigkeit wurde hier ebenso wie in Kapitel 5 vorgenommen. ${ }^{884}$ Sie entspricht ferner der Bestimmung der Einschlägigkeit des Rückfalls (vgl. Tabelle 6.1).

Schaubild 6.16 zeigt die Art des Rückfalls in Abhängigkeit zur Einschlägigkeit der Voreintragung bei Täterinnen, die eine Bezugsentscheidung wegen einer einfachen Körperverletzung (linke Seite) oder eines sonstigen Körperverletzungsdelikts (rechte Seite) erhalten haben.

Es wird deutlich, dass für die nicht vorbestraften Frauen die niedrigste Rückfallquote besteht. Die höchste Rückfallrate der Täterinnen einer einfachen Körperverletzung weisen mit $47 \%$ die wegen eines anderen Gewaltdelikts vorbestraften Frauen auf. Die höchste einschlägige Rückfallrate ist hingegen für die wegen einfacher Körperverletzung verurteilten Frauen, die bereits einschlägig vorbestraft sind $(12 \%)$, zu verzeichnen, dicht gefolgt von den mit einem anderen Gewaltdelikt vorbestraften Frauen (10\%).

Die einschlägigen Rückfallraten für die Täterinnen eines sonstigen Körperverletzungsdelikts sind durchweg niedriger. Hingegen sind ihre Anteile an den Rückfällen wegen eines anderen Gewaltdelikts höher. Dies dürfte vermutlich daran liegen, dass in dieser Gruppe u.a. die einfachen Körperverletzungen berücksichtigt werden. Bei allen Körperverletzungsdelikten ist die Rückfallrate bei den Rückfällen mit anderen Delikten am höchsten, und zwar unabhängig von der Einschlägigkeit der Voreintragungen.

\footnotetext{
883 Vgl. hierzu auch Ausführungen unter 4.4.1.
}

884 Vgl. Tabelle 5.5. 
Schaubild 6.16: Einschlägige Voreintragungen und Rückfälle bei Bezugsentscheidungen aufgrund von Körperverletzungsdelikten*

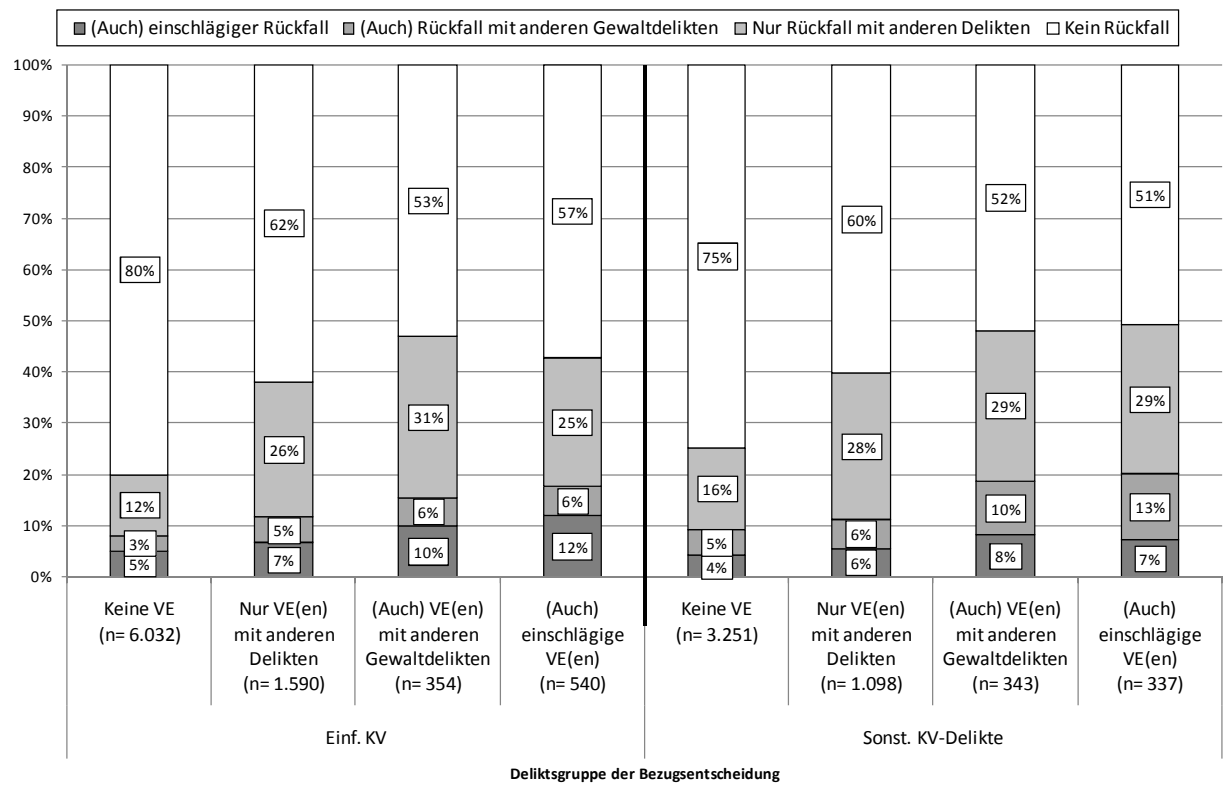

* Absolutrablen siehe Tab. 6.15 a im Anhang

Die kriminelle Karriere der Täterinnen eines sonstigen Gewaltdelikts ${ }^{885}$ stellt sich hingegen etwas anders dar (vgl. Schaubild 6.17).

Bei den Gewaltdelikten ist der höchste Anteil von einschlägigem Rückfall bei den Täterinnen mit einschlägigen Voreintragungen zu verzeichnen: $10 \%$ der einschlägig vorbestraften Gewalttäterinnen werden auch wieder einschlägig rückfällig. Es zeigt sich ferner erneut, dass Gewalttäterinnen im Fall eines Rückfalls am häufigsten wegen anderer Delikte wieder registriert werden. Die höchste Rückfallrate für Rückfälle mit einem anderen Gewaltdelikt kann für die Gewalttäterinnen mit Voreintragungen wegen eines anderen Gewaltdelikts mit $15 \%$ festgestellt werden. In den anderen Konstellationen unterscheiden sich die Rückfallraten der einschlägig und nicht einschlägig vorbestraften Frauen nur geringfügig voneinander.

885 Von einer Darstellung der Rückfallraten nach Tötungsdelikten wurde abgesehen, da die Stichprobe zu klein ist. So befinden sich in der Gruppe der einschlägig vorbestraften Tötungsdelinquenten nur zwei Frauen, vgl. Tab. 6.15a im Anhang. 
Schaubild 6.17: Einschlägige Voreintragungen und Rückfälle bei Bezugsentscheidungen aufgrund von sonstigen Gewaltdelikten*

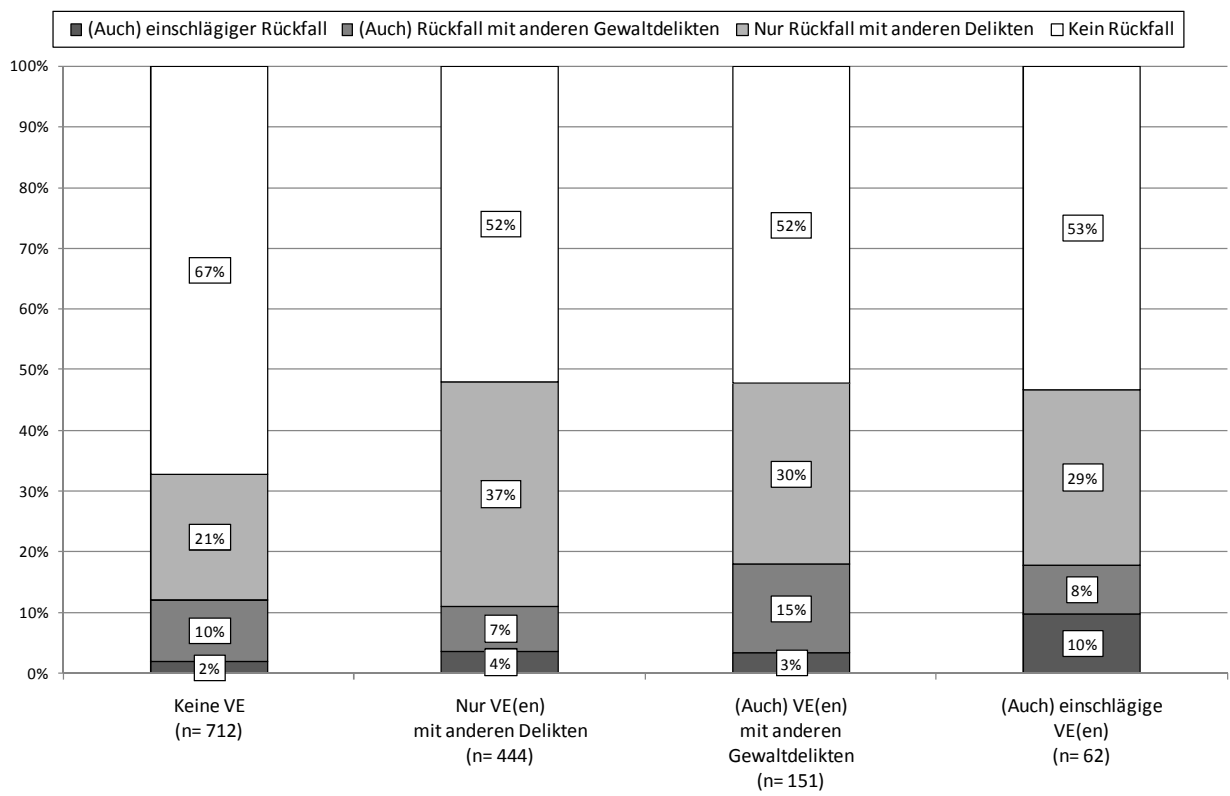

* Absolutzablen siehe Tab. 6.15b im Anhang

\subsubsection{Vermögensdelikte i.w.S.}

Schaubild 6.18 veranschaulicht die Art des Rückfalls unter Berücksichtigung der Art der Voreintragungen für Täterinnen eines schwereren Diebstahldelikts (linke Seite von Schaubild 6.18) sowie eines einfachen Diebstahls oder einer Unterschlagung (rechte Seite von Schaubild 6.18).

Für die schweren Diebstahlsformen zeigen sich insgesamt recht hohe Rückfallraten. Die höchste einschlägige Rückfallrate ist für die einschlägig vorbestraften Täterinnen zu verzeichnen (10\%), die niedrigste für die nicht vorbestraften Frauen (2\%). Insgesamt werden Täterinnen eines Delikts gem. SS 243, 244, 244a StGB am häufigsten wegen eines anderen Diebstahldelikts (\$\$ 242, $246 \mathrm{StGB}$ ) rückfällig. Bei den einschlägig Vorbestraften beträgt der Anteil beispielsweise $28 \%$. Daraus lässt sich schließen, dass selbst die Täterinnen, die über eine verhältnismäßig hohe kriminelle Energie verfügen, am häufigsten wegen weniger schwerwiegenden Delikten ( $\left.\iint 242,246 \mathrm{StGB}\right)$ wieder registriert werden.

Ein deutlicher Unterschied ergibt sich im Vergleich zu den Täterinnen eines einfachen Diebstahls oder einer Unterschlagung. Wenn diese Täterinnen rückfällig werden, dann zumeist einschlägig. Bei den einschlägig vorbestraften Frauen beträgt die einschlägige Rückfallrate $32 \%$, bei den wegen eines anderen Diebstahldelikts vorbestraften Täterinnen beträgt die Quote $29 \%$. 
Schaubild 6.18: Einschlägige Voreintragungen und Rückfälle bei Bezugsentscheidungen aufgrund von Diebstablsdelikten*

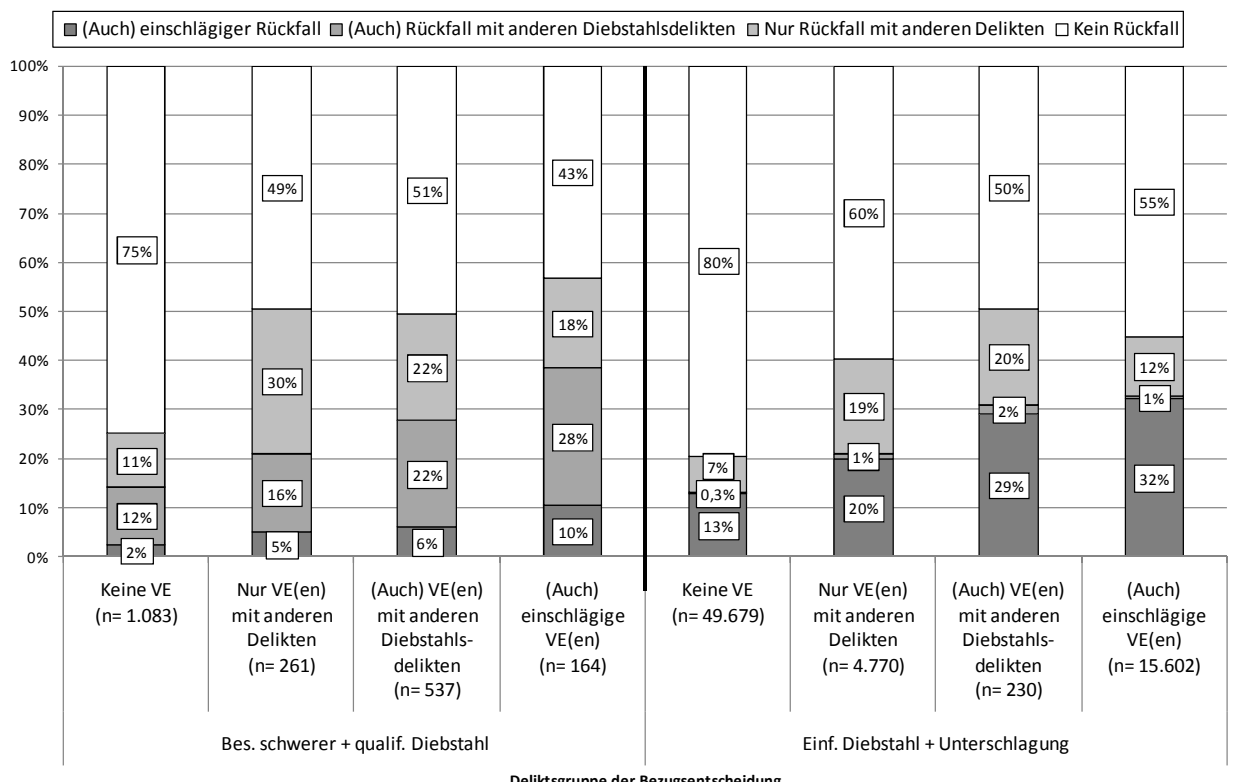

* Absolutrablen siehe Tab. 6.16a im Anhang

Die Feststellung Einseles, dass Diebinnen im Laufe ihrer kriminellen Karriere vermehrt auf Delikte ausweichen für die ,größere Routine, kriminelle Aktivität oder berufliche Stellung "886 erforderlich seien, kann insoweit nicht bestätigt werden. Die Anteile des Rückfalls mit anderen Delikten sind, unabhängig von der Einschlägigkeit der Voreintragung, niedriger als die Anteile des einschlägigen Rückfalls. Bei den $\iint 242,246$ StGB ist der Anteil von Rückfällen wegen eines anderen Diebstahldelikts besonders gering. Häufiger kommt es noch zu Rückfällen mit anderen Delikten. Insgesamt lässt sich für Täterinnen eines einfachen Diebstahls oder einer Unterschlagung ganz eindeutig die Einhaltung einer Deliktsstruktur erkennen. Dies wird besonders deutlich, wenn man sich die zugrunde liegenden Fallzahlen vor Augen hält: In der Gruppe der einschlägig vorbestraften Täterinnen, die einschlägig rückfällig geworden sind, konnten 5.004 Frauen gezählt werden. Bei den wegen eines anderen Diebstahldelikts vorbestraften Frauen sind in der Gruppe der einschlägig Rückfälligen hingegen nur 67 Frauen registriert. Auch die Frauen, die als Bezugsdelikt eine schwerere Diebstahlsform begangen haben, werden im Falle eines Rückfalls am häufigsten mit einem einfachen Diebstahl oder einer Unterschlagung wieder registriert. Denn, wie bereits festgestellt, sind die Rückfallra-

886 Einsele, in: MschrKrim 1968, S. 28, 37. 
ten in der Gruppe der Vorbestraften wegen eines anderen Diebstahldelikts, in der die $\iint 242,246$ StGB registriert werden, am größten.

Ähnlich Ergebnisse zeigen sich bei Betrachtung der Täuschungsdelikte ${ }^{887}$, nämlich dem Betrug u.a. (linke Seite von Schaubild 6.19) sowie dem Erschleichen von Leistungen (rechte Seite von Schaubild 6.19).

Schaubild 6.19: Einschlägige Voreintragungen und Rückfälle bei Bezugsentscheidungen aufgrund von Täuschungsdelik.ten*

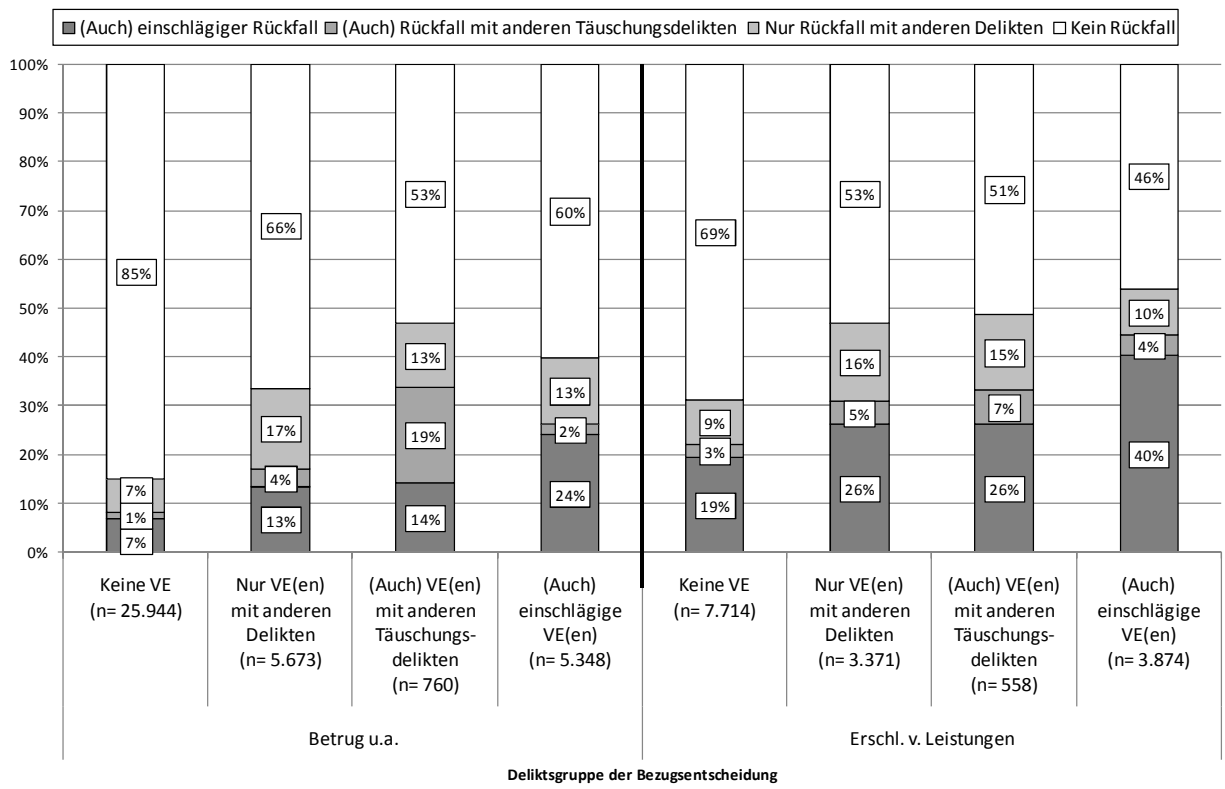

* Absolutzablen siebe Tab. $6.16 b \mathrm{im}$ Anhang

Erwartungsgemäß sind wieder die Rückfallraten für die Täterinnen ohne Voreintragungen am niedrigsten. Am höchsten ist die Rückfallrate mit $47 \%$ bei den Täterinnen, die eine Bezugsentscheidung aufgrund eines Betrugsdelikts u.a. erhalten haben und die wegen eines anderen Täuschungsdelikts vorbestraft sind. In dieser Gruppe ist im Übrigen auch der Anteil der wegen eines anderen Täuschungsdelikts Rückfälligen mit $19 \%$ besonders hoch. Ähnlich wie beim Diebstahl dürfte dies damit zusammenhängen, dass in dieser Gruppe das weniger schwerwiegende und häufig von Frauen begangene Erschleichen von Leistungen mitberücksichtigt wird. Die höchste einschlägige Rückfallrate weisen jedoch die auch bereits einschlägig vorbestraften Täterinnen eines Betruges u.a. mit $24 \%$ auf.

${ }^{887} \mathrm{Da}$ den hier berücksichtigten Delikten ein Täuschungselement gemeinsam ist, wird im Folgenden von Täuschungsdelikten gesprochen. 
Beim Erschleichen von Leistungen zeigt sich, dass die höchste allgemeine Rückfallquote für die einschlägig Vorbestraften vorliegt. Diese weisen im Übrigen mit $40 \%$ auch die höchste einschlägige Rückfallquote auf. Insgesamt wird die Rückfälligkeit hier, ähnlich wie beim einfachen Diebstahl, stark vom einschlägigen Rückfall dominiert. Besonders selten werden die Täterinnen eines Erschleichens von Leistungen wegen eines anderen Täuschungsdelikts erneut strafrechtlich auffällig, eher werden sie noch wegen eines anderen Delikts rückfällig. Es zeigt sich mithin, dass sich Täterinnen eines Erschleichens von Leistungen kaum außerhalb dieser Deliktsstruktur bewegen. Dies ist vermutlich auf die Bagatellhaftigkeit des Delikts zurückzuführen: Frauen, die in diesem Bereich strafrechtlich auffallen, werden im Falle eines Rückfalls zumeist wieder wegen eines solchen Delikts erfasst. Sie begehen in der Regel keine schwerwiegenderen Straftaten. Gleiches gilt für die Täterinnen eines einfachen Diebstahls oder einer Unterschlagung.

\subsubsection{Sonstige Delikte}

Schaubild 6.20 fasst die wohl zumeist zu den Verkehrsdelikten ${ }^{888}$ zählenden fahrlässigen Körperverletzungen und fahrlässigen Tötungen (linke Seite) mit den Verkehrsdelikten ohne (Mitte des Schaubilds) und unter Alkoholeinfluss (rechte Seite) in einer Graphik zusammen.

Es zeigt sich, dass sich die Rückfallraten hier deutlich von den bislang erörterten Deliktsgruppen unterscheiden. Am höchsten ist die Rückfallquote mit $37 \%$ bei den Täterinnen eines Verkehrsdelikts ohne Alkoholeinfluss, die auch einschlägige Voreintragungen aufweisen. Fast genauso hoch (36\%) ist die Rückfallrate der Täterinnen eines Verkehrsdelikts ohne Alkoholeinfluss die wegen eines anderen Verkehrsdelikts vorbestraft mit.

Die Rückfallraten der Verkehrstäterinnen unter Alkoholeinfluss oder einer fahrlässigen Körperverletzung bzw. Tötung sind verhältnismäßig niedrig. Betrachtet man diese beiden Deliktsgruppen, so lässt sich feststellen, dass die Rückfallrate bei den Täterinnen eines Verkehrsdelikts unter Alkoholeinfluss, die eine Voreintragung wegen eines anderen Verkehrsdelikts aufweisen, mit 30\% am höchsten ist. In dieser Gruppe ist auch der einschlägige Rückfall mit $9 \%$ am stärksten ausgeprägt. Der einschlägige Rückfall spielt im Übrigen überhaupt nur bei den Verkehrsstraftäterinnen unter Alkoholeinfluss eine Rolle. Bei den Täterinnen einer fahrlässigen Körperverletzung bzw. fahrlässigen Tötung beträgt die einschlägige Rückfallrate in allen Gruppen $0 \%$, bei den Frauen, die wegen eines Verkehrsdelikts ohne Alkoholeinfluss registriert wurden, höchstens $2 \%$. Kirchner kam ebenfalls zu diesem Ergebnis: Er stellte bei gemeinsamer Betrachtung der Geschlechter auf der Grundlage der BZR-Daten für das Bezugsjahr 1994 fest, dass „Alkoholtäter beim Rückfall ,ibrem" Deliket durchaus ,treu“ bleiben." "889

${ }^{888}$ Zum Zusammenhang vgl. Kap. 4, 1.4.1.1.

889 Kirchner, in: Heinz/Jehle (Hrsg.), Rückfallforschung, S. 261, 267. 
Schaubild 6.20: Einschlägige Voreintragungen und Rückfälle bei Bezugsentscheidungen aufgrund von Verkehrsdelikten*

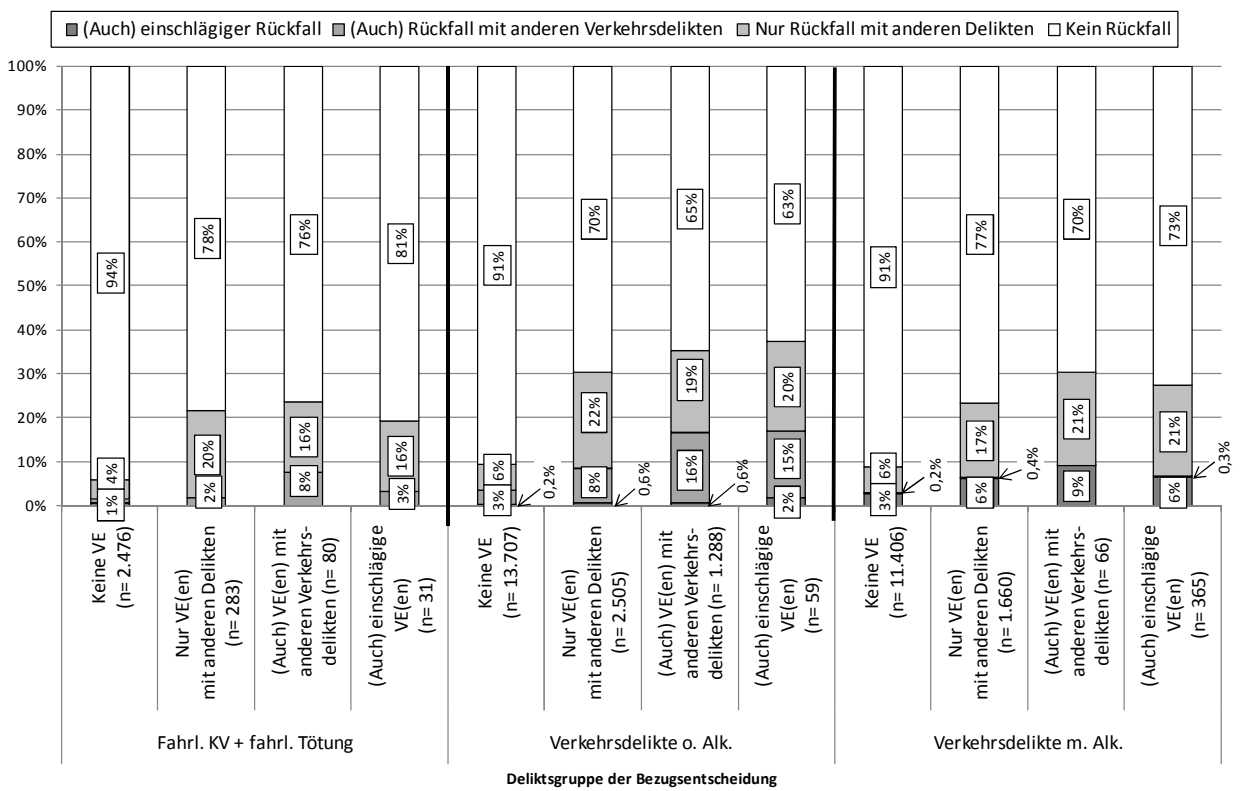

* Absolutzablen siehe Tab. 6.17a im Anhang

Insgesamt betrachtet, werden alle Verkehrstäterinnen hauptsächlich mit anderen Delikten wieder registriert.

Bei den Drogendelinquenten ist die Rückfallquote insgesamt wieder etwas höher (vgl. Schaubild 6.21).

Die niedrigste Rückfallquote (22\%) weisen die nicht vorbestraften Täterinnen und die höchste $(49 \%)$, die wegen eines Diebstahldelikts vorbestraften Frauen auf. Der Anteil am einschlägigen Rückfall ist, unabhängig von der Einschlägigkeit der Voreintragungen, durchweg sehr niedrig. Täterinnen eines Drogendelikts werden im Falle eines Rückfalls am ehesten wegen anderer Delikte erneut straffällig, aber auch die Rückfälligkeit mit einem Diebstahldelikt spielt mit $20 \%$ bei den wegen eines Diebstahldelikts vorbestraften und $19 \%$ bei den einschlägig vorbestraften Frauen durchaus eine Rolle. Wie bereits erwähnt dürfte dies damit zusammenhängen, dass Drogendelinquenten oftmals wegen anderer Delikte auffällig werden, die der Finanzierung der Sucht dienen sollen. ${ }^{890}$

${ }^{890}$ Vgl. Ausführungen unter Kap. 5, 2.5.2. 


\section{Schaubild 6.21: Einschlägige Voreintragungen und Rückfälle bei Bezugsentscheidungen wegen} Delikten nach dem BtMG*

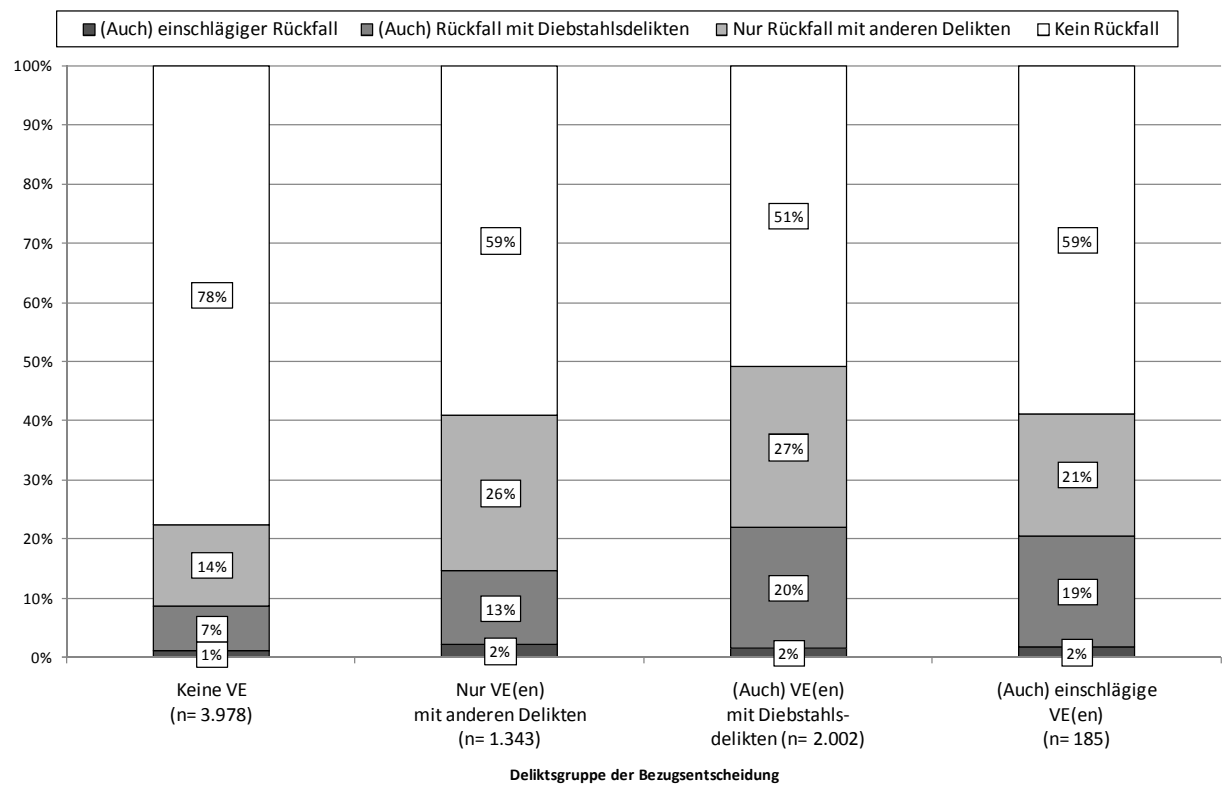

* Absolutrablen siehe Tab. $6.17 b$ im Anhang

Es ist daher nicht verwunderlich, dass die einschlägigen Rückfallraten trotz der insgesamt recht hohen Rückfälligkeit von Drogendelinquentinnen sehr niedrig sind.

\subsection{Rückfallgeschwindigkeit}

Von Interesse ist weiterhin, wie schnell straffällig gewordene Frauen wieder rückfällig werden. Empirische Studien zu dieser Thematik kommen zu dem Ergebnis, dass sich die meisten Rückfälle nach Beginn des Risikozeitraums ereignen. ${ }^{891} \mathrm{Al}$ lerdings beziehen sich diese Ergebnisse zumeist auf die Geschlechter insgesamt, sodass frauenspezifische Aussagen kaum getroffen werden können.

Loos kam in seiner Untersuchung zu dem Ergebnis, dass sich $61 \%$ der Rückfälle heranwachsender Frauen im Landgerichtsbezirk Koblenz in den ersten zwölf Monaten ereignen. ${ }^{892}$ Einsele stellte für die Gruppe der erwachsenen Frauen fest, dass sich mehr als die Hälfte der Rückfälle in den ersten zwölf Monaten nach Haftentlassung ereignen. ${ }^{893}$ Jugendliche würden hingegen in den ersten zwölf Mo-

\footnotetext{
891 Albrecht, Legalbewährung bei zu Geldstrafe und Freiheitstrafe Verurteilten, S. 67 f.; Heinz, in: ZJJ 2004, S. 35, 40.

892 Loos, S. 115 sowie Ausführungen unter Kap. 6, 3.

${ }^{893}$ Einsele, in: MschrKrim 1968, S. 334, 358 f. sowie Ausführungen unter Kap. 6, 3.
} 
naten mit $61 \%$ schneller rückfällig. Beide Autoren konnten allerdings nur auf eine kleine Anzahl von Probandinnen zurückgreifen. ${ }^{894}$

Schaubild 6.22: Dauer bis zum ersten Rückfall nach Altersgruppen*

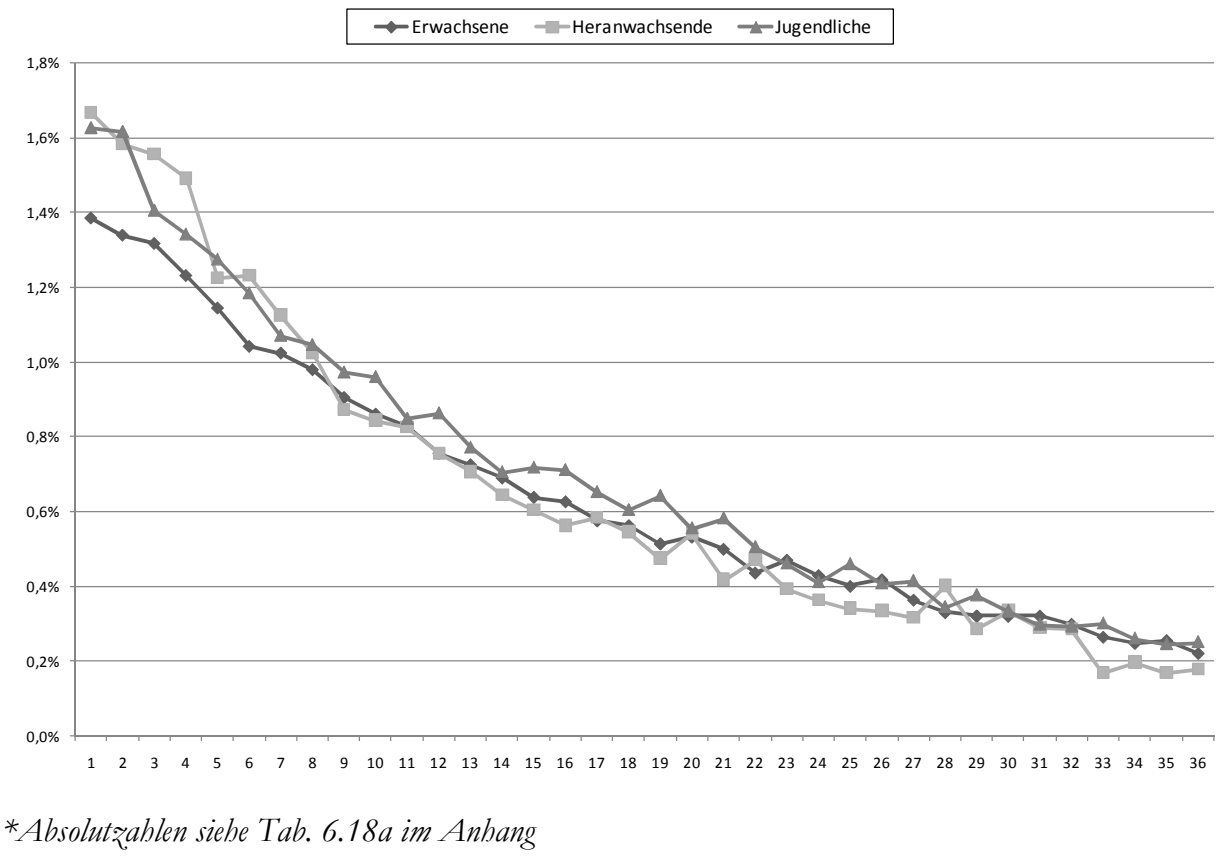

Schaubild 6.22 stellt die Rückfallgeschwindigkeit anhand der Monate bis zum ersten Rückfall dar und differenziert nach Altersgruppen für straffällige Frauen. Die Dauer berechnet sich als Differenz zwischen der Bezugsentscheidung und dem Tatdatum der ersten Rückfalltat. Betrachtet werden die Anteile an allen straffällig gewordenen Frauen. 23\% der erwachsenen, $24 \%$ der heranwachsenden und $25 \%$ der jugendlichen Täterinnen werden rückfällig.

Vergleicht man die Altersgruppen miteinander, so fällt auf, dass die Gruppe der Heranwachsenden in den ersten Monaten am schnellsten rückfällig wird, dann aber von den Jugendlichen überholt wird. Die erwachsenen Frauen werden am langsamsten rückfällig. Für alle Altersgruppen ereignen sich die meisten Rückfälle innerhalb der ersten zwölf Monate: bei den Erwachsenen finden $13 \%$, bei den Jugendlichen und bei den Heranwachsenden jeweils $14 \%$ der Rückfälle in diesem Zeitraum statt. Nach 24 Monaten haben sich sodann bereits $22 \%$ (Jugendliche) bzw. $20 \%$ (Heranwachsende) sowie 19\% (Erwachsene) der Rückfälle ereignet. Insgesamt sind die Unterschiede zwischen den Altersgruppen jedoch minimal. Es

${ }^{894}$ Vgl. hierzu Ausführungen unter Kap. 6, 3; Grundsätzlich ist jedoch zu berücksichtigen, dass die Studien allein schon aufgrund des Zeitablaufs nicht vergleichbar sind, vgl. auch Fn. 868. 
zeigt sich allerdings, dass das Rückfallrisiko in den ersten Monaten sehr viel höher ist.

Betrachtet man nur die Raten für die Rückfälligen, so kommt man zu dem Ergebnis, dass in den ersten zwölf Monaten bei den Erwachsenen $55 \%$, bei den Jugendlichen $56 \%$ und bei den Heranwachsenden sogar $60 \%$ der Rückfälle stattfinden. Nach 24 Monaten haben sich bereits $86 \%$ (Heranwachsende) bzw. $84 \%$ (Jugendliche und Erwachsene) der Rückfälle ereignet. Die Ergebnisse von Einsele und Loos können insoweit bestätigt werden.

\subsection{Folgeentscheidungen nach Alter und Nationalität}

Aufgrund der bereits vorangegangenen Ergebnisse, nach denen besonders hohe Rückfallquoten nach Jugendstrafen vorliegen, ist von einer starken Beeinflussung der Rückfälligkeit durch das Alter ${ }^{895}$ der Täterinnen auszugehen.

Schaubild 6.23: Art der Folgeentscheidung nach Altersgruppe bei der Bezugsentscheidung*

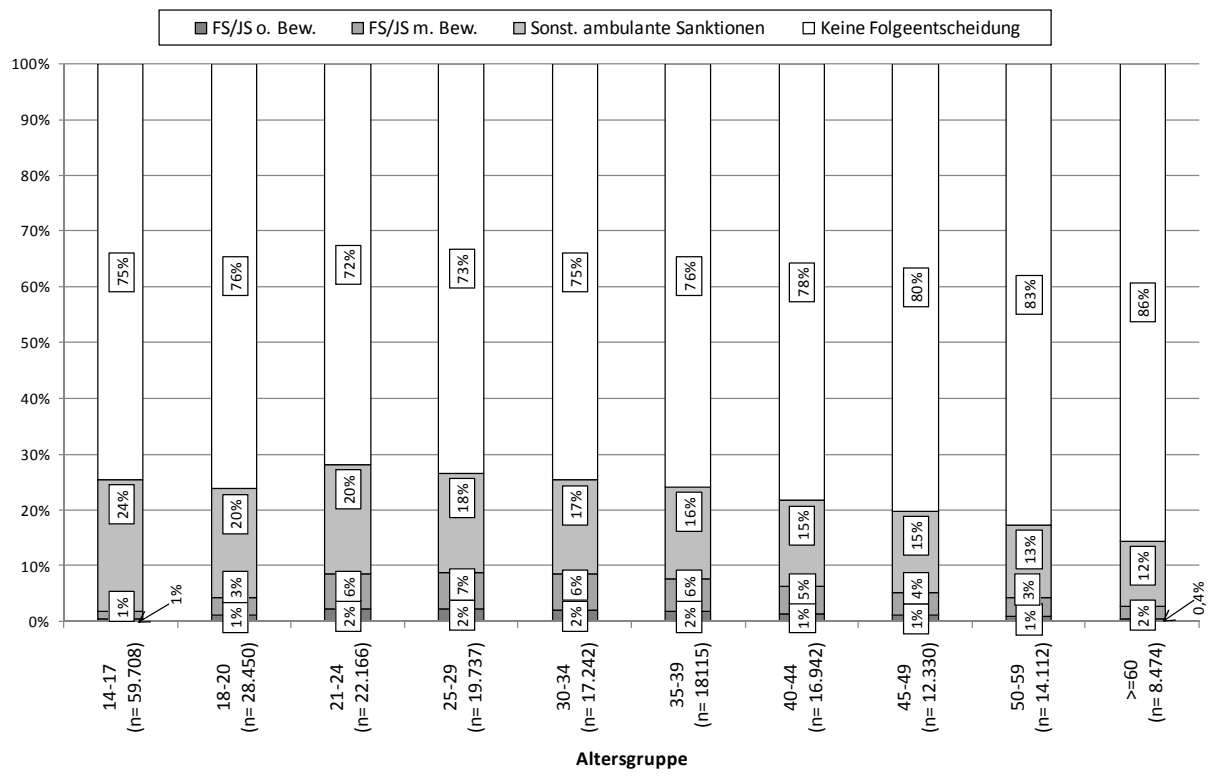

* Absolutzablen siebe Tab. 6.19a im Anhang

Schaubild 6.23 bestätigt die Vermutung, dass die Rückfallbelastung stark altersabhängig ist: Am stärksten ist die Gruppe der 21-24-jährigen Frauen mit 28 \% betroffen, dicht gefolgt von den 25-29-jährigen mit $27 \%$. Aber auch die Gruppen

${ }^{895}$ Alter bedeutet die Differenz in Jahren zwischen dem Geburtsdatum und dem Zeitpunkt der letzten der Bezugsentscheidung zugrunde liegenden Tat. 
der Jugendlichen $(26 \%)$ und Heranwachsenden $(24 \%)$ werden häufig rückfällig. $\mathrm{Ab}$ der Altersgruppe der 21-24-jährigen, ist ein stetiger Rückgang der Rückfälligkeit zu verzeichnen. Differenziert man weiter nach Art der Folgeentscheidung und betrachtet den Verlauf der schwersten stationären Sanktionen so wird deutlich, dass Frauen im Alter von 25-39 am häufigsten stationäre Sanktionen als Folgeentscheidungen erhalten.

Schaubild 6.24: Rückfallrate nach Art der Bezugsentscheidung und Nationalität

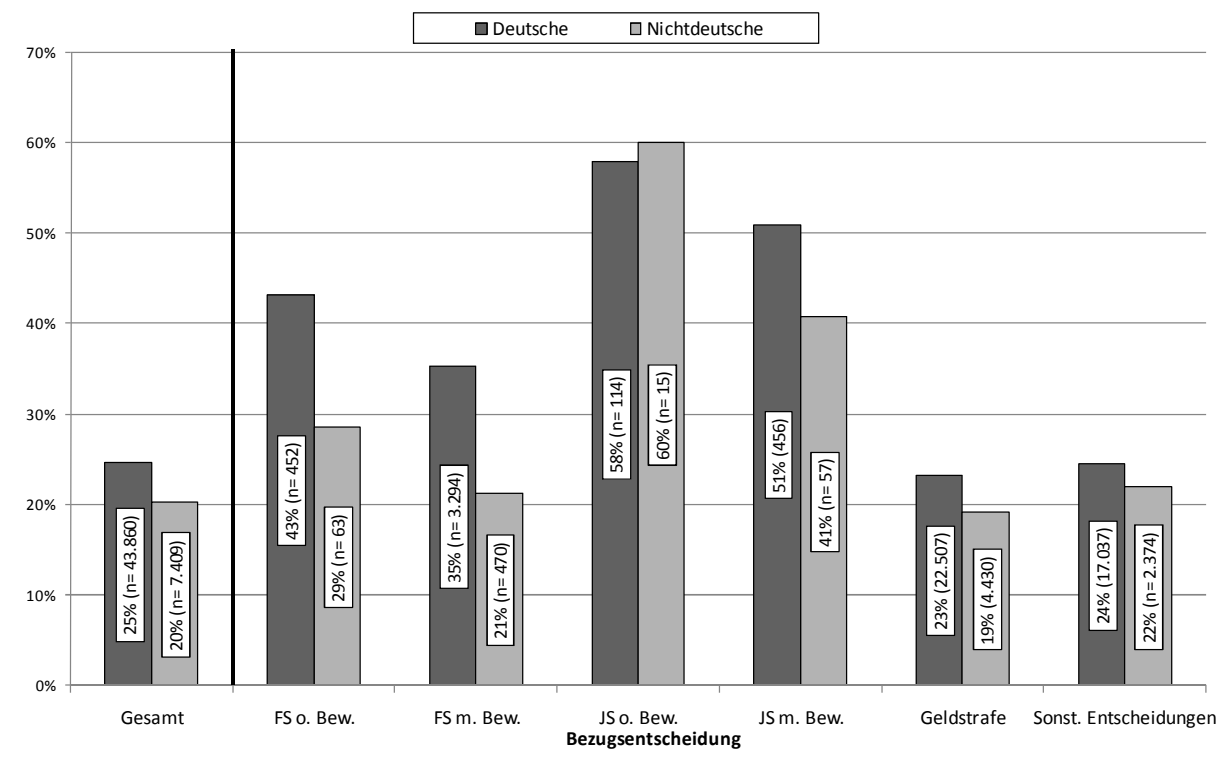

Wie bereits unter Kapitel 4, 2.2 erwähnt, sind $17 \%$ der verurteilten Frauen im Bezugsjahr nichtdeutsch. Dieser Anteil hat sich im Rückfalldatensatz, nicht verändert. Schaubild 6.24 stellt die Rückfallraten getrennt für deutsche und nichtdeutsche Frauen dar.

Es zeigt sich, dass die Rückfallrate der nichtdeutschen straffälligen Frauen mit knapp $20 \%$ unter der der deutschen Frauen mit $25 \%$ liegt. Der größte Unterschied besteht bei der Freiheitsstrafe ohne Bewährung: $43 \%$ der deutschen Frauen werden hier erneut wegen einer Straftat registriert, wohingegen es bei den nichtdeutschen Frauen lediglich $29 \%$ sind. Auch bei den Freiheitsstrafen mit Bewährung, ist ein Unterschied von 14 Prozentpunkten zwischen den Rückfallraten der deutschen und nichtdeutschen Frauen zu verzeichnen. Bei den Jugendstrafen mit Bewährung beträgt die Differenz immerhin noch $10 \%$. Im Gegensatz dazu ist der Unterschied bei den ambulanten Sanktionen, also der Geldstrafe und den sonstigen Entscheidungen nach JGG, mit jeweils $4 \%$ und 3\% Differenz sehr gering. Darüber hinaus fällt die Rückfallquote nach Jugendstrafen ohne Bewäh- 
rung ins Auge: Hier weisen die nichtdeutschen sogar eine um zwei Prozentpunkte höhere Rückfallrate auf als die deutschen Frauen.

Ein Grund für die zumeist höheren Rückfallquoten der Deutschen könnte darin zu sehen sein, dass nichtdeutsche Frauen, insbesondere nach Erhalt schwerer Sanktionen, ausgewiesen oder abgeschoben werden und dementsprechend etwaige Rückfälle nicht registriert werden können. ${ }^{896}$ Dieser Erklärung steht jedoch die hohe Rückfallrate nichtdeutscher Frauen nach Jugendstrafen ohne Bewährung entgegen. Hier ist allerdings zu beachten, dass das AufenthG erhöhte Voraussetzungen für die Ausweisung jugendlicher Straftäter vorsieht (vgl. \56 II AufenthG). Ferner darf bei der Interpretation des Ergebnisses nicht vergessen werden, dass insgesamt nur 25 nichtdeutsche Frauen nach einer Jugendstrafe ohne Bewährung weiterverfolgt wurden, sodass der Rückfallrate von $60 \%$ gerade einmal 15 Frauen zugrunde liegen.

\subsection{Zwischenfazit}

Die Rückfallkriminalität von Frauen ist mit insgesamt $24 \%$ verhältnismäßig gering. Die Betrachtung der rückfälligen Frauen hat ergeben, dass die Rückfallquote insgesamt, aber auch die Sanktionsart in der Folgeentscheidung stark von der Sanktion in der Bezugsentscheidung abhängig ist. Dabei hat bereits die hohe Rückfallrate nach Jugendstrafen einen altersabhängigen Effekt gezeigt, der durch eine Analyse der Art der Folgeentscheidung nach Altersgruppen bestätigt werden konnte: Die Rückfallrate sinkt kontinuierlich ab dem Alter von 25 Jahren. Die vorstehenden Ausführungen haben zudem deutlich gemacht, dass neben dem Alter und der Schwere der Bezugsentscheidung auch die Anzahl und Art der Voreintragungen Einfluss auf die Rückfallkriminalität von Frauen hat: Mit steigender Anzahl von Voreintragungen nimmt auch die Rückfallwahrscheinlichkeit zu. Eine ähnliche Beziehung besteht zwischen der Schwere der Voreintragungen und der späteren Folgesanktion. Je schwerer die Voreintragungen, desto höher sind auch die Rückfallrate und der Anteil der stationären Sanktionen. Darüber hinaus ist die Rückfallrate deliktsabhängig. Bezugsentscheidungen aufgrund von Verkehrsdelikten weisen allgemein das geringste Rückfallrisiko auf, wohingegen die Rückfallraten nach Bezugsentscheidungen aufgrund von sonstigen Gewaltdelikten, schweren Diebstahlsformen und Erschleichen von Leistungen recht hoch sind. Die Wahrscheinlichkeit eine stationäre Sanktion als Folgeentscheidung zu erhalten, ist ebenfalls für sonstige Gewaltdelikte und schwere Diebstahlsformen, aber auch für Delikte nach dem BtMG besonders hoch. Im Übrigen konnte festgestellt werden, dass nach Bezugsentscheidungen wegen eines Vermögensdelikts i.w.S. der einschlägige Rückfall den größten Anteil an Rückfällen ausmacht. Bei den Gewaltdelikten überwiegt hingegen der Anteil von allgemeinen Rückfällen. Bezieht man

${ }^{896}$ Jehle/Albrecbt/Hohmann-Fricke/Tetal, Legalbewährung nach strafrechtlichen Sanktionen, 2010, S. 41; vgl. aber auch $₫ 54$ BZRG. 
dann noch die Einschlägigkeit der Voreintragungen in die Untersuchung mit ein, so zeigt sich besonders bei den Täterinnen von Vermögensdelikten i.w.S. die Einhaltung einer Deliktsstruktur. Schließlich wurde festgestellt, dass Frauen in den ersten zwölf Monaten am schnellsten rückfällig werden.

\section{Rückfallkriminalität von Frauen und Männern im Vergleich auf der Grundlage der Daten des BZR}

Nachdem bislang nur die Rückfallkriminalität von Frauen untersucht wurde, wird nunmehr eine geschlechtervergleichende Betrachtung vorgenommen. Eine solche ist, insbesondere vor dem Hintergrund der Fragestellung in Kapitel 5, für die vorliegende Untersuchung lohnenswert. Dort zeigte sich, dass eine mildere Sanktionierung von Frauen im Vergleich zu Männern unter Berücksichtigung mehrerer Variablen kaum noch erkennbar ist. Aber wie werden Frauen im Falle eines Rückfalls im Vergleich zu den Männern sanktioniert? Ist auch bei einer genaueren Analyse der Sanktionsart der Folgeentscheidungen eine mildere Sanktionierung kaum mehr erkennbar? Der folgende Abschnitt soll u.a. diesen Fragen nachgehen. Dabei ist, wie bei der Sanktionierungspraxis im Hinblick auf die Bezugsentscheidung (Kapitel 5), auch bei der Sanktionierung der Folgeentscheidung immer daran zu denken, dass verschiedene, die Strafzumessung beeinflussende Faktoren, aus unterschiedlichsten Gründen hier nicht berücksichtigungsfähig sind. Unterschiede bzw. eine etwaige mildere Behandlung von Frauen oder Männern könnten daher auch immer auf andere individuelle Tätereigenschaften, die in eine richterliche Prognose mit einfließen, zurückzuführen sein. ${ }^{897}$ Darüber hinaus soll die kriminelle Karriere von Täterinnen und Tätern im Rahmen der deliktsspezifischen Betrachtung gegenüber gestellt und die Rückfallgeschwindigkeit miteinander verglichen werden.

\subsection{Art der Folgeentscheidung}

Schaubild 6.25 verdeutlicht die Art der Folgeeintragung für Frauen und Männer im Vergleich und bezieht sich nur auf die Rückfälligen. Es zeigt sich, dass Frauen im Falle eines Rückfalls milder sanktioniert werden als Männer. Grundsätzlich sind Männer bei den härteren und Frauen bei den leichteren Sanktionen stärker vertreten. So erhalten $10 \%$ der Männer, jedoch nur $5 \%$ der Frauen eine Freiheitsstrafe ohne Bewährung als Folgeeintragung. Bei Freiheitsstrafen mit Bewährung stehen sich Werte von 17\% (Männer) und 14\% (Frauen) gegenüber. 3\% der Männer und $1 \%$ der Frauen werden im Falle eines Rückfalls zu einer Jugendstrafe ohne Bewährung verurteilt. Eine Jugendstrafe mit Bewährung bekommen $4 \%$ der rückfälligen Männer und $2 \%$ der rückfälligen Frauen.

${ }^{897}$ Vgl. auch unter Kap. 5, 2. 
Schaubild 6.25: Sanktionsart der Folgeeintragung nach Geschlecht*

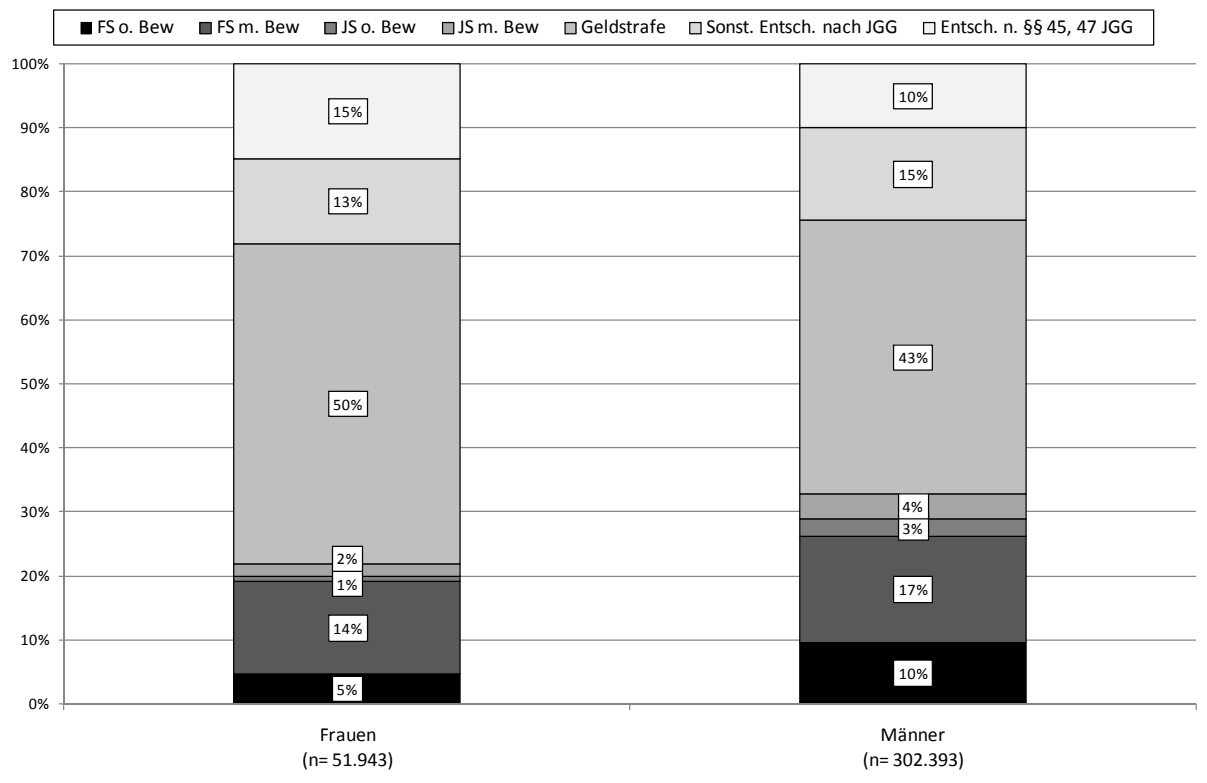

* Absolutzablen siebe Tab. 6.20a im Anhang

Bei der leichteren Sanktion der Geldstrafe überwiegt der prozentuale Anteil bei den Frauen mit $50 \%$ den der Männer mit $43 \%$. Auch bei den Einstellungen nach dem JGG weisen die Frauen im Vergleich zu den Männern die höheren Werte $(15 \%$ zu $10 \%)$ auf. Bei den sonstigen Entscheidungen des JGG übersteigt wiederum der prozentuale Anteil bei den Männern mit 15\% den der Frauen mit 13\%. Dieses Ergebnis spricht für sich genommen noch nicht für eine Besserbehandlung von Frauen, da hier weitere Faktoren, wie beispielsweise das zugrunde liegende Delikt, noch keine Berücksichtigung gefunden haben.

\subsection{Rückfallrate nach Sanktionsart der Bezugsentscheidung}

Schaubild 6.26 veranschaulicht die allgemeine Rückfallrate nach Sanktionsart der Bezugsentscheidung von Frauen und Männern im Vergleich.

Die Rückfallrate der Frauen liegt mit $24 \%$ deutlich unter der der Männer mit $36 \%$. Frauen sind über alle Ausgangssanktionen hinweg weniger rückfällig, wobei auffällt, dass die prozentuale Differenz zwischen den verschiedenen Sanktionsarten schwankt. Am höchsten ist die Differenz bei den sonstigen Entscheidungen nach dem JGG mit 21 Prozentpunkten, am niedrigsten bei der Freiheitsstrafe mit Bewährung, hier beträgt sie lediglich sechs Prozentpunkte. Ähnliche Ergebnisse konnten bereits mit den Daten des Bundeszentralregisters für das Basisjahr 1994 erzielt werden. 
Schaubild 6.26: Rückfallrate nach Sank.tionsart der Bezugsentscheidung

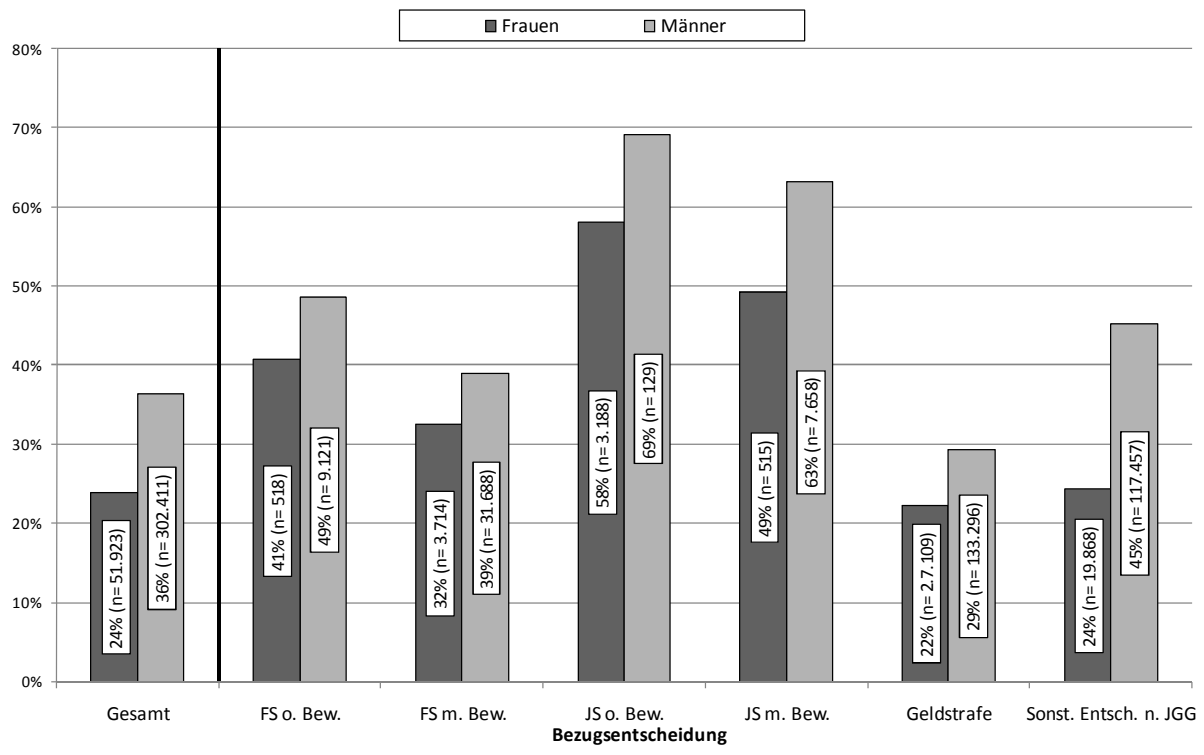

Dort betrug die Rückfallrate der Frauen 24 \%, die der Männer 38 \%. Die stärkste Differenz war auch für das Basisjahr 1994 bei den sonstigen jugendstrafrechtlichen Reaktionen (mit 27 Prozentpunkten). Am geringsten war der Unterschied hingegen bei der Jugendstrafe ohne Bewährung mit lediglich 1,3 Prozentpunkten. 898

Frauen werden mithin seltener rückfällig (vgl. Schaubild 6.26) und im Falle eines Rückfalls milder sanktioniert (vgl. Schaubild 6.25).

\subsection{Rückfallgeschwindigkeit}

Interessant ist ferner, ob sich bei der Rückfallgeschwindigkeit geschlechtsspezifische Unterschiede ergeben.

Schaubild 6.27 verdeutlicht die Dauer bis zum ersten Rückfall für alle Verurteilungen von Frauen und Männern. Es wird deutlich, dass Männer vor allem in den ersten 24 Monaten schneller rückfällig werden als Frauen: Bei den Männern ereignen sich $20 \%$ der Rückfälle von insgesamt $36 \%$ in den ersten zwölf Monaten, bei den Frauen sind es $13 \%$ von insgesamt $24 \%$. Der Unterschied zwischen den Geschlechtern ist jedoch minimal: So beträgt die Differenz im ersten Monat lediglich $0,7 \%$ und wird dann immer geringer. In den letzten zwölf Monaten werden Frauen und Männer in etwa gleich schnell rückfällig. ${ }^{899}$

898 Jehle/Heinz/Sutterer, Legalbewährung nach strafrechtlichen Sanktionen, 2003, S. 47.

${ }^{899}$ Eine differenzierte Betrachtung der Rückfallgeschwindigkeit nach Deliktsgruppen und Geschlecht befindet sich im Tabellenanhang, vgl. Tab. 6.21 b-m im Anhang. 


\section{Schaubild 6.27: Dauer bis zum ersten Rückfall nach Geschlecht*}

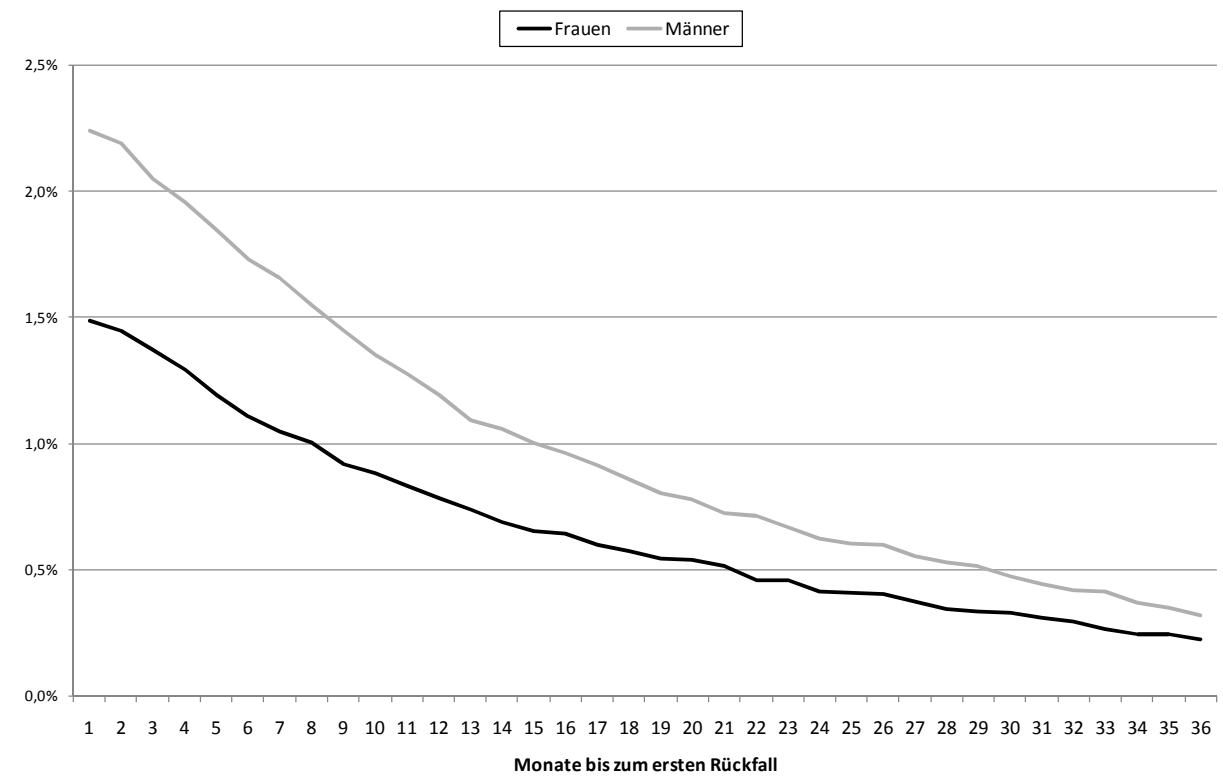

* Absolutzablen siehe Tab. 6.21 a im Anhang

\subsection{Folgeentscheidung nach Bezugsentscheidungen aufgrund von Dieb- stahl gem. $\$ 242$ StGB}

Vermutlich wird die mildere Sanktionierung im Falle eines Rückfalls unter Berücksichtigung des Delikts und der Informationen über die Voreintragungen an Bedeutung verlieren. Die in Kapitel 5 gewonnen Ergebnisse deuten bereits darauf hin. Im Folgenden wird die Rückfallkriminalität von Frauen und Männern anhand des Massendelikts Diebstahl einander gegenübergestellt.

\subsubsection{Art der Folgeentscheidung}

Schaubild 6.28 stellt die Folgeentscheidungen von Frauen und Männer nach einer Bezugsentscheidung wegen Diebstahls einander gegenüber.

Für Frauen ist nach einer Bezugsentscheidung wegen Diebstahls mit $73 \%$ häufiger kein Rückfall zu verzeichnen als für Männern mit $55 \%$. Im Falle eines Rückfalls erhalten beide am häufigsten eine Geldstrafe als Sanktion (Frauen in $11 \%$ und Männer in $16 \%$ der Fälle). Der Anteil von Freiheits- und Jugendstrafen mit Bewährung für die Gruppe der Männer (8 \%) übersteigt den Anteil von Bewährungsstrafen bei den Frauen (4\%) um das Doppelte, ihren Anteil von stationären Folgeentscheidungen sogar um das Dreifache (2\% bei den Frauen zu $6 \%$ bei den Männer). 
Schaubild 6.28: Art der Folgeentscheidung bei Bezugsentscheidungen aufgrund von Diebstahl nach Geschlecht*

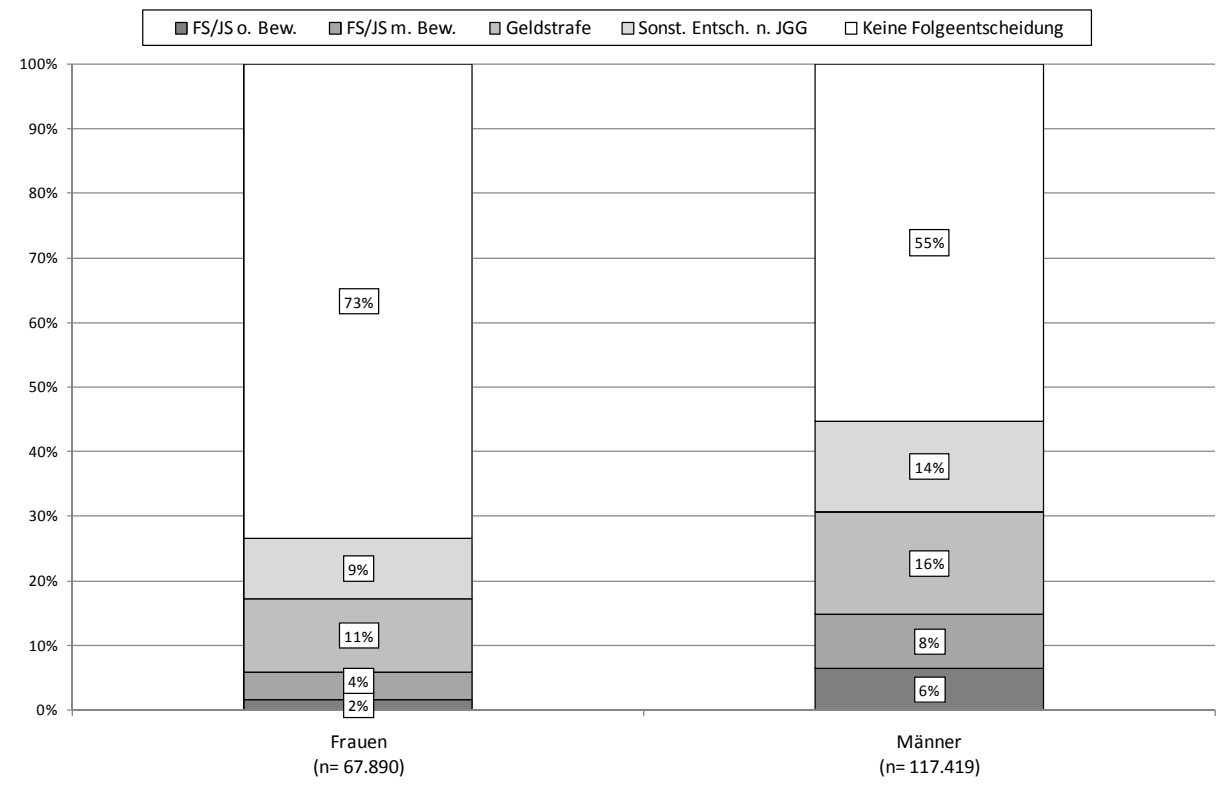

* Absolutzablen siehe Tab. 6.22a im Anhang

In einem weiteren Schritt wird nun die Sanktionsart der Bezugsentscheidung mit hinzugezogen. Aus Schaubild 6.29 geht die Sanktionsart der Folgeentscheidung nach Sanktionsart der Bezugsentscheidung für das Delikt Diebstahl hervor. Hier werden nur die rückfälligen Frauen und Männer betrachtet.

Es zeigt sich, dass Frauen über alle Bezugsentscheidungen hinweg seltener stationäre Sanktionen in der Folgeentscheidung erhalten. Der Anteil von stationären Sanktionen nach einer Jugendstrafe ohne Bewährung als Bezugssanktion, beträgt bei den Männern $62 \%$ und bei den Frauen $47 \%$. Die Anteile von stationären Sanktionen als Folgeeintragung nach Freiheitsstrafen ohne Bewährung als Bezugssanktion, betragen $64 \%$ (Männer) zu $49 \%$ (Frauen). Dafür bekommen Frauen im Vergleich zu Männern in der Regel häufiger Freiheits- oder Jugendstrafen mit Bewährung als Folgesanktion. So erhalten z.B. Frauen, für die als Bezugsentscheidung eine Freiheitstrafe ohne Bewährung registriert ist, in $32 \%$ der Fälle eine Bewährungsstrafe als Folgesanktion; bei den Männern sind es hingegen nur $20 \%$. Lediglich nach Geldstrafen und sonstigen Entscheidungen nach dem JGG erhalten Männer im Vergleich zu Frauen verhältnismäßig häufiger Bewährungsstrafen als Folgesanktion. 
Schaubild 6.29: Art der Folgeentscheidung nach Sanktionsart der Bequgsentscheidung aufgrund von Diebstabl nach Geschlecht*

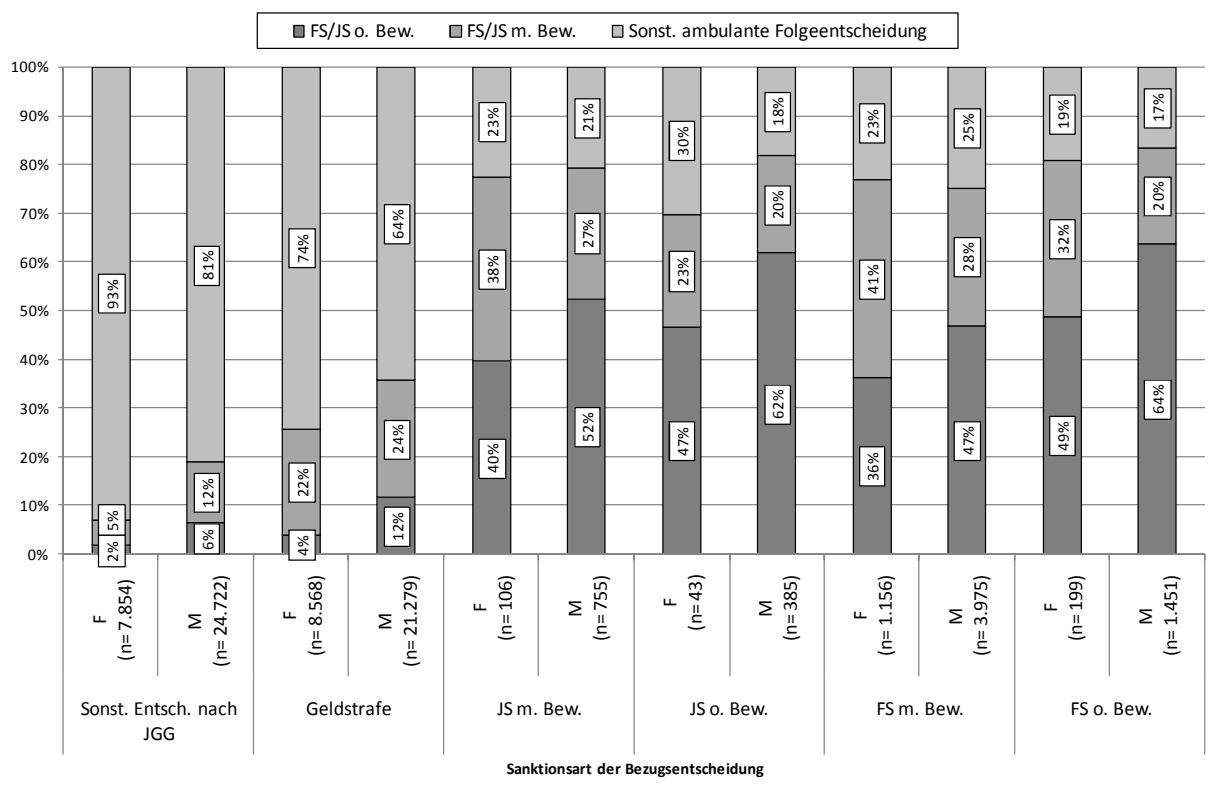

* Absolutrablen siehe Tab. 6.23 a im Anhang

In Schaubild 6.30 wird eine noch differenziertere Betrachtung der Rückfälligen auf der Ebene der Bezugsentscheidung vorgenommen. Auf der linken Seite werden bedingte und unbedingte Jugendstrafen und auf der rechten Seite Haftentlassung nach Vollverbüßung und nach Strafrestaussetzung für beide Geschlechter miteinander verglichen. Der Fokus liegt wieder nur auf den rückfällig gewordenen Frauen und Männern.

Die Tendenz aus Schaubild 6.29 bestätigt sich auch bei differenzierterer Betrachtung des Rückfalls nach Jugendstrafen: Gegen Männer werden sowohl nach ausgesetzten als auch nach nicht ausgesetzten Jugendstrafen bis zu zwei Jahren anteilsmäßig häufiger stationäre Sanktionen als Folgeentscheidungen verhängt, wohingegen Frauen verhältnismäßig häufiger Bewährungsstrafen erhalten.

Vergleicht man die Art der Folgeentscheidung von Frauen und Männern nach allen verbüßten Jugendstrafen, so ergibt sich, dass der Anteil von stationären Folgesanktionen nach Strafrestaussetzung mit 35 \% bei den Frauen deutlich niedriger ist, als der entsprechende Anteil nach Vollverbüßung mit $57 \%$. Dies stellt sich bei den Männern anders dar: Hier ist der Anteil von stationären Sanktionen als Folgeeintragung nach Strafrestaussetzung mit 64 \% sogar etwas größer als nach vollverbüßten Jugendstrafen mit $61 \%$. 
Schaubild 6.30: Art der Folgeentscheidung nach Jugendstrafe aufgrund von Diebstabl nach Geschlecht*

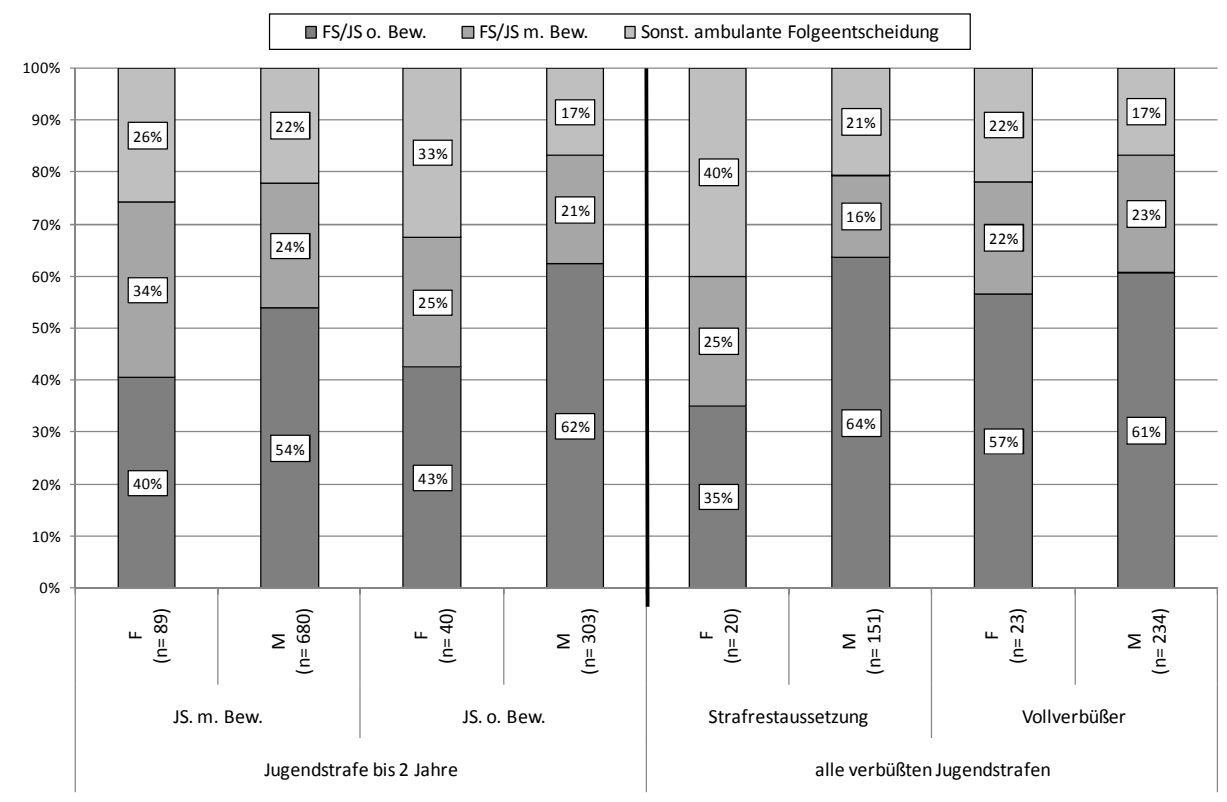

* Absolutzablen siehe Tab. 6.24a im Anhang

Ferner ist auffällig, dass bei der Art der Folgeentscheidung nach Vollverbüßung zwischen Frauen und Männern kaum mehr Unterschiede bestehen: $57 \%$ der Frauen und $61 \%$ der Männer erhalten im Falle eines Rückfalls eine Freiheits- oder Jugendstrafe ohne Bewährung; $22 \%$ der Frauen und $23 \%$ der Männer werden in diesem Fall mit einer ausgesetzten Freiheits- oder Jugendstrafe wieder registriert.

Angelehnt an Schaubild 6.30 widmet sich Schaubild 6.31 den Freiheitsstrafen. Zunächst wird deutlich, dass der Unterschied zwischen den Anteilen von stationären Folgesanktionen nach Strafrestaussetzung hier nicht mehr ganz so ausgeprägt ist wie bei den Jugendstrafen. So erhalten $47 \%$ der Frauen und $50 \%$ der Männer eine Freiheits- oder Jugendstrafe ohne Bewährung nach Strafrestaussetzung. Nach wie vor sind für Männer häufiger stationäre Sanktionen als Folgeentscheidungen registriert als für Frauen. Betrachtet man jedoch die Freiheits- und Jugendstrafen mit und ohne Bewährung zusammen, so ergibt sich, dass die Anteile sich stark ähneln: Beispielsweise erhalten $77 \%(36 \%+41 \%)$ der Frauen und $75 \%$ der Männer $(28 \%+47 \%)$ nach bedingten Freiheitsstrafen bis zu zwei Jahren eine Freiheits- oder Jugendstrafe mit oder ohne Bewährung. Nach dieser Berechnung überwiegt auch nach Strafrestaussetzung der Anteil von Jugend- und Freiheitsstrafen als Folgesanktion bei den Frauen den entsprechenden Anteil bei den Männern leicht (82\% Frauen und $80 \%$ Männer). 
Schaubild 6.31: Art der Folgeentscheidung nach Freiheitsstrafe aufgrund von Diebstahl nach Geschlecht*

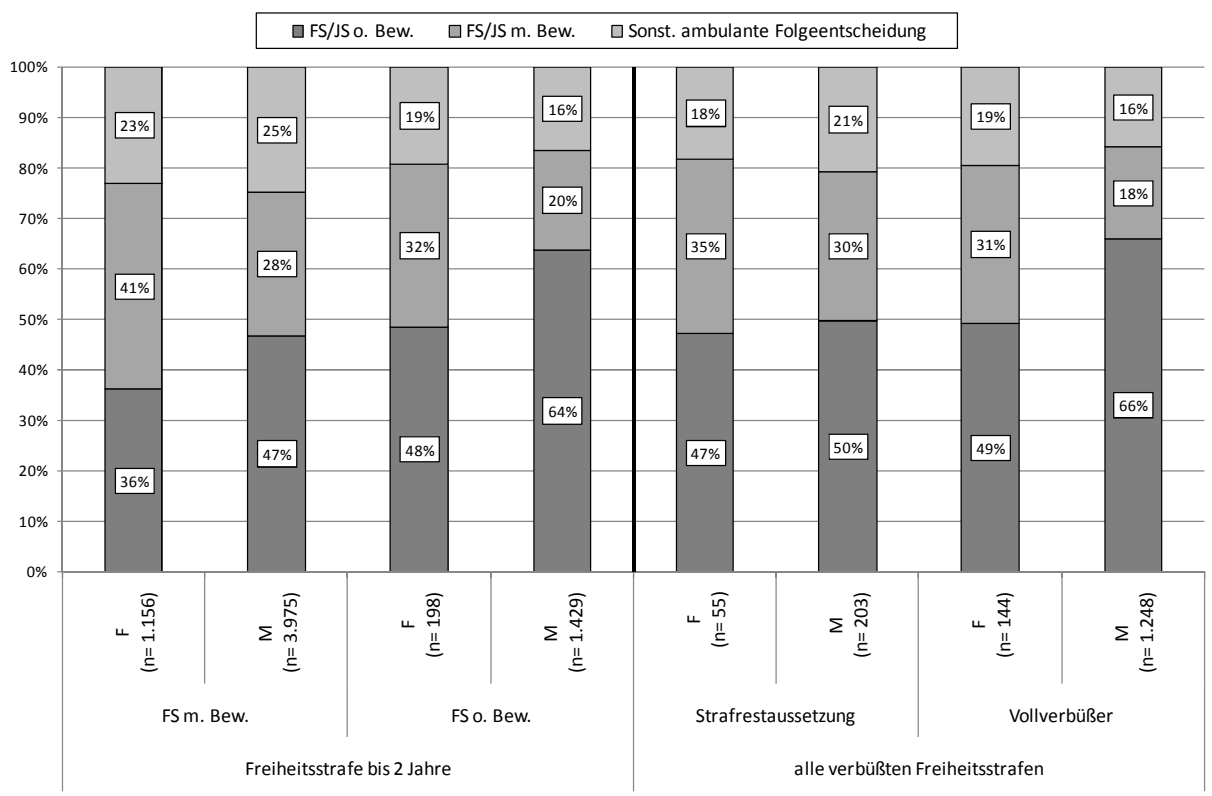

* Absolutzablen siehe Tab. 6.25a im Anhang

Bei den unbedingten Freiheitsstrafen bis zu zwei Jahren und den Vollverbüßern (jeweils $80 \%$ der Frauen und $84 \%$ der Männer) kann hingegen ein etwas größerer Anteil von Freiheits- und Jugendstrafen als Folgesanktion für die Männer verzeichnet werden.

Schaubild 6.32 stellt die Art der Folgeentscheidung für Frauen und Männer gegenüber, die als Bezugssanktion aufgrund von Diebstahl eine Geldstrafe erhalten haben, wobei nach Anzahl der Tagessätze differenziert ist.

Für beide Geschlechter ergibt sich die gleiche Tendenz: Mit steigender Anzahl der Tagessätze bei der Geldstrafe als Bezugssanktion, steigt auch die Wahrscheinlichkeit einer stationären Folgeeintragung. Männer erhalten über alle Tagessatzgruppen hinweg verhältnismäßig häufiger stationäre Sanktionen, wohingegen für Frauen ab der Gruppe 31-50 Tagessätze häufiger Bewährungsstrafen registriert sind. 
Schaubild 6.32: Art der Folgeentscheidung nach Geldstrafe aufgrund von Diebstabl und Geschlecht*

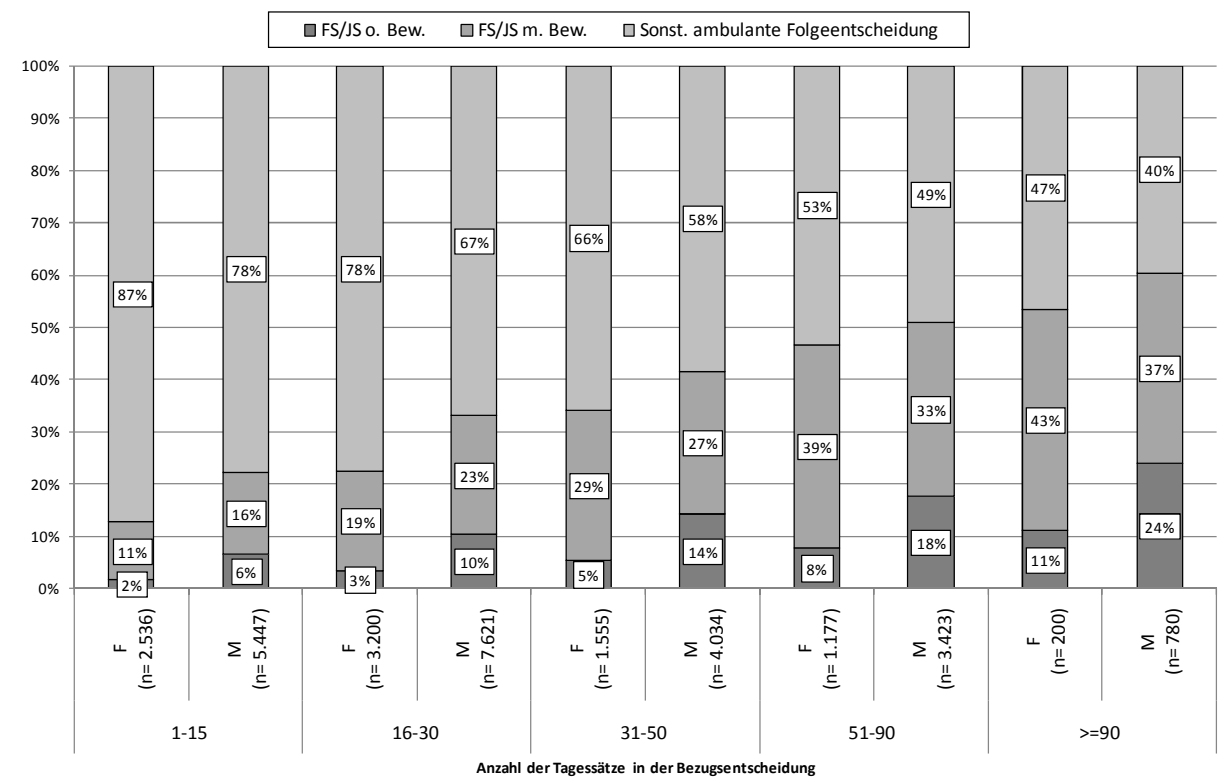

* Absolutzablen siehe Tab. 6.26a im Anhang

\subsubsection{Folgeentscheidung und Voreintragungen}

Neben der bisherigen Betrachtungsweise von der Bezugsentscheidung aus in die Zukunft wird nun zusätzlich, durch die Berücksichtigung der Voreintragungen, eine retrospektive Betrachtung erfolgen.

Schaubild 6.33 bezieht sich erneut nur auf die Gruppe der rückfällig gewordenen Jugendlichen und Heranwachsenden. Da diese Altersgruppen betrachtet werden, sind auch kaum Fälle von Freiheitsstrafen zu verzeichnen. Es wird deutlich, dass sowohl bei Frauen als auch bei Männern mit steigender Anzahl der Voreintragungen die Wahrscheinlichkeit, eine stationäre Folgeentscheidungen zu erhalten, steigt, wobei hier auch bei fünf und mehr Voreintragungen noch ein Unterschied von 14 Prozentpunkten (20\% Frauen und $34 \%$ Männer) zwischen den Anteilen von stationären Folgesanktionen besteht. 
Schaubild 6.33: Art der Folgeentscheidung nach Anzabl der Voreintragungen bei Bezugsentscheidungen aufgrund von Diebstabl nach Geschlecht Jugendliche/ Heranwachsende)*

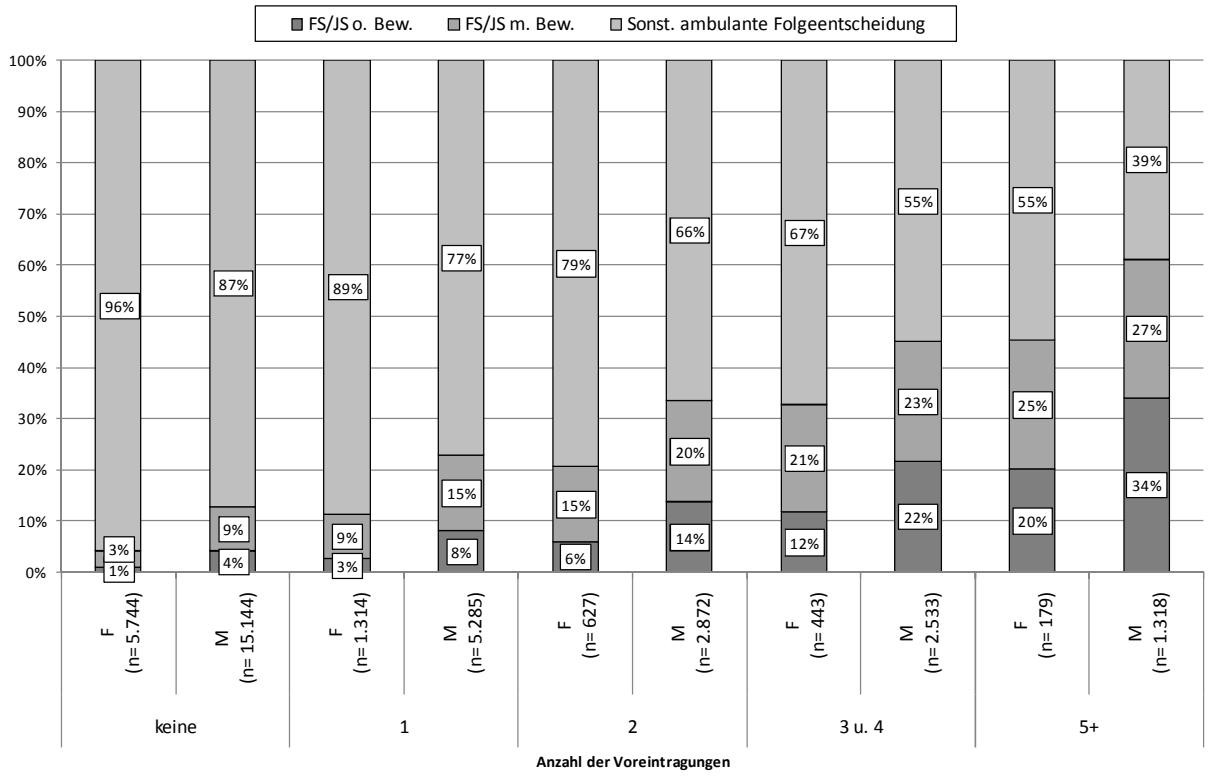

* Absolutrablen siehe Tab. 6.27a im Anhang

Eine solche Tendenz dürfte sich auch bei Berücksichtigung der Art der schwersten Voreintragung ergeben. Vermutlich sind dort aber die Anteile von ausgesetzten Freiheitsstrafen bei den Frauen teilweise größer als bei den Männern. Denn dieses Ergebnis konnte bereits in Kapitel 5 für die Bezugsentscheidung erzielt werden. .00

Wie vermutet, hat auch die Art der Voreintragung den gleichen Effekt auf die Art der Folgeeintragung, wie die Anzahl der Voreintragungen (vgl. Schaubild 6.34): Mit steigender Schwere der Voreintragungen steigt auch die Schwere der Folgesanktion. Darüber hinaus bestätigt sich die Annahme, dass Frauen häufiger Bewährungsstrafen als Sanktion in der Folgeeintragung erhalten: So ist für $30 \%$ der Frauen, für die als Voreintragung eine Freiheits- oder Jugendstrafe ohne Bewährung zu verzeichnen ist, eine Freiheits- oder Jugendstrafe mit Bewährung als Folgesanktion registriert; bei den Männern sind es lediglich $20 \%$. Gleichwohl ist insgesamt der Anteil der härtesten Sanktionen, Freiheits- und Jugendstrafe ohne Bewährung, bei den Männern über alle Gruppen hinweg größer als der Anteil bei den Frauen.

900 Vgl. Kap. 5, 2.6.1.3.2. 
Schaubild 6.34: Art der Folgeentscheidung nach Art der schwersten Voreintragung bei Bezugsentscheidungen aufgrund von Diebstabl nach Geschlecht (Jugendliche/ Heranwachsende)*

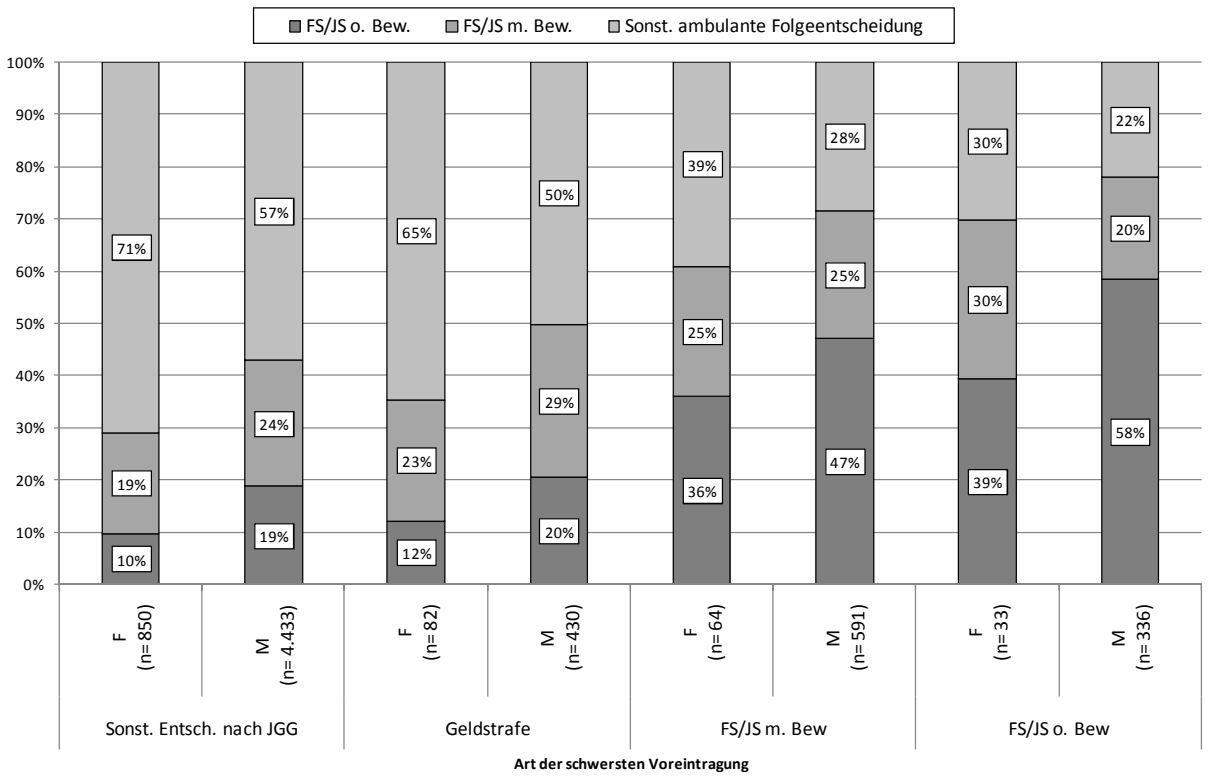

* Absolutzablen siehe Tab. 6.28a im Anhang

Betrachten wir nun die Altersgruppe der Erwachsenen. Ausgehend von den Ergebnissen in Kapitel 5 dürften sich die Unterschiede bei der Sanktionierung zwischen weiblichen und männlichen Tätern für die Gruppe der Erwachsenen, auch im Hinblick auf die Art der Folgeentscheidung, vermindern.

Die Ergebnisse aus Schaubild 6.35 bestätigen diese Annahme bereits deutlich: Zwar erhalten die Diebe nach wie vor bei fünf und mehr Voreintragungen häufiger eine stationäre Folgesanktion als die Diebinnen. Allerdings sind die Diebinnen ab einer Voreintragung anteilsmäßig häufiger bei den zur Bewährung ausgesetzten Freiheits- und Jugendstrafen registriert. Dies führt dazu, dass der kumulierte Anteil von Freiheits- und Jugendstrafen mit und ohne Bewährung bei den Frauen mit fünf und mehr Voreintragungen mit $60 \%$ fast genauso hoch ist wie der Anteil der Männer mit $61 \%$. Bei der Gruppe mit zwei Voreintragungen ist dieser kumulierte Anteil für beide Geschlechter mit $42 \%$ gleich hoch; bei drei und vier Voreintragungen übersteigt der Anteil bei den Frauen sogar den der Männer (51 \% Frauen und $49 \%$ Männer). 
Schaubild 6.35: Art der Folgeentscheidung nach Anzabl der Voreintragungen bei Bezugsentscheidungen aufgrund von Diebstabl nach Geschlecht (Erwachsene)*

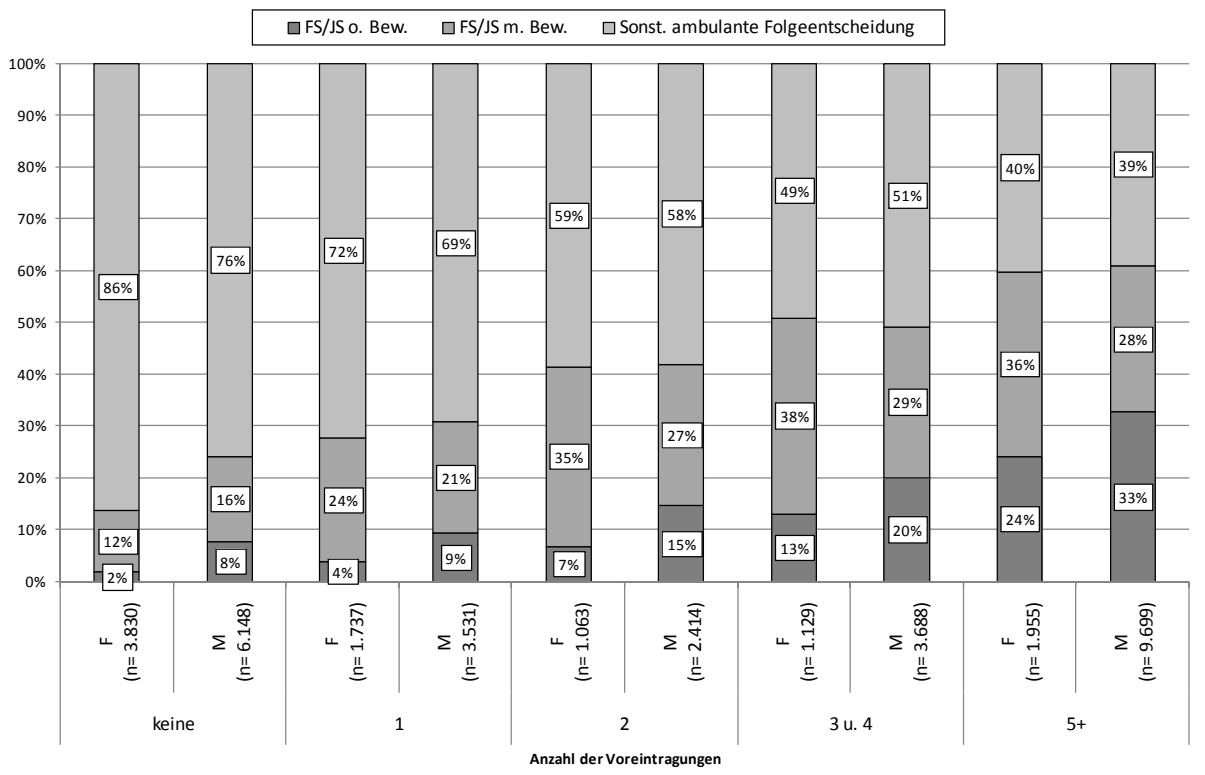

* Absolutzablen siebe Tab. 6.29a im Anbang

Noch deutlicher wird die Annäherung der Geschlechter bei der Sanktionierung der Folgeentscheidung für die Altersgruppe der Erwachsenen, wenn man die Art der schwersten Voreintragung als Variable hinzuzieht (vgl. Schaubild 6.36): Nach wie vor sind für Männer größere Anteile von stationären Sanktionen in der Folgeeintragungen zu verzeichnen. Jedoch führt die bereits oben durchgeführte kumulierte Betrachtung der Freiheits- und Jugendstrafen mit und ohne Bewährung für die Frauen und Männer, die als schwerste Voreintragung eine Freiheits- oder Jugendstrafe mit Bewährung erhalten haben, zu Anteilen von $56 \%$ (Frauen) bzw. $54 \%$ (Männer). Für die Gruppe derjenigen, die als schwerste Voreintragung eine stationäre Sanktion erhalten haben, stehen sich Anteile von 69\% (Frauen) und $67 \%$ (Männer) gegenüber.

Insgesamt macht es die Analyse der Art der Folgeentscheidung nach Anzahl und Art der schwersten Voreintragung wahrscheinlich, dass grundsätzlich der gleiche Einfluss wie auf die Sanktionsart der Bezugsentscheidung besteht. Auch im Falle eines Rückfalls nach einer Bezugsentscheidung aufgrund von Diebstahl, erhalten Männer häufiger stationäre Sanktionen. Erwachsene Frauen mit mehreren bzw. schweren Voreintragungen erhalten hingegen häufiger Bewährungsstrafen als Männer, wobei diese Anteile teilweise so hoch sind, dass sie in Kumulation mit den stationären Folgesanktionen höher sind als bei den Männern. 
Schaubild 6.36: Art der Folgeentscheidung nach Art der schwersten Voreintragungen bei Bezugsentscheidungen aufgrund von Diebstahl nach Geschlecht (Erwachsene)*

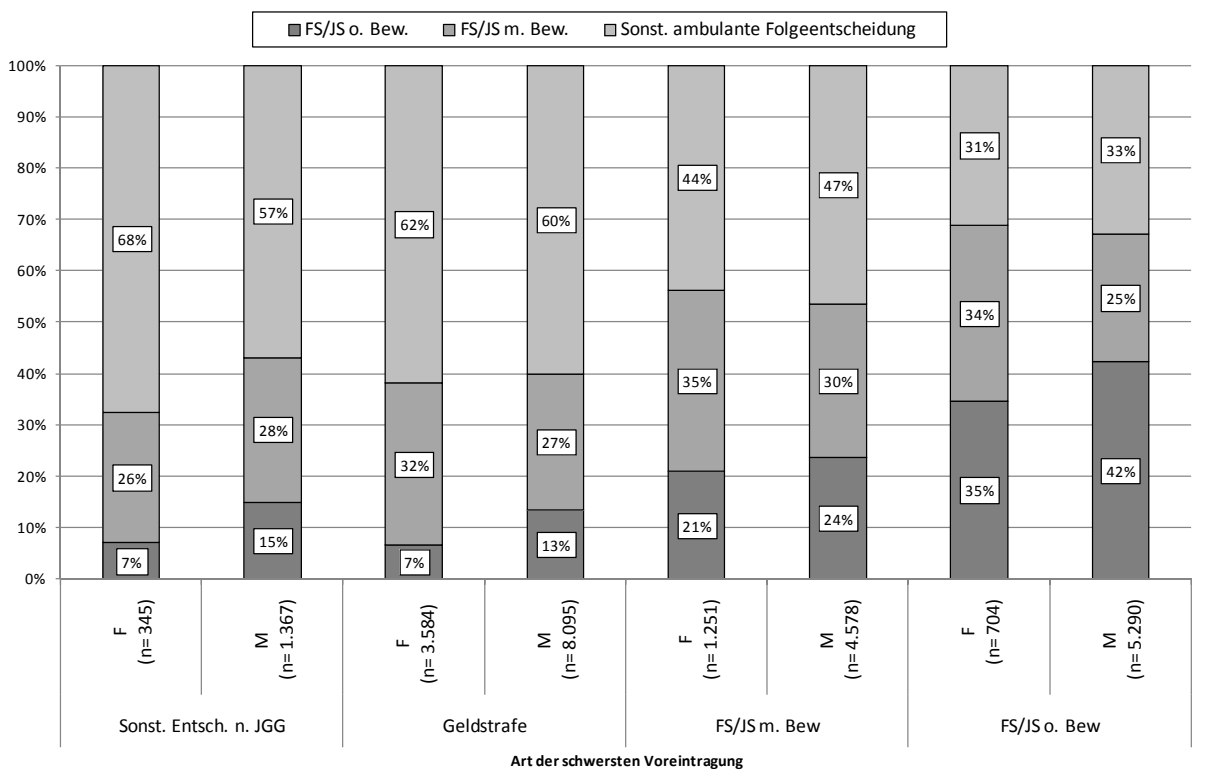

* Absolutrablen siehe Tab. 6.30a im Anhang

Als nächstes wird überprüft, ob die Einschlägigkeit der Voreintragung für Frauen und Männer in gleichem Maß Einfluss auf die Sanktionsart der Folgeentscheidung ausübt. In Kapitel 5 wurde festgestellt, dass die Einschlägigkeit der Voreintragungen für Männer größeren Einfluss auf die Schwere der Bezugssanktion hat.

Schaubild 6.37 stellt die Art der Folgeentscheidung aufgrund von Diebstahl nach Einschlägigkeit der Voreintragungen dar. In der Gruppe der einschlägigen Voreintragungen wurden die Personen dann berücksichtigt, wenn sie auch eine solche wegen Diebstahls gem. \242 StGB aufweisen. In der Gruppe „(auch) Voreintragungen wegen eines anderen Diebstahldelikts“ wurden alle Diebinnen und Diebe mit Voreintragungen aufgrund von $\iint 243$, 244, 244a StGB sowie \246 StGB erfasst. Alle anderen Personen mit einer Bezugsentscheidung aufgrund von Diebstahl fallen dementsprechend in die Kategorie „nur Voreintragungen mit anderen Delikten“.

Es zeigt sich zunächst, dass sich die Einschlägigkeit der Voreintragung für beide Geschlechter sanktionsschärfend auf die Folgeentscheidung auswirkt. Aber dieser Einfluss ist bei den Männern ausgeprägter als bei den Frauen. So erhalten $25 \%$ der Männer und nur $13 \%$ der Frauen nach einer Bezugsentscheidung aufgrund von Diebstahl mit einer einschlägigen Voreintragung eine Freiheits- oder Jugendstrafe ohne Bewährung als Folgesanktion. Auch der Einfluss einschlägiger 
Voreintragungen auf die Bewährungsstrafen ist bei den Männern in der Regel größer. Nur bei einschlägigen Voreintragungen erhalten Frauen häufiger Bewährungsstrafen als Männer.

\section{Schaubild 6.37: Art der Folgeentscheidung nach Bezugsentscheidungen aufgrund von Diebstabl nach Einschlägigkeit der Voreintragungen und Geschlecht*}

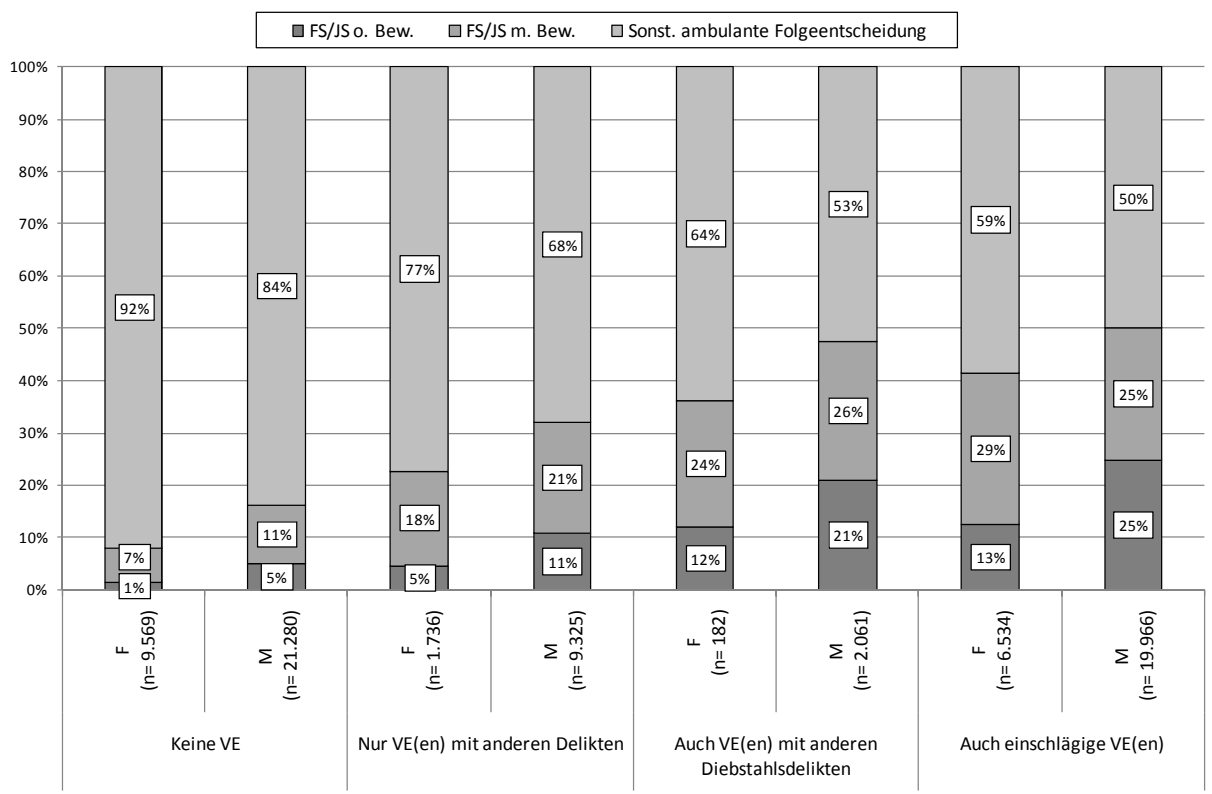

* Absolutrablen siehe Tab. 6.31 a im Anbang

\subsubsection{Multifaktorielle Analyse}

Die soeben vorgestellten Ergebnisse bestätigen die Resultate der in Kapitel 5 durchgeführten Untersuchung. Auch die Folgesanktion ist zunächst bei Frauen weniger schwer als bei Männern: Sie werden seltener rückfällig und im Falle eines Rückfalls erhalten sie mildere Sanktionen. Es konnte aber festgestellt werden, dass sich die Unterschiede zwischen den rückfälligen Frauen und rückfälligen Männern bei der Sanktionsart der Folgeentscheidung relativieren, wenn man weitere Faktoren hinzuzieht. So ist der Unterschied zwischen den erwachsenen Diebinnen und Dieben unter Berücksichtigung der Anzahl oder der Art der schwersten Voreintragung nicht mehr groß. Vermutlich dürfte daher der Unterschied noch weiter schrumpfen, wenn man eine noch größere Vergleichbarkeit der Täterinnen und Täter schafft, indem für beide Geschlechter die gleichen Variablen simultan berücksichtigt werden. Anknüpfend an die Analyse der Sanktionierungspraxis in Kapitel 5, 2.6.4 sollen nun auch an dieser Stelle multiple Faktoren gleichlaufend 
berücksichtigt werden, um zu analysieren, ob sich in diesem Fall noch eine unterschiedliche Sanktionierung in der Folgeeintragung bei den Geschlechtern ergibt.

Überprüft wird die Sanktionsart der Folgeentscheidung, von der mindestens eine einschlägig ist, für erwachsene Deutsche, die eine Bezugsentscheidung wegen Diebstahls gem. $\ 242 \mathrm{StGB}$ erhalten haben, mit mindestens fünf Voreintragungen, von denen mindestens eine einschlägig ist und mindestens eine mit Jugendoder Freiheitsstrafe mit oder ohne Bewährung sanktioniert wurde. Die Einschlägigkeit erfasst an dieser Stelle nur Verurteilungen wegen Diebstahls gem. $\ 242$ StGB. Das Ergebnis spiegelt Schaubild 6.38 wieder.

\section{Schaubild 6.38: Art der Folgeentscheidung nach dem StGB nach Berugsentscheidung aufgrund} von Diebstabl unter Berïcksichtigung multipler Faktoren nach Geschlecht*

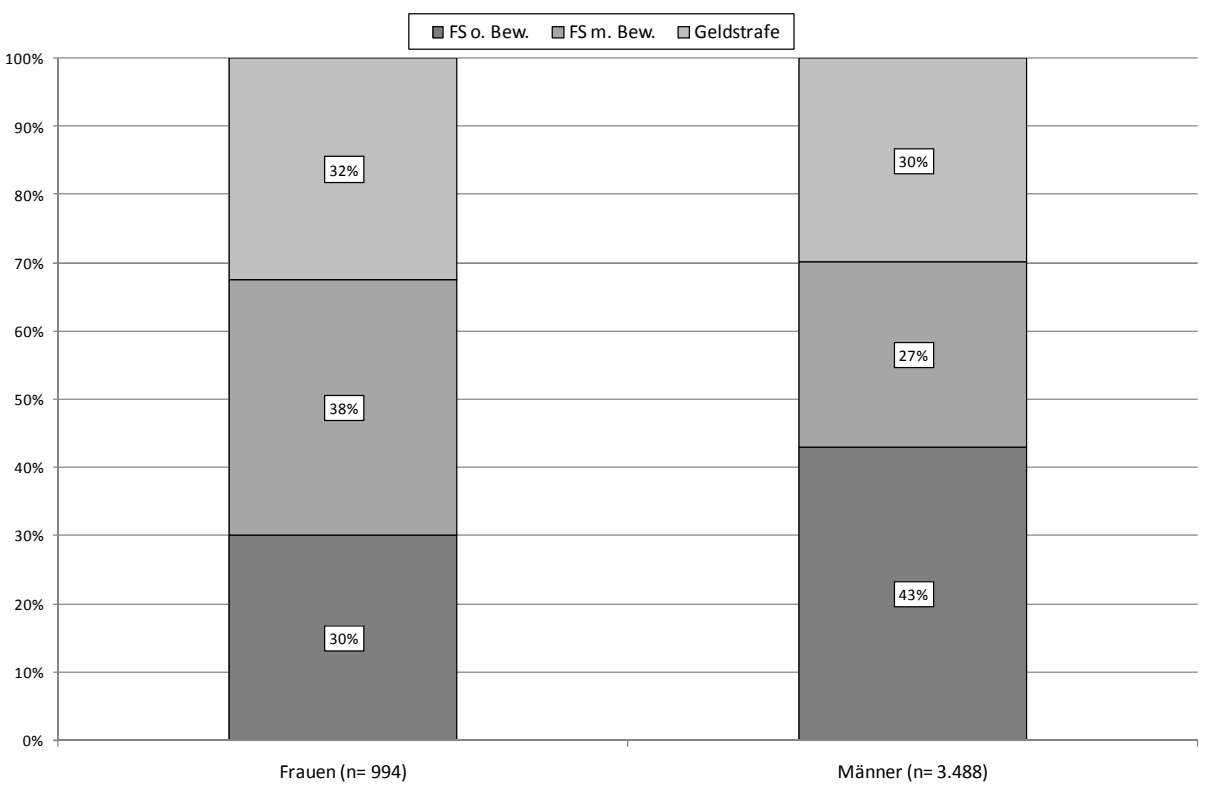

* Absolutzablen siebe Tab. 6.32a im Anhang

Männer erhalten in $43 \%$ der Fälle als Folgesanktion eine Freiheitsstrafe ohne Bewährung, bei den Frauen sind es nur 30\%. Frauen erhalten hingegen in $38 \%$ der Fälle Freiheitstrafen mit Bewährung. Dieser Anteil ist damit bei den Frauen wieder verhältnismäßig größer als der Anteil von Bewährungsstrafen bei den Männern. Insgesamt erhalten Frauen und Männer folglich fast zu einem gleich großen Anteil unbedingte und bedingte Freiheitsstrafen $(68 \%$ der Frauen und $70 \%$ der Männer). Auffällig ist, dass der Unterschied von 13 Prozentpunkten zwischen den Anteilen von unbedingten Freiheitsstrafen fast doppelt so groß ist 
wie noch bei Überprüfung der Bezugssanktion. Dort bestand lediglich ein 7\%iger Unterschied. ${ }^{901}$

Festgehalten werden kann, dass die betrachtete Gruppe von Frauen und Männern zu fast gleichen Anteilen Freiheitsstrafen (insgesamt) erhält. Die restlichen $32 \%$ der Frauen und $30 \%$ der Männer erhalten als Folgesanktion eine Geldstrafe. Bei Frauen werden jedoch auch in der hier eingeschränkten Gruppe häufiger die Voraussetzungen für die Strafaussetzung zur Bewährung gem. \56 StGB bejaht. Die vielen im Rahmen des $\int 56$ StGB zu berücksichtigenden Faktoren, die in die Beurteilung durch den Richter mit einfließen, können an dieser Stelle nicht berücksichtigt werden. ${ }^{902}$

5.4.4 Einschlägige Voreintragung, Bezugsentscheidung und einschlägiger Rückfall Unabhängig von der Frage der unterschiedlichen Sanktionierung ist darüber hinaus von Interesse, inwiefern Diebinnen und Diebe im Verlauf ihrer kriminellen Karriere erneut wegen Diebstahls, anderer Diebstahlsdelikte oder übrigen Straftaten auffallen.

Hierfür greift Schaubild 6.39 die Darstellung aus Schaubild 6.15 auf. Vorliegend wird allerdings nunmehr der einschlägige Rückfall im Geschlechtervergleich nur für die Rückfälligen und nur für den einfachen Diebstahl überprüft. In Schaubild 6.15 wurde der einfache Diebstahl zusammen mit der Unterschlagung betrachtet. Letztere fällt nunmehr in die Gruppe der (auch) Rückfälle aufgrund eines anderen Diebstahldelikts.

Zunächst ist zu beachten, dass Frauen auch nach einer Bezugsentscheidung aufgrund von Diebstahl grundsätzlich seltener rückfällig werden als Männer (vgl. Schaubild 6.28). Die rückfälligen Frauen werden nach einer Bezugsentscheidung wegen Diebstahl in $65 \%$ der Fälle einschlägig rückfällig, bei den Männern sind es hingegen nur $46 \%$. Frauen werden kaum wegen eines anderen Diebstahldelikts wiederverurteilt (2\%), bei den Männern ist der Anteil größer (8\%). Ein deutlicher Unterschied besteht zwischen den Rückfällen wegen eines anderen Delikts: $46 \%$ der Männer und lediglich $33 \%$ der Frauen werden wegen eines anderen Delikts erneut strafrechtlich auffällig. Es wird somit deutlich, dass die Differenz zwischen Frauen und Männern bei der Rückfälligkeit nach einer Bezugsentscheidung wegen Diebstahls in erster Linie der Tatsache geschuldet ist, dass Männer wegen anderer Delikte wiederverurteilt werden. Frauen werden hingegen zumeist einschlägig rückfällig.

901 Vgl. Kap. 5, 2.6.4.

902 Vgl. hierzu auch Ausführungen unter Kap. 5,2 sowie 5, 2.6.4. 
Schaubild 6.39: Einschlägige Rückfalle nach Bezugsentscheidungen aufgrund von Diebstabl nach Geschlecht*

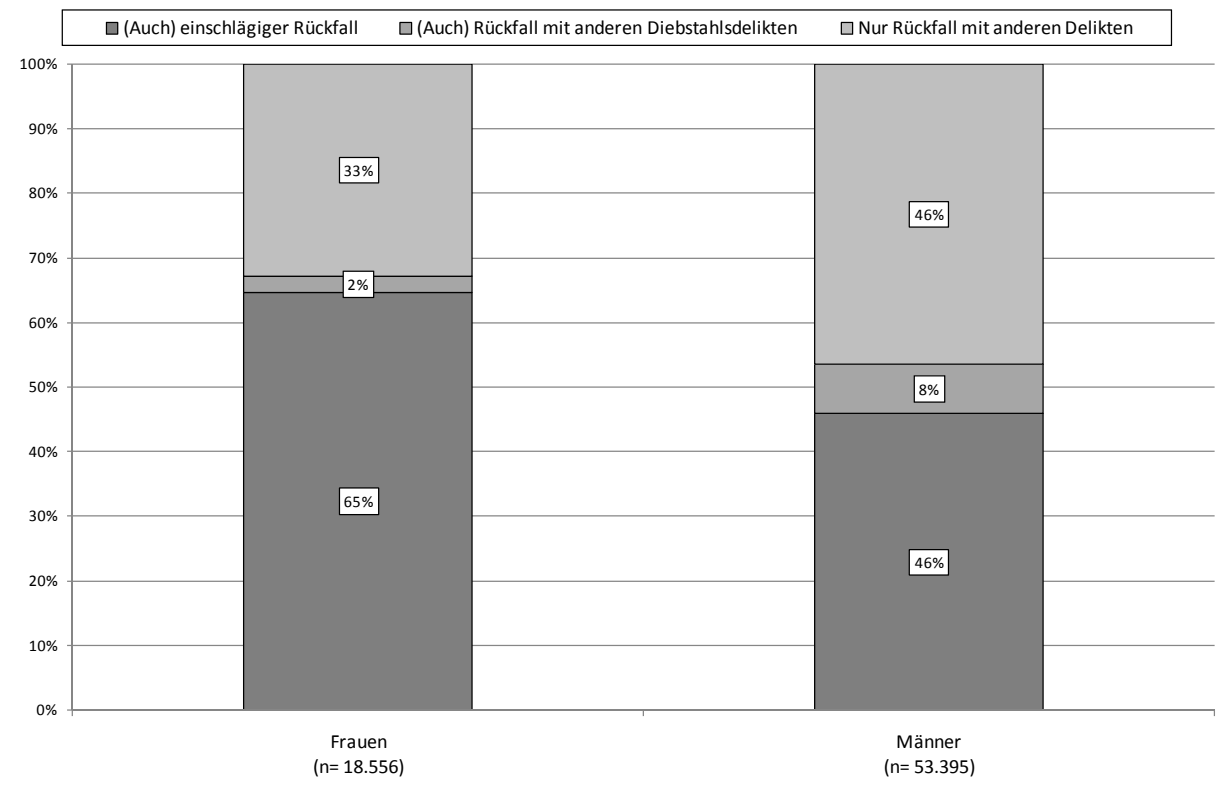

* Absolutzablen siehe Tab. 6.33 a im Anhang

Nun werden die einschlägigen Voreintragungen als weitere Variable in die Analyse einbezogen. Auch hier wird in der Gruppe der (auch) einschlägigen Voreintragungen diesmal nur der einfache Diebstahl gem. \ 242 StGB berücksichtigt.

Die Unterschlagung gem. \246 StGB fällt wiederum in die Gruppe der Voreintragungen wegen eines anderen Diebstahldelikts.

Schaubild 6.40 verdeutlicht eindrucksvoll, dass sich bei den Diebinnen im Verlauf ihrer kriminellen Karriere die Deliktsstruktur verfestigt. Ganze 72 \% der rückfällig gewordenen Diebinnen mit mindestens einer Voreintragung aufgrund von Diebstahl werden erneut wegen Diebstahls gem. \242 StGB rückfällig. Generell beträgt der Anteil von einschlägigem Rückfall bei den Diebinnen über alle Voreintragungsgruppen hinweg mindestens $50 \%$ und ist dementsprechend immer verhältnismäßig höher als bei den Männern. Diese scheinen im Verlauf ihrer kriminellen Karriere auf ein breiteres Deliktsspektrum auszuweichen. Lediglich bei den Dieben mit einschlägigen Voreintragungen überwiegt der Anteil von einschlägigem Rückfall (54\%) den Anteil der Rückfälle mit anderen Delikten (39\%). 
Schaubild 6.40: Einschlägige Voreintragungen und Rückfälle nach Bequgsentscheidungen aufgrund von Diebstahl nach Geschlecht*

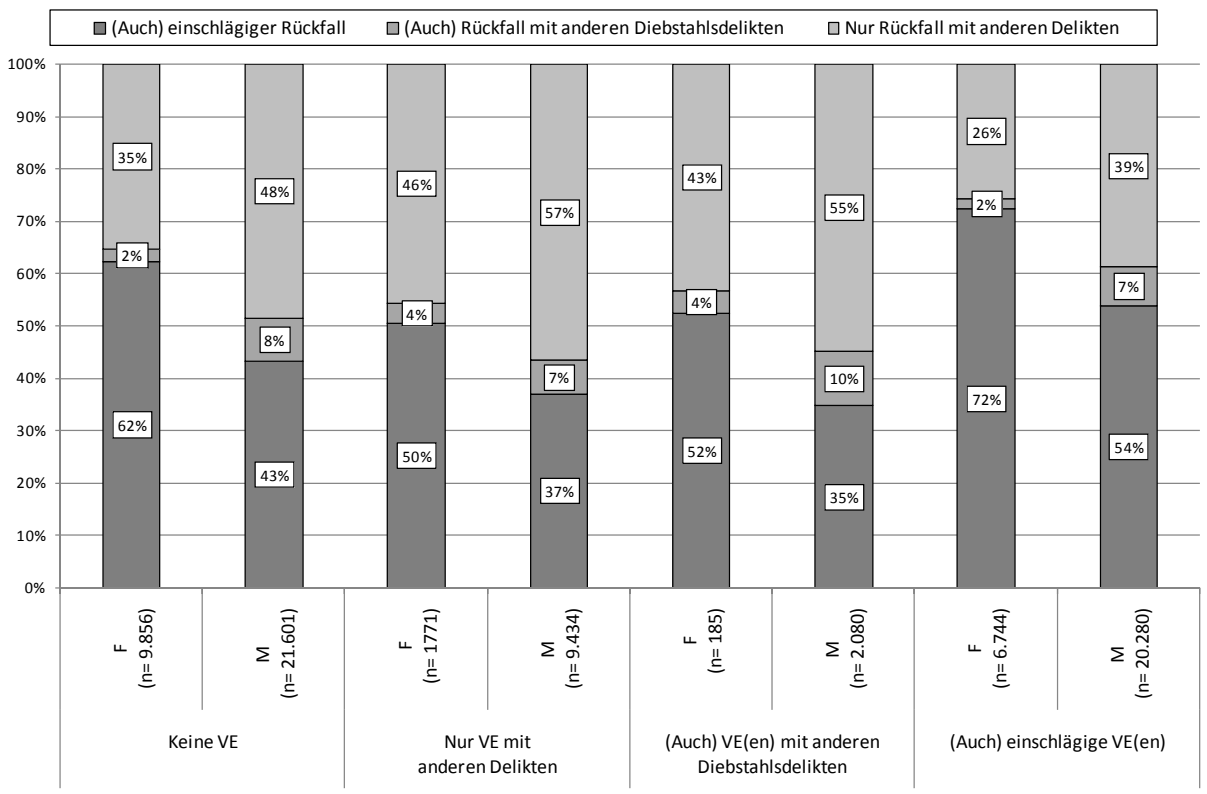

* Absolutrablen siehe Tab. 6.34a im Anhang

\subsection{Folgeentscheidung nach Bezugsentscheidungen aufgrund von Betrug gem. $\ 263$ StGB}

Als nächstes werden Folgeentscheidungen nach Bezugsentscheidungen aufgrund von Betrug gem. \ 263 StGB einer detaillierteren Betrachtung unterzogen. Auf eine graphische Darstellung der Ergebnisse wird hier verzichtet, wenn die Resultate den soeben vorgestellten Ergebnissen stark ähneln und kein Mehrwert des Aussagegehalts zu erwarten ist. Die den Aussagen zugrunde liegenden Auswertungen sind allerdings in Tabellenform im Anhang vorhanden.

\subsubsection{Art der Folgeentscheidung}

Schaubild 6.41 veranschaulicht die Art der Folgeentscheidung bei Bezugsentscheidungen wegen Betruges für beide Geschlechter im Vergleich.

Es zeigt sich, dass obwohl hier ein Delikt betrachtet wird, bei dem Frauen relativ häufig registriert und ähnlich sanktioniert werden wie Männer, Frauen doch deutlich seltener erneut verurteil werden. Frauen erhalten in $77 \%$ und Männer in $68 \%$ aller Fälle keine Wiederverurteilung. 
Schaubild 6.41: Art der Folgeentscheidung bei Bezugsentscheidungen aufgrund von Betrug und Geschlecht*

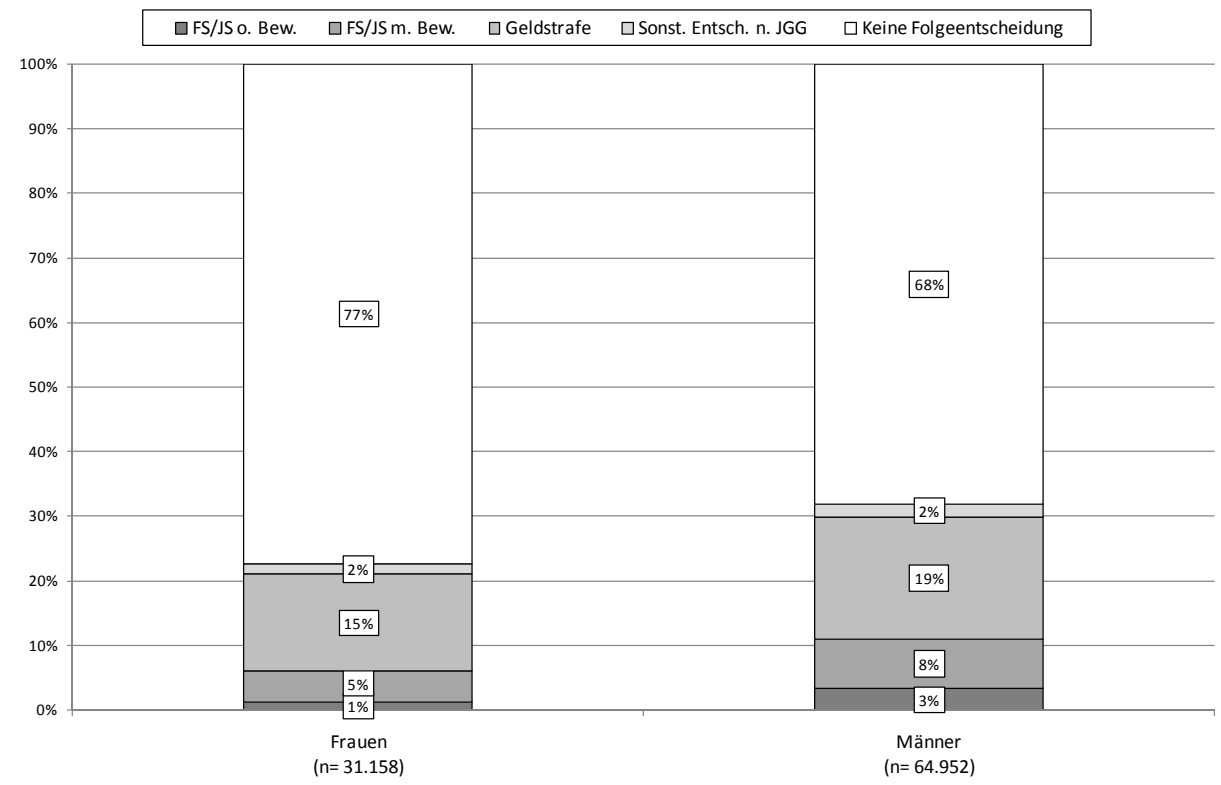

* Absolutzablen siehe Tab. 6.35 a im Anhang

Betrachtet man nur die rückfälligen Betrügerinnen und Betrüger, so stellt man fest, dass beide am häufigsten eine Geldstrafe als Folgesanktion erhalten (15\% der Frauen und $19 \%$ der Männer). Am zweithäufigsten erhalten sowohl Männer $(8 \%)$ als auch Frauen $(5 \%)$ eine Freiheits- oder Jugendstrafe mit Bewährung als Sanktion in der Folgeentscheidung, bei den Männern gefolgt von den Freiheitsstrafen ohne Bewährung mit $3 \%$. Bei den Frauen beträgt der Anteil von stationären Sanktionen lediglich $1 \%$. Die sonstigen Entscheidungen und Einstellungen nach JGG machen immerhin noch einen Anteil von jeweils $2 \%$ aus.

Die Rückfallrate nach Sanktionsart der Bezugsentscheidung für das Delikt Betrug stellt sich in der Tendenz so dar, wie in Schaubild 6.29 beim Diebstahl.903 Frauen erhalten über alle Bezugsentscheidungen hinweg seltener stationäre Folgesanktionen. Dafür sind im Vergleich zu den Männern auch hier in der Regel häufiger Freiheits- oder Jugendstrafen mit Bewährung als Folgesanktion registriert: Frauen, für die als Sanktion in der Bezugsentscheidung eine Freiheitsstrafe ohne Bewährung verzeichnet ist, erhalten in $38 \%$ der Fälle eine Bewährungsstrafe als Folgesanktion, bei den Männern sind es hingegen nur $24 \%$. Lediglich nach Geld-

${ }^{903}$ Vgl. Tab. 6.36a im Anhang. 
strafen und sonstigen Entscheidungen nach dem JGG erhalten Männer häufiger Bewährungsstrafen als Frauen.

Die differenziertere Betrachtung auf der Ebene der Bezugsentscheidung wird für die Art der Folgeentscheidung nach Freiheitsstrafen bis zu zwei Jahren in Schaubild 6.42 graphisch dargestellt.

Schaubild 6.42: Art der Folgeentscheidung nach Freiheitsstrafe aufgrund von Betrug nach Geschlecht*

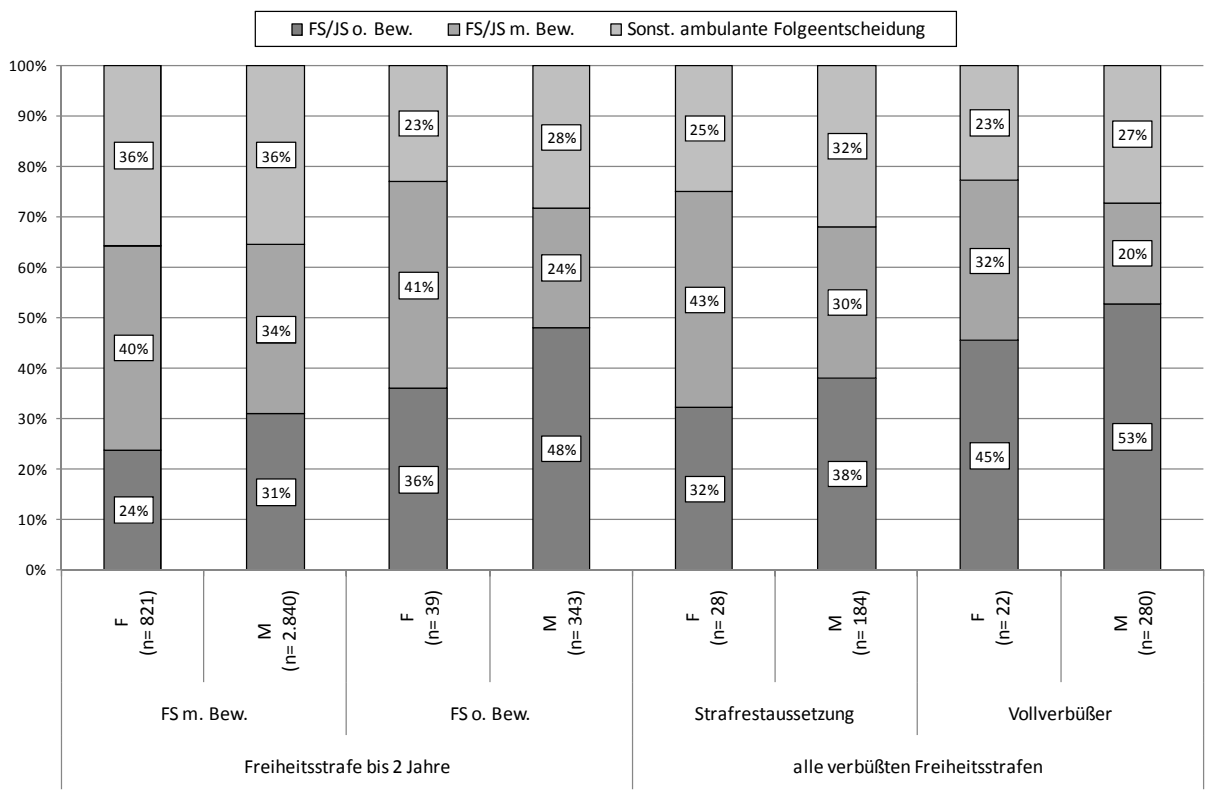

* Absolutzablen siebe Tab. 6.37 a im Anhang.

Die Analyse der Art der Folgeentscheidung nach Freiheitsstrafen bis zu zwei Jahren sowie Strafrestaussetzungen und Vollverbüßungen macht deutlich, dass Männer über alle Gruppen hinweg häufiger stationäre Folgesanktionen erhalten als Frauen. Im Unterschied zu Schaubild 6.31, sind für die Betrügerinnen jedoch noch häufiger Bewährungsstrafen als Folgesanktion zu verzeichnen. So beträgt beispielsweise der Anteil von ausgesetzten Freiheits- und Jugendstrafen als Folgeentscheidungen nach einer unbedingten Freiheitsstrafe bei den Frauen $41 \%$, bei den Männern nur $24 \%$. Dies führt dazu, dass Frauen bei Kumulation der Anteile von Freiheits- und Jugendstrafen mit und ohne Bewährung als Folgesanktion hier in fast allen Kategorien (außer nach Freiheitsstrafen mit Bewährung) anteilsmäßig häufiger als Männer Freiheits- oder Jugendstrafen erhalten. Zu berücksichtigen ist dabei aber, dass die hier zugrunde liegenden Fallzahlen für die Frauen recht nied- 
rig sind. Eine entsprechende Auswertung für Jugendstrafen bis zu zwei Jahren erübrigte sich aufgrund der noch niedrigeren Fallzahlen für die Frauen. ${ }^{904}$

Die Art der Folgeentscheidung nach Geldstrafen aufgrund von Betrug zeigt für beide Geschlechter einen Anstieg der Anteile von stationären Folgeeintragungen mit Zunahme der Anzahl der Tagessätze. Im Unterschied zu den Ergebnissen aus Schaubild 6.32 erhalten Frauen über alle Tagessatzgruppen hinweg nur sonstige ambulante Sanktionen als Folgeeintragung verhältnismäßig häufiger als Männer. Die Männer erhalten mithin nach Geldstrafen häufiger sowohl bedingte als auch unbedingte Freiheits- und Jugendstrafen. ${ }^{905}$

\subsubsection{Folgeentscheidung und Voreintragungen}

Bei Hinzunahme der Voreintragungen ist zu vermuten, dass für Frauen ebenso wie für Männer, die Schwere der Folgesanktion mit steigender Vorstrafenanzahl deutlich zunimmt. Ferner ist anzunehmen, dass Frauen mit fünf und mehr Vorstrafen nicht mehr milder sanktioniert werden, da die Vorstrafenbelastung mit in die Urteilsfindung eingeht.

Für die Gruppe der Jugendlichen und Heranwachsenden haben sich bei der Analyse der Art der Folgeeintragung nach Anzahl906 und Art der Voreintragungen ${ }^{907}$ keine erwähnenswerten Unterschiede zu Schaubild 6.33 und Schaubild 6.34 ergeben. Allerdings lohnt sich für die Gruppe der Erwachsenen eine genauere Betrachtung.

Schaubild 6.43 zeigt, dass mit zunehmender Anzahl der Voreintragungen die Wahrscheinlichkeit einer stationären Folgesanktion sowohl für erwachsene Frauen als auch für erwachsene Männer steigt. Je höher die Anzahl der Voreintragungen, desto höher ist die Wahrscheinlichkeit, mit einer Freiheits- oder Jugendstrafe ohne Bewährung wieder registriert zu werden. Wie zu erwarten, zeigen die Täter ohne Voreintragungen die mit Abstand größten Anteile von sonstigen ambulanten Sanktionen. Betrachtet man nun die kumulierten Anteile von Freiheits- und Jugendstrafe mit und ohne Bewährung auf der Ebene der Art der Folgeentscheidung, so zeigt sich ein noch bemerkenswerterer Verlauf als bereits bei der Betrachtung des Delikts Diebstahl (vgl. Schaubild 6.35): Schon ab der Gruppe mit einer Voreintragung sind dort die Anteile bei Frauen und Männern mit 30\% gleich groß. Bei zwei Voreintragungen ist der Anteil von stationären Folgesanktionen bei den Frauen mit $8 \%$ fast genauso hoch wie der bei den Männern mit 9\%. Der kumulierte Anteil mit den Bewährungsstrafen ist mit 38\% um einen Prozentpunkt höher als bei den Männern. Der Unterschied von einem Prozentpunkt bleibt bis zu fünf und mehr Voreintragungen bestehen.

\footnotetext{
904 Lediglich für vier Frauen, die eine Bezugsentscheidung wegen Betrugs erhalten haben, ist eine unbedingte Jugendstrafe als Folgesanktion registriert.

$905 \mathrm{Vgl}$. Tab. 6.38a im Anhang.

906 Vgl. Tab. 6.39a im Anhang.

907 Vgl. Tab. 6.40a im Anhang.
} 
Schaubild 6.43: Art der Folgeentscheidung nach Anzabl der Voreintragungen bei Bezugsentscheidungen aufgrund von Betrug nach Geschlecht (Erwachsene)*

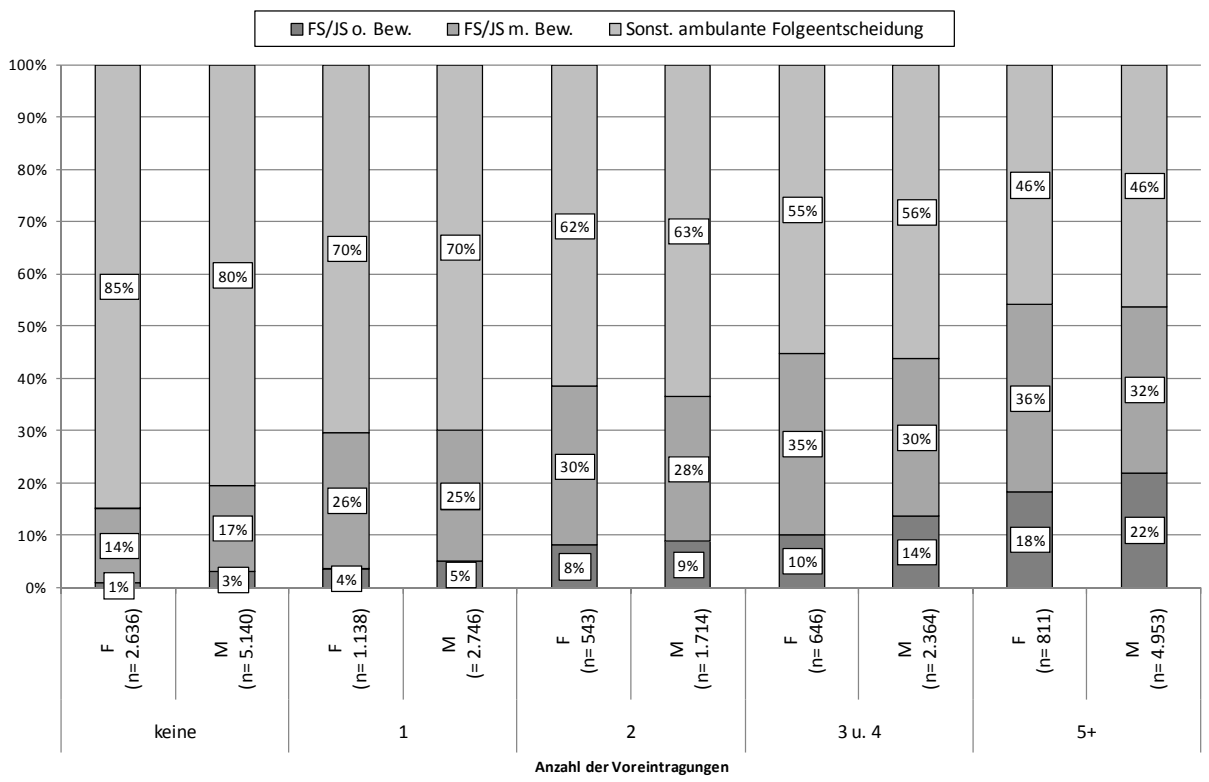

* Absolutzablen siehe Tab. 6.41a im Anhang

Bei Folgeentscheidungen nach Art der schwersten Voreintragung für Betrugsdelinquenten (Schaubild 6.44), zeigt sich ein ähnlicher Verlauf wie nach der Anzahl der Voreintragungen: Zunächst steigt für beide Geschlechter mit zunehmender Schwere der Sanktion in der Voreintragung die Wahrscheinlichkeit, auch eine schwere Folgesanktion zu erhalten. Bei den schwersten Voreintragungen, den Freiheits- und Jugendstrafen ohne Bewährung, übersteigt der kumulierte Anteil von Freiheits- und Jugendstrafen mit und ohne Bewährung auf der Ebene der Folgesanktion bei den Frauen den der Männer um drei Prozentpunkte; bei Freiheits- oder Jugendstrafen mit Bewährung als schwerste Sanktion in der Voreintragung erhalten die Betrügerinnen mit $19 \%$ häufiger als Männer mit 18 \% eine stationäre Folgesanktion. Der kumulierte Anteil von Freiheits- und Jugendstrafen als Sanktion in der Folgeentscheidung liegt bei den Frauen vier Prozentpunkte über dem der Männer.

Die Analyse der Art der Folgeentscheidung nach Einschlägigkeit der Voreintragungen bei Bezugsentscheidungen wegen Betrugs hat wiederum kaum Unterschiede zu den Ergebnissen für das Delikt Diebstahl ergeben (vgl. Schaubild 6.37). 
Der Einfluss der Einschlägigkeit einer Voreintragung auf die Schwere der Folgesanktion ist auch hier für Betrüger größer als für Betrügerinnen. ${ }^{908}$

Schaubild 6.44: Art der Folgeentscheidung nach Art der schwersten Voreintragungen bei Bezugsentscheidungen aufgrund von Betrug nach Geschlecht (Erwachsene)*

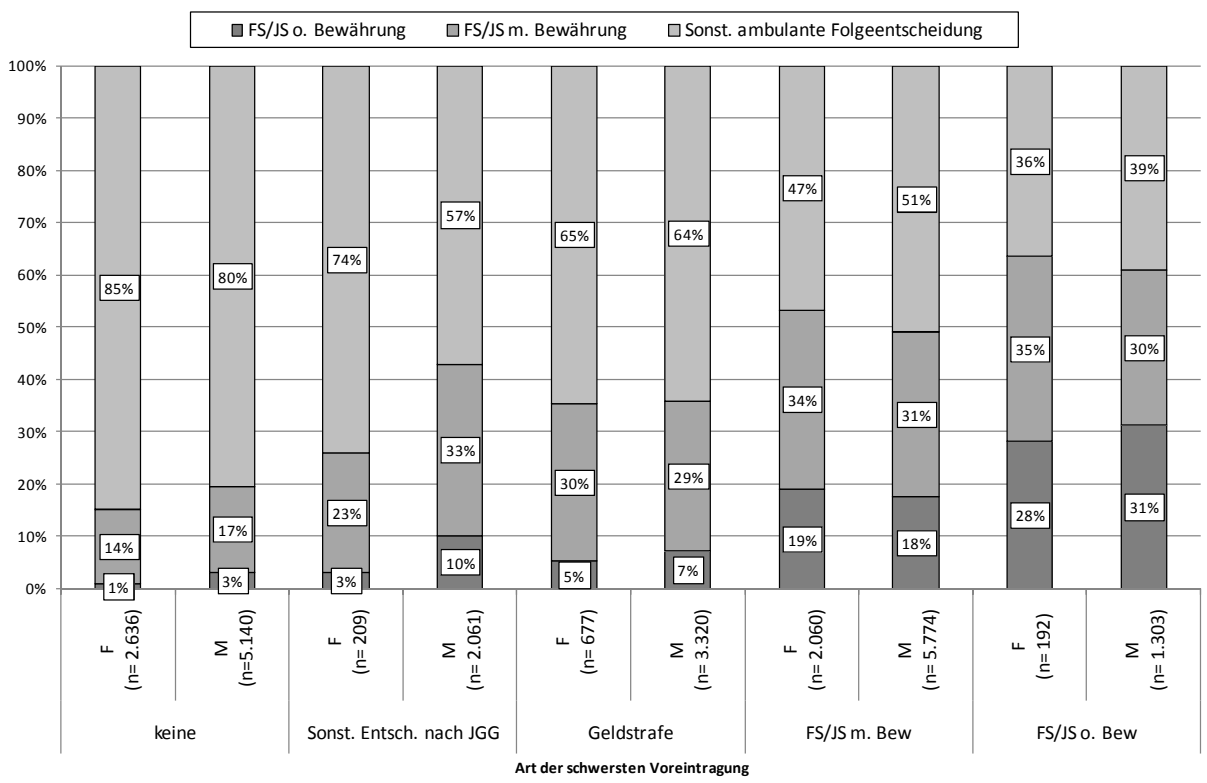

* Absolutzablen siehe Tab. 6.42 a im Anhang

\subsubsection{Multifaktorielle Analyse}

Inwiefern für das Delikt Betrug noch geschlechtsspezifische Unterschiede bei der Sanktionsart der Folgeentscheidung zu erkennen sind, wenn man mehrere Variable simultan berücksichtigt, soll mit Hilfe einer multifaktoriellen Analyse überprüft werden. Wie beim Diebstahl wurde auch hier die Gruppe der erwachsenen Deutschen mit mindestens fünf Voreintragungen, von denen mindestens eine einschlägig ist und von denen die schwerste Voreintragung mit Freiheits- oder Jugendstrafe mit oder ohne Bewährung sanktioniert wurde, betrachtet. Darüber hinaus ist auch die Folgeentscheidung einschlägig. Als einschlägig wurde an dieser Stelle nur eine Verurteilung aufgrund des Delikts der Bezugsentscheidung, also aufgrund von \263 StGB, gezählt.

Ein Unterschied zwischen den hier betrachteten Gruppen ist nun kaum mehr erkennbar: In der Gruppe der betrachteten Betrügerinnen erhalten 31 \% der Personen eine stationäre Folgesanktion, in der Gruppe der Betrüger ist dieser Anteil

908 Vgl. Tab. 6.43a im Anhang. 
mit $35 \%$ nur geringfügig größer. Der Anteil von Freiheitsstrafen mit Bewährung beträgt bei den Frauen $37 \%$, bei den Männern $35 \%$. Der kumulierte Anteil von Freiheitsstrafen mit und ohne Bewährung als Sanktion in der Folgeentscheidung ist mithin bei Betrügerinnen und Betrügern fast gleich groß: Der Anteil bei den Männern ist mit 70 \% lediglich um einen Prozentpunkt größer als bei den Frauen mit $69 \%$.

Schaubild 6.45: Art der Folgeentscheidung nach dem StGB nach Bequgsentscheidung aufgrund von Betrug unter Berücksichtigung multipler Faktoren nach Geschlecht*

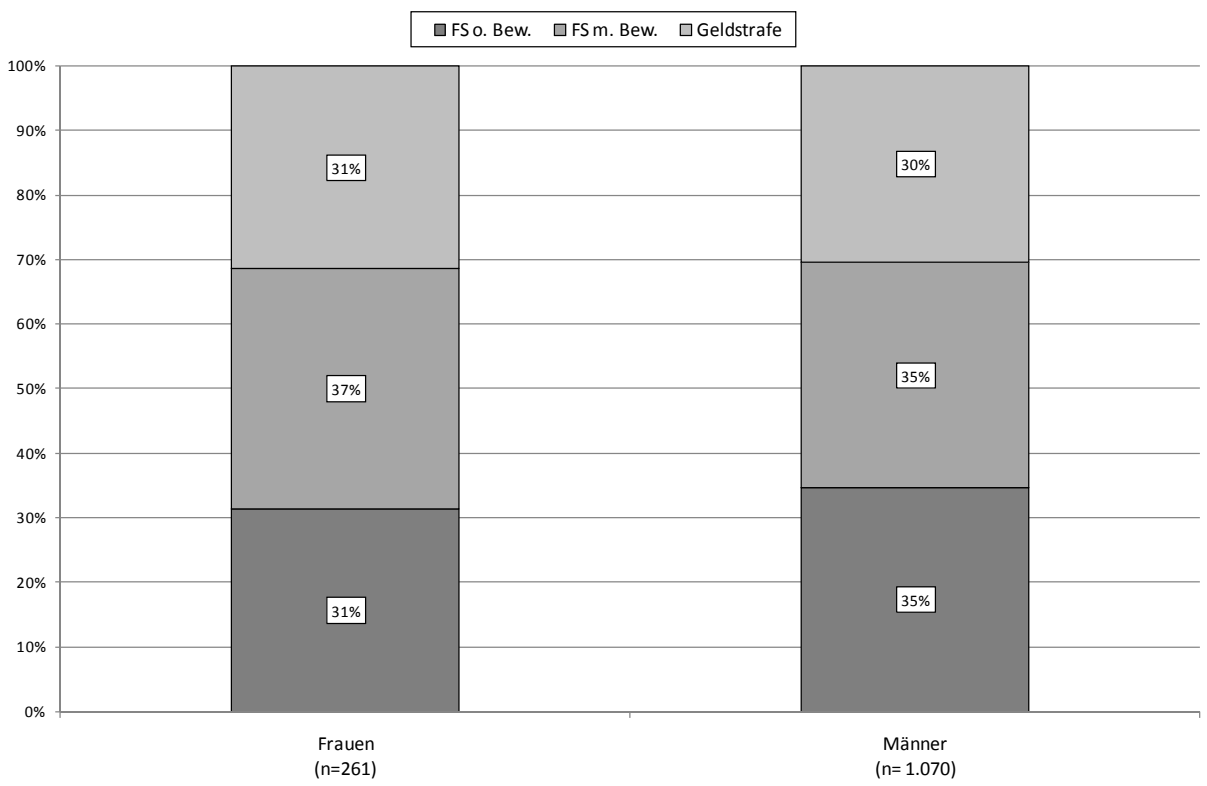

* Absolutzablen siehe Tab. 6.44a im Anhang

Die Analyse des Delikts Betrug zeigt also mit den vorliegend für die Auswertung zur Verfügung stehenden Variablen keine mildere Behandlung von Frauen aufgrund eines „Frauenbonus“. Die Variable Geschlecht hat hier keinen Einfluss mehr auf die Art der Folgeentscheidung. Zwar werden Freiheitsstrafen bei Frauen nach wie vor häufiger zur Bewährung ausgesetzt. Dies bedeutet aber keine Besserbehandlung von Frauen aufgrund ihres Geschlechts, sondern vielmehr, dass für sie häufiger eine günstige Legalprognose gestellt wird (vgl. \56 StGB).

5.5.4 Einschlägige Voreintragung, Bezugsentscheidung und einschlägiger Rückfall Fraglich ist schließlich, ob eine genauere Betrachtung der kriminellen Karriere der Betrügerinnen ähnliche Unterschiede zu den Betrügern ergibt, wie dies für die Gruppe der Diebinnen und Diebe festgestellt werden konnte. 
Schaubild 6.46 zeigt, die Art des Rückfalls nach Bezugsentscheidungen wegen Betrug für die Geschlechter im Vergleich.

Es wird deutlich, dass Frauen (51\%) und Männer (37\%) am häufigsten einschlägig rückfällig werden. Allerdings werden Frauen häufiger als Männer einschlägig rückfällig. Zudem werden sie auch anteilsmäßig häufiger wegen eines anderen Täuschungsdelikts wieder registriert. Der große Unterschied zwischen

\section{Schaubild 6.46: Einschlägige Rückfälle nach Bezugsentscheidungen aufgrund von Betrug nach Geschlecht*}

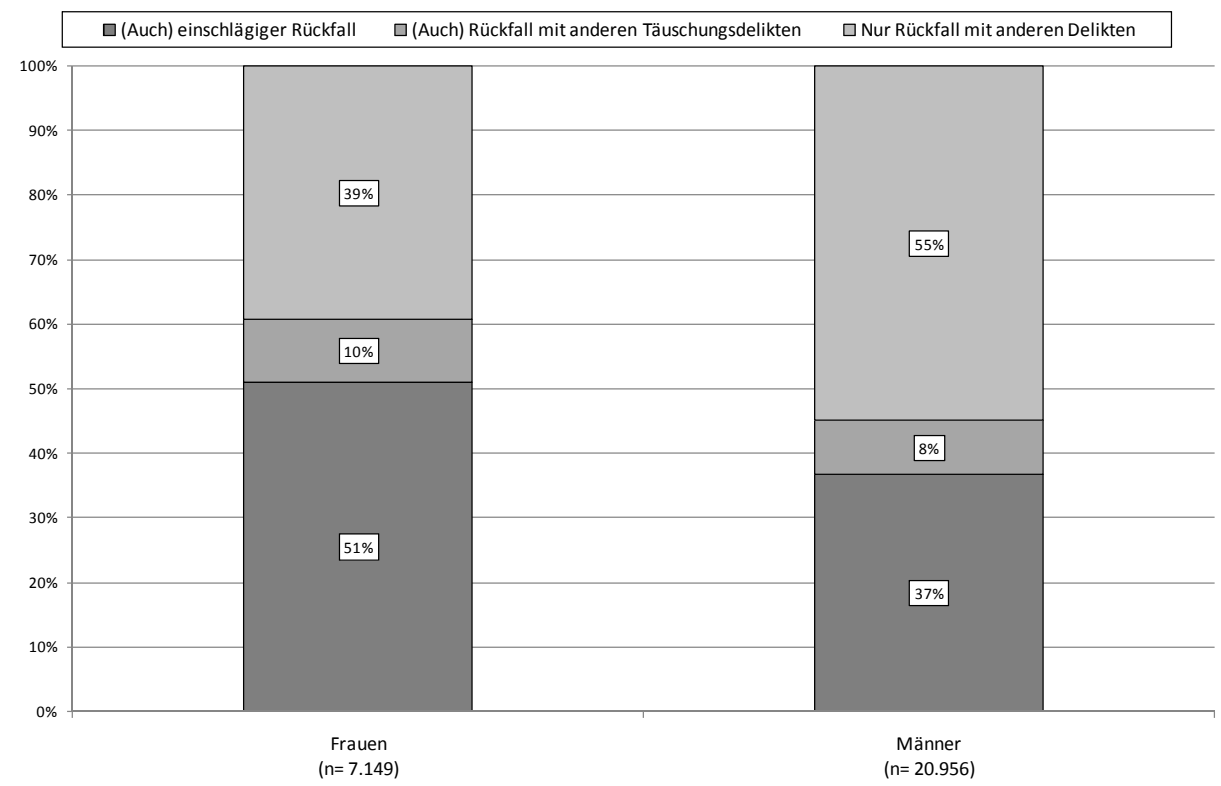

* Absolutzablen siehe Tab. 6.45a im Anhang

Frauen und Männern bei den Anteilen des einschlägigen Rückfalls ist der Tatsache geschuldet, dass Männer wiederum eher wegen anderer Delikte erneut straffällig werden: Hier überwiegt der Anteil bei den Männern den der Frauen um 16 Prozentpunkte. Wie beim zuvor betrachteten Diebstahl wird deutlich, dass Frauen in erster Linie einschlägig rückfällig werden, wohingegen Männer ein breiteres Deliktsspektrum bedienen.

Schaubild 6.47 bezieht die einschlägigen Voreintragungen mit ein. Somit kann aus Sicht der Bezugsentscheidung sowohl eine pro- als auch eine retrospektive Betrachtungsweise stattfinden.

Über alle Gruppen der Voreintragungen hinweg ist der Anteil des einschlägigen Rückfalls für die Gruppe der Frauen verhältnismäßig größer als für die Männer. Vor allen Dingen die Frauen, die auch bereits eine einschlägige Voreintragung 
nach \263 StGB aufweisen, werden in $62 \%$ der Fälle wieder aufgrund von \ 263 StGB verurteilt. Bei den Männern sind es immerhin 50\%. Das Bild der Einhaltung einer festen Deliktsstruktur zeigt sich mithin nicht nur für die Diebinnen, sondern auch für die Betrügerinnen. Gleiches gilt für die Männer, allerdings ist das Phänomen hier nicht so ausgeprägt wie bei den Frauen. Auffällig ist zudem, dass die Betrügerinnen und Betrüger, die eine Voreintragung aufgrund eines anderes Täuschungsdelikts erhalten haben, auch häufiger wegen eines solchen Täuschungsdelikts wieder registriert werden (43\% der Frauen und $32 \%$ der Männer).

Schaubild 6.47: Einschlägige Voreintragungen und Rückfälle nach Bequgsentscheidungen aufgrund von Betrug nach Geschlecht*

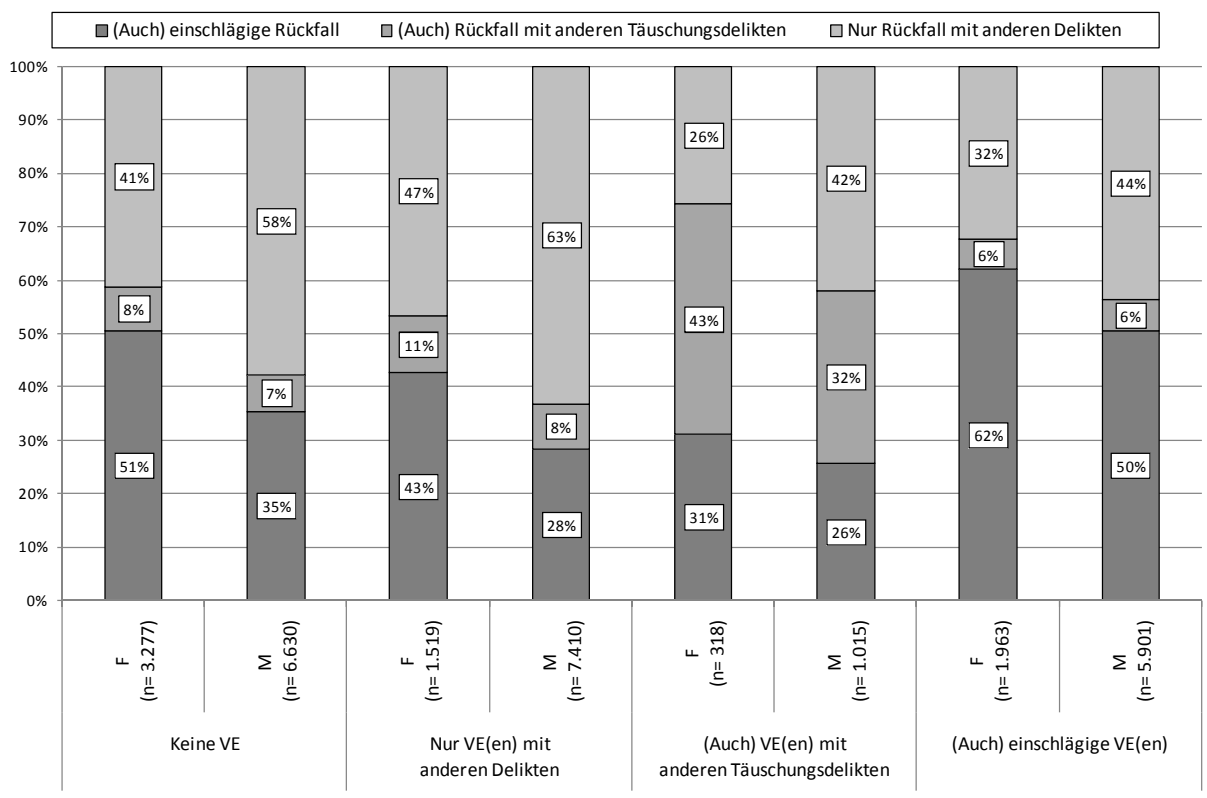

* Absolutrablen siehe Tab. 6.46a im Anhang

\subsection{Zwischenfazit}

Die vergleichende Analyse der Rückfallkriminalität der Geschlechter hat zunächst ergeben, dass Männer schneller rückfällig werden als Frauen, wobei der Unterschied minimal ist. Für beide Geschlechter ereignen sich die meisten Rückfälle in den ersten zwölf Monaten. Generell werden Frauen seltener rückfällig als Männer. Dieser Unterschied bleibt auch bei deliktsspezifischer Betrachtung bestehen. Bei der kriminellen Karriere von Frauen und Männern für die hier genauer untersuchten Delikte Diebstahl gem. \242 StGB und Betrug gem. \263 StGB zeigten sich durchaus Differenzen: Während insbesondere die Diebinnen kaum außerhalb dieses Delikts strafrechtlich auffällig werden, ist dies bei den Männern nicht der 
Fall. Männer weisen ein breiteres Deliktsspektrum auf. Eine „Steigerung“ der kriminellen Karriere durch die Begehung schwererer Diebstahlsformen konnte nicht festgestellt werden. Auch bei den Männern sind die Anteile von Rückfällen mit anderen Diebstahlsdelikten recht niedrig, wofür jedoch wiederum der Anteil von Rückfällen wegen anderer Delikte recht hoch und auch größer als bei den Frauen ist. Bei den Betrügerinnen bestätigt sich das bereits beim Diebstahl gewonnene Bild: Der Anteil des einschlägigen Rückfalls an allen Rückfällen ist gröBer als der entsprechende Anteil bei den Männern. Die Gruppe der Rückfälle wegen eines anderen Täuschungsdelikts spielt nur bei den bereits wegen eines Täuschungsdelikts vorbestraften Betrügerinnen und Betrügern eine größere Rolle.

Die Auswertungen der Art der Folgeeintragungen erfolgten insbesondere vor dem Hintergrund der Fragestellung aus Kapitel 5, die hier wieder aufgegriffen wurde. Es zeigt sich, dass die Unterschiede in der Sanktionierung auch der Folgeentscheidung durch Hinzunahme weiterer Variablen nahezu verschwinden. Zwar besteht nach der multifaktoriellen Analyse für das Delikt Diebstahl noch eine recht große Differenz zwischen den Anteilen von stationären Folgesanktionen. Dadurch zeigt sich aber lediglich, dass für die untersuchten Frauen häufiger die Voraussetzungen des $\ 56$ StGB bejaht wurden. Dies ist jedoch nicht mit einer milderen Behandlung aufgrund des Geschlechts gleichzusetzen. Vielmehr dürften hier durch den Beurteilungsspielraum in $\ 56 \mathrm{StGB}$ rechtliche und nicht ,ritterliche" Gründe eine Rolle spielen. ${ }^{909}$ Zwar können bei dem in der multifaktoriellen Analyse berücksichtigten Personenkreis nicht mehr die Voreintragungen, Art des Delikts, das Alter oder die Nationalität Gründe für den Unterschied sein. Nicht auszuschließen ist aber nach wie vor eine Beeinflussung beispielsweise durch die Höhe des Schadens oder eine günstigere Sozialprognose für Frauen. Auch die Tatsache, dass die hier überprüften erwachsenen Frauen nach wie vor häufiger als Männer mit der Erziehung und Betreuung ihrer Kinder betraut sind, die durch eine Gefängnisstrafe gleichfalls bestraft würden, könnte ein Grund sein. ${ }^{910}$

Die weitere Überprüfung des Delikts Betrug hat schließlich im Rahmen der multifaktoriellen Analyse kaum mehr Unterschiede bei der Sanktionierung der Folgeeintragung zwischen den Geschlechtern ergeben, sodass eine „ritterliche“ Behandlung oder ein Geschlechterbonus nicht bestehen.

\section{Gesamtfazit}

Insgesamt hat sich gezeigt, dass sich die Deliktsstruktur von Frauen und Männern im Lauf ihrer kriminellen Karriere teilweise durchaus unterscheidet. Besonders die betrachteten Diebinnen und Betrügerinnen bleiben ihrer Deliktsstruktur häufiger „treu“ als Männer. Gleichwohl sind auch bei Frauen die Rückfallraten nach sons-

\footnotetext{
909 So auch Jones, S. 20 ff.; Maelicke, in: ZfStrVo 1993, S. 226, 227.

${ }^{910}$ So auch Jones, S. 25; Maelicke, in: ZfStrVo 1993, S. 226, 227.
} 
tigen Gewaltdelikten und schwereren Diebstahlsformen am höchsten, was den bekannten Befunden für die Männer entspricht. ${ }^{911}$

Mit Hilfe der Datenanalyse konnten eine ganze Reihe von Variablen als bedeutsam für die Rückfälligkeit von Frauen identifiziert werden. Das Alter, die Sanktionsart der Bezugsentscheidung, das der Bezugsentscheidung zugrunde liegende Delikt sowie die Art und Anzahl der Voreintragungen beeinflussen die Rückfälligkeit von Frauen. Der anschließende Geschlechtervergleich hat deutlich gemacht, dass die genannten Faktoren sowohl für Frauen als auch für Männer bedeutsam sind. Insoweit gibt es kaum Unterschiede zwischen den Geschlechtern. Die Sanktionsart der Voreintragung hat allerdings auf die Wiederverurteilungen von Frauen einen stärkeren Einfluss. Je mehr Vergleichbarkeit zwischen den Gruppen geschaffen wurde, umso weniger war eine nachsichtigere Behandlung von Frauen durch mildere Sanktionierung zu erkennen. Bei Täterinnen werden stationäre Sanktionen jedoch in der Regel häufiger zur Bewährung ausgesetzt als bei Tätern, wobei auch dieser Unterschied mit zunehmender Vergleichbarkeit der Gruppen bei Betrachtung des Delikts Betrug so gut wie verschwindet. Vielmehr ist die unterschiedliche Deliktsstruktur von Frauen und Männern, die sowohl in den Ergebnissen in Kapitel 4 als auch in den kriminelle Karrieredarstellungen des vorliegenden Kapitels zum Ausdruck kommt, der Grund dafür, dass Frauen in der Gesamtbetrachtung häufiger mildere Folgesanktionen erhalten.

911 Vgl. hierzu die Ergebnisse der aktuellen Rückfallstudie: Jeble/Albrecht/Hohmann-Fricke/Tetal, Legalbewährung nach strafrechtlichen Sanktionen, 2010, S. 101. 



\section{Kapitel 7: Zusammenfassung und Bewertung der Ergebnisse}

\section{Zusammenfassung der Ergebnisse}

Auf der Grundlage der Daten des BZR konnten im Rahmen der hier vorgelegten Arbeit für das Bezugsjahr 2004 ausführliche Befunde zum Umfang und zur Struktur weiblicher Kriminalität und Rückfallkriminalität sowie zur geschlechtsspezifischen Sanktionierungspraxis der Gerichte ermittelt werden. Für die unterschiedlichen Betrachtungsebenen wurde auf Grundlage der BZR-Daten mit zwei Datensätzen gearbeitet: Zum einen mit dem Entscheidungsdatensatz. $(\mathrm{n}=1.086 .303)$, in dem alle Personen mit einer Entscheidung im Bezugsjahr 2004 erfasst wurden, und zum anderen mit dem Rückfalldatensatz. $(\mathrm{n}=1.051 .887)$, in dem alle Personen, die im Bezugsjahr 2004 zu einer ambulanten Sanktion verurteilt oder nach Verbüßung einer stationären strafrechtlichen Sanktion entlassen wurden, in die Analyse einbezogen wurden.

\subsection{Frauenkriminalität im Querschnitt}

\subsubsection{Umfang und Struktur der Frauenkriminalität}

Zunächst konnten die bereits in Kapitel 1 dargestellten Ergebnisse zum Umfang und zur Struktur weiblicher Kriminalität im Hellfeld nach den Daten der PKS und 
der StVS auch mit dem Entscheidungsdatensatz auf Grundlage der Daten des BZR bestätigt werden: Frauen weisen sowohl qualitativ als auch quantitativ eine andere Deliktsstruktur auf als Männer. Von den 1.086 .303 erfassten Personen sind lediglich $20 \%$ weiblich.

Eine detaillierte Betrachtung der Deliktsstruktur konnte aufzeigen, dass Frauen am häufigsten weniger schwerwiegende Delikte begehen. In $59 \%$ der Fälle liegt der Verurteilung ein Vermögensdelikt i.w.S. zugrunde. Bei den Männern ist dieser Anteil mit 32\% geringer. Im Gegensatz dazu begehen Frauen lediglich in $7 \%$ der Fälle Gewaltdelikte; bei den Männern beträgt der Anteil für Gewaltdelikte $13 \%$.

Darüber hinaus hat die deliktsspezifische Analyse deutlich gemacht, dass „frauentypische“ Delikte, also solche, die von Frauen häufiger begangen werden als von Männer, kaum zu einer Eintragung in das BZR führen. Lediglich bei der Verletzung der Fürsorge- und Erziehungspflicht gem. \171 StGB ist der Frauenanteil höher als $50 \%$. Betrachtet man die übrigen Deliktsgruppen, so fällt auf, dass der Anteil von Frauen an der Gesamtkriminalität von $20 \%$ vor allem von ihrem Anteil an der falschen Verdächtigung (46\%) und den Aussagedelikten (33\%) übertroffen wird.

Eine differenziertere Betrachtung der Gewaltdelikte hat ergeben, dass sowohl weibliche als auch männliche Gewalttäter im untersuchten Bezugsjahr 2004 in erster Linie wegen Körperverletzungsdelikten verurteilt wurden. Allerdings übersteigt der Anteil von Körperverletzungsdelikten bei den Frauen mit $90 \%$ den Anteil bei den Männern mit 83 \%. Betrachtet man die Anteile der Geschlechter an den jeweiligen Gewaltdeliktsgruppen, so zeigt sich, dass der Frauenanteil bei der Misshandlung von Schutzbefohlenen gem. $\ 225$ StGB am größten ist, aber mit $39 \%$ immer noch deutlich unter dem Anteil der männlichen Täter liegt.

Die Vermögensdelikte i.w.S. werden bei beiden Geschlechtern stark vom einfachen Diebstahl (53\% Frauen zu $42 \%$ Männer) und vom einfachen Betrug (24\% Frauen zu $23 \%$ Männer) dominiert. An diesen beiden Delikten ist zudem der Anteil weiblicher Täter mit 36 \% (Diebstahl) bzw. 32 \% (Betrug) am größten.

\subsubsection{Alter}

Die meisten Täterinnen und Täter sind relativ jung. Ohne die Reaktionen nach $\int S 45,47$ JGG werden beide Geschlechter am häufigsten im Heranwachsendenalter straffällig. Im Vergleich dazu ergibt sich bei Berücksichtigung der Entscheidungen nach $\$ \int 45,47$ JGG, dass die Täterinnen mit 14 und die Täter mit 17 Jahren am häufigsten mit einer Bezugsentscheidung im BZR registriert wurden. Täterinnen sind demnach in der Regel jünger als Täter.

Betrachtet man die Altersstruktur nur für die Frauen differenziert nach Deliktsgruppen, so ergibt sich, dass Gewalttäterinnen mit Ausnahme der Gruppe der Tötungsdelikte am häufigsten im Alter zwischen 14 und 15 Jahren eine Bezugsentscheidung erhalten haben. Gleiches gilt für die Täterinnen eines Diebstahldelikts oder einer Unterschlagung. Beim Erschleichen von Leistungen und beim 
Betrug sind die Frauen zum Tatzeitpunkt hingegen mit 19 bzw. 20 Jahren älter als der Durchschnitt. Täterinnen einer fahrlässigen Tötung oder Körperverletzung, eines Verkehrsdelikts ohne Alkoholeinfluss oder Delikts nach dem BtMG sind am häufigsten im Alter von 18 Jahren registriert worden. Frauen, die wegen eines Verkehrsdelikts unter Alkoholeinfluss verurteilt worden sind, werden hingegen erst im Alter von 40-42 Jahren am häufigsten verurteilt.

\subsubsection{Nationalität}

Von den straffälligen Frauen sind insgesamt $17 \%$ nichtdeutsch. Erwartungsgemäß ist der Anteil der nichtdeutschen Frauen an der Gesamtzahl der Verurteilten bei den sonstigen Delikten am höchsten, da in dieser Kategorie die Verstöße gegen das AuslG und AsylverfG erfasst wurden. Mit 22\% ist ihr Anteil an den schweren Diebstahlsformen am zweithöchsten. Besonders niedrig ist der Anteil von Nichtdeutschen an den verurteilten Frauen bei Verkehrsdelikten unter Alkoholeinfluss (7 \%) und Delikten nach dem BtMG (9\%).

Betrachtet man nur die nichtdeutschen Täterinnen, so zeigt sich, dass sich ihre Deliktsstruktur, bis auf den großen Anteil von Verstößen gegen das AuslG und AsylverfG (15\%), kaum von der der deutschen Täterinnen unterscheidet.

\subsection{Sanktionierung der Frauenkriminalität}

\subsubsection{Sanktionierung nach Jugendstrafrecht}

Sowohl Frauen als auch Männer werden am seltensten zu einer Jugendstrafe ohne Bewährung verurteilt und erhalten am häufigsten Entscheidungen gemäß $\$ \$ 45,47$ JGG. Frauen werden allerdings im Vergleich zu Männern seltener zu einer schwerwiegenderen Sanktion nach Jugendstrafrecht verurteilt. Im Vergleich zu den Männern ergibt sich außerdem, dass Jugendstrafen bei Frauen häufiger zur Bewährung ausgesetzt werden. Männer erhalten zudem vergleichsweise länger andauernde Jugendstrafen. Bei Frauen werden Jugendstrafen von sechs Monaten bis zu einem Jahr häufiger zur Bewährung ausgesetzt als solche von einem bis zu zwei Jahren.

\subsubsection{Anwendung des $₫ 105$ I JGG}

Bei der Anwendung des $\ 105$ I JGG besteht zwischen den Geschlechtern kaum ein Unterschied. In $80 \%$ der Fälle wurden bei heranwachsenden Frauen und in $78 \%$ der Fälle bei heranwachsenden Männern die Voraussetzungen des \105 I JGG bejaht. Die deliktsgruppenspezifische Betrachtung hat für beide Geschlechter ergeben, dass bei Gewaltdelikten besonders häufig Jugendstrafrecht auf Heranwachsende angewandt wird und bei Verkehrsdelikten unter Alkoholeinfluss besonders selten. 


\subsubsection{Sanktionierung nach allgemeinem Strafrecht}

Frauen werden im Vergleich zu Männern seltener zu einer Freiheitsstrafe mit oder ohne Bewährung verurteilt. Sie erhalten häufiger mildere Sanktionen wie die Geldstrafe. Ferner erhalten Frauen in der Regel kürzere Freiheitsstrafen als Männer. Die Aussetzungsquote bei den grundsätzlich aussetzungsfähigen Freiheitstrafen ist in der Gruppe von sechs Monaten bis zu einem Jahr am größten und für Freiheitsstrafen von einem bis zu zwei Jahren am niedrigsten. Über alle Dauergruppen hinweg wird bei Frauen die Freiheitsstrafe eher zur Bewährung ausgesetzt als bei Männern. Frauen und Männer werden in etwa gleich häufig unter Bewährungsaufsicht gestellt. Bei beiden Geschlechtern steigt die Wahrscheinlichkeit der Anordnung der Bewährungshilfe mit zunehmender Dauer der Freiheitsstrafe, wobei sich kaum Unterschiede ergeben.

Ferner erhalten Frauen nicht nur häufiger die mildere Sanktion der Geldstrafe, sondern sie werden auch bei Erhalt einer Geldstrafe zu weniger Tagessätzen verurteilt.

Darüber hinaus konnte festgestellt werden, dass gegenüber Frauen sowohl bei den Verkehrsdelikten ohne als auch bei den Verkehrsdelikten unter Alkoholeinfluss eher eine verkehrsrechtliche Sanktion in Form eines Fahrverbots oder einer Entziehung der Fahrerlaubnis verhängt wird: Bei den Verkehrsdelikten ohne Alkoholeinfluss haben Frauen in 39 \% und Männer in $35 \%$ der Fälle eine verkehrsrechtliche Sanktion erhalten. Bei den Verkehrsdelikten unter Alkoholeinfluss wurde bei den Frauen in $94 \%$ und bei den Männern in $89 \%$ der Fälle eine solche Sanktion verhängt.

\subsubsection{Sanktionierung und Voreintragungen}

Die Analyse der Anzahl der Voreintragungen hat ergeben, dass Frauen seltener vorbestraft sind als Männer; auch wenn sie strafrechtlich bereits aufgefallen sind, so ist dies relativ selten vorgekommen: Lediglich $4 \%$ der Frauen weisen mehr als fünf Voreintragungen auf, wohingegen der entsprechende Anteil bei den Männern $12 \%$ beträgt.

In einem weiteren Schritt wurde die Art der Bezugsentscheidung in Abhängigkeit von der Anzahl von Voreintragungen betrachtet. Sowohl für die nach Jugendstrafrecht sanktionierten, als auch für die nach allgemeinem Strafrecht sanktionierten Frauen und Männer zeigt sich eine deutliche Beziehung zwischen der Anzahl der Voreintragungen und der Art der Bezugsentscheidung. Der Anteil von leichteren Sanktionen wie den Entscheidungen nach $\iint 45,47$ JGG oder der Geldstrafe nimmt für beide Geschlechter kontinuierlich mit steigender Anzahl der Voreintragungen ab. Sowohl der Anteil von bedingten als auch der von unbedingten Jugend- und Freiheitsstrafen steigt entsprechend an. Allerdings ist der Anteil der schwerwiegenderen Sanktionen bei den Frauen durchweg niedriger als bei Männern. Bei den Bezugssanktionen nach allgemeinem Strafrecht ist dieser Unter- 
schied jedoch nicht so ausgeprägt wie bei den Sanktionen in der Bezugsentscheidung nach Jugendstrafrecht.

Darüber hinaus wurde die Art der schwersten Voreintragung für Frauen und Männer im Vergleich analysiert. Betrachtet wurden nur die Personen mit mindestens einer Voreintragung. Es zeigt sich, dass Frauen die im Bezugsjahr 2004 verurteilt oder mit einer jugendstrafrechtlichen Reaktion belegt wurden, nicht nur weniger Voreintragungen, sondern auch im Falle einer Voreintragung eine weniger schwerwiegende Sanktion erhalten haben als Männer. Bei Mitberücksichtigung der Art der Bezugsentscheidungen offenbart sich eine ähnliche Beziehung wie zwischen der Anzahl der Voreintragungen und der Art der Bezugsentscheidung: Je schwerer die Sanktion der Voreintragung, umso schwerer auch die Sanktion nach Jugendstrafrecht und allgemeinem Strafrecht. Bei den jugendstrafrechtlichen Reaktionen werden die Täterinnen auch unter Berücksichtigung der Art der schwersten Voreintragung noch milder sanktioniert als Männer. Bei den Bezugsentscheidungen nach allgemeinem Strafrecht ergibt sich hingegen ein anderes Bild: Hier übersteigt der Anteil von Freiheitsstrafen mit Bewährung bei den Frauen den entsprechenden Anteil bei den Männern, wenn eine bedingte oder unbedingte Jugend- oder Freiheitsstrafe als Voreintragung vorliegt. Dies führt dazu, dass der Anteil von Freiheitsstrafen insgesamt (unbedingte und bedingte Freiheitsstrafen zusammengerechnet) in diesen Kategorien bei den Täterinnen höher bzw. genauso hoch ist wie bei den Tätern. In dieser Konstellation werden Frauen folglich nicht milder behandelt als Männer. Allerdings wird die Freiheitsstrafe bei den Frauen nach wie vor häufiger zur Bewährung ausgesetzt, was jedoch nichts mit einer nachsichtigeren Behandlung aufgrund des Geschlechts zu tun hat.

\subsubsection{Sanktionierung und Deliktsgruppen}

Es wurde zudem der Einfluss der Deliktsgruppe auf die Sanktionsart der Bezugsentscheidung für Frauen und Männer untersucht. Männer erhalten über alle Deliktsgruppen hinweg häufiger Jugendstrafen mit und ohne Bewährung als Frauen. Täter werden ferner in allen Deliktskategorien häufiger zu Freiheitsstrafen ohne Bewährung verurteilt. Der Anteil von Freiheitstrafen mit Bewährung ist bei den Frauen lediglich nach sonstigen Gewaltdelikten (\$S 113, 177, 178, 239a, 239b, 249252, 255 StGB), schweren Diebstahlsformen (\$S 243, 244, 244a StGB) und Delikten nach dem BtMG größer als bei den Männern. Dies führt jedoch nicht dazu, dass ihr Anteil von Freiheitsstrafen insgesamt gesehen den der Männer übersteigt. Sie erhalten vielmehr über alle Deliktskategorien im Vergleich zu den Männern häufiger Geldstrafen.

Die Einschlägigkeit einer Voreintragung wirkt sich für beide Geschlechter sanktionsschärfend aus, bei den Frauen jedoch nicht in dem Maße wie bei den Männern. 


\subsubsection{Sanktionierung bei Diebstahl gem. \242 StGB}

Die spezifische Analyse des Delikts Diebstahl gem. \242 StGB zeigt zunächst, dass Täterinnen auch hier seltener schwerwiegende Sanktionen nach Jugendstrafrecht und allgemeinem Strafrecht erhalten als Männer. Jugend- und Freiheitsstrafen werden bei Frauen häufiger zur Bewährung ausgesetzt als bei Männern. Die Tendenz der milderen Sanktionierung von Frauen wird auch bei Geldstrafen wegen Diebstahls deutlich: Bei den Diebinnen wird häufiger die geringe Anzahl von 1-15 Tagessätzen verhängt. Die Unterschiede zwischen den Geschlechtern sind insgesamt aber recht gering.

Auch Frauen, die wegen Diebstahls verurteilt worden sind, weisen weniger Voreintragungen auf als Männer. Im Falle einer Voreintragung erhalten sie zudem eine weniger schwerwiegende Sanktion.

Bezieht man auch die Art der Bezugsentscheidung in die Analyse ein, so zeigt sich, dass auch bei den jugendstrafrechtlichen Sanktionen die Schwere der Sanktion mit steigender Anzabl der Voreintragungen zunimmt. Männer erhalten nach wie vor häufiger schwerere Sanktionen als Frauen. Der Unterschied zwischen den Geschlechtern ist aber nicht mehr so ausgeprägt wie bei der Darstellung über sämtliche Delikte hinweg. Bei den Sanktionen nach allgemeinem Strafrecht ist eine mildere Sanktionierung von Frauen dann nicht mehr zu erkennen: Hier ist bemerkenswert, dass Frauen bei zwei und mehr Voreintragungen insgesamt (d.h. bei Addition der Anteile von Freiheitsstrafen mit und ohne Bewährung) häufiger Freiheitsstrafen erhalten als Männer.

Dieses Ergebnis lässt sich ebenfalls für die Bezugssanktionen des JGG nach Art der schwersten Voreintragung erzielen. Hier übersteigt der Anteil von Jugendstrafen ohne Bewährung der Diebinnen, die als schwerste Voreintragung eine Jugend- oder Freiheitsstrafe mit oder ohne Bewährung erhalten haben mit $40 \%$ den Anteil bei den Männern, der nur $32 \%$ beträgt. Auch wenn in dieser Kategorie nur 20 Frauen registriert wurden, so ist gleichwohl eine Tendenz erkennbar, dass sich die Art der Voreintragung bei den Diebinnen genauso stark auswirkt wie bei den Dieben. Dies wird durch die Ergebnisse für die Bezugsentscheidungen des StGB nach Art der schwersten Voreintragung bestätigt. Dort konnte wieder auf eine breite Datenbasis zurückgegriffen werden. Männer werden hier mit höchstens zwei Prozentpunkten Unterschied nur noch minimal häufiger zu Freiheitsstrafen ohne Bewährung verurteilt. Frauen erhalten hingegen deutlich häufiger Freiheitsstrafen mit Bewährung, was dazu führt, dass ihr Anteil von Freiheitsstrafen insgesamt bei denjenigen, die als schwerste Voreintragung eine Freiheits- oder Jugendstrafe mit oder ohne Bewährung erhalten haben, den Anteil bei den Männern übersteigt. Eine nachsichtigere Sanktionierung der Frauen ist hier folglich nicht erkennbar, was letztendlich durch die multifaktorielle Analyse, bei der sich für die mildeste Sanktion der Geldstrafe nahezu gleich hohe Anteile von $49 \%$ (Frauen) und $52 \%$ (Männer) gegenüberstehen, bestätigt wird. 
Schließlich konnten für den Einfluss der Einschlägigkeit der Voreintragungen auf die Sanktionierung von Diebinnen und Diebin keine wesentlichen Unterschiede zu den Ergebnissen der Betrachtung sämtlicher Delikte festgestellt werden. Einschlägige Voreintragungen führen bei den Diebinnen allerdings häufiger zu Freiheitsstrafen als Voreintragungen mit anderen Diebstahlsdelikten.

\subsubsection{Sanktionierung bei Betrug gem. \263 StGB}

Die Analyse der Sanktionierung von Betrügerinnen und Betrügern konnte im Wesentlichen die bereits für die Diebinnen und Diebe gefundenen Ergebnisse bekräftigen. Auch hier verdeutlicht die Überprüfung der Bezugsentscheidungen nach allgemeinem Strafrecht in Abhängigkeit von der Anzabl der Voreintragungen, dass Frauen ab einer Anzahl von zwei Voreintragungen häufiger Freiheitsstrafen erhalten als Männer, weshalb in dieser Konstellation von einer milderen Behandlung der Männer gesprochen werden kann. Im Gegensatz zu den Diebinnen und Diebin besteht zwischen den Anteilen von Freiheitsstrafen ohne Bewährung kaum noch ein Unterschied zwischen den Geschlechtern. Die Differenz beträgt lediglich bis zu einem Prozentpunkt und bei den Personen mit fünf und mehr Voreintragungen zwei Prozentpunkte. Betrachtet man die Bezugssanktionen nach dem StGB nach Art der schwersten Voreintragungen für die Betrügerinnen und Betrüger, so lässt sich auch hier eine mildere Behandlung von Männern erkennen: Sowohl der Anteil von bedingten, als auch der Anteil von unbedingten Freiheitsstrafen bei den Personen, für die eine Freiheits- oder Jugendstrafe mit oder ohne Bewährung registriert ist, übersteigt bei den Frauen den Anteil der Männer. Im Vergleich zum zuvor untersuchten Diebstahl ist die schärfere Sanktionierung von Frauen hier noch ausgeprägter, was sich auch in der anschließenden multifaktoriellen Analyse niederschlägt. Der kumulierte Anteil von Freiheitsstrafen beträgt bei den Betrügerinnen $55 \%$, bei den Betrügern sind es $51 \%$.

Einschlägige Voreintragungen führen bei den Täterinnen, die aufgrund eines Betruges verurteilt wurden, häufiger zu einer Jugendstrafe ohne Bewährung als bei den Täterinnen eines Diebstahls. Ferner führt das Vorhandensein von Voreintragungen wegen eines anderen Diebstahldelikts bei den Diebinnen und Diebin häufiger zu unbedingten Freiheitsstrafen als bei den Betrügerinnen und Betrügern.

\subsection{Rückfallkriminalität von Frauen}

Insgesamt werden rund $24 \%$ der Frauen während des Beurteilungszeitraums von drei Jahren erneut wegen einer Straftat im BZR registriert. Im Falle eines Rückfalls dominiert die Geldstrafe. Stationäre Sanktionen spielen mit ca. 1\% kaum eine Rolle. Gleichwohl zeigt sich, dass letztere im Verhältnis zu den Bezugsentscheidungen deutlich angewachsen sind: $0,7 \%$ der Frauen haben als Sanktion in der Bezugsentscheidung eine Jugend- oder Freiheitsstrafe ohne Bewährung erhalten, 
wohingegen fast doppelt so viele, nämlich 1,3\%, eine stationäre Sanktion als Folgeeintragung aufweisen.

\subsubsection{Rückfallrate nach Sanktionsart der Bezugsentscheidung}

Zwischen der Schwere der Bezugsentscheidung und der Legalbewährung konnte ein deutlicher Zusammenhang festgestellt werden: Je schwerer die Sanktionsart der Bezugsentscheidung, desto häufiger und schwerer ist auch der Rückfall.

Für die Sanktionsgruppe der Geldstrafe lässt sich feststellen, dass die Wahrscheinlichkeit, eine stationäre Folgesanktion zu bekommen, mit zunehmender Anzahl der Tagessätze leicht ansteigt. Insgesamt betrachtet ist die Rückfallrate nach Erhalt einer Geldstrafe mit $23 \%$ besonders niedrig.

Die detailliertere Analyse der Folgeentscheidungen nach Jugendstrafen hat ergeben, dass nach bedingten Jugendstrafen bis zu zwei Jahren eine niedrigere Rückfallrate zu verzeichnen ist als für die unbedingten Jugendstrafen bis zu zwei Jahren. Auch im Falle eines Rückfalls ist die Sanktionsart der Folgeeintragung bei den bedingten Jugendstrafen weniger schwer als bei den unbedingten. Bei allen verbüßten Jugendstrafen ist die Rückfallrate nach Vollverbüßung höher als nach Strafrestaussetzung. Ferner erhalten Frauen, die nach Vollverbüßung rückfällig werden, schwerere Sanktionen als die Frauen, die nach Strafrestaussetzung rückfällig geworden sind. Die gleiche Tendenz ergibt sich für die Freiheitsstrafen bis zu zwei Jahren sowie für alle verbüßten Freiheitsstrafen. Differenziert man die stationäre Sanktion in der Bezugsentscheidung nach ihrer Dauer, so ergibt sich, dass bei den Jugendstrafen die Rückfallrate von Frauen mit $68 \%$ nach den kürzeren Jugendstrafen von sechs Monaten bis zu einem Jahr am höchsten ist. Betrachtet man die Rückfälle nach Freiheitsstrafen, so lassen sich die höchsten Rückfallquoten für die kurzen Freiheitsstrafen $(51 \%)$ und ebenfalls für solche von sechs Monaten bis zu einem Jahr verzeichnen (50\%).

\subsubsection{Folgeentscheidung und Voreintragungen}

Zudem wurden die Folgeentscheidungen in Abhängigkeit der Voreintragungen überprüft. Hierbei zeigt sich, dass sowohl die Anzabl als auch Art der Voreintragungen Einfluss auf die Rückfallkriminalität von Frauen haben: Mit steigender Anzahl von Voreintragungen nimmt auch die Rückfallwahrscheinlichkeit sowie der Anteil von stationären Sanktionen zu. Eine ähnliche Beziehung besteht zwischen der Schwere der Voreintragungen und der späteren Folgesanktion. Je schwerer die Voreintragungen, desto höher ist auch die Rückfallrate und der Anteil der stationären Sanktionen. Besonders stark ist der Einfluss von unbedingten Freiheits- und Jugendstrafen als Sanktion in der Voreintragung auf die Sanktionsart der Folgeentscheidungen bei jugendlichen und heranwachsenden Frauen. 30 \% der Frauen erhalten in diesen Fällen eine stationäre Folgeentscheidung. 


\subsubsection{Folgeentscheidung und Deliktsgruppen}

Darüber hinaus ist die Rückfallrate deliktsabhängig. Bezugsentscheidungen aufgrund von Verkehrsdelikten weisen allgemein das geringste Rückfallrisiko auf, wohingegen die Rückfallraten nach Bezugsentscheidungen aufgrund von sonstigen Gewaltdelikten, schweren Diebstahlsformen und Erschleichen von Leistungen recht hoch sind. Die Wahrscheinlichkeit, eine stationäre Sanktion als Folgeentscheidung zu erhalten, ist ebenfalls für sonstige Gewaltdelikte und schwere Diebstahlsformen, aber auch für Delikte nach dem BtMG besonders groß. Eine detailliertere Analyse der Art der Folgeentscheidung nach Art der Bezugsentscheidung aufgrund von sonstigen Gewaltdelikten, schweren Diebstahlsformen sowie Delikten nach dem BtMG verdeutlicht, dass die höchsten Rückfallraten und die größten Anteile von stationären Folgesanktionen nach unbedingten Jugend- und Freiheitsstrafen zu verzeichnen sind.

1.3.4 Einschlägige Voreintragungen, Bezugsentscheidung und einschlägiger Rückfall

Im Übrigen konnte festgestellt werden, dass nach Bezugsentscheidungen wegen eines Vermögensdelikts i.w.S. der einschlägige Rückfall den größten Anteil an Rückfällen ausmacht. Am höchsten ist der Anteil nach einer Bezugsentscheidung aufgrund von Erschleichen von Leistungen mit $26 \%$. Für die Verkehrstäterinnen spielt der einschlägige Rückfall hingegen kaum eine Rolle. Bei den Gewaltdelikten entfallen die meisten Rückfälle auf andere Deliktsgruppen. Bezieht man dann noch die Einschlägigkeit der Voreintragungen in die Untersuchung mit ein, so zeigt sich besonders bei den Täterinnen eines einfachen Diebstahls oder einer Unterschlagung sowie eines Erschleichen von Leistungen die Einhaltung einer Deliktsstruktur: Die bereits einschlägig vorbestraften Täterinnen werden hier zumeist auch wieder einschlägig rückfällig.

\subsubsection{Rückfallgeschwindigkeit}

Frauen werden in den ersten zwölf Monaten häufiger rückfällig. Dies gilt für alle Altersgruppen. Die Gruppe der erwachsenen Täterinnen wird am langsamsten rückfällig. Insgesamt ergeben sich allerdings nur minimale Unterschiede zwischen der Rückfallgeschwindigkeit der Altersgruppen.

\subsubsection{Alter und Nationalität}

Die Analyse der Art der Folgeentscheidung nach Altersgruppen hat einen altersabhängigen Effekt bestätigt. Die Rückfallrate von straffälligen Frauen sinkt kontinuierlich ab dem Alter von 25 Jahren.

Die Rückfallrate nichtdeutscher Frauen liegt mit 20\% unter derjenigen der deutschen, die $25 \%$ beträgt. Wahrscheinlich aufgrund von Abschiebungen besteht erwartungsgemäß der größte Unterschied zwischen Rückfällen nach Frei- 
heitsstrafen ohne Bewährung: Hier werden $43 \%$ der deutschen und lediglich $29 \%$ der nichtdeutschen Frauen erneut mit einer Straftat registriert. Nach Jugendstrafe ohne Bewährung erhalten nichtdeutsche Frauen hingegen mit $60 \%$ häufiger Folgeentscheidungen als deutsche Frauen mit 58 \%, wobei zu berücksichtigen ist, dass hier insgesamt nur 25 nichtdeutsche Frauen registriert sind.

\subsection{Rückfallkriminalität von Frauen und Männern im Vergleich}

Frauen werden mit $24 \%$ zu $35 \%$ seltener rückfällig als Männer. Eine Analyse nur der Rückfälligen hat ergeben, dass Täterinnen im Falle eines Rückfalls milder sanktioniert werden als Männer. Grundsätzlich sind Frauen bei den leichteren und Männer bei den härteren Sanktionen stärker vertreten. Dabei sind Frauen über alle Ausgangssanktionen hinweg weniger rückfällig. Die Differenzen zwischen den Sanktionsarten sind bei Freiheitsstrafen mit Bewährung mit sechs Prozentpunkten am niedrigsten und bei solchen ohne Bewährung mit 21 Prozentpunkten am höchsten. Diese Ergebnisse waren zu erwarten, da an dieser Stelle noch keine weiteren Variablen wie das Delikt oder die Vorstrafenbelastung in die Analyse einbezogen wurden.

Darüber hinaus sind Männer in den ersten zwölf Monaten schneller rückfällig als Frauen. Die Differenz beträgt jedoch nur 0,7 Prozentpunkte.

\subsubsection{Folgeentscheidung nach Bezugsentscheidungen aufgrund von Diebstahl gem. \242 StGB}

Frauen werden auch nach einer Bezugsentscheidung wegen Diebstahls seltener rückfällig als Männer und im Falle eines Rückfalls milder sanktioniert. Sie erhalten ferner über alle Bezugssanktionen hinweg seltener stationäre Sanktionen als Folgeentscheidung.

Betrachtet man die Art der Folgeentscheidung nach Jugend- und Freiheitsstrafen genauer, so zeigt sich, dass gegen Männer sowohl nach ausgesetzten als auch nach nicht ausgesetzten Jugend- und Freiheitsstrafen bis zu zwei Jahren häufiger stationäre Sanktionen als Folgeentscheidung erlassen werden, wohingegen Frauen häufiger Bewährungsstrafen erhalten. Gleiches gilt auch für die Art der Folgeentscheidung nach Jugendstrafen, deren Strafrest ausgesetzt wurde. Bei den Personen, die eine Jugendstrafe in vollem Umfang verbüßt haben, ist der Unterschied zwischen den Geschlechtern nicht mehr ganz so ausgeprägt: $57 \%$ der Diebinnen und $61 \%$ der Diebe werden in diesem Fall erneut mit einer stationären Sanktion registriert. Hingegen ist der Anteil von Jugend- und Freiheitsstrafen insgesamt als Folgesanktion bei den Frauen, deren Rest der Freiheitsstrafe ausgesetzt wurde, größer als bei den Männern.

Die Analyse der Geldstrafe hat ergeben, dass für Männer über alle Tagessatzgruppen hinweg häufiger stationäre Folgesanktionen zu verzeichnen sind als für Frauen. 
Darüber hinaus wurden auch hier die Voreintragungen in die Untersuchung mit einbezogen. Betrachtet wurden nur die Rückfälligen. Für die Gruppe der Jugendlichen und Heranwachsenden zeigte sich, dass sowohl bei Frauen als auch bei Männern mit steigender Anzabl der Voreintragungen die Wahrscheinlichkeit einer stationären Folgesanktion steigt. Die jungen Diebe erhalten häufiger Freiheitsoder Jugendstrafen als die jungen Diebinnen. Wie bei Analyse der Bezugsentscheidung in Kapitel 5 ist diese mildere Sanktionierung bei den erwachsenen Täterinnen nicht mehr zu erkennen. Hier erhalten die Frauen mit fünf und mehr Voreintragungen fast genauso häufig eine Jugend- oder Freiheitsstrafe wie Männer (60\% der Frauen und $61 \%$ der Männer). Bei drei bis vier Voreintragungen übersteigt der kumulierte Anteil von Jugend- und Freiheitsstrafen mit und ohne Bewährung mit $51 \%$ den der Männer mit $49 \%$.

Die Untersuchung der Art der Folgeentscheidung nach Art der schwersten Voreintragung für die Gruppe der Jugendlichen und Heranwachsenden macht deutlich, dass die Anteile von Freiheits- und Jugendstrafen bei den Männern die bei den Frauen leicht überwiegen. Durch Berücksichtigung der Art der schwersten Voreintragungen wird noch offensichtlicher, dass eine mildere Sanktionierung von Frauen auch in der Folgeentscheidung nicht besteht: Erwachsene Frauen mit schweren Voreintragungen erhalten häufiger Bewährungsstrafen als Männer, wobei diese Anteile teilweise so hoch sind, dass sie in Kumulation mit den stationären Folgesanktionen höher sind als bei den Männern. Die multifaktorielle Analyse hat dieses Ergebnis bestätigt. Hier sind die Anteile von unbedingten und bedingten Freiheitstrafen bei den Frauen mit 68 \% fast genauso hoch wie bei den Männern mit $70 \%$.

Die Einschlägigkeit von Voreintragungen wirkt sich für beide Geschlechter sanktionsschärfend auf die Folgeentscheidung aus. Der Einfluss ist jedoch bei den Männern ausgeprägter. Sowohl Frauen als auch Männer werden nach Erhalt einer Bezugsentscheidung aufgrund von Diebstahl am häufigsten einschlägig rückfällig. Im Vergleich zu den Männern ist der Anteil bei den Frauen jedoch um 19 Prozentpunkte höher. Bei Analyse der kriminellen Karriere von Frauen und Männern durch Berücksichtigung einschlägiger Voreintragungen und einschlägiger Rückfälle für das Delikt Diebstahl sind weitere Differenzen bei den Geschlechtern zu erkennen: Während insbesondere die Diebinnen kaum wegen anderer Delikte strafrechtlich auffällig werden, ist dies bei den Dieben nicht der Fall. Männer weisen ein breiteres Deliktsspektrum auf. Eine „Steigerung“ der kriminellen Karriere durch die Begehung schwererer Diebstahlsformen konnte nicht festgestellt werden. Auch bei den Männern sind die Anteile von Rückfällen mit anderen Diebstahlsdelikten recht niedrig, wofür jedoch wiederum der Anteil von Rückfällen wegen anderer Delikte recht hoch und auch größer als bei den Frauen ist. 


\subsubsection{Folgeentscheidung nach Bezugsentscheidungen aufgrund von Betrug} gem. \ $263 \mathrm{StGB}$

Betrügerinnen werden ebenfalls seltener rückfällig als Betrüger und zudem im Falle eines Rückfalls milder sanktioniert. Die Analyse der Art der Folgeentscheidung nach Freiheitsstrafen bis zu zwei Jahren sowie Strafrestaussetzung und Vollverbüßung hat deutlich gemacht, dass Frauen über alle Gruppen entweder genauso häufig oder häufiger Freiheits- oder Jugendstrafen als Folgesanktion erhalten.

Bei Untersuchung der Anzahl der Voreintragungen für die Gruppe der Erwachsenen hat sich ergeben, dass die kumulierten Anteile von Freiheits- und Jugendstrafen mit und ohne Bewährung ab zwei Voreintragungen bei Frauen größer sind als bei Männern. Das gleiche Ergebnis konnte unter Berücksichtigung der Art der schwersten Voreintragung erzielt werden. Hier ist der Anteil von stationären Freiheitsstrafen bei Freiheits- oder Jugendstrafen mit Bewährung als schwerste Voreintragung bei den Betrügerinnen mit 19 \% etwas größer als bei den Betrügern mit $18 \%$. Die multifaktorielle Analyse bestätigt schließlich, dass eine nachsichtigere Behandlung von Frauen aufgrund ihres Geschlechts nicht nachgewiesen werden kann: $69 \%$ der Betrügerinnen und $70 \%$ der Betrüger erhalten in den gebildeten Vergleichsgruppen eine Freiheitsstrafe als Folgesanktion.

Einschlägige Voreintragungen haben bei Betrügern einen stärkeren Einfluss auf die Schwere der Folgesanktion als bei Betrügerinnen. Sowohl Frauen als auch Männer, die eine Bezugsentscheidung aufgrund von Betrug erhalten haben, werden am häufigsten einschlägig rückfällig, wobei der Anteil bei den Frauen den bei den Männern um 14 Prozentpunkte übersteigt. Betrachtet man die kriminelle Karriere anhand der einschlägigen Voreintragungen und einschlägigen Rückfälle, bestätigt sich bei den Betrügerinnen das bereits beim Diebstahl gewonnene Bild: Täterinnen und Täter werden selten wegen anderer Delikte strafrechtlich auffällig, wobei sich dies bei den Betrügerinnen noch deutlicher zeigt als bei den Betrügern. Die Gruppe der Rückfälle wegen eines anderen Täuschungsdelikts spielt nur bei den bereits wegen eines Täuschungsdelikts vorbestraften Betrügerinnen und Betrügern eine größere Rolle.

\section{Bewertung der Ergebnisse}

Die vorliegende Arbeit konnte auf das umfassende Datenmaterial des BZR zurückgreifen, wodurch es gelungen ist, die bislang zahlenmäßig umfangreichste Untersuchung der Sanktionierungspraxis der Gerichte gegenüber straffälligen Frauen sowie deren Rückfälligkeit durchzuführen. Bei der Bewertung der Ergebnisse sind die in Kapitel 3 dargelegten Einschränkungen der Untersuchungsanlage zu beachten, die sich vor allen Dingen aus der Eigenart der Daten des BZR ergeben. Für die Auswertungen zur Rückfallkriminalität muss beachtet werden, dass der betrachtete Rückfallzeitraum auf drei Jahre begrenzt ist. Im Gegensatz zu den 
Diversionsregelungen im Jugendstrafrecht $(\mathbb{S} 45,47 \mathrm{JGG})$ sind Verfahrenseinstellungen nach dem Opportunitätsprinzip nach allgemeinem Strafrecht (vor allem $\iint 153$, 153a StPO) nicht im BZR erfasst und konnten daher auch nicht für die vorliegende Untersuchung ausgewertet werden.

Insbesondere ist zu berücksichtigen, dass bei der durchgeführten Überprüfung eines etwaigen „Frauenbonus“ viele Faktoren, die auf die Strafzumessung Einfluss haben, nicht erfasst werden konnten. Gleichwohl standen mit dem Alter, der Vorstrafenbelastung und dem Delikt wichtige Variablen für die Auswertung zur Verfügung. Die Analyse der Sanktionierungspraxis in Kapitel 5 hat ergeben, dass der vieldiskutierte „Frauenbonus“ nicht besteht. Allein die Tatsache, dass sich bei bivariater Betrachtung des Geschlechts und der Sanktion feststellen lässt, dass Männer schwerwiegendere Sanktionen erhalten als Frauen, macht noch keine Besserbehandlung aus. Vielmehr gibt es Gründe für diese mildere Sanktionierung, die nichts mit einem „Bonus“ zu tun haben. So begehen Frauen weniger schwerwiegende Delikte als Männer. Ferner sind für Frauen seltener Voreintragungen registriert, und im Falle einer Voreintragung lag bereits dort zumeist eine leichtere Sanktion zugrunde. Unter diesen Bedingungen erhalten auch Männer keine schwerwiegenden Sanktionen. Daher wurden in der vorliegenden Untersuchung die zur Verfügung stehenden sozio- und legalbiographischen Merkmale für Frauen und Männer parallelisiert. Hier zeigte sich dann, dass auch Frauen unter bestimmten Bedingungen nicht mehr mild bestraft werden. Gleiches konnte in Kapitel 6 für die Sanktionierung in der Folgeentscheidung festgestellt werden. Freiheits- und Jugendstrafen werden allerdings bei den Frauen, auch in den ausgelesenen Gruppen, die den multifaktoriellen Analysen zugrunde lagen, grundsätzlich eher zur Bewährung ausgesetzt als bei den Männern. Folglich wird für sie in der Regel eine günstigere Sozialprognose i.S.d. $\int 56 \mathrm{StGB}$ gestellt, was nicht mit einer nachsichtigeren Behandlung von Frauen aufgrund ihres Geschlechts gleichzusetzen ist.

Damit konnten die Ergebnisse der Studien, die das Bestehen eines etwaigen „Frauenbonus“ verneinten, auf Grundlage der BZR-Daten für den bundesweiten Verurteilungsjahrgang 2004 bestätigt werden. ${ }^{912}$ Darüber hinaus gehend wurden allerdings noch andere praxisrelevante Resultate ermittelt. Besonders auffällig ist, dass der Einfluss der Sanktionsart der Voreintragung bei den Personen, die eine bedingte oder unbedingte Freiheits- oder Jugendstrafe als Sanktion in der Voreintragung erhalten haben, auf die Sanktionsart der späteren Entscheidungen (Bezugs- und Folgeentscheidungen) bei den Frauen stärker ist als bei den Männern. Die schwerwiegendsten Sanktionen sind hier für Frauen mit einer stationären Sanktion in der Voreintragung zu verzeichnen. Dies könnte ein weiteres Indiz dafür sein, dass der Strafvollzug sich auf Frauen in stärkerem Maße negativ auswirkt als auf Männer. In diesem Zusammenhang könnte die überproportional

912 Vgl. Albrecht, Strafzumessung bei schwerer Kriminalität; Rolinski, Die Prägnanztendenz im Strafurteil; für Tötungsdelikte Oberlies, Tötungsdelikte zwischen Männern und Frauen. Näheres zu diesen und weiteren Studien unter Kap. 5, 1.2.2. 
häufige Drogenabhängigkeit inhaftierter Frauen eine Rolle spielen. Hier ist weitere Forschung wünschenswert, wobei die vorliegende Untersuchung einen Rahmen bildet, in den weitere Studien eingebettet werden können.

Eine große Forschungslücke besteht bzgl. der Rückfallkriminalität von Frauen. Mit der hier dargelegten Rückfalluntersuchung war es möglich, gute Basisraten zu liefern. Dabei hat sich gezeigt, dass bei Frauen prinzipiell die gleichen Faktoren die Rückfälligkeit beeinflussen wie bekanntermaßen bei den Männern.

In Anbetracht der Ergebnisse kann man letztendlich Oberlies in folgender Aussage zustimmen:

„Frauen werden nicht begünstigt, weil sie Frauen sind, sondern sie sind mittelbar begünstigt, weil bei ibnen Faktoren häufiger vorliegen, die sich - für Männer wie für Franen allgemein günstig auswirken. "913

913 Oberlies, in: KJ 1990, S. 318, 330. 


\section{Literaturverzeichnis}

Adler, Freda: Sisters in crime, New York 1976.

Albrecht, Hans-Jörg: Legalbewährung bei zu Geldstrafe und Freiheitsstrafe Verurteilten, Freiburg 1982.

Albrecht, Hans-Jörg: Registrierten und Bestraftenkohorten und Rückfallforschung, in: Heinz, Wolfgang/ Jehle, Jörg-Martin (Hrsg.): Rückfallforschung, Wiesbaden 2004, S. 55-70.

Albrecht, Hans-Jörg: Strafzumessung bei schwerer Kriminalität: Eine vergleichende theoretische und empirische Studie zur Herstellung und Darstellung des Strafmaßes, Berlin 1994.

Amelunxen, Clemens: Die Kriminalität der Frau seit 1945, Hamburg 1958.

Baier, Dirk/ Pfeiffer, Christian/ Rabold, Susann/ Simonsen, Julia/ Kappes, Cathleen: Kinder und Jugendliche in Deutschland: Gewalterfahrungen, Integration, Medienkonsum. Zweiter Bericht zum gemeinsamen Forschungsprojekt des Bundesministeriums des Innern und des KFN, Hannover 2010. Internetpublikation: http://www.kfn.de/versions/kfn/assets/fob109.pdf, Stand: 04/2012. 
Baier, Dirk/ Pfeiffer, Christian/ Simonsen, Julial Rabold, Susann: Jugendliche in Deutschland als Opfer und Täter von Gewalt. Erster Forschungsbericht zum gemeinsamen Forschungsprojekt des Bundesministeriums des Innern und des KFN, Hannover 2009. Internetpublikation: http://www.kfn.de/ versions/kfn/assets/fb107.pdf, Stand: 04/2012.

Baier, Dirk/ Pfeiffer, Christian/Windzio, Michael/ Rabold, Susann: Schülerbefragung 2005: Gewalterfahrungen, Schulabsentismus und Medienkonsum von Kindern und Jugendlichen. Abschlussbericht über eine repräsentative Befragung von Schülerinnen und Schülern der 4. und 9. Jahrgangsstufe, Hannover 2006. Internetpublikation: http://www.kfn.de/versions/kfn/assets/abschlussbericht_schuelerbefragung2005.pdf, Stand: 04/2012.

Baier, Dirk/ Rabold, Susann/ Kappes, Cathleen/ Kudlacek, Dominik: Sicherheit und Kriminalität in Stade. Ergebnisse einer Schüler- und Erwachsenenbefragung, Hannover 2009. Internetpublikation: http://www.kfn.de/versions/kfn/ assets/fb106.pdf, Stand: 04/2012.

Bange, Dirk/ Deegener, Günther: Sexueller Missbrauch an Kindern: Ausmaß, Hintergründe, Folgen, Weinheim 1996.

Bauermeister, Matthias: Die Tötung Neugeborener unter der Geburt (Kindstötung \217 StGB) - Eine bundesweite Verbundstudie für die Jahre 1980-1989 -, Diss., Kiel 1994.

Baumgart, Marc Christoph: Illegale Drogen - Strafjustiz - Therapie, Diss., Freiburg 1994.

Becker, Howard Saul: Außenseiter: Zur Soziologie abweichenden Verhaltens, Frankfurt am Main 1981.

Becker, Sophinette.: Das weibliche Körperselbst und die Perversion. Warum Frauen sexualisierte Aggressionen anders externalisieren als Männer, in: Forum der Psychoamalyse 2005, S. 242-254.

Bethge, Hans Jürgen: Der Ladendiebstahl unter besonderer Berücksichtigung des Diebstahls in Selbstbedienungsläden, Diss., Kiel 1996.

Bietsch, Erika: Analyse geschlechtsspezifischer Unterschiede im Bewährungsprozess, in: Kerner, Hans-Jürgen/ Kury, Helmut/ Sessar, Klaus (Hrsg.): Deutsche Forschungen zur Kriminalitätsentstehung und Kriminalitätskontrolle, Bd. 6/3, Köln 1983, S. 1591-1612.

Birnbaum, Karl: Kriminalpsychopathologie und psychobiologische Verbrecherkunde, Berlin 1921.

Bjerke, Tore: Sex differences and aggression, in: Dennen, Johan van der (Hrsg.): The nature of the sexes, Groningen 1992, S. 95-106.

Blankenburg, Erhard/ Sessar, Klaus/ Steffen, Wiebke: Die Staatsanwaltschaft im Prozess strafrechtlicher Sozialkontrolle, Berlin 1978. 
Blath, Richard: Die Bedeutung einer Rückfallstatistik für die Strafrechtspolitik, in: Heinz, Wolfgang/ Jehle, Jörg-Martin (Hrsg.): Rückfallforschung, Wiesbaden 2004, S. 133-144.

BMFSFJ (Hrsg.): Gewalt gegen Männer in Deutschland. Personale Gewaltwiderfahrnisse von Männern in Deutschland. Pilotstudie. Internetpublikation: http://www.bmfsfj.de/RedaktionBMFSFJ/Abteilung4/Pdf-Anlagen/studiegewalt-maenner-langfassung,property $=$ pdf,bereich $=$ bmfsf, sprache $=$ de, $r w b=$ true.pdf, Stand: 04/2012.

Bock, Michael: Kriminologie: für Studium und Praxis, 3. Auflage, München 2007.

Boeblen, Marie: Frauen im Gefängnis: Ihr Werdegang und ihre Bewährung, Chur 2000.

Böhm, Bernhard: Hauptverhandlung und Legalbewährung: eine rechtstatsächliche Untersuchung zur Legalbewährung nach Verfahrensexperimenten, München 1998.

Brinkmann, Bernd/ Du Chesne, Alfred: Tötungsdelikte/Suizide/Unfälle, in: Brinkmann, Bernd/ Madea, Burkhard (Hrsg.): Handbuch gerichtliche Medizin, Berlin/ Heidelberg 2004, S. 229-258.

Brökling, Elsbeth: Frauenkriminalität: Darstellung und Kritik kriminologischer und devianzsoziologischer Theorien, Stuttgart 1980.

Brubns, Kirsten/ Wittmann, Svendy: „Ich meine, mit Gewalt kannst du dir Respekt verschaffen." Mädchen und junge Frauen in gewaltbereiten Jugendgruppen, Opladen 2002.

Brubns, Kirsten/ Wittmann, Svendy: Mädchenkriminalität - Mädchengewalt, in: Raithel, Jürgen/ Mansel, Jürgen (Hrsg.): Kriminalität und Gewalt im Jugendalter: Hell- und Dunkelfeldbefunde im Vergleich, München 2003, S. 41-63.

Bruhns, Kirsten: Gewaltbereite Mädchen, in: Elz, Jutta (Hrsg.): Täterinnen: Befunde, Analysen, Perspektiven, Wiesbaden 2009, S. 177-194.

Bundeskeriminalamt (Hrsg.): Polizeiliche Kriminalstatistik Bundesrepublik Deutschland, Berichtsjahre 1995-2009, Wiesbaden.

Bundesministerium des Innern/ Bundesministerium der Justiz (Hrsg.): Erster Periodischer Sicherheitsbericht, Berlin 2001.

Bundesministerium des Innern/ Bundesministerium der Justiz. (Hrsg.): Zweiter Periodischer Sicherheitsbericht, Berlin 2006.

Burgheim, Joachim: Diskussionen: Besonderheiten weiblicher Tötungsverbrechen, in: MschrKrim 1994, S. 232-237.

Chesney-Lind, Meda: Girl's crime and woman's place - toward a feminist model of female delinquency, in: CrimDel 1989, S. 5-30. 
Christiansen, Hans: Die Beleidigung: eine strafrechtlich-kriminologische Untersuchung unter besonderer Berücksichtigung der Fälle sozialtypischen Verhaltens, dargestellt an Hand der im Landgerichtsbezirk Kiel in den Jahren 19601962 durchgeführten Verfahren, Diss., Kiel 1965.

Christiansen, Karl O.: A preliminary study of criminality among twins, in: Mednick, Sarnoff A./ Christiansen, Karl O. (Hrsg.): Biosocial base of criminal behavior, New York 1977, S. 89-108.

Christiansen, Karl O.: A review of studies of criminality among twins, in: Mednick, Sarnoff A./ Christiansen, Karl O. (Hrsg.): Biosocial base of criminal behavior, New York 1977, S. 45-88.

Cohen, Albert K:: Kriminelle Jugend: zur Soziologie jugendlichen Bandenwesens, Hamburg 1961.

Covington, Jeanette: Gender differences in criminality among heroin users, in: JResCrimDel 1985, S. 329-353.

Cremer, Carl-Gustav: Untersuchungen zur Kriminalität der Frau, Versuch einer Phänomenologie und einer Diskussion der wichtigsten aetiologischen Ansätze, Diss., Lübeck 1974.

Crites, Laura: Women offenders: myth vs. reality, in: Crites, Laura (Hrsg.): The female offender, Toronto 1976, S. 33-44.

Cullen, Francis T./ Golden, Kathryn M./ Cullen, John B.: Sex and delinquency, in: Crim 1979, S. 307-310, S. 301-310.

Damrow, Hildegard: Frauen vor Gericht, Frankfurt am Main 1969.

Datesman, Susan K./ Scarpitti, Frank R./ Stephenson, Richard M.: Female delinquency: an application of self and opportunity theories, in: JResCrimDel, 1975, S. 107123.

Dennen, Johan van der: Sex differences in sexual and aggressive behavioural system, in: Dennen, Johan van der (Hrsg.): The nature of the sexes, Groningen 1992, S. 107-124.

Doering, Hans-Geory: Beleidigung und Privatklage, Göttingen 1971.

Drewniak, Regine: Strafrichterinnen als Hoffnungsträgerinnen? Eine vergleichende Analyse strafrechtlicher Orientierungen von Richterinnen und Richtern, Diss., Göttingen 1993.

Dürkop, Marlies/ Hardtmann, Gertrud: Frauenkriminalität, in: KJ 1974, S. 219-236.

Durkheim, Emile: Die Regeln der soziologischen Methode, 4. Auflage, Frankfurt am Main 1999.

Eckert, Roland/ Reiss, Christa/ Wetzstein, Thomas A.: „Ich will halt anders sein wie die anderen“". Abgrenzung, Gewalt und Kreativität bei Gruppen Jugendlicher, Opladen 2000.

Einsele, Helga: Wandelt sich die weibliche Kriminalität?, in: Haesler, Walter T. (Hrsg.): Weibliche und männliche Kriminalität, Diessenhofen 1982, S. 53-80. 
Einsele, Helga: Weibliche Kriminalität und Frauenstrafvollzug, in: Sieverts, Rudolf/ Schneider, Hans-Joachim (Hrsg.): HwbKrim, Bd. 3, 2. Auflage, Berlin/ New York 1975, S. 608-656.

Einsele, Helga: Zur Straffälligkeit der Frau, in: MschrKrim 1968, S. 28-79.

Einsele, Helga: Zur Straffälligkeit der Frau, Teil II: Die minderjährigen Frauen, in: MschrKrim 1968, S. 334-362.

Eisenbach-Stangl, Irmgard: Weiblicher Körper und männliche Vernunft. Abweichungen und Kontrolle von Frauen, in: KB 1979, S. 4-38.

Eisenberg, Ulrich: Jugendgerichtsgesetz, Kommentar, 4. Auflage, München 2010.

Eisenberg, Ulrich: Kriminologie, 6. Auflage, München 2005.

Elsner, Erich/ Molnar, Hans: Kriminalität Heranwachsender und Jungerwachsener in München: Untersuchung zu Ursachen und Entwicklung der Kriminalität in der Altersgruppe der 18-24-Jährigen am Beispiel eines Großstadtpräsidiums, München 2001.

Epstein, Eleanor M.: The self-concept of the delinquent female, in: Smith College studies in social work 1962, S. 220-234.

Erhardt, Elmar: Drogenabhängigkeit und Beschaffungskriminalität, Wiesbaden 1991.

Exner, Franæ: Kriminologie, 3. Auflage, Heidelberg 1949.

Eysenck, Hans Jürgen: Kriminalität und Persönlichkeit, Wien 1977.

Fasoula, Evdoxia: Rückfall nach Diversionsentscheidungen im Jugendstrafrecht und im allgemeinem Strafrecht, Diss., München 2003.

Feest, Johannes: Frauenkriminalität, in: Kaiser, Günther/ Kerner, Hans-Jürgen/ Sack, Fritz/ Schellhoss, Hartmut (Hrsg.): Kleines kriminologisches Wörterbuch, 2. Auflage, Heidelberg 1985, S 118-123.

Figueira-McDonough, Josefina: Discrimination or sex differences? Criteria for evaluating the juvenile justice system's handling of minor offenses, in: CrimDel 1987, S. 403-424.

Finder, Gabriel: Der Fall Vukobrankovics: Begutachtung und Verurteilung einer Verbrecherin um 1920, in: KrimJ 1994, S. 47-69.

Fischer, Thomas: Strafgesetzbuch und Nebengesetze, Kommentar, 58. Auflage, München 2011.

Fischer-Jeble, Petra: Frauen im Strafvollzug. Eine empirische Untersuchung über Lebensentwicklung und Delinquenz strafgefangener Frauen, Diss., Stuttgart 1991.

Floru, Lucian: Der Begriff des „Pathologischen Stehlens“, in: MschrKrim 1974, S. $72-88$.

Franke, Kirsten: Frauen und Kriminalität: eine kritische Analyse kriminologischer und soziologischer Theorien, Konstanz 2000. 
Freud, Sigmund: Abriss der Psychoanalyse, Frankfurt am Main 1989.

Funken, Christiane: Frau - Frauen - Kriminelle: Zur aktuellen Diskussion über „Frauenkriminalität“, Diss., Opladen 1989.

Funken, Christiane: Versuch zur „Frauenkriminalität““, in: KrimJ 1987, S. 109-118.

Galtung, Johan: Gewalt, Frieden und Friedensforschung, in: Funke, Manfred (Hrsg.): Friedensforschung - Entscheidungshilfe gegen Gewalt, 2. Auflage, Bonn 1978, S. 99-132.

Gast, Peter: Die Mörder, Leipzig 1930.

Geiger, Manfred/ Steinert, Erika: Straffällige Frauen und das Konzept der „Durchgehenden sozialen Hilfe", Berlin/ Köln 1996.

Geiger-Battermann, Bernd/ Kreuzer, Max: Gewalt ist auch weiblich, in: BewHi 2009, S. 15-31.

Geiger-Battermann, Bernd/ Kreuzer, Max: Gewalt ist auch weiblich: Lebensgeschichten und die Innenwelt gewaltbereiter Mädchen und junger Frauen, Gladbacher Gewaltstudie, Bd.1, Mönchengladbach 2008.

Geiger-Battermann, Bernd: Knast ist nichts für Mädchen - Aspekte einer genderspezifischen Gewaltprävention, in: Kreuzer, Max/ Geiger-Battermann, Bernd (Hrsg.): Gewalt ist auch weiblich: Analysen - Hintergründe - Interventionen, Gladbacher Gewaltstudie, Bd. 2, Mönchengladbach 2009.

Geißler, Rainer/ Marißen, Norbert: Anmerkung zur Analyse und Bewertung von Frauenkriminalität, in: KZfSS 1990, S. 144-148.

Geißler, Rainer/ Marißen, Norbert: Junge Frauen und Männer vor Gericht: Geschlechtsspezifische Kriminalität und Kriminalisierung, in: KZfSS 1988, S. 505-526.

Geißler, Rainer/ Marißen, Norbert: Milde für junge Frauen bei der Strafverfolgung: Der Frauenbonus oder das Paradox der geschlechtsspezifischen Gleichbehandlung, in: KZfSS 1992, S. 549-558.

Generalbundesanwalt beim Bundesgerichtshof (Hrsg.): Rückfallstatistik '89 für das Basisjahr 1983 aus den Eintragungen im Bundeszentralregister, Berlin 1989.

Gerber, Hilke: Frauen, die Kinder sexuell missbrauchen - eine explorative Studie, Diss., Berlin 2004.

Gipser, Dietlinde: Frauen und Kriminalität, in: Gipser, Dietlinde/ Stein-Hilbers, Marlene (Hrsg.): Wenn Frauen aus der Rolle fallen: Alltägliches Leben und abweichendes Verhalten von Frauen, 2. Auflage, Basel 1987, S. 169-183.

Gipser, Dietlinde: Mädchenkriminalität, Soziale Bedingungen abweichenden Verhaltens, München 1975.

Glueck, Sheldon/ Glueck, Eleanor: Five hundred delinquent women, New York 1934.

Glueck, Sheldon/ Glueck, Eleanor: Unraveling juvenile delinquency, Cambridge/ Mass. 1957. 
Göppinger, Hans: Der Täter in seinen sozialen Bezügen: Ergebnisse aus der Tübinger Jungtäter-Vergleichsuntersuchung, Berlin 1983.

Göppinger, Hans: Kriminologie, 4. Auflage, München 1980.

Göppinger, Hans: Kriminologie, 5. Auflage, München 1997.

Göppinger, Hans: Kriminologie, 6. Auflage, München 2008.

Gottfredson, Michael/ Hirschi, Travis: A general theory of crime, Stanford 1990.

Graalmann, Kirsten: Die Rückfälligkeit von Drogenstraftätern. Eine Untersuchung zur Entwicklung krimineller Karrieren, Diss., Weinheim 1982.

Gréus, Ralf: Das Absehen von der Verfolgung jugendlicher Straftäter in der Praxis, Diss., Heidelberg 1978.

Grützediek, Elke: Intensivtäterinnen beim Diebstahl, Diss., Frankfurt am Main 2001.

Haag, Detlev: Betrügerische Hochstapelei und Schwindel, Diss., Frankfurt am Main 1977.

Hagemann-White, Carol: Sozialisation: Weiblich-männlich?, Opladen 1984.

Harrendorf, Stefan: Rückfälligkeit und kriminelle Karrieren von Gewalttätern, Diss., Göttingen 2007.

Hartmann, Susanne: Der soziale Bonus im Jugendstrafverfahren: Zum Einfluß sozialbiographischer Daten auf die Urteilsfindung, Baden-Baden 1994.

Haverkamp, Rita: Frauen im Strafvollzug im Lichte der europäischen Strafvollzugsgrundsätze: Eine empirische Studie in Deutschland und in Schweden, in: Lösel, Friedrich /Bender, Doris/ Jehle, Jörg-Martin (Hrsg.): Kriminologie und wissensbasierte Kriminalpolitik, Mönchengladbach 2007, S. 339-353.

Haynie, Dana L.: Delinquent peers revisited: does network structure matter?, in: AJS 2001, S. 1013-1057.

Haynie, Dana L.: Friendship networks and delinquency: the relative nature of peer delinquency, in: JQuantCrim 2002, S. 99-134.

Heinz, Wolfgang: Die neue Rückfallstatistik - Legalbewährung junger Straftäter, in: ZJJ 2004, S. 35-48.

Hein₹, Wolfgang: Frauenkriminalität, in: BewHi 2002, S. 131-152.

Heinz, Wolfgang: Geschlecht und Kriminalität, in: Kreuzer, Christine (Hrsg.): Frauen im Recht - Entwicklung und Perspektive, Baden-Baden 2001, S. 61-110.

Hein₹, Wolfgang: Kriminalität in Deutschland unter besonderer Berücksichtigung der Jugend- und Gewaltkriminalität. Internetpublikation: http://www.unikonstanz.de/rtf/kik/Heinz_Kriminalitaet_in_Deutschland.htm, Stand: 04/2012. 
Heinz, Wolfgang: Kriminalität von Deutschen nach Alter und Geschlecht im Spiegel von Polizeilicher Kriminalstatistik und Strafverfolgungsstatistik, Konstanz 2004. Internetpublikation: www.uni-konstanz.de/rtf/kik/krimdeu2002.pdf, Stand: 04/2012.

Heinz, Wolfgang: Kriminalprävention auf justizieller Ebene: Hilft weniger mehr? Alternativen zu „klassischen“ Sanktionen - Erfahrungen aus Deutschland, 2005. Internetpublikation: http://www.uni-konstanz.de/rtf/kis/Heinz_ Alternativen_zu_klassischen_Sanktionen.pdf, Stand: 04/2012.

Heinz, Wolfgang: Rückfall als kriminologischer Forschungsgegenstand - Rückfallstatistik als kriminologisches Erkenntnismittel, in: Heinz, Wolfgang/ Jehle, Jörg-Martin (Hrsg.): Rückfallforschung, Wiesbaden 2004, S. 11-52.

Heitmeyer, Wilhelm/ Collmann, Birgit/ Conrads, Jutta/ Matuschek, Ingo/ Kraul, Dietmar/ Kühnel Wolfgang/ Möller, Renate/ Ulbrich-Herrmann, Matthias: Gewalt: Schattenseiten der Individualisierung bei Jugendlichen aus unterschiedlichen Milieus, Weinheim/ München 1995.

Hengesch, Georges: Weibliche/ männliche Kriminalität, in: MschrKrim 1990, S. $331-335$.

von Hentig, Hans: Das Verbrechen, Bd. III, Berlin 1963.

Herbort, Ursula: Wer kommt vor das Gericht: Die Entscheidung der Staatsanwaltschaft über Anklage und Einstellung im Jugendstrafverfahren, Diss., Pfaffenweiler 1992.

Hermann, Dieter: Geschlechtsspezifische Unterschiede hinsichtlich Gewaltkriminalität, in: Schöch, Heinz/ Jehle, Jörg-Martin (Hrsg.): Angewandte Kriminologie zwischen Freiheit und Sicherheit, Mönchengladbach 2004, S. 567-581.

Herrfabrdt, Rolf: Zur Kriminalität weiblicher Minderjähriger: Untersuchung an Hand von 200 Akten aus vier Jugendstrafanstalten, Göttingen 1971.

Herø, Ruth G.: Jugendstrafrecht - Jungenstrafrecht? Wie das Jugendstrafrecht und die Justiz männliche Herrschaft festigen, in: KrimJ 1994, S. 296-309.

Hilgendorf, Eric: Sinn und Unsinn geschlechtsspezifischer Differenzierung im Strafrecht, in: Kreuzer, Christine (Hrsg.): Frauen im Recht - Entwicklung und Perspektive, Baden-Baden 2001, S. 111-130.

Hirschi, Travis: Causes of delinquency, 3. Auflage, Berkeley 1974.

Hoeveler, H.-J.: Kriminologie des Täters, in: Niggemeyer, B./ Gallus, H./ Hoeveler, H.-J. (Hrsg.): Kriminologie - Leitfaden für Kriminalbeamte -, Wiesbaden 1967, S. 169-280.

Hornthal, Steffen: Analyse psychologischer Merkmale im Ermessen von Polizeibeamten, Diss., Hamburg 1975.

Jacobsen, Gönke Christin: Sozialstruktur und Gender, Analyse geschlechtsspezifischer Kriminalität mit der Anomietheorie Mertons, Wiesbaden 2008. 
James, Jennifer/Thornton, William: Women's liberation and the female delinquent, JResCrimDel 1980, S. 230-244.

Jeble, Jörg-Martin/ Hein₹, Wolfgang/ Sutterer, Peter: Legalbewährung nach strafrechtlichen Sanktionen - Eine kommentierte Rückfallstatistik, Berlin 2003.

Jehle, Jörg-Martin: Die deutsche Rückfallstatistik - Konzeption und Ertrag, in: Heinz, Wolfgang/ Jehle, Jörg-Martin (Hrsg.): Rückfallforschung, Wiesbaden 2004, S. 145-171.

Jehle, Jörg-Martin: Schutz kindlicher Opfer im Strafverfahren, in: Kindesmisshandlung und -vernachlässigung 2008, S. 20-40.

Jeble, Jörg-Martin: Strafrechtspflege in Deutschland, 5. Auflage, Mönchengladbach 2009.

Jeble/ Jörg-Martin/ Albrecht, Hans-Jörg/ Hobmann-Fricke, Sabine/ Tetal, Carina: Legalbewährung nach strafrechtlichen Sanktionen: Eine bundesweite Rückfalluntersuchung 2004 bis 2007, Berlin 2010.

Joerss, Ingomar: Die gefährliche Körperverletzung - eine strafrechtliche kriminologische Untersuchung unter Berücksichtigung einer Aktenuntersuchung im Landgerichtsbezirk Kiel 1959-1961, Diss., Kiel 1969.

Julian, Frank: Gender and crime: different sex - different treatment, in: Culliver, Concetta (Hrsg.): Female criminality, New York/ London 1993, S. 343-362.

Kaiser, Günther: Das Bild der Frau im neueren kriminologischen Schrifttum, in: ZStW 1986, S. 658-678.

Kaiser, Günther: Kriminologie: eine Einführung in die Grundlagen, 9. Auflage, Heidelberg 1993.

Kaletta, Andrea: Risikofaktoren krimineller Rückfälligkeit: Der Einfluss der Häufigkeit der Unterbringung, der Gesamtunterbringungszeit und des Alters bei Erstunterbringung, Diss., München 2006.

Kaufmann, Hilde: Das Bild der Frau im älteren kriminologischen Schrifttum, in: MSchrKrim 1967, S. 143-153.

Kavemann, Barbara: Gewalt in Paarbeziehungen, in: Elz, Jutta (Hrsg.): Täterinnen: Befunde, Analysen, Perspektiven, S. 104-114.

Kavemann, Barbara: Täterinnen - die Gewaltausübung von Frauen im privaten Raum im Kontext der feministischen Diskussion über Gewalt im Geschlechterverhältnis, in: NK 2009, S. 46-50.

Kavemann, Barbara: Viel schlimmer oder halb so schlimm? Wenn Frauen Mädchen und Jungen sexuell missbrauchen, in: Wodtke-Werner, Verena (Hrsg.): „Nicht wegschauen!“, Vom Umgang mit Sexual(straf)tätern, Weinheim 1998, S. 31-44.

Kawamura-Reindl, Gabriele: Frauenstrafvollzug in Deutschland: Bestandsaufnahme und Empfehlungen, in: Elz (Hrsg.): Täterinnen: Befunde, Analysen, Perspektiven, S. 213-236. 
Keckeisen, Wolfgang: Die gesellschaftliche Definition abweichenden Verhaltens. Perspektiven und Grenzen des Labeling Approach, München 1974.

Kersten, Joachim: Risiken und Nebenwirkungen. Zur gesellschaftlichen Konstruktion von Männlichkeit, in: Scarbath, Horst/Schlottau, Heike/ Straub, Veronika/ Waldmann, Klaus (Hrsg.): Geschlechter. Zur Kritik und Neubestimmung geschlechtsbezogener Sozialisation und Bildung, Opladen 1999, S. 77-87.

Keupp, Lut:: Zur Problematik der weiblichen Delinquenz, in: MschrKrim 1982, S. 219-229.

Kin₹ig, Jörg: Die Sicherungsverwahrung auf dem Prüfstand: Ergebnisse einer theoretischen und empirischen Bestandsaufnahme des Zustandes einer Maßregel, Diss., Freiburg im Breisgau 1996.

Kirchner, Martin: Rückfallkriminalität von Verkehrsstraftätern, in: Heinz, Wolfgang/ Jehle, Jörg-Martin (Hrsg.): Rückfallforschung, Wiesbaden 2004, S. 261 287.

Klopp, Anne-Marie: Frauenstrafvollzug: Frauen im Strafvollzug in Europa, Weimar 2003.

Knöllinger, Claudial Förster, Klaus: „Kleptomanie“ - Mythos oder Realität?, in: BewHi 2000, S. 43-51.

Köbner, Otto: Die Methode einer wissenschaftlichen Rückfallstatistik als Grundlage einer Reform der Kriminalstatistik, in: ZStW 1893, S. 615-740.

Kommoß, Klaus: Opfer- und Tatverdächtigenstruktur häuslicher Gewalt aus der „Sicht" der Berliner Polizei 2001, in: Berliner Forum Gewaltprävention 2002, S. 73-76.

Konopka, Gisela: The adolescent girl in conflict, New Jersey 1966.

Körner, Burghard: Das soziale Machtgefälle zwischen Mann und Frau als gesellschaftlicher Hintergrund der Kriminalisierung: Darstellung an Hand der Strafgesetzgebung und höchstrichterlichen Rechtsprechung zu den vorsätzlichen Tötungsdelikten einschließlich der Kindestötung, München 1992.

Kot:, Peter: Die Wahl der Verfahrensart durch den Staatsanwalt. Empirische Untersuchung zu den Faktoren, die die Erhebung der öffentlichen Klage, den Antrag auf Erlaß eines Strafbefehls und die vorläufige Verfahrenseinstellung unter Anordnung von Auflagen und Weisungen beeinflussen, Diss., Frankfurt am Main 1983.

Krämer, Klaus: Delinquenz, Suchtmittelumgang und andere Formen abweichenden Verhaltens: Ein Geschlechtervergleich, Freiburg im Breisgau 1992.

Kreuzer, Artbur: Verhältnis von Drogen und Kriminalität, in: Kreuzer, Arthur (Hrsg.): Handbuch des Betäubungsmittelstrafrechts, München 1998, S. 97-183. 
Kreuzer, Arthur/ Görgen, Thomas/ Krüger, Ralf/ Münch, Volker/ Schneider, Hans: Jugenddelinquenz in Ost und West: Vergleichende Untersuchung bei ost- und westdeutschen Studienanfängern in der Tradition Gießener Delinquenzbefragungen, Bonn 1993.

Kreuzer, Arthur/ Görgen, Thomas/ Münch, Volker/ Schneider, Hans: Delinquenz im Systemvergleich, in: Boers, Klaus/ Ewald, Uwe/ Kerner, Hans-Jürgen/ Lautsch, Erwin/ Sessar, Klaus (Hrsg.): Sozialer Umbruch und Kriminalität, Bd. 1, Bonn 1994, S. 137-164.

Kreuzer, Arthur: Cherchez la femme? Beiträge aus Gießener Delinquenzbefragungen zur Diskussion um Frauenkriminalität, in: Hirsch, Hans-Joachim/ Kaiser, Günter/ Marquart, Helmut (Hrsg.): Gedächtnisschrift für Hilde Kaufmann, Berlin 1986, S. 291-308.

Kreuzer, Arthur: Drogen und Delinquenz. Eine jugendkriminologisch-empirische Untersuchung der Erscheinungsformen und Zusammenhänge, Wiesbaden 1975.

Kreuzer, Arthur/ Römer-Klees, Ruth/ Schneider, Hans: Beschaffungskriminalität Drogenabhängiger, Wiesbaden 1991.

Kreyssig, Ulrike/ Kurth, Anne.: Daneben gelebt... Drogenabhängige Mädchen und ihre Lebenswelt, in: Sachverständigenkommission Sechster Jugendbericht (Hrsg.): Alltag und Biographie von Mädchen, Opladen 1984, S. 49-102.

Kroetsch, Marlies: Tötungsdelikte an Kindern unter 6 Jahren, Hannover 2011. Internetpublikation: http://www.kfn.de/versions/kfn/assets/fob111.pdf, Stand: 04/2012.

Kuckuck, Claudia: Jugendgewalt - ein männliches und weibliches Phänomen: Ansätze einer geschlechterbewussten Gewaltpräventionsarbeit, Saarbrücken 2007.

Kühl, Kristian: Strafgesetzbuch, Kommentar, 27. Auflage, München 2011.

Künžl, Christine: Verrückte Erzählungen: Vergewaltigungstrauma und das Problem der Glaubwürdigkeit, in: Seidler, Günther H./ Eckart, Wolfgang U. (Hrsg.): Verletzte Seelen: Möglichkeiten und Perspektiven einer historischen Traumaforschung, Gießen 2005, S. 213-228.

Kürzinger, Josef: Kriminologie: eine Einführung in die Lehre vom Verbrechen, 2. Auflage, Stuttgart 1996.

Kun₹, Karl-Ludwig: Kriminologie, 5. Auflage, Stuttgart/Wien 2008.

Lamnek, Siegfried: Neue Theorien abweichenden Verhaltens, 1. Auflage, München 1994.

Lamnek, Siegfried: Theorien abweichenden Verhaltens: Eine Einführung für Soziologen, Psychologen, Pädagogen, Juristen, Politologen, Kommunikationswissenschaftler und Sozialarbeiter, 6. Auflage, München 1996. 
Lassen, Hans-Lorenæ: Rückfälligkeit und Bewährung von 200 Probanden, die nach Widerruf einer Strafaussetzung zur Bewährung in der Strafanstalt Wolfenbüttel Freiheitsstrafen verbüßten, unter besonderer Berücksichtigung ihres Anstaltsverhaltens, Diss., Göttingen 1973.

Laubenthal, Klaus/ Nestler, Nina: Geltungsbereich und Sanktionskatalog des JGG, in: Dollinger, Bernd/ Schmidt-Semisch, Henning (Hrsg.): Handbuch der Jugendkriminalität, Wiesbaden 2010, S. 475-482.

Lauritzen, Christian-Matthaeus: Die Kriminalität der Frau, Diss., Kiel 1972.

Leder, Hans-Claus: Der Stand kriminologischer Arbeit über Frauen- und Mädchenkriminalität - desorientiert für Politik, Kriminalpolitik, Sozialarbeiterpraxis und Wissenschaft, in: MschrKrim 1984, S. 313-327.

Leder, Hans-Claus: Frauen- und Mädchenkriminalität: Kritische Bestandsaufnahme aus devianzsoziologischer und wissenschaftstheoretischer Sicht, 3. Auflage, Frankfurt am Main 1997.

Legnaro, Aldo/ Aengenheister, Astrid: Schuld und Strafe. Das soziale Geschlecht von Angeklagten und die Aburteilung von Tötungsdelikten, Pfaffenweiler 1999.

Legnaro, Aldo: Männer und Frauen vor Strafgericht: Aspekte geschlechtsspezifisch unterschiedlicher Thematisierung, in: ZfRSoz 1987, S. 231-252.

Lemert, Edwin M.: Der Begriff der sekundären Devianz, in: Lüderssen, Klaus/ Sack, Fritz (Hrsg.): Seminar. Abweichendes Verhalten I. Die selektiven Normen der Gesellschaft, Frankfurt am Main 1975, S. 433-476.

Lindner, Andrea: 100 Jahre Frauenkriminalität: Die quantitative und qualitative Entwicklung der weiblichen Delinquenz von 1902 bis 2002, Diss., Ulm 2005.

von Lippa, Christoph: Der Ehrenschutz im deutschen Strafrecht, Bonn 1966.

Lombroso, Cesare/ Ferrero, Guglielmo: Das Weib als Verbrecherin und Prostituierte: Anthropologische Studien gegründet auf einer Darstellung der Biologie und Psychologie des normalen Weibes, Hamburg 1894.

Loos, Fritz-Robert: Rückfallkriminalität bei heranwachsenden Frauen in den Jahren 1970 - 1975 im Landgerichtsbezirk Koblenz: eine sozialpsychiatrische Studie, Diss., Bonn 1981.

Ludwig-Mayerhofer, Wolfgang/ Rzepkea, Dorothea: Noch einmal: Geschlechtsspezifische Kriminalisierung im Jugendstrafrecht?, in: KZfSS 1993, S. 542-557.

Ludwig-Mayerhofer, Wolfgang: Die staatsanwaltliche Diversionspraxis im Jugendstrafrecht, in: Albrecht, Peter-Alexis (Hrsg.): Informalisierung des Rechts: Empirische Untersuchungen zur Handhabung und zu den Grenzen der Opportunität im Jugendstrafrecht, S. 47-225.

Maelicke, Hannelore: Frauenkriminalität, Frauenstrafvollzug und ambulante Alternativen: Für einen eigenständigen Umgang mit Frauenkriminalität, in: ZfStrVo 1993, S. 226-230.

Mannheim, Hermann: Vergleichende Kriminologie, Bd. 2, Stuttgart 1974. 
Mansel, Jürgen: Die Selektivität strafrechtlicher Sozialkontrolle. Frauen und Delinquenz im Hell- und Dunkelfeld, als Opfer und Täter, als Anzeigende und Angezeigte, in: Lamnek, Sigfried/ Boatcà, Manuela (Hrsg.): Geschlecht, Gewalt, Gesellschaft, Opladen 2003, S. 384-406.

Marshall, Ineke Haen: The women`s movement and female criminality in the Netherlands, in: Barak-Glantz, Israel/ Johnson, Elmer H. (Hrsg.): Comparative criminology, London/ New Delhi 1983, S. 87-102.

McGloin, Jean Marie/ ONeill Shermer, Lauren: Self-Control and deviant peer network structure, in: JResCrimDel 2009, S. 35-72.

Meier, Bernd-Dieter: Kriminologie, 4. Auflage, München 2010.

Meier, Bernd-Dieter: Strafrechtliche Sanktionen, 3. Auflage, Berlin/ Heidelberg 2009.

Memminger, Ilse: Untersuchung zur weiblichen Frühkriminalität, Diss., Göttingen 1970.

Mergen, Armand: Der geborene Verbrecher, Hamburg 1968.

Merton, Robert K.: Sozialstruktur und Anomie, in: Sack, Fritz/ König, René (Hrsg.): Kriminalsoziologie, Frankfurt am Main 1968, S. 283-313.

Michaelis, Jörg: Kriminologisch-kriminalistische Aspekte des Ladendiebstahls unter besonderer Berücksichtigung des Warenhausdiebstahls, Diss., Frankfurt am Main 1991.

Miller, Anne: Jugendliche Straftäterinnen - unterschieden sie sich von delinquenten Jungen?, Diss., Tübingen 2009. Internetpublikation: http://tobias-lib.unituebingen.de/volltexte/2009/3886/pdf/Jugendliche_Straftaeterinnen.pdf, Stand: 04/2012.

Mischau, Anina: Frauenforschung und feministische Ansätze in der Kriminologie: dargestellt am Beispiel kriminologischer Theorien zur Kriminalität und Kriminalisierung von Frauen, Diss., 2. Auflage, Herbolzheim 2003.

Möbius, Paul J.: Über den physiologischen Schwachsinn des Weibes, 12. Auflage, Halle 1922.

Möller, Heidi: Frauen legen Hand an: Untersuchung zu Frauen und Kriminalität, Tübingen 1996.

Morning, Wolfgang: Symptome schwerer Rückfälligkeit bei jungen Vermögenstätern, Diss., Hamburg 1970.

Moser, Tilmann: Jugendkriminalität und Gesellschaftsstruktur: zum Verhältnis von soziologischen, psychologischen und psychoanalytischen Theorien des Verbrechens, Frankfurt am Main 1972.

Müller-Engelmann, Kurt Peter: Der Raub: zur Kriminologie und strafrechtlichen Regelung dieser Deliktstypen unter besonderer Berücksichtigung der Geschichte und der Kriminalistik, Diss., Frankfurt am Main 1973.

Mumm, Dieter: Zum Wesen der Aussagedelikte, Hamburg 1964. 
Niggli, Marcel A.: Kriminologische Überlegungen zur Strafzumessung, 1997. Internetpublikation: http://www.unifr.ch/lman/downloads/publikationen/ strafzumessung.pdf, Stand: 04/2012.

Nolte, Carsten: Rückfälligkeit Jugendlicher und Heranwachsender nach der VerbüBung von Jugendarrest, Diss., Göttingen 1978.

Nowack, Wolf: Hilfsbereitschaft gegenüber weiblichen und männlichen Straftätern, in: Albrecht, Günter/ Brusten, Manfred (Hrsg.): Soziale Probleme und soziale Kontrolle: neue empirische Forschungen, Bestandsaufnahmen und kritische Analysen, Opladen 1982, S. 185-194.

Oberlies, Dagmar: Der Versuch, das Ungleiche zu vergleichen, in: KJ 1990, S. 318331.

Oberlies, Dagmar: Geschlechtsspezifische Kriminalität und Kriminalisierung oder: Wie sich Frauenkriminalität errechnen lässt, in: KZfSS 1990, S. 129-143.

Oberlies, Dagmar: Tötungsdelikte zwischen Männern und Frauen. Eine Untersuchung geschlechtsspezifischer Unterschiede anhand von 174 Gerichtsurteilen, in: MschrKrim 1997, S. 133-147.

Oberlies, Dagmar: Tötungsdelikte zwischen Männern und Frauen: Eine Untersuchung geschlechtsspezifischer Unterschiede aus dem Blickwinkel gerichtlicher Rekonstruktion, Pfaffenweiler 1995.

Ochmann, Albert: Diebstahlsdelikte von Frauen und ihre Ursachen, Hamburg 1965.

Osburg, Susanne: Forensisch-psychiatrisch begutachtete Ladendiebe - eine Typologie, in: MschrKrim 1992, S. 10-18.

Ostendorf, Heribert: Jugendgerichtsgesetz, Kommentar, 8. Auflage, Baden-Baden 2009.

Ostendorf, Heribert: Jugendstrafrecht, 6. Auflage, Baden-Baden 2011.

Oswald, Margit E.: Psychologie des richterlichen Strafens, Stuttgart 1994.

Oswald, Margit: E.: Was wird gemessen bei der Strafzumessung?, in: GA 1988, S. 147-163.

Parsons, Talcott: Certain primary sources and patterns of aggression in the social structure of the western word, in: Parsons, Talcott (Hrsg.): Essays in sociological theory, Glencoe 1954, S. 298-322.

Pfäflin, Friedemann: Sexualstraftaten, in: Venzlaff, Ulrich/ Foerster, Klaus (Hrsg.): Psychiatrische Begutachtung: Ein praktisches Handbuch für Ärzte und Juristen, 5. Auflage, München 2009, S. 329-360.

Pollak, Otto: The criminality of women, New York 1961.

Pongrat:, Lieselotte/ Jürgensen, Peter: Kinderdelinquenz und kriminelle Karrieren: Eine statistische Nachuntersuchung delinquenter Kinder im Erwachsenenalter, Pfaffenweiler 1990.

Popitz, Heinrich: Der Begriff der sozialen Rolle als Element der soziologischen Theorie, 3. Auflage, Tübingen 1972. 
Popp, Ulrike/ Meier, Ulrich/ Tillmann, Klaus-Jürgen: Es gibt auch Täterinnen: Zu einem bisher vernachlässigten Aspekt der schulischen Gewaltdiskussion, in: ZSE 2001, S. 170-191.

Popp, Ulrike: Geschlechtersozialisation und Gewalt an Schulen, in: Holtappels, Heinz Günter/ Heitmeyer, Wilhelm/ Melzer, Wolfgang/ Tillmann, KlausJürgen (Hrsg.): Forschung über Gewalt an Schulen: Erscheinungsformen und Ursachen, Konzepte und Prävention, München 1997, S. 207-223.

Quenzer, Carolin: Jugendliche und heranwachsende Sexualstraftäter: eine empirische Studie über Rückfälligkeit und Risikofaktoren im Vergleich mit Gewaltstraftätern, Diss., Berlin 2010.

Raab, Monika: Männliche Richter - weibliche Angeklagte: Einstellungen und Alltagstheorien von Strafrichtern, Diss., München 1992.

Rabold, Susann/ Baier, Dirk/ Pfeiffer, Christian: Jugendgewalt und Jugenddelinquenz in Hannover. Aktuelle Befunde und Entwicklung seit 1998, 2008. Internetpublikation: http://www.kfn.de/versions/kfn/assets/fb105.pdf, Stand: 04/2012.

Rautenberg, Marcus: Zusammenhänge zwischen Devianzbereitschaft, kriminellem Verhalten und Drogenmißbrauch, Baden-Baden 1998.

Reckless, Walter C.: Halttheorie, in: MschrKrim 1961, S. 1-14.

Reiss, Albert J.: Delinquence as the failure of personal and social controls, in: ASR 1951, S. 196-207.

Rengier, Rudolf: Strafrecht - Besonderer Teil II: Delikte gegen die Person und die Allgemeinheit, 1. Auflage, München 2009.

Ritter, Johann Wilhelm: Fragmente aus dem Nachlasse eines jungen Physikers, Faksimile-Druck nach der Ausgabe von 1810, Heidelberg 1969.

Rolinski, Klaus: Die Prägnanztendenz im Strafurteil, Diss., Mainz 1968.

Rotermann, Ina/ Köhler, Denis/ Hinrichs, Günter: Legalbewährung jugendlicher und heranwachsender Sexual- und Gewaltstraftäter: eine Studie zur prädiktiven Validität von Risiko- und Schutzfaktoren, Frankfurt am Main 2009.

Rückert, Sabine: Tote haben keine Lobby: Die Dunkelziffer der vertuschten Morde, Hamburg 2000.

Rüther, Werner: Abweichendes Verhalten und „labeling approach“, Köln 1975.

Sack, Fritz: Definition von Kriminalität als politisches Handeln: Der Labeling approach, in: KrimJ 1972, S. 3-31.

Sack, Fritz: Neue Perspektiven in der Kriminologie, in: Sack, Fritz/ König, René (Hrsg.): Kriminalsoziologie, Frankfurt am Main 1968, S. 431-475.

Sagel-Grande, Irene: Zur Erklärung der Frauenkriminalität, in: ZStW 1988, S. 422 - 430. 
Saimeh, Nablah: „Mein eigen Fleisch und Blut“ - Mütter, die töten, in: Greuel, Luise/ Petermann, Axel (Hrsg.): Macht - Nähe - Gewalt (?), (Sexuelle) Gewalt- und Tötungsdelikte im sozialen Nahraum, Lengerich/ Berlin/ Bremen 2007, S. 55-69.

Sauer-Burghard, Brunbilde/ Zill, Gerda: Frauen in der Rechtsprechung, Opladen 1984.

Schäfer, Gerhard/ Sander, Günther M./ van Gemmeren, Gerhard: Praxis der Strafzumessung, 4. Auflage, München 2008.

Schaffstein, Friedrich/ Beulke, Werner: Jugendstrafrecht: Eine systematische Darstellung, 13. Auflage, Stuttgart 1998.

Schmitz, Alwin: Die Kriminalität der Frau, Diss., Mainz 1963.

Schmölzer, Gabriele: Aktuelle Diskussionen zum Thema $>$ Frauenkriminalität $<$ - ein Einstieg in die Auseinandersetzung mit gegenwärtigen Erklärungsversuchen, in: MschrKrim 1995, S. 219-235.

Schmölžer, Gabriele: Aktuelle Erklärungsversuche zur Frauenkriminalität und ihr Hintergrund, in: Rössner, Dieter/ Jehle, Jörg-Martin (Hrsg.): Kriminalität, Prävention und Kontrolle, Heidelberg 1999, S. 313-325.

Schmölzer, Gabriele: Geschlecht und Kriminalität: Zur kriminologischen Diskussion der Frauenkriminalität, 2003. Internetpublikation: http://www.querellesnet.de/index.php/qn/article/view/228/236, Stand: 04/2012.

Schneider, Hans-Joachim: Frauenkriminalität und Frauenstrafvollzug, in: Hirsch, Hans-Joachim/ Kaiser, Günther/ Marquart, Helmut (Hrsg.): Gedächtnisschrift für Hilde Kaufmann, Berlin 1986, S. 267-290.

Schneider, Hans-Joachim: Frauenkriminalität und Mädchendelinquenz, in: Schneider, Hans-Joachim (Hrsg.): Internationales Handbuch der Kriminologie, Bd. 1: Grundlagen der Kriminologie, Berlin 2007, S. 435-468.

Schneider, Hans-Joachim: Kriminologie der Gewalt, Stuttgart/ Leipzig 1994.

Schneider, Hans-Joachim: Kriminologie, Berlin/ New York 1987.

Scholz, Peter: Motive und Ursachen bei Körperverletzungen im Landgerichtsbezirk Bonn (1945-1955), Bonn 1958.

Schönke, Adolf/ Schröder, Horst: Strafgesetzbuch, Kommentar, 28. Auflage, München 2010.

Schorsch, Eberhard: Die sexuellen Deviationen und sexuell motivierte Straftaten, in: Venzlaff, Ulrich (Hrsg.): Psychiatrische Begutachtung: ein praktisches Handbuch für Ärzte und Juristen, 1. Auflage, Stuttgart/ New York 1986, S. 279315.

Schulte, Rainer: Betrugskriminalität Heranwachsender dargestellt anhand von Akten des Landgerichtsbezirks Mannheim aus den Jahren 1960 und 1961, Diss., Heidelberg 1967. 
Schur, Edwin: Labeling women deviant: gender, stigma, and social control, Philadelphia 1983.

Schwind, Hans-Dieter/ Baumann, Jürgen/ Schneider, Ursula/ Winter, Manfred: Gewalt in der Bundesrepublik Deutschland. Endgutachten der Unabhängigen Regierungskommission zur Verhinderung und Bekämpfung von Gewalt (Gewaltkommission), in: Schwind, Hans-Dieter/ Baumann, Jürgen u.a. (Hrsg.): Ursachen, Prävention und Kontrolle von Gewalt, Berlin 1990.

Schwind, Hans-Dieter/ Fetchenhauer, Detlef/ Ablborn, Wiffried/ Weiß, Rüdiger: Kriminalitätsphänomene im Langzeitvergleich am Beispiel einer deutschen Großstadt: Bochum 1975 - 1986 - 1998, Neuwied/ Kriftel 2001.

Schwind, Hans-Dieter/ Roitsch, Karin/ Ablborn, Wilfried/ Gielen, Birgit: Gewalt in der Schule am Beispiel von Bochum, WEISSER RING (Hrsg.): 2. Auflage, Mainz 1997.

Schwind, Hans-Dieter: Kriminologie. Eine praxisorientierte Einführung mit Beispielen, 21. Auflage, Heidelberg 2011.

Sessar, Klaus: Rechtliche und soziale Prozesse einer Definition der Tötungskriminalität, Freiburg 1981.

Siebecke-Giese, Evemarie: Das Familien- und Lebensbild weiblicher Straftäter, Stuttgart 1960.

Silkenbeumer, Mirja: Im Spiegel ihrer Lebensgeschichten. Gewalttätiges Verhalten Jugendlicher und Geschlechtszugehörigkeit, Münster 2000.

Simon, Rita James: Woman and crime, Lexington 1975.

Simons, Robert L./ Miller, Martin G./ Aigner, Stephen M.: Contemporary theories of deviance and female delinquency: an empirical test, in: JResCrimDel 1980, S. 42-57.

Smart, Carol: The new female criminal: reality or myth?, in: BritJCrim 1979, S. 5059.

Smaus, Gerlinda: Das Strafrecht und die Frauenkriminalität, in: KrimJ 1990, S. 266283.

Smith, Douglas A./ Paternoster, Raymond: The gender gap in theories of deviance issues and evidence, JResCrimDel 1987, S. 140-172.

Stammermann, Ulla/ Gransee, Carmen: Zur Reproduktion von Normalitätsvorstellungen von Weiblichkeit durch Kriminalisierungsprozesse - eine Rekonstruktion von Medienwirklichkeiten, in: Frehsee, Detlev/ Löschper, Gabi/ Smaus, Gerlinde (Hrsg.): Konstruktion der Wirklichkeit durch Kriminalität und Strafe, Baden-Baden 1997, S. 435-455.

Statistisches Bundesamt (Hrsg.): Fachserie 1/ Reihe 1.3: Bevölkerungsfortschreibung 2004, Wiesbaden 2005.

Statistisches Bundesamt (Hrsg.): Fachserie 10: Rechtspflege, Reihe 3: Strafverfolgung 1995-2009, Wiesbaden. 
Steffen, Wiebke: Analyse polizeilicher Ermittlungstätigkeit aus der Sicht des späteren Strafverfahrens, Wiesbaden 1976.

Steffen, Wiebke: Reaktion von Polizei und Justiz auf Frauen, in: Gipser, Dietlinde/ Stein-Hilbers, Marlene (Hrsg.): Wenn Frauen aus der Rolle fallen: Alltägliches Leben und abweichendes Verhalten von Frauen, 2. Auflage, Basel 1987, S. 201-216.

Steffensmeier, Darrell/ Steffensmeier, Renee Hoffman: Trends in female delinquency, in: Crim 1980, S. 62-85.

Stein-Hilbers, Marlene: Zur Frage der geschlechtsspezifisch unterschiedlichen Strafverfolgung, in: KrimJ 1978, S. 281-291.

Stenke, Doris/Bergelt, Sandra/ Börner, Franriska: Jungengewalt - Mädchengewalt ein Exkurs, in: Forschungsgruppe Schulevaluation (Hrsg.): Gewalt als soziales Problem in Schulen. Die Dresdner Studie: Untersuchungsergebnisse und Präventionsstrategien, Opladen 1998.

Story, Renate: Jugendstrafrechtliche Reaktionen und Legalbewährung. Ergebnisse einer Untersuchung zur erneuten justiziellen Registrierung nach formeller und informeller jugendstrafrechtlicher Sanktionierung von Jugendlichen des Geburtsjahrgangs 1961 anhand von Daten des Bundeszentralregisters, in: Bundesministerium der Justiz (Hrsg.): Diversion im Jugendstrafverfahren der Bundesrepublik Deutschland, Bonn 1992, S. 133-220.

Streng, Fran:: Jugendstrafrecht, 2. Auflage, Heidelberg 2008.

Sutherland, Edwin/ Cressey, Donald Ray: Principles of criminology, Philadelphia 1966.

Sutherland, Edwin: Die Theorie der differentiellen Kontakte, in: Sack, Fritz/ König, René (Hrsg.): Kriminalsoziologie, 2. Auflage, Frankfurt am Main 1974, S. 395399.

Tellegen, Auke/ Lykken, David T./ Bouchard, Thomas J./ Wilcox, Kimberly J./ Segal, Nancy L./ Rich, Stephen: Personality similarity in twins reared apart and together, in: Journal of Personality and Social Psychology 1988, S. 1031-1039.

Theurer, Andrea: Emanzipation - Der Schlüssel zur Erklärung der Frauenkriminalität?: Eine empirische Untersuchung über den Zusammenhang zwischen weiblicher Kriminalität und der Geschlechtsrollenorientierung, Diss. jur., Universität Regensburg 1996.

Thomas, William Isaac: Sex and society: studies in the social psychology of sex, Chicago 1907.

Thomas, William Isaac: The unadjusted girl, Breinigsville 1925.

Ubl, Karsten: Die Gewaltverbrecherin im kriminologischen und literarischen Diskurs des frühen 20. Jahrhunderts, in: Hilbig, Antje/ Kajatin, Claudia/ Miethe, Ingrid (Hrsg.): Frauen und Gewalt: Interdisziplinäre Untersuchungen zu geschlechtsgebundener Gewalt in Theorie und Praxis, Würzburg 2003, S. 91104. 
Versen, Paul: Erscheinungsformen und Strafzumessung bei der Körperverletzung, Mussbach 1951.

Wagner, Joachim: Staatliche Sanktionspraxis beim Ladendiebstahl. Eine kriminologische, kriminalpolitische und strafrechtsdogmatische Studie, Göttingen 1979.

Wahl, Klaus: Aggression und Gewalt. Ein biologischer, psychologischer und sozialwissenschaftlicher Überblick, Heidelberg 2009.

Walter, Michael: Gewaltkriminalität, 2. Auflage, Stuttgart/ München 2008.

Walters, Glenn D.: A meta-analysis of the gene - crime relationship, in: Crim 1992, S. 595-613.

Wandiger, Udo: Tötungsdelikte an Neugeborenen und älteren Kindern zwischen 1969 und 1982 (eine Studie für die Aachener Region), Diss., Mainz 1984.

Weigelt, Enrico: Bewähren sich Bewährungsstrafen? Eine empirische Untersuchung der Praxis und des Erfolgs der Strafaussetzung von Freiheits- und Jugendstrafen, Diss., Göttingen 2008.

Weiß, Tatjana: Täterin Frau: Gewaltverhalten von Frauen im gesellschaftlichen und institutionellen Bewusstsein, Saarbrücken 2007.

West, Donald James/ Farrington, David P.: Who becomes delinquent? Second report of the Cambridge Study in delinquent development, London 1973.

West, Donald James: Applied criminology in England, in: Göppinger, Hans (Hrsg.): Angewandte Kriminologie - international, Bonn 1988, S. 21-29.

Wetzels, Peter/ Enzmann, Dirk/ Mecklenburg, Eberhard/ Pfeiffer, Christian: Jugend und Gewalt. Eine repräsentative Dunkelfeldanalyse in München und acht anderen deutschen Städten. Baden-Baden 2001.

Widmann, Bernhard: Die Prävalenz psychischer Störungen bei Frauen in Haft, Diss., Aachen 2006. Internetpublikation: http://darwin.bth.rwth-aachen.de/ opus3/volltexte/2007/1708/pdf/Widmann_Bernhard.pdf, Stand: 04/2012.

Widom, Catby Spaty/ Ames, Ashley: Biology and female crime, in: Moffitt, Terrie/ Mednick, Sarnoff A. (Hrsg.): Biological contribution to crime causation, Boston/ Lancaster 1988, S. 308-331.

Wille, Reinhard./ Schwar:, Jürgen: Aussagedelikte der Kindesmutter aus gerichtsärztlicher Sicht, in: MschrKrim 1966, S. 263-273.

Wilmers, Nicola/ Enzmann, Dirk/ Schaefer, Dagmar, Herbers, Karin/ Greve, Werner/ Wetzels, Peter: Jugendliche in Deutschland zur Jahrtausendwende: Gefährlich oder gefährdet? Baden-Baden 2002.

Wirth, Wolfgang: Das Drogenproblem im Justizvollzug. Zahlen und Fakten, in: BewHi 2002, S. 104-122.

Witkin, Hermann A./ Mednick, Sarnoff A./ Schulsinger, Fini et al.: XYY and XXY men: criminality and aggression, in: Mednick, Sarnoff/ Christiansen, Karl O. (Hrsg.): Biosocial bases of criminal behavior, London/ Sydney 1977, S. 165187. 
Wittenberg, Jochen: Diebstahlskriminalität von Jugendlichen. Eine Überprüfung der Theorie des geplanten Verhaltens am Beispiel des Ladendiebstahls, Münster/ New York/ München 2009.

Wocher, Christoph: Die Entwicklung der weiblichen Kriminalität von 1912-1948, Diss., Tübingen 1951.

World Health Organization Europe: Gesundheit von Frauen im Strafvollzug. Beseitigung von Ungleichheiten zwischen den Geschlechtern im Strafvollzug, Kopenhogen 2009. Internetpublikation: http://www.euro.who.int/_data/ assets/pdf_file/0005/76514/E92347G.pdf, Stand: 04/2012.

Wulffen, Erich: Das Weib als Sexualverbrecherin: ein Handbuch für Juristen, Polizei- und Strafvollzugsbeamte, Ärzte, Pädagogen und Laienrichter, 3. Auflage, Hamburg 1931.

Wyss, Eva: Hexen und Verführerinnen. Werden Frauen als Täterinnen im Strafverfahren benachteiligt oder bevorzugt?, in: Künzel, Christine/ Temme, Gaby (Hrsg.): Täterinnen und/ oder Opfer? Frauen in Gewaltstrukturen, Hamburg 2007, S. 198-216.

Zang, Klaus: Psychische Auffälligkeiten und Kriminalität bei Männern mit einem überzähligen Y-Chromosom, in: Göppinger, Hans/ Vossen, Rainer (Hrsg.): Humangenetik und Kriminologie: Kinderdelinquenz und Frühkriminalität, Stuttgart 1984, S. 19-31.

Zerbin-Rüdin, Edith: Gegenwärtiger Stand der Zwillings- und Adoptionsstudien zu Kriminalität, in: Göppinger, Hans/ Vossen, Rainer (Hrsg.): Humangenetik und Kriminologie: Kinderdelinquenz und Frühkriminalität, Stuttgart 1984, S. 1-18.

Zirpins, Walter: Der Betrug, in: Sieverts, Rudolf (Hrsg.): HwbKrim, Bd. 1, 2. Auflage, Berlin 1966, S. 81-95.

Zurbold, Heike: Kriminalität und Kriminalisierung drogengebrauchender Frauen: Kritische Analyse der justiziellen Sanktionspraxis und Möglichkeiten der Depönalisierung, Berlin 1998. 


\section{Tabellenanhang}

\section{Vorbemerkung}

Die folgenden Tabellen weisen detailliert die Ergebnisse der im Rahmen der vorliegenden Untersuchung dargestellten Auswertungen aus. Sie enthalten die absoluten Zahlen sowie zum Teil die Prozentwerte. Zu beachten ist, dass für jede Tabelle die Fälle ausgeschlossen wurden, die sich nicht einer der gebildeten Kategorien zuordnen lassen, sodass sich die Werte in den einzelnen Tabellen nicht immer zur Gesamtzahl der Bezugs- bzw. Folgeentscheidungen addieren lassen. 


\section{Tabellen zu Kapitel 1}

Tab. 1.1a: TVBZ für Deutsche nach Geschlecht und Altersgruppe, 2009

\begin{tabular}{|l|r|r|}
\hline & & \\
\hline & Frauen & Männer \\
\hline 10 bis $<10$ & 237 & 935 \\
\hline 12 bis $<14$ & 615 & 1.953 \\
\hline 14 bis $<16$ & 2.368 & 4.599 \\
\hline 16 bis $<18$ & 4.619 & 8.416 \\
\hline 18 bis $<21$ & 3.774 & 10.302 \\
\hline 21 bis $<23$ & 3.173 & 10.722 \\
\hline 23 bis $<25$ & 2.827 & 9.555 \\
\hline 25 bis $<30$ & 2.515 & 8.401 \\
\hline 30 bis $<40$ & 2.053 & 6.753 \\
\hline 40 bis $<50$ & 1.538 & 4.521 \\
\hline 50 bis $<60$ & 1.200 & 3.298 \\
\hline $60>$ & 860 & 2.392 \\
\hline
\end{tabular}

Quelle: BKA (Hrsg.), PKS der jeweiligen Jahrgänge, Tab. 61. 
Tab. 1.2a: Deliktsstruktur von tatverdächtigen Frauen, 2009

\begin{tabular}{|c|c|c|}
\hline & abs. & in $\%$ \\
\hline $\begin{array}{l}\text { Gewaltdelikte } \\
\text { Hierunter: }\end{array}$ & 87.302 & $14 \%$ \\
\hline $\begin{array}{|ll|}- & \text { Tötungsdelikte (Mord, Totschlag, } \\
& \text { Körperverletzung mit Todesfolge) }\end{array}$ & 389 & $0,1 \%$ \\
\hline $\begin{array}{l}\text { Sonstige Gewaltdelikte (Vergewalti- } \\
\text { gung sowie sexuelle Nötigung, } \\
\text { Raubdelikte, Geiselnahme, erpresse- } \\
\text { rischer Menschenraub, Widerstand } \\
\text { gegen Vollstreckungsbeamte) }\end{array}$ & 6.352 & $1 \%$ \\
\hline - $\quad$ Einfache Körperverletzung & 53.721 & $9 \%$ \\
\hline $\begin{array}{l}\text { - Sonstige Körperverletzungsdelikte } \\
\text { (gefährliche u. schwere Körperverlet- } \\
\text { zung, Misshandlung von Schutzbe- } \\
\text { fohlenen) }\end{array}$ & 26.840 & $4 \%$ \\
\hline $\begin{array}{l}\text { Besonders schwerer und qualifizierter Dieb- } \\
\text { stahl }\end{array}$ & 11.450 & $2 \%$ \\
\hline Einfacher Diebstahl, Unterschlagung & 173.008 & $28 \%$ \\
\hline Betrug, Untreue, Urkundendelikte & 120.985 & $20 \%$ \\
\hline Erschl. v. Leistungen & 41.871 & $7 \%$ \\
\hline Beleidigung & 49.171 & $8 \%$ \\
\hline Sachbeschädigung & 21.906 & $4 \%$ \\
\hline Delikte nach BtMG & 22.489 & $4 \%$ \\
\hline $\begin{array}{l}\text { Fahrlässige Tötung, fahrlässige Körperverlet- } \\
\text { zung }\end{array}$ & 6.354 & $1 \%$ \\
\hline $\begin{array}{l}\text { Sonstige Delikte } \\
\text { Hierunter: }\end{array}$ & 78.909 & $13 \%$ \\
\hline $\begin{array}{ll}\text { Straftaten gegen die persönliche } \\
\text { Freiheit (ohne Geiselnahme und er- } \\
\text { presserischen Menschenraub) }\end{array}$ & 25.933 & $4 \%$ \\
\hline $\begin{array}{l}\text { Widerstand gegen die Staatsgewalt } \\
\text { und Straftaten gegen die öffentliche } \\
\text { Ordnung (ohne Widerstand gegen } \\
\text { Vollstreckungsbeamte) } \\
\end{array}$ & 18.121 & $3 \%$ \\
\hline $\begin{array}{l}\text { Straftaten gegen das AufenthG, } \\
\text { AsylVerfG + FreizügG/EU }\end{array}$ & 17.410 & $3 \%$ \\
\hline Sonstige Delikte & 17.445 & $3 \%$ \\
\hline Straftaten insgesamt ${ }^{*}$ & 613.445 & $100 \%$ \\
\hline
\end{tabular}

Quelle: BKA (Hrsg.), PKS 2009, Tab. 48, S. 85.

* Die Auflistung basiert auf Tab. 48 und ist daher nicht vollständig. Die Tatverdächtigen bei den einzelnen Straftatengruppen lassen sich wegen der Erfassungsregeln der PKS nicht zu einer Gesamtzahl addieren, vgl. BKA (Hrsg.), PKS 2009, S. 20 f., 85; Die Gruppierung wurde z.T. anders als in Tab. 48 vorgenommen und orientiert sich an der eigenen Kategorisierung (vgl. Kap.4). 
Tab. 1.3a: TV BZ nach Diebstahlsart, Geschlecht und Altersgruppe, 2009

\begin{tabular}{|c|c|c|c|c|c|c|c|c|c|c|}
\hline & \multicolumn{2}{|c|}{ Jugendliche } & \multicolumn{2}{|c|}{$\begin{array}{c}\text { Heran- } \\
\text { wachsende }\end{array}$} & \multicolumn{2}{|c|}{$\begin{array}{c}\text { Jung- } \\
\text { erwachsene }\end{array}$} & \multicolumn{2}{|c|}{ Erwachsene } & \multicolumn{2}{|c|}{$\begin{array}{l}\text { TV Gesamt } \\
\text { (ab } 8 \text { Jahre) }\end{array}$} \\
\hline & $F$ & M & $\mathbf{F}$ & M & $\mathbf{F}$ & M & $\mathbf{F}$ & $M$ & $\mathbf{F}$ & M \\
\hline $\begin{array}{l}\text { Diebstahl ohne er- } \\
\text { schwerende Um- } \\
\text { stände(inklusive } \\
\text { Ladendiebstahl) }\end{array}$ & 2.017 & 2.880 & 697 & 1.822 & 445 & 1.119 & 230 & 516 & 348 & 714 \\
\hline nur Ladendiebstahl & 1.682 & 1.572 & 434 & 645 & 267 & 569 & 171 & 318 & 269 & 422 \\
\hline $\begin{array}{l}\text { Diebstahl unter er- } \\
\text { schwerenden Umstän- } \\
\text { den }\end{array}$ & 140 & 1.195 & 96 & 1.052 & 62 & 459 & 16 & 128 & 24 & 217 \\
\hline
\end{tabular}

Quelle: BKA (Hrsg.), PKS 2009, Tab. 64b, 64c.

Tab. 1.4a: Entwicklung der TVBZ von Frauen bei Straftaten insgesamt ab 1995

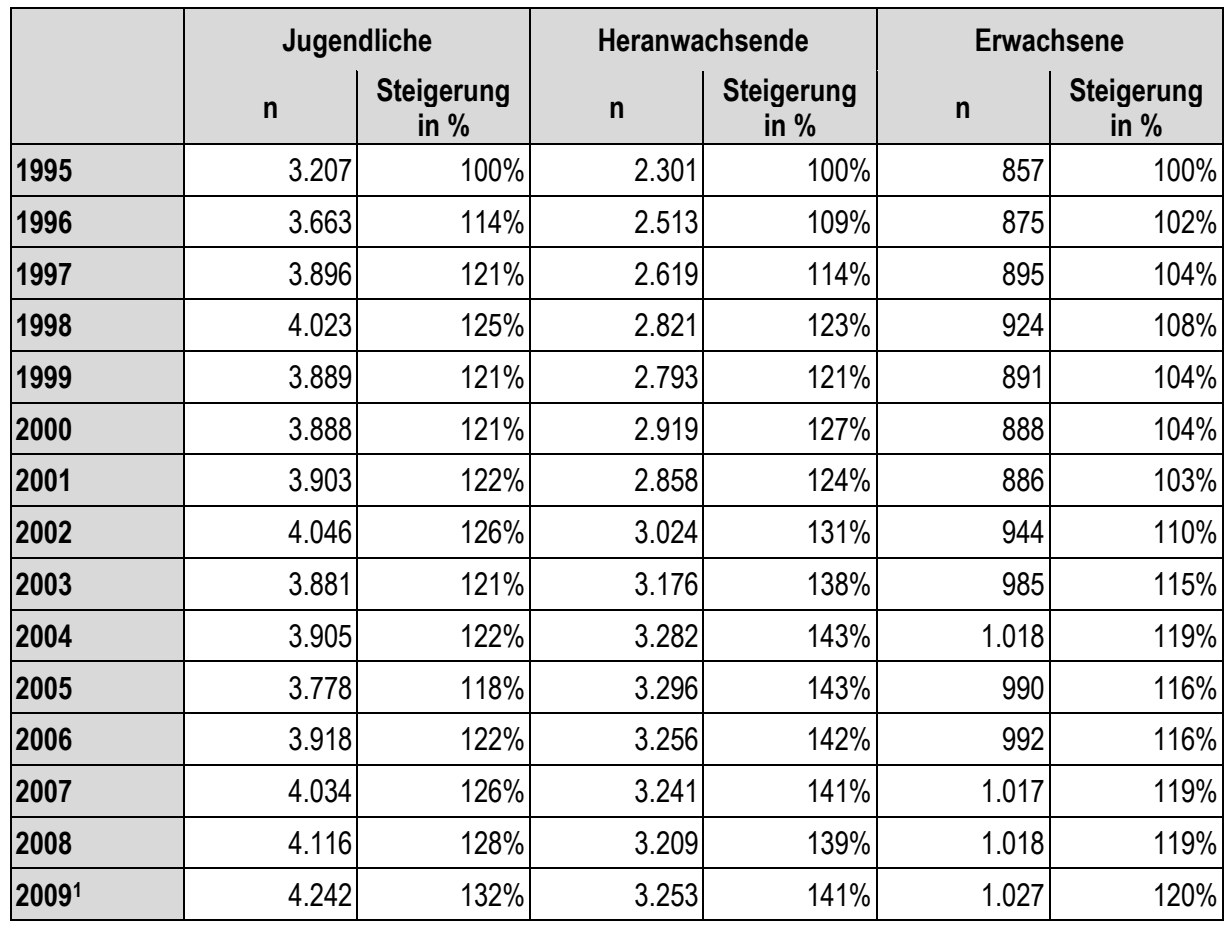

Quelle: BKA (Hrsg.), PKS der jeweiligen Jahrgänge, Tab. 33, 61.

\footnotetext{
${ }^{1}$ Da die PKS seit 2009 die TVBZ nur für die Tatverdächtigen nach der neuen Zählung aufweist, wurde die hier zugrunde liegende TVBZ für das Jahr 2009 mit den Daten aus BKA (Hrsg.), PKS 2009, Tabelle 33 und 61 berechnet.
} 
Tab. 1.5a: Entwicklung der TVBZ von Männern bei Straftaten insgesamt ab 1995

\begin{tabular}{|c|c|c|c|c|c|c|}
\hline & \multicolumn{2}{|c|}{ Jugendliche } & \multicolumn{2}{|c|}{ Heranwachsende } & \multicolumn{2}{|c|}{ Erwachsene } \\
\hline & $\mathrm{n}$ & $\begin{array}{c}\text { Steigerung } \\
\text { in } \%\end{array}$ & $\mathrm{n}$ & $\begin{array}{c}\text { Steigerung } \\
\text { in } \%\end{array}$ & $\mathrm{n}$ & $\begin{array}{c}\text { Steigerung } \\
\text { in } \%\end{array}$ \\
\hline 1995 & 9.498 & $100 \%$ & 10.216 & $100 \%$ & 2.992 & $100 \%$ \\
\hline 1996 & 9.948 & $105 \%$ & 10.912 & $107 \%$ & 3.070 & $103 \%$ \\
\hline 1997 & 10.167 & $107 \%$ & 11.162 & $109 \%$ & 3.124 & $104 \%$ \\
\hline 1998 & 10.402 & $110 \%$ & 11.511 & $113 \%$ & 3.167 & $106 \%$ \\
\hline 1999 & 10.408 & $110 \%$ & 11.495 & $113 \%$ & 3.087 & $103 \%$ \\
\hline 2000 & 10.463 & $110 \%$ & 11.841 & $116 \%$ & 3.163 & $106 \%$ \\
\hline 2001 & 10.761 & $113 \%$ & 11.777 & $115 \%$ & 3.162 & $106 \%$ \\
\hline 2002 & 10.453 & $110 \%$ & 11.793 & $115 \%$ & 3.286 & $110 \%$ \\
\hline 2003 & 10.161 & $107 \%$ & 12.046 & $118 \%$ & 3.395 & $113 \%$ \\
\hline 2004 & 10.123 & $107 \%$ & 12.350 & $121 \%$ & 3.482 & $116 \%$ \\
\hline 2005 & 9.557 & $101 \%$ & 12.089 & $118 \%$ & 3.423 & $114 \%$ \\
\hline 2006 & 9.535 & $100 \%$ & 11.776 & $115 \%$ & 3.382 & $113 \%$ \\
\hline 2007 & 9.876 & $104 \%$ & 11.589 & $113 \%$ & 3.424 & $114 \%$ \\
\hline 2008 & 9.686 & $102 \%$ & 11.312 & $111 \%$ & 3.392 & $113 \%$ \\
\hline $2009^{2}$ & 9.606 & $101 \%$ & 11.147 & $109 \%$ & 3.375 & $113 \%$ \\
\hline
\end{tabular}

Quelle: BKA (Hrsg.), PKS der jeweiligen Jahrgänge, Tab. 33, 61.

Tab. 1.6a: VBZ für Deutsche nach Geschlecht und Altersgruppe, 2009

\begin{tabular}{|l|r|r|r|r|r|r|}
\hline & $\mathbf{1 4}$ bis $>\mathbf{1 8}$ & $\mathbf{1 8}$ bis $\mathbf{2 1}$ & $\mathbf{2 1}$ bis $\mathbf{2 5}$ & $\mathbf{2 5}$ bis $\mathbf{3 0}$ & $\mathbf{3 0}$ bis $\mathbf{> 4 0}$ & \multicolumn{2}{|c|}{$\mathbf{4 0}$} \\
\hline Frauen & 571 & 826 & 1.131 & 852 & 568 & 210 \\
\hline Männer & 2.736 & 4.539 & 5.277 & 3.738 & 2.247 & 835 \\
\hline
\end{tabular}

Quelle: StatBA (Hrsg.), StVS 2009, Tab. 1.2.

\footnotetext{
${ }^{2}$ Da die PKS seit 2009 die TVBZ nur für die Tatverdächtigen nach der neuen Zählung aufweist, wurde die hier zugrunde liegende TVBZ für das Jahr 2009 mit den Daten aus BKA (Hrsg.), PKS 2009, Tabelle 33 und 61 berechnet.
} 
Tab.: 1.7a: TVBZ und VBZ für Deutsche nach Geschlecht und Altersgruppe, 2009

\begin{tabular}{|l|r|r|r|r|r|r|}
\hline & \multicolumn{2}{|c|}{ Jugendliche } & \multicolumn{2}{c|}{ Heranwachsende } & \multicolumn{2}{c|}{ Erwachsene } \\
& \multicolumn{1}{|c|}{ TVBZ } & \multicolumn{1}{c|}{ VBZ } & \multicolumn{1}{c|}{ TVBZ } & \multicolumn{1}{c|}{ VBZ } & \multicolumn{1}{c|}{ TVBZ } & \multicolumn{1}{c|}{ VBZ } \\
\hline Frauen & 4.181 & 571 & 3.173 & 826 & 1.013 & 354 \\
\hline Männer & 9.391 & 2.736 & 10.722 & 4.539 & 3.273 & 1.546 \\
\hline
\end{tabular}

Quelle: BKA (Hrsg.), PKS 2009, Tab. 61 sowie StatBA (Hrsg.), StVS 2009, Tab. 1.1.

Tab. 1.8a: Delik.tsstruk.tur von verurteilten Frauen, 2009

\begin{tabular}{|c|c|c|}
\hline & abs. & in $\%$ \\
\hline $\begin{array}{l}\text { Gewaltdelikte } \\
\text { Hierunter: }\end{array}$ & 8.842 & $6 \%$ \\
\hline $\begin{array}{ll}\text { - } & \text { Tötungsdelikte (Mord, Totschlag, } \\
& \text { Körperverletzung mit Todesfolge) }\end{array}$ & 72 & $0 \%$ \\
\hline $\begin{array}{l}\text { Sonstige Gewaltdelikte (Vergewalti- } \\
\text { gung sowie sexuelle Nötigung, } \\
\text { Raubdelikte, Geiselnahme, erpresse- } \\
\text { rischer Menschenraub, Widerstand } \\
\text { gegen Vollstreckungsbeamte) }\end{array}$ & 1.157 & $1 \%$ \\
\hline - $\quad$ Einfache Körperverletzung & 4.270 & $3 \%$ \\
\hline $\begin{array}{ll}\text { - Sonstige Körperverletzungsdelikte } \\
\text { (gefährliche u. schwere Körperver- } \\
\text { letzung, Misshandlung von Schutz- } \\
\text { befohlenen) }\end{array}$ & 3.343 & $2 \%$ \\
\hline $\begin{array}{l}\text { Besonders schwerer und qualifizierter Dieb- } \\
\text { stahl }\end{array}$ & 1.838 & $1 \%$ \\
\hline Einfacher Diebstahl, Unterschlagung & 33.502 & $21 \%$ \\
\hline Betrug, Untreue, Urkundendelikte & 40.244 & $26 \%$ \\
\hline Erschl. v. Leistungen & 15.264 & $10 \%$ \\
\hline Beleidigung & 2.750 & $2 \%$ \\
\hline Sachbeschädigung & 1.196 & $1 \%$ \\
\hline Delikte nach BtMG & 6.131 & $4 \%$ \\
\hline $\begin{array}{l}\text { Fahrlässige Tötung, fahrlässige Körperverlet- } \\
\text { zung (außerhalb des Straßenverkehrs) } \\
\end{array}$ & 1.109 & $1 \%$ \\
\hline Verkehrsdelikte mit Alkoholeinfluss & 12.856 & $8 \%$ \\
\hline Verkehrsdelikte ohne Alkoholeinfluss & 14.269 & $9 \%$ \\
\hline Sonstige Delikte & 17.969 & $11 \%$ \\
\hline Verurteilungen insgesamt & 155.970 & $100 \%$ \\
\hline
\end{tabular}

Quelle: StatBA (Hrsg.), StVS 2009, Tab. 2.1. 
Tab. 1.9a: Entwicklung der VBZ von Frauen bei Straftaten insgesamt ab 1995

\begin{tabular}{|c|c|c|c|c|c|c|}
\hline & \multicolumn{2}{|c|}{ Jugendliche } & \multicolumn{2}{|c|}{ Heranwachsende } & \multicolumn{2}{|c|}{ Erwachsene } \\
\hline & n & $\begin{array}{l}\text { Steigerung } \\
\text { in } \%\end{array}$ & $\mathrm{n}$ & $\begin{array}{l}\text { Steigerung } \\
\text { in } \%\end{array}$ & $\mathbf{n}$ & $\begin{array}{c}\text { Steigerung } \\
\text { in } \%\end{array}$ \\
\hline 1995 & 290 & $100 \%$ & 623 & $100 \%$ & 330 & $100 \%$ \\
\hline 1996 & 343 & $118 \%$ & 660 & $106 \%$ & 330 & $100 \%$ \\
\hline 1997 & 389 & $134 \%$ & 746 & $120 \%$ & 335 & $102 \%$ \\
\hline 1998 & 426 & $147 \%$ & 785 & $126 \%$ & 352 & $107 \%$ \\
\hline 1999 & 444 & $153 \%$ & 821 & $132 \%$ & 348 & $105 \%$ \\
\hline 2000 & 458 & $158 \%$ & 814 & $131 \%$ & 338 & $102 \%$ \\
\hline 2001 & 468 & $161 \%$ & 825 & $132 \%$ & 328 & $99 \%$ \\
\hline 2002 & 502 & $173 \%$ & 837 & $134 \%$ & 324 & $98 \%$ \\
\hline 2003 & 491 & $169 \%$ & 879 & $141 \%$ & 340 & $103 \%$ \\
\hline 2004 & 504 & $174 \%$ & 952 & $153 \%$ & 374 & $113 \%$ \\
\hline 2005 & 520 & $179 \%$ & 949 & $152 \%$ & 379 & $115 \%$ \\
\hline 2006 & 524 & $181 \%$ & 926 & $149 \%$ & 363 & $110 \%$ \\
\hline \multicolumn{7}{|c|}{ Ab 2007 sind die Zahlen für Gesamtdeutschland berücksichtigt. } \\
\hline 2007 & 507 & $175 \%$ & 884 & $142 \%$ & 365 & $111 \%$ \\
\hline 2008 & 512 & $177 \%$ & 838 & $135 \%$ & 364 & $110 \%$ \\
\hline 2009 & 571 & $197 \%$ & 826 & $133 \%$ & 354 & $107 \%$ \\
\hline
\end{tabular}

Quelle: StatBA (Hrsg.), StVS der jeweiligen Jahrgänge, Tab. 1.1. 
Tab. 1.10a: Entwicklung der VBZ von Männern bei Straftaten insgesamt ab 1995

\begin{tabular}{|c|c|c|c|c|c|c|}
\hline & \multicolumn{2}{|c|}{ Jugendliche } & \multicolumn{2}{|c|}{ Heranwachsende } & \multicolumn{2}{|c|}{ Erwachsene } \\
\hline & $\mathbf{n}$ & $\begin{array}{l}\text { Steigerung } \\
\text { in } \%\end{array}$ & $\mathbf{n}$ & $\begin{array}{l}\text { Steigerung } \\
\text { in } \%\end{array}$ & $\mathbf{n}$ & $\begin{array}{l}\text { Steigerung } \\
\text { in } \%\end{array}$ \\
\hline 1995 & 2.002 & $100 \%$ & 4.473 & $100 \%$ & 1.774 & $100 \%$ \\
\hline 1996 & 2.098 & $105 \%$ & 4.566 & $102 \%$ & 1.772 & $100 \%$ \\
\hline 1997 & 2.278 & $114 \%$ & 4.924 & $110 \%$ & 1.793 & $101 \%$ \\
\hline 1998 & 2.473 & $124 \%$ & 5.136 & $115 \%$ & 1.806 & $102 \%$ \\
\hline 1999 & 2.522 & $126 \%$ & 5.079 & $114 \%$ & 1.708 & $96 \%$ \\
\hline 2000 & 2.533 & $127 \%$ & 5.064 & $113 \%$ & 1.638 & $92 \%$ \\
\hline 2001 & 2.595 & $130 \%$ & 5.154 & $115 \%$ & 1.611 & $91 \%$ \\
\hline 2002 & 2.714 & $136 \%$ & 5.198 & $116 \%$ & 1.576 & $89 \%$ \\
\hline 2003 & 2.632 & $131 \%$ & 5.202 & $116 \%$ & 1.603 & $90 \%$ \\
\hline 2004 & 2.774 & $139 \%$ & 5.388 & $120 \%$ & 1.698 & $96 \%$ \\
\hline 2005 & 2.746 & $137 \%$ & 5.216 & $117 \%$ & 1.703 & $96 \%$ \\
\hline 2006 & 2.740 & $137 \%$ & 5.017 & $112 \%$ & 1.630 & $92 \%$ \\
\hline \multicolumn{7}{|c|}{ Ab 2007 sind die Zahlen für Gesamtdeutschland berücksichtigt. } \\
\hline 2007 & 2.666 & $133 \%$ & 4.865 & $109 \%$ & 1.650 & $93 \%$ \\
\hline 2008 & 2.707 & $135 \%$ & 4.575 & $102 \%$ & 1.622 & $91 \%$ \\
\hline 2009 & 2.736 & $137 \%$ & 4.539 & $101 \%$ & 1.546 & $87 \%$ \\
\hline
\end{tabular}

Quelle: StatBA (Hrsg.), StVS der jeweiligen Jahrgänge, Tab. 1.1. 


\section{Tabellen zu Kapitel 4}

Tab. 4.1a: Deliktsstruktur von Frauen und Männern nach Deliktsgruppe

\begin{tabular}{|l|r|r|r|r|r|r|}
\hline & \multicolumn{2}{|c|}{ Frauen } & \multicolumn{2}{c|}{ Männer } & \multicolumn{2}{c|}{$\begin{array}{l}\text { Gesamt } \\
\text { abs. }\end{array}$} \\
\hline
\end{tabular}


Tab. 4.1b: Gewaltdelikte von Frauen und Männern

\begin{tabular}{|c|c|c|c|c|c|c|}
\hline & \multicolumn{2}{|c|}{ Frauen } & \multicolumn{2}{|c|}{ Männer } & \multicolumn{2}{|c|}{ Gesamt } \\
\hline & abs. & in \%* & abs. & in \%* & abs. & in $\% *$ \\
\hline $\begin{array}{l}\text { Tötungsdelikte } \\
\text { Hierunter: }\end{array}$ & 82 & $10 \%$ & 773 & $90 \%$ & 855 & $100 \%$ \\
\hline - $\quad$ Mord & 21 & $7 \%$ & 270 & $93 \%$ & 291 & $100 \%$ \\
\hline _ Totschlag & 51 & $10 \%$ & 438 & $90 \%$ & 489 & $100 \%$ \\
\hline $\begin{array}{ll}\text { - } & \text { Körperverletzung mit } \\
\text { Todesfolge }\end{array}$ & 10 & $13 \%$ & 65 & $87 \%$ & 75 & $100 \%$ \\
\hline \begin{tabular}{|l|} 
Einfache \\
Körperverletzung \\
\end{tabular} & 8.570 & $14 \%$ & 52.198 & $86 \%$ & 60.768 & $100 \%$ \\
\hline $\begin{array}{l}\text { Sonstige Körperverletzungs- } \\
\text { delikte (ohne Misshandlung von } \\
\text { Schutzbefohlenen) } \\
\text { Hierunter: } \\
\quad \text { - Beteiliquna an einer }\end{array}$ & 4.947 & $14 \%$ & 31.298 & $86 \%$ & 36.245 & $100 \%$ \\
\hline $\begin{array}{l}\text { Schlägerei } \\
\text { - Gefährliche Körner- }\end{array}$ & 0 & $0 \%$ & 5 & $100 \%$ & 5 & \\
\hline verletzung & 4.936 & $14 \%$ & 31.198 & $86 \%$ & 36.134 & $100 \%$ \\
\hline $\begin{array}{ll}- & \text { Schwere Körperver- } \\
& \text { letzung }\end{array}$ & 11 & & 95 & $90 \%$ & 106 & $100 \%$ \\
\hline $\begin{array}{l}\text { Misshandlung von Schutz- } \\
\text { befohlenen }\end{array}$ & 73 & $39 \%$ & 115 & $61 \%$ & 188 & $100 \%$ \\
\hline $\begin{array}{l}\begin{array}{l}\text { Widerstand gegen Voll- } \\
\text { streckungsbeamte }\end{array} \\
\end{array}$ & 420 & $10 \%$ & 3.846 & $90 \%$ & 4.266 & $100 \%$ \\
\hline Raubdelikte & 919 & $8 \%$ & 9.918 & $92 \%$ & 10.837 & $100 \%$ \\
\hline Sexuelle Gewaltdelikte & 18 & $1 \%$ & 2.187 & $99 \%$ & 2.205 & $100 \%$ \\
\hline Gesamt & 15.029 & $13 \%$ & 100.335 & $87 \%$ & 115.364 & $100 \%$ \\
\hline
\end{tabular}

*Zeilenprozente 
Tab. 4.1c: Vermögensdelikte i.w.S. von Frauen und Männern

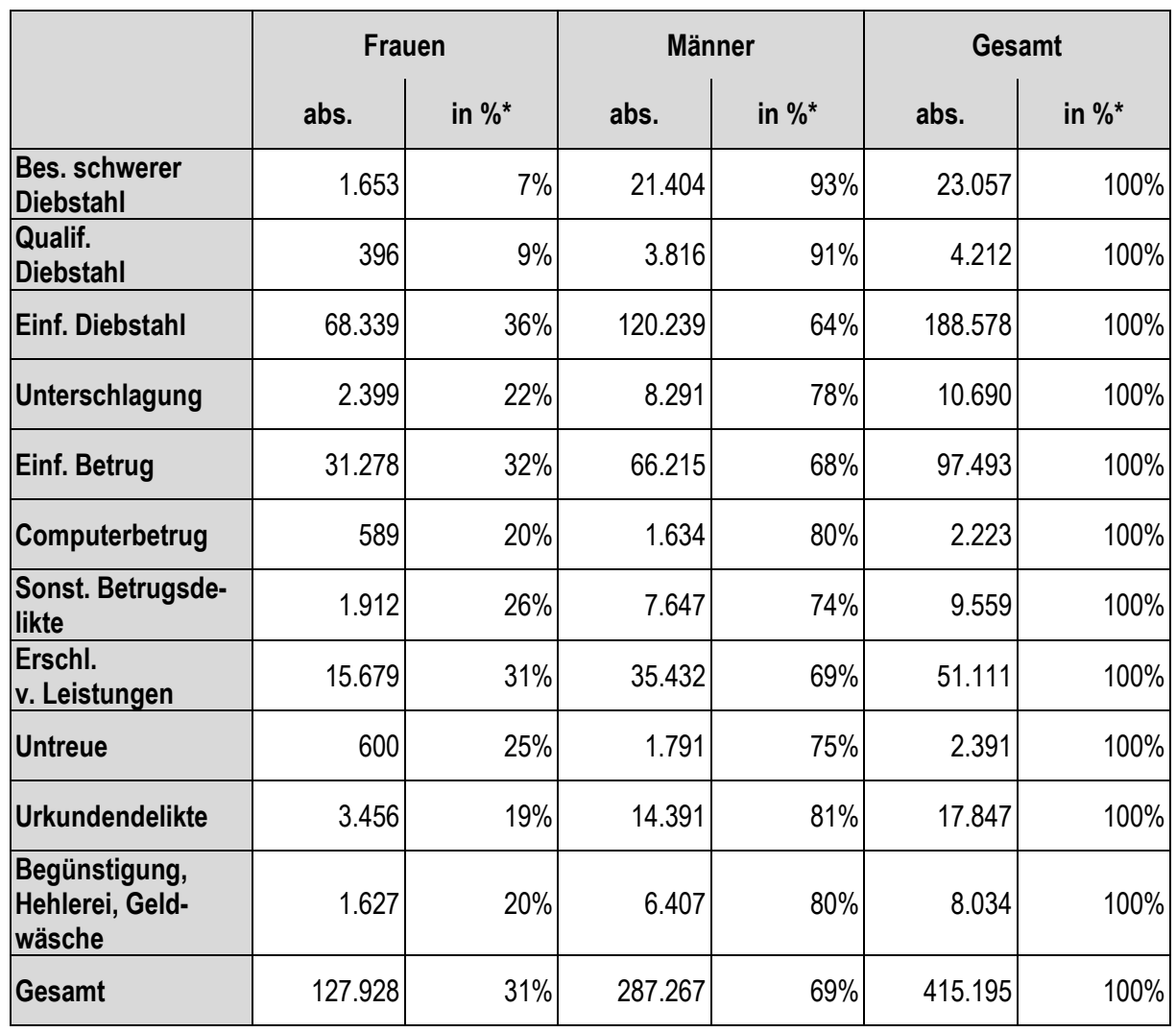

* Zeilenprozente 
Tab. 4.1d: Sonstige Delikte von Frauen und Männern

\begin{tabular}{|c|c|c|c|c|c|c|}
\hline & \multicolumn{2}{|c|}{ Frauen } & \multicolumn{2}{|c|}{ Männer } & \multicolumn{2}{|c|}{ Gesamt } \\
\hline & abs. & in \%* & abs. & in \%* & abs. & in \%* \\
\hline $\begin{array}{l}\text { Fahrlässige Körperverletzung, } \\
\text { fahrlässige Tötung }\end{array}$ & 2.872 & $22 \%$ & 10.269 & $78 \%$ & 13.141 & $100 \%$ \\
\hline $\begin{array}{l}\text { Verkehrsdelikte ohne Alkoholein- } \\
\text { fluss }\end{array}$ & 17.574 & $14 \%$ & 110.485 & $86 \%$ & 128.059 & $100 \%$ \\
\hline $\begin{array}{l}\text { Verkehrsdelikte mit } \\
\text { Alkoholeinfluss }\end{array}$ & 13.513 & $12 \%$ & 97.356 & $88 \%$ & 110.869 & $100 \%$ \\
\hline Delikte nach BtMG & 7.547 & $11 \%$ & 58.417 & $89 \%$ & 65.964 & $100 \%$ \\
\hline \begin{tabular}{|l|} 
Sonstige Delikte \\
Hierunter:
\end{tabular} & 28.797 & $16 \%$ & 149.184 & $84 \%$ & 177.981 & $100 \%$ \\
\hline - Hausfriedensbruch & 1.246 & $19 \%$ & 5.485 & $81 \%$ & 6.731 & $100 \%$ \\
\hline - $\quad$ Aussagedelikte & 1.996 & $33 \%$ & 3.994 & $67 \%$ & 5.990 & $100 \%$ \\
\hline - $\quad$ Falsche Verdächtigung & 1.663 & $46 \%$ & 1.973 & $54 \%$ & 3.636 & $100 \%$ \\
\hline - Beleidigung & 3.304 & $17 \%$ & 16.333 & $83 \%$ & 19.637 & $100 \%$ \\
\hline - $\quad$ Nötigung und Bedrohung & 1.250 & $10 \%$ & 11.751 & $90 \%$ & 13.001 & $100 \%$ \\
\hline - Sachbeschädigung & 2.454 & $8 \%$ & 28.561 & $92 \%$ & 31.015 & $100 \%$ \\
\hline $\begin{array}{ll}- & \text { Verstöße gegen AusIG + } \\
& \text { AsylverfG }\end{array}$ & 5.925 & $23 \%$ & 20.221 & $77 \%$ & 26.146 & $100 \%$ \\
\hline - $\quad$ Andere & 10.959 & $15 \%$ & 60.866 & $85 \%$ & 71.825 & $100 \%$ \\
\hline Gesamt & 70.303 & $14 \%$ & 425.711 & $86 \%$ & 496.014 & $100 \%$ \\
\hline
\end{tabular}

* Zeilenprozente 
Tab. 4.2a: Bezugsentscheidung nach Alter und Geschlecht

\begin{tabular}{|c|c|c|c|c|}
\hline \multirow{2}{*}{$\begin{array}{c}\text { Alter zur Tatzeit in } \\
\text { Jahren }\end{array}$} & \multicolumn{2}{|c|}{ Frauen } & \multicolumn{2}{|c|}{ Männer } \\
\hline & mit $\S \S 45,47$ JGG & ohne $\S \S 45,47$ JGG & mit $\S \S 45,47$ JGG & ohne $\S \S 45,47$ JGG \\
\hline 14 & 17.193 & 1.652 & 35.738 & 5.599 \\
\hline 15 & 16.724 & 2.062 & 49.323 & 9.448 \\
\hline 16 & 14.137 & 2.148 & 51.167 & 13.335 \\
\hline 17 & 11.870 & 2.245 & 46.651 & 15.041 \\
\hline 18 & 10.427 & 3.512 & 43.106 & 21.612 \\
\hline 19 & 9.634 & 3.983 & 39.979 & 23.481 \\
\hline 20 & 8.520 & 4.367 & 36.565 & 24.266 \\
\hline 21 & 6.150 & 5.911 & 29.713 & 29.106 \\
\hline 22 & 5.860 & 5.826 & 28.097 & 27.973 \\
\hline 23 & 5.605 & 5.599 & 26.821 & 26.794 \\
\hline 24 & 4.956 & 4.956 & 23.799 & 23.787 \\
\hline 25 & 4.683 & 4.679 & 22.497 & 22.489 \\
\hline 26 & 4.270 & 4.269 & 20.749 & 20.739 \\
\hline 27 & 4.004 & 4.004 & 18.997 & 18.990 \\
\hline 28 & 3.708 & 3.706 & 17.721 & 17.713 \\
\hline 29 & 3.675 & 3.675 & 16.910 & 16.906 \\
\hline 30 & 3.548 & 3.548 & 16.146 & 16.145 \\
\hline 31 & 3.498 & 3.498 & 16.423 & 16.421 \\
\hline 32 & 3.527 & 3.527 & 16.713 & 16.713 \\
\hline 33 & 3.593 & 3.593 & 16.540 & 16.540 \\
\hline 34 & 3.624 & 3.624 & 16.039 & 16.038 \\
\hline 35 & 3.656 & 3.656 & 16.155 & 16.155 \\
\hline 36 & 3.754 & 3.753 & 15.862 & 15.861 \\
\hline 37 & 3.741 & 3.741 & 15.505 & 15.505 \\
\hline 38 & 3.742 & 3.742 & 15.506 & 15.506 \\
\hline 39 & 3.762 & 3.762 & 15.335 & 15.335 \\
\hline \begin{tabular}{|l|}
40 \\
\end{tabular} & 3.720 & 3.720 & 14.694 & 14.694 \\
\hline 41 & 3.741 & 3.741 & 13.958 & 13.958 \\
\hline 42 & 3.529 & 3.529 & 13.239 & 13.239 \\
\hline 43 & 3.379 & 3.379 & 12.459 & 12.459 \\
\hline 44 & 3.065 & 3.065 & 11.673 & 11.673 \\
\hline 45 & 2.840 & 2.840 & 10.783 & 10.783 \\
\hline \begin{tabular}{|l}
46 \\
\end{tabular} & 2.704 & 2.704 & 10.073 & 10.073 \\
\hline 47 & 2.557 & 2.557 & 9.314 & 9.314 \\
\hline \begin{tabular}{|l}
48 \\
\end{tabular} & 2.309 & 2.309 & 8.816 & 8.816 \\
\hline 49 & 2.260 & 2.260 & 8.035 & 8.035 \\
\hline \begin{tabular}{|l}
50 \\
\end{tabular} & 2.058 & 2.058 & 7.604 & 7.604 \\
\hline 51 & 1.917 & 1.917 & 7.029 & 7.029 \\
\hline \begin{tabular}{|l}
52 \\
\end{tabular} & 1.776 & 1.776 & 6.628 & 6.628 \\
\hline 53 & 1.763 & 1.763 & 6.233 & 6.233 \\
\hline
\end{tabular}




\begin{tabular}{|c|c|c|c|c|}
\hline \multirow{2}{*}{\begin{tabular}{|c|}
$\begin{array}{c}\text { Alter zur Tatzeit in } \\
\text { Jahren }\end{array}$ \\
\end{tabular}} & \multicolumn{2}{|c|}{ Frauen } & \multicolumn{2}{|c|}{ Männer } \\
\hline & mit $\$ \S 45,47$ JGG & ohne $\S \S 45,47$ JGG & mit $\S \S 45,47$ JGG & ohne $\S \S 45,47$ JGG \\
\hline 54 & 1.507 & 1.507 & 5.736 & 5.736 \\
\hline 55 & 1.338 & 1.338 & 5.004 & 5.004 \\
\hline 56 & 1.149 & 1.149 & 4.543 & 4.543 \\
\hline 57 & 1.062 & 1.062 & 3.966 & 3.966 \\
\hline 58 & 890 & 890 & 3.388 & 3.388 \\
\hline 59 & 962 & 962 & 3.778 & 3.778 \\
\hline 60 & 873 & 873 & 3.529 & 3.529 \\
\hline 61 & 823 & 823 & 3.148 & 3.148 \\
\hline 62 & 780 & 780 & 3.115 & 3.115 \\
\hline 63 & 761 & 761 & 3.056 & 3.056 \\
\hline 64 & 689 & 689 & 2.599 & 2.599 \\
\hline 65 & 608 & 608 & 2.180 & 2.180 \\
\hline 66 & 492 & 492 & 1.874 & 1.874 \\
\hline 67 & 446 & 446 & 1.551 & 1.551 \\
\hline 68 & 427 & 427 & 1.313 & 1.313 \\
\hline 69 & 355 & 355 & 1.202 & 1.202 \\
\hline 70 & 288 & 288 & 847 & 847 \\
\hline 71 & 249 & 249 & 753 & 753 \\
\hline 72 & 217 & 217 & 733 & 733 \\
\hline 73 & 210 & 210 & 719 & 719 \\
\hline 74 & 186 & 186 & 607 & 607 \\
\hline 75 & 190 & 190 & 524 & 524 \\
\hline 76 & 167 & 167 & 478 & 478 \\
\hline 77 & 166 & 166 & 403 & 403 \\
\hline 78 & 137 & 137 & 329 & 329 \\
\hline 79 & 100 & 100 & 243 & 243 \\
\hline 80 & 103 & 103 & 216 & 216 \\
\hline 81 & 84 & 84 & 191 & 191 \\
\hline 82 & 68 & 68 & 183 & 183 \\
\hline 83 & 60 & 60 & 157 & 157 \\
\hline 84 & 43 & 43 & 114 & 114 \\
\hline 85 & 18 & 18 & 56 & 56 \\
\hline 86 & 18 & 18 & 32 & 32 \\
\hline 87 & 15 & 15 & 20 & 20 \\
\hline 88 & 3 & 3 & 9 & 9 \\
\hline
\end{tabular}


Tab. 4.3a: Gewaltdelikte von Frauen nach Alter mit und ohne Entscheidungen nach $\iint$ 45, 47 $J G G$

\begin{tabular}{|c|c|c|c|c|c|c|c|c|}
\hline \multirow{2}{*}{$\begin{array}{c}\text { Alter zur } \\
\text { Tatzeit in } \\
\text { Jahren }\end{array}$} & \multicolumn{2}{|c|}{ Tötungsdelikte } & \multicolumn{2}{|c|}{ einf. KV } & \multicolumn{2}{|c|}{ sonstige KV } & \multicolumn{2}{|c|}{$\begin{array}{l}\text { sonstige Gewaltde- } \\
\text { likte }\end{array}$} \\
\hline & $\begin{array}{c}\text { mit } \S \S 45, \\
47 \text { JGG }\end{array}$ & $\begin{array}{c}\text { ohne } \\
\$ \S 45,47 \\
\text { JGG }\end{array}$ & $\begin{array}{c}\text { mit } \S \S 45, \\
47 \text { JGG }\end{array}$ & $\begin{array}{c}\text { ohne } \\
\S \S 45,47 \\
\text { JGG }\end{array}$ & $\begin{array}{c}\text { mit } \S \S 45 \\
47 \text { JGG }\end{array}$ & $\begin{array}{c}\text { ohne } \\
\S \S 45,47 \\
\text { JGG }\end{array}$ & $\begin{array}{c}\text { mit } § \S 45, \\
47 \text { JGG }\end{array}$ & $\begin{array}{c}\text { ohne } \\
\S \S 45,47 \\
\text { JGG }\end{array}$ \\
\hline 14 & 4 & 2 & 1.073 & 142 & 1.059 & $\begin{array}{r}262 \\
\end{array}$ & 178 & 77 \\
\hline 15 & 1 & 1 & 1.142 & 177 & 1.010 & 291 & 170 & 91 \\
\hline 16 & 2 & 2 & 897 & 161 & 672 & 226 & 173 & 93 \\
\hline 17 & 5 & 5 & 676 & 154 & 455 & 160 & 96 & 52 \\
\hline 18 & 1 & 1 & 467 & 197 & 302 & 133 & 77 & 43 \\
\hline 19 & 5 & 5 & 371 & 169 & 225 & 108 & 70 & 52 \\
\hline 20 & 2 & 2 & 331 & 188 & 181 & 92 & 44 & 33 \\
\hline 21 & - & - & 171 & 164 & 78 & 74 & 32 & 32 \\
\hline 22 & 3 & 3 & 159 & 156 & 75 & 73 & 40 & 39 \\
\hline 23 & 1 & 1 & 153 & 153 & 58 & 58 & 29 & 29 \\
\hline 24 & 2 & 2 & 121 & 121 & 41 & 41 & 22 & 22 \\
\hline 25 & 1 & 1 & 106 & 106 & 40 & 40 & 19 & 19 \\
\hline 26 & - & - & 115 & 115 & 44 & 44 & 20 & 20 \\
\hline 27 & 1 & 1 & 110 & 110 & 29 & 29 & 20 & 20 \\
\hline 28 & 1 & 1 & 103 & 103 & 37 & 36 & 12 & 12 \\
\hline 29 & 4 & 4 & 89 & 89 & 37 & 37 & 12 & 12 \\
\hline 30 & 2 & 2 & 101 & 101 & 23 & 23 & 18 & 18 \\
\hline 31 & 1 & 1 & 97 & 97 & 37 & 37 & 13 & 13 \\
\hline 32 & 3 & 3 & 107 & 107 & 37 & 37 & 21 & 21 \\
\hline 33 & - & - & 103 & 103 & 45 & 45 & 21 & 21 \\
\hline 34 & 3 & 3 & 119 & 119 & 34 & 34 & 15 & 15 \\
\hline 35 & 4 & 4 & 119 & 119 & 23 & 23 & 20 & 20 \\
\hline 36 & 1 & 1 & 115 & 115 & 37 & 37 & 22 & 22 \\
\hline 37 & 3 & 3 & 105 & 105 & 32 & 32 & 13 & 13 \\
\hline 38 & 3 & 3 & 105 & 105 & 37 & 37 & 13 & 13 \\
\hline 39 & 3 & 3 & 107 & 107 & 41 & 41 & 22 & 22 \\
\hline 40 & 2 & 2 & 100 & 100 & 33 & 33 & 22 & 22 \\
\hline 41 & 2 & 2 & 104 & 104 & 28 & 28 & 7 & 7 \\
\hline 42 & 2 & 2 & 93 & 93 & 24 & 24 & 13 & 13 \\
\hline 43 & 2 & 2 & 92 & 92 & 29 & 29 & 10 & 10 \\
\hline 44 & - & - & 61 & 61 & 18 & 18 & 15 & 15 \\
\hline 45 & 1 & 1 & 74 & 74 & 19 & 19 & 13 & 13 \\
\hline 46 & - & - & 54 & 54 & 17 & 17 & 8 & 8 \\
\hline \begin{tabular}{|l|}
47 \\
\end{tabular} & 2 & 2 & 53 & 53 & 19 & 19 & 9 & 9 \\
\hline 48 & - & - & 50 & 50 & 16 & 16 & 6 & 6 \\
\hline 49 & 1 & 1 & 56 & 56 & 10 & 10 & 8 & 8 \\
\hline 50 & 2 & 2 & 38 & 38 & 16 & 16 & 7 & 7 \\
\hline 51 & 3 & 3 & 55 & 55 & 14 & 14 & 10 & 10 \\
\hline 52 & - & - & 43 & 43 & 9 & 9 & 3 & 3 \\
\hline 53 & 2 & 2 & 36 & 36 & 10 & 10 & 7 & 7 \\
\hline 54 & 3 & 3 & 27 & 27 & 11 & 11 & 2 & 2 \\
\hline
\end{tabular}




\begin{tabular}{|c|c|c|c|c|c|c|c|c|}
\hline \multirow{2}{*}{$\begin{array}{c}\text { Alter zur } \\
\text { Tatzeit in } \\
\text { Jahren }\end{array}$} & \multicolumn{2}{|c|}{ Tötungsdelikte } & \multicolumn{2}{|c|}{ einf. KV } & \multicolumn{2}{|c|}{ sonstige KV } & \multicolumn{2}{|c|}{$\begin{array}{l}\text { Sonstige Gewaltde- } \\
\text { likte }\end{array}$} \\
\hline & $\begin{array}{c}\text { mit } \S \S 45 \\
47 \text { JGG }\end{array}$ & $\begin{array}{c}\text { ohne } \\
\S \S 45,47 \\
\text { JGG }\end{array}$ & $\begin{array}{c}\text { mit } \S \S 45 \\
47 \text { JGG }\end{array}$ & $\begin{array}{c}\text { ohne } \\
\S \S 45,47 \\
\text { JGG }\end{array}$ & $\begin{array}{c}\text { mit } \S \S 45, \\
47 \text { JGG }\end{array}$ & \begin{tabular}{|c} 
ohne \\
$\S \S 45,47$ \\
JGG
\end{tabular} & $\begin{array}{c}\text { mit } \S \S 45 \\
47 \text { JGG }\end{array}$ & $\begin{array}{c}\text { ohne } \\
\S \S 45,47 \\
\text { JGG }\end{array}$ \\
\hline 55 & - & - & 34 & $\begin{array}{r}34 \\
\end{array}$ & 5 & 5 & 2 & 2 \\
\hline 56 & - & - & 25 & 25 & 9 & 9 & 2 & 2 \\
\hline 57 & - & - & 19 & 19 & 5 & 5 & 2 & 2 \\
\hline 58 & - & - & 16 & 16 & 4 & 4 & 5 & 5 \\
\hline 59 & - & - & 31 & 31 & 4 & 4 & 1 & 1 \\
\hline 60 & 2 & 2 & 28 & 28 & 4 & 4 & - & - \\
\hline 61 & - & - & 24 & 24 & 1 & 1 & 4 & 4 \\
\hline 62 & - & - & 30 & 30 & 1 & 1 & 1 & 1 \\
\hline 63 & - & & 29 & 29 & 6 & 6 & 2 & 2 \\
\hline 64 & - & - & 25 & 25 & 3 & 3 & 2 & 2 \\
\hline 65 & - & & 25 & 25 & 3 & 3 & - & - \\
\hline 66 & - & & 18 & 18 & 2 & 2 & 2 & 2 \\
\hline 67 & - & - & 20 & 20 & 4 & 4 & - & - \\
\hline 68 & - & - & 18 & 18 & 1 & 1 & - & - \\
\hline 69 & - & & 10 & 10 & 1 & 1 & - & - \\
\hline 70 & - & - & 12 & 12 & 2 & 2 & - & - \\
\hline 71 & - & - & 13 & 13 & - & - & 1 & 1 \\
\hline 72 & - & - & 10 & 10 & 1 & 1 & - & - \\
\hline 73 & - & - & 8 & 8 & 1 & 1 &. & 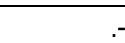 \\
\hline 74 & - & & 8 & 8 & - & . & - & - \\
\hline 75 & - & - & 12 & 12 & 1 & 1 & 1 & 1 \\
\hline 76 & - & - & 9 & 9 & - & . & - & - \\
\hline 77 & - & - & 7 & 7 & - & - & - & - \\
\hline 78 & - & - & 7 & 7 & - & . & - & \\
\hline 79 & - & - & 6 & 6 & - & . & - & \\
\hline 80 & 1 & 1 & 6 & 6 & - & - & - & . \\
\hline 81 & - & - & 5 & 5 & - & . & - & \\
\hline 82 & - & - & 3 & 3 & - & . & - & . \\
\hline 83 & - & - & 8 & 8 & - & . & - & . \\
\hline 84 & - & & 4 & 4 & - & . & 4 & \\
\hline 85 & - & - & 1 & 1 & - & - & - & \\
\hline
\end{tabular}


Tab. 4.3b: Vermögensdelikte i.w.S. von Frauen nach Alter mit und ohne $\iint 45,47 J G G$

\begin{tabular}{|c|c|c|c|c|c|c|c|c|}
\hline \multirow{2}{*}{$\begin{array}{c}\text { Alter zur } \\
\text { Tatzeit in } \\
\text { Jahren }\end{array}$} & \multicolumn{2}{|c|}{$\begin{array}{l}\text { Bes. schwerer und } \\
\text { qualif. Diebstahl }\end{array}$} & \multicolumn{2}{|c|}{$\begin{array}{l}\text { Einf. Diebstahl und } \\
\text { Unterschlagung }\end{array}$} & \multicolumn{2}{|c|}{ Betrug u.a. } & \multicolumn{2}{|c|}{$\begin{array}{c}\text { Erschleichen } v \text {. Leis- } \\
\text { tungen }\end{array}$} \\
\hline & $\begin{array}{c}\text { mit } \S \S 45, \\
47 \mathrm{JGG}\end{array}$ & \begin{tabular}{|c} 
ohne $\$ \S$, \\
45,47 JGG
\end{tabular} & $\begin{array}{c}\text { mit } \S \S 45, \\
47 \text { JGG }\end{array}$ & \begin{tabular}{|} 
ohne §§, \\
45,47 JGG
\end{tabular} & \begin{tabular}{|c|}
$\operatorname{mit} \S \S 45$, \\
$47 \mathrm{JGG}$
\end{tabular} & $\begin{array}{c}\text { ohne } \S \S, \\
45,47 \text { JGG }\end{array}$ & $\begin{array}{c}\text { mit } \S \S 45 \\
47 \text { JGG }\end{array}$ & $\begin{array}{c}\text { ohne } \S \S, \\
45,47 \text { JGG }\end{array}$ \\
\hline 14 & 231 & 82 & 10.666 & 738 & 454 & 51 & 673 & 35 \\
\hline 15 & 220 & 90 & 8.882 & 807 & 729 & 74 & 896 & 80 \\
\hline \begin{tabular}{|l|}
16 \\
\end{tabular} & 210 & 104 & 6.605 & 824 & 786 & 105 & 1.136 & 145 \\
\hline 17 & 180 & 110 & 4.683 & 730 & 888 & 192 & 1.401 & 258 \\
\hline \begin{tabular}{|l|}
18 \\
\end{tabular} & 149 & 93 & 3.283 & 878 & 1.176 & 461 & 1.395 & 407 \\
\hline \begin{tabular}{|l|}
19 \\
\end{tabular} & 116 & 85 & 2.696 & 873 & 1.427 & 688 & 1.421 & 539 \\
\hline 20 & 103 & 76 & 2.201 & 874 & 1.445 & 867 & 1.228 & 532 \\
\hline 21 & 66 & 64 & 1.303 & 1.274 & 1.427 & 1.381 & 873 & 784 \\
\hline 22 & 52 & 52 & 1.233 & 1.231 & 1.430 & 1.424 & 741 & 728 \\
\hline 23 & 46 & 46 & 1.193 & 1.191 & 1.402 & 1.401 & 635 & 635 \\
\hline 24 & 48 & 48 & 1.014 & 1.014 & 1.300 & 1.300 & 504 & 504 \\
\hline 25 & 64 & 64 & 1.038 & 1.036 & 1.251 & 1.251 & 392 & 392 \\
\hline 26 & 49 & 49 & 943 & 943 & 1.098 & 1.098 & 346 & 346 \\
\hline 27 & 35 & 35 & 859 & 859 & 1.018 & 1.018 & 289 & 289 \\
\hline 28 & 39 & 39 & 798 & 798 & 965 & 965 & 258 & 258 \\
\hline 29 & 30 & 30 & 796 & 796 & 998 & 998 & 216 & 216 \\
\hline 30 & 31 & 31 & 825 & 825 & 928 & 928 & 189 & 189 \\
\hline 31 & 35 & 35 & 749 & 749 & 932 & 932 & 214 & 214 \\
\hline 32 & 26 & 26 & 784 & 784 & 938 & 938 & 145 & 145 \\
\hline 33 & 25 & 25 & 787 & 787 & 941 & 941 & 188 & 188 \\
\hline 34 & 27 & 27 & 741 & 741 & 932 & 932 & 185 & 185 \\
\hline 35 & 25 & 25 & 766 & 766 & 883 & 883 & 178 & 178 \\
\hline 36 & 23 & 23 & 824 & 823 & 943 & 943 & 168 & 168 \\
\hline \begin{tabular}{|l|}
37 \\
\end{tabular} & 17 & 17 & 799 & 799 & 910 & 910 & 151 & 151 \\
\hline 38 & 20 & 20 & 793 & 793 & 920 & 920 & 127 & 127 \\
\hline 39 & 17 & 17 & 831 & 831 & 961 & 961 & 154 & 154 \\
\hline 40 & 16 & 16 & 772 & 772 & 914 & 914 & 136 & 136 \\
\hline 41 & 13 & 13 & 781 & 781 & 894 & 894 & 148 & 148 \\
\hline \begin{tabular}{|l|}
42 \\
\end{tabular} & 12 & 12 & 772 & 772 & 820 & 820 & 150 & 150 \\
\hline \begin{tabular}{|l|}
43 \\
\end{tabular} & 14 & 14 & 734 & 734 & 774 & 774 & 134 & 134 \\
\hline 44 & 14 & 14 & 688 & 688 & 678 & 678 & 118 & 118 \\
\hline 45 & 13 & 13 & 639 & 639 & 629 & 629 & 90 & 90 \\
\hline \begin{tabular}{|l|}
46 \\
\end{tabular} & 11 & 11 & 623 & 623 & 623 & 623 & 100 & 100 \\
\hline \begin{tabular}{|l|}
47 \\
\end{tabular} & 9 & 9 & 628 & 628 & 588 & 588 & 82 & 82 \\
\hline 4 & 5 & 5 & 581 & 581 & 559 & 559 & 72 & 72 \\
\hline 49 & 3 & 3 & 597 & 597 & 501 & 501 & 77 & 77 \\
\hline 50 & 7 & 7 & 531 & 531 & 480 & 480 & 62 & 62 \\
\hline 51 & 3 & 3 & 510 & 510 & 417 & 417 & 59 & 59 \\
\hline 52 & 1 & 1 & 472 & 472 & 410 & 410 & 40 & 40 \\
\hline 53 & 6 & 6 & 516 & 516 & 418 & 418 & 50 & 50 \\
\hline 54 & 7 & 7 & 438 & 438 & 340 & 340 & 44 & 44 \\
\hline 55 & 4 & 4 & 439 & 439 & 258 & 258 & 34 & 34 \\
\hline 56 & 2 & 2 & 397 & 397 & 216 & 216 & 29 & 29 \\
\hline 57 & 4 & 4 & 345 & 345 & 193 & 193 & 28 & 28 \\
\hline 58 & 2 & 2 & 303 & 303 & 147 & 147 & 22 & 22 \\
\hline 59 & 1 & 1 & 347 & 347 & 140 & 140 & 15 & 15 \\
\hline 60 & 1 & 1 & 330 & 330 & 124 & 124 & 10 & 10 \\
\hline 61 & 2 & 2 & 311 & 311 & 106 & 106 & 10 & 10 \\
\hline 62 & 1 & 1 & 325 & 32 & 78 & 78 & 6 & \\
\hline
\end{tabular}


Tabellenanhang

\begin{tabular}{|c|c|c|c|c|c|c|c|c|}
\hline \multirow{2}{*}{$\begin{array}{c}\text { Alter zur } \\
\text { Tatzeit in } \\
\text { Jahren }\end{array}$} & \multicolumn{2}{|c|}{$\begin{array}{l}\text { Bes. schwerer und } \\
\text { qualif. Diebstahl }\end{array}$} & \multicolumn{2}{|c|}{$\begin{array}{l}\text { Einf. Diebstahl und } \\
\text { Unterschlagung }\end{array}$} & \multicolumn{2}{|c|}{ Betrug u.a. } & \multicolumn{2}{|c|}{$\begin{array}{l}\text { Erschleichen v. Leis- } \\
\text { tungen }\end{array}$} \\
\hline & $\begin{array}{c}\operatorname{mit} \S \S 45, \\
47 \mathrm{JGG}\end{array}$ & $\begin{array}{c}\text { ohne } \S \S \\
45, \\
47 \text { JGG }\end{array}$ & $\begin{array}{c}\operatorname{mit} \S \S 45, \\
47 \text { JGG }\end{array}$ & $\begin{array}{c}\text { ohne } \S \S \\
45,47 \text { JGG }\end{array}$ & $\begin{array}{c}\operatorname{mit} \S \S 45, \\
47 \text { JGG }\end{array}$ & $\begin{array}{c}\text { ohne } \S \S \\
45,47 \mathrm{JGG}\end{array}$ & $\begin{array}{c}\operatorname{mit} \S \S 45, \\
47 \text { JGG }\end{array}$ & $\begin{array}{c}\text { ohne } \$ \S \\
45,47 \mathrm{JGG}\end{array}$ \\
\hline 63 & 2 & 2 & 298 & 298 & 73 & 73 & 15 & 15 \\
\hline \begin{tabular}{|l|}
64 \\
\end{tabular} & 1 & 1 & 292 & 292 & 69 & 69 & 8 & 8 \\
\hline 65 & 5 & 5 & 268 & 268 & 51 & 51 & 3 & 3 \\
\hline 66 & -1 & -1 & 217 & 217 & 48 & 48 & 6 & 6 \\
\hline \begin{tabular}{|l|}
67 \\
\end{tabular} & 1 & 1 & 197 & 197 & 38 & 38 & 3 & 3 \\
\hline 68 & - & - & 180 & 180 & 37 & 37 & 4 & 4 \\
\hline 69 & 1 & 1 & 160 & 160 & 26 & 26 & 6 & 6 \\
\hline 70 & 1 & 1 & 131 & 131 & 16 & 16 & 3 & 3 \\
\hline 71 & - & - & 115 & 115 & 17 & 17 & 2 & 2 \\
\hline \begin{tabular}{|l|}
72 \\
\end{tabular} & - & -1 & 91 & 91 & 19 & 19 & 2 & 2 \\
\hline 73 & 1 & 1 & 99 & 99 & 9 & 9 & 2 & 2 \\
\hline 74 & - & - & 80 & 80 & 9 & 9 & - & \\
\hline \begin{tabular}{|l|}
75 \\
\end{tabular} & - & -1 & 88 & 88 & 9 & 9 & 2 & 2 \\
\hline 76 & -1 & -1 & 62 & 62 & 8 & 8 & 1 & \\
\hline \begin{tabular}{|l}
777 \\
\end{tabular} & - & - & 67 & 67 & 6 & 6 & - & \\
\hline 78 & -1 & -1 & 51 & 51 & 3 & 3 & - & \\
\hline \begin{tabular}{|l|}
79 \\
\end{tabular} & - & - & 32 & 32 & 3 & 3 & - & \\
\hline 80 & - & -1 & 33 & 33 & 1 & 1 & 1 & 1 \\
\hline 81 & 1 & 1 & 30 & 30 & 1 & 1 & 2 & 2 \\
\hline 82 & - & -1 & 25 & 25 & -1 & - & - & \\
\hline \begin{tabular}{|l|}
83 \\
\end{tabular} & -1 & -1 & 17 & 17 & - & - & - & \\
\hline 84 & - & - & 12 & 12 & 2 & 2 & - & \\
\hline 85 & - & 82 & 7 & 7 & - & + & - & \\
\hline
\end{tabular}


Tab. 4.3c: Sonstige Delikte von Frauen nach Alter mit und obne $\iiint 45,47$ JGG

\begin{tabular}{|c|c|c|c|c|c|c|c|c|}
\hline \multirow{2}{*}{$\begin{array}{c}\text { Alter zur } \\
\text { Tatzeit in } \\
\text { Jahren }\end{array}$} & \multicolumn{2}{|c|}{$\begin{array}{c}\text { Fahrlässige Tötung } \\
\text { und fahrlässige Kör- } \\
\text { perverletzung }\end{array}$} & \multicolumn{2}{|c|}{$\begin{array}{l}\text { Verkehrsdelikte ohne } \\
\text { Alkoholeinfluss }\end{array}$} & \multicolumn{2}{|c|}{$\begin{array}{l}\text { Verkehrsdelikte mit } \\
\text { Alkoholeinfluss }\end{array}$} & \multicolumn{2}{|c|}{ Delikte nach BtMG } \\
\hline & $\begin{array}{c}\text { mit } \S \S \\
45,47 \text { JGG }\end{array}$ & \begin{tabular}{|c} 
ohne $\S \S$ \\
45,47 JGG
\end{tabular} & $\begin{array}{c}\text { mit } \S \S \\
45,47 \text { JGG }\end{array}$ & \begin{tabular}{|c|} 
ohne $\S \S$ \\
45,47 JGG
\end{tabular} & $\begin{array}{c}\text { mit } \S \S 45, \\
47 \text { JGG }\end{array}$ & $\begin{array}{c}\text { ohne } \S \S \\
45,47 \text { JGG }\end{array}$ & $\begin{array}{c}\operatorname{mit} \S \S 45 \\
47 \mathrm{JGG}\end{array}$ & $\begin{array}{c}\text { ohne } \S \S \\
45,47 \text { JGG }\end{array}$ \\
\hline 14 & 45 & 1 & 171 & 16 & 7 & 5 & 321 & 36 \\
\hline 15 & 54 & 3 & 731 & 53 & 17 & 7 & 543 & 78 \\
\hline 16 & 57 & 5 & 825 & 73 & 19 & 8 & 605 & 113 \\
\hline 17 & 49 & 8 & 902 & 85 & 29 & 15 & 642 & 186 \\
\hline 18 & 222 & 70 & 1.119 & 424 & 167 & 152 & 616 & 229 \\
\hline 19 & 184 & 76 & 847 & 374 & 224 & 211 & 588 & 272 \\
\hline 20 & 158 & 82 & 646 & 350 & 307 & 301 & 576 & 337 \\
\hline 21 & 81 & 79 & 477 & 472 & 320 & 320 & 357 & 339 \\
\hline 22 & 84 & 84 & 455 & 454 & 334 & 334 & 336 & 334 \\
\hline 23 & 52 & 52 & 444 & 444 & 325 & 325 & 310 & 309 \\
\hline 24 & 69 & 69 & 371 & 371 & 300 & 300 & 267 & 267 \\
\hline 25 & 56 & 56 & 367 & 367 & 312 & 312 & 195 & 195 \\
\hline 26 & 57 & 57 & 344 & 344 & 281 & 281 & 181 & 181 \\
\hline 27 & 59 & 59 & 339 & 339 & 282 & 282 & 163 & 163 \\
\hline 28 & 59 & 59 & 288 & 288 & 243 & 243 & 148 & 148 \\
\hline 29 & 46 & 46 & 319 & 319 & 263 & 263 & 116 & 116 \\
\hline 30 & 57 & 57 & 257 & 257 & 280 & 280 & 120 & 120 \\
\hline 31 & 40 & 40 & 282 & 282 & 248 & 248 & 118 & 118 \\
\hline 32 & 43 & 43 & 292 & 292 & 315 & 315 & 101 & 101 \\
\hline 33 & 49 & 49 & 301 & 301 & 330 & 330 & 117 & 117 \\
\hline 34 & 45 & 45 & 296 & 296 & 337 & 337 & 116 & 116 \\
\hline 35 & 53 & 53 & 307 & 307 & 426 & 426 & 99 & 99 \\
\hline 36 & 63 & 63 & 325 & 325 & 391 & 391 & 99 & 99 \\
\hline 37 & 61 & 61 & 323 & 323 & 446 & 446 & 115 & 115 \\
\hline 38 & 75 & 75 & 333 & 333 & 458 & 458 & 89 & 89 \\
\hline 39 & 45 & 45 & 319 & 319 & 422 & 422 & 89 & 89 \\
\hline 40 & 62 & 62 & 330 & 330 & 456 & 456 & 80 & 80 \\
\hline \begin{tabular}{|l|}
411 \\
\end{tabular} & 59 & 59 & 333 & 333 & 491 & 491 & 66 & 66 \\
\hline 42 & 49 & 49 & 302 & 302 & 498 & 498 & 61 & 61 \\
\hline 43 & 45 & 45 & 296 & 296 & 452 & 452 & 65 & 65 \\
\hline 44 & 49 & 49 & 274 & 274 & 386 & 386 & 40 & 40 \\
\hline 45 & 51 & 51 & 242 & 242 & 426 & 426 & 38 & 38 \\
\hline 46 & 44 & 44 & 233 & 233 & 350 & 350 & 30 & 30 \\
\hline 47 & 39 & 39 & 225 & 225 & 312 & 312 & 27 & 27 \\
\hline 48 & 27 & 27 & 189 & 189 & 300 & 300 & 17 & 17 \\
\hline \begin{tabular}{|l|l}
49 \\
\end{tabular} & 29 & 29 & 195 & 195 & 304 & 304 & 22 & 22 \\
\hline 50 & 42 & 42 & 198 & 198 & 256 & 256 & 15 & 15 \\
\hline 51 & 40 & 40 & 181 & 181 & 237 & 237 & 8 & 8 \\
\hline 52 & 41 & 41 & 160 & 160 & 208 & 208 & 8 & 8 \\
\hline 53 & 31 & 31 & 170 & 170 & 201 & 201 & 5 & 5 \\
\hline 54 & 24 & 24 & 172 & 172 & 152 & 152 & 9 & 9 \\
\hline 55 & 26 & 26 & 147 & 147 & 138 & 138 & 6 & 6 \\
\hline \begin{tabular}{|l|}
56 \\
\end{tabular} & 20 & 20 & 124 & 124 & 133 & 133 & 4 & 4 \\
\hline 57 & 26 & 26 & 126 & 126 & 135 & 135 & 4 & 4 \\
\hline 58 & 18 & 18 & 112 & 112 & 110 & 110 & 1 & 1 \\
\hline 59 & 24 & 24 & 121 & 121 & 123 & 123 & 3 & 3 \\
\hline 60 & 23 & 23 & 121 & 121 & 114 & 114 & 3 & 3 \\
\hline 61 & 18 & 18 & 109 & 109 & 110 & 110 & 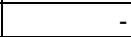 & \\
\hline
\end{tabular}




\begin{tabular}{|c|c|c|c|c|c|c|c|c|}
\hline \multirow{2}{*}{$\begin{array}{c}\text { Alter zur } \\
\text { Tatzeit in } \\
\text { Jahren }\end{array}$} & \multicolumn{2}{|c|}{$\begin{array}{c}\text { Fahrlässige Tötung } \\
\text { und fahrlässige Kör- } \\
\text { perverletzung }\end{array}$} & \multicolumn{2}{|c|}{$\begin{array}{l}\text { Verkehrsdelikte ohne } \\
\text { Alkoholeinfluss }\end{array}$} & \multicolumn{2}{|c|}{$\begin{array}{l}\text { Verkehrsdelikte mit } \\
\text { Alkoholeinfluss }\end{array}$} & \multicolumn{2}{|c|}{ Delikte nach BtMG } \\
\hline & $\begin{array}{c}\text { mit } \S \S \\
45,47 \text { JGG } \\
\end{array}$ & $\begin{array}{c}\text { ohne } \S \S \\
45,47 \text { JGG }\end{array}$ & $\begin{array}{c}\text { mit } \S \S \\
45,47 \mathrm{JGG}\end{array}$ & $\begin{array}{c}\text { ohne } \S \S \\
45,47 \text { JGG }\end{array}$ & $\begin{array}{c}\text { mit } \S \S \\
45,47 \mathrm{JGG}\end{array}$ & $\begin{array}{c}\text { ohne } \S \S \\
45,47 \text { JGG }\end{array}$ & $\begin{array}{c}\text { mit } \S \S \\
45,47 \text { JGG }\end{array}$ & $\begin{array}{c}\text { ohne } \S \S \\
45,47 \text { JGG }\end{array}$ \\
\hline 62 & 19 & 19 & 121 & 121 & 90 & 90 & 1 & 1 \\
\hline 63 & 20 & 20 & 114 & 114 & 89 & 89 & 3 & 3 \\
\hline 64 & 21 & 21 & 104 & 104 & 77 & 77 & - & \\
\hline 65 & 13 & 13 & 101 & 101 & 66 & 66 & 1 & 1 \\
\hline 66 & 10 & 10 & 84 & 84 & 45 & 45 & - & \\
\hline 67 & 21 & 21 & 76 & 76 & 36 & 36 & - & \\
\hline 68 & 14 & 14 & 76 & 76 & 44 & 44 & - & \\
\hline 69 & 8 & 8 & 95 & 95 & 18 & 18 & - & \\
\hline 70 & 12 & 12 & 72 & 72 & 12 & 12 & -1 & \\
\hline 71 & 9 & 9 & 57 & 57 & 11 & 11 & - & \\
\hline 72 & 8 & 8 & 60 & 60 & 6 & 6 & 1 & 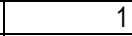 \\
\hline 73 & 5 & 5 & 59 & 59 & 6 & 6 & -1 & \\
\hline 74 & 8 & 8 & 58 & 58 & 9 & 9 & - & \\
\hline 75 & 5 & 5 & 54 & 54 & 4 & 4 & - & \\
\hline 76 & 12 & 12 & 58 & 58 & 5 & 5 & 7 & \\
\hline 77 & 8 & 8 & 56 & 56 & 7 & 7 & 1 & \\
\hline 78 & 6 & 6 & 55 & 55 & 4 & 4 & 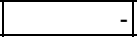 & \\
\hline 79 & 5 & 5 & 45 & 45 & - & - & - & \\
\hline 80 & 8 & 8 & 43 & 43 & 3 & 3 & -1 & \\
\hline 81 & 4 & 4 & 32 & 32 & 2 & 2 & 1 & 1 \\
\hline 82 & 2 & 2 & 29 & 29 & 2 & 2 & -1 & \\
\hline 83 & 1 & 1 & 32 & 32 & - & - & - & \\
\hline 84 & 2 & 2 & 22 & 22 & 1 & 1 & & \\
\hline 85 & 1 & 1 & 9 & 9 & & & 1 & \\
\hline
\end{tabular}


Tab. 4.4a: Deliktsstruktur von nichtdeutschen Frauen und Männern

\begin{tabular}{|c|c|c|c|c|c|c|}
\hline & \multicolumn{2}{|c|}{ Frauen } & \multicolumn{2}{|c|}{ Männer } & \multicolumn{2}{|c|}{ Gesamt } \\
\hline & abs. & in $\%$ & abs. & in $\%$ & abs. & in $\%$ \\
\hline Tötungsdelikte & 16 & $0 \%$ & 218 & $0 \%$ & 234 & $0 \%$ \\
\hline Einf. KV & 1.118 & $3 \%$ & 9.247 & $6 \%$ & 10.365 & $5 \%$ \\
\hline Sonst. KV-Delikte & 750 & $2 \%$ & 6.456 & $4 \%$ & 7.206 & $4 \%$ \\
\hline $\begin{array}{l}\text { Sonst. Gewaltdelik- } \\
\text { te }\end{array}$ & 219 & $1 \%$ & 3.983 & $3 \%$ & 4.202 & $2 \%$ \\
\hline $\begin{array}{l}\text { Bes. schwerer u. } \\
\text { qualif. Diebstahl }\end{array}$ & 437 & $1 \%$ & 5.421 & $4 \%$ & 5.858 & $3 \%$ \\
\hline $\begin{array}{l}\text { Einf. Diebstahl u. } \\
\text { Unterschlagung }\end{array}$ & 13.986 & $39 \%$ & 25.637 & $17 \%$ & 39.623 & $21 \%$ \\
\hline Betrug u.a. & 5.145 & $15 \%$ & 19.244 & $13 \%$ & 24.389 & $13 \%$ \\
\hline Erschl.v. Leistugen & 2.454 & $7 \%$ & 7.270 & $5 \%$ & 9.724 & $5 \%$ \\
\hline $\begin{array}{l}\text { Fahrl. KV u. fahrl. } \\
\text { Tötung } \\
\end{array}$ & 235 & $1 \%$ & 1.545 & $1 \%$ & 1.780 & $1 \%$ \\
\hline $\begin{array}{l}\text { Verkehrsdelikte } 0 . \\
\text { Alkoholeinfluss }\end{array}$ & 2.091 & $6 \%$ & 16.872 & $11 \%$ & 18.963 & $10 \%$ \\
\hline $\begin{array}{l}\text { Verkehrsdelikte m. } \\
\text { Alkoholeinfluss } \\
\end{array}$ & 906 & $3 \%$ & 11.037 & $7 \%$ & 11.943 & $6 \%$ \\
\hline Delikte n. BtMG & 653 & $2 \%$ & 11.170 & $7 \%$ & 11.823 & $6 \%$ \\
\hline $\begin{array}{l}\text { Verstöße gg. AusIG } \\
+ \text { AsylverfG }\end{array}$ & 5.163 & $15 \%$ & 18.123 & $12 \%$ & 23.286 & $12 \%$ \\
\hline Sonst. Delikte & 2.280 & $6 \%$ & 17.616 & $11 \%$ & 19.896 & $11 \%$ \\
\hline Gesamt & 35.453 & $100 \%$ & 153.839 & $100 \%$ & 189.292 & $100 \%$ \\
\hline
\end{tabular}


Tab. 4.5a: Bezugsentscheidung nach Alter und Nationalität

\begin{tabular}{|c|c|c|c|c|}
\hline \multirow{2}{*}{$\begin{array}{l}\text { Alter zur Tatzeit in } \\
\text { Jahren }\end{array}$} & \multicolumn{2}{|c|}{ Nichtdeutsche Frauen } & \multicolumn{2}{|c|}{ Deutsche Frauen } \\
\hline & mit $§ \S 45,47$ JGG & $\begin{array}{c}\text { ohne } \$ \S 45,47 \\
\text { JGG }\end{array}$ & mit $\S \S 45,47$ JGG & $\begin{array}{c}\text { ohne } \$ \S 45,47 \\
\text { JGG }\end{array}$ \\
\hline 14 & 1.995 & 262 & 15.037 & 1.370 \\
\hline 15 & 1.948 & 296 & 14.628 & 1.748 \\
\hline 16 & 1.889 & 340 & 12.088 & 1.789 \\
\hline 17 & 1.619 & 281 & 10.134 & 1.937 \\
\hline 18 & 1.510 & 476 & 8.800 & 3.004 \\
\hline 19 & 1.614 & 594 & 7.931 & 3.363 \\
\hline 20 & 1.553 & 706 & 6.887 & 3.631 \\
\hline 21 & 1.145 & 1.100 & 4.950 & 4.761 \\
\hline 22 & 1.173 & 1.168 & 4.646 & 4.618 \\
\hline 23 & 1.222 & 1.219 & 4.318 & 4.315 \\
\hline 24 & 1.174 & 1.174 & 3.732 & 3.732 \\
\hline 25 & 1.167 & 1.164 & 3.461 & 3.460 \\
\hline 26 & 1.138 & 1.138 & 3.090 & 3.089 \\
\hline 27 & 1.132 & 1.132 & 2.828 & 2.828 \\
\hline 28 & 1.112 & 1.111 & 2.534 & 2.534 \\
\hline 29 & 1.118 & 1.118 & 2.514 & 2.514 \\
\hline 30 & 1.025 & 1.025 & 2.477 & 2.477 \\
\hline 31 & 991 & 991 & 2.460 & 2.460 \\
\hline 32 & 908 & 908 & 2.577 & 2.577 \\
\hline 33 & 918 & 918 & 2.632 & 2.632 \\
\hline 34 & 896 & 896 & 2.698 & 2.698 \\
\hline 35 & 833 & 833 & 2.788 & 2.788 \\
\hline 36 & 712 & 711 & 3.015 & 3.015 \\
\hline 37 & 711 & 711 & 2.990 & 2.990 \\
\hline 38 & 638 & 638 & 3.073 & 3.073 \\
\hline 39 & 651 & 651 & 3.083 & 3.083 \\
\hline 40 & 576 & 576 & 3.120 & 3.120 \\
\hline 41 & 587 & 587 & 3.133 & 3.133 \\
\hline 42 & 524 & 524 & 2.973 & 2.973 \\
\hline 43 & 555 & 555 & 2.801 & 2.801 \\
\hline 44 & 456 & 456 & 2.576 & 2.576 \\
\hline 45 & 405 & 405 & 2.407 & 2.407 \\
\hline 46 & 419 & 419 & 2.264 & 2.264 \\
\hline 47 & 377 & 377 & 2.164 & 2.164 \\
\hline 48 & 392 & 392 & 1.900 & 1.900 \\
\hline 49 & 334 & 334 & 1.899 & 1.899 \\
\hline 50 & 293 & 293 & 1.744 & 1.744 \\
\hline 51 & 308 & 308 & 1.593 & 1.593 \\
\hline 52 & 287 & 287 & 1.461 & 1.461 \\
\hline 53 & 233 & 233 & 1.508 & 1.508 \\
\hline
\end{tabular}




\begin{tabular}{|c|c|c|c|c|}
\hline \multirow{2}{*}{$\begin{array}{l}\text { Alter zur Tatzeit in } \\
\text { Jahren }\end{array}$} & \multicolumn{2}{|c|}{ Nichtdeutsche Frauen } & \multicolumn{2}{|c|}{ Deutsche Frauen } \\
\hline & mit $\S \S 45,47$ JGG & $\begin{array}{c}\text { ohne } \$ \S 45,47 \\
\text { JGG }\end{array}$ & mit $\S \S 45,47$ JGG & $\begin{array}{c}\text { ohne } \$ \S 45,47 \\
\text { JGG }\end{array}$ \\
\hline 54 & 232 & 232 & 1.266 & 1.266 \\
\hline 55 & 230 & 230 & 1.098 & 1.098 \\
\hline 56 & 165 & 165 & 972 & 972 \\
\hline 57 & 141 & 141 & 912 & 912 \\
\hline 58 & 135 & 135 & 752 & 752 \\
\hline 59 & 91 & 91 & 865 & 865 \\
\hline 60 & 67 & 67 & 798 & 798 \\
\hline 61 & 60 & 60 & 758 & 758 \\
\hline 62 & 64 & 64 & 715 & 715 \\
\hline 63 & 68 & 68 & 690 & 690 \\
\hline 64 & 43 & 43 & 644 & 644 \\
\hline 65 & 40 & 40 & 566 & 566 \\
\hline 66 & 29 & 29 & 459 & 459 \\
\hline 67 & 37 & 37 & 407 & 407 \\
\hline 68 & 25 & 25 & 396 & 396 \\
\hline 69 & 20 & 20 & 334 & 334 \\
\hline 70 & 15 & 15 & 269 & 269 \\
\hline 71 & 22 & 22 & 224 & 224 \\
\hline 72 & 16 & 16 & 198 & 198 \\
\hline 73 & 9 & 9 & 201 & 201 \\
\hline 74 & 13 & 13 & 171 & 171 \\
\hline 75 & 8 & 8 & 180 & 180 \\
\hline 76 & 7 & 7 & 157 & 157 \\
\hline 77 & 3 & 3 & 162 & 162 \\
\hline 78 & 2 & 2 & 134 & 134 \\
\hline 79 & 2 & 2 & 98 & 98 \\
\hline 80 & 4 & - & 103 & 103 \\
\hline 81 & 1 & 1 & 82 & 82 \\
\hline 82 & - & - & 67 & 67 \\
\hline 83 & - & - & 60 & 60 \\
\hline 84 & - & - & 43 & 43 \\
\hline 85 & - & - & 18 & 18 \\
\hline 86 & 1 & 1 & 16 & 16 \\
\hline 87 & - & - & 15 & 15 \\
\hline 88 & - & - & 3 & 3 \\
\hline
\end{tabular}




\section{Tabellen zu Kapitel 5}

Tab. 5.1a: Anteil von Frauen und Männern an der Art der Bezugsentscheidung

\begin{tabular}{|l|r|r|r|r|r|r|r|}
\hline & \multicolumn{4}{|c|}{ Sanktionen nach Jugendstrafrecht } & \multicolumn{3}{|c|}{$\begin{array}{c}\text { Sanktionen nach allgemeinem } \\
\text { Strafrecht }\end{array}$} \\
& JS o. Bew. & JS m. Bew. & $\begin{array}{c}\text { Sonst. } \\
\text { Entsch. } n .\end{array}$ & $\begin{array}{c}\text { Entsch. n. } \\
\text { JGG 45, 47 } \\
\text { JGG }\end{array}$ & FS o. Bew. & FS m. Bew. & Geldstrafe \\
\hline Frauen & 221 & 947 & 12.697 & 68.824 & 2.025 & 10.872 & 121.271 \\
\hline Männer & 5.211 & 10.796 & 69.541 & 190.573 & 28.107 & 72.899 & 458.096 \\
\hline Gesamt & 5.432 & 11.743 & 82.238 & 259.397 & 30.132 & 83.771 & 579.367 \\
\hline
\end{tabular}

Tab. 5.2a: Jugendstrafrechtlichen Reaktionen nach Geschlecht

\begin{tabular}{|c|c|c|c|}
\hline & Frauen & Männer & Gesamt \\
\hline JS o. Bew. & 221 & 5.211 & 5.432 \\
\hline JS m. Bew. & 947 & 10.796 & 11.743 \\
\hline Jugendarrest & 1.761 & 14.468 & 16.229 \\
\hline Sonstige Entsch. n. JGG & 10.936 & 55.073 & 66.009 \\
\hline Entsch. n. §§ 45, 47 JGG & 68.824 & 190.573 & 259.397 \\
\hline Gesamt & 82.689 & 276.121 & 358.810 \\
\hline
\end{tabular}

Tab. 5.3a: Dauer der Jugendstrafe ohne Bewährung nach Geschlecht

\begin{tabular}{|l|r|r|r|}
\hline & \multicolumn{2}{|c|}{ Frauen } & \multicolumn{2}{c|}{ Männer } & \multicolumn{2}{c|}{ Gesamt } \\
\hline$>$ 6 Mon. bis zu 1 Jahr & 74 & 1.063 & 1.137 \\
\hline 1 bis 2 Jahre & 91 & 2.145 & 2.236 \\
\hline 2 bis zu 3 Jahre & 35 & 1.307 & 1.342 \\
\hline 3 bis zu 5 Jahre & 15 & 575 & 590 \\
\hline über 5 Jahre & 6 & 121 & 127 \\
\hline Gesamt & 221 & 5.211 & 5.432 \\
\hline
\end{tabular}

Tab. 5.4a: Aussetzungsquote bei Jugendstrafe nach Geschlecht

\begin{tabular}{|l|r|r|r|r|}
\hline & \multicolumn{3}{|c|}{ Frauen } & \multicolumn{2}{|c|}{$\begin{array}{c}\text { Männer } \\
\end{array}$} & 6 Mon. bis zu 1 Jahr & $\begin{array}{c}\text { 1 Jahr bis zu 2 } \\
\text { Jahren }\end{array}$ & 6 Mon. bis zu 1 Jahr & $\begin{array}{c}\text { 1 Jahr bis zu 2 } \\
\text { Jahren }\end{array}$ \\
\hline JS m. Bew. & 658 & 227 & 6.845 & 3.404 \\
\hline JS o. Bew & 74 & 91 & 1.063 & 2.145 \\
\hline Gesamt & 732 & 318 & 7.908 & 5.549 \\
\hline
\end{tabular}


Tab. 5.5a: Anwendung von \105 JGG auf heranwachsende Frauen nach Deliktsgruppen

\begin{tabular}{|c|c|c|c|c|c|c|}
\hline & $\S 105$ JGG a & jewendet & $\begin{array}{r}\S 105 \\
\text { nicht anq }\end{array}$ & $\begin{array}{l}\text { GG } \\
\text { vendet }\end{array}$ & Ges & \\
\hline & abs. & in $\% *$ & abs. & in \%* & abs. & in $\% *$ \\
\hline Tötungsdelikte & 8 & $100 \%$ & 0 & $0 \%$ & 8 & $100 \%$ \\
\hline Einf. KV & 868 & $74 \%$ & 300 & $26 \%$ & 1.168 & $100 \%$ \\
\hline Sonst. KV-Delikte & 669 & $95 \%$ & 37 & $5 \%$ & 706 & $100 \%$ \\
\hline $\begin{array}{l}\text { Sonst. Gewalt- } \\
\text { delikte }\end{array}$ & 176 & $93 \%$ & 14 & $7 \%$ & 189 & $100 \%$ \\
\hline $\begin{array}{l}\text { Bes. schwerer + } \\
\text { qualif. Diebstahl }\end{array}$ & 339 & $92 \%$ & 28 & $8 \%$ & 367 & $100 \%$ \\
\hline $\begin{array}{l}\text { Einf. Diebstahl } \\
+ \text { Unterschl. }\end{array}$ & 7.101 & $87 \%$ & 1.063 & $13 \%$ & 8.164 & $100 \%$ \\
\hline Betrug u.a. & 2.902 & $72 \%$ & 1.112 & $28 \%$ & 4.014 & $100 \%$ \\
\hline \begin{tabular}{|l|} 
Erschleichen \\
v. Leistungen
\end{tabular} & 3.199 & $79 \%$ & 841 & $21 \%$ & 4.040 & $100 \%$ \\
\hline \begin{tabular}{|l|} 
Fahrl. KV + \\
fahrl. Tötung
\end{tabular} & 384 & $68 \%$ & 180 & $32 \%$ & 564 & $100 \%$ \\
\hline Verkehr o. Alk. & 1.861 & $71 \%$ & 750 & $29 \%$ & 2.611 & $100 \%$ \\
\hline Verkehr m. Alk. & 277 & $40 \%$ & 420 & $60 \%$ & 697 & $100 \%$ \\
\hline \begin{tabular}{|l|} 
Delikte \\
n. BtMG \\
\end{tabular} & 1.591 & $90 \%$ & 181 & $10 \%$ & 1.772 & $100 \%$ \\
\hline Sonstige & 3.226 & $80 \%$ & 804 & $20 \%$ & 4.030 & $100 \%$ \\
\hline
\end{tabular}

* Zeilenprozente 
Tab. 5.5b: Anwendung von $\int 105$ JGG auf heranwachsende Männer nach Deliketsgruppen

\begin{tabular}{|c|c|c|c|c|c|c|}
\hline & $\S 105$ JGG a & ewendet & $\begin{array}{r}\$ 105 \\
\text { nicht ang }\end{array}$ & Iendet & Ges & \\
\hline & abs. & in $\%$ & abs. & in $\%$ & abs. & in $\%$ \\
\hline Tötungsdelikte & 70 & $90 \%$ & 8 & $10 \%$ & 78 & $100 \%$ \\
\hline Einf. KV & 6.440 & $79 \%$ & 1.665 & $21 \%$ & 8.105 & $100 \%$ \\
\hline Sonst. KV-Delikte & 6.809 & $93 \%$ & 502 & $7 \%$ & 7.311 & $100 \%$ \\
\hline $\begin{array}{l}\text { Sonst. Gewalt- } \\
\text { delikte }\end{array}$ & 2.900 & $94 \%$ & 171 & $6 \%$ & 3.071 & $100 \%$ \\
\hline $\begin{array}{l}\text { Bes. schwerer + } \\
\text { qualif. Diebstahl }\end{array}$ & 4.809 & $92 \%$ & 436 & $8 \%$ & 5.240 & $100 \%$ \\
\hline $\begin{array}{l}\text { Einf. Diebstahl } \\
+ \text { Unterschl. } \\
\end{array}$ & 14.498 & $84 \%$ & 2.847 & $16 \%$ & 17.345 & $100 \%$ \\
\hline Betrug u.a. & 5.302 & $71 \%$ & 2.142 & $29 \%$ & 7.444 & $100 \%$ \\
\hline \begin{tabular}{|l|} 
Erschleichen \\
v. Leistungen
\end{tabular} & 5.949 & $75 \%$ & 1.963 & $25 \%$ & 7.939 & $100 \%$ \\
\hline $\begin{array}{l}\text { Fahrl. KV + } \\
\text { fahrl. Tötung }\end{array}$ & 1.134 & $64 \%$ & 650 & $36 \%$ & 1.784 & $100 \%$ \\
\hline Verkehr o. Alk. & 9.086 & $67 \%$ & 4.378 & $33 \%$ & 13.464 & $100 \%$ \\
\hline Verkehr m. Alk. & 3.174 & $39 \%$ & 5.046 & $61 \%$ & 8.220 & $100 \%$ \\
\hline $\begin{array}{l}\text { Delikte } \\
\text { n. BtMG }\end{array}$ & 13.107 & $87 \%$ & 1.938 & $13 \%$ & 15.045 & $100 \%$ \\
\hline Sonstige & 18.834 & $81 \%$ & 4.459 & $19 \%$ & 23.293 & $100 \%$ \\
\hline
\end{tabular}

* Zeilenprozente

Tab. 5.6a: Sanktionen des StGB nach Geschlecht

\begin{tabular}{|l|r|r|r|}
\hline & \multicolumn{1}{|c|}{ Frauen } & \multicolumn{1}{c|}{ Männer } & \multicolumn{1}{c|}{ Gesamt } \\
\hline FS o. Bew. & 2.025 & 28.107 & 30.132 \\
\hline FS m. Bew. & 10.872 & 72.899 & 83.771 \\
\hline Geldstrafe & 121.271 & 458.096 & 579.367 \\
\hline Gesamt & 134.168 & 559.102 & 693.270 \\
\hline
\end{tabular}


Tab. 5.7a: Dauer der Freiheitsstrafe obne Bewährung nach Geschlecht

\begin{tabular}{|l|r|r|r|}
\hline & Frauen & \multicolumn{1}{|c|}{ Männer } & \multicolumn{1}{c|}{ Gesamt } \\
\hline Bis zu 6 Mon. & 726 & 6.740 & 7.466 \\
\hline 6 Mon. bis zu 1 Jahr & 569 & 8.306 & 8.875 \\
\hline 1 bis 2 Jahre & 273 & 4.336 & 4.609 \\
\hline 2 bis zu 3 Jahre & 251 & 4.010 & 4.261 \\
\hline 3 bis zu 5 Jahre & 142 & 3.066 & 3.208 \\
\hline über 5 Jahre & 58 & 1.549 & 1.607 \\
\hline lebenslang & 5 & 97 & 102 \\
\hline Gesamt & 2.024 & 28.104 & 30.128 \\
\hline
\end{tabular}

Tab. 5.8a: Aussetzungsquote bei Freiheitsstrafe nach Geschlecht

\begin{tabular}{|c|c|c|c|c|c|c|}
\hline & $\begin{array}{l}\text { bis zu } \\
6 \text { Mon. }\end{array}$ & $\begin{array}{c}\text { Frauen } \\
6 \text { Mon. bis } \\
\mathrm{zu} \\
1 \mathrm{Jahr} \\
\end{array}$ & $\begin{array}{c}1 \text { Jahr bis } \\
\text { zu } \\
2 \text { Jahren }\end{array}$ & $\begin{array}{l}\text { bis zu } \\
6 \text { Mon. }\end{array}$ & $\begin{array}{c}\text { Männer } \\
6 \text { Mon. bis } \\
\text { zu } \\
\text { 1 Jahr }\end{array}$ & $\begin{array}{c}1 \text { Jahr bis } \\
\text { zu } \\
2 \text { Jahren }\end{array}$ \\
\hline FS o. Bew & 726 & 569 & 273 & 6.740 & 8.306 & 4.336 \\
\hline FS m. Bew. & 4.601 & 4.767 & 1.504 & 25.243 & 35.232 & 12.422 \\
\hline Gesamt & 5.327 & 5.336 & 1777 & 31.983 & 43.538 & 16.758 \\
\hline
\end{tabular}

Tab. 5.9a: Anzahl der Tagessätze bei Geldstrafen nach Geschlecht

\begin{tabular}{|l|r|r|r|}
\hline & \multicolumn{1}{|c|}{ Frauen } & \multicolumn{1}{c|}{ Männer } & \multicolumn{1}{c|}{ Gesamt } \\
\hline $1-15$ & 22.906 & 55.401 & 78.307 \\
\hline $16-30$ & 46.790 & 161.595 & 208.385 \\
\hline $\mathbf{3 1 - 5 0}$ & 26.149 & 119.174 & 145.323 \\
\hline $\mathbf{5 1 - 9 0}$ & 19.678 & 91.928 & 111.606 \\
\hline Über 90 & 5.548 & 28.633 & 34.181 \\
\hline Gesamt & 121.071 & 456.731 & 577.802 \\
\hline
\end{tabular}

Tab. 5.10a: Anzabl der Voreintragungen nach Geschlecht

\begin{tabular}{|l|r|r|r|}
\hline & \multicolumn{1}{|c|}{ Frauen } & Männer & \multicolumn{1}{c|}{ Gesamt } \\
\hline Keine & 152.815 & 448.950 & 601.765 \\
\hline $\mathbf{1}$ & 33.009 & 147.307 & 180.316 \\
\hline $\mathbf{2}$ & 14.103 & 80.139 & 94.242 \\
\hline $\mathbf{3}$ und $\mathbf{4}$ & 11.580 & 86.882 & 98.462 \\
\hline $\mathbf{5}$ und $\mathbf{m e h r}$ & 9.501 & 102.017 & 115.518 \\
\hline Gesamt & 221.008 & 865.295 & 1.086 .303 \\
\hline
\end{tabular}


Tab. 5.11a: Art der schwersten Voreintragung nach Geschlecht

\begin{tabular}{|c|c|c|c|}
\hline & Frauen & Männer & Gesamt \\
\hline FS/ JS o. Bew & 3.740 & 58.759 & 62.499 \\
\hline FS/ JS m. Bew & 9.115 & 75.702 & 84.817 \\
\hline Geldstrafe & 29.020 & 129.360 & 158.380 \\
\hline Sonst. Entsch. n. JGG & 7.492 & 57.751 & 62.243 \\
\hline Entsch. n. §§ 45, 47 JGG & 17.380 & 81.932 & 99.312 \\
\hline Gesamt & 66.747 & 403.504 & 470.251 \\
\hline
\end{tabular}

Tab. 5.12a: Jugendstrafrechtliche Reaktionen nach Anzabl der Voreintragungen und Geschlecht

\begin{tabular}{|c|c|c|c|c|c|c|c|c|c|c|}
\hline \multirow{3}{*}{$\begin{array}{l}\text { Art der jugendstraf- } \\
\text { rechtlichen Reaktion }\end{array}$} & \multicolumn{10}{|c|}{ Anzahl der Voreintragungen } \\
\hline & \multicolumn{2}{|c|}{ keine } & \multicolumn{2}{|c|}{1} & \multicolumn{2}{|c|}{2} & \multicolumn{2}{|c|}{3 und 4} & \multicolumn{2}{|c|}{5 und mehr } \\
\hline & $\mathbf{F}$ & M & $\mathbf{F}$ & M & $\mathbf{F}$ & M & $\mathbf{F}$ & M & $\mathbf{F}$ & M \\
\hline JS o. Bew. & 33 & 687 & 55 & 1.005 & 47 & 1.103 & 60 & 1.596 & 26 & 820 \\
\hline JS m. Bew. & 267 & 2.070 & 215 & 2.150 & 194 & 2.122 & 199 & 3.001 & 72 & 1.453 \\
\hline $\begin{array}{l}\text { Entsch. n. } \$ \S 45,47 \\
\text { JGG }\end{array}$ & 56.937 & 138.144 & 8.452 & 33.460 & 2.212 & 10.841 & 984 & 6.302 & 239 & 1.826 \\
\hline $\begin{array}{l}\text { Sonst. Entsch. } n \text {. } \\
\text { JGG }\end{array}$ & 6.089 & 24.609 & 3.383 & 19.106 & 1.798 & 2.358 & 1.156 & 10.463 & 271 & 3.005 \\
\hline Gesamt & 63.326 & 165.510 & 12.105 & 55.721 & 4.251 & 26.424 & 2.399 & 21.362 & 608 & 7.104 \\
\hline
\end{tabular}

Tab. 5.13: Jugendstrafrecbtliche Reaktionen nach Art der schwersten Voreintragung und Geschlecht

\begin{tabular}{|c|c|c|c|c|c|c|c|c|}
\hline \multirow{3}{*}{$\begin{array}{c}\text { Art der } \\
\text { jugendstrafrechtlichen } \\
\text { Reaktionen }\end{array}$} & \multicolumn{8}{|c|}{ Art der schwersten Voreintragung } \\
\hline & \multicolumn{2}{|c|}{$\begin{array}{c}\text { Ambulante Reaktio- } \\
\text { nen nach JGG }\end{array}$} & \multicolumn{2}{|c|}{ Geldstrafe } & \multicolumn{2}{|c|}{ FS/ JS m. Bew. } & \multicolumn{2}{|c|}{ FS/ JS o. Bew. } \\
\hline & $\mathbf{F}$ & M & $\mathbf{F}$ & M & $\mathbf{F}$ & M & $\mathbf{F}$ & M \\
\hline JS o. Bew. & 147 & 3.576 & 7 & 167 & 12 & 225 & 16 & 484 \\
\hline JS m. Bew. & 597 & 7.624 & 48 & 442 & 16 & 318 & 12 & 267 \\
\hline Sonst. Entsch. n. JGG & 6.307 & 42.438 & 162 & 1.129 & 93 & 947 & 15 & 277 \\
\hline Entsch. $n . \S \S 45,47$ JGG & 11.615 & 50.412 & 134 & 789 & 72 & 695 & 18 & 356 \\
\hline Gesamt & 18.666 & 104.050 & 351 & 2.527 & 193 & 2.185 & 61 & 1.384 \\
\hline
\end{tabular}


Tab. 5.14a: Sanktionen des StGB nach Anzabl der Voreintragungen und Geschlecht

\begin{tabular}{|c|c|c|c|c|c|c|c|c|c|c|}
\hline \multirow{3}{*}{$\begin{array}{c}\text { Art der } \\
\text { Sanktionen des StGB }\end{array}$} & \multicolumn{10}{|c|}{ Anzahl der Voreintragungen } \\
\hline & \multicolumn{2}{|c|}{ keine } & \multicolumn{2}{|c|}{1} & \multicolumn{2}{|c|}{2} & \multicolumn{2}{|c|}{3 und 4} & \multicolumn{2}{|c|}{5 und mehr } \\
\hline & $\mathbf{F}$ & M & $\mathbf{F}$ & M & $\mathbf{F}$ & M & $\mathbf{F}$ & M & $\mathbf{F}$ & M \\
\hline FS o. Bew. & 273 & 3.758 & 146 & 1.883 & 153 & 2.003 & 398 & 4.830 & 1.055 & 15.633 \\
\hline FS m. Bew. & 3.830 & 20.027 & 1.593 & 10.143 & 1.282 & 8.331 & 1.843 & 13.015 & 2.324 & 21.383 \\
\hline Geldstrafe & 84.534 & 255.886 & 17.747 & 71.309 & 7.724 & 38.439 & 6.274 & 41.922 & 4.992 & 50.540 \\
\hline Gesamt & 88.637 & 279.671 & 19.486 & 83.335 & 9.159 & 48.773 & 8.515 & 59.767 & 8.371 & 87.556 \\
\hline
\end{tabular}

Tab. 5.15a: Sanktionen des StGB nach Art der schwersten Voreintragung und Geschlecht

\begin{tabular}{|c|c|c|c|c|c|c|c|c|}
\hline \multirow{3}{*}{$\begin{array}{c}\text { Art der } \\
\text { jugendstrafrechtlichen } \\
\text { Reaktionen }\end{array}$} & \multicolumn{8}{|c|}{ Art der schwersten Voreintragung } \\
\hline & \multicolumn{2}{|c|}{$\begin{array}{l}\text { Ambulante Reak- } \\
\text { tionen nach JGG }\end{array}$} & \multicolumn{2}{|c|}{ Geldstrafe } & \multicolumn{2}{|c|}{ FS/ JS m. Bew. } & \multicolumn{2}{|c|}{ FS/ JS o. Bew. } \\
\hline & $\mathbf{F}$ & $\mathbf{M}$ & $\mathbf{F}$ & M & $\mathbf{F}$ & M & $\mathbf{F}$ & M \\
\hline FS o. Bew. & 17 & 418 & 139 & 1822 & 764 & 7.485 & 766 & 13.445 \\
\hline FS m. Bew. & 295 & 3.362 & 3.271 & 18.802 & 2.401 & 17.175 & 908 & 11.799 \\
\hline Geldstrafe & 5.505 & 30.291 & 23.689 & 97.594 & 5.214 & 43.272 & 1.669 & 25.431 \\
\hline Gesamt & 5.817 & 34.071 & 27.099 & 118.218 & 8.379 & 67.932 & 3.343 & 50.675 \\
\hline
\end{tabular}


Tab. 5.16a: Jugendstrafrechtlichen Reaktionen nach Deliktsgruppe von Frauen

\begin{tabular}{|c|c|c|c|c|c|}
\hline & JS o. Bew. & JS m. Bew. & $\begin{array}{c}\text { Sonstige } \\
\text { Entsch. } \mathrm{n} \text {. } \\
\text { JGG }\end{array}$ & $\begin{array}{c}\text { Entsch. n. } \\
\S \S 45,47 \text { JGG }\end{array}$ & Gesamt \\
\hline Tötungsdelikte & 13 & 4 & 1 & 2 & 20 \\
\hline Einf. KV & 10 & 41 & 833 & 3.779 & 4.663 \\
\hline Sonst. KV-Delikte & 15 & 122 & 1.101 & 2.639 & 3.877 \\
\hline Sonst. Gewaltdelikte & 34 & 122 & 268 & 368 & 792 \\
\hline $\begin{array}{l}\text { Bes. schwerer und } \\
\text { qualif. Diebstahl }\end{array}$ & 37 & 109 & 467 & 572 & 1.185 \\
\hline $\begin{array}{l}\text { Einf. Diebstahl und } \\
\text { Unterschlagung }\end{array}$ & 47 & 151 & 4.443 & 33.328 & 37.969 \\
\hline Betrug u.a. & 12 & 110 & 1.226 & 4.511 & 5.859 \\
\hline Erschl. v. Leistungen & 0 & 12 & 1.151 & 6.256 & 7.419 \\
\hline $\begin{array}{l}\text { Fahrl. KV und fahrl. } \\
\text { Tötung }\end{array}$ & 0 & 1 & 63 & 526 & 590 \\
\hline $\begin{array}{l}\text { Verkehrsdelikte } 0 . \\
\text { Alkoholeinfluß }\end{array}$ & 1 & 2 & 621 & 3.872 & 4.496 \\
\hline $\begin{array}{l}\text { Verkehrsdelikte m. } \\
\text { Alkoholeinfluß }\end{array}$ & 3 & 0 & 275 & 71 & 349 \\
\hline Delikte n. BtMG & 34 & 205 & 852 & 2.661 & 3.752 \\
\hline
\end{tabular}


Tab. 5.17a: Jugendstrafrechtlichen Reaktionen nach Deliktsgruppe von Männern

\begin{tabular}{|l|r|r|r|r|r|}
\hline & JS o. Bew. & JS m. Bew. & $\begin{array}{c}\text { Sonstige } \\
\text { Entsch. } n \text {. } \\
\text { JGG }\end{array}$ & $\begin{array}{r}\text { Entsch. nach } \\
\S \S \text { 45, 47 JGG }\end{array}$ & Gesamt \\
\hline Tötungsdelikte & 92 & 15 & 2 & 5 & 114 \\
\hline Einf. KV & 284 & 552 & 5.775 & 12.900 & 19.511 \\
\hline Sonst. KV-Delikte & 743 & 1.598 & 7.296 & 9.104 & 18.741 \\
\hline Sonst. Gewaltdelikte & 1.125 & 2.009 & 2.486 & 2.049 & 7.669 \\
\hline $\begin{array}{l}\text { Bes. schwerer und } \\
\text { qualif. Diebstahl }\end{array}$ & 1.014 & 1.777 & 5.893 & 5.163 & 13.847 \\
\hline $\begin{array}{l}\text { Einf. Diebstahl und } \\
\text { Unterschlagung }\end{array}$ & 580 & 862 & 12.437 & 44.669 & 58.548 \\
\hline Betrug u.a. & 164 & 417 & 2.559 & 7.699 & 10.839 \\
\hline Erschl. v. Leistungen & 22 & 67 & 2.276 & 9.115 & 11.480 \\
\hline $\begin{array}{l}\text { Fahrl. KV und fahrl. } \\
\text { Tötung }\end{array}$ & 6 & 43 & 449 & 1.650 & 2.148 \\
\hline $\begin{array}{l}\text { Verkehrsdelikte 0. } \\
\text { Alkoholeinfluß }\end{array}$ & 105 & 250 & 8.950 & 34.243 & 43.548 \\
\hline $\begin{array}{l}\text { Verkehrsdelikte m. } \\
\text { Alkoholeinfluß }\end{array}$ & 34 & 92 & 3.588 & 670 & 4.384 \\
\hline \begin{tabular}{l} 
Delikte n. BtMG \\
\hline
\end{tabular} & 711 & 2.127 & 7.850 & 15.444 & 26.132 \\
\hline
\end{tabular}


Tab. 5.18a: Sanktionen des StGB nach Deliktsgruppe von Frauen

\begin{tabular}{|c|c|c|c|c|}
\hline & FS o. Bew. & FS m. Bew. & Geldstrafe & Gesamt \\
\hline Tötungsdelikte & 37 & 8 & 1 & 46 \\
\hline Einf. KV & 29 & 118 & 3.724 & 3.871 \\
\hline Sonst. KV-Delikte & 61 & 618 & 424 & 1.103 \\
\hline Sonst. Gewaltdelikte & 71 & 197 & 281 & 549 \\
\hline $\begin{array}{l}\text { Bes. schwerer und } \\
\text { qualif. Diebstahl }\end{array}$ & 98 & 499 & 254 & 851 \\
\hline \begin{tabular}{|l|} 
Einf. Diebstahl und \\
Unterschlagung
\end{tabular} & 668 & 2.464 & 29.434 & 32.566 \\
\hline Betrug u.a. & 371 & 3.116 & 26.466 & 29.953 \\
\hline Erschl. v. Leistungen & 37 & 191 & 7.987 & 8.215 \\
\hline $\begin{array}{l}\text { Fahrl. KV und fahrl. } \\
\text { Tötung }\end{array}$ & 5 & 37 & 2.237 & 2.279 \\
\hline $\begin{array}{l}\text { Verkehrsdelikte } 0 . \\
\text { Alkoholeinfluß }\end{array}$ & 33 & 344 & 12.672 & 13.049 \\
\hline \begin{tabular}{|l|} 
Verkehrsdelikte $\mathrm{m}$. \\
Alkoholeinfluß
\end{tabular} & 8 & 277 & 12.858 & 13.143 \\
\hline Delikte n. BtMG & 375 & 1.151 & 2.236 & 3.762 \\
\hline
\end{tabular}


Tab. 5.19a: Sanktionen des StGB nach Deliktsgruppe von Männern

\begin{tabular}{|c|c|c|c|c|}
\hline & FS o. Bew. & FS m. Bew. & Geldstrafe & Gesamt \\
\hline Tötungsdelikte & 524 & 31 & 5 & 560 \\
\hline Einf. KV & 1.218 & 3.548 & 27.557 & 32.323 \\
\hline \begin{tabular}{|l|} 
Sonst. \\
KV-Delikte \\
\end{tabular} & 1.375 & 7.790 & 3.181 & 12.346 \\
\hline Sonst. Gewaltdelikte & 2.613 & 2.723 & 2.683 & 8.019 \\
\hline $\begin{array}{l}\text { Bes. schwerer und } \\
\text { qualif. Diebstahl }\end{array}$ & 3.174 & 5.580 & 2.428 & 11.182 \\
\hline $\begin{array}{l}\text { Einf. Diebstahl und } \\
\text { Unterschlagung }\end{array}$ & 4.414 & 6.813 & 58.137 & 69.364 \\
\hline Betrug u.a. & 2.616 & 9.569 & 60.468 & 72.653 \\
\hline Erschl. v. Leistungen & 351 & 814 & 22.599 & 23.764 \\
\hline $\begin{array}{l}\text { Fahrl. KV und fahrl. } \\
\text { Tötung }\end{array}$ & 57 & 381 & 7.660 & 8.098 \\
\hline \begin{tabular}{|l|} 
Verkehrsdelikte 0. \\
Alkoholeinfluß \\
\end{tabular} & 1.840 & 5.783 & 59.016 & 66.639 \\
\hline \begin{tabular}{|l|} 
Verkehrsdelikte $\mathrm{m}$. \\
Alkoholeinfluß \\
\end{tabular} & 686 & 4.109 & 87.985 & 92.780 \\
\hline Delikte n. BtMG & 5.136 & 8.717 & 18.193 & 32.046 \\
\hline
\end{tabular}


Tab. 5.20a: Jugendstrafrechtliche Reaktionen nach Einschlägigkeit der Voreintragungen und Geschlecht

\begin{tabular}{|c|c|c|c|c|c|c|c|c|}
\hline \multirow{3}{*}{$\begin{array}{c}\text { Art der } \\
\text { jugendstrafrechtlichen } \\
\text { Reaktionen }\end{array}$} & \multicolumn{8}{|c|}{ Einschlägigkeit der Voreintragung } \\
\hline & \multicolumn{2}{|c|}{ Keine VE } & \multicolumn{2}{|c|}{$\begin{array}{l}\text { Nur VE(en) mit } \\
\text { anderen Delikten }\end{array}$} & \multicolumn{2}{|c|}{$\begin{array}{l}\text { Auch VE(en) mit } \\
\text { Delikten einer } \\
\text { verwandten } \\
\text { Deliktsgruppe }\end{array}$} & \multicolumn{2}{|c|}{$\begin{array}{c}\text { Auch ein- } \\
\text { schlägige VE(en) }\end{array}$} \\
\hline & $\mathbf{F}$ & M & $\mathbf{F}$ & M & $\mathbf{F}$ & M & $\mathbf{F}$ & M \\
\hline JS o. Bew. & 33 & 687 & 58 & 1.585 & 56 & 1.293 & 62 & 1.352 \\
\hline JS m. Bew. & 267 & 2.070 & 227 & 3.061 & 175 & 2.247 & 233 & 2.680 \\
\hline $\begin{array}{l}\text { Entsch. } n . \S \S 45,47 \\
\text { JGG }\end{array}$ & 6.089 & 24.609 & 2.560 & 18.150 & 815 & 6.996 & 2.584 & 13.258 \\
\hline Sonst. Entsch. n. JGG & 56.937 & 138.144 & 5.405 & 23.076 & 1.027 & 5.215 & 3.421 & 10.505 \\
\hline Gesamt & 63.326 & 165.510 & 8.250 & 45.872 & 2.073 & 15.751 & 6.300 & 27.795 \\
\hline
\end{tabular}

Tab. 5.21a: Sanktionen des StGB nach Einschlägigkeit der Voreintragungen und Geschlecht

\begin{tabular}{|c|c|c|c|c|c|c|c|c|}
\hline \multirow{3}{*}{$\begin{array}{c}\text { Art der } \\
\text { Sanktionen des StGB }\end{array}$} & \multicolumn{8}{|c|}{ Einschlägigkeit der Voreintragung } \\
\hline & \multicolumn{2}{|c|}{ Keine VE } & \multicolumn{2}{|c|}{$\begin{array}{l}\text { Nur VE(en) mit } \\
\text { anderen Delikten }\end{array}$} & \multicolumn{2}{|c|}{$\begin{array}{l}\text { Auch VE(en) mit } \\
\text { Delikten einer } \\
\text { verwandten } \\
\text { Deliktsgruppe }\end{array}$} & \multicolumn{2}{|c|}{$\begin{array}{c}\text { Auch ein- } \\
\text { schlägige VE(en) }\end{array}$} \\
\hline & $\mathbf{F}$ & M & $\mathbf{F}$ & M & $\mathbf{F}$ & $M$ & $\mathbf{F}$ & M \\
\hline FS o. Bew. & 273 & 3.758 & 229 & 3.824 & 177 & 3.574 & 1.163 & 13.649 \\
\hline FS m. Bew. & 3.830 & 20.027 & 1.355 & 12.140 & 761 & 7.797 & 4.113 & 22.787 \\
\hline Geldstrafe & 84.534 & 255.886 & 11.923 & 71.903 & 2.682 & 21.354 & 16.126 & 61.503 \\
\hline Gesamt & 88.637 & 279.671 & 13.507 & 87.867 & 3.620 & 32.725 & 21.402 & 97.939 \\
\hline
\end{tabular}

Tab. 5.22a: Jugendstrafrechtlichen Reaktionen aufgrund von Diebstahl nach Geschlecht

\begin{tabular}{|c|c|c|c|}
\hline & Frauen & Männer & Gesamt \\
\hline JS o. Bew. & 47 & 567 & 614 \\
\hline JS m. Bew. & 145 & 832 & 977 \\
\hline Sonstige Entsch. n. JGG & 4.299 & 11.699 & 15.998 \\
\hline Entsch. n. §§ 45, 47 JGG & 32.694 & 42.351 & 75.045 \\
\hline Gesamt & 37.185 & 55.449 & 92.634 \\
\hline
\end{tabular}


Tab. 5.23a: Aussetzungsquote bei Jugendstrafe aufgrund von Diebstabl nach Geschlecht

\begin{tabular}{|l|r|r|r|r|}
\hline & \multicolumn{2}{|c|}{ Frauen } & \multicolumn{2}{c|}{ Männer } \\
& 6 Mon. bis zu 1 Jahr & $\begin{array}{c}\text { 1 Jahr bis zu 2 } \\
\text { Jahren }\end{array}$ & 6 Mon. bis zu 1 Jahr & $\begin{array}{c}\text { 1 Jahr bis zu 2 } \\
\text { Jahren }\end{array}$ \\
\hline JS m. Bew. & 9 & 6 & 80 & 74 \\
\hline JS o. Bew & 30 & 2 & 227 & 32 \\
\hline Gesamt & 39 & 8 & 307 & 106 \\
\hline
\end{tabular}

Tab. 5.24a: Sanktionen des StGB aufgrund von Diebstabl nach Geschlecht

\begin{tabular}{|c|c|c|c|}
\hline & Frauen & Männer & Gesamt \\
\hline FS o. Bew. & 660 & 4.306 & 4.966 \\
\hline FS m. Bew. & 2.326 & 6.290 & 8.616 \\
\hline Geldstrafe & 27.977 & 53.633 & 81.610 \\
\hline Gesamt & 30.963 & 64.229 & 95.192 \\
\hline
\end{tabular}

Tab. 5.25a: Aussetzungsquote bei Freiheitsstrafe aufgrund von Diebstabl nach Geschlecht

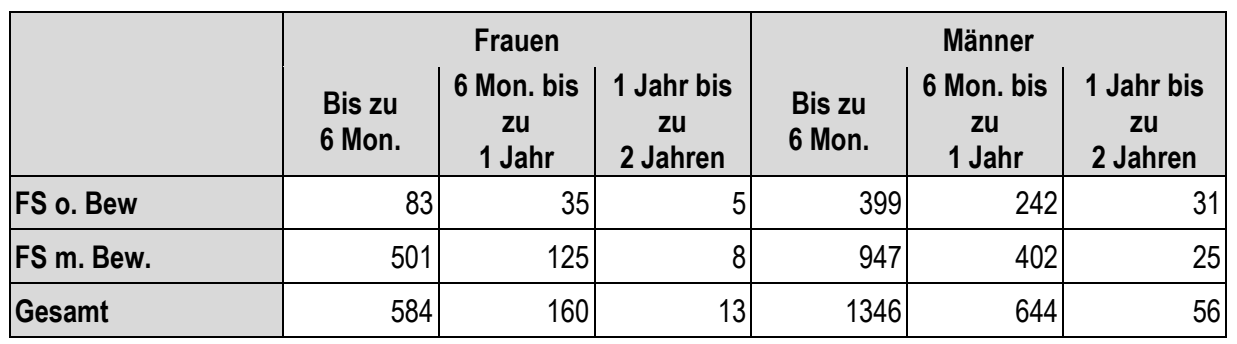

Tab. 5.26a: Anzabl der Tagessätze bei Geldstrafen aufgrund von Diebstabl nach Geschlecht

\begin{tabular}{|c|c|c|c|}
\hline & Frauen & Männer & Gesamt \\
\hline $1-15$ & 10.111 & 16.522 & 26.633 \\
\hline $16-30$ & 10.286 & 19.157 & 29.443 \\
\hline $31-50$ & 4.148 & 8.906 & 13.054 \\
\hline $51-90$ & 2.875 & 7.282 & 10.157 \\
\hline Über 90 & 557 & 1.766 & 2.323 \\
\hline Gesamt & 27.977 & 53.633 & 81.610 \\
\hline
\end{tabular}


Tab. 5.27a: Bequgsentscheidungen aufgrund von Diebstabl nach Anzahl der Voreintragungen und Geschlecht

\begin{tabular}{|l|r|r|}
\hline & Frauen & Männer \\
\hline Keine & 48.281 & 61.186 \\
\hline $\mathbf{1}$ & 9.377 & 19.719 \\
\hline $\mathbf{3}$ und 4 & 4.007 & 10.644 \\
\hline $\mathbf{5}$ und mehr & 3.286 & 11.762 \\
\hline Gesamt & 3.388 & 16.928 \\
\hline
\end{tabular}

Tab. 5.28a: Bezugsentscheidungen aufgrund von Diebstabl nach Art der schwersten

Voreintragung und Geschlecht

\begin{tabular}{|l|r|r|}
\hline & Frauen & Männer \\
\hline FS/ JS o. Bew & 1.332 & 9.934 \\
\hline FS/ JS m. Bew & 2.712 & 9.813 \\
\hline Geldstrafe & 8.648 & 17.236 \\
\hline Sonst. Entsch. n. JGG & 1.925 & 7.929 \\
\hline Entsch. n. §§ 45, 47 JGG & 5.130 & 12.642 \\
\hline Gesamt & 19.747 & 57.554 \\
\hline
\end{tabular}

Tab. 5.29a: Jugendstrafrechtlichen Reaktionen aufgrund von Diebstabl nach Anzabl der Voreintragungen und Geschlecht

\begin{tabular}{|c|c|c|c|c|c|c|c|c|c|c|}
\hline \multirow{3}{*}{$\begin{array}{c}\text { Art der } \\
\text { jugendstrafrecht- } \\
\text { lichen Reaktionen }\end{array}$} & \multicolumn{10}{|c|}{ Anzahl der Voreintragungen } \\
\hline & \multicolumn{2}{|c|}{ keine } & \multicolumn{2}{|c|}{1} & \multicolumn{2}{|c|}{2} & \multicolumn{2}{|c|}{3 und 4} & \multicolumn{2}{|c|}{5 und mehr } \\
\hline & $\mathbf{F}$ & M & $\mathbf{F}$ & M & $\mathbf{F}$ & M & $\mathbf{F}$ & M & $\mathbf{F}$ & M \\
\hline JS o. Bew. & 2 & 57 & 8 & 114 & 14 & 101 & 15 & 190 & 8 & 105 \\
\hline JS m. Bew. & 16 & 85 & 34 & 133 & 37 & 177 & 35 & 275 & 23 & 162 \\
\hline $\begin{array}{l}\text { Entsch. n. } \$ \S 45,47 \\
\text { JGG }\end{array}$ & 2.079 & 4.041 & 1.189 & 3.245 & 627 & 2.164 & 337 & 1.752 & 67 & 497 \\
\hline $\begin{array}{l}\text { Sonst. Entsch. } n . \\
\text { JGG }\end{array}$ & 29.222 & 33.543 & 2.665 & 6.027 & 540 & 1.674 & 206 & 860 & 61 & 247 \\
\hline Gesamt & 31.319 & 37.726 & 3.896 & 9.519 & 1.218 & 4.116 & 593 & 3.077 & 159 & 1.011 \\
\hline
\end{tabular}


Tab. 5.30a: Jugendstrafrechtlichen Reaktionen aufgrund von Diebstabl nach Art der schwersten Voreintragung und Geschlecht

\begin{tabular}{|l|r|r|r|r|r|r|r|r|}
\hline \multirow{2}{*}{$\begin{array}{c}\text { Art der } \\
\text { jugendstrafrechtlichen } \\
\text { Reaktionen }\end{array}$} & \multicolumn{7}{|c|}{$\begin{array}{c}\text { Ambulante } \\
\text { Reaktionen nach } \\
\text { JGG }\end{array}$} & \multicolumn{2}{|c|}{ Geldstrafe } & \multicolumn{2}{|c|}{ JS/ FS m. Bew. } & \multicolumn{2}{|c|}{ JS/ FS o. Bew. } \\
\hline JS o. Bew. & 31 & 405 & 1 & 11 & 5 & 23 & 8 & 63 \\
\hline JS m. Bew. & 115 & 650 & 6 & 27 & 5 & 27 & 3 & 35 \\
\hline Sonst. Entsch. n. JGG & 3.410 & 7.279 & 29 & 171 & 19 & 127 & 6 & 52 \\
\hline Entsch. n. §§ 45, 47 JGG & 2.156 & 8.514 & 22 & 114 & 19 & 95 & 3 & 48 \\
\hline Gesamt & 5.712 & 16.848 & 58 & 323 & 48 & 272 & 20 & 198 \\
\hline
\end{tabular}

Tab. 5.31a: Sanktionen des StGB aufgrund von Diebstabl nach Anzabl der Voreintragungen und Geschlecht

\begin{tabular}{|c|c|c|c|c|c|c|c|c|c|c|}
\hline \multirow{3}{*}{$\begin{array}{c}\text { Art der } \\
\text { Sanktionen des } \\
\text { StGB } \\
\end{array}$} & \multicolumn{10}{|c|}{ Anzahl der Voreintragungen } \\
\hline & \multicolumn{2}{|c|}{ keine } & \multicolumn{2}{|c|}{1} & \multicolumn{2}{|c|}{2} & \multicolumn{2}{|c|}{3 und 4} & \multicolumn{2}{|c|}{5 und mehr } \\
\hline & $\mathbf{F}$ & M & $\mathbf{F}$ & M & $\mathbf{F}$ & M & $\mathbf{F}$ & M & $\mathbf{F}$ & M \\
\hline FS o. Bew. & 12 & 64 & 18 & 92 & 28 & 203 & 124 & 677 & 478 & 3.270 \\
\hline FS m & 200 & 612 & 164 & 454 & 328 & 584 & 634 & 1.374 & 1.000 & 3.266 \\
\hline Gelds & 16.714 & 22.673 & 5.269 & 9.584 & 2.407 & 5.683 & 1.898 & 6.538 & 1.689 & 9.155 \\
\hline Gesamt & 16.926 & 23.349 & 5.451 & 10.130 & 2.763 & 6.470 & 2.656 & 8.589 & 3.167 & 15.691 \\
\hline
\end{tabular}

Tab. 5.32a: Sanktionen des StGB aufgrund von Diebstabl nach Art der schwersten Voreintragung und Geschlecht

\begin{tabular}{|l|r|r|r|r|r|r|r|r|}
\hline \multirow{2}{*}{$\begin{array}{c}\text { Art der } \\
\text { Sanktionen des StGB }\end{array}$} & \multicolumn{7}{|c|}{$\begin{array}{c}\text { Ambulante Reak- } \\
\text { tionen nach JGG } \\
\text { F }\end{array}$} & \multicolumn{2}{|c|}{ Geldstrafe } & \multicolumn{2}{|c|}{ JS/FS m. Bew. } & \multicolumn{2}{|c|}{ JS/FS o. Bew. } \\
& 1 & 25 & 14 & 95 & 285 & 1.178 & 333 & 2.730 \\
\hline JS o. Bew. & 46 & 141 & 790 & 1.479 & 823 & 1.844 & 412 & 2.011 \\
\hline JS m. Bew. & 1.281 & 3.505 & 7.732 & 15.242 & 1.534 & 6.438 & 555 & 4.901 \\
\hline $\begin{array}{l}\text { Sonstige ambulante } \\
\text { Reaktionen }\end{array}$ & 1.328 & 3.671 & 8.536 & 16.816 & 2.642 & 9.460 & 1.300 & 9.642 \\
\hline Gesamt & & & & & & & & \\
\hline
\end{tabular}


Tab. 5.33a: Jugendstrafrechtlichen Reaktionen aufgrund von Diebstahl nach Einschlägigkeit der Voreintragungen und Geschlecht

\begin{tabular}{|c|c|c|c|c|c|c|c|c|}
\hline \multirow{3}{*}{$\begin{array}{c}\text { Art der } \\
\text { jugendstrafrechtlichen } \\
\text { Reaktionen }\end{array}$} & \multicolumn{8}{|c|}{ Einschlägigkeit der Voreintragung } \\
\hline & \multicolumn{2}{|c|}{ Keine VE } & \multicolumn{2}{|c|}{$\begin{array}{l}\text { Nur VE(en) mit } \\
\text { anderen Delikten }\end{array}$} & \multicolumn{2}{|c|}{$\begin{array}{l}\text { Auch VE(en) mit } \\
\text { Delikten einer } \\
\text { verwandten } \\
\text { Deliktsgruppe }\end{array}$} & \multicolumn{2}{|c|}{$\begin{array}{l}\text { Auch einschlägi- } \\
\text { ge VE(en) }\end{array}$} \\
\hline & $\mathbf{F}$ & M & $\mathbf{F}$ & M & $\mathbf{F}$ & M & $\mathbf{F}$ & M \\
\hline JS o. Bew. & 2 & 57 & 10 & 112 & 2 & 61 & 33 & 337 \\
\hline JS m. Bew. & 16 & 85 & 23 & 162 & 5 & 74 & 101 & 511 \\
\hline $\begin{array}{l}\text { Entsch. n. } \S \S 45,47 \\
\text { JGG }\end{array}$ & 2.079 & 4.041 & 584 & 2.785 & 61 & 677 & 1.575 & 4.196 \\
\hline Sonst. Entsch. n. JGG & 29.222 & 33.543 & 1.259 & 4.392 & 64 & 506 & 2.149 & 3.910 \\
\hline Gesamt & 31.319 & 37.726 & 1.876 & 7.451 & 132 & 1.318 & 3.858 & 8.954 \\
\hline
\end{tabular}

Tab. 5.34a: Sanktionen des StGB aufgrund von Diebstabl nach Einschlägigkeit der Voreintragungen und Geschlecht

\begin{tabular}{|c|c|c|c|c|c|c|c|c|}
\hline \multirow{3}{*}{$\begin{array}{c}\text { Art der } \\
\text { Sanktionen des StGB }\end{array}$} & \multicolumn{8}{|c|}{ Einschlägigkeit der Voreintragung } \\
\hline & \multicolumn{2}{|c|}{ Keine VE } & \multicolumn{2}{|c|}{$\begin{array}{c}\text { Nur VE(en) mit } \\
\text { anderen Delikten }\end{array}$} & \multicolumn{2}{|c|}{$\begin{array}{l}\text { Auch VE(en) mit } \\
\text { Delikten einer } \\
\text { verwandten } \\
\text { Deliktsgruppe }\end{array}$} & \multicolumn{2}{|c|}{$\begin{array}{l}\text { Auch einschlägige } \\
\text { VE(en) }\end{array}$} \\
\hline & $\mathbf{F}$ & M & $\mathbf{F}$ & M & $\mathbf{F}$ & M & $\mathbf{F}$ & M \\
\hline FS o. Bew. & 12 & 64 & 40 & 324 & 13 & 293 & 595 & 3.625 \\
\hline FS m. Bew. & 200 & 612 & 157 & 925 & 31 & 420 & 1.938 & 4.333 \\
\hline Geldstrafe & 16.714 & 22.673 & 2.603 & 11.625 & 194 & 17.26 & 8.466 & 17.609 \\
\hline Gesamt & 16.926 & 23.349 & 2.800 & 12.874 & 238 & 2.439 & 10.999 & 25.567 \\
\hline
\end{tabular}

Tab. 5.35: Sanktionen des StGB aufgrund von Diebstabl unter Berücksichtigung multipler Variablen nach Geschlecht

\begin{tabular}{|c|c|c|}
\hline & Frauen & Männer \\
\hline FS o. Bew. & 378 & 2.411 \\
\hline FS m. Bew. & 690 & 2.123 \\
\hline Geldstrafe & 1.016 & 4.993 \\
\hline Gesamt & 2.084 & 9.527 \\
\hline
\end{tabular}


Tab. 5.36a: Jugendstrafrechtlichen Reaktionen aufgrund von Betrug nach Geschlecht

\begin{tabular}{|l|r|r|r|r|}
\hline & \multicolumn{3}{|c|}{ Frauen } & \multicolumn{2}{|c|}{ Männer } \\
\hline JS o. Bew. & abs. & in $\%$ & abs. & $2 \%$ \\
\hline JS m. Bew. & 97 & $0,2 \%$ & 126 & $5 \%$ \\
\hline $\begin{array}{l}\text { Sonstige Entsch. } \mathbf{n} . \\
\text { JGG }\end{array}$ & 989 & $2 \%$ & 344 & $23 \%$ \\
\hline $\begin{array}{l}\text { Entsch. } \boldsymbol{n} \text {. §§ 45, 47 } \\
\text { JGG }\end{array}$ & 3.492 & $22 \%$ & 1.735 & $71 \%$ \\
\hline Gesamt & 4.587 & $10 \%$ & 5.308 & $100 \%$ \\
\hline
\end{tabular}

Tab. 5.37a: Aussetzungsquote bei Jugendstrafe aufgrund von Betrug nach Geschlecht

\begin{tabular}{|c|c|c|c|c|c|c|c|c|}
\hline & \multicolumn{4}{|c|}{ Frauen } & \multicolumn{4}{|c|}{ Männer } \\
\hline & \multicolumn{2}{|c|}{$\begin{array}{l}6 \text { Mon. bis } \\
\text { zu } 1 \text { Jahr }\end{array}$} & \multicolumn{2}{|c|}{$\begin{array}{c}1 \text { Jahr bis zu } \\
2 \text { Jahren }\end{array}$} & \multicolumn{2}{|c|}{$\begin{array}{l}6 \text { Mon. bis } \\
\text { zu } 1 \text { Jahr }\end{array}$} & \multicolumn{2}{|c|}{$\begin{array}{c}1 \text { Jahr bis zu } 2 \\
\text { Jahren }\end{array}$} \\
\hline & abs. & in $\%$ & abs. & in $\%$ & abs. & in $\%$ & abs. & in $\%$ \\
\hline JS m. Bew. & 3 & $14 \%$ & 1 & $14 \%$ & 20 & $22 \%$ & 13 & $30 \%$ \\
\hline JS o. Bew & 19 & $86 \%$ & 6 & $86 \%$ & 72 & $78 \%$ & 31 & $70 \%$ \\
\hline Gesamt & 22 & $100 \%$ & 7 & $100 \%$ & 92 & $100 \%$ & 44 & $100 \%$ \\
\hline
\end{tabular}

Tab. 5.38a: Sanktionen des StGB aufgrund von Betrug nach Geschlecht

\begin{tabular}{|l|r|r|r|r|}
\hline & \multicolumn{2}{|c|}{ Frauen } & \multicolumn{2}{c|}{ Männer } \\
& abs. & in $\%$ & abs. & \multicolumn{1}{|c|}{ In } \\
\hline FS o. Bew. & 316 & $1 \%$ & 2.109 & $4 \%$ \\
\hline FS m. Bew. & 2.575 & $10 \%$ & 7.422 & $13 \%$ \\
\hline Geldstrafe & 23.663 & $89 \%$ & 48.646 & $84 \%$ \\
\hline Gesamt & 26.554 & $100 \%$ & 58.177 & $100 \%$ \\
\hline
\end{tabular}


Tab. 5.39a: Aussetzungsquote bei Freiheitsstrafe aufgrund von Betrug nach Geschlecht

\begin{tabular}{|c|c|c|c|c|c|c|c|c|c|c|c|c|}
\hline & \multicolumn{6}{|c|}{ Frauen } & \multicolumn{6}{|c|}{ Männer } \\
\hline & \multicolumn{2}{|c|}{$\begin{array}{c}\text { Bis zu } 6 \\
\text { Mon. }\end{array}$} & \multicolumn{2}{|c|}{$\begin{array}{l}6 \text { Mon. bis } \\
\text { zu } 1 \text { Jahr }\end{array}$} & \multicolumn{2}{|c|}{$\begin{array}{l}1 \text { Jahr bis zu } \\
2 \text { Jahren }\end{array}$} & \multicolumn{2}{|c|}{$\begin{array}{c}\text { Bis zu } 6 \\
\text { Mon. }\end{array}$} & \multicolumn{2}{|c|}{$\begin{array}{l}6 \text { Mon. bis } \\
\text { zu } 1 \text { Jahr }\end{array}$} & \multicolumn{2}{|c|}{$\begin{array}{c}1 \text { Jahr bis zu } \\
2 \text { Jahren }\end{array}$} \\
\hline & abs. & in $\%$ & abs. & in $\%$ & abs. & in $\%$ & abs. & in & abs. & in $\%$ & abs. & in $\%$ \\
\hline JS m. Bew. & 2 & r & 45 & 10 & 11 & $18 \%$ & 96 & 17 & 146 & $18^{\circ}$ & 00 & 30 \\
\hline JS o. & 196 & $89 \%$ & 194 & $81 \%$ & 50 & $82 \%$ & 462 & $83 \%$ & 664 & $82 \%$ & 199 & 70 \\
\hline Gesamt & 221 & $100 \%$ & 239 & $100 \%$ & 61 & $100 \%$ & 558 & $100 \%$ & 810 & $100 \%$ & 284 & 100 \\
\hline
\end{tabular}

Tab. 5.40a: Anzahl der Tagessätze bei Geldstrafen aufgrund von Betrug nach Geschlecht

\begin{tabular}{|l|r|r|r|r|}
\hline & \multicolumn{2}{|c|}{ Frauen } & \multicolumn{2}{c|}{ Männer } \\
& abs. & \multicolumn{1}{|c|}{ in $\%$} & abs. & \multicolumn{1}{c|}{ in $\%$} \\
\hline $1-15$ & 2.991 & $13 \%$ & 4.904 & $10 \%$ \\
\hline $\mathbf{1 6 - 3 0}$ & 8.588 & $36 \%$ & 16.426 & $34 \%$ \\
\hline $\mathbf{3 1 - 5 0}$ & 5.257 & $22 \%$ & 11.287 & $23 \%$ \\
\hline $\mathbf{5 1 - 9 0}$ & 5.400 & $23 \%$ & 12.114 & $25 \%$ \\
\hline Über $\mathbf{9 0}$ & 1.427 & $6 \%$ & 3.915 & $8 \%$ \\
\hline Gesamt & 23.663 & $100 \%$ & 48.646 & $100 \%$ \\
\hline
\end{tabular}

Tab. 5.41a: Bezugsentscheidungen aufgrund von Betrug nach Anzahl der schwersten Voreintragung nach Geschlecht

\begin{tabular}{|l|r|r|r|r|}
\hline & \multicolumn{2}{|c|}{ Frauen } & \multicolumn{2}{c|}{ Männer } \\
& abs. & \multicolumn{1}{|c|}{ in $\%$} & abs. & \multicolumn{1}{c|}{ in $\%$} \\
\hline Keine & 21.347 & $68 \%$ & 33.561 & $51 \%$ \\
\hline $\mathbf{1}$ & 4.782 & $15 \%$ & 10.534 & $16 \%$ \\
\hline $\mathbf{2}$ & 2.088 & $7 \%$ & 6.115 & $9 \%$ \\
\hline $\mathbf{3}$ und 4 & 1.784 & $6 \%$ & 7.048 & $11 \%$ \\
\hline $\mathbf{5}$ und mehr & 1.277 & $4 \%$ & 8.957 & $14 \%$ \\
\hline Gesamt & 31.278 & $100 \%$ & 66.215 & $100 \%$ \\
\hline
\end{tabular}


Tab. 5.42a: Bequgsentscheidungen aufgrund von Betrug nach Art der schwersten Voreintragung nach Geschlecht

\begin{tabular}{|l|r|r|r|r|}
\hline & \multicolumn{2}{|c|}{ Frauen } & \multicolumn{2}{c|}{ Männer } \\
& abs. & \multicolumn{1}{|c|}{ in $\%$} & \multicolumn{1}{c|}{ abs. } & \multicolumn{1}{c|}{ in $\%$} \\
\hline FS/ JS o. Bew & 477 & $5 \%$ & 4.633 & $15 \%$ \\
\hline FS/ JS m. Bew & 1.689 & $17 \%$ & 7.939 & $25 \%$ \\
\hline Geldstrafe & 5.459 & $56 \%$ & 13.798 & $44 \%$ \\
\hline Sonst. Entsch. n. JGG & 710 & $7 \%$ & 2.404 & $8 \%$ \\
\hline Entsch. n. §§ 45, 47 JGG & 1.405 & $14 \%$ & 2.785 & $9 \%$ \\
\hline Gesamt & 9.740 & $100 \%$ & 31.559 & $100 \%$ \\
\hline
\end{tabular}

Tab. 5.43a: Jugendrichterlichen Reaktionen aufgrund von Betrug nach Anzahl der Voreintragungen und Geschlecht

\begin{tabular}{|c|c|c|c|c|c|c|c|c|c|c|}
\hline \multirow{3}{*}{$\begin{array}{l}\text { Art der } \\
\text { jugendstrafrecht- } \\
\text { lichen Reaktionen }\end{array}$} & \multicolumn{10}{|c|}{ Anzahl der Voreintragungen } \\
\hline & \multicolumn{2}{|c|}{ keine } & \multicolumn{2}{|c|}{1} & \multicolumn{2}{|c|}{2} & \multicolumn{2}{|c|}{3 und 4} & \multicolumn{2}{|c|}{5 und mehr } \\
\hline & $\mathbf{F}$ & M & $\mathbf{F}$ & M & $\mathbf{F}$ & M & $\mathbf{F}$ & M & $\mathbf{F}$ & M \\
\hline JS o. Bew. & $\begin{array}{r}0 \\
(0 \%)\end{array}$ & $\begin{array}{r}8 \\
(0,2 \%)\end{array}$ & $\begin{array}{r}5 \\
(1 \%)\end{array}$ & $\begin{array}{r}27 \\
(2 \%)\end{array}$ & $(0 \%)$ & $\begin{array}{r}27 \\
(3 \%)\end{array}$ & $\begin{array}{r}4 \\
(2 \%)\end{array}$ & $\begin{array}{r}46 \\
(6 \%)\end{array}$ & $(0 \%)^{-}$ & $\begin{array}{r}18 \\
(7 \%)\end{array}$ \\
\hline JS m. Bew. & $\begin{array}{r}21 \\
(1 \%)\end{array}$ & $\begin{array}{r}46 \\
(1 \%)\end{array}$ & $\begin{array}{r}25 \\
(3 \%)\end{array}$ & $\begin{array}{r}62 \\
(4 \%) \\
\end{array}$ & $\begin{array}{r}22 \\
(7 \%)\end{array}$ & $\begin{array}{r}64 \\
(8 \%)\end{array}$ & $\begin{array}{r}26 \\
(13 \%) \\
\end{array}$ & $\begin{array}{r}107 \\
(15 \%) \\
\end{array}$ & $\begin{array}{r}3 \\
(7 \%)\end{array}$ & $\begin{array}{r}65 \\
(25 \%) \\
\end{array}$ \\
\hline $\begin{array}{l}\text { sonst. Entsch. } n . \\
\text { JGG }\end{array}$ & $\begin{array}{r}482 \\
(15 \%)\end{array}$ & $\begin{array}{r}509 \\
(12 \%)\end{array}$ & $\begin{array}{r}252 \\
(31 \%)\end{array}$ & $\begin{array}{r}452 \\
(29 \%)\end{array}$ & $\begin{array}{r}134 \\
(42 \%)\end{array}$ & $\begin{array}{r}336 \\
(40 \%)\end{array}$ & $\begin{array}{r}98 \\
(51 \%)\end{array}$ & $\begin{array}{r}331 \\
(45 \%)\end{array}$ & $\begin{array}{r}23 \\
(53 \%)\end{array}$ & $\begin{array}{r}107 \\
(41 \%)\end{array}$ \\
\hline $\begin{array}{l}\text { Entsch. n. } \S \S 45,47 \\
\text { JGG }\end{array}$ & $\begin{array}{r}2.724 \\
(84 \%) \\
\end{array}$ & \begin{tabular}{|l|}
3.554 \\
$(86 \%)$ \\
\end{tabular} & $\begin{array}{r}524 \\
(65 \%) \\
\end{array}$ & $\begin{array}{r}1.020 \\
(65 \%) \\
\end{array}$ & $\begin{array}{r}161 \\
(51 \%) \\
\end{array}$ & $\begin{array}{r}410 \\
(49 \%) \\
\end{array}$ & $\begin{array}{r}66 \\
(34 \%) \\
\end{array}$ & $\begin{array}{r}250 \\
(34 \%) \\
\end{array}$ & $\begin{array}{r}17 \\
(40 \%) \\
\end{array}$ & $\begin{array}{r}74 \\
(28 \%) \\
\end{array}$ \\
\hline Gesamt & $\begin{array}{r}3.227 \\
(100 \%)\end{array}$ & $\begin{array}{r}4.117 \\
(100 \%) \\
\end{array}$ & $\begin{array}{r}806 \\
(100 \%) \\
\end{array}$ & $\begin{array}{r}1.561 \\
(100 \%) \\
\end{array}$ & $\begin{array}{r}317 \\
(100 \%) \\
\end{array}$ & $\begin{array}{r}837 \\
(100 \%) \\
\end{array}$ & $\begin{array}{r}194 \\
(100 \%) \\
\end{array}$ & $\begin{array}{r}734 \\
(100 \%) \\
\end{array}$ & $\begin{array}{r}43 \\
(100 \%) \\
\end{array}$ & $\begin{array}{r}264 \\
(100 \%) \\
\end{array}$ \\
\hline
\end{tabular}


Tab. 5.44a: Jugendrichterlichen Reaktionen aufgrund von Betrug nach Art der schwersten Voreintragung und Geschlecht

\begin{tabular}{|c|c|c|c|c|c|c|c|c|}
\hline \multirow{3}{*}{$\begin{array}{c}\text { Art der } \\
\text { jugendstrafrechtlichen } \\
\text { Reaktionen }\end{array}$} & \multicolumn{8}{|c|}{ Art der schwersten Voreintragungen } \\
\hline & \multicolumn{2}{|c|}{\begin{tabular}{|l|} 
Ambulante Reak- \\
tionen nach JGG
\end{tabular}} & \multicolumn{2}{|c|}{ Geldstrafe } & \multicolumn{2}{|c|}{ JS/FS m. Bew. } & \multicolumn{2}{|c|}{ JS/FS o. Bew. } \\
\hline & $F$ & M & $\mathbf{F}$ & M & $\mathbf{F}$ & M & $\mathbf{F}$ & M \\
\hline JS o. & $\begin{array}{r}6 \\
(0 \%) \\
\end{array}$ & $\begin{array}{r}92 \\
(3 \%) \\
\end{array}$ & $(0 \%)$ & $\begin{array}{r}8 \\
(5 \%) \\
\end{array}$ & $(0 \%)$ & $\begin{array}{r}6 \\
(7 \%) \\
\end{array}$ & $\begin{array}{r}1 \\
(20 \%)\end{array}$ & $(26 \%)$ \\
\hline JS n & $\begin{array}{r}55 \\
(4 \%) \\
\end{array}$ & $\begin{array}{r}244 \\
(8 \%) \\
\end{array}$ & $\begin{array}{r}16 \\
(21 \%) \\
\end{array}$ & $\begin{array}{r}28 \\
(19 \%) \\
\end{array}$ & $\begin{array}{r}2 \\
(14 \%) \\
\end{array}$ & $\begin{array}{r}12 \\
(14 \%) \\
\end{array}$ & $\begin{array}{r}2 \\
(40 \%) \\
\end{array}$ & \\
\hline sonst. E & $\begin{array}{r}457 \\
(36 \%) \\
\end{array}$ & $\begin{array}{l}1.117 \\
(36 \%) \\
\end{array}$ & $\begin{array}{r}37 \\
(49 \%) \\
\end{array}$ & $\begin{array}{r}54 \\
(36 \%)\end{array}$ & $\begin{array}{r}8 \\
(57 \%)\end{array}$ & $\begin{array}{r}34 \\
(41 \%)\end{array}$ & $\begin{array}{r}2 \\
(40 \%)\end{array}$ & $\begin{array}{r}7 \\
(16 \%)\end{array}$ \\
\hline $\begin{array}{l}\text { Entsch. n. § } \\
\text { JGG }\end{array}$ & $\begin{array}{r}738 \\
(59 \%) \\
\end{array}$ & $\begin{array}{r}1.639 \\
(53 \%) \\
\end{array}$ & $\begin{array}{r}22 \\
(29 \%) \\
\end{array}$ & $\begin{array}{r}58 \\
(39 \%) \\
\end{array}$ & $\begin{array}{r}4 \\
(29 \%) \\
\end{array}$ & $\begin{array}{r}31 \\
(37 \%) \\
\end{array}$ & $\begin{array}{r}0 \\
(0 \%) \\
\end{array}$ & $\begin{array}{r}17 \\
(40 \%) \\
\end{array}$ \\
\hline Gesa & $\begin{array}{r}1.256 \\
(100 \%) \\
\end{array}$ & $\begin{array}{r}3.092 \\
(100 \%)\end{array}$ & $\begin{array}{r}75 \\
(100 \%)\end{array}$ & $\begin{array}{r}148 \\
(100 \%)\end{array}$ & $\begin{array}{r}14 \\
(100 \%)\end{array}$ & $\begin{array}{r}83 \\
(100 \%)\end{array}$ & $\begin{array}{r}5 \\
(100 \%)\end{array}$ & $\begin{array}{r}43 \\
(100 \%)\end{array}$ \\
\hline
\end{tabular}

Tab. 5.45a: Sanktionen des StGB aufgrund von Betrug nach Anzabl der Voreintragungen und Geschlecht

\begin{tabular}{|c|c|c|c|c|c|c|c|c|c|c|}
\hline \multirow{3}{*}{$\begin{array}{c}\text { Art der } \\
\text { Sanktionen des StGB }\end{array}$} & \multicolumn{10}{|c|}{ Anzahl der Voreintragungen } \\
\hline & \multicolumn{2}{|c|}{ keine } & \multicolumn{2}{|c|}{1} & \multicolumn{2}{|c|}{2} & \multicolumn{2}{|c|}{3 und 4} & \multicolumn{2}{|c|}{5 und mehr } \\
\hline & $\mathbf{F}$ & M & $\mathbf{F}$ & M & $\mathbf{F}$ & M & $\mathbf{F}$ & M & $\mathbf{F}$ & M \\
\hline FS o. Bew. & 21 & 183 & 20 & 157 & 40 & 150 & 93 & 420 & 142 & 1.199 \\
\hline FS m. Bew. & 948 & 2.011 & 430 & 955 & 334 & 902 & 440 & 1.325 & 423 & 2.229 \\
\hline Geldstrafe & 17.079 & 27.088 & 3.504 & 7.778 & 1.378 & 4.161 & 1.046 & 4.478 & 656 & 5.141 \\
\hline Gesamt & 18.048 & 29.282 & 3.954 & 8.890 & 1.752 & 5.213 & 1.579 & 6.223 & 1.221 & 8.569 \\
\hline
\end{tabular}

Tab. 5.46a: Sanktionen des StGB aufgrund von Betrug nach Art der schwersten Voreintragung und Geschlecht

\begin{tabular}{|l|r|r|r|r|r|r|r|r|}
\hline \multirow{2}{*}{$\begin{array}{c}\text { Art der Sanktionen des } \\
\text { StGB }\end{array}$} & \multicolumn{7}{|c|}{ Art der schwersten Voreintragung } \\
\cline { 2 - 10 } & $\begin{array}{l}\text { Ambulante Reak- } \\
\text { tionen nach JGG } \\
\text { F }\end{array}$ & \multicolumn{2}{|c|}{ Geldstrafe } & \multicolumn{2}{|c|}{ JS/ FS m. Bew. } & \multicolumn{2}{|c|}{ JS/ FS o. Bew. } \\
& 1 & 9 & 15 & 130 & 161 & 669 & 101 & 970 \\
\hline FS o. Bew. & 44 & 116 & 832 & 1.931 & 552 & 1.977 & 165 & 1.176 \\
\hline FS m. Bew. & 801 & 1.935 & 4.510 & 11.461 & 952 & 5.130 & 204 & 2.391 \\
\hline Geldstrafe & 846 & 2.060 & 5.357 & 13.522 & 1.665 & 7.776 & 470 & 4.537 \\
\hline Gesamt & & & & & & & & M \\
\hline
\end{tabular}


Tab. 5.47a: Jugendstrafrechtliche Reaktionen aufgrund von Betrug nach Einschlägigkeit der Voreintragungen und Geschlecht

\begin{tabular}{|c|c|c|c|c|c|c|c|c|}
\hline \multirow{3}{*}{$\begin{array}{c}\text { Art der } \\
\text { jugendstrafrechtlichen } \\
\text { Reaktionen }\end{array}$} & \multicolumn{8}{|c|}{ Einschlägigkeit der Voreintragung } \\
\hline & \multicolumn{2}{|c|}{ Keine VE } & \multicolumn{2}{|c|}{$\begin{array}{l}\text { Nur VE(en) mit } \\
\text { anderen Delik- } \\
\text { ten }\end{array}$} & \multicolumn{2}{|c|}{$\begin{array}{l}\text { Auch VE(en) mit } \\
\text { Delikten einer } \\
\text { verwandten } \\
\text { Deliktsgruppe }\end{array}$} & \multicolumn{2}{|c|}{$\begin{array}{l}\text { Auch einschlä- } \\
\text { gige VE(en) }\end{array}$} \\
\hline & $\mathbf{F}$ & M & $\mathbf{F}$ & M & $\mathbf{F}$ & M & $\mathbf{F}$ & M \\
\hline JS o. Bew. & 0 & 8 & 3 & 91 & 4 & 11 & 2 & 16 \\
\hline JS m. Bew. & 21 & 46 & 47 & 200 & 11 & 41 & 18 & 57 \\
\hline Sonst. Entsch. n. JGG & 482 & 509 & 355 & 934 & 91 & 181 & 61 & 111 \\
\hline Entsch. $n . \S \S 45,47$ JGG & 2.724 & 3.554 & 595 & 1.454 & 94 & 173 & 79 & 127 \\
\hline Gesamt & 3.227 & 4.117 & 1.000 & 2.679 & 200 & 406 & 160 & 311 \\
\hline
\end{tabular}

Tab. 5.48a: Sanktionen des StGB aufgrund von Betrug nach Einschlägigkeit der Voreintragungen und Geschlecht

\begin{tabular}{|c|c|c|c|c|c|c|c|c|}
\hline \multirow{3}{*}{$\begin{array}{c}\text { Art der } \\
\text { Sanktionen des StGB }\end{array}$} & \multicolumn{8}{|c|}{ Einschlägigkeit der Voreintragung } \\
\hline & \multicolumn{2}{|c|}{ Keine VE } & \multicolumn{2}{|c|}{$\begin{array}{l}\text { Nur VE(en) mit } \\
\text { anderen Delikten }\end{array}$} & \multicolumn{2}{|c|}{$\begin{array}{c}\text { Auch VE(en) mit } \\
\text { Delikten einer } \\
\text { verwandten } \\
\text { Deliktsgruppe }\end{array}$} & \multicolumn{2}{|c|}{$\begin{array}{c}\text { Auch einschlägi- } \\
\text { ge VE(en) }\end{array}$} \\
\hline & $\mathbf{F}$ & M & $\mathbf{F}$ & M & $\mathbf{F}$ & M & $\mathbf{F}$ & M \\
\hline FS o. Bew. & 21 & 183 & 45 & 456 & 19 & 174 & 231 & 1.296 \\
\hline FS m. Bew. & 948 & 2.011 & 428 & 2.066 & 144 & 518 & 1.055 & 2.827 \\
\hline Geldstrafe & 17.079 & 27.088 & 3.090 & 12.577 & 686 & 2.360 & 2.808 & 6.621 \\
\hline Gesamt & 18.048 & 29.282 & 3.563 & 15.099 & 849 & 3.052 & 4.094 & 10.744 \\
\hline
\end{tabular}

Tab. 5.49a: Sanktionen des StGB aufgrund von Betrug unter Berücksichtigung multipler Faktoren nach Geschlecht

\begin{tabular}{|c|c|c|}
\hline & Frauen & Männer \\
\hline FS o. Bew. & 104 & 721 \\
\hline FS m. Bew. & 264 & 1.084 \\
\hline Geldstrafe & 301 & 1.743 \\
\hline Gesamt & 669 & 3.548 \\
\hline
\end{tabular}




\section{Tabellen zu Kapitel 6}

Tab. 6.1a: Art der Bezugsentscheidung und Art der Folgeentscheidung innerhalb von drei Jabren von Frauen

\begin{tabular}{|l|r|r|}
\hline & \multicolumn{1}{|c|}{ Bezugsentscheidung } & \multicolumn{2}{c|}{ Folgeentscheidung } \\
\hline FS/ JS o. Bew. & 1.496 & 2.851 \\
\hline FS/ JS m. Bew. & 12.695 & 8.512 \\
\hline Geldstrafe & 121.249 & 25.956 \\
\hline Sonst. Entsch. n. JGG & 12.712 & 7.000 \\
\hline Entsch. n. §§ 45, 47 JGG & 68.855 & 7.735 \\
\hline Keine Folgeentscheidung & & 165.375 \\
\hline Gesamt & 217.007 & 217.429 \\
\hline
\end{tabular}

Tab. 6.2a: Art der Folgeentscheidung nach Sanktionsart der Bezugsentscheidung

\begin{tabular}{|c|c|c|c|c|c|c|c|c|}
\hline \multirow{2}{*}{$\begin{array}{l}\text { Art der Folge- } \\
\text { entscheidung }\end{array}$} & \multicolumn{5}{|c|}{$\begin{array}{l}\text { Sanktionsart der } \\
\text { Bezugsentscheidung nach } \\
\text { Jugendstrafrecht }\end{array}$} & \multicolumn{3}{|c|}{$\begin{array}{l}\text { Sanktionsart der Bezugsent- } \\
\text { scheidung nach allgemeinem } \\
\text { Strafrecht }\end{array}$} \\
\hline & $\begin{array}{l}\text { JS o. } \\
\text { Bew. }\end{array}$ & $\begin{array}{l}\text { JS m. } \\
\text { Bew. }\end{array}$ & $\begin{array}{l}\text { Jugend- } \\
\text { arrest }\end{array}$ & $\begin{array}{l}\text { Sonst. } \\
\text { Entsch. } \\
\text { n. JGG }\end{array}$ & $\begin{array}{l}\text { Entsch. } \\
\text { n. } \$ \$ 45 \text {, } \\
47 \text { JGG }\end{array}$ & $\begin{array}{l}\text { FS o. } \\
\text { Bew. }\end{array}$ & $\begin{array}{l}\text { FS m. } \\
\text { Bew. }\end{array}$ & $\begin{array}{l}\text { Geld- } \\
\text { strafe }\end{array}$ \\
\hline FS/ JS o. Bew & 51 & 186 & 75 & 141 & 137 & 218 & 1.091 & 948 \\
\hline FS/ JS m. Bew & 36 & 156 & 190 & 453 & 576 & 153 & 1.395 & 5.545 \\
\hline $\begin{array}{l}\text { Sonst. ambu- } \\
\text { lante Reaktio- } \\
\text { nen }\end{array}$ & 42 & 173 & 631 & 3.485 & 14.177 & 146 & 1.294 & 20.612 \\
\hline \begin{tabular}{|l|} 
keine Folge- \\
entscheidung
\end{tabular} & 93 & 532 & 869 & 6.868 & 53.962 & 756 & 7.864 & 94.140 \\
\hline Gesamt & 222 & 1.047 & 1.765 & 10.947 & 68.852 & 1.273 & 11.644 & 121.245 \\
\hline
\end{tabular}


Tab. 6.3a: Art der Folgeentscheidung nach Geldstrafe

\begin{tabular}{|l|r|r|r|r|r|r|}
\hline \multirow{2}{*}{$\begin{array}{l}\text { Art der Folgeent- } \\
\text { scheidung }\end{array}$} & \multicolumn{6}{|c|}{ Anzahl der Tagessätze in der Bezugsentscheidung } \\
\cline { 2 - 7 } & \multicolumn{1}{|c|}{$1-15$} & \multicolumn{1}{|c|}{$16-30$} & \multicolumn{1}{|c|}{$\mathbf{3 1 - 5 0}$} & \multicolumn{1}{c|}{$\mathbf{5 1 - 9 0}$} & \multicolumn{1}{|c|}{ Über 90 } & \multicolumn{1}{c|}{ Gesamt } \\
\hline FS/JS o. Bew & 100 & 277 & 223 & 261 & 87 & 948 \\
\hline FS/JS m. Bew & 596 & 1.618 & 1.415 & 1.432 & 484 & 5.545 \\
\hline $\begin{array}{l}\text { Sonst. ambulante } \\
\text { Entscheidungen }\end{array}$ & 4.572 & 7.980 & 4.161 & 3.132 & 755 & 20.600 \\
\hline $\begin{array}{l}\text { Keine Folgeentschei- } \\
\text { dung }\end{array}$ & 17.646 & 36.915 & 20.349 & 14.817 & 4.223 & 93.950 \\
\hline Gesamt & 22.914 & 46.790 & 26.148 & 19.642 & 5.549 & 121.043 \\
\hline
\end{tabular}

Tab. 6.4a: Art der Folgeentscheidung nach Jugendstrafe

\begin{tabular}{|c|c|c|c|c|}
\hline \multirow{2}{*}{$\begin{array}{c}\text { Art der Folgeentschei- } \\
\text { dung }\end{array}$} & \multicolumn{2}{|c|}{ Jugendstrafe bis 2 Jahre } & \multicolumn{2}{|c|}{ Alle verbüßten Jugendstrafen } \\
\hline & JS m. Bew. & JS o. Bew. & Strafrestaussetzung & Vollverbüßung \\
\hline FS/ JS o. Bew. & 164 & 42 & 25 & 26 \\
\hline FS/ JS m. Bew & 121 & 26 & 17 & 19 \\
\hline \begin{tabular}{|l|} 
Sonst. ambulante \\
Folgeentscheidungen
\end{tabular} & 166 & 35 & 25 & 17 \\
\hline $\begin{array}{l}\text { Keine Folgeentschei- } \\
\text { dung }\end{array}$ & 522 & 62 & 64 & 29 \\
\hline Gesamt & 973 & 165 & 131 & 91 \\
\hline
\end{tabular}


Tab. 6.5a: Art der Folgeentscheidung nach Freiheitsstrafe

\begin{tabular}{|c|c|c|c|c|}
\hline \multirow{2}{*}{$\begin{array}{c}\text { Art der Folgeentschei- } \\
\text { dung }\end{array}$} & \multicolumn{2}{|c|}{ Freiheitsstrafe bis 2 Jahre } & \multicolumn{2}{|c|}{ Alle verbüßten Freiheitsstrafen } \\
\hline & FS m. Bew. & FS o. Bew. & $\begin{array}{c}\text { Strafrestaus } \\
\text { setzung }\end{array}$ & Vollverbüßung \\
\hline FS/ JS o. Bew. & 1.091 & 195 & 64 & 154 \\
\hline FS/ JS m. Bew & 1.395 & 133 & 60 & 93 \\
\hline \begin{tabular}{|l|} 
Sonst. ambulante \\
Folgeentscheidungen \\
\end{tabular} & 1.298 & 111 & 64 & 83 \\
\hline \begin{tabular}{|l|}
$\begin{array}{l}\text { Keine Folge- } \\
\text { entscheidung }\end{array}$ \\
\end{tabular} & 7.864 & 444 & 479 & 277 \\
\hline Gesamt & 11.648 & 883 & 667 & 607 \\
\hline
\end{tabular}

Tab. 6.6a: Art der Folgeentscheidung nach Anzabl der Voreintragungen für jugendliche und beranwachsende Frauen

\begin{tabular}{|l|r|r|r|r|r|}
\hline \multirow{2}{*}{$\begin{array}{l}\text { Art der Folgeentschei- } \\
\text { dung }\end{array}$} & \multicolumn{5}{|c|}{ Anzahl der Voreintragungen } \\
\cline { 2 - 6 } & \multicolumn{1}{|c|}{ Keine } & \multicolumn{1}{|c|}{$\mathbf{1}$} & \multicolumn{1}{|c|}{$\mathbf{3}$} & $\mathbf{3}-4$ & 5 und mehr \\
\hline FS/ JS 0. Bew & 154 & 112 & 100 & 175 & 105 \\
\hline FS/ JS m. Bew & 510 & 403 & 293 & 305 & 162 \\
\hline $\begin{array}{l}\text { Sonst. ambulante Ent- } \\
\text { scheidungen }\end{array}$ & 12.352 & 3.905 & 1.768 & 1.207 & 391 \\
\hline $\begin{array}{l}\text { Keine Folge- } \\
\text { entscheidung }\end{array}$ & 53.189 & 8.659 & 2.633 & 1.413 & 326 \\
\hline Gesamt & 66.205 & 13.079 & 4.794 & 3.100 & 984 \\
\hline
\end{tabular}

Tab. 6.7a: Art der Folgeentscheidung nach Art der schwersten der Voreintragung für jugendliche und heranwachsende Frauen

\begin{tabular}{|l|r|r|r|r|r|}
\hline \multirow{2}{*}{$\begin{array}{c}\text { Art der Folgeent- } \\
\text { scheidung }\end{array}$} & \multicolumn{5}{|c|}{ Art der schwersten Voreintragungen } \\
\cline { 2 - 7 } & $\begin{array}{c}\text { Entsch. n. §§ } \\
\text { 45, 47 JGG }\end{array}$ & $\begin{array}{c}\text { Sonst. Entsch. } \\
\text { n. JGG }\end{array}$ & Geldstrafe & $\begin{array}{c}\text { JS/ FS m. } \\
\text { Bew. }\end{array}$ & JS/ FS o. Bew. \\
\hline FS/ JS 0. Bew & 96 & 246 & 30 & 76 & 44 \\
\hline FS/ JS m. Bew & 423 & 577 & 84 & 57 & 22 \\
\hline $\begin{array}{l}\text { Sonst. ambulante } \\
\text { Entscheidungen }\end{array}$ & 4.569 & 2.276 & 285 & 114 & 27 \\
\hline $\begin{array}{l}\text { Keine Folge- } \\
\text { entscheidung }\end{array}$ & 9.451 & 2.941 & 402 & 185 & 52 \\
\hline Gesamt & 14.539 & 6.040 & 801 & 432 & 145 \\
\hline
\end{tabular}


Tab. 6.8a: Art der Folgeentscheidung nach Anzabl der Voreintragungen für erwachsene Frauen

\begin{tabular}{|c|c|c|c|c|c|}
\hline \multirow{2}{*}{$\begin{array}{l}\text { Art der Folge- } \\
\text { entscheidung }\end{array}$} & \multicolumn{5}{|c|}{ Anzahl der Voreintragungen } \\
\hline & Keine & 1 & 2 & $3-4$ & 5 und mehr \\
\hline FS/ JS o. Bew & 210 & 196 & 216 & 416 & 1.166 \\
\hline FS/ JS m. Bew & 1.593 & 1.173 & 964 & 1.209 & 1.900 \\
\hline $\begin{array}{l}\text { Sonst. ambulante Ent- } \\
\text { scheidungen }\end{array}$ & 10.343 & 3.915 & 2.075 & 2.061 & 2.577 \\
\hline Keine Folgeentscheidung & 72.359 & 12.263 & 5.155 & 4.593 & 4.744 \\
\hline Gesamt & 84.505 & 17.547 & 8.410 & 8.279 & 10.387 \\
\hline
\end{tabular}

Tab. 6.9a: Art der Folgeentscheidung nach Art der schwersten Voreintragung für erwachsene Frauen

\begin{tabular}{|l|r|r|r|r|r|}
\hline \multirow{2}{*}{$\begin{array}{c}\text { Art der Folgeent- } \\
\text { scheidung }\end{array}$} & \multicolumn{5}{|c|}{ Art der schwersten Voreintragungen } \\
\cline { 2 - 6 } & $\begin{array}{r}\text { Entsch. n. §§ } \\
\text { 45, 47 JGG }\end{array}$ & $\begin{array}{c}\text { Sonst. Entsch. } \\
\text { n. JGG }\end{array}$ & Geldstrafe & $\begin{array}{c}\text { JS/ FS m. } \\
\text { Bew. }\end{array}$ & JS/ FS o. Bew. \\
\hline FS/ JS 0. Bew & 20 & 63 & 634 & 728 & 549 \\
\hline FS/ JS m. Bew & 124 & 157 & 3.121 & 1.310 & 534 \\
\hline $\begin{array}{l}\text { Sonst. ambulante } \\
\text { Entscheidungen }\end{array}$ & 575 & 415 & 7.199 & 1.776 & 661 \\
\hline $\begin{array}{l}\text { Keine Folge- } \\
\text { entscheidung }\end{array}$ & 1.682 & 738 & 18.034 & 4.849 & 1.400 \\
\hline Gesamt & 2.401 & 1.418 & 28.988 & 8.663 & 3.144 \\
\hline
\end{tabular}


Tab. 6.10a: Art der Folgeentscheidung nach Deliktsgruppen

\begin{tabular}{|l|r|r|r|r|r|}
\hline \multicolumn{7}{|c|}{$\begin{array}{c}\text { Deliktsgruppe der } \\
\text { Bezugsentscheidung }\end{array}$} & \multicolumn{5}{|c|}{\begin{tabular}{c} 
Art der Folgeentscheidung \\
\cline { 2 - 6 }
\end{tabular}} & $\begin{array}{r}\text { FS/ JS o. } \\
\text { Bew. }\end{array}$ & $\begin{array}{c}\text { FS/ JS } \\
\text { m. Bew. }\end{array}$ & $\begin{array}{c}\text { sonst. ambulante } \\
\text { Folgeentscheidung }\end{array}$ & $\begin{array}{c}\text { keine Folgeentschei- } \\
\text { dung }\end{array}$ & Gesamt \\
\hline Tötungsdelikte & 2 & 2 & 2 & 101 & 107 \\
\hline Einf. KV & 77 & 219 & 1.892 & 6.328 & 8.516 \\
\hline Sonst. KV-Delikte & 87 & 186 & 1.303 & 3.453 & 5.029 \\
\hline Sonst. Gewaltdelikte & 84 & 103 & 358 & 824 & 1.369 \\
\hline $\begin{array}{l}\text { Bes. schwerer + qualif. } \\
\text { Diebstahl }\end{array}$ & 119 & 168 & 463 & 1.295 & 2.045 \\
\hline $\begin{array}{l}\text { Einf. Diebstahl + Un- } \\
\text { terschlagung }\end{array}$ & 1.075 & 2.992 & 14.578 & 51.636 & 70.281 \\
\hline Betrug u.a. & 413 & 1.697 & 6.012 & 29.603 & 37.725 \\
\hline Erschl. von Leistungen & 207 & 782 & 5.234 & 9.294 & 15.517 \\
\hline $\begin{array}{l}\text { Fahrl. KV + fahrl. Tö- } \\
\text { tung }\end{array}$ & 4 & 24 & 197 & 2.645 & 2.870 \\
\hline Verkehrsdelikte 0. Alk. & 88 & 425 & 1.949 & 15.097 & 17.559 \\
\hline Verkehrsdelikte m. Alk. & 32 & 339 & 1.091 & 12.035 & 13.497 \\
\hline Delikte n. BtMG & 313 & 479 & 5.055 & 7.508 \\
\hline
\end{tabular}


Tab. 6.11a: Art der Folgeentscheidung nach Art der Bezugsentscheidung aufgrund von Tötungsdelikten

\begin{tabular}{|l|r|r|r|r|r|r|}
\hline \multirow{2}{*}{$\begin{array}{c}\text { Art der Folgeent- } \\
\text { scheidung }\end{array}$} & \multicolumn{7}{|c|}{ Art der Bezugsentscheidung } \\
\cline { 2 - 8 } & FS o. Bew. & FS m. Bew. & JS o. Bew. & JS m. Bew. & Geldstrafe & $\begin{array}{c}\text { Sonst. } \\
\text { Entsch. } n \\
\text { JGG }\end{array}$ \\
\hline FS/ JS o. Bew & 1 & 1 & - & - & - & - \\
\hline FS/ JS m. Bew & 1 & - & 1 & - & - & - \\
\hline $\begin{array}{l}\text { Sonst. ambulante } \\
\text { Entscheidungen }\end{array}$ & - & - & 1 & 1 & - & 3 \\
\hline $\begin{array}{l}\text { Keine Folgeentschei- } \\
\text { dung }\end{array}$ & 41 & 8 & 15 & 4 & 1 & 3 \\
\hline Gesamt & 43 & 9 & 17 & 5 & 1 & \\
\hline
\end{tabular}

Tab. 6.11b: Art der Folgeentscheidung nach Art der Bezugsentscheidung aufgrund von einfacher Körperverletzung

\begin{tabular}{|c|c|c|c|c|c|c|}
\hline \multirow{2}{*}{$\begin{array}{l}\text { Art der Folgeent- } \\
\text { scheidung }\end{array}$} & \multicolumn{6}{|c|}{ Art der Bezugsentscheidung } \\
\hline & FS o. Bew. & FS m. Bew. & JS o. Bew. & JS m. Bew. & Geldstrafe & $\begin{array}{c}\text { Sonst. } \\
\text { Entsch. } n \text {. } \\
\text { JGG }\end{array}$ \\
\hline FS/ JS o. Bew & 4 & 10 & 2 & 12 & 23 & 26 \\
\hline FS/ JS m. Bew & 1 & 14 & 2 & 8 & 95 & 99 \\
\hline $\begin{array}{l}\text { Sonst. ambulante } \\
\text { Entscheidungen }\end{array}$ & 2 & 22 & 2 & 7 & 481 & 1.376 \\
\hline $\begin{array}{l}\text { Keine Folgeentschei- } \\
\text { dung }\end{array}$ & 4 & 80 & 1 & 18 & 3.112 & 3.106 \\
\hline Gesamt & 11 & 126 & 7 & 45 & 3.711 & 4.607 \\
\hline
\end{tabular}


Tab. 6.11c: Art der Folgeentscheidung nach Art der Bezugsentscheidung aufgrundvon sonstigen Körperverletzungsdelikten

\begin{tabular}{|l|r|r|r|r|r|r|}
\hline \multirow{2}{*}{$\begin{array}{c}\text { Art der Folgeent- } \\
\text { scheidung }\end{array}$} & \multicolumn{7}{|c|}{ Art der Bezugsentscheidung } \\
\cline { 2 - 7 } & FS o. Bew. & FS m. Bew. & JS o. Bew. & JS m. Bew. & Geldstrafe & $\begin{array}{c}\text { Sonst. } \\
\text { Entsch. } n \\
\text { JGG }\end{array}$ \\
\hline FS/ JS o. Bew & 4 & 34 & 2 & 21 & 2 & 24 \\
\hline FS/ JS m. Bew & 4 & 54 & 1 & 21 & 24 & 81 \\
\hline $\begin{array}{l}\text { Sonst. ambulante } \\
\text { Entscheidungen }\end{array}$ & 12 & 99 & 4 & 19 & 92 & 1.076 \\
\hline $\begin{array}{l}\text { Keine Folgeent- } \\
\text { scheidung }\end{array}$ & 23 & 454 & 5 & 70 & 304 & 2.558 \\
\hline Gesamt & 43 & 641 & 12 & 131 & 422 & 3.739 \\
\hline
\end{tabular}

Tab. 6.11d: Art der Folgeentscheidung nach Art der Bezugsentscheidung aufgrund von sonstigen Gewaltdeliken

\begin{tabular}{|l|r|r|r|r|r|r|}
\hline \multirow{2}{*}{$\begin{array}{c}\text { Art der Folgeent- } \\
\text { scheidung }\end{array}$} & \multicolumn{7}{|c|}{ Art der Bezugsentscheidung } \\
\cline { 2 - 7 } & FS o. Bew. & FS m. Bew. & JS o. Bew. & JS m. Bew. & Geldstrafe & $\begin{array}{c}\text { Sonst. } \\
\text { Entsch. } n \\
\text { JGG }\end{array}$ \\
\hline FS/ JS o. Bew & 14 & 18 & 8 & 29 & 0 & 15 \\
\hline FS/ JS m. Bew & 5 & 30 & 6 & 16 & 15 & 31 \\
\hline $\begin{array}{l}\text { Sonst. ambulante } \\
\text { Entscheidungen }\end{array}$ & 9 & 33 & 2 & 35 & 52 & 227 \\
\hline $\begin{array}{l}\text { Keine Folgeent- } \\
\text { scheidung }\end{array}$ & 39 & 136 & 11 & 62 & 207 & 363 \\
\hline Gesamt & 67 & 217 & 27 & 142 & 274 & 636 \\
\hline
\end{tabular}


Tab. 6.12a: Art der Folgeentscheidung nach Art der Bequgsentscheidung aufgrund von einfachem Diebstahl

\begin{tabular}{|l|r|r|r|r|r|r|}
\hline \multirow{2}{*}{$\begin{array}{c}\text { Art der Folgeent- } \\
\text { scheidung }\end{array}$} & \multicolumn{7}{|c|}{ Art der Bezugsentscheidung } \\
\cline { 2 - 7 } & FS o. Bew. & FS m. Bew. & JS o. Bew. & JS m. Bew. & Geldstrafe & $\begin{array}{c}\text { Sonst. } \\
\text { Entsch. } n \\
\text { JGG }\end{array}$ \\
\hline FS/ JS o. Bew & 98 & 422 & 21 & 42 & 352 & 140 \\
\hline FS/ JS m. Bew & 64 & 481 & 10 & 42 & 1.965 & 429 \\
\hline $\begin{array}{l}\text { Sonst. ambulante } \\
\text { Entscheidungen }\end{array}$ & 38 & 275 & 13 & 26 & 6.718 & 7.503 \\
\hline $\begin{array}{l}\text { Keine Folgeent- } \\
\text { scheidung }\end{array}$ & 155 & 1.451 & 20 & 56 & 20.239 & 29.700 \\
\hline Gesamt & 355 & 2.629 & 64 & 166 & 29.274 & 37.772 \\
\hline
\end{tabular}

Tab. 6.12b: Art der Folgeentscheidung nach Art der Bezugsentscheidung aufgrund von besonders schwerem und qualifiziertem Diebstabl

\begin{tabular}{|l|r|r|r|r|r|r|}
\hline \multirow{2}{*}{$\begin{array}{c}\text { Art der Folgeent- } \\
\text { scheidung }\end{array}$} & \multicolumn{7}{|c|}{ Art der Bezugsentscheidung } \\
\cline { 2 - 7 } & FS o. Bew. & FS m. Bew. & JS o. Bew. & JS m. Bew. & Geldstrafe & $\begin{array}{c}\text { Sonst. } \\
\text { Entsch. } n \\
\text { JGG }\end{array}$ \\
\hline FS/ JS o. Bew & 14 & 67 & 6 & 18 & 3 & 11 \\
\hline FS/ JS m. Bew & 5 & 65 & 5 & 18 & 31 & 44 \\
\hline $\begin{array}{l}\text { Sonst. ambulante } \\
\text { Entscheidungen }\end{array}$ & 13 & 59 & 5 & 18 & 45 & 323 \\
\hline $\begin{array}{l}\text { Keine Folgeent- } \\
\text { scheidung }\end{array}$ & 33 & 354 & 14 & 64 & 167 & 661 \\
\hline Gesamt & 65 & 545 & 30 & 118 & 246 & 1.039 \\
\hline
\end{tabular}


Tab. 6.12c: Art der Folgeentscheidung nach Art der Bezugsentscheidung aufgrund von Betrug u.a.

\begin{tabular}{|l|r|r|r|r|r|r|}
\hline \multirow{2}{*}{$\begin{array}{c}\text { Art der Folgeent- } \\
\text { scheidung }\end{array}$} & \multicolumn{7}{|c|}{ Art der Bezugsentscheidung } \\
\cline { 2 - 7 } & FS o. Bew. & FS m. Bew. & JS o. Bew. & JS m. Bew. & Geldstrafe & $\begin{array}{c}\text { Sonst. } \\
\text { Entsch. } n \\
\text { JGG }\end{array}$ \\
\hline JS/ FS 0. Bew & 21 & 220 & 1 & 18 & 128 & 25 \\
\hline JS/ FS m. Bew & 23 & 367 & 1 & 19 & 1.154 & 97 \\
\hline $\begin{array}{l}\text { Sonst. ambulante } \\
\text { Entscheidungen }\end{array}$ & 14 & 344 & 3 & 21 & 4.309 & 1.129 \\
\hline $\begin{array}{l}\text { Keine Folgeent- } \\
\text { scheidung }\end{array}$ & 131 & 2.394 & 6 & 64 & 20.827 & 4.490 \\
\hline Gesamt & 189 & 3.325 & 11 & 122 & 26.418 & 5.740 \\
\hline
\end{tabular}

Tab. 6.12d: Art der Folgeentscheidung nach Art der Bequgsentscheidung aufgrund von Erschleichen von Leistungen

\begin{tabular}{|l|r|r|r|r|r|r|}
\hline \multirow{2}{*}{$\begin{array}{c}\text { Art der Folgeent- } \\
\text { scheidung }\end{array}$} & \multicolumn{7}{|c|}{ Art der Bezugsentscheidung } \\
\cline { 2 - 7 } & FS o. Bew. & FS m. Bew. & JS o. Bew. & JS m. Bew. & Geldstrafe & $\begin{array}{c}\text { Sonst. } \\
\text { Entsch. } \mathbf{n} \\
\text { JGG }\end{array}$ \\
\hline JS/ FS o. Bew & 5 & 33 & 0 & 3 & 129 & 37 \\
\hline JS/ FS m. Bew & 5 & 44 & 0 & 4 & 580 & 149 \\
\hline $\begin{array}{l}\text { Sonst. ambulante } \\
\text { Entscheidungen }\end{array}$ & 3 & 25 & 1 & 2 & 2.756 & 2.447 \\
\hline $\begin{array}{l}\text { Keine Folgeent- } \\
\text { scheidung }\end{array}$ & 7 & 95 & 1 & 5 & 4.405 & 4.781 \\
\hline Gesamt & 20 & 197 & 2 & 14 & 7.870 & 7.414 \\
\hline
\end{tabular}


Tab. 6.13a: Art der Folgeentscheidung nach Art der Bezugsentscheidung aufgrund von fahrlässiger Tötung und fahrlässiger Körperverletzung

\begin{tabular}{|l|r|r|r|r|r|r|}
\hline \multirow{2}{*}{$\begin{array}{c}\text { Art der Folgeent- } \\
\text { scheidung }\end{array}$} & \multicolumn{7}{|c|}{ Art der Bezugsentscheidung } \\
\cline { 2 - 7 } & FS o. Bew. & FS m. Bew. & JS o. Bew. & JS m. Bew. & Geldstrafe & $\begin{array}{c}\text { Sonst. } \\
\text { Entsch. } n \\
\text { JGG }\end{array}$ \\
\hline FS/ JS o. Bew & - & 2 & - & - & 2 & -136 \\
\hline FS/ JS m. Bew & - & - & 1 & - & 21 & 1 \\
\hline $\begin{array}{l}\text { Sonst. ambulante } \\
\text { Entscheidungen }\end{array}$ & - & 6 & - & - & 136 & 54 \\
\hline $\begin{array}{l}\text { Keine Folgeent- } \\
\text { scheidung }\end{array}$ & 1 & 31 & -1 & 1 & 2.078 & 533 \\
\hline Gesamt & 1 & 39 & 1 & 1 & 2.237 & 589 \\
\hline
\end{tabular}

Tab. 6.13b: Art der Folgeentscheidung nach Art der Bequgsentscheidung aufgrund von Verkehrsdelikten unter Alkoholeinfluss

\begin{tabular}{|l|r|r|r|r|r|r|}
\hline \multirow{2}{*}{$\begin{array}{c}\text { Art der Folgeent- } \\
\text { scheidung }\end{array}$} & \multicolumn{7}{|c|}{ Art der Bezugsentscheidung } \\
\cline { 2 - 7 } & FS o. Bew. & FS m. Bew. & JS o. Bew. & JS m. Bew. & Geldstrafe & $\begin{array}{c}\text { Sonst. } \\
\text { Entsch. } n \text {. } \\
\text { JGG }\end{array}$ \\
\hline FS/ JS o. Bew & - & 11 & - & - & 20 & 1 \\
\hline FS/ JS m. Bew & - & 26 & - & - & 309 & 4 \\
\hline $\begin{array}{l}\text { Sonst. ambulante } \\
\text { Entscheidungen }\end{array}$ & - & 27 & - & - & 1.024 & 39 \\
\hline $\begin{array}{l}\text { Keine Folgeent- } \\
\text { scheidung }\end{array}$ & 1 & 216 & - & - & 11.505 & 302 \\
\hline Gesamt & 1 & 280 & - & - & 12.858 & 346 \\
\hline
\end{tabular}


Tab. 6.13c: Art der Folgeentscheidung nach Art der Bequgsentscheidung aufgrund von Verkebrsdelikten obne Alkoboleinfluss

\begin{tabular}{|l|r|r|r|r|r|r|}
\hline \multirow{2}{*}{$\begin{array}{c}\text { Art der Folgeent- } \\
\text { scheidung }\end{array}$} & \multicolumn{7}{|c|}{ Art der Bezugsentscheidung } \\
\cline { 2 - 7 } & FS o. Bew. & FS m. Bew. & JS o. Bew. & JS m. Bew. & Geldstrafe & $\begin{array}{c}\text { Sonst. } \\
\text { Entsch. } n \\
\text { JGG }\end{array}$ \\
\hline FS/ JS o. Bew & - & 5 & - & - & 8 & - \\
\hline FS/ JS m. Bew & 1 & 6 & - & - & 77 & 2 \\
\hline $\begin{array}{l}\text { Sonst. ambulante } \\
\text { Entscheidungen }\end{array}$ & - & 2 & - & - & 471 & 110 \\
\hline $\begin{array}{l}\text { Keine Folgeent- } \\
\text { scheidung }\end{array}$ & 1 & 37 & - & - & 7.380 & 1.143 \\
\hline Gesamt & 2 & 50 & - & - & 7.936 & 1.257 \\
\hline
\end{tabular}

Tab. 6.13d: Art der Folgeentscheidung nach Art der Bezugsentscheidung aufgrund von Delikten nach dem BtMG

\begin{tabular}{|l|r|r|r|r|r|r|}
\hline \multirow{2}{*}{$\begin{array}{c}\text { Art der Folgeent- } \\
\text { scheidung }\end{array}$} & \multicolumn{7}{|c|}{ Art der Bezugsentscheidung } \\
\cline { 2 - 7 } & FS o. Bew. & FS m. Bew. & JS o. Bew. & JS m. Bew. & Geldstrafe & $\begin{array}{c}\text { Sonst. } \\
\text { Entsch. } n \\
\text { JGG }\end{array}$ \\
\hline FS/ JS o. Bew & 30 & 138 & 9 & 33 & 79 & 22 \\
\hline FS/ JS m. Bew & 22 & 132 & 7 & 22 & 199 & 96 \\
\hline $\begin{array}{l}\text { Sonst. ambulante } \\
\text { Entscheidungen }\end{array}$ & 35 & 183 & 8 & 37 & 480 & 917 \\
\hline $\begin{array}{l}\text { Keine Folgeent- } \\
\text { scheidung }\end{array}$ & 193 & 789 & 17 & 137 & 1.443 & 2.474 \\
\hline Gesamt & 280 & 1.242 & 41 & 229 & 2.201 & 3.509 \\
\hline
\end{tabular}


Tab. 6.14a: Art des Rückfalls nach Deliktsgruppen der Bezugsentscheidung

\begin{tabular}{|l|r|r|r|r|r|}
\hline \multirow{2}{*}{\begin{tabular}{c} 
Deliktsgruppe der $\begin{array}{c}\text { Bezugs } \\
\text { entscheidung }\end{array}$ \\
\cline { 2 - 6 }
\end{tabular}} & Kein Rückfall & $\begin{array}{c}\text { Nur Rückfall } \\
\text { mit anderen } \\
\text { Delikten }\end{array}$ & $\begin{array}{c}\text { (Auch) Rück- } \\
\text { fall mit Delik- } \\
\text { ten einer } \\
\text { verwandten } \\
\text { Deliktsgruppe }\end{array}$ & $\begin{array}{c}\text { (Auch) ein- } \\
\text { schlägiger } \\
\text { Rückfall }\end{array}$ & Gesamt \\
\hline Tötungsdelikte & 101 & 4 & 2 & -107 \\
\hline Einf. KV & 6.310 & 1.387 & 307 & 512 & 8.516 \\
\hline Sonst. KV-Delikte & 3.442 & 1.031 & 309 & 247 & 5.029 \\
\hline Sonst. Gewaltdelikte & 822 & 374 & 133 & 40 & 1.369 \\
\hline $\begin{array}{l}\text { Bes. Schwerer + } \\
\text { qualif.Diebstahl }\end{array}$ & 1.283 & 341 & 333 & 88 & 2.045 \\
\hline $\begin{array}{l}\text { Einf. Diebstahl + Un- } \\
\text { terschlagung }\end{array}$ & 51.090 & 6.522 & 308 & 12.361 & 70.281 \\
\hline Betrug u.a. & 29.490 & 3.504 & 786 & 3.945 & 37.725 \\
\hline Erschl. von Leistungen & 9.170 & 1.703 & 554 & 4.090 & 15.517 \\
\hline $\begin{array}{l}\text { Fahrl. KV + fahrl. } \\
\text { Tötung }\end{array}$ & 2.641 & 183 & 32 & 14 & 2.870 \\
\hline Verkehrsdelikte 0. Alk. & 15.058 & 1.601 & 854 & 46 & 17.559 \\
\hline Verkehrsdelikte m. Alk. & 12.007 & 1.007 & 27 & 13.497 \\
\hline Delikte n. BtMG & 5.005 & 1.489 & 904 & 7.508 \\
\hline
\end{tabular}


Tab. 6.15a: Einschlägige Voreintragungen und Rückfälle bei Bezugsentscheidungen aufgrund von Körperverletzungsdelikten

\begin{tabular}{|c|c|c|c|c|c|c|c|c|}
\hline \multirow[b]{2}{*}{$\begin{array}{l}\text { Art des Rück- } \\
\text { falls }\end{array}$} & \multicolumn{4}{|c|}{ Einfache Körperverletzung } & \multicolumn{4}{|c|}{ Sonstige Körperverletzungsdelikte } \\
\hline & Keine VE & $\begin{array}{l}\text { Nur VE(en) } \\
\text { mit ande- } \\
\text { ren Delik- } \\
\text { ten }\end{array}$ & \begin{tabular}{|c|} 
(Auch) \\
VE(en) mit \\
anderen \\
Gewaltde- \\
likten
\end{tabular} & $\begin{array}{l}\text { (Auch) } \\
\text { einschlä- } \\
\text { gige } \\
\text { VE(en) }\end{array}$ & Keine VE & $\begin{array}{c}\text { Nur VE(en) } \\
\text { mit ande- } \\
\text { ren Delik- } \\
\text { ten }\end{array}$ & $\begin{array}{c}\text { (Auch) } \\
\text { VE(en) mit } \\
\text { anderen } \\
\text { Gewaltde- } \\
\text { likten }\end{array}$ & $\begin{array}{c}\text { (Auch) } \\
\text { einschlä- } \\
\text { gige } \\
\text { VE(en) }\end{array}$ \\
\hline Kein Rückfall & 4.829 & 984 & 188 & 309 & 2.431 & 662 & 178 & 171 \\
\hline $\begin{array}{l}\text { Nur Rückfall } \\
\text { mit anderen } \\
\text { Delikten } \\
\end{array}$ & 720 & 421 & 111 & 135 & 520 & 312 & 101 & 98 \\
\hline $\begin{array}{l}\text { (Auch) Rück- } \\
\text { fall mit ande- } \\
\text { ren Gewaltde- } \\
\text { likten }\end{array}$ & 176 & 79 & 20 & 32 & 166 & 63 & 36 & 44 \\
\hline $\begin{array}{l}\text { (Auch) ein- } \\
\text { schlägiger } \\
\text { Rückfall } \\
\end{array}$ & 307 & 106 & 35 & 64 & 134 & 61 & 28 & 24 \\
\hline Gesamt & 6.032 & 1.590 & 354 & 540 & 3.251 & 1.098 & 343 & 337 \\
\hline
\end{tabular}

Tab. 6.15b: Einschlägige Voreintragungen und Rückfälle bei Bequgsentscheidungen aufgrund von Tötungsdelikten und sonstigen Gewaltdelikten

\begin{tabular}{|c|c|c|c|c|c|c|c|c|}
\hline \multirow[b]{2}{*}{$\begin{array}{l}\text { Art des Rück- } \\
\text { falls }\end{array}$} & \multicolumn{4}{|c|}{ Tötungsdelikte } & \multicolumn{4}{|c|}{ Sonstige Gewaltdelikte } \\
\hline & Keine VE & $\begin{array}{c}\text { Nur VE(en) } \\
\text { mit ande- } \\
\text { ren Delik- } \\
\text { ten }\end{array}$ & $\begin{array}{c}\text { (Auch) } \\
\text { VE(en) mit } \\
\text { anderen } \\
\text { Gewaltde- } \\
\text { likten }\end{array}$ & $\begin{array}{c}\text { (Auch) } \\
\text { einschlä- } \\
\text { gige } \\
\text { VE(en) }\end{array}$ & Keine VE & $\begin{array}{c}\text { Nur VE(en) } \\
\text { mit ande- } \\
\text { ren Delik- } \\
\text { ten }\end{array}$ & \begin{tabular}{|c|} 
(Auch) \\
VE(en) mit \\
anderen \\
Gewaltde- \\
likten
\end{tabular} & $\begin{array}{c}\text { (Auch) } \\
\text { einschlä- } \\
\text { gige } \\
\text { VE(en) }\end{array}$ \\
\hline Kein Rückfall & 71 & 21 & 8 & 1 & 479 & 231 & 79 & 33 \\
\hline $\begin{array}{l}\text { Nur Rückfall } \\
\text { mit anderen } \\
\text { Delikten } \\
\end{array}$ & 1 & 2 & & 1 & 147 & 164 & 45 & 18 \\
\hline $\begin{array}{l}\text { (Auch) Rück- } \\
\text { fall mit ande- } \\
\text { ren Gewaltde- } \\
\text { likten }\end{array}$ & & & 2 & & 73 & 33 & 22 & 5 \\
\hline $\begin{array}{l}\text { (Auch) ein- } \\
\text { schlägiger } \\
\text { Rückfall }\end{array}$ & & & & & 13 & 16 & 5 & 6 \\
\hline Gesamt & 72 & 23 & 10 & 2 & 712 & 444 & 151 & 62 \\
\hline
\end{tabular}


Tab. 6.16a: Einschlägige Voreintragungen und Rückfälle bei Bezugsentscheidungen aufgrund von Diebstablsdelikten

\begin{tabular}{|c|c|c|c|c|c|c|c|c|}
\hline \multirow[b]{2}{*}{$\begin{array}{l}\text { Art des Rück- } \\
\text { falls }\end{array}$} & \multicolumn{4}{|c|}{$\begin{array}{l}\text { Besonders schwerer und qualifizierter Dieb- } \\
\text { stahl }\end{array}$} & \multicolumn{4}{|c|}{ Einfacher Diebstahl und Unterschlagung } \\
\hline & Keine VE & $\begin{array}{c}\text { Nur VE(en) } \\
\text { mit ande- } \\
\text { ren Delik- } \\
\text { ten }\end{array}$ & \begin{tabular}{|c|} 
(Auch) \\
VE(en) mit \\
anderen \\
Dieb- \\
stahls- \\
delikten \\
\end{tabular} & $\begin{array}{l}\text { (Auch) } \\
\text { einschlä- } \\
\text { gige } \\
\text { VE(en) }\end{array}$ & Keine VE & $\begin{array}{c}\text { Nur VE(en) } \\
\text { mit ande- } \\
\text { ren Delik- } \\
\text { ten }\end{array}$ & \begin{tabular}{|c|} 
(Auch) \\
VE(en) mit \\
anderen \\
Dieb- \\
stahls- \\
delikten \\
\end{tabular} & $\begin{array}{l}\text { (Auch) } \\
\text { einschlä- } \\
\text { gige } \\
\text { VE(en) }\end{array}$ \\
\hline Kein Rückfall & 811 & 129 & 272 & 71 & 39.506 & 2.848 & 114 & 8.622 \\
\hline \begin{tabular}{|l|} 
Nur Rückfall \\
mit anderen \\
Delikten \\
\end{tabular} & 118 & 77 & 116 & 30 & 3.690 & 920 & 45 & 1.867 \\
\hline $\begin{array}{l}\text { (Auch) Rück- } \\
\text { fall mit ande- } \\
\text { ren Dieb- } \\
\text { stahls-delikten }\end{array}$ & 128 & 42 & 117 & 46 & 147 & 48 & 4 & 109 \\
\hline $\begin{array}{l}\text { (Auch) ein- } \\
\text { schlägiger } \\
\text { Rückfall } \\
\end{array}$ & 26 & 13 & 32 & 17 & 6.336 & 954 & 67 & 5.004 \\
\hline Gesamt & 1.083 & 261 & 537 & 164 & 49.679 & 4.770 & 230 & 15.602 \\
\hline
\end{tabular}

Tab. 6.16b: Einschlägige Voreintragungen und Rückfälle bei Bequgsentscheidungen aufgrund von Täuschungsdelikten

\begin{tabular}{|l|r|r|r|r|r|r|r|r|}
\hline & \multicolumn{4}{|c|}{ Betrug u.a. } & \multicolumn{4}{c|}{ Erschl. v. Leistungen } \\
\cline { 2 - 9 } $\begin{array}{l}\text { Art des } \\
\text { Rückfalls }\end{array}$ & Keine VE & $\begin{array}{c}\text { Nur VE(en) } \\
\text { mit ande- } \\
\text { ren Delik- } \\
\text { ten }\end{array}$ & $\begin{array}{c}\text { (Auch) } \\
\text { VE(en) mit } \\
\text { anderen } \\
\text { Täu- } \\
\text { schungs- } \\
\text { delikten }\end{array}$ & $\begin{array}{c}\text { (Auch) } \\
\text { einschlä- } \\
\text { gige } \\
\text { VE(en) }\end{array}$ & Keine VE & $\begin{array}{c}\text { Nur VE(en) } \\
\text { mit ande- } \\
\text { ren Delik- } \\
\text { ten }\end{array}$ & $\begin{array}{c}\text { (Auch) } \\
\text { anderen } \\
\text { Täu- } \\
\text { schungs- } \\
\text { delikten }\end{array}$ & $\begin{array}{c}\text { (Auch) } \\
\text { einschlä- } \\
\text { gige } \\
\text { VE(en) }\end{array}$ \\
\hline Kein Rückfall & 22.095 & 3.768 & 404 & 3.223 & 5.308 & 1.791 & 287 & 1.784 \\
\hline $\begin{array}{l}\text { Nur Rückfall } \\
\text { mit anderen } \\
\text { Delikten }\end{array}$ & 1.744 & 940 & 100 & 720 & 708 & 539 & 86 & 370 \\
\hline $\begin{array}{l}\text { (Auch) } \\
\text { Rückfall mit } \\
\text { anderen } \\
\text { Täuschungs- } \\
\text { delikten }\end{array}$ & 310 & 206 & 148 & 122 & 199 & 159 & 39 & 157 \\
\hline $\begin{array}{l}\text { (Auch) } \\
\text { einschlägi- } \\
\text { ger Rückfall }\end{array}$ & 1.795 & 759 & 108 & 1.283 & 1.499 & 882 & 146 & 1.563 \\
\hline Gesamt & 25.944 & 5.673 & 760 & 5.348 & 7.714 & 3.371 & 558 & 3.874 \\
\hline
\end{tabular}


Tab. 6.17a: Einschlägige Voreintragungen und Rückfälle bei Bezugsentscheidungen aufgrund von Verkebrsdelikten

\begin{tabular}{|c|c|c|c|c|c|c|}
\hline \multirow[b]{2}{*}{$\begin{array}{l}\text { Deliktsgruppe der } \\
\text { Bezugsentscheidung }\end{array}$} & \multirow[b]{2}{*}{$\begin{array}{l}\text { Art der Vorein- } \\
\text { tragung }\end{array}$} & \multicolumn{5}{|c|}{ Art des Rückfalls } \\
\hline & & kein Rückfall & $\begin{array}{c}\text { nur Rückfall } \\
\text { mit anderen } \\
\text { Delikten }\end{array}$ & \begin{tabular}{|c|} 
(auch) \\
Rückfall mit \\
anderen \\
$\begin{array}{c}\text { Verkehrsde- } \\
\text { likten }\end{array}$ \\
\end{tabular} & $\begin{array}{c}\text { (auch) } \\
\text { einschlägi- } \\
\text { ger Rückfall }\end{array}$ & Gesamt \\
\hline \multirow{4}{*}{$\begin{array}{l}\text { Fahrl. KV + fahrl. } \\
\text { Tötung }\end{array}$} & keine VE & 2.333 & 109 & 20 & 14 & 2.476 \\
\hline & \begin{tabular}{|l} 
nur VE(en) \\
mit anderen \\
Delikten
\end{tabular} & 222 & 56 & 5 & & 283 \\
\hline & \begin{tabular}{|l|} 
(auch) VE(en) \\
mit anderen \\
Verkehrsdelikten
\end{tabular} & 61 & 13 & 6 & - & 80 \\
\hline & \begin{tabular}{|l} 
(auch) einschlä- \\
gige \\
VE(en) \\
\end{tabular} & 25 & 5 & 1 & - & 31 \\
\hline \multirow{4}{*}{ Verkehrsdelikte o. Alk. } & keine VE & 12.440 & 804 & 442 & 21 & 13.707 \\
\hline & \begin{tabular}{|l|} 
nur VE(en) \\
mit anderen \\
Delikten \\
\end{tabular} & 1.748 & 544 & 197 & 16 & 2.505 \\
\hline & \begin{tabular}{|l|} 
(auch) VE(en) \\
mit anderen \\
Verkehrsdelikten \\
\end{tabular} & 833 & 241 & 206 & 8 & 1.288 \\
\hline & $\begin{array}{l}\text { (auch) einschlä- } \\
\text { gige } \\
\text { VE(en) }\end{array}$ & 37 & 12 & 9 & 1 & 59 \\
\hline \multirow{4}{*}{ Verkehrsdelikte m. Alk. } & keine VE & 10.423 & 638 & 19 & 326 & 11.406 \\
\hline & \begin{tabular}{|l|} 
nur VE(en) \\
mit anderen \\
Delikten \\
\end{tabular} & 1.273 & 279 & 7 & 101 & 1.660 \\
\hline & $\begin{array}{l}\text { (auch) VE(en) } \\
\text { mit anderen } \\
\text { Verkehrsdelikten }\end{array}$ & 46 & 14 & & 6 & 66 \\
\hline & $\begin{array}{l}\text { (auch) einschlä- } \\
\text { gige } \\
\text { VE(en) }\end{array}$ & 265 & 76 & 1 & 23 & 365 \\
\hline
\end{tabular}


Tab. 6.17b: Einschlägige Voreintragungen und Rückfälle bei Bequgsentscheidungen aufgrund von Delikten nach dem BtMG

\begin{tabular}{|l|r|r|r|r|}
\hline \multirow{2}{*}{ Art des Rückfalls } & \multicolumn{5}{|c|}{ Delikte nach dem BtMG } \\
\cline { 2 - 6 } & Keine VE & $\begin{array}{c}\text { Nur VE(en) mit } \\
\text { anderen Delikten }\end{array}$ & $\begin{array}{c}\text { (Auch) VE(en) mit } \\
\text { anderen Diebstahls- } \\
\text { delikten }\end{array}$ & $\begin{array}{c}\text { (Auch) einschlä- } \\
\text { gige VE(en) }\end{array}$ \\
\hline Kein Rückfall & 3.084 & 794 & 1.018 & 109 \\
\hline $\begin{array}{l}\text { Nur Rückfall mit } \\
\text { anderen Delikten }\end{array}$ & 552 & 353 & 546 & 38 \\
\hline $\begin{array}{l}\text { (Auch) Rückfall mit } \\
\text { anderen Diebstahls- } \\
\text { delikten }\end{array}$ & 295 & 168 & 406 & 35 \\
\hline $\begin{array}{l}\text { (Auch) einschlägi- } \\
\text { ger Rückfall }\end{array}$ & 47 & 28 & 32 & 35 \\
\hline Gesamt & 3.978 & 1.343 & 2.002 & 3 \\
\hline
\end{tabular}

Tab. 6.18a: Dauer bis zum ersten Rückfall nach Altersgruppe

\begin{tabular}{|l|r|r|r|r|r|r|}
\hline & \multicolumn{2}{|c|}{ Erwachsene } & \multicolumn{2}{c|}{ Heranwachsende } & \multicolumn{2}{c|}{ Jugendliche } \\
& abs. & \multicolumn{1}{c}{ in $\%$} & abs. & \multicolumn{1}{c|}{ in $\%$} & abs. & \multicolumn{1}{c|}{ in $\%$} \\
\hline Kein Rückfall & 99.114 & $77 \%$ & 21.684 & $76 \%$ & 44.565 & $75 \%$ \\
\hline Bis 3 Mon. & 5.216 & $4 \%$ & 1.367 & $5 \%$ & 2.778 & $5 \%$ \\
\hline Über 3 bis 6 Mon. & 4.410 & $3 \%$ & 1.122 & $4 \%$ & 2.272 & $4 \%$ \\
\hline Über 6 bis 12 Mon. & 6.908 & $5 \%$ & 1.549 & $5 \%$ & 3.443 & $6 \%$ \\
\hline $\begin{array}{l}\text { Über 12 bis 18 } \\
\text { Mon. }\end{array}$ & 4.924 & $4 \%$ & 1.037 & $4 \%$ & 2.488 & $4 \%$ \\
\hline Über 18 bis 24 & 3.714 & $3 \%$ & 757 & $3 \%$ & 1.888 & $3 \%$ \\
\hline Über 24 bis 30 & 2.772 & $2 \%$ & 572 & $2 \%$ & 1.398 & $2 \%$ \\
\hline $\begin{array}{l}\text { Über 30 bis 36 } \\
\text { Mon. }\end{array}$ & 2.070 & $2 \%$ & 366 & $1 \%$ & 986 & $2 \%$ \\
\hline Gesamt & 129.128 & $100 \%$ & 28.454 & $100 \%$ & 59.818 & $100 \%$ \\
\hline
\end{tabular}


Tab. 6.19a: Art der Folgeentscheidung nach Altersgruppe in der Bezugsentscheidung

\begin{tabular}{|l|r|r|r|r|r|}
\hline $\begin{array}{c}\text { Altersgruppe in der } \\
\text { Bezugsentscheidung }\end{array}$ & $\begin{array}{l}\text { FS/ JS o. } \\
\text { Bew. }\end{array}$ & $\begin{array}{c}\text { FS/ JS m. } \\
\text { Bew. }\end{array}$ & $\begin{array}{c}\text { Sonst. ambu- } \\
\text { lante Sankti- } \\
\text { onen }\end{array}$ & $\begin{array}{c}\text { Keine Folge- } \\
\text { entscheidung }\end{array}$ & Gesamt \\
\hline $\mathbf{1 4 - 1 7}$ & 325 & 801 & 14.046 & 44.536 & 59.708 \\
\hline $\mathbf{1 8 - 2 0}$ & 321 & 872 & 5.573 & 21.684 & 28.450 \\
\hline $\mathbf{2 1 - 2 4}$ & 501 & 1.391 & 4.336 & 15.938 & 22.166 \\
\hline $\mathbf{2 5 - 2 9}$ & 464 & 1.283 & 3.502 & 14.488 & 19.737 \\
\hline $\mathbf{3 0 - 3 4}$ & 363 & 1.100 & 2.909 & 12.870 & 17.242 \\
\hline $\mathbf{3 5 - 3 9}$ & 323 & 1.072 & 2.963 & 13.757 & 18.115 \\
\hline $\mathbf{4 0 - 4 4}$ & 244 & 814 & 2.623 & 13.261 & 16.942 \\
\hline $\mathbf{4 5 - 4 9}$ & 151 & 490 & 1.809 & 9.880 & 12.330 \\
\hline $\mathbf{5 0 - 5 9}$ & 124 & 493 & 1.830 & 11.665 & 14.112 \\
\hline$>\mathbf{6 0}$ & 34 & 196 & 989 & 7.255 & 8.474 \\
\hline
\end{tabular}

Tab. 6.20a: Sanktionsart der Folgeeintragung nach Geschlecht

\begin{tabular}{|c|c|c|}
\hline & Frauen & Männer \\
\hline FS o. Bew. & 2.410 & 29.037 \\
\hline FS m. Bew. & 7.516 & 50.135 \\
\hline JS o. Bew. & 440 & 8.201 \\
\hline JS m. Bew. & 996 & 12.042 \\
\hline Geldstrafe & 25.954 & 128.932 \\
\hline Sonst. Entsch. nach JGG & 6.958 & 43.872 \\
\hline Entsch. n. §§ 45, 47 JGG & 7.669 & 30.174 \\
\hline Gesamt & 51.943 & 302.393 \\
\hline
\end{tabular}


Tab. 6.21a: Dauer bis zum ersten Rückfall nach Geschlecht

\begin{tabular}{|l|r|r|r|r|r|r|}
\hline & \multicolumn{2}{|c|}{ Frauen } & \multicolumn{2}{c|}{ Männer } & \multicolumn{2}{c|}{ Insgesamt } \\
\hline Kein Rückfall & 165.375 & $77 \%$ & 531.641 & $64 \%$ & 697.016 & $66 \%$ \\
\hline Bis 3 Mon. & 9.364 & $4 \%$ & 54.057 & $6 \%$ & 63.421 & $6 \%$ \\
\hline Über 3 bis 6 Mon. & 7.807 & $4 \%$ & 46.203 & $6 \%$ & 54.010 & $5 \%$ \\
\hline Über 6 bis 12 Mon. & 11.902 & $6 \%$ & 70.685 & $8 \%$ & 82.587 & $8 \%$ \\
\hline Über 12 bis 18 & 8.458 & $4 \%$ & 49.181 & $6 \%$ & 57.639 & $5 \%$ \\
\hline Mon. & 6.364 & $3 \%$ & 36.005 & $4 \%$ & 42.369 & $4 \%$ \\
\hline Über 18 bis 24 & 4.747 & $2 \%$ & 27.329 & $3 \%$ & 32.076 & $3 \%$ \\
\hline Über 24 bis 30 & 3.426 & $2 \%$ & 19.343 & $2 \%$ & 22.769 & $2 \%$ \\
\hline $\begin{array}{l}\text { Über 30 bis 36 } \\
\text { Mon. }\end{array}$ & 217.443 & $100 \%$ & 834.444 & $100 \%$ & 1.051 .887 & $100 \%$ \\
\hline Gesamt & & & & \multicolumn{1}{c}{ in $\%$} & & \multicolumn{1}{c|}{ abs. } \\
\hline
\end{tabular}

Tab. 6.21b: Dauer bis zum ersten Rückfall nach Bezugsentscheidungen aufgrund von Tötungsdelikten nach Geschlecht

\begin{tabular}{|l|r|r|r|r|r|r|}
\hline & \multicolumn{2}{|c|}{ Frauen } & \multicolumn{2}{c|}{ Männer } & \multicolumn{2}{c|}{ Insgesamt } \\
& abs. & \multicolumn{1}{c|}{ in $\%$} & abs. & \multicolumn{1}{c|}{ in $\%$} & abs. & \multicolumn{1}{c|}{ in $\%$} \\
\hline Kein Rückfall & 101 & $94 \%$ & 637 & $80 \%$ & 738 & $82 \%$ \\
\hline Bis 3 Mon. & - & $0 \%$ & 17 & $2 \%$ & 17 & $2 \%$ \\
\hline Über 3 bis 6 Mon. & - & $0 \%$ & 16 & $2 \%$ & 16 & $2 \%$ \\
\hline Über 6 bis 12 Mon. & 1 & $1 \%$ & 46 & $6 \%$ & 47 & $5 \%$ \\
\hline Über 12 bis 18 & 3 & $3 \%$ & 34 & $4 \%$ & 37 & $4 \%$ \\
\hline Mon. & - & $0 \%$ & 23 & $3 \%$ & 23 & $3 \%$ \\
\hline Über 18 bis 24 & 1 & $1 \%$ & 12 & $2 \%$ & 13 & $1 \%$ \\
\hline Über 24 bis 30 & 1 & $1 \%$ & 12 & $2 \%$ & 13 & $1 \%$ \\
\hline $\begin{array}{l}\text { Über 30 bis 36 } \\
\text { Mon. }\end{array}$ & 107 & $100 \%$ & 797 & $100 \%$ & 904 & $100 \%$ \\
\hline Gesamt & & & & &
\end{tabular}


Tab. 6.21c: Dauer bis zum ersten Rückfall nach Bezugsentscheidungen aufgrund von einfacher Körperverletzung nach Geschlecht

\begin{tabular}{|l|r|r|r|r|r|r|}
\hline & \multicolumn{2}{|c|}{ Frauen } & \multicolumn{2}{c|}{ Männer } & \multicolumn{2}{c|}{ Insgesamt } \\
& abs. & \multicolumn{1}{|c}{ in $\%$} & abs. & \multicolumn{1}{c|}{ in $\%$} & \multicolumn{1}{c|}{ abs. } & \multicolumn{1}{c|}{ in $\%$} \\
\hline Kein Rückfall & 6.328 & $74 \%$ & 30.473 & $59 \%$ & 36.801 & $61 \%$ \\
\hline Bis 3 Mon. & 354 & $4 \%$ & 3.714 & $7 \%$ & 4.068 & $7 \%$ \\
\hline Über 3 bis 6 Mon. & 313 & $4 \%$ & 3.122 & $6 \%$ & 3.435 & $6 \%$ \\
\hline Über $\mathbf{6}$ bis 12 Mon. & 507 & $6 \%$ & 5.030 & $10 \%$ & 5.537 & $9 \%$ \\
\hline $\begin{array}{l}\text { Über 12 bis 18 } \\
\text { Mon. }\end{array}$ & 400 & $5 \%$ & 3.449 & $7 \%$ & 3.849 & $6 \%$ \\
\hline Über 18 bis 24 & 286 & $3 \%$ & 2.470 & $5 \%$ & 2.756 & $5 \%$ \\
\hline Über 24 bis 30 & 178 & $2 \%$ & 1.878 & $4 \%$ & 2.056 & $3 \%$ \\
\hline $\begin{array}{l}\text { Über 30 bis 36 } \\
\text { Mon. }\end{array}$ & 150 & $2 \%$ & 1.268 & $2 \%$ & 1.418 & $2 \%$ \\
\hline Gesamt & 8.516 & $100 \%$ & 51.404 & $100 \%$ & 59.920 & $100 \%$ \\
\hline
\end{tabular}

Tab. 6.21d: Dauer bis zum ersten Rückfall nach Bequgsentscheidungen aufgrund von sonstigen Körperverletzungsdelikten nach Geschlecht

\begin{tabular}{|l|r|r|r|r|r|r|}
\hline & \multicolumn{2}{|c|}{ Frauen } & \multicolumn{2}{c|}{ Männer } & \multicolumn{2}{c|}{ Insgesamt } \\
& abs. & \multicolumn{1}{c|}{ in $\%$} & abs. & \multicolumn{1}{c|}{ in $\%$} & \multicolumn{1}{c|}{ abs. } & \multicolumn{1}{c|}{ in $\%$} \\
\hline Kein Rückfall & 3.453 & $69 \%$ & 17.053 & $54 \%$ & 20.506 & $56 \%$ \\
\hline Bis 3 Mon. & 270 & $5 \%$ & 2.488 & $8 \%$ & 2.758 & $8 \%$ \\
\hline Über 3 bis 6 Mon. & 256 & $5 \%$ & 2.243 & $7 \%$ & 2.499 & $7 \%$ \\
\hline Über 6 bis 12 Mon. & 384 & $8 \%$ & 3.360 & $11 \%$ & 3.744 & $10 \%$ \\
\hline $\begin{array}{l}\text { Über 12 bis 18 } \\
\text { Mon. }\end{array}$ & 260 & $5 \%$ & 2.382 & $8 \%$ & 2.642 & $7 \%$ \\
\hline Über 18 bis 24 & 158 & $3 \%$ & 1.755 & $6 \%$ & 1.913 & $5 \%$ \\
\hline Über 24 bis 30 & 140 & $3 \%$ & 1.273 & $4 \%$ & 1.413 & $4 \%$ \\
\hline $\begin{array}{l}\text { Über 30 bis 36 } \\
\text { Mon. }\end{array}$ & 108 & $2 \%$ & 887 & $3 \%$ & 995 & $3 \%$ \\
\hline Gesamt & 5.029 & $100 \%$ & 31.441 & $100 \%$ & 36.470 & $100 \%$ \\
\hline
\end{tabular}


Tab. 6.21e: Dauer bis zum ersten Rückfall nach Bequgsentscheidungen aufgrund von sonstigen Gewaltdelikten nach Geschlecht

\begin{tabular}{|l|r|r|r|r|r|r|}
\hline & \multicolumn{2}{|c|}{ Frauen } & \multicolumn{2}{c|}{ Männer } & \multicolumn{2}{c|}{ Insgesamt } \\
& abs. & \multicolumn{1}{|c|}{ in $\%$} & abs. & \multicolumn{1}{c|}{ in $\%$} & \multicolumn{1}{c|}{ abs. } & \multicolumn{1}{c|}{ in } \\
\hline Kein Rückfall & 824 & $60 \%$ & 7.967 & $50 \%$ & 8.791 & $51 \%$ \\
\hline Bis 3 Mon. & 113 & $8 \%$ & 1.394 & $9 \%$ & 1.507 & $9 \%$ \\
\hline Über 3 bis 6 Mon. & 94 & $7 \%$ & 1.230 & $8 \%$ & 1.324 & $8 \%$ \\
\hline Über 6 bis 12 Mon. & 114 & $8 \%$ & 1.936 & $12 \%$ & 2.050 & $12 \%$ \\
\hline Über 12 bis 18 & 96 & $7 \%$ & 1.279 & $8 \%$ & 1.375 & $8 \%$ \\
\hline $\begin{array}{l}\text { Mon. } \\
\text { Über 18 bis 24 }\end{array}$ & 62 & $5 \%$ & 889 & $6 \%$ & 951 & $6 \%$ \\
\hline Über 24 bis 30 & 46 & $3 \%$ & 683 & $4 \%$ & 729 & $4 \%$ \\
\hline $\begin{array}{l}\text { Über 30 bis 36 } \\
\text { Mon. }\end{array}$ & 20 & $1 \%$ & 440 & $3 \%$ & 460 & $3 \%$ \\
\hline Gesamt & 1.369 & $100 \%$ & 15.818 & $100 \%$ & 17.187 & $100 \%$ \\
\hline
\end{tabular}

Tab. 6.21f: Dauer bis zum ersten Rückfall nach Bequgsentscheidungen aufgrund von besonders schwerem und qualifiziertem Diebstahl nach Geschlecht

\begin{tabular}{|l|r|r|r|r|r|r|}
\hline & \multicolumn{2}{|c|}{ Frauen } & \multicolumn{2}{c|}{ Männer } & \multicolumn{2}{c|}{ Insgesamt } \\
& abs. & \multicolumn{1}{c|}{ in $\%$} & \multicolumn{1}{c|}{ abs. } & \multicolumn{1}{c|}{ in $\%$} & \multicolumn{1}{c|}{ abs. } & \multicolumn{1}{c|}{ in $\%$} \\
\hline Kein Rückfall & 1.295 & $63 \%$ & 11.757 & $47 \%$ & 13.052 & $48 \%$ \\
\hline Bis 3 Mon. & 149 & $7 \%$ & 2.681 & $11 \%$ & 2.830 & $10 \%$ \\
\hline Über 3 bis 6 Mon. & 119 & $6 \%$ & 2.294 & $9 \%$ & 2.413 & $9 \%$ \\
\hline Über 6 bis 12 Mon. & 174 & $9 \%$ & 3.253 & $13 \%$ & 3.427 & $13 \%$ \\
\hline $\begin{array}{l}\text { Über 12 bis 18 } \\
\text { Mon. }\end{array}$ & 118 & $6 \%$ & 2.093 & $8 \%$ & 2.211 & $8 \%$ \\
\hline Über 18 bis 24 & 88 & $4 \%$ & 1.356 & $5 \%$ & 1.444 & $5 \%$ \\
\hline Über 24 bis 30 & 64 & $3 \%$ & 1.011 & $4 \%$ & 1.075 & $4 \%$ \\
\hline $\begin{array}{l}\text { Über 30 bis 36 } \\
\text { Mon. }\end{array}$ & 38 & $2 \%$ & 710 & $3 \%$ & 748 & $3 \%$ \\
\hline Gesamt & 2.045 & $100 \%$ & 25.155 & $100 \%$ & 27.200 & $100 \%$ \\
\hline
\end{tabular}


Tab. 6.21g: Dauer bis zum ersten Rückfall nach Bezugsentscheidungen aufgrund von einfachem Diebstabl und Unterschlagung nach Geschlecht

\begin{tabular}{|l|r|r|r|r|r|r|}
\hline & \multicolumn{2}{|c|}{ Frauen } & \multicolumn{2}{c|}{ Männer } & \multicolumn{2}{c|}{ Insgesamt } \\
\hline Kein Rückfall & 51.636 & $73 \%$ & 69.460 & $55 \%$ & 121.096 & $62 \%$ \\
\hline Bis 3 Mon. & 3.449 & $5 \%$ & 11.305 & $9 \%$ & 14.754 & $8 \%$ \\
\hline Über 3 bis 6 Mon. & 2.817 & $4 \%$ & 9.011 & $7 \%$ & 11.828 & $6 \%$ \\
\hline Über 6 bis 12 Mon. & 4.253 & $6 \%$ & 12.950 & $10 \%$ & 17.203 & $9 \%$ \\
\hline $\begin{array}{l}\text { Über 12 bis 18 } \\
\text { Mon. }\end{array}$ & 2.994 & $4 \%$ & 8.761 & $7 \%$ & 11.755 & $6 \%$ \\
\hline Über 18 bis 24 & 2.200 & $3 \%$ & 6.181 & $5 \%$ & 8.381 & $4 \%$ \\
\hline Über 24 bis 30 & 1.688 & $2 \%$ & 4.660 & $4 \%$ & 6.348 & $3 \%$ \\
\hline $\begin{array}{l}\text { Über 30 bis 36 } \\
\text { Mon. }\end{array}$ & 1.244 & $2 \%$ & 3.317 & $3 \%$ & 4.561 & $2 \%$ \\
\hline Gesamt & 70.281 & $100 \%$ & 125.645 & $100 \%$ & 195.926 & $100 \%$ \\
\hline
\end{tabular}

Tab. 6.21 h: Dauer bis zum ersten Rückfall nach Bezugsentscheidungen aufgrund von Betrug u.a. nach Geschlecht

\begin{tabular}{|l|r|r|r|r|r|r|}
\hline & \multicolumn{2}{|c|}{ Frauen } & \multicolumn{2}{c|}{ Männer } & \multicolumn{2}{c|}{ Insgesamt } \\
& abs. & \multicolumn{1}{c|}{ in $\%$} & abs. & \multicolumn{1}{c|}{ in $\%$} & \multicolumn{1}{c|}{ abs. } & \multicolumn{1}{c|}{ in $\%$} \\
\hline Kein Rückfall & 29.603 & $78 \%$ & 63.415 & $70 \%$ & 93.018 & $73 \%$ \\
\hline Bis 3 Mon. & 1.278 & $3 \%$ & 4.415 & $5 \%$ & 5.693 & $4 \%$ \\
\hline Über 3 bis 6 Mon. & 1.177 & $3 \%$ & 3.942 & $4 \%$ & 5.119 & $4 \%$ \\
\hline Über 6 bis 12 Mon. & 1.875 & $5 \%$ & 6.244 & $7 \%$ & 8.119 & $6 \%$ \\
\hline $\begin{array}{l}\text { Über 12 bis 18 } \\
\text { Mon. }\end{array}$ & 1.376 & $4 \%$ & 4.566 & $5 \%$ & 5.942 & $5 \%$ \\
\hline Über 18 bis 24 & 1.107 & $3 \%$ & 3.491 & $4 \%$ & 4.598 & $4 \%$ \\
\hline Über 24 bis 30 & 753 & $2 \%$ & 2.570 & $3 \%$ & 3.323 & $3 \%$ \\
\hline $\begin{array}{l}\text { Über 30 bis 36 } \\
\text { Mon. }\end{array}$ & 556 & $1 \%$ & 1.739 & $2 \%$ & 2.295 & $2 \%$ \\
\hline Gesamt & 37.725 & $100 \%$ & 90.382 & $100 \%$ & 128.107 & $100 \%$ \\
\hline
\end{tabular}


Tab. 6.21i: Dauer bis zum ersten Rückefall nach Bequgsentscheidungen aufgrund von Erschleichen von Leistungen nach Geschlecht

\begin{tabular}{|l|r|r|r|r|r|r|}
\hline & \multicolumn{2}{|c|}{ Frauen } & \multicolumn{2}{c|}{ Männer } & \multicolumn{2}{c|}{ Insgesamt } \\
& abs. & \multicolumn{1}{|c|}{ in $\%$} & abs. & \multicolumn{1}{c|}{ in $\%$} & \multicolumn{1}{c|}{ abs. } & \multicolumn{1}{c|}{ in $\%$} \\
\hline Kein Rückfall & 9.294 & $60 \%$ & 15.566 & $45 \%$ & 24.860 & $50 \%$ \\
\hline Bis 3 Mon. & 1.315 & $8 \%$ & 3.818 & $11 \%$ & 5.133 & $10 \%$ \\
\hline Über 3 bis 6 Mon. & 996 & $6 \%$ & 3.199 & $9 \%$ & 4.195 & $8 \%$ \\
\hline Über 6 bis 12 Mon. & 1.422 & $9 \%$ & 4.526 & $13 \%$ & 5.948 & $12 \%$ \\
\hline Über 12 bis 18 & 964 & $6 \%$ & 2.845 & $8 \%$ & 3.809 & $8 \%$ \\
\hline $\begin{array}{l}\text { Mon. } \\
\text { Über 18 bis 24 }\end{array}$ & 667 & $4 \%$ & 1.902 & $6 \%$ & 2.569 & $5 \%$ \\
\hline Über 24 bis 30 & 530 & $3 \%$ & 1.495 & $4 \%$ & 2.025 & $4 \%$ \\
\hline $\begin{array}{l}\text { Über 30 bis 36 } \\
\text { Mon. }\end{array}$ & 329 & $2 \%$ & 935 & $3 \%$ & 1.264 & $3 \%$ \\
\hline Gesamt & 15.517 & $100 \%$ & 34.286 & $100 \%$ & 49.803 & $100 \%$ \\
\hline
\end{tabular}

Tab. 6.21j: Dauer bis zum ersten Rückfall nach Bezugsentscheidungen aufgrund von fahrlässiger Tötung bzw. fahrlässiger Körperverletzung nach Geschlecht

\begin{tabular}{|l|r|r|r|r|r|r|}
\hline & \multicolumn{2}{|c|}{ Frauen } & \multicolumn{2}{c|}{ Männer } & \multicolumn{2}{|c|}{ Insgesamt } \\
& abs. & \multicolumn{1}{|c|}{ in $\%$} & abs. & \multicolumn{1}{c|}{ in $\%$} & \multicolumn{1}{c|}{ abs. } & \multicolumn{1}{c|}{ in $\%$} \\
\hline Kein Rückfall & 2.645 & $92 \%$ & 8.458 & $82 \%$ & 11.103 & $84 \%$ \\
\hline Bis 3 Mon. & 25 & $1 \%$ & 283 & $3 \%$ & 308 & $2 \%$ \\
\hline Über 3 bis 6 Mon. & 32 & $1 \%$ & 218 & $2 \%$ & 250 & $2 \%$ \\
\hline Über 6 bis 12 Mon. & 40 & $1 \%$ & 403 & $4 \%$ & 443 & $3 \%$ \\
\hline $\begin{array}{l}\text { Über 12 bis 18 } \\
\text { Mon. }\end{array}$ & 45 & $2 \%$ & 319 & $3 \%$ & 364 & $3 \%$ \\
\hline Über 18 bis 24 & 37 & $1 \%$ & 252 & $2 \%$ & 289 & $2 \%$ \\
\hline Über 24 bis 30 & 23 & $1 \%$ & 200 & $2 \%$ & 223 & $2 \%$ \\
\hline $\begin{array}{l}\text { Über 30 bis 36 } \\
\text { Mon. }\end{array}$ & 23 & $1 \%$ & 148 & $1 \%$ & 171 & $1 \%$ \\
\hline Gesamt & 2.870 & $100 \%$ & 10.281 & $100 \%$ & 13.151 & $100 \%$ \\
\hline
\end{tabular}


Tab. 6.21k: Dauer bis zum ersten Rückfall nach Bezugsentscheidungen aufgrund von Verkehrsdelikten ohne Alkoholeinfluss nach Geschlecht

\begin{tabular}{|l|r|r|r|r|r|r|}
\hline & \multicolumn{2}{|c|}{ Frauen } & \multicolumn{2}{c|}{ Männer } & \multicolumn{2}{|c|}{ Insgesamt } \\
& abs. & \multicolumn{1}{c|}{ in $\%$} & abs. & \multicolumn{1}{c|}{ in $\%$} & \multicolumn{1}{c|}{ abs. } & \multicolumn{1}{c|}{ in $\%$} \\
\hline Kein Rückfall & 15.097 & $86 \%$ & 73.872 & $67 \%$ & 88.969 & $70 \%$ \\
\hline Bis 3 Mon. & 478 & $3 \%$ & 6.368 & $6 \%$ & 6.846 & $5 \%$ \\
\hline Über 3 bis 6 Mon. & 354 & $2 \%$ & 5.459 & $5 \%$ & 5.813 & $5 \%$ \\
\hline Über 6 bis 12 Mon. & 514 & $3 \%$ & 8.378 & $8 \%$ & 8.892 & $7 \%$ \\
\hline Über 12 bis 18 & 379 & $2 \%$ & 5.859 & $5 \%$ & 6.238 & $5 \%$ \\
\hline Mon. & 326 & $2 \%$ & 4.259 & $4 \%$ & 4.585 & $4 \%$ \\
\hline Über 18 bis 24 & 233 & $1 \%$ & 3.343 & $3 \%$ & 3.576 & $3 \%$ \\
\hline Über 24 bis 30 & 178 & $1 \%$ & 2.362 & $2 \%$ & 2.540 & $2 \%$ \\
\hline $\begin{array}{l}\text { Über 30 bis 36 } \\
\text { Mon. }\end{array}$ & 17.559 & $100 \%$ & 109.900 & $100 \%$ & 127.459 & $100 \%$ \\
\hline Gesamt & & & &
\end{tabular}

Tab. 6.21l: Dauer bis zum ersten Rückfall nach Bezugsentscheidungen aufgrund von Verkehrsdelikten unter Alkoboleinfluss nach Geschlecht

\begin{tabular}{|l|r|r|r|r|r|r|}
\hline & \multicolumn{2}{|c|}{ Frauen } & \multicolumn{2}{c|}{ Männer } & \multicolumn{2}{c|}{ Insgesamt } \\
& abs. & \multicolumn{1}{|c|}{ in $\%$} & abs. & \multicolumn{1}{c|}{ in $\%$} & \multicolumn{1}{c|}{ abs. } & \multicolumn{1}{c|}{ in $\%$} \\
\hline Kein Rückfall & 12.035 & $89 \%$ & 78.700 & $81 \%$ & 90.735 & $82 \%$ \\
\hline Bis 3 Mon. & 213 & $2 \%$ & 2.594 & $3 \%$ & 2.807 & $3 \%$ \\
\hline Über 3 bis 6 Mon. & 167 & $1 \%$ & 2.317 & $2 \%$ & 2.484 & $2 \%$ \\
\hline Über 6 bis 12 Mon. & 288 & $2 \%$ & 3.918 & $4 \%$ & 4.206 & $4 \%$ \\
\hline Über 12 bis 18 & 237 & $2 \%$ & 3.108 & $3 \%$ & 3.345 & $3 \%$ \\
\hline Mon. & 215 & $2 \%$ & 2.646 & $3 \%$ & 2.861 & $3 \%$ \\
\hline Über 18 bis 24 & 188 & $1 \%$ & 2.150 & $2 \%$ & 2.338 & $2 \%$ \\
\hline $\begin{array}{l}\text { Über 24 bis 30 } \\
\text { Mon. 30 bis 36 }\end{array}$ & 154 & $1 \%$ & 1.798 & $2 \%$ & 1.952 & $2 \%$ \\
\hline Gesamt & 13.497 & $100 \%$ & 97.231 & $100 \%$ & 110.728 & $100 \%$ \\
\hline
\end{tabular}


Tab. 6.21m: Dauer bis zum ersten Rück.fall nach Bezugsentscheidungen aufgrund von Delikten nach dem BtMG nach dem Geschlecht

\begin{tabular}{|l|r|r|r|r|r|r|}
\hline & \multicolumn{2}{|c|}{ Frauen } & \multicolumn{2}{c|}{ Männer } & \multicolumn{2}{c|}{ Insgesamt } \\
\hline Kabs. & \multicolumn{1}{|c|}{ in $\%$} & abs. & \multicolumn{1}{c|}{ in $\%$} & \multicolumn{1}{c|}{ abs. } & \multicolumn{1}{c|}{ in $\%$} \\
\hline Bis 3 Mon. & 5.055 & $67 \%$ & 31.523 & $56 \%$ & 36.578 & $57 \%$ \\
\hline Über 3 bis 6 Mon. & 372 & $5 \%$ & 3.781 & $7 \%$ & 4.153 & $6 \%$ \\
\hline Über 6 bis 12 Mon. & 588 & $8 \%$ & 6.123 & $11 \%$ & 6.711 & $10 \%$ \\
\hline Über 12 bis 18 & 375 & $5 \%$ & 4.196 & $7 \%$ & 4.571 & $7 \%$ \\
\hline $\begin{array}{l}\text { Mon. } \\
\text { Über 18 bis 24 }\end{array}$ & 283 & $4 \%$ & 3.034 & $5 \%$ & 3.317 & $5 \%$ \\
\hline Über 24 bis 30 & 234 & $3 \%$ & 2.226 & $4 \%$ & 2.460 & $4 \%$ \\
\hline $\begin{array}{l}\text { Über 30 bis 36 } \\
\text { Mon. }\end{array}$ & 135 & $2 \%$ & 1.624 & $3 \%$ & 1.759 & $3 \%$ \\
\hline Gesamt & 7.508 & $100 \%$ & 56.661 & $100 \%$ & 64.169 & $100 \%$ \\
\hline
\end{tabular}

Tab. 6.22a: Art der Folgeentscheidung bei Bezugsentscheidungen aufgrund von Diebstabl nach Geschlecht

\begin{tabular}{|l|r|r|}
\hline & Frauen & Männer \\
\hline FS/ JS o. Bew. & 1.056 & 7.513 \\
\hline FS/ JS m. Bew. & 2.881 & 9.864 \\
\hline Geldstrafe & 7.796 & 18.610 \\
\hline Sonst. Entsch. n. JGG & 6.286 & 16.618 \\
\hline Keine Folgeentscheidung & 49.871 & 64.814 \\
\hline Gesamt & 67.890 & 117.419 \\
\hline
\end{tabular}


Tab. 6.23a: Art der Folgeentscheidung nach Sanktionsart der Bezugsentscheidung aufgrund von Diebstabl nach Geschlecht

\begin{tabular}{|c|c|c|c|c|c|}
\hline \multirow{2}{*}{$\begin{array}{l}\text { Sanktionsart } \\
\text { der Bezugs- } \\
\text { entscheidung }\end{array}$} & \multirow[b]{2}{*}{ Geschlecht } & \multicolumn{4}{|c|}{ Art der Folgeentscheidung } \\
\hline & & $\begin{array}{l}\text { FS/ JS } \\
\text { o. Bew. }\end{array}$ & $\begin{array}{l}\text { FS/ JS } \\
\text { m. Bew. }\end{array}$ & $\begin{array}{c}\text { Sonst. ambulante } \\
\text { Folge- } \\
\text { entscheidungen }\end{array}$ & Gesamt \\
\hline \multirow{2}{*}{ FS o. Bew. } & $F$ & 97 & 64 & 38 & 199 \\
\hline & M & 926 & 285 & 240 & 1.451 \\
\hline \multirow{2}{*}{ FS m. Bew. } & $F$ & 418 & 471 & 267 & 1.156 \\
\hline & $M$ & 1.862 & 1.127 & 986 & 3.975 \\
\hline \multirow{2}{*}{ JS o. Bew. } & $F$ & 20 & 10 & 13 & 43 \\
\hline & $M$ & 238 & 77 & 70 & 385 \\
\hline \multirow{2}{*}{ JS m. Bew. } & $F$ & 42 & 40 & 24 & 106 \\
\hline & $M$ & 396 & 203 & 156 & 755 \\
\hline \multirow{2}{*}{ Geldstrafe } & $F$ & 340 & 1.881 & 6.437 & 8.658 \\
\hline & M & 2.486 & 5.118 & 13.675 & 21.279 \\
\hline \multirow{2}{*}{$\begin{array}{l}\text { Sonst. Entsch. } \\
\text { n. JGG }\end{array}$} & $F$ & 139 & 415 & 7.300 & 7.854 \\
\hline & $M$ & 1.605 & 3.050 & 20.117 & 24.772 \\
\hline
\end{tabular}

Tab. 6.24a: Art der Folgeentscheidung nach Jugendstrafe aufgrund von Diebstabl nach Geschlecht

\begin{tabular}{|c|c|c|c|c|c|c|c|c|}
\hline \multirow{3}{*}{$\begin{array}{l}\text { Art der Folgeentschei- } \\
\text { dung }\end{array}$} & \multicolumn{4}{|c|}{ Jugendstrafe bis 2 Jahre } & \multicolumn{4}{|c|}{ Alle verbüßten Jugendstrafen } \\
\hline & \multicolumn{2}{|c|}{ JS m. Bew. } & \multicolumn{2}{|c|}{ JS o. Bew. } & \multicolumn{2}{|c|}{$\begin{array}{l}\text { Strafrest- } \\
\text { aussetzuna }\end{array}$} & \multicolumn{2}{|c|}{$\begin{array}{l}\text { Vollver- } \\
\text { büßung }\end{array}$} \\
\hline & $\mathbf{F}$ & M & $\mathbf{F}$ & M & $\mathbf{F}$ & M & $\mathbf{F}$ & M \\
\hline FS/ JS o. Bew. & 36 & 366 & 17 & 189 & 7 & 96 & 13 & 142 \\
\hline FS/ JS m. Bew & 30 & 164 & 10 & 63 & 5 & 24 & 5 & 53 \\
\hline $\begin{array}{l}\text { Sonst. ambulante Folge- } \\
\text { entscheidungen }\end{array}$ & 23 & 150 & 13 & 51 & 8 & 31 & 5 & 39 \\
\hline Gesamt & 89 & 680 & 40 & 303 & 20 & 151 & 23 & 234 \\
\hline
\end{tabular}


Tab. 6.25a: Art der Folgeentscheidung nach Freiheitsstrafe aufgrund von Diebstabl nach Geschlecht

\begin{tabular}{|c|c|c|c|c|c|c|c|c|}
\hline \multirow{3}{*}{$\begin{array}{c}\text { Art der Folgeentschei- } \\
\text { dung }\end{array}$} & \multicolumn{4}{|c|}{ Freiheitsstrafe bis 2 Jahre } & \multicolumn{4}{|c|}{ Alle verbüßten Freiheitsstrafen } \\
\hline & \multicolumn{2}{|c|}{ FS m. Bew. } & \multicolumn{2}{|c|}{ FS o. Bew. } & \multicolumn{2}{|c|}{$\begin{array}{l}\text { Strafrest- } \\
\text { aussetzung }\end{array}$} & \multicolumn{2}{|c|}{$\begin{array}{l}\text { Vollver- } \\
\text { büßung }\end{array}$} \\
\hline & $\mathbf{F}$ & M & $\mathbf{F}$ & M & $\mathbf{F}$ & M & $\mathbf{F}$ & M \\
\hline FS/ JS o. Bew. & 418 & 1.862 & 96 & 912 & 26 & 101 & 71 & 825 \\
\hline FS/ JS m. Bew & 471 & 1.127 & 64 & 282 & 19 & 60 & 45 & 225 \\
\hline \begin{tabular}{|l|} 
Sonst. ambulante \\
Folgeentscheidungen
\end{tabular} & 267 & 986 & 38 & 235 & 10 & 42 & 28 & 198 \\
\hline Gesamt & 1.156 & 3.975 & 198 & 1.429 & 55 & 203 & 144 & 1.248 \\
\hline
\end{tabular}

Tab. 6.26a: Art der Folgeentscheidung nach Geldstrafe aufgrund von Diebstabl nach Geschlecht

\begin{tabular}{|c|c|c|c|c|c|c|c|c|c|c|}
\hline \multirow{3}{*}{$\begin{array}{l}\text { Art der Folgeent- } \\
\text { scheidung }\end{array}$} & \multicolumn{10}{|c|}{ Anzahl der Tagessätze } \\
\hline & \multicolumn{2}{|c|}{$1-15$} & \multicolumn{2}{|c|}{$16-30$} & \multicolumn{2}{|c|}{$31-50$} & \multicolumn{2}{|c|}{$51-90$} & \multicolumn{2}{|c|}{$>=90$} \\
\hline & $\mathbf{F}$ & M & $\mathbf{F}$ & M & $\mathbf{F}$ & M & $\mathbf{F}$ & M & $\mathbf{F}$ & M \\
\hline FS/ JS o. Bew. & 40 & 351 & 106 & 783 & 82 & 575 & 90 & 601 & 22 & 186 \\
\hline FS/ JS m. Bew & 282 & 857 & 609 & 1.733 & 449 & 1.103 & 460 & 1.144 & 85 & 285 \\
\hline \begin{tabular}{|l|} 
Sonst. ambulante \\
Folgeentscheidungen
\end{tabular} & 2.214 & 4.239 & 2.485 & 5.105 & 1.024 & 2.356 & 627 & 1.678 & 93 & 309 \\
\hline Gesamt & 2.536 & 5.447 & 3.200 & 7.621 & 1.555 & 4.034 & 1.177 & 3.423 & 200 & 780 \\
\hline
\end{tabular}

Tab. 6.27a: Art der Folgeentscheidung nach Anzabl der Voreintragungen bei Bezugsentscheidungen aufgrund von Diebstabl nach Geschlecht (Jugendliche/ Heranwachsende)

\begin{tabular}{|c|c|c|c|c|c|c|c|c|c|c|}
\hline \multirow{3}{*}{$\begin{array}{l}\text { Art der Folgeent- } \\
\text { scheidung }\end{array}$} & \multicolumn{10}{|c|}{ Anzahl der Voreintragungen } \\
\hline & \multicolumn{2}{|c|}{ Keine } & \multicolumn{2}{|c|}{1} & \multicolumn{2}{|c|}{2} & \multicolumn{2}{|c|}{3 und 4} & \multicolumn{2}{|c|}{5 und mehr } \\
\hline & $\mathbf{F}$ & M & $\mathbf{F}$ & M & $\mathbf{F}$ & M & $\mathbf{F}$ & M & $\mathbf{F}$ & M \\
\hline FS/ JS o. Bew. & 60 & 617 & 35 & 426 & 37 & 393 & 52 & 550 & 36 & 449 \\
\hline FS/ JS m. Bew & 178 & 1334 & 114 & 782 & 92 & 571 & 93 & 590 & 45 & 356 \\
\hline \begin{tabular}{|l|} 
Sonst. ambulante \\
Folgeentscheidungen
\end{tabular} & 5.506 & 13.193 & 1.165 & 4.077 & 498 & 1.908 & 298 & 1.393 & 98 & 513 \\
\hline Gesamt & 5.744 & 15.144 & 1.314 & 5.285 & 627 & 2.872 & 443 & 2.533 & 179 & 1.318 \\
\hline
\end{tabular}


Tab. 6.28a: Art der Folgeentscheidung nach Art der schwersten Voreintragung bei Bezugsentscheidungen aufgrund von Diebstabl nach Geschlecht (Jugendliche/ Heranwachsende)

\begin{tabular}{|c|c|c|c|c|c|c|c|c|c|c|}
\hline \multirow{3}{*}{$\begin{array}{l}\text { Art der Folgeent- } \\
\text { scheidung }\end{array}$} & \multicolumn{10}{|c|}{ Art der schwersten Voreintragung } \\
\hline & \multicolumn{2}{|c|}{ Keine } & \multicolumn{2}{|c|}{ FS/ JS o. Bew. } & \multicolumn{2}{|c|}{$\begin{array}{l}\text { FS/ JS m. } \\
\text { Bew. }\end{array}$} & \multicolumn{2}{|c|}{ Geldstrafe } & \multicolumn{2}{|c|}{$\begin{array}{c}\text { Sonst. } \\
\text { Entsch. n. } \\
\text { JGG }\end{array}$} \\
\hline & $\mathbf{F}$ & M & $\mathbf{F}$ & M & $\mathbf{F}$ & M & $\mathbf{F}$ & M & $\mathbf{F}$ & M \\
\hline FS/ JS o. Bew. & 60 & 617 & 13 & 196 & 23 & 278 & 10 & 88 & 83 & 830 \\
\hline FS/ JS m. Bew & 178 & 1.334 & 10 & 66 & 16 & 145 & 19 & 126 & 163 & 1.073 \\
\hline \begin{tabular}{|l|} 
Sonst. ambulante \\
Folgeentscheidungen
\end{tabular} & 5.506 & 13.193 & 10 & 74 & 25 & 168 & 53 & 216 & 604 & 2.530 \\
\hline Gesamt & 5.744 & 15.144 & 33 & 336 & 64 & 591 & 82 & 430 & 850 & 4.433 \\
\hline
\end{tabular}

Tab. 6.29a: Art der Folgeentscheidung nach Anzahl der Voreintragungen bei Bezugsentscheidungen aufgrund von Diebstahl nach Geschlecht (Erwachsene)

\begin{tabular}{|c|c|c|c|c|c|c|c|c|c|c|}
\hline \multirow{3}{*}{$\begin{array}{c}\text { Art der Folgeentschei- } \\
\text { dung }\end{array}$} & \multicolumn{10}{|c|}{ Anzahl der Voreintragungen } \\
\hline & \multicolumn{2}{|c|}{ Keine } & \multicolumn{2}{|c|}{1} & \multicolumn{2}{|c|}{2} & \multicolumn{2}{|c|}{3 und 4} & \multicolumn{2}{|c|}{5 und mehr } \\
\hline & $\mathbf{F}$ & M & $\mathbf{F}$ & M & $\mathbf{F}$ & M & $\mathbf{F}$ & $M$ & $F$ & $M$ \\
\hline FS/ JS o. Bew. & 73 & 478 & 69 & 332 & 73 & 353 & 148 & 742 & 473 & 3.173 \\
\hline FS/ JS m. Bew & 457 & 1.008 & 412 & 755 & 367 & 660 & 427 & 1.072 & 696 & 2.736 \\
\hline \begin{tabular}{|l|} 
Sonst. ambulante \\
Folgeentscheidungen
\end{tabular} & 3.300 & 4.662 & 1.256 & 2.444 & 623 & 1.401 & 554 & 1.874 & 786 & 3.790 \\
\hline Gesamt & 3.830 & 6.148 & 1.737 & 3.531 & 1.063 & 2.414 & 1.129 & 3.688 & 1.955 & 9.699 \\
\hline
\end{tabular}


Tab. 6.30a: Art der Folgeentscheidung nach Art der schwersten Voreintragung bei Bezugsentscheidungen aufgrund von Diebstabl nach Geschlecht (Erwachsene)

\begin{tabular}{|c|c|c|c|c|c|c|c|c|c|c|}
\hline \multirow{3}{*}{$\begin{array}{c}\text { Art der Folgeentschei- } \\
\text { dung }\end{array}$} & \multicolumn{10}{|c|}{ Art der schwersten Voreintragung } \\
\hline & \multicolumn{2}{|c|}{ Keine } & \multicolumn{2}{|c|}{$\begin{array}{l}\text { FS/ JS o. } \\
\text { Bew. }\end{array}$} & \multicolumn{2}{|c|}{$\begin{array}{l}\text { FS/ JS m. } \\
\text { Bew. }\end{array}$} & \multicolumn{2}{|c|}{ Geldstrafe } & \multicolumn{2}{|c|}{$\begin{array}{l}\text { Sonst. } \\
\text { Entsch. } n \text {. } \\
\text { JGG }\end{array}$} \\
\hline & $\mathbf{F}$ & M & $\mathbf{F}$ & M & $\mathbf{F}$ & M & $\mathbf{F}$ & M & $\mathbf{F}$ & M \\
\hline FS/ JS o. Bew. & 73 & 478 & 244 & 2.235 & 261 & 1.082 & 234 & 1.079 & 24 & 204 \\
\hline FS/ JS m. Bew & 457 & 1.008 & 240 & 1.318 & 443 & 1.365 & 1.131 & 2.154 & 88 & 386 \\
\hline $\begin{array}{l}\text { Sonst. ambulante Fol- } \\
\text { geentscheidungen }\end{array}$ & 3.300 & 4.664 & 220 & 1.737 & 547 & 2.131 & 2.219 & 4.862 & 233 & 777 \\
\hline Gesamt & 3.830 & 6.150 & 704 & 5.290 & 1251 & 4.578 & 3.584 & 8.095 & 345 & 1.367 \\
\hline
\end{tabular}

Tab. 6.31a: Art der Folgeentscheidung nach Bezugsentscheidungen aufgrund von Diebstabl nach Einschlägigkeit der Voreintragungen und Geschlecht

\begin{tabular}{|c|c|c|c|c|c|c|c|c|}
\hline \multirow{3}{*}{$\begin{array}{c}\text { Art der } \\
\text { Folgeentscheidung }\end{array}$} & \multicolumn{8}{|c|}{ Einschlägigkeit der Voreintragungen } \\
\hline & \multicolumn{2}{|c|}{ Keine VE } & \multicolumn{2}{|c|}{$\begin{array}{l}\text { Nur VE(en) mit } \\
\text { anderen Delikten }\end{array}$} & \multicolumn{2}{|c|}{\begin{tabular}{|c|} 
(Auch) VE(en) mit \\
anderen Dieb- \\
stahlsdelikten
\end{tabular}} & \multicolumn{2}{|c|}{$\begin{array}{l}\text { (Auch) einschlä- } \\
\text { gige VE(en) }\end{array}$} \\
\hline & $\mathbf{F}$ & M & $\mathbf{F}$ & M & $\mathbf{F}$ & M & $\mathbf{F}$ & M \\
\hline FS/ JS o. Bew. & 133 & 1.093 & 81 & 1.015 & 22 & 434 & 820 & 4.971 \\
\hline FS/ JS m. Bew. & 634 & 2.338 & 314 & 1.963 & 44 & 543 & 1.889 & 5.02 \\
\hline $\begin{array}{l}\text { Sonst. ambulante } \\
\text { Folgeentscheidungen }\end{array}$ & 8.802 & 17.849 & 1.341 & 6.347 & 116 & 1.084 & 3.825 & 9.9 \\
\hline Gesamt & 9.569 & 21.280 & 1.736 & 9.325 & 182 & 2.061 & 6.534 & 19.96 \\
\hline
\end{tabular}

Tab. 6.32a: Art der Folgeentscheidung nach dem StGB nach Bezugsentscheidungen aufgrund von Diebstabl unter Berücksichtigung multipler Faktoren nach Geschlecht

\begin{tabular}{|c|c|c|}
\hline & Frauen & Männer \\
\hline FS o. Bew. & 299 & 1.502 \\
\hline FS m. Bew. & 373 & 945 \\
\hline Geldstrafe & 322 & 1.041 \\
\hline Gesamt & 994 & 3.488 \\
\hline
\end{tabular}


Tab. 6.33a: Einschlägige Rückfälle nach Bezugsentscheidungen aufgrund von Diebstabl nach Geschlecht

\begin{tabular}{|l|r|r|r|r|}
\hline & $\begin{array}{c}\text { Nur Rückfall mit anderen } \\
\text { Delikten }\end{array}$ & $\begin{array}{c}\text { (Auch) Rückfall } \\
\text { mit anderen Dieb- } \\
\text { stahls-delikten }\end{array}$ & $\begin{array}{c}\text { (Auch) einschlägi- } \\
\text { ger Rückfall }\end{array}$ & \multicolumn{1}{c|}{ Gesamt } \\
\hline Frauen & 6.093 & 453 & 12.010 & 18.556 \\
\hline Männer & 24.796 & 4.090 & 24.509 & 53.395 \\
\hline
\end{tabular}

Tab. 6.34a: Einschlägige Voreintragungen und Rück.fälle bei Bezugsentscheidungen aufgrund von Diebstahl nach Geschlecht

\begin{tabular}{|c|c|c|c|c|c|c|c|c|}
\hline \multirow[t]{2}{*}{$\begin{array}{l}\text { Art des Rück- } \\
\text { falls }\end{array}$} & \multicolumn{2}{|c|}{ Keine VE } & \multicolumn{2}{|c|}{$\begin{array}{l}\text { Nur VE(en) mit } \\
\text { anderen } \\
\text { Delikten }\end{array}$} & \multicolumn{2}{|c|}{$\begin{array}{c}\text { (Auch) VE(en) mit } \\
\text { anderen } \\
\text { Diebstahls } \\
\text { delikten }\end{array}$} & \multicolumn{2}{|c|}{$\begin{array}{l}\text { (Auch) } \\
\text { einschlägige } \\
\text { VE(en) }\end{array}$} \\
\hline & $F$ & M & $F$ & M & $F$ & M & $F$ & M \\
\hline $\begin{array}{l}\text { Nur Rückfall } \\
\text { mit anderen } \\
\text { Delikten }\end{array}$ & 3.472 & 10.470 & 808 & 5.331 & 80 & 1.139 & 1.733 & 7.856 \\
\hline $\begin{array}{l}\text { (Auch) Rück- } \\
\text { fall mit ande- } \\
\text { ren Dieb- } \\
\text { stahls-delikten }\end{array}$ & 240 & 1.765 & 70 & 619 & 8 & 218 & 135 & 1.488 \\
\hline $\begin{array}{l}\text { (Auch) ein- } \\
\text { schlägiger } \\
\text { Rückfall }\end{array}$ & 6.144 & 9.366 & 893 & 3.484 & 97 & 723 & 4.876 & 10.936 \\
\hline Gesamt & 9.856 & 21.601 & 1.771 & 9.434 & 185 & 2.080 & 6.744 & 20.280 \\
\hline
\end{tabular}

Tab. 6.35a: Art der Folgeentscheidung bei Bezugsentscheidungen aufgrund von Betrug nach Geschlecht

\begin{tabular}{|l|r|r|}
\hline & Frauen & Männer \\
\hline FS/ JS o. Bew. & 367 & 2.161 \\
\hline FS/ JS m. Bew. & 1.506 & 5.006 \\
\hline Geldstrafe & 4.677 & 12.219 \\
\hline Sonst. Entsch. n. JGG & 502 & 1.336 \\
\hline Keine Folgeentscheidung & 24.106 & 44.230 \\
\hline Gesamt & 31.158 & 64.952 \\
\hline
\end{tabular}


Tab. 6.36a: Art der Folgeentscheidung nach Sanktionsart der Bezugsentscheidung aufgrund von Betrug nach Geschlecht

\begin{tabular}{|c|c|c|c|c|c|c|c|c|c|}
\hline \multirow{3}{*}{\multicolumn{2}{|c|}{$\begin{array}{l}\text { Sanktionsart der } \\
\text { Bezugsentscheidung } \\
\text { nach Geschlecht }\end{array}$}} & \multicolumn{8}{|c|}{ Art der Folgeentscheidung } \\
\hline & & \multicolumn{2}{|c|}{$\begin{array}{l}\text { FS/ JS } \\
\text { o. Bew. }\end{array}$} & \multicolumn{2}{|c|}{$\begin{array}{c}\text { FS/ JS } \\
\text { m. Bew. }\end{array}$} & \multicolumn{2}{|c|}{\begin{tabular}{|c|} 
Sonst. \\
ambulante \\
Folgeentscheidungen
\end{tabular}} & \multicolumn{2}{|c|}{ Gesamt } \\
\hline & & abs. & in $\%$ & abs. & in $\%$ & abs. & & abs. & in $\%$ \\
\hline \multirow{2}{*}{ FS o. Bew. } & $F$ & 19 & $38 \%$ & 19 & $38 \%$ & 12 & $24 \%$ & 50 & $100 \%$ \\
\hline & $M$ & 218 & $47 \%$ & 111 & $24 \%$ & 135 & $29 \%$ & 464 & $100 \%$ \\
\hline \multirow{2}{*}{ FS m. Bew. } & $F$ & 196 & $24 \%$ & 332 & $40 \%$ & 293 & $36 \%$ & 821 & $100 \%$ \\
\hline & $M$ & 877 & $31 \%$ & 954 & $34 \%$ & 1.009 & $36 \%$ & 2.840 & $100 \%$ \\
\hline \multirow{2}{*}{ JS o. Bew. } & $F$ & 1 & $25 \%$ & - & $0 \%$ & 3 & $75 \%$ & 4 & $100 \%$ \\
\hline & $M$ & 29 & $43 \%$ & 20 & $29 \%$ & 19 & $28 \%$ & 68 & $100 \%$ \\
\hline \multirow{2}{*}{ JS m. Bew. } & $F$ & 16 & $33 \%$ & 17 & $35 \%$ & 16 & $33 \%$ & 49 & $100 \%$ \\
\hline & $M$ & 97 & $38 \%$ & 80 & $31 \%$ & 80 & $31 \%$ & 257 & $100 \%$ \\
\hline \multirow{2}{*}{ Geldstrafe } & $F$ & 115 & $2 \%$ & 1.056 & $21 \%$ & 3.967 & $77 \%$ & 5.138 & $100 \%$ \\
\hline & $M$ & 798 & $6 \%$ & 3.389 & $24 \%$ & 10.059 & $71 \%$ & 14.246 & $100 \%$ \\
\hline \multirow{2}{*}{$\begin{array}{l}\text { Sonst. Entsch. } \\
\text { n. JGG }\end{array}$} & $F$ & 20 & $2 \%$ & 78 & $8 \%$ & 880 & $90 \%$ & 978 & $100 \%$ \\
\hline & $M$ & 142 & $5 \%$ & 446 & $16 \%$ & 2.241 & $79 \%$ & 2.829 & $100 \%$ \\
\hline
\end{tabular}

Tab. 6.37a: Art der Folgeentscheidung nach Freiheitsstrafe aufgrund von Betrug nach Geschlecht

\begin{tabular}{|c|c|c|c|c|c|c|c|c|}
\hline \multirow{3}{*}{$\begin{array}{l}\text { Art der Folgeent- } \\
\text { scheidung }\end{array}$} & \multicolumn{4}{|c|}{ Freiheitsstrafe bis 2 Jahre } & \multicolumn{4}{|c|}{ Alle verbüßten Freiheitsstrafen } \\
\hline & \multicolumn{2}{|c|}{ FS m. Bew. } & \multicolumn{2}{|c|}{ FS 0. Bew. } & \multicolumn{2}{|c|}{$\begin{array}{l}\text { Strafrest- } \\
\text { aussetzung }\end{array}$} & \multicolumn{2}{|c|}{$\begin{array}{l}\text { Vollver- } \\
\text { büßung }\end{array}$} \\
\hline & $\mathbf{F}$ & M & $\mathbf{F}$ & M & $\mathbf{F}$ & M & $\mathbf{F}$ & M \\
\hline JS/ FS o. Bew. & 196 & 877 & 14 & 165 & 9 & 70 & 10 & 148 \\
\hline JS/ FS m. Bew & 332 & 954 & 16 & 81 & 12 & 55 & 7 & 56 \\
\hline \begin{tabular}{|l|} 
Sonst. ambulante \\
Folgeentscheidungen
\end{tabular} & 293 & 1.009 & 9 & 97 & 7 & 59 & 5 & 76 \\
\hline Gesamt & 821 & 2.840 & 39 & 343 & 28 & 184 & 22 & 280 \\
\hline
\end{tabular}


Tab. 6.38a: Art der Folgeentscheidung nach Geldstrafe aufgrund von Betrug nach Geschlecht

\begin{tabular}{|c|c|c|c|c|c|c|c|c|c|c|}
\hline \multirow{3}{*}{$\begin{array}{l}\text { Art der Folgeent- } \\
\text { scheidung }\end{array}$} & \multicolumn{10}{|c|}{ Anzahl der Tagessätze } \\
\hline & \multicolumn{2}{|c|}{$1-15$} & \multicolumn{2}{|c|}{$16-30$} & \multicolumn{2}{|c|}{$31-50$} & \multicolumn{2}{|c|}{$51-90$} & \multicolumn{2}{|c|}{$>=90$} \\
\hline & $\mathbf{F}$ & M & $\mathbf{F}$ & M & $\mathbf{F}$ & $M$ & $\mathbf{F}$ & M & $\mathbf{F}$ & M \\
\hline JS/ FS & $\begin{array}{r}13 \\
(2 \%) \\
\end{array}$ & $\begin{array}{r}39 \\
(3 \%) \\
\end{array}$ & $\begin{array}{r}21 \\
(1 \%) \\
\end{array}$ & $\begin{array}{r}214 \\
(5 \%)\end{array}$ & $\begin{array}{r}27 \\
(2 \%) \\
\end{array}$ & $\begin{array}{r}168 \\
(5 \%)\end{array}$ & $\begin{array}{r}40 \\
(3 \%)\end{array}$ & $\begin{array}{r}261 \\
(7 \%)\end{array}$ & $\begin{array}{r}15 \\
(4 \%)\end{array}$ & $\begin{array}{r}12 \\
(10 \%\end{array}$ \\
\hline JS/ F & $\begin{array}{r}72 \\
(11 \%)\end{array}$ & $\begin{array}{r}212 \\
(15 \%)\end{array}$ & $\begin{array}{r}274 \\
(15 \%)\end{array}$ & $\begin{array}{r}898 \\
(19 \%)\end{array}$ & $\begin{array}{r}266 \\
(23 \%)\end{array}$ & $\begin{array}{r}805 \\
(24 \%)\end{array}$ & $\begin{array}{r}319 \\
(27 \%)\end{array}$ & \begin{tabular}{|l|}
1.039 \\
$(29 \%)$
\end{tabular} & $\begin{array}{r}129 \\
(35 \%)\end{array}$ & $\begin{array}{r}444 \\
(36 \%)\end{array}$ \\
\hline \begin{tabular}{|l} 
Sonst \\
Folge
\end{tabular} & $\begin{array}{r}555 \\
(87 \%) \\
\end{array}$ & $\begin{array}{l}1.149 \\
(82 \%) \\
\end{array}$ & $\begin{array}{r}1.490 \\
(83 \%) \\
\end{array}$ & $\begin{array}{l}3.533 \\
(76 \%) \\
\end{array}$ & $\begin{array}{r}876 \\
(75 \%) \\
\end{array}$ & $\begin{array}{l}2.439 \\
(71 \%) \\
\end{array}$ & $\begin{array}{r}833 \\
(70 \%) \\
\end{array}$ & \begin{tabular}{|l|}
2.293 \\
$(64 \%)$ \\
\end{tabular} & $\begin{array}{r}223 \\
(61 \%) \\
\end{array}$ & $\begin{array}{r}674 \\
(54 \%) \\
\end{array}$ \\
\hline Ges & $\begin{array}{r}640 \\
(100 \%)\end{array}$ & $\begin{array}{r}1.400 \\
(100 \%)\end{array}$ & $\begin{array}{r}1.785 \\
(100 \%)\end{array}$ & $\begin{array}{r}4.645 \\
(100 \%)\end{array}$ & $\begin{array}{r}1.169 \\
(100 \%)\end{array}$ & $\begin{array}{r}3.412 \\
(100 \%)\end{array}$ & $\begin{array}{r}1.192 \\
(100 \%)\end{array}$ & $\begin{array}{r}3.593 \\
(100 \%) \\
\end{array}$ & $\begin{array}{r}367 \\
(100 \%)\end{array}$ & $\begin{array}{r}1.239 \\
(100 \%)\end{array}$ \\
\hline
\end{tabular}

Tab. 6.39a: Art der Folgeentscheidung nach Anzahl der Voreintragungen bei Bezugsentscheidungen aufgrund von Betrug nach Geschlecht (Jugendliche/ Heranwachsende)

\begin{tabular}{|c|c|c|c|c|c|c|c|c|c|c|}
\hline \multirow{3}{*}{$\begin{array}{l}\text { Art der Folgeent- } \\
\text { scheidung }\end{array}$} & \multicolumn{10}{|c|}{ Anzahl der Voreintragungen } \\
\hline & \multicolumn{2}{|c|}{ Keine } & \multicolumn{2}{|c|}{1} & \multicolumn{2}{|c|}{2} & \multicolumn{2}{|c|}{3 und 4} & \multicolumn{2}{|c|}{5 und mehr } \\
\hline & $\mathbf{F}$ & M & $\mathbf{F}$ & M & $\mathbf{F}$ & M & $\mathbf{F}$ & M & $\mathbf{F}$ & M \\
\hline $\mathrm{JS} / \mathrm{F}$ & $\begin{array}{r}7 \\
(1 \%) \\
\end{array}$ & $\begin{array}{r}46 \\
(3 \%) \\
\end{array}$ & $\begin{array}{r}15 \\
(5 \%) \\
\end{array}$ & $\begin{array}{r}39 \\
(5 \%) \\
\end{array}$ & $\begin{array}{r}8 \\
(5 \%) \\
\end{array}$ & $\begin{array}{r}41 \\
(7 \%) \\
\end{array}$ & $\begin{array}{r}11 \\
(8 \%) \\
\end{array}$ & $\begin{array}{r}93 \\
(15 \%) \\
\end{array}$ & $\begin{array}{r}2 \\
(1 \%) \\
\end{array}$ & \begin{tabular}{|r|}
83 \\
$(24 \%)$ \\
\end{tabular} \\
\hline JSI & $\begin{array}{r}48 \\
(8 \%) \\
\end{array}$ & $\begin{array}{r}142 \\
(10 \%) \\
\end{array}$ & $\begin{array}{r}48 \\
(15 \%) \\
\end{array}$ & $\begin{array}{r}149 \\
(18 \%) \\
\end{array}$ & $\begin{array}{r}24 \\
(14 \%) \\
\end{array}$ & $\begin{array}{r}131 \\
(23 \%) \\
\end{array}$ & $\begin{array}{r}25 \\
(18 \%) \\
\end{array}$ & $\begin{array}{r}172 \\
(28 \%) \\
\end{array}$ & $\begin{array}{r}11 \\
(26 \%) \\
\end{array}$ & $\begin{array}{r}109 \\
(32 \%) \\
\end{array}$ \\
\hline \begin{tabular}{|l} 
Sonst \\
Folge
\end{tabular} & $\begin{array}{r}536 \\
(91 \%)\end{array}$ & $\begin{array}{l}1.237 \\
(87 \%)\end{array}$ & $\begin{array}{r}265 \\
(81 \%)\end{array}$ & $\begin{array}{r}655 \\
(78 \%)\end{array}$ & $\begin{array}{r}144 \\
(82 \%) \\
\end{array}$ & $\begin{array}{r}407 \\
(70 \%)\end{array}$ & $\begin{array}{r}105 \\
(74 \%)\end{array}$ & $\begin{array}{r}357 \\
(57 \%)\end{array}$ & $\begin{array}{r}30 \\
(70 \%)\end{array}$ & $\begin{array}{r}152 \\
(44 \%) \\
\end{array}$ \\
\hline Gesamt & $\begin{array}{r}591 \\
(100 \%)\end{array}$ & $\begin{array}{r}1.425 \\
(100 \%)\end{array}$ & $\begin{array}{r}328 \\
(100 \%)\end{array}$ & $\begin{array}{r}843 \\
(100 \%)\end{array}$ & $\begin{array}{r}176 \\
(100 \%)\end{array}$ & $\begin{array}{r}579 \\
(100 \%) \\
\end{array}$ & $\begin{array}{r}141 \\
(100 \%)\end{array}$ & $\begin{array}{r}622 \\
(100 \%)\end{array}$ & $\begin{array}{r}141 \\
(100 \%)\end{array}$ & $\begin{array}{r}265 \\
(100 \%) \\
\end{array}$ \\
\hline
\end{tabular}

Tab. 6.40a: Art der Folgeentscheidung nach Art der schwersten Voreintragung bei Bezugsentscheidungen aufgrund von Betrug nach Geschlecht (Jugendliche/ Heranwachsende)

\begin{tabular}{|c|c|c|c|c|c|c|c|c|c|c|}
\hline \multirow{3}{*}{$\begin{array}{l}\text { Art der Folgeent- } \\
\text { scheidung }\end{array}$} & \multicolumn{10}{|c|}{ Art der schwersten Voreintragungen } \\
\hline & \multicolumn{2}{|c|}{ Keine } & \multicolumn{2}{|c|}{ FS/ JS o. Bew. } & \multicolumn{2}{|c|}{$\begin{array}{c}\text { FS/ JS m. } \\
\text { Bew. }\end{array}$} & \multicolumn{2}{|c|}{ Geldstrafe } & \multicolumn{2}{|c|}{$\begin{array}{c}\text { Sonst. Entsch } \\
\text { n. JGG }\end{array}$} \\
\hline & $\mathbf{F}$ & M & $\mathbf{F}$ & M & $\mathbf{F}$ & M & $\mathbf{F}$ & M & $\mathbf{F}$ & M \\
\hline$J S / F$ & $\begin{array}{r}7 \\
(1 \%) \\
\end{array}$ & $\begin{array}{r}46 \\
(3 \%) \\
\end{array}$ & $\begin{array}{r}3 \\
(60 \%) \\
\end{array}$ & \begin{tabular}{|r|}
32 \\
$(44 \%)$ \\
\end{tabular} & \begin{tabular}{|r|}
5 \\
$(36 \%)$ \\
\end{tabular} & \begin{tabular}{|r|}
45 \\
$(25 \%)$ \\
\end{tabular} & $\begin{array}{r}4 \\
(5 \%) \\
\end{array}$ & $\begin{array}{r}20 \\
(9 \%) \\
\end{array}$ & $\begin{array}{r}24 \\
(4 \%) \\
\end{array}$ & $\begin{array}{r}159 \\
(8 \%) \\
\end{array}$ \\
\hline JS/ FS m & $\begin{array}{r}48 \\
(8 \%) \\
\end{array}$ & $\begin{array}{r}142 \\
(10 \%) \\
\end{array}$ & $\begin{array}{r}1 \\
(20 \%) \\
\end{array}$ & $\begin{array}{r}19 \\
(26 \%) \\
\end{array}$ & $(0 \%)$ & $\begin{array}{r}60 \\
(33 \%) \\
\end{array}$ & $\begin{array}{r}17 \\
(22 \%) \\
\end{array}$ & $\begin{array}{r}63 \\
(29 \%) \\
\end{array}$ & \begin{tabular}{|r|}
50 \\
$(15 \%)$ \\
\end{tabular} & $\begin{array}{r}419 \\
(22 \%) \\
\end{array}$ \\
\hline $\begin{array}{l}\text { Sonst. amb } \\
\text { Folgeentscl }\end{array}$ & $\begin{array}{r}536 \\
(91 \%) \\
\end{array}$ & $\begin{array}{l}1.237 \\
(87 \%)\end{array}$ & $\begin{array}{r}1 \\
(20 \%)\end{array}$ & $\begin{array}{r}22 \\
(30 \%) \\
\end{array}$ & $\begin{array}{r}9 \\
(64 \%) \\
\end{array}$ & $\begin{array}{r}76 \\
(42 \%) \\
\end{array}$ & $\begin{array}{r}56 \\
(73 \%) \\
\end{array}$ & $\begin{array}{r}134 \\
(62 \%) \\
\end{array}$ & \begin{tabular}{|r|r|}
478 \\
$(81 \%)$ \\
\end{tabular} & $\begin{array}{l}1.339 \\
(70 \%)\end{array}$ \\
\hline Gesamt & $\begin{array}{r}591 \\
(100 \%)\end{array}$ & $\begin{array}{r}1.425 \\
(100 \%)\end{array}$ & $\begin{array}{r}5 \\
(100 \%)\end{array}$ & $\begin{array}{r}73 \\
(100 \%) \\
\end{array}$ & $\begin{array}{r}14 \\
(100 \%)\end{array}$ & $\begin{array}{r}181 \\
(100 \%) \\
\end{array}$ & $\begin{array}{r}77 \\
(100 \%) \\
\end{array}$ & $\begin{array}{r}217 \\
(100 \%)\end{array}$ & \begin{tabular}{|r|}
592 \\
$(100 \%)$ \\
\end{tabular} & $\begin{array}{r}1.917 \\
(100 \%)\end{array}$ \\
\hline
\end{tabular}


Tab. 6.41a: Art der Folgeentscheidung nach Anzabl der Voreintragungen bei Bezugsentscheidungen aufgrund von Betrug nach Geschlecht (Erwachsene)

\begin{tabular}{|c|c|c|c|c|c|c|c|c|c|c|}
\hline \multirow{3}{*}{$\begin{array}{l}\text { Art der Folgeent- } \\
\text { scheidung }\end{array}$} & \multicolumn{10}{|c|}{ Anzahl der Voreintragungen } \\
\hline & \multicolumn{2}{|c|}{ Keine } & \multicolumn{2}{|c|}{1} & \multicolumn{2}{|c|}{2} & \multicolumn{2}{|c|}{3 und 4} & \multicolumn{2}{|c|}{5 und mehr } \\
\hline & $\mathbf{F}$ & M & $\mathbf{F}$ & M & $\mathbf{F}$ & M & $\mathbf{F}$ & M & $\mathbf{F}$ & M \\
\hline JS/ FS o. Bew. & 23 & 156 & 42 & 136 & 44 & 152 & 66 & 323 & 149 & 1.092 \\
\hline JS/ FS m. Bew & 377 & 852 & 295 & 693 & 165 & 475 & 223 & 713 & 290 & 1.569 \\
\hline \begin{tabular}{|l|} 
Sonst. ambulante \\
Folgeentscheidungen
\end{tabular} & 2.236 & 4.132 & 801 & 1.917 & 334 & 1.087 & 357 & 1.328 & 372 & 2.292 \\
\hline Gesamt & 2.636 & 5.140 & 1.138 & 2.746 & 543 & 1.714 & 646 & 2.364 & 811 & 4.953 \\
\hline
\end{tabular}

Tab. 6.42a: Art der Folgeentscheidung nach Art der schwersten Voreintragung bei Bezugsentscheidungen aufgrund von Betrug nach Geschlecht (Erwachsene)

\begin{tabular}{|l|r|r|r|r|r|r|r|r|r|r|}
\hline \multirow{2}{*}{$\begin{array}{l}\text { Art der Folgeent- } \\
\text { scheidung }\end{array}$} & \multicolumn{8}{|c|}{ Art der schwersten Voreintragungen } \\
\cline { 2 - 12 } & \multicolumn{2}{|c|}{ Keine } & \multicolumn{1}{|c|}{ FS/ JS o. Bew. } & \multicolumn{2}{|c|}{ FS/ JS m. } & \multicolumn{2}{|c|}{$\begin{array}{c}\text { Geldstrafe } \\
\text { Bewst. Entsch. } \\
\text { n. JGG }\end{array}$} \\
\hline JS/ FS o. Bew. & 23 & 156 & 59 & 645 & 129 & 584 & 107 & 412 & 6 & 132 \\
\hline JS/ FS m. Bew & 377 & 852 & 74 & 611 & 232 & 1.045 & 623 & 1.662 & 44 & 428 \\
\hline $\begin{array}{l}\text { Sonst. ambulante } \\
\text { Folgeentschei- } \\
\text { dungen }\end{array}$ & 2.236 & 4.132 & 76 & 805 & 316 & 1.691 & 1.330 & 3.700 & 142 & 743 \\
\hline Gesamt & 2.636 & 5.140 & 209 & 2.061 & 677 & 3.320 & 2.060 & 5.774 & 192 & 1.303 \\
\hline
\end{tabular}


Tab. 6.43a: Art der Folgeentscheidung nach Bezugsentscheidungen aufgrund von Betrug nach Einschlägigkeit der Voreintragungen und Geschlecht

\begin{tabular}{|c|c|c|c|c|c|c|c|c|}
\hline \multirow{3}{*}{$\begin{array}{c}\text { Art der } \\
\text { Folgeentscheidung }\end{array}$} & \multicolumn{8}{|c|}{ Einschlägigkeit der Voreintragungen } \\
\hline & \multicolumn{2}{|c|}{ Keine VE } & \multicolumn{2}{|c|}{$\begin{array}{c}\text { Nur VE(en) mit } \\
\text { anderen Delikten }\end{array}$} & \multicolumn{2}{|c|}{$\begin{array}{l}\text { (Auch) VE(en) mit } \\
\text { anderen Täu- } \\
\text { schungsdelikten }\end{array}$} & \multicolumn{2}{|c|}{$\begin{array}{l}\text { (Auch) einschlä- } \\
\text { gige VE(en) }\end{array}$} \\
\hline & $\mathbf{F}$ & M & $\mathbf{F}$ & M & $\mathrm{F}$ & M & $\mathbf{F}$ & M \\
\hline JS/ FS o. & $\begin{array}{r}30 \\
(1 \%)\end{array}$ & $\begin{array}{r}202 \\
(3 \%) \\
\end{array}$ & $\begin{array}{r}100 \\
(6 \%)\end{array}$ & $\begin{array}{r}768 \\
(10 \%)\end{array}$ & $\begin{array}{r}14 \\
(4 \%)\end{array}$ & $\begin{array}{r}127 \\
(13 \%)\end{array}$ & $\begin{array}{r}223 \\
(12 \%) \\
\end{array}$ & \\
\hline JS/ F & $\begin{array}{r}425 \\
(13 \%) \\
\end{array}$ & $\begin{array}{r}994 \\
(15 \%) \\
\end{array}$ & $\begin{array}{r}340 \\
(22 \%) \\
\end{array}$ & $\begin{array}{r}1.885 \\
(26 \%) \\
\end{array}$ & $\begin{array}{r}74 \\
(24 \%) \\
\end{array}$ & $\begin{array}{r}238 \\
(24 \%) \\
\end{array}$ & $\begin{array}{r}667 \\
(34 \%)\end{array}$ & $\begin{array}{l}1.889 \\
(32 \%) \\
\end{array}$ \\
\hline $\begin{array}{l}\text { Sonst. ambulante } \\
\text { Folgeentschei- } \\
\text { dungen }\end{array}$ & $\begin{array}{l}2.772 \\
(86 \%)\end{array}$ & $\begin{array}{r}5.369 \\
(15 \%)\end{array}$ & $\begin{array}{l}1.134 \\
(72 \%)\end{array}$ & $\begin{array}{l}4.693 \\
(64 \%)\end{array}$ & $\begin{array}{r}226 \\
(72 \%)\end{array}$ & $\begin{array}{r}633 \\
(63 \%)\end{array}$ & $\begin{array}{r}1.048 \\
(54 \%)\end{array}$ & $\begin{array}{l}2.8 \\
(49\end{array}$ \\
\hline$G$ & $\begin{array}{r}3.227 \\
(100 \%) \\
\end{array}$ & $\begin{array}{r}6.565 \\
(100 \%) \\
\end{array}$ & $\begin{array}{r}1.574 \\
(100 \%) \\
\end{array}$ & $\begin{array}{r}7.346 \\
(100 \%) \\
\end{array}$ & $\begin{array}{r}314 \\
(100 \%) \\
\end{array}$ & $\begin{array}{r}998 \\
(100 \%) \\
\end{array}$ & $\begin{array}{r}1.938 \\
(100 \%) \\
\end{array}$ & $\begin{array}{r}5.822 \\
(100 \%) \\
\end{array}$ \\
\hline
\end{tabular}

Tab. 6.44a: Art der Folgeentscheidung nach dem StGB nach Bequgsentscheidungen aufgrund von Betrug unter Berücksichtigung multipler Faktoren nach Geschlecht

\begin{tabular}{|c|c|c|}
\hline & Frauen & Männer \\
\hline FS o. Bew. & 82 & 371 \\
\hline FS m. Bew. & 97 & 373 \\
\hline Geldstrafe & 82 & 326 \\
\hline Gesamt & 261 & 1.070 \\
\hline
\end{tabular}

Tab. 6.45a: Einschlägige Rückfälle nach Bequgsentscheidungen aufgrund von Betrug nach Geschlecht

\begin{tabular}{|l|r|r|r|r|}
\hline & $\begin{array}{c}\text { Nur Rückfall mit } \\
\text { anderen Delikten }\end{array}$ & $\begin{array}{c}\text { (Auch) Rückfall } \\
\text { mit anderen Täu- } \\
\text { schungs-delikten }\end{array}$ & $\begin{array}{c}\text { (Auch) einschlägi- } \\
\text { ger Rückfall }\end{array}$ & \multicolumn{2}{|c|}{ Gesamt } \\
\hline Frauen & 2.812 & 688 & 3.649 & 7.149 \\
\hline Männer & 11.521 & 1.751 & 7.684 & 20.956 \\
\hline
\end{tabular}


Tab. 6.46a: Einschlägige Voreintragungen und Rückeälle bei Bezugsentscheidungen aufgrund von Betrug nach Geschlecht

\begin{tabular}{|c|c|c|c|c|c|c|c|c|}
\hline \multirow{2}{*}{$\begin{array}{l}\text { Art des Rück- } \\
\text { falls }\end{array}$} & \multicolumn{2}{|c|}{ Keine VE } & \multicolumn{2}{|c|}{$\begin{array}{c}\text { Nur VE(en) mit } \\
\text { anderen Delikten }\end{array}$} & \multicolumn{2}{|c|}{$\begin{array}{l}\text { (Auch) VE(en) mit } \\
\text { anderen Täu- } \\
\text { schungsdelikten }\end{array}$} & \multicolumn{2}{|c|}{$\begin{array}{c}\text { (Auch) einschlägige } \\
\text { VE(en) }\end{array}$} \\
\hline & $F$ & M & $\mathbf{F}$ & M & $F$ & M & $\mathbf{F}$ & M \\
\hline $\begin{array}{l}\text { Nur Rückfall mit } \\
\text { anderen Delik- } \\
\text { ten }\end{array}$ & 1.351 & 3.832 & 744 & 4.687 & 82 & 427 & 635 & 2.575 \\
\hline $\begin{array}{l}\text { (Auch) Rückfall } \\
\text { mit } \\
\text { anderen Täu- } \\
\text { schungs- } \\
\text { delikten }\end{array}$ & 271 & 451 & 169 & 620 & 137 & 328 & 111 & 352 \\
\hline $\begin{array}{l}\text { (Auch) ein- } \\
\text { schlägiger } \\
\text { Rückfall }\end{array}$ & 1.655 & 2.347 & 678 & 2.103 & 99 & 260 & 1.217 & 2.974 \\
\hline Gesamt & 3.277 & 6.630 & 1.591 & 7.410 & 318 & 1.015 & 1.963 & 5.901 \\
\hline
\end{tabular}




\begin{abstract}
Cegenstand der Arbeit ist der Umgang der Kriminaljustiz mit Straftaten von Frauen - ein weithin vernachlässigtes Thema im Bereich der empirischen Kriminologie. Ausgewertet werden sämtliche Eintragungen im Bundeszentralund Erziehungsregister zu Personen, die im Jahr 2004 mit einer relevanten Bezugsentscheidung im Register erfasst waren. Dadurch konnten über eine Millionen Straffällige, darunter rund 200.000 Frauen, mit allen zu ihnen im Register gespeicherten strafrechtlichen Entscheidungen in die Untersuchung einbezogen werden. Diese konzentriert sich dabei im Wesentlichen auf zwei Themenkomplexe: Einmal wird die Strafzumessung bei weiblichen im Vergleich zu männlichen Straffälligen differenziert untersucht. Dabei zeigt sich, dass Frauen entgegen landläufiger Meinung keinen Strafzumessungsbonus genießen. Zum anderen wird aufgezeigt, dass das Maß der Rückfälligkeit straffälliger Frauen sich je nach justizieller Reaktion unterscheidet und von Kriterien wie Art und Anzahl der Voreintragungen abhängt.
\end{abstract}

